\title{
Flow unit prediction with limited permeability data using artificial neural network analysis
}

\author{
Benjamin Hale Thomas \\ West Virginia University
}

Follow this and additional works at: https://researchrepository.wvu.edu/etd

\section{Recommended Citation}

Thomas, Benjamin Hale, "Flow unit prediction with limited permeability data using artificial neural network analysis" (2002). Graduate Theses, Dissertations, and Problem Reports. 2431.

https://researchrepository.wvu.edu/etd/2431

This Dissertation is protected by copyright and/or related rights. It has been brought to you by the The Research Repository @ WVU with permission from the rights-holder(s). You are free to use this Dissertation in any way that is permitted by the copyright and related rights legislation that applies to your use. For other uses you must obtain permission from the rights-holder(s) directly, unless additional rights are indicated by a Creative Commons license in the record and/ or on the work itself. This Dissertation has been accepted for inclusion in WVU Graduate Theses, Dissertations, and Problem Reports collection by an authorized administrator of The Research Repository @ WVU.

For more information, please contact researchrepository@mail.wvu.edu. 


\title{
FLOW UNIT PREDICTION WITH LIMITED PERMEABILITY DATA USING ARTIFICIAL NEURAL NETWORK ANALYSIS
}

\author{
Benjamin Hale Thomas \\ Dissertation submitted to the \\ College of Engineering and Mineral Resources \\ at West Virginia University \\ in partial fulfillment of the requirements \\ for the degree of \\ Doctor of Philosophy \\ in \\ Petroleum and Natural Gas Engineering
}

\author{
Khashayar Aminian, Ph.D., Chair \\ Samuel Ameri, M.S. \\ Michael Hohn, Ph.D. \\ Robert Chase, Ph.D. \\ H. Ilkin Bilgesu, Ph.D. \\ Shahab Mohaghegh, Ph.D.
}

Morgantown, West Virginia

2002

Keywords: Reservoir Simulation, Artificial Neural Networks, Reservoir Characterization, Flow Units, Permeability Prediction, Waterflooding, Gordon Sandstone, Jacksonburg-Stringtown Field Copyright 2002 Benjamin Hale Thomas 


\section{ABSTRACT \\ FLOW UNIT PREDICTION WITH LIMITED PERMEABILITY DATA USING ARTIFICIAL NEURAL NETWORK ANALYSIS}

\section{Benjamin Hale Thomas}

The Appalachian Basin has numerous abandoned or marginally producing oilfields having significant recoverable oil remaining in place. Typically production records and reservoir data is not available. Presented is a new methodology, applicable to any field having limited records, designed for reservoir characterization via flow unit identification.

This methodology utilizes limited core permeability data from a few wells as a key to predicting flow units within a field when only logbased data is available. Primary software tools used include NeuroShell 2, an artificial neural network (ANN) program, and the Boast98 numerical simulator.

Various techniques for flow unit identification including graphic approaches using the permeability-porosity relationship within a given flow unit and ANN (Kohonen) analysis are utilized as a part of the methodology developed. The core data and flow units are utilized in neural network models designed to predict flow units and permeability field-wide using only electric well logs. Field wide prediction of flow units and permeability are products of the study.

The study field selected was the Jacksonburg-Stringtown field. The producing horizon is the Upper Devonian Gordon sandstone. Discovered in 1895, waterflood operations were commenced in 1981. The characterization study utilizes core data and electric logs (gamma ray- density) from six core wells for flow unit identification.

Two dual five spots were selected in the field for verification of this new methodology. Reservoir simulation analysis utilizing the predicted flow units and permeability was completed for comparison to actual production records. A close match was achieved. As another comparison step a single layer simulation model for the two patterns was generated. The single layer model included the same inputs as the flow unit model except for thickness and average permeability. The simulation model utilizing flow units was a far more accurate prediction method. 


\section{ACKNOWLEDGEMENTS}

As I complete the final stages of my research project and doctoral studies, I have much to be thankful for. I thank God for our safe travel during the many long trips to the university, good health and blessing me with supporting family, friends, professors, and fellow graduate research students - all of whom played a significant part in this accomplishment.

I extend my appreciation to Dr. Khashayar Aminian, my graduate advisor and committee Chairman. His experience, knowledge and willingness to support my efforts are a big part of my success.

In 1994, I began my graduate studies. Chairman Ameri has always offered positive support, in every aspect, as the Department Chairman and a committee member.

Having been through the doctoral process I have gained a deep appreciation for my committee members. They have willingly given their time and energy. I extend my sincere appreciation to Dr. Ilkin Bilgesu, Dr. Robert Chase, Dr. Michael Hohn and Dr. Shahab Mohaghegh, my other committee members.

I also would like to thank Dr. Ronald McDowell and David Matchen of the West Virginia Geologic Surveys. Their geologic expertise and assistance was greatly appreciated. 
My son, Jeremy, has watched my efforts for these many years. By example, I hope my perseverance, sacrifice and passion influence his life goals and aspirations.

Lastly and most importantly, I write of my wife, Connie. Her tireless support and believing that we could accomplish my goal has been steadfast. She has endured long days and nights of travel, managed the household with little help from me, and willingly gave up our time together for several years in order that I could accomplish my goal. She has earned my endless respect and appreciation for her unselfish support. I look forward to spending time with her, the one I love. 


\section{TABLE OF CONTENTS}

\section{Page}

ABSTRACT

ii

ACKNOWLEDGMENTS

iii

TABLE OF CONTENTS

v

LIST OF TABLES

$\mathbf{x}$

LIST OF FIGURES

xiv

NOMENCLATURE

xxi

CHAPTER 1 INTRODUCTION

1.1 Introductory Discussion 1

$\begin{array}{lll}1.2 & \text { Research Objectives } & 1\end{array}$

1.3 Primary Research Tools 2

1.4 Research Value 4

CHAPTER 2 VERIFICATION FIELD HISTORY

$2.1 \quad$ Field History 5

2.2 Geologic Overview 9

CHAPTER 3 RESERVOIR CHARACTERIZATION AND THE FLOW UNIT

3.1 Introductory Discussion

$\begin{array}{lll}3.2 & \text { Reservoir Description } & 13\end{array}$

$\begin{array}{lll}3.3 & \text { Permeability-Porosity Relationship } & 17\end{array}$

$\begin{array}{lll}3.4 & \text { Pore Geometry } & 18\end{array}$

3.5 Outcrop Derived Models of Permeability 22 
3.6 Pre-Flow Unit Review 23

$\begin{array}{lll}3.7 & \text { The Flow Unit } & 26\end{array}$

3.7.1 The Hartzog Draw Field 26

3.7.2 The Flow Unit Concept and Discussion 30

3.7.3 Comparison of Depositional, Layered and 31 Flow Unit Models - A Case Study

3.7.4 Identifying Flow Units using Flow Capacity and 35 Storage Capacity as Indicators

3.7.5 The Flow Zone Indicator

CHAPTER 4 ARTIFICIAL NEURAL NETWORKS

$\begin{array}{lll}4.1 & \text { Overview } & 44\end{array}$

$\begin{array}{lll}4.2 & \text { The Neuron } & 45\end{array}$

4.3 The Backpropagation Model 46

4.4 The NeuroShell Program 49

4.5 Neural Network Core and Log Data Inputs 53

CHAPTER 5 METHODOLOGY

5.1 Introductory Discussion

5.2 Determining the Flow Units 57

$\begin{array}{lll}5.2 .1 & \text { Overview } & 57\end{array}$

5.2.2 Manual Review of the Digitized Log Data 58

5.2.3 Cumulative Porosity-Height versus Cumulative $\quad 59$

Permeability-Height

5.2.4 Semi-Log Graph of Permeability versus Porosity 60

$\begin{array}{lll}\text { 5.2.5 FZI Analysis } & 61\end{array}$ 
5.2.7 Geologic Input 63

5.3 Developing the Final ANN Permeability Model 64

5.3.1 Utilizing the Preliminary Flow Unit 64

5.3.2 Initial Flow Unit Designation 64

5.3.3 Developing the ANN Model for Permeability Prediction 64

5.3.4 Permeability Prediction Utilizing the Neural Network 65

5.3.5 Utilizing the Predetermined Test Set 67

5.4 Flow Unit Identification - Without Core Data 69

$\begin{array}{lll}\text { 5.4.1 Discussion } & 69\end{array}$

5.4.2 Flow Unit Prediction Utilizing the Neural Network $\quad \mathbf{7 0}$

5.4.3 Transition Zone near Flow Unit Boundaries 71

5.4.4 Predicting Permeability in the Transition Zone 71

5.4.5 Reclassifying the Predicted Flow Units for the 73 ANN Permeability Model

5.4.6 Model Description Summary 74

5.5 Earlier Verification Work 75

$\begin{array}{lll}5.6 & \text { Verification Field } & 76\end{array}$

$\begin{array}{ll}\text { 5.6.1 Study Area } & 76\end{array}$

5.6.2 Core Wells Utilized in the Research 76

5.6.3 Two Five Spots Selected for Verification 79

5.7 Simulation Analysis - Verification Step 85

5.7.1 Simulation Introduction $\quad 85$

5.7.2 Necessary Input Data for the Simulator 86 
5.7.4 Comparing Flow Unit Simulation to Single Layer Model 90

5.8 Applying the Reservoir Characterization Results 90 to the Field

CHAPTER 6 RESULTS AND DISCUSSION

$\begin{array}{lll}6.1 & \text { Introduction } & 92\end{array}$

6.2 Preliminary Flow Unit Identification Process Results 92

$\begin{array}{ll}\text { 6.2.1 General Observations } & 92\end{array}$

6.2.2 Cumulative k-h versus Cumulative $\phi-h$ - Core Data 94

6.2.3 Cumulative k-h versus Cumulative $\phi-h$ - Miniperm Data 96

6.2.4 Cumulative $k-h$ versus Cumulative $\phi-h$ - Core Data 98 versus Miniperm Data

6.2.5 Questionable Flow Unit Below Flow Unit Two 100

6.2.6 Permeability-Porosity Scatter Plots 102

$\begin{array}{lll}\text { 6.2.7 Flow Zone Indicator (FZI) } & 106\end{array}$

6.2.8 Artificial Neural Network Kohonen Analysis $\quad 110$

6.2.9 Summary of the Preliminary Flow Unit Identification 113 Process

6.3 The Neural Network for Permeability Prediction 114

6.3.1 Model 1-K for Permeability Prediction 114

6.3.2 Model 2-K for Permeability Prediction 116

6.3.3 Model 2-K Selected as the Final Model for 117 Permeability Prediction

$\begin{array}{lll}\text { 6.4 Predicting the Flow Unit } & 119\end{array}$

6.4.1 Predicting Permeability in the Transition Zone 121 
6.4.2 Two Step Process to Model Flow Unit Designation for ANN Permeability Model

6.4.3 Preparing the Predicted Flow Units for the ANN Permeability Model

6.5 Two Flow Unit Model Verified via Simulation Results 125

6.6 Single Layer Simulation Comparison

6.7 Field Maps Generated

6.8 Methodology Summary - Overview

6.8.2 Methodology Summary

6.8.3 Steps Leading to Flow Unit Identification Using Only Well Log Data

CHAPTER 7 CONCLUSIONS

CHAPTER 8 RECOMMENDATIONS

REFERENCES

APPENDIX A

APPENDIX B

APPENDIX C

196

APPENDIX D

214

APPENDIX E

222

APPENDIX F

APPENDIX G

APPENDIX H 


\section{LIST OF TABLES}

\section{Page}

Table 2.1 Field Recovery Summary 7

$\begin{array}{lll}\text { Table 2.2 } & \text { Crude Oil Analysis } & 8\end{array}$

$\begin{array}{lll}\text { Table 2.3 Gas Analysis } & 8\end{array}$

Table 2.4 Produced Water Analysis 8

Table 3.1 Values of Porosity and Water Saturation 29 from Analysis of Wells Cored with Oil-Based Muds (Hearn, 1984)

Table 3.2 Properties of the Layered Model (Slatt, 1988) 32

Table 3.3 Properties of the Flow Unit Model (Slatt, 1988) 33

Table 5.1 Summary of Jacksonburg-Stringtown 78 Research Cores (Gil, 2000)

$\begin{array}{lll}\text { Table 5.2 } & \text { Produced Oil PVT Properties } & 87\end{array}$

$\begin{array}{lll}\text { Table 5.3 Produced Natural Gas PVT Properties } & 87\end{array}$

$\begin{array}{lll}\text { Table 5.4 } & \text { Produced Water PVT Properties } & 87\end{array}$

Table 5.5 Relative Permeability - Horner \#9 88

Table 6.1 General Observations Gamma Ray-Density Log 94 and Core Measurement versus Depth

Table 6.2 Summary of R Squared Values for Two Flow 104 Units for Permeability-Porosity Scatter Plots

Table 6.3 Summary of R Squared Values for Two Flow 107 Units for Flow Zone Indicator (FZI) Plots

Table 6.4 Summary of the Interval Identified as Flow Units 109 by the $\mathbf{k}-\varnothing$ Scatter Plot and (FZI) Plots 
Table 6.5 Description of the Flow Units

Table 6.6 Kohonen Network Summary

114

Core Permeability and Log Measurements

Table 6.7 Permeability Prediction Model (Model 1-K) R Squared Values

115

Table 6.8 Permeability Prediction Model (Model 2-K) R Squared Values

Table 6.9 Flow Unit Prediction Model

119

Summary of R Squared Values

Table 6.10 Portion of the ANN Flow Unit Model 3-FU (Ball \# 19)

Table 6.11 Kohonen Network (Three Categories)

Table 6.12 Summary of R Squared Values

Flow Unit Prediction for Model 4-FU

123

Table 6.13 Average Properties Used in the Simulation

126

Table A.1 T. Heirs \# 8

163

Table A.2 Horner \# 9

165

Table A.3 Ball \# 19

166

$\begin{array}{lll}\text { Table A.4 LeMasters \# } 13 & 169\end{array}$

$\begin{array}{lll}\text { Table A.5 } & \text { Ball \# } 18 & 171\end{array}$

$\begin{array}{lll}\text { Table A.6 Horner \# } 11 & 174\end{array}$

Table B.1 Cumulative k-h versus p-h 179

Table B.2 Cumulative k-h versus p-h 181 Horner \# 9 - Core Results

Table B.3 Cumulative $k-h$ versus $p-h$ Ball \# 19 - Core Results 
Table B.4 Cumulative $k-h$ versus $p-h$

Table B.5 Cumulative k-h versus $\mathrm{p}-\mathrm{h}$

Ball \# 18 - Core Results

Table B.6 Cumulative k-h versus $\mathrm{p}-\mathrm{h}$

193

Horner \# 11 - Core Results

Table B.7 Potential Flow Unit Boundary Point Analysis

Core Permeability and Core Measurement

Table C.1 Cumulative k-h versus Por-h

200

(Minipermeameter Readings) T. Heirs \# 8

Table C.2 Cumulative k-h versus Por-h

202

(Minipermeameter Readings) Horner \# 9

Table C.3 Cumulative k-h versus Por-h

204

(Minipermeameter Readings) Ball \# 19

Table C.4 Cumulative k-h versus Por-h

207

(Minipermeameter Readings) LeMasters \# 13

Table C.5 Cumulative k-h versus Por-h

(Minipermeameter Readings) Ball \# 18

210

Table C.6 Potential Flow Unit Boundary Point Analysis

213 Miniperm Values and Core Porosity

Table D.1 Permeability-Porosity Scatter Plot Data

T. Heirs \# 8 Core Data Utilized for Analysis

Table D.2 Permeability-Porosity Scatter Plot Data Horner \# 9 Core Data Utilized for Analysis

Table D.3 Permeability-Porosity Scatter Plot Data Ball \# 19 Core Data Utilized for Analysis

Table D.4 Permeability-Porosity Scatter Plot Data LeMasters \# 13 Core Data Utilized for Analysis

Table D.5 Permeability-Porosity Scatter Plot Data Ball \# 18 Core Data Utilized for Analysis 
Table D.6 Permeability-Porosity Scatter Plot Data Horner \# 11 Core Data Utilized for Analysis

Table F.1 Kohonen Network (Two Output Categories) 228

Table F.2 Kohonen Network (Three Output Categories) 233

Table F.3 Kohonen Network (Two Output Categories) 238

Table F.4 Kohonen Network (Three Output Categories) 241

Table H.1 Neural Network Model for Permeability Prediction 249 Model 1-K

Table H.2 Neural Network Model for Permeability Prediction 252 Model 2-K

Table H.3 Table of ANN Model for Flow Unit Prediction 255 Model 4-FU

Table H.4 Summary of Final Flow Units 265

Table I.1 Summary of Results from ANN Prediction for 270 Field Application Flow Unit One-Detail

Table I.2 Summary of Results from ANN Prediction for 276 Field Application Flow Unit Two-Detail 


\section{LIST OF FIGURES}

Page

Figure 2.1 The Jacksonburg-Stringtown Field 5

Figure 2.2 Daily Oil Production in the 6 Jacksonburg-Stringtown Field 1896-1991

Figure 2.3 Cumulative Oil Production in the 6 Jacksonburg-Stringtown Field 1896-1991

Figure 2.4 Structure Contour Map - Top of Gordon Sand 10

Figure 2.5 Core Description and Electric Log for Ball \# 18

$\begin{array}{lll}\text { Figure 4.0 A Simplified Neural Network } & 47\end{array}$

Figure 5.1 Flow Unit Identification Methodology 58

$\begin{array}{lll}\text { Figure 5.2 } & \text { Flow Unit Identification Methodology } & 75\end{array}$ Major Methodology Steps in Flow Chart Form with Comments and Notes

Figure 5.3 Cored Well Locations within the Jacksonburg-Stringtown Field

Figure 5.4 East-West Cross Section Shows Logs and 80 Stratigraphic Units

Figure 5.5 Jacksonburg-Stringtown Field Showing Verification Area

Figure 5.6 Verification Patterns Selected 82

Figure 5.7 Ball \# 18 Secondary Production History 82

Figure 5.8 Ball \# 21 Secondary Production History 83

Figure 5.9 Cumulative Injected Volumes per Well 84

Figure 5.10 Monthly Injected Volumes per Well 84

Figure 5.11 Monthly Surface Pressure for Injection Wells 85 
Figure 5.12 Comparisons of Relative Permeability (Gil, 2000) 89

Figure 5.13 Flow Unit Identification Methodology 91

Major Methodology Steps in Flow Chart Form

Figure 6.1 Cumulative Flow Capacity versus Cumulative 95

Storage Capacity (Core Results) Ball \# 19

Figure 6.2 Cumulative Flow Capacity versus Cumulative

Storage Capacity (Core Results) Ball \# 18

Figure 6.3 Cumulative Flow Capacity versus Cumulative Storage Capacity (Miniperm) Ball \# 19

Figure 6.4 Cumulative Flow Capacity versus Cumulative Storage Capacity (Miniperm) Ball \# 18

Figure 6.5 Cumulative Flow Capacity versus Cumulative Storage Capacity (Core and Miniperm) LeMasters \# 13

Figure 6.6 Cumulative Flow Capacity versus Cumulative 99 Storage Capacity (Core and Miniperm) Ball \# 18

Figure 6.7 Cumulative Flow Capacity versus Cumulative 101 Storage Capacity (Core Results) Ball \#19 Third Potential Flow Unit

Figure 6.8 Cumulative Flow Capacity versus Cumulative 101 Storage Capacity (Miniperm) Ball \#19 Third Potential Flow Unit

Figure 6.9 Permeability-Porosity Scatter Plot (T. Heirs \# 8) 103

Figure 6.10 Permeability-Porosity Scatter Plot (Horner \# 9) 103

Figure 6.11 Permeability-Porosity Scatter Plot Composite 105 Six Core Wells (Single Layer)

Figure 6.12 Permeability-Porosity Scatter Plot Composite 105 Six Core Wells (Two Flow Units)

Figure 6.13 Flow Zone Indicator versus Normalized Porosity 107 T. Heirs \# 8 
Figure 6.14 Flow Zone Indicator versus Normalized Porosity 108 Horner \# 9

Figure 6.15 Flow Zone Indicator versus Normalized Porosity 108 Composite Six Core Wells (Single Layer)

Figure 6.16 Flow Zone Indicator versus Normalized Porosity 109 Composite Six Core Wells (Two Flow Units)

Figure 6.17 Horner \# 11 Predicted versus Actual Permeability 118

Figure 6.18 Ball \# 19 Predicted versus Actual Permeability 118

Figure 6.19 Flow Unit Designation and an ANN Model to 124 Address Transition Zone

Figure 6.20 Ball \# 18 Cumulative Oil Production 127 (Actual versus Predicted)

Figure 6.21 Ball \# 18 Cumulative Water Production (Actual versus Predicted)

128

Figure 6.22 Ball \# 21 Cumulative Oil Production 128 (Actual versus Predicted)

Figure 6.23 Ball \# 21 Cumulative Water Production 129 (Actual versus Predicted)

Figure 6.24 Ball \# 18, 21 Cumulative Oil Production (Actual versus Predicted)

Figure 6.25 Ball \# 18, 21 Cumulative Water Production 130 (Actual versus Predicted)

Figure 6.26 Ball \# 18, 21 Daily Oil Production 130 (Actual versus Predicted)

Figure 6.27 Ball \# 18,19

(Core Perm versus Log Porosity)

Figure 6.28 Ball \# 18, 21 Cumulative Oil Production 133 Single Layer Model (Predicted versus Actual)

Figure 6.29 Ball \# 18, 21 Cumulative Water Production 133 Single Layer Model (Predicted versus Actual) 
Figure 6.30 Ball \# 18 Cumulative Oil Produced

Single Layer Model (Predicted versus Actual)

Figure 6.31 Ball \# 21 Cumulative Oil Produced

Single Layer Model (Predicted versus Actual)

Figure 6.32 Flow Unit One (Thickness)

136

Figure 6.33 Flow Unit One (Average Permeability)

Figure 6.34 Flow Unit One (kh)

Figure 6.35 Flow Unit Two (Thickness)

139

Figure 6.36 Flow Unit Two (Average Permeability)

Figure 6.37 Flow Unit Two (kh)

Figure 6.38 Cumulative Primary Production Map per Well Basis

Figure A.1 T. Heirs \# 8 Gamma Ray-Log Porosity and

154 Core Measurements

Figure A.2 T. Heirs \# 8 Gamma Ray-Log Density and Core Permeability

Figure A.3 T. Heirs \# 8 Log Porosity versus Core Porosity with Core Permeability

Figure A.4 Horner \# 9 Gamma Ray-Log Porosity and Core Measurements

Figure A.5 Horner \# 9 Gamma Ray-Log Density and Core Permeability

Figure A.6 Horner \# 9 Log Porosity versus Core Porosity with Core Permeability

Figure A.7 Ball \# 19 Gamma Ray-Log Porosity and Core Measurements

Figure A.8 Ball \# 19 Gamma Ray-Log Density and Core Permeability 
Figure A.9 Ball \# 19 Log Porosity versus Core Porosity with Core Permeability

Figure A.10 LeMasters \# 13 Gamma Ray-Log Porosity and Core Measurements

Figure A.11 LeMasters \# 13 Gamma Ray-Log Density and Core Permeability

Figure A.12 LeMasters \# 13 Log Porosity versus Core Porosity with Core Permeability

Figure A.13 Ball \#18 Gamma Ray-Log Porosity and Core Measurements

Figure A.14 Ball \#18 Gamma Ray-Log Density and Core Permeability

Figure A.15 Ball \#18 Log Porosity versus Core Porosity with Core Permeability

Figure A.16 Horner \# 11 Gamma Ray-Log Porosity and 161 Core Measurements

Figure A.17 Horner \# 11 Gamma Ray-Log Density and 162 Core Permeability

Figure A.18 Horner \# 11 Log Porosity versus Core 162 Porosity with Core Permeability

Figure B.1 Cumulative Flow Capacity versus Cumulative Storage Capacity (Core Results) T. Heirs \# 8

Figure B.2 Cumulative Flow Capacity versus Cumulative 176 Storage Capacity (Core Results) Horner \# 9

Figure B.3 Cumulative Flow Capacity versus Cumulative 177 Storage Capacity (Core Results) Ball \# 19

Figure B.4 Cumulative Flow Capacity versus Cumulative Storage Capacity (Core Results) LeMasters \# 13

Figure B.5 Cumulative Flow Capacity versus Cumulative 178 Storage Capacity (Core Results) Ball \# 18 
Figure B.6 Cumulative Flow Capacity versus Cumulative

Storage Capacity (Core Results) Horner \# 11

Figure C.1 Cumulative Flow Capacity versus Cumulative Storage Capacity (Miniperm) T. Heirs \# 8

Figure C.2 Cumulative Flow Capacity versus Cumulative Storage Capacity (Miniperm) Horner \# 9

Figure C.3 Cumulative Flow Capacity versus Cumulative Storage Capacity (Miniperm) Ball \# 19

Figure C.4 Cumulative Flow Capacity versus Cumulative Storage Capacity (Miniperm) LeMasters \# 13

Figure C.5 Cumulative Flow Capacity versus Cumulative Storage Capacity (Miniperm) Ball \# 18

Figure D.1 Permeability-Porosity Scatter Plot (T. Heirs \# 8) 215

Figure D.2 Permeability-Porosity Scatter Plot (Horner \# 9) 215

Figure D.3 Permeability-Porosity Scatter Plot (Ball \# 19) 216

Figure D.4 Permeability-Porosity Scatter Plot 216 (LeMasters \# 13)

Figure D.5 Permeability-Porosity Scatter Plot (Ball \# 18) 217

Figure D.6 Permeability-Porosity Scatter Plot (Horner \# 11) 217

Figure D.7 Permeability-Porosity Scatter Plot 218 Composite Six Core Wells (Two Flow Units)

Figure D.8 Permeability-Porosity Scatter Plot 218 Composite Six Core Wells (Single Flow Unit)

Figure E.1 Flow Zone Indicator versus Normalized Porosity 223 T. Heirs \# 8

Figure E.2 Flow Zone Indicator versus Normalized Porosity 223 Horner \# 9

Figure E.3 Flow Zone Indicator versus Normalized Porosity 224 Ball \# 19 
Figure E.4 Flow Zone Indicator versus Normalized Porosity 224 LeMasters \# 13

Figure E.5 Flow Zone Indicator versus Normalized Porosity 225 Ball \# 18

Figure E.6 Flow Zone Indicator versus Normalized Porosity 225 Horner \# 11

Figure E.7 Flow Zone Indicator versus Normalized Porosity 226 Composite Six Core Wells (Two Flow Units)

Figure E.8 Flow Zone Indicator versus Normalized Porosity 226 Composite Six Core Wells (Single Layer)

Figure G.1 T. Heirs \# 8 Cumulative Flow Capacity versus 245 Cumulative Storage Capacity (Core and Miniperm)

Figure G.2 Horner \# 9 Cumulative Flow Capacity versus 245 Cumulative Storage Capacity (Core and Miniperm)

Figure G.3 Ball \# 19 Cumulative Flow Capacity versus Storage Capacity (Core and Miniperm)

Figure G.4 LeMasters \# 13 Cumulative Flow Capacity versus 246 Cumulative Storage Capacity (Core and Miniperm)

Figure G.5 Ball \# 18 Cumulative Flow Capacity versus 247 Cumulative Storage Capacity (Core and Miniperm)

Figure H.1 Horner \# 11 (Predicted vs Actual Permeability) 266

Figure H.2 T Heirs \# 8 (Predicted vs Actual Permeability) 266

Figure H.3 Horner \# 9 (Predicted vs Actual Permeability) 267

Figure H.4 Ball \# 19 (Predicted vs Actual Permeability) 267

Figure H.5 LeMasters \# 13 (Predicted vs Actual Permeability) 268 Figure H.6 Ball \#18 (Predicted vs Actual Permeability) 268 


\section{NOMENCLATURE}

ANN: Artificial Neural Network

Bo: Oil Formation Volume Factor, RB/STB

BOPD: Barrels of Oil per Day

Bg: Gas Formation Volume Factor, RCF/SCF

DX: $\quad x$-direction Grid Block Dimension, $\mathrm{ft}$.

FZI: Flow Zone Indicator

GR: Gamma Ray

GRNN: General Regression Neural Network

$h$ : Thickness, ft.

k: Permeability, md

$k_{r}$ : Relative Permeability

$P c_{\text {corr: }}$ Capillary Pressure Corrected for an Oil-Water System, psia

$P C_{\text {exp: }}$ Capillary Pressure Obtained for a Water-Air System, psia

PID: Flow Index per Layer, STB/D

$r$ : Linear Correlation Coefficient

$r^{2}$ : Coefficient of Determination

$R^{2}$ : Coefficient

$R Q I: \quad$ Reservoir Quality Indicator

Rs: Gas-Oil Ratio, SCF/STB

$r_{w}:$ Wellbore Radius, $\mathrm{ft}$.

$S v_{g r}:$ Specific Surface Area per Grain Unit Volume

$K_{z}$ : Kozeny Constant

ow-o: Interfacial Tension for Water-Oil, dyne/cm

$\sigma \mathrm{W}$-a: Interfacial Tension for Air-Water, dyne/cm

$\phi_{\mathrm{e}}$ : Effective Porosity

$\phi_{n}: \quad$ Normalized Porosity Index (also seen as $\varnothing_{z \text { ) }}$

$\phi$ : Porosity, \% 


\section{CHAPTER 1}

\section{INTRODUCTION}

\subsection{Introductory Discussion}

Reservoir characterization is the ongoing process of defining reservoir properties and geological conditions for evaluating reservoir performance and forecasting future behavior (Neog, 2000). The ability to predict reservoir performance via simulation work is enhanced as reservoir properties are better defined. Flow unit identification can be utilized during the reservoir characterization process. The flow unit is a volume of total reservoir rock within which geological and petrophysical properties that affect fluid flow are internally consistent and different from properties of other rock volumes (Ebanks, 1987). A given flow unit exhibits a certain permeability-porosity relationship and has similar properties for fluid flow. Within each flow unit, utilizing fluid flow properties enhances reservoir simulation. The flow unit division allows fluid flow within the reservoir to be better understood and categorized in a useful manner for simulation analysis.

\subsection{Research Objectives}

The Appalachian Basin has numerous abandoned or marginally productive oilfields in the region. Typically production 
records are nonexistent which hampers further development interest. The objective of this research is to develop a methodology for reservoir characterization specifically modeled for the Appalachian Basin when reservoir records are limited.

The permeability-porosity relationship within each flow unit allows us to identify the flow units using various techniques. However, without permeability distribution, flow unit prediction is not possible. This research seeks to predict flow units using only well log data when a limited number of cores are available for analysis. By following this methodology the researcher is able to:

- Identify flow units based on well log data (gamma ray-density)

- Predict the flow unit properties in wells having only well log data

- Determine the distribution of flow units within the reservoir.

\subsection{Primary Research Tools}

In order to test this methodology an Appalachian Basin oilfield was selected which has far more complete production records than typically available in the Appalachian Basin. The 9,000-acre Jacksonburg-Stringtown field is currently being waterflooded. Field record retention by the operator is far better than what is normally encountered in the Appalachian Basin. This offered the unique opportunity to verify the methodology developed by comparing 
simulator results (predicted) against actual secondary recovery production results. It is important to clarify that this research and the methods identified for flow unit identification has application to all reservoirs. The Jacksonburg-Stringtown field offered a unique opportunity to test and verify the methodology developed.

For Appalachian reservoirs this methodology requires that a limited number of cores be secured from wells at the time of drilling. The cores are utilized to secure permeability and porosity measurements. It is also recommended that a few core samples from each flow unit be tested on order to develop relative permeability data for simulation analysis. At a minimum a gamma ray-density log is required for each cored well. With this limited data, utilizing this methodology flow unit identification and permeability estimation within each flow unit can be done. The extent to which the prediction tool can be applied, to other wells in the field, is limited by the number of available logs from other existing wells.

Artificial Neural Networks (ANNs) were found to be very useful for predicting permeability and flow units. The use of ANNs to predict permeability had previously been demonstrated when geophysical log data was used. This research extends this application by developing a methodology to identify flow units within the reservoir when permeability is not known and available reservoir information is limited to electric log data. The benefit of flow unit 
identification, with very limited reservoir data, improves permeability prediction within each flow unit and more enhances reservoir simulation analysis. Being able to better predict reservoir performance by identifying flow units can be significant when evaluating future potential of Appalachian based reservoirs.

\subsection{Research Value}

The success of this research may well lead to heightened interest in many of the previously prolific oil reservoirs situated throughout the Appalachian Basin. This procedure has application in natural gas and oil reservoirs. Most abandoned or marginally productive fields in the Appalachian Basin are primarily oil fields. As a result oil reservoirs having secondary recovery potential are the primary interest. 


\section{CHAPTER 2}

\section{VERIFICATION FIELD HISTORY}

\subsection{Field History}

The Jacksonburg-Stringtown field was discovered in 1895. The field is located in portions of Wetzel, Tyler and Doddridge counties, West Virginia and encompasses nearly 9,000 acres (Figure 2.1). Between 1895 and 1901 over 500 wells were drilled through the Gordon sandstone. Drilled on average well spacing of 13 acres; the wells initially produced up to 300 BOPD. Standard completion called for open-hole completion through the pay with nitroglycerine being used for stimulation. The field was a solution gas drive and gravity drainage reservoir.

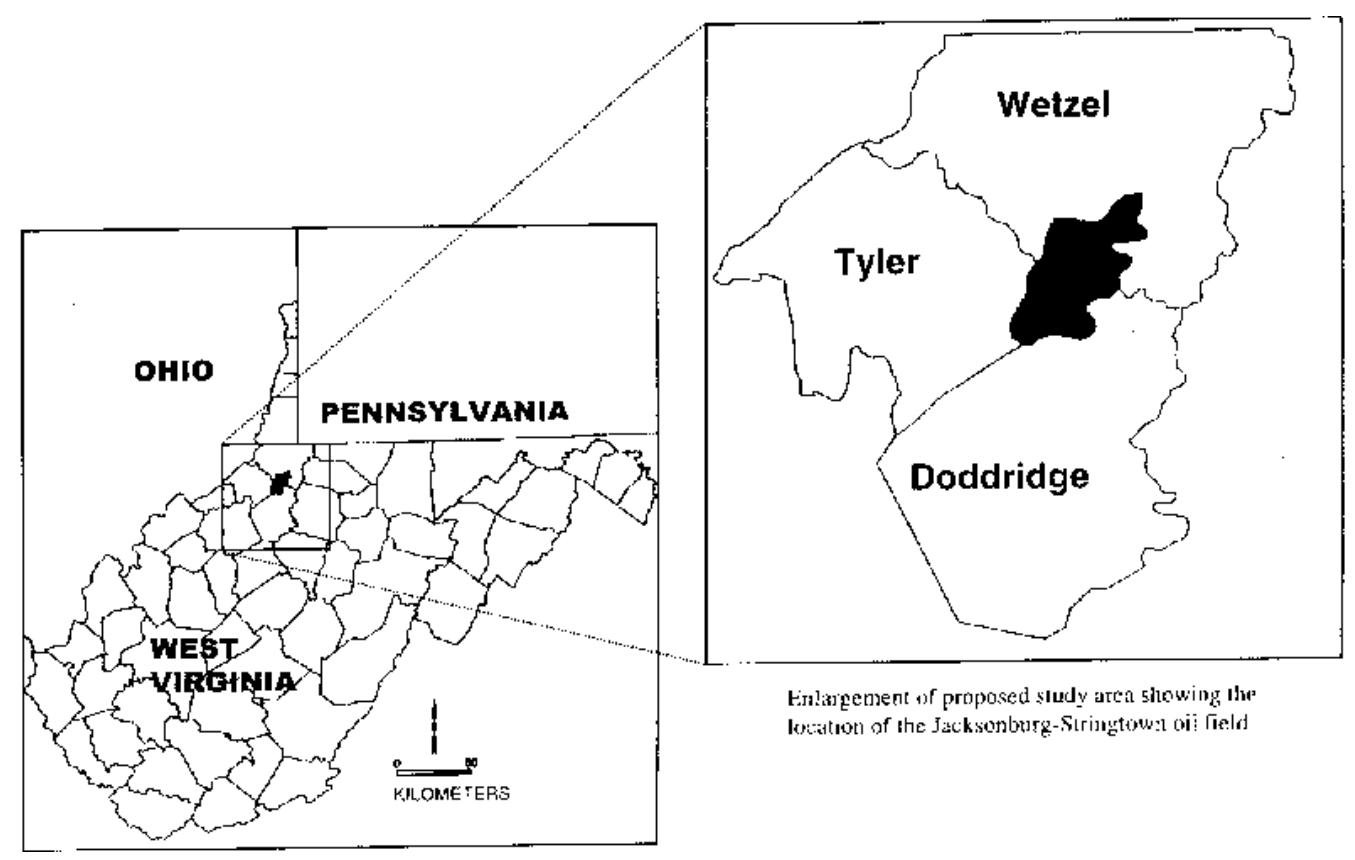

Figure 2.1 The Jacksonburg-Stringtown Field 
By 1910 most of the wells were plugged and abandoned. Production records indicate 12 million barrels of oil (MMBO) were recovered. Figures 2.2 and 2.3 present the daily and cumulative oil production for the field from 1896 to 1991 . Internal company records estimated initial oil in place to be 88.5 MMBO.

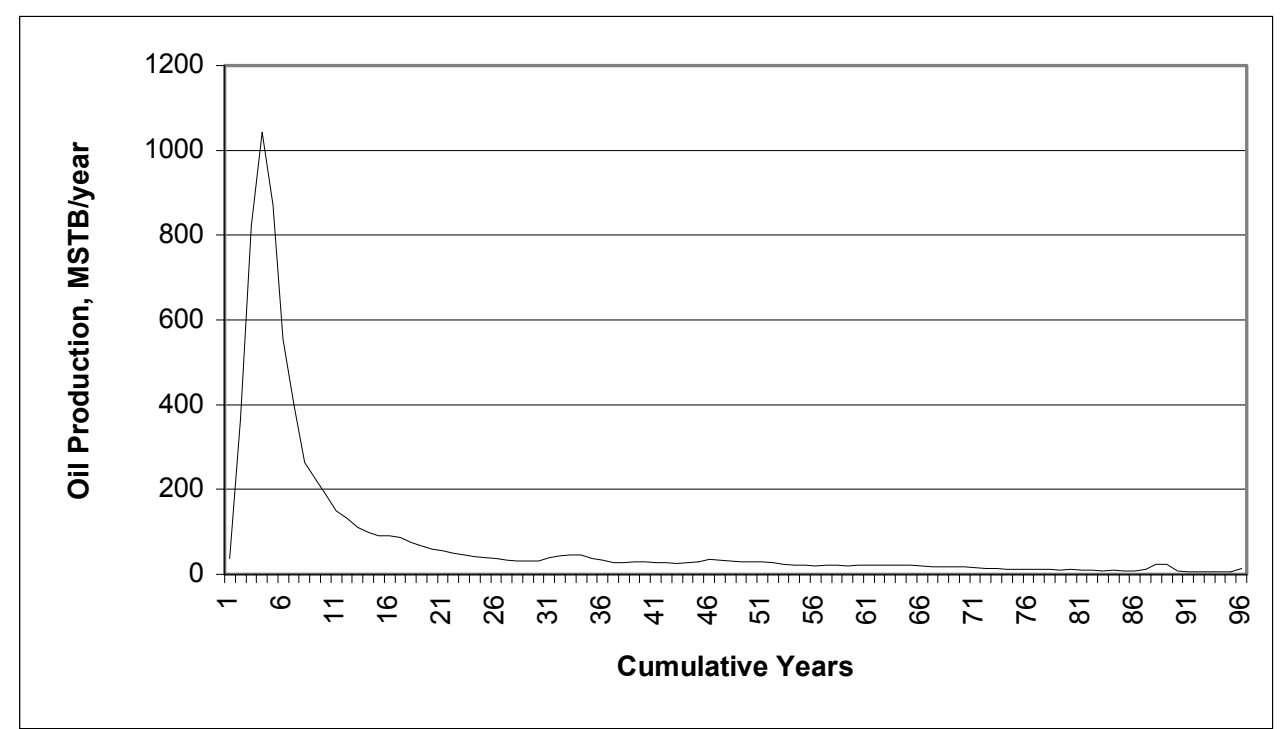

Figure 2.2 Daily Oil Production in the Jacksonburg-Stringtown Field 1896-1991

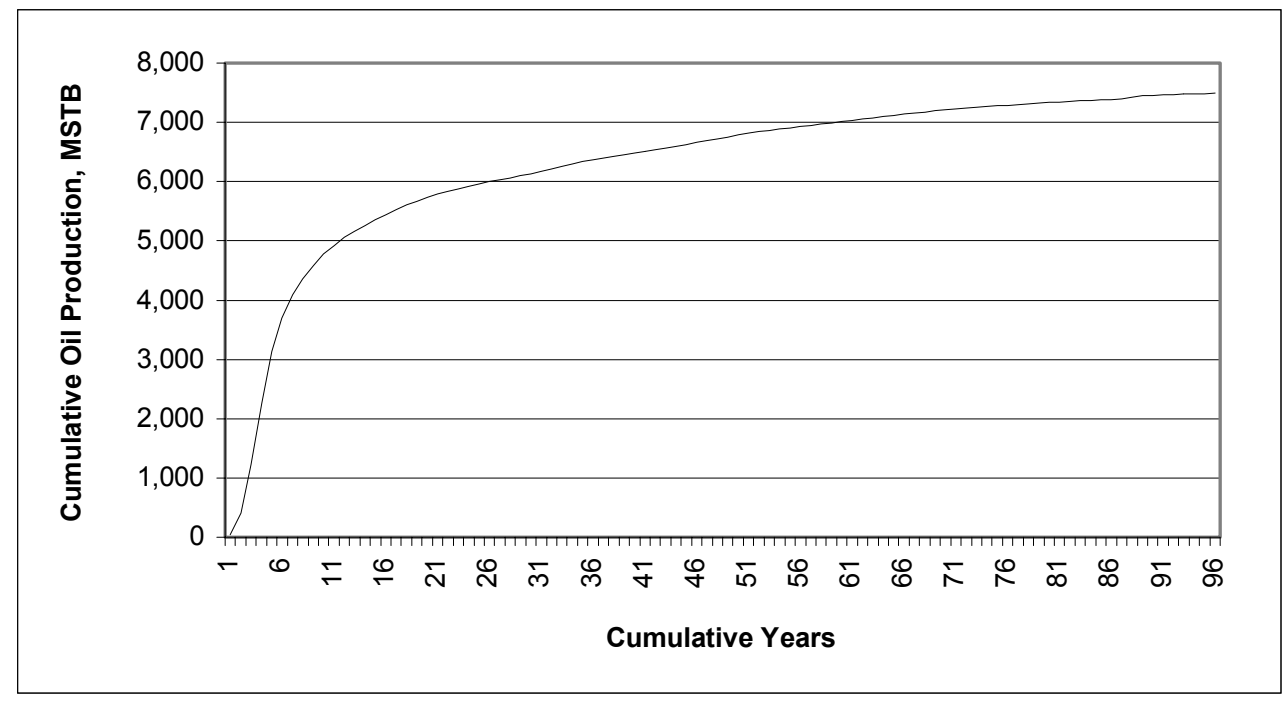

Figure 2.3 Cumulative Oil Production in the Jacksonburg-Stringtown

Field 1896-1991 
In the mid 1930's a gas re-injection program commenced and continued through the 1950's. Five injection wells were utilized in the field. Additional recoveries, due to gas re-injection, were limited to only portions of the field. Table 2.1 is a summary of recovery estimates from various internal company reports.

The Gordon sandstone formation depth ranges from approximately 2,800 feet to 3,100 feet. The surface elevation above sea level varies from approximately 925 feet to 1,150 feet, which accounts for nearly all of the depth variation. Company records indicated an oil viscosity of $3.5 \mathrm{cp}$ at $85^{\circ} \mathrm{F}$ and a gravity of $45.3^{\circ} \mathrm{API}$ at $60^{\circ}$ F. Table 2.2, 2.3, and 2.4 summarize the oil, gas and production water properties as reflected in company records.

Table 2.1 Field Recovery Summary

\begin{tabular}{|lc|}
\hline \multicolumn{1}{|c}{ Description } & Barrels Per Acre \\
Primary Recovery Estimate (King, 1980) & 1,454 \\
Primary Recovery Estimate (Morrison, 1991) & 1,590 \\
Gas Re-Injection Recovery (Boone, 1986) & 154 \\
34 Acre Pilot Waterflood Recovery (Boone, 1986) & 1,300 \\
(Recovery estimates captured from internal Pennzoil correspondence)
\end{tabular}


Table 2.2 Crude Oil Analysis

\begin{tabular}{|l|l|}
\hline Property & \\
\hline Crude Gravity, $^{\circ} \mathrm{API}$ & 45.3 \\
\hline IBF, ${ }^{\circ} \mathrm{F}$ & 96 \\
\hline${\text { Viscosity @ } 85^{\circ} \mathrm{F}}$ & $3.5 \mathrm{cp}$ \\
\hline Density @ $85^{\circ} \mathrm{F}$ & $0.7903 \mathrm{~g} / \mathrm{ml}$ \\
\hline$\%$ Tar & 1 \\
\hline
\end{tabular}

Table 2.3 Gas Analysis

\begin{tabular}{|l|l|}
\hline Property & \\
\hline Specific Gravity & 0.628 \\
\hline BTU/CF @ 14.73 psia & \\
Dry Basis & 989.8 \\
Wet Basis & 972.6 \\
\hline Molecular Weight & 18.2 \\
\hline Compressibility Factor & 0.998 \\
\hline
\end{tabular}

Table 2.4 Produced Water Analysis

\begin{tabular}{|l|l|l|}
\hline Property & M-1 & H-12 \\
\hline Specific Gravity @ 75 ${ }^{\circ}$ F & 1.089 & 1.002 \\
\hline PH & 4.3 & 7.46 \\
\hline $\begin{array}{l}\text { Total Dissolved Solids, } \\
\text { mg/l }\end{array}$ & 129116 & 7006 \\
\hline
\end{tabular}


In 1981, a dual five spot pilot waterflood was commenced in the field. The pilot area covered 34 acres of the reservoir. An average of 1,300 barrels of oil per acre (BOPA) was recovered in four years (Boone, 1986).

Based on the pilot recoveries; development proceeded to a full-scale waterflood of the field. Over 140 new wells were drilled as injectors or producers. The terrain dictated that some wells be drilled directionally to their bottom hole target location. Some infield sites remain to be drilled. Secondary recovery of the field is currently in progress.

\subsection{Geologic Overview}

The producing horizon in the field is the Upper Devonian Gordon sandstone. The formation is known to be extremely heterogeneous as a result of stratigraphy, structure and post diagenetic impact (Figure 2.4). Gross thickness can be up to $\mathbf{5 0}$ feet. The pay thickness varies from 4 feet up to 20 feet. Permeability can range from $<5 \mathrm{md}$ to values in excess of $250 \mathrm{md}$. This varying thickness is due to a non-uniform pre-depositional surface and erosional impact during post deposition. The sand is a shallow marine, shoreline deposit trending in a northeast-southwest direction. In portions of the field the pay zone is situated below a conglomerate. Permeability within the conglomerate varies widely. 
As a result the conglomerate can act either as a highly permeable thief zone for injected fluids or be impermeable for fluid flow. Figure 2.5 presents a core description and associated electric log for the Ball \# 18 well. This well is one of the core wells in the field and is also in the portion of the field used for verification.

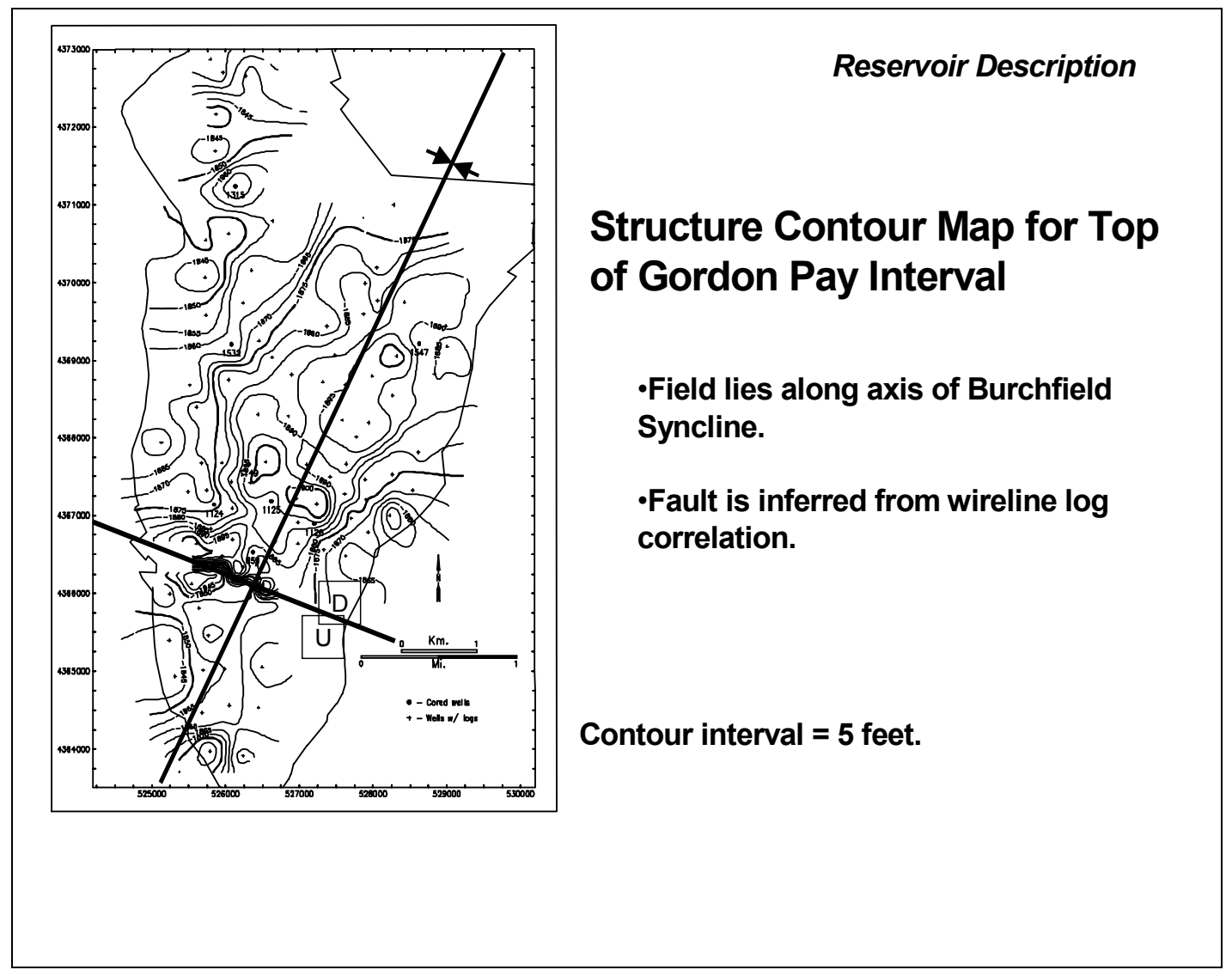

Figure 2.4 Structure Contour Map - Top of Gordon Sand 


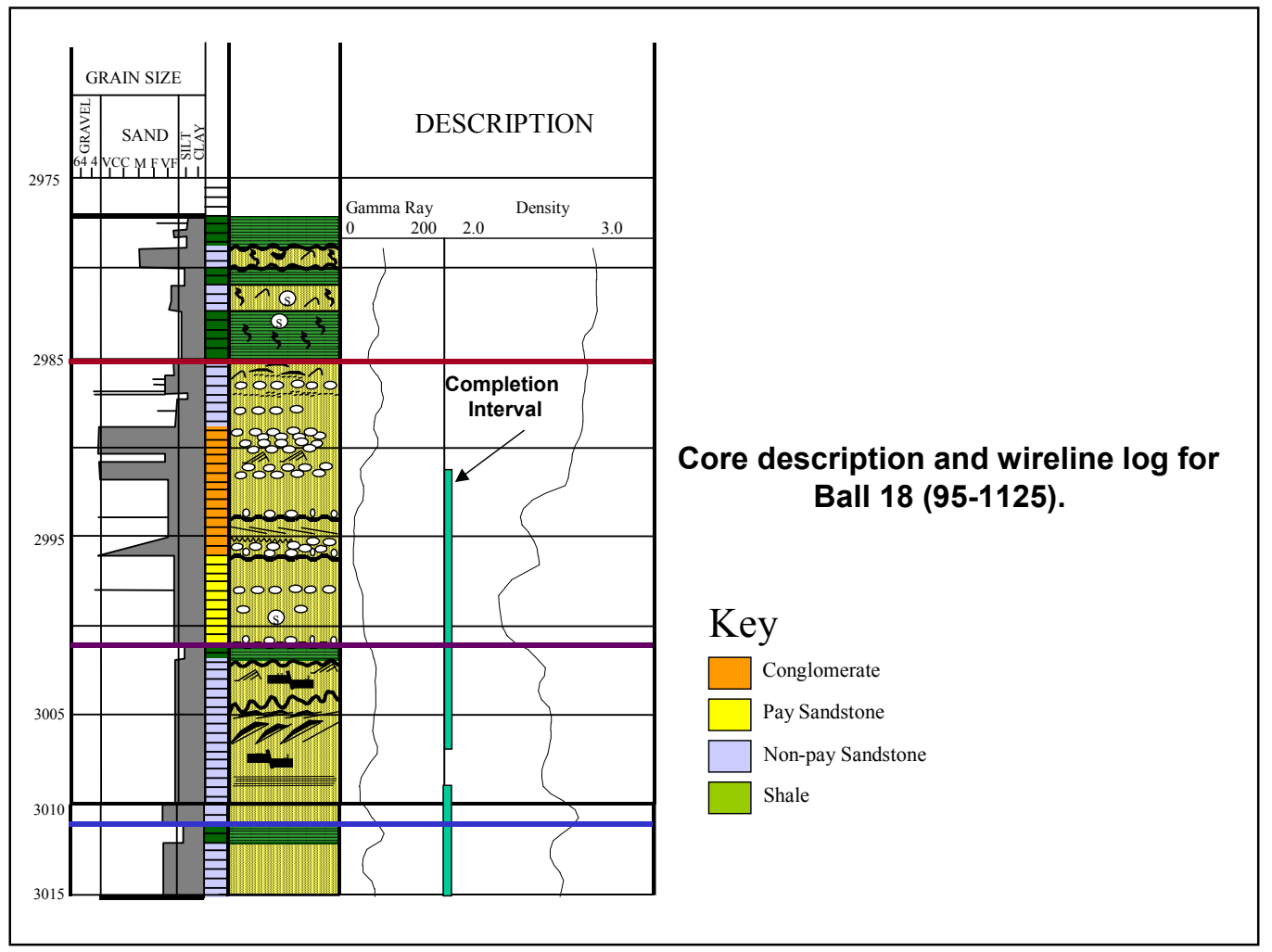

Figure 2.5 Core Description and Electric Log for Ball \# 18 


\section{CHAPTER 3}

\section{RESERVOIR CHARACTERIZATION}

AND THE FLOW UNIT

\subsection{Introductory Discussion}

In 1977 Forrest F. Craig authored a paper titled "Optimized Recovery Through Continuing Interdisciplinary Cooperation" (Craig, 1977). Craig noted that prior to numerical simulation reservoir models - detailed geological and performance data was not useful for the common hand calculations frequently done for reservoir prediction. The reservoir engineer had more data than could be used in the model(s). As a result, there was little need for close communication between the geologist and engineer.

However, as more advanced technology became available to the reservoir engineer, the need for information flow within the organization began to increase. The author recognized that we had entered a period where the capability of the tools to use reservoir data exceeded the availability of the data. As a result of the additional capability, the reservoir engineer finds himself seeking more data, both in quantity and detail from the geologist, production engineer, and other technical staff members. The geologist, as well, is able to use this open flow of information to enhance his understanding of the geologic process. Accordingly engineering and geologic skills, strengthened by ongoing information exchange, 
interpretation and judgment, guide our understanding of the reservoir.

Reservoir characterization is an ongoing process of defining reservoir properties and geological conditions for evaluating reservoir performance and forecasting future behavior (Neog, 2000). As a result geology, geophysics, and engineering are utilized in order to fully characterize a given reservoir.

\subsection{Reservoir Description}

Ideally the economic benefit of reservoir characterization is being realized in new and existing fields. In the United States most field discovery and development has occurred. Reservoir characterization is a process whereby ultimate recoverable reserves can be increased. "Only when a clear picture of the reservoir is developed can it be determined whether new technology should be applied, which reservoirs to apply it to, and what the timing of the application should be" (Holtz, 1996). The process of developing of a reservoir description should be initiated during the early stage of reservoir development. However, some companies elect to postpone the investment of staff and expenses required for characterization work. 
The development of a reservoir description or the characterization process can be broken down into four major study areas (Willhite, 1986).

- Rock Studies

- Framework Studies

- Reservoir Quality Studies

- Integration Studies

Rock Studies

Identifying the depositional environment is an essential step in order to estimate reservoir properties. The geologist will study the cores, analyze thin sections, and develop a vertical sequence of sedimentation. One objective is a three-dimensional analysis of the reservoir rock distribution as a result of depositional conditions. The rock study is to correlate the rock properties of permeability, porosity, and capillary pressure with the identified rock types. As a part of this study, other considerations may include vertical versus horizontal permeability, water saturation versus permeability and porosity versus permeability. The geologist will also identify various "facies" within the reservoir. This term is used to describe a sedimentary body having distinct physical, chemical and biological attributes (Monroe, 1992). 
Framework Studies

The purpose of the framework study is to determine the number and distribution of reservoir zones. Efforts to determine reservoir continuity identify flow barriers and non-reservoir zones are essential. Correlation work between wells using logs, cores, core descriptions and seismic data are needed to complete the framework step. In sandstone formations understanding the shale barriers and the separation of sand units in the reservoir occurs as a part of the framework analysis.

Reservoir Quality Studies

The objective of the reservoir quality study is to identify and describe variations in rock properties and fluid saturations in the reservoir. In the event more than one zone or intervals with different properties exist the properties are defined for each zone. This includes net sand thickness and fluid saturations. Net sand is an essential part of the study. Minimum values of hydrocarbon saturation, porosity or permeability values are frequently used. Relationships between porosity and permeability are often analyzed graphically. In addition, directional permeability can also be evaluated. The geologist's understanding of the depositional environment coupled with core results greatly enhances the level of reservoir knowledge. An understanding of directional permeability 
can also have significant impact on reservoir development and recovery design.

Within a given facies the reservoir properties can vary significantly. This variation has lead to a further subdivision known as Flow Units (FU). Flow units are regions in the sedimentary sequence that are judged to control the movement of injected or produced fluids within the reservoir (Hearn, 1984). Further discussion will be dedicated to this concept in section 3.7.1.

Integration Studies

The final step during the process of developing a reservoir description is to transfer the study results into a three-dimensional model of the reservoir. Generally the three-dimensional model of the reservoir is designed as a mathematical model. The objective is to build a model that will predict production similar to actual results and handle field modifications in order to simulate future reservoir performance.

As new production history is gained, wells are drilled and/or updated reservoir data is gained the reservoir description can be adjusted. During field development until the field approaches abandonment this process should be considered ongoing. After a valid model is built various future development alternatives can be tested via the model. As a result, the ultimate recoverable reserves, 
estimated development costs and risk adjusted economic analysis can be developed in order to identify the optimal development plan for a given reservoir.

\subsection{Permeability-Porosity Relationship}

The classic scatter plot of permeability versus porosity on semi-log scale has historically been utilized to aid in identifying the relationship between core permeability and core porosity. Amaefule and others (1993) noted that there is apparently no theoretical basis to support this traditional cross plot and that permeability plotted as a function only appears to be log normally distributed. Often times the scatter of the data negates the value of this technique. Using the core data the empirical permeability is estimated from the log derived porosity equation:

$$
\log k=a \phi+b
$$

It has been documented that porosity is generally not dependent upon grain size. As a general rule permeability is very much grain size dependent. Amaefule and others (1993) illustrated this by considering a reservoir having high and low permeability zones. In their example the porosity was equal for two cores having high and low permeability. As a result the researchers noted the limitation of the classic approach. However, it was observed that 
different porosity-permeability relationships are supporting detail regarding the presence of multiple flow units.

\subsection{Pore Geometry}

Davies (1999) further discussed the permeability-porosity relationship. In the case study the plot of all data exhibited significant scatter. Davies sought to characterize the reservoir in terms of pore geometry. Changes in pore geometry in the reservoir can occur due to changes in lithology, the depositional environment and chemical changes that have occurred post deposition. Such events impact grain size, grain shape, sorting and packing. Using pore geometry as a basis the researchers identified individual rock types in the reservoir. As a result of the subdivision plots of permeability versus porosity supported the rock type breakdown.

The researchers presented a methodology for reservoir characterization directed at permeability prediction and the resulting improvement in predicting production or injection behavior. Davies and others (1999) investigated and analyzed the "rock type" in two reservoirs. They characterized rock types based on unique pore geometry. The method utilized image analysis via a scanning electron microscope specially equipped for automated image analysis procedures in order to identify various pore geometries. When integrated with other petrophysical measurements (porosity, 
permeability, etc.), rock types of non-cored sections were identified from the logs. As a result the reservoir can be defined in terms of flow units.

Pore geometry analysis coupled with log data allow for significant reservoir characterization. The parameters of pore geometry measurement consider several different aspects of the pore and pore system in order to identify and/or differentiate the rock types. Core samples and at times, under favorable circumstances, samples from drill cuttings are utilized for pore geometry analysis. Ideally core samples are removed from the core for testing at predetermined intervals (.5-1.0 feet) through the entire pay section. These samples are used to determine typical petrophysical properties (porosity, permeability, relative permeability, capillary pressures etc.). Thin section and scanning electron analysis related to pore geometry modeling must be taken from the same core plug sample area. This is essential in order to correlate the pore geometry analysis with the petrophysical properties.

At the microscopic level a core description was developed which categorized the texture and lithology for each core sample. The thin section and electron microscope analysis results in direct measurement of shale and clay volumes, grain size detail, sorting analysis, and mineral composition. This analysis is done at each core point for correlation with the petrophysical and log properties. 
Davies and others (1999) classified pore types in terms of several parameters. The scanning electron microscope is essential for this type of analysis:

- Pore Size and Shape - Determined via scanning electron work.

- Pore Throat Size - Determined via scanning electron work and capillary tests.

- Aspect Ratio - Ratio of pore body to throat size.

- Coordination Number - The number of pore throats intersecting each pore.

- Pore Arrangement - Pore distribution is analyzed via the scanning electron work.

The researchers utilized the pore typing method and other analysis to characterize the rock at the pore structure level. Davies and others noted that the pore geometry directly controls hydrocarbon displacement efficiency. In many reservoirs the original depositional environment or lithology are not adequate to properly characterize the reservoir. Digenetic processes are known to alter the permeability-porosity relationships.

Pore geometry analysis does not consider depositional environment of lithology. Within each rock type porosity and permeability is related strictly to pore structure. The traditional semi-log plot of permeability versus porosity resulted in a high degree of scatter in the Davies and others (1999) research. In this case study porosity and permeability were closely related for each 
rock type or pore structure. Regression analysis equations were developed for each rock type. The equations were then used for a field wide permeability prediction.

The North Robinson Clearfork Unit selected by Davies and others (1999) as a case study field has a thick productive pay section. Historically the producing and injection wells had been perforated based on porosity detail gained from electric logs (perforate and stimulate the highest porosity sections). The log suite included the gamma ray, photoelectric factor, bulk density, neutron porosity and dual laterolog. Higher permeability rock types had lower porosity. The highest porosity sections occurred in rock types having low permeability. The method of perforation selection and zone completion needed modification.

Flow units were identified by evaluating the rock type and the petrophysical properties within each rock type. Flow units having different hydraulic properties will have different pore throat properties as well. Accurate flow unit identification can occur by detailing changes in the pore throat system. This analysis leads to a layering profile, which was useful in identifying distinct flow units. As a result the outcome of reservoir modeling more closely matched actual production results. In addition future in-fill wells could be better identified. 


\subsection{Outcrop Derived Models of Permeability}

The ability to predict reservoir permeability within the reservoir remains difficult variable to determine. Often times the data gained by core analysis from the reservoir is not adequate to predict permeability distribution in the reservoir. As the reservoir becomes more heterogeneous the ability to predict becomes further reduced. One approach to better understand the scales and magnitude of reservoir heterogeneity of a given reservoir is to evaluate exposed outcrops having similar or analogous sediments.

Successful outcrop studies can lead to permeability modeling within a given reservoir by gaining valuable permeability data from the outcrop. Outcrops selected typically exhibit similar lithologic and sedimentologic features and are approximately the same geologic age. The outcrop is exposed and as a result the measured permeability can be impacted.

Lewis (1988) noted that the main cause of reservoir heterogeneity is depositional architecture. The researcher suggested that a series of scales could be used to classify the variables resulting from reservoir heterogeneity. Such a classification system could be from outcrops. The results can then be applied to a specific reservoir - adjusted to the reservoir based on

actual core data. A major assumption of this approach is that the "porosity and permeability measured at the outcrop is analogous to 
those in similar sediment types in the subsurface" (Lewis, 1988). Lewis limited his study to carbonates and did not discuss digenetic impact. This application is limited in the Appalachian Basin due to the lack of outcrops from producing or analogous formations that can be utilized.

\subsection{Pre-Flow Unit Review}

D.G. Harris (1975) discussed the role of geology in reservoir simulation studies. The primary thrust of Harris's work was to describe the geologic activities needed for building realistic mathematic reservoir models. Harris identified and discussed four stages of the geologic activity. In 1986 Willhite drew heavily from this work and incorporated more of the teaming aspect (engineering and geology) in the four steps.

- Step One: Rock studies to establish lithology, to determine depositional environment and to distinguish reservoir rock from non-reservoir rock;

- Step Two: Framework studies to establish the structural style and determine the three dimensional continuity character and gross thickness trends of the reservoir rock;

- Step Three: Reservoir quality studies to determine the framework variability of the reservoir rock in terms of porosity, permeability and capillary properties and

- Step Four: Integration studies to develop the hydrocarbon pore volume and fluid transmissibility pattern in three dimensions. 
Of particular interest in this very detailed process is the identification of the "key" rock units. This description was for identifying the lithological unit and included shale, siltstone and sandstone. By 1975 researchers recognized the value of characterizing the lithology of the reservoir.

Craig and others (1975) discussed the need for reservoir development and management to occur through teams developed from various technical disciplines. The researcher noted that the progress of reservoir simulation software to handle reservoir data had necessitated the need for increased communication and information sharing between the geologist, production engineer and reservoir engineer. Craig recognized the need to call upon the geologist, with his knowledge of depositional processes, to provide more reservoir descriptions for use in engineering calculations. Further, he recognized the reservoir engineer's need, with his understanding of fluid flow mechanisms, to relate all available pressure and production data to the geologic descriptions so that the most likely possibilities may be considered. 
In 1981 researchers Hunt and Hearn (Hearn, 1981) presented an initial case study titled "Reservoir Management of the Hartzog Draw Field". This case study is important to this research for two reasons:

1. The research and analysis of this field ultimately leads to the recognition, identification and definition of the flow unit.

2. This case study demonstrates the value of bringing technical expertise together in order to fully interpret a reservoir for maximum understanding.

The Hartzog Draw Field is located in the Powder River Basin. The field was discovered in 1975 and is twenty-two miles long and varies in width from one to four miles. Within the field, the working interest ownership was held by 85 different operators. In 1977 the Hartzog Draw Operators Committee was formed. The operators were interested in unitizing the field so that secondary or enhanced recovery could be considered as field development progressed. The committee organization formed several producer sub-committees as follows:

- Technical Committee

- Geologic Committee

- Formation Evaluation Committee

- Fluids and Pressure Committee

- Special Studies Committee 
In order to accomplish the unitization objective the process required a complete reservoir analysis. As a result of bringing the various producers together onto the various committees field data and knowledge transfer was maximized. Open communication between the committees was an integral part of the process. The primary objective of the case study was to present the unitization process which included the gathering and processing of all technical field data and required cooperation between the various working interest owners of tracts in the field.

The process presented the opportunity to review actual results with predicted pilot flood results for a field, which received significant technical attention and analysis. The planned pilot called for a 160 -acre pilot waterflood. A layered reservoir approach was used as a means of accounting for the varying permeability.

\subsection{The Flow Unit}

\subsubsection{The Hartzog Draw Field}

In 1984 researchers Hearn, Ebanks, Tye and Ranganthan published research results for the Hartzog Draw Field titled "Geological factors Influencing Reservoir Performance of the Hartzog Draw Field, Wyoming". Intense data gathering and interpretation had previously occurred. In addition the researchers had the performance results of a pilot waterflood. Nine new wells 
drilled as a part of the pilot program were fully cored. The earlier work of breaking the reservoir down into lithology units did not work well. There was significant variability in the reservoir properties of each facies.

The "Flow Unit" concept was introduced. The reservoir was subdivided into different intervals. Flow units were used to determine the distribution of rock types that most strongly controlled behavior as fluids were produced or injected. Hearn, Ebanks and others (1984) defined the flow unit as a reservoir zone that is continuous laterally and vertically, and has similar permeability, porosity, and bedding characteristics.

"The stratigraphic sequence of the facies is based on their occurrence in vertical sections, such as outcrops or cores. This sequence is the framework in which the flow units are defined on the basis of not only their geologic characteristics and position in the vertical sequence but also on their petrophysical properties, especially porosity and permeability. Certain ranges of porosity and permeability that occur in a particular part of the sedimentary sequence are used to subdivide the reservoir along lines that represent gradations in reservoir quality - i.e., the ability of the rocks to transmit fluids, both laterally and vertically" (Hearn, Ebanks and others, 1984). 
The flow unit concept provided for a more:

- quantitative definition and mapping of the parts of the reservoir in terms of reservoir behavior and

- realistic building block for reservoir zonation which was beneficial to numerical simulation of the reservoir performance.

In the case study the researchers analyzed potential variables

that resulted in different flow units being identified. These included:

1. Pore Size Distribution: Pore size distribution was determined on various core samples from mercury injection data. Average pore size distribution curves were generated for each flow unit. The data plots of the saturated pore volume (\%) versus radius of pores supported five flow units having different pore networks.

2. Bedding: The reservoir in the case study contained different sedimentary structures in different facies of the Shannon sandstone. In three flow units it was determined that the shale laminae did not have significant lateral extent. This lead to the conclusion that the laminae in these units would not impact reservoir continuity between the producer and injector wells. The analysis of the other unit and the lowest section of one of the above units confirmed "more continuous" shale laminae between the thin sandbeds and would therefore impact flood performance.

3. Vertical Permeability: Although not useful for flow unit identification in the case study, the authors briefly discussed the value of vertical/horizontal core permeability ratios as a potential tool to identify different flow units.

4. Mineral and Pore Geometry: "Pore geometry is a resultant of several different diagenetic, that is, post depositional, physical and chemical processes" (Hearn, 1984). Different facies will contain different proportions of minerals. Diagenetic processes operate differently as the proportions of minerals vary. The authors evaluated the cores in terms of percent of clay, the compaction of ductile grains and the resulting loss of primary porosity due to glauconite, chert, and rock fragments. 
In addition, porosity enhancement resulted from dissolution of portions of the carbonate - primarily the calcite. This resulted in significant changes to the geometry of the pore system. For portions of the reservoir having high percentages of clay $(20 \%$ versus $3 \%$ ), the pores were clay lined. This clay, which serves as a cementing agent has reduced the porosity. This portion of the reservoir had very low permeability.

5. Water Saturation: Connate water saturation was found to vary based on rock type and porosity. Reservoir performance is impacted by rock composition and texture.

In the study two wells were drilled on an oil-based mud in order to gain connate saturation data. The various facies were grouped into three general categories. Table 3.1 summarizes the research results.

Table 3.1 Values of Porosity and Water Saturation from Analysis of Wells Cored with Oil-Based Muds (Hearn, 1984)

\begin{tabular}{|l|l|l|l|}
\hline Rock Type & Flow Units & Porosity \% & Water Saturation \% \\
\hline $\begin{array}{l}\text { Least Clay } \\
\text { Matrix - } \\
\text { No Shale } \\
\text { Laminae }\end{array}$ & $3,4,5$ & $14-20$ & $5-24$ \\
\hline $\begin{array}{l}\text { Moderate Clay - } \\
\text { Few Laminae }\end{array}$ & 2,3 & $8-14$ & $15-40$ \\
\hline $\begin{array}{l}\text { Abundant Clay - } \\
\text { Many Laminae } \\
\text { Burrows }\end{array}$ & 1 & $5-11$ & $36-60$ \\
\hline
\end{tabular}

Hearn, Ebanks and others (1984), was able to recognize and map five flow units in the pilot area. The basis for the flow units included stratigraphic and petrographic analysis of cores, correlation of logs, and major rock types were determined. The flow 
units identified had similar porosity, permeability, bedding characteristics and by their position in the vertical sequence. Each flow unit included stratigraphic units with similar properties for fluid flow.

Although the study lacked specific details it was noted that the identified flow units as a part of the reservoir characterization process resulted in good correlation with injection and production histories in the pilot area.

\subsubsection{The Flow Unit Concept and Discussion}

In 1987 at the annual convention of the American Association of Petroleum Geologist Ebanks presented an abstract titled "Flow Unit Concept - Integrated Approach to Reservoir Description for Engineering Projects (Ebanks, 1987). The presentation was at a round table session and no complete paper was included as a part of the proceedings. The abstract captures the flow unit concept in a concise manner and is included herein in its entirety:

"The successful application of secondary and tertiary technology requires an accurate understanding of the internal architecture of the reservoir. Engineers have difficulty incorporating geological heterogeneity in their numerical models for simulating reservoir behavior. The concept of flow units has been developed to integrate geological and engineering data into a system for reservoir description.

A flow unit is a volume of the total reservoir rock within which geological and petrophysical properties that affect fluid flow are internally consistent and predictably different from properties of other rock volumes (i.e. flow units). Flow units are defined by 
geological properties, such as texture, mineralogy, sedimentary structures, bedding contacts, and the nature of permeability barriers, combined with quantitative petrophysical properties, such as porosity, permeability, capillary, and fluid saturations. Studies in the subsurface and in surface outcrops have shown that flow units do not always coincide with geological lithofacies.

The flow unit approach provides a means of uniquely subdividing reservoirs into volumes that approximate the architecture of a reservoir at a scale consistent with reservoir simulations. Thus reservoir engineers can incorporate critical geological information into a reservoir simulation without greatly increasing the complexity of their models. This approach has advantages over more traditional methods of reservoir zonation whereby model layers are determined on the basis of vertical distributions of permeability and porosity from core analysis and wireline logs."

3.7.3 Comparison of Depositional, Layered and Flow Unit Models A Case Study

Slatt (1988) developed three types of reservoir description models for the Balmoral field, North Sea. These included the depositional model, layer model and the flow unit model. Slatt determined that the flow unit model provided the most complete reservoir description based on well data due to the flow unit model including a variety of geological and petrophysical properties. The researcher also noted that the model can provide inputs for reservoir simulation work and has value for reservoir development and improved management. Tables 3.2 and 3.3 summarize the properties of the layered versus the flow unit model.

The depositional model was developed via a core analysis of sixteen wells. The detailed core analysis was used to correlate to the 
log responses. Other tools used to interpret the environment were isopached stratigraphic intervals and correlations with other similar field examples.

Table 3.2 Properties of the Layered Model (Slatt, 1988)

\begin{tabular}{|c|l|c|l|}
\hline LAYER & FACIES & $\begin{array}{l}\text { AVERAGE } \\
\text { POROSITY \% }\end{array}$ & $\begin{array}{l}\text { AVERAGE } \\
\text { PERMEABILITY } \\
\text { (md) }\end{array}$ \\
\hline I & Channel Sand & 26.4 & 956 \\
\hline II & $\begin{array}{l}\text { Slope } \\
\text { Claystone }\end{array}$ & Low & Low \\
\hline III & Channel Sand & 27.1 & 1378 \\
\hline IV & Fan Lobe Sand & 28.2 & 593 \\
\hline V & $\begin{array}{l}\text { Fan Lobe } \\
\text { Channel Sand }\end{array}$ & 28.4 & 489 \\
\hline
\end{tabular}


Table 3.3 Properties of the Flow Unit Model (Slatt, 1988)

\begin{tabular}{|c|c|c|c|c|c|c|}
\hline $\begin{array}{ll}\mathbf{F} & \mathbf{U} \\
\mathbf{L} & \mathbf{N} \\
\mathbf{O} & \mathbf{I} \\
\mathbf{W} & \mathbf{T}\end{array}$ & $\begin{array}{l}\mathbf{P} \\
\mathbf{E} \\
\mathbf{R} \\
\mathrm{M} \\
\mathrm{md}\end{array}$ & $\begin{array}{l}\text { Poro- } \\
\text { sity } \\
\%\end{array}$ & $\begin{array}{l}\text { Md GRAIN } \\
\text { SIZE (mm) }\end{array}$ & $\begin{array}{l}\text { Md } \\
\text { PORE } \\
\text { THRT } \\
\text { SIZE } \\
(\mathbf{m m})\end{array}$ & $\begin{array}{l}\text { SATURATION } \\
\text { BRINE @ 200 } \\
\text { psi (\%) }\end{array}$ & $\begin{array}{l}\text { CHARACTER- } \\
\text { ISTICS }\end{array}$ \\
\hline $\mathbf{E}$ & $\begin{array}{l}> \\
1000\end{array}$ & $\begin{array}{l}23- \\
34\end{array}$ & $\begin{array}{l}.182- \\
.304\end{array}$ & $\begin{array}{l}.01- \\
.013\end{array}$ & $6-12$ & $\begin{array}{l}\text { Large Sand } \\
\text { Channel } \\
\text { Facies }\end{array}$ \\
\hline $\mathbf{G}$ & $\begin{array}{l}100- \\
1000\end{array}$ & $\begin{array}{c}20- \\
34\end{array}$ & $\begin{array}{l}.083- \\
.242\end{array}$ & .007 & $11-24$ & $\begin{array}{l}\text { Massive Sanc } \\
\text { Channel/ } \\
\text { Lobe Facies }\end{array}$ \\
\hline Pc & $\begin{array}{c}.01- \\
> \\
1000\end{array}$ & $\begin{array}{l}4- \\
28\end{array}$ & $\begin{array}{l}.113- \\
.245\end{array}$ & .002 & 30-37 & $\begin{array}{l}\text { Massive Sanc } \\
\text { with Calcite } \\
\text { Cement } \\
\text { Zones } \\
\text { Channel } \\
\text { Lobe Facies }\end{array}$ \\
\hline $\mathbf{P i}$ & $\begin{array}{l}.1- \\
> \\
1000\end{array}$ & $\begin{array}{l}7- \\
32\end{array}$ & $.1-.23$ & .002 & 31 & $\begin{array}{l}\text { Interbedded } \\
\text { Sand Mud } \\
\text { Channel } \\
\text { Lobe Facies }\end{array}$ \\
\hline Pm & $\begin{array}{l}\text { No } \\
\mathbf{k}\end{array}$ & $\begin{array}{l}\text { No } \\
\mathbf{k}\end{array}$ & - & - & - & $\begin{array}{l}\text { Clay } \\
\text { Mudstone }\end{array}$ \\
\hline
\end{tabular}

The researchers followed with a second case study report on the Balmoral field in 1990. Slatt (1990) noted that the flow unit model allowed for the interpretation of many of the geological and 
petrophysical properties into the reservoir description. As a result the level of reservoir understanding is increased and the best inputs for simulation models are developed which leads to improved recovery and reservoir management (Slatt, 1990).

The depositional model was useful for identifying regional trends of given facies and providing valuable information regarding sediment transport paths and the depositional environment. However, the model could not be utilized in terms of useful engineering applications.

The layered model was designed to meet three criteria in addition to being utilized to calculate volumetrics of the reservoir. The model was to:

1. Have a simple design and offer simple layers.

2. Layers selected should have a geologic basis.

3. The reservoir properties should vary between layers.

4. The core plug porosity and permeability data must be used in the model developed.

The core data utilized included 818 core plugs. It was determined that the various reservoir facies would be used to satisfy condition three. Accordingly a five-layer model was designed that was useful for more accurate reservoir volumetrics. Electric logs include gamma ray-density log, sonic log and resistivity logs. Other logs were not referenced in the case study. 


\subsubsection{Identifying Flow Units Using Flow Capacity and Storage Capacity as Indicators}

Guangming, etal (1993) examined the Endicott Field situated on the North Slope of Alaska. The researchers sought to use core data and well log data as a means to predict permeability and the resulting flow units previously identified in the core wells. Regression analysis between core data and well log data was utilized. The researchers had full interval core data available for every $1 / 2$ foot of the interval for the cored wells. Data included vertical and horizontal permeability and porosity. Digitized log data was compiled in a like manner. Some of the logs utilized in the study included gamma ray density porosity, sonic porosity, and resistivity logs. The figures presented indicate that productive intervals are up to 1,000 feet thick. Core data at $1 / 2$ foot intervals from eleven wells situated across the field were utilized.

The researchers broke the formation down into facies (depositional environment) representing major zones. The major zones were further broken down into sub-zones. The mechanism to determine the flow units considered $k-h, \phi-h$, and the ratio of net to gross sand within the sub zones. The researchers utilized three screening methods to differentiate the sub zones: 
1. (Point Permeability) - (Average Permeability of the Zone) (Average Permeability of the Zone)

2. (Shale Content of .5 ft Section) - (Average Shale of the Zone) (Average Shale of the Zone)

3. (Porosity of $.5 \mathrm{ft}$ Section) - (Average Porosity of the Zone) (Average Porosity of the Zone)

The researchers defined the flow unit as a volume of rock body having similar properties that influence the flow of fluids through it (Guangming, 1993). As a result they proposed to group the sub zones based on their transmissibility, storativity, and net to gross ratio.

Cluster analysis was used to break out the sub zones into four specific flow units. The researchers used a statistical analysis procedure to predict permeability. Observations regarding this research include:

1. The core database was extensive. Approximately 20,000 data points were available.

2. The permeability prediction via the statistical analysis procedure was for all data. It was not specific to unique porosity-permeability relationships within each flow unit. 


\subsubsection{The Flow Zone Indicator}

Amaefule, Tiab and others (1993) proposed a new method to identify and characterize flow units. The technique developed by Amaefule, Tiab and others is focused at extracting characterization detail at the pore throat level or scale. Further discussion regarding pore throat analysis is included in the reservoir characterization section (Davies). The pore geometry determines the hydraulic quality of the rock. Amaefule, Tiab and others (1993) demonstrated a methodology by which reservoir pore throats are analyzed which results in the ability to identify flow units with similar hydraulic properties.

The researchers developed this new methodology by modifying the Kozeny-Carmen equation. This equation expressed permeability in terms of porosity and specific surface area. Three new terms were defined as a part of the research:

$$
\begin{array}{ll}
\text { Flow Zone Indicator (FZI): } & 1 /\left(\left(\mathrm{Sv}_{\mathrm{gr}}\right)\left(\mathrm{k}_{\mathrm{z}}\right)^{.5}\right) \\
\text { Reservoir Quality Index (um): } & .0314\left(\mathrm{k} / \phi_{\mathrm{e}}\right)^{.5} \\
\text { Normalized Porosity Index }\left(\phi_{\mathrm{z}}\right): & \begin{array}{r}
\phi_{\mathrm{e}} /\left(1-\phi_{\mathrm{e}}\right) \\
=
\end{array} \\
& \text { effective pore volume } \\
& \text { to grain volume ratio }
\end{array}
$$

Where $S v_{g r}$ is defined as the specific surface area per unit grain volume, $k_{z}$ is the Kozeny constant, which reflects grain shape, pore 
shape and tortuosity for the flow unit. The FZI value is considered to be constant within a flow unit.

$\mathrm{FZI}$ is also defined as:

$$
\mathbf{F Z I}=\mathbf{R Q I}{ }^{*} \phi_{\mathbf{z}}
$$

The derivation from the Kozeny-Carmen equation yields the following logarithmic relationship:

$$
\log R Q \mid=\log \phi_{z}+\log F Z I
$$

A log-log plot of data from a given flow unit or similar FZI value will be situated on a straight line with a slope of 1.0. The researchers further demonstrated that other flow units will fall on adjacent parallel lines. Each flow unit will have a separate FZI value. The FZI value or indicator will be for a given flow unit having similar pore throat characteristics (Tiab, Donaldson, 1996). Further the value of FZI can be determined from the intercept at $\phi_{z}=1.0$. The researchers also presented a permeability prediction equation utilizing the FZI value:

$$
k=1,014(F Z I)^{2} \quad\left(\phi_{\mathrm{e}}^{3} / \phi_{\mathrm{e}}^{2}\right)
$$

The flow zone indicator incorporates the geological considerations including flow unit specific pore geometry. As a result, flow unit analysis can occur when complete petrophysical data from the core is available. Lacking geological input and guidance results in statistical techniques being used to identify flow 
units. These may include frequency diagrams, error analysis, cluster analysis and normality tests.

Amaefule, Tiab and others (1993) presented summaries of six reservoir cases. The validation of the FZI concept was confirmation work using the scanning electron analysis and pore throat characterization via mercury saturation analysis.

The researchers did not include in the study results specific core plug detail regarding the number of samples or distance between core plug testing points. However, for boundary definition of the flow units core plugs for testing would need to occur at regular intervals through the entire reservoir. In addition for certain reservoirs it seems reasonable to expect transition zones between flow units. This also was not discussed in the research.

Gunter and others (1997) endeavored to develop graphical tools that would determine the number of flow units within the reservoir. This method requires continuous core porosity, permeability and saturation detail for the entire horizon. The researchers considered the flow unit to be a stratigraphically continuous layer of similar reservoir process speed that maintains the geologic framework and characteristics of rock types. The rock type is considered to be reservoir units having distinct porositypermeability relationships and unique water saturations for the position in the reservoir above the free water level. A given rock 
type would be deposited under similar processes and experienced similar diagenetic processes resulting a unique permeabilityporosity relationship. The graphical tools determined to be key and utilized by the authors were:

\section{Winland Porosity-Permeability Cross Plot}

This graphical tool is a semi-log plot of permeability versus porosity. The plot has isopore throat lines, which have been calculated from the Winland equation during a capillary test run at $35 \%$ mercury saturation. The Winland equation uses permeability input in md and porosity as a percentage:

$$
\log \text { R35 = .732 + .588(k) }-.864(\log \phi)
$$

\section{Stratigraphic Flow Profile}

This graphical tool is a plot used to present the flow unit interpretation and includes a correlation log such as a gamma ray, a geologic core description, columns showing porosity, permeability, the R35 value, the permeability/porosity ratio, storage capacity and percent flow capacity. The profile is presented in various columns and is correlated with the selected log.

3. Stratigraphic Modified Lorenz Plot (SMLP)

(SMLP) is a plot of Percentage of Flow Capacity versus Percentage of Storage Capacity. The process is to display the 
cumulative percentages in stratigraphic order including each core sample. Points of inflection indicate potentially different flow units. It is important to note that water saturation must be taken into account when calculating the storage capacity. The shape and slope of the plot can provide insight into the reservoir flow characteristics. This information is then tied back to the Stratigraphic Flow Profile for correlation and analysis.

\section{Modified Lorenz Plot}

The Modified Lorenz Plot is a plot similar to the SMLP plot except the plot is based on the flow units developed prior to this step. The stratigraphic position is maintained.

Gunter and others tested the methodology on a series of reservoirs. After the flow units were identified a reservoir simulator was used for verification. The researchers did not provide any details about the simulator results for the case study reservoirs. The researchers made reference to permeability corrections which were done to take into account the affect of stress and relative permeability data at the given water saturation levels in each reservoir. No details regarding the corrections were included in the case study.

Soto and others (October, 2001) presented a case study predicting permeability using hydraulic flow units and soft 
computing systems. This study called for using the soft computing systems for predicting the flow zone indicator (FZI) which is a constant within a given flow unit or hydraulic flow unit.

The authors demonstrated that core permeability could be predicted with a high degree of confidence if the FZI value is known. The focus of the study was then directed at predicting the FZI value. The authors used a correlation model to analyze the various log variables in order to determine which were dominant. The statistical analysis determined that the gamma ray, deep resistivity and effective porosity measurements were required to generate a trustworthy model, which could predict the log of FZI.

The next step called for the application of an adaptive network based fuzzy inference system (ANFIS). The fuzzy logic toolbox from MATLAB was used. The model output was then compared to actual FZI values from core well data. The resulting $R^{2}$ value for the log-log plot of FZI core versus FZI ANFIS model was .88.

After the $\mathrm{FZI}$ is calculated the permeability is predicted using the equation for permeability prediction drawn from the previously presented work of Amaefule, Tiab, and others. Using the predicted permeability and FZI, the flow zones can be determined.

The authors utilized 412 core plug data points in the sample case. The log suites ran on the wells included resistivity, gamma ray as well as some additional specialized gamma ray logs such as 
gamma ray spectrometry measurement. Specific log information is not provided in the study. However, based on the results presented significant log information was available for this study. 


\section{CHAPTER 4}

\section{ARTIFICIAL NEURAL NETWORKS}

\subsection{Overview}

Artificial Neural Networks (ANN) are designed to mimic the biological brain in terms of pattern recognition and the learning process. Researchers have hypothesized that millions of neurons in the brain work together in parallel, each trying to solve the given problem at hand. Artificial Neural Networks are information process systems that are a rough approximation and a simplified simulation of the biological process and have performance characteristics similar to those of biological neural networks (Mohaghegh, 2000).

ANNs work very well at solving problems when it is difficult to propose exact mathematical models. Mohaghegh and others (1994) noted pattern recognition as one of the neural network's strengths. Artificial neural networks learn the nature of the dependency between input and output variables. Learning is based on pattern recognition. The network classifies new patterns and predicts an output based on the learned patterns. Neural networks often have application when relationships of parameters are too complicated or require too much time to solve via conventional methods.

There are two types of neural networks - supervised and unsupervised. Supervised networks classify patterns and make decisions based on the patterns of inputs and outputs they have 
learned. In other words during learning the output is provided as a means of training the network. Providing correct answers is an integral part of the learning/training process. Backpropagation is a common supervised network type.

The unsupervised network classifies a set of training data into a specified number of categories. The network will classify the data into the number of categories specified by the modeler. The Kohonen network is one of the most common unsupervised networks. The Kohonen network has a simple architecture of one layer of input and output. As with all unsupervised networks, the Kohonen network is provided the input data and learns without being shown the correct output for the input data. The Kohonen network is useful for separating data into a specified number of categories.

\subsection{The Neuron}

The neuron is the primary element of the ANN. The purpose of the neuron is to receive an input(s) and generate output(s) or simply stated to execute a given task. The neuron processes the information received by applying a mathematical activation function to the input thus producing an output signal. As illustrated by Figure 4.0 a typical ANN has three layers of neurons (input, middle or hidden, and output layer). Each "layer of neurons" is connected to the next neuron layer. As a result, the output of the first layer 
becomes the input for the next layer. The neuron output is "weighted" by the model in order to produce results that are close to the correct outputs in the training set. The mathematical function described above occurs in the middle layer. The ANN learns by repeatedly adjusting the weighting of the neuron outputs until the results produced are similar to the correct outputs in the training set. A useful ANN must be able to predict an output with good results for data not previously seen by the network.

\subsection{The Backpropagation Model}

Soto and others, (2001) noted that most artificial neural networks use multi-layer backpropagation architecture to apply knowledge gained from training experiences, which allows the network to make new decisions, classifications, and predictions. Often referred to as supervised training or a supervised network, the back propagation models are trained using the nodes, which reflect the input and target variables. The connections between inputs and outputs are hidden layers (the neurons). 


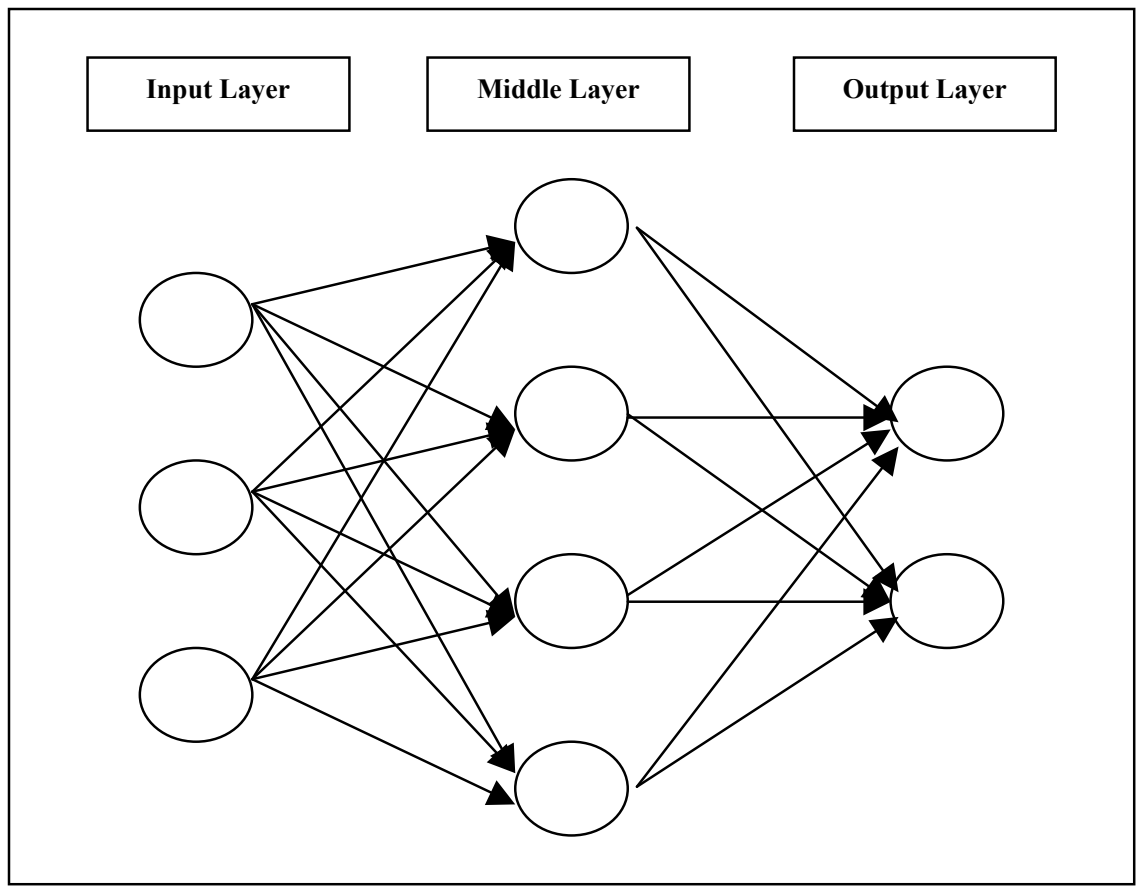

Figure 4.0 A Simplified Neural Network

At each neuron the input is composed of the weighted outputs of the previous layer. As a result of the non-linear weighting the neural network can handle very complex problems. The weighting of the inputs by the model is determined during the testing and training phase. The model-building phase continues until the error during the testing phase is minimized - or the model is optimized.

The backpropagation network compares the known output to the model prediction. The models are trained using the user selected inputs and the known outputs. The difference between the known and predicted output is propagated back through the network. The network adjusts the weighting of each neuron 
connection and learning continues until an acceptable level of error is reached. More complex neural networks can also be built that have multiple outputs as opposed to single outputs.

The database to be introduced to the neural network is broken down into three groups (training, test, verification). The training set is used to train and create the network. The actual output of the training set data is used to develop weighting of the neurons in the network. During training, as a part of the learning process, at established intervals (epoch), the test set is used as a means of testing the network. The test patterns are used to determine how well the network is working. Training continues as long as the computed output error between the actual and predicted outputs of the test set is decreasing. The weighting of the neurons is adjusted and utilizing the training set data, learning continues. In other words, training continues until the best test set output results is obtained. In summary, the final ANN is identified as the network producing of the lowest amount of error between the predicted and actual output and is based on the best test set performance.

Typically approximately $\mathbf{8 0 \%}$ of the data is used for testing and training. The other $20 \%$ of the data is categorized as verification data or the production set. This real data is not used during testing and training. The verification data has not been seen by the network. This data set is used as a test to determine if the newly built network 
can accurately predict output results. The predicted output results are compared to the actual output results.

\subsection{The NeuroShell Program}

During this research a commercially available ANN program was utilized. The NeuroShell 2 program, a product of the Ward Systems Group, was used for this research. The program automatically defaults to backpropagation architecture. It includes multiple hidden slabs with different activation functions. The program offers the user the option to select other architectures. However, earlier researchers working with similar data found that the back propagation architecture selected by the program created the best prediction model.

The NeuroShell program offers a set of statistical tools to assist in model building and analysis. They include linear and multiple correlation tools. The linear correlation $(r)$ measures the strength of the linear relationship between paired values of $x$ and $y$ in a given sample. Karl Pearson developed the linear correlation coefficient. Also referred to as the Pearson product moment correlation coefficient, this tool is also an important statistical tool in most popular spreadsheet programs such as Microsoft Excel. The linear correlation coefficient $(r)$ is defined by the following formula: 


$$
\mathbf{r}=\frac{n \sum x y-\left(\sum x\right)\left(\sum y\right)}{\sqrt{\left.n\left(\sum x^{2}\right)-\left(\sum x\right)^{2}\right) n\left(\sum y^{2}\right)-\left(\sum y\right)^{2}}}
$$

The value for $r$ is between -1.0 and 1.0. When $r$ approaches zero there is no significant linear correlation between $x$ and $y$ or as $r$ approaches -1.0 or 1.0 this indicates significant correlation between $x$ and $y$. A negative value for $r$ indicates that the $x-y$ relationship has a negative correlation. The computed value for $r$ measures the strength of the linear relationship. If the relationship is not linear this coefficient should not be applied.

The linear relationship can be defined by a straight line equation which best describes the regression line. The commonly used equation describes the relationship between the two variables ( $x$ and $y$ ) and is referred to as the regression line, line of best fit or least squares line. The general formula for the regression equation is:

$$
y=b+m x
$$

Although the regression equation is not a part of the NeuroShell program, the linear correlation $(r)$ describes the strength of the linear relationship defined by the regression equation. The regression line, which best fits the data, is determined via the least squares method. When using the regression equation to predict y it 
is always recommended to limit the application inside the data set area. The regression line and associated equation are readily available in commercial spreadsheet programs.

The NeuroShell statistical package also includes the coefficient of determination. This value describes the amount of variance in $y$ that is explained by the regression line. It is computed utilizing the linear correlation coefficient $(r)$ :

$$
r^{2}=(\text { explained variance }) /(\text { total variance })
$$

The coefficient of determination $\left(r^{2}\right)$ is useful to consider the portion of variance which is explained by the regression line. As an example, if $r^{2}=.75$ then $75 \%$ of the total variance is explained by the regression line. Accordingly $25 \%$ of the total variation in y remains unexplained.

The coefficient of determination is used regularly during neural network analysis work. It is often used to compare various model results. During model building and the analysis process it is also important to view the actual versus model predicted output graphically. A visual sense of the results in conjunction with statistical analysis is a more useful approach as opposed to solely relying upon the statistical output. 
Multiple regression is a means to express a linear relationship between an independent variable $y$ and two or more independent variables $\left(x_{1}, x_{2}, \ldots . x_{n}\right)$ (Triola, 1998). The coefficient of multiple determination $\left(R^{2}\right)$ is a measure of how well the multiple regression equation fits the sample data. It is defined as follows:

$$
\mathbf{R}^{2}=\frac{\sum(y-\hat{y})^{2}}{\sum(y-\bar{y})^{2}}
$$

When the value of $R^{2}$ value is near 1.0 this indicates a good fit. A very poor fit would be near 0.0 and a perfect fit would be 1.0 . Triola (1998) noted that the coefficient of multiple determination increases as more variables are added included. As a result the highest $R^{2}$ is achieved by including all possible or available variables. The NeuroShell program includes this statistical program as an option. However, most of the model analysis used during this research has been related to comparing predicted model output to actual output, a linear relationship.

Another feature of the NeuroShell program is the contribution factor detail. The input variables have a different weighting or importance in the model developed. The program allows the modeler to view the contribution factor; a measure of the importance of each variable or input in predicting the output of the network. This option is only used for backpropagation networks. The 
contribution factors are developed from an analysis of the weighting of the trained neural networks.

The NeuroShell program also offers the option to run the Kohonen network. The Kohonen is a self-organizing map network. Unlike the supervised network, which includes the backpropagation model, unsupervised networks do not compare actual and predicted output. The Kohonen network learns from the input data provided and categorizes the data into the number of sets defined by the modeler. This application has use when the data has different characteristics or properties. The network can also interpret observations having properties similar to more than one group. As a result such observations would be identified as a category between the two other categories.

\subsection{Neural Network Core and Log Data Inputs}

For the Jacksonburg-Stringtown field core data was available from eight wells. One core well was situated on the edge of the field and was excluded from the study. A second excluded well was cored however; core recovery was not successful. The six remaining wells had varying amounts of core data. For the thicker sections of sand a core plug was secured every foot. In some instances sections were skipped due to shale breaks or low permeability sections and core plugs were taken as determined by the geologist. No standardized approach appeared to have been used. 
In order to identify the artificial neural network best able to predict a given output, it is necessary to try various inputs. The inputs tested during modeling primarily included digitized based log data. The wells in the field commonly had a gamma ray-density porosity log ran on them at the time of completion. Inputs considered included:

- Gamma ray log value

- Bulk density measurement

- Base line value from the gamma ray log

- Base line value from the density log

- First derivative of the gamma ray log

- Second derivative of the gamma ray log

- First derivative of the bulk density log

- Second derivative of the bulk density log

- $x$ value of the well location coordinates

- $y$ value of the well location coordinates

- Core depths

- Volume of shale based on the gamma ray

- Gross thickness of various lithologic units

- Net thickness of various lithologic units

- Flow units

Outputs considered included:

- Predicted Permeability

- Predicted Flow Units

Chapters 2.0 and 5.0 can be referenced for additional field background information. 


\section{CHAPTER 5}

\section{METHODOLOGY}

\subsection{Introductory Discussion}

The main objective of this research was to develop a reservoir characterization methodology for flow unit identification using only electric log data. As a part of the methodology, preliminary flow unit identification is required using limited core and electric log data. By identifying the flow units within the reservoir, an improved method of permeability prediction is developed. The primary tool used for this research was Artificial Neural Network analysis (ANN).

To predict the reservoir flow units, the ANN backpropagation modeling required a two-step approach. Tedious preliminary work was directed at identifying the flow units in the reservoir. This required searching out and identifying the unique permeabilityporosity relationships within each flow unit present. Identifying the flow units can require an interpretation of the geology, depositional environment and lithology. This type of geologic support can often guide the flow unit identification process. This process utilized actual core results of permeability-porosity for selected wells in the field and the associated gamma ray-density logs. The initial ANN model developed had permeability as the output. 
After the ANN permeability model developed, the objective was to enhance the permeability prediction by identifying flow units and incorporating them into the model as an input. By identifying unique permeability-porosity relationships within each flow unit, the ANN model for predicting permeability improved. The key and essential research step was to develop an ANN for flow unit prediction within the field. This required training the ANN by using the previously identified core well flow units from the initial flow unit identification study. ANN training for flow unit prediction using only log data was possible by utilizing the flow units identified in the wells with core data.

In order to confirm the methodology is valid, a verification step was necessary. Verification of the procedure was done via utilizing a study field with far more complete records than what is typically available in the Appalachian Basin. The verification step required the utilization of the flow units identified and the permeability predictions as inputs for simulation work. The goal was to match predicted production results against actual.

This chapter presents the major steps utilized. This includes discussion of the techniques used to identify the flow units, the application of artificial neural network analysis for flow unit prediction, ANN models for permeability prediction within each 
identified flow unit and the verification phase as a method to confirm the methodology.

\subsection{Determining the Flow Units}

\subsubsection{Overview}

Several methods were evaluated and tested as potential tools to assist in identifying flow units, when limited data about the reservoir is available. These methods have application for flow unit application in any reservoir. The Jacksonburg-Stringtown field was selected for this research due to excellent records retention. Previously discussed in the literature review chapters, the methods found to have application are summarized in the following sections. This methodology is designed for reservoir evaluation when good records retention is lacking or reservoir characterization data is absent. Due to the lack of typical data, flow unit identification utilizing these methods should be done in a comprehensive manner utilizing all of the methods discussed. Individually no single method identified herein should be relied upon for flow unit identification.

An essential part of this methodology is the flow identification phase. During this phase preliminary flow units are identified for the core well data. The techniques utilized are discussed in sections 5.2.2 through 5.2.7. Final flow unit designations are developed during the ANN modeling phase for permeability prediction 
discussed in section 5.3. Figure 5.1 presents an overview of the initial flow identification methodology.

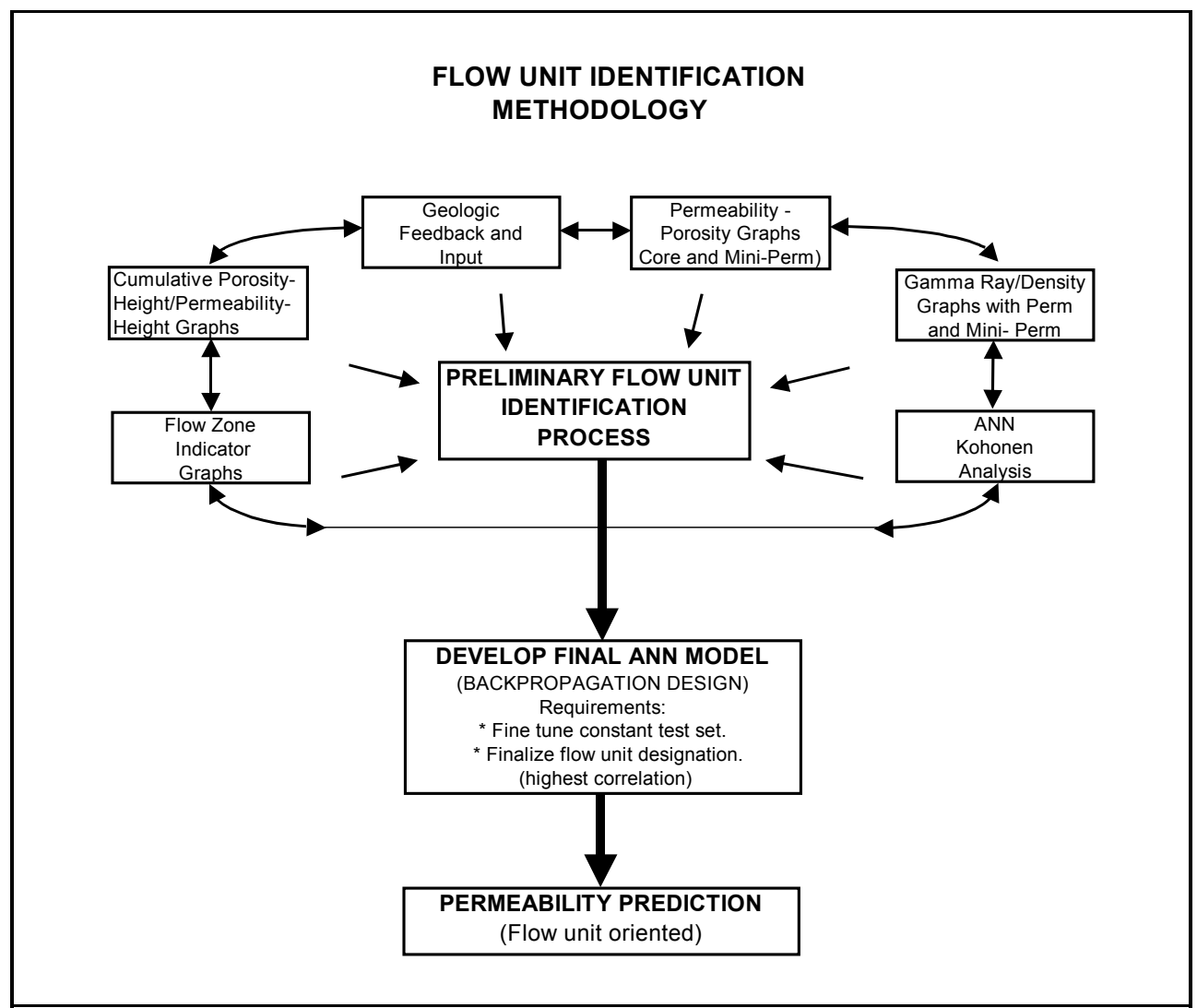

Figure 5.1 Flow Unit Identification Methodology

\subsubsection{Manual Review of the Digitized Log Data}

During the interpretive steps - as the flow unit identification process proceeds, it is important to routinely review and become most familiar with the log data. Graphing the digitized gamma raydensity log values along with permeability against depth for each well proved to be a valuable analytical tool. The researcher may be able to begin to develop a sense of potential flow unit breaks that can guide the research. The lack of other data related to the cored 
interval, such as thin section and grain size analysis, places greater reliance upon the correlation between the methods outlined. Becoming intimately familiar with each well log characteristic proved to be very useful to the research progress. Appendix A. presents the log information for each well log with permeability measurements in graphic and table form. The operator tested a few core data points outside the sand intervals. These are not included in Appendix A. The permeability values include core permeability and minipermeameter values. The Horner \# 11 does not have miniperm values due to the core no longer being available.

\subsubsection{Cumulative Porosity-Height vs Cumulative Permeability-Height} An initial well screening tool utilized a graph of cumulative storage capacity $(\phi-h)$ versus cumulative flow capacity $(k-h)$. Changes in the slope of the data, referred to as deflection points, are potential indicators of flow unit boundaries. In addition, this method can be helpful in identifying flow units having high or low flow capacity and/or storage capacity. This can be helpful during the simulation phase of reservoir modeling. The data for each core well was tabulated, plotted on an individual well basis and potential boundaries identified (Appendix B). The distance between core points varies. For some core wells, the operator did core analysis 
for each foot of a selected section of sand. In other wells, there could be up to four feet between certain core points. Therefore, potential flow unit boundaries can be narrowed down to the interval between the two core points. The exact location or depth is more difficult to pinpoint using this method when data gaps exist.

In a similar manner, a second series of cumulative storage capacity versus cumulative flow capacity graphs were developed based on the minipermeameter measurements. For this analysis only five cores were available. The minipermeameter measurements were secured from the cores several years after the actual coring operation. The porosity values were taken from the log data. The data for each minipermeameter measurement of the well cores were tabulated and each well graphed and potential boundaries identified (Appendix C). These results were compared to those of the actual cores in Appendix B.

\subsubsection{Semi-Log Graph of Permeability versus Porosity}

The semi-log scatter graph of core permeability versus core porosity has been commonly used in industry. The correlation of permeability-porosity data within a given flow unit is generally much greater than the total core data correlation when multiple flow units are included. The procedure used in this analysis was a trial and error approach searching out flow unit breaks for each well that 
offered the highest correlation of data within each flow unit for all six wells. In other words, one or two flow units were identified for each well. The highest correlation within each flow unit for all six wells was the ultimate objective of this graphing technique. The initial analysis was completed based on the individual scatter plot for a given well along with the earlier discussed cumulative plots of storage versus flow capacity, log graphs and geologic input. In some instances the lack of several core data points within a given flow unit limited the ability to develop a high correlation within a flow unit or identify the flow unit boundaries. Appendix D. can be referenced for the scatter plots for each well and the composite plots of the flow units for all six wells.

\subsubsection{FZl Analysis}

The flow zone indicator (FZI) was used in conjunction with the semi-log graph of permeability versus porosity. The typical procedure required both plots to be done at each break point selected. The correlations of the entire data and the intervals broken down were compared. This was done on an individual well basis for each core well. Both of these graphing techniques were done based on the permeability and porosity values obtained from the Core Lab's report. The log porosity values and permeability were also analyzed. However, the overall correlations were enhanced when the 
core porosity was utilized. The FZI values tabulated for each core well and FZl scatter plots are presented in Appendix E.

\subsubsection{ANN Kohonen Self Organizing Map}

Artificial neural network analysis included Kohonen networks or "unsupervised" training. The objective was to utilize the Kohonen method to categorize the log and core data as a tool for flow unit identification.

The ANN was provided with selected log inputs and core permeability for each core well. The inputs for the ANN were gamma ray, density, gamma ray slope, density slope, gamma ray baseline, density baseline and core permeability. Three ANN models were run separating the data into two, three and four categories or groups. The option selected within the program called for a "normalized" approach meaning the winning neuron output was designated to have the highest value. The second option utilized designated the winning cluster as one and all others as zero. As opposed to generating the actual neuron value within each category, the normalized approach coupled with the whole number assigned to the category was designed to more clearly identify potential flow units. Simply put, given log input and permeability data from the core results; could the data set be dissected into categories that represented flow units? 
Certain wells exhibited a transition zone between the two flow units. In these zones the data appears to represent a mixture of the characteristics unique to each flow unit. This mixture would be reflective of a heterogeneous reservoir. For these transition points the data point is categorized based on the prevailing category identified. Categorizing data using the ANN was another identification and verification tool for determining the number of flow units present. Appendix F. presents the data inputs and the ANN outputs of the various ANN outputs. Two phases of ANN Kohonen analysis occurred during the research. Initial analysis was done using all core data. No screening of the data had yet occurred. Certain core points would later be disqualified - typically due to not being a part of the flow units identified. More refined confirmation ANN Kohonen analysis was done on the final ANN.

\subsubsection{Geologic Input}

Flow units can be independent of changes in lithology or depositional environment. As an example, diagenetic structure can impact flow unit designation. However, in many cases the flow units will correspond to variation in the lithology or depositional environment. An integral part of flow unit identification is to incorporate geologic understanding of the depositional environment into the analysis. For this research the participating geologists of 
the Appalachian Oil and Natural Gas Research Consortium proved invaluable. Geologic input assisted the flow unit identification process as well as the simulation phase.

\subsection{Developing the Final ANN Permeability Model}

\subsubsection{Utilizing the Preliminary Flow Unit}

As can be seen in Figure 5.1 it is necessary to finalize the ANN model for permeability prediction after developing preliminary flow unit designations using the various techniques. The ANN for permeability prediction is developed using the core data from six core wells and the associated log based data (from gamma raydensity logs).

\subsubsection{Initial Flow Unit Designation}

Drawing from the preliminary flow unit identification process, flow units for each core well was selected. These initial flow unit selections were designated as the initial flow unit input in the backpropagation model for permeability prediction.

\subsubsection{Developing the ANN Model for Permeability Prediction}

The permeability model inputs were selected based on developing the highest correlation between predicted and actual 
core permeability. The ANN for permeability prediction was developed using the core data from six wells. Several log-based inputs were tested. Possible inputs were discussed in chapter three. Ultimately six log-based inputs were found to develop the highest $R$ squared values between predicted versus actual permeability. The log-based inputs are listed in section 5.2.6. It was found that the addition of the flow unit significantly strengthened the ANN model for permeability prediction.

\subsubsection{Permeability Prediction Utilizing the Neural Network}

Two artificial neural network models were ultimately developed for permeability prediction. In both models a backpropagation network was trained to predict permeability. Several inputs were utilized during testing in order to determine the best inputs for modeling. Model improvement was determined by comparing predicted output to actual permeability. Both final permeability output models required seven inputs. The digitized gamma ray and density electric log values were used to generate ANN inputs (digitized log values, their first derivative values, base lines). This accounted for six inputs.

The permeability prediction was improved when the flow unit designation was added to the ANN as the seventh input. In order to develop the strongest permeability prediction model various flow 
unit designations were tested. Flow unit designations between flow unit boundaries and the beginning or ending points of flow units were varied on a per well basis in order to develop the strongest model. A single core data point that moves from one flow unit to the other impacts the resulting ANN model. Core data between the flow units were moved back and forth in order to improve the model and finalize the flow units in each well.

Two ANN permeability prediction models were developed. The significant model difference was in the cut-off points of the core data. The cut-off points determine the beginning of flow unit one or the end of flow unit two. The "Model 1-K" permeability model provides for a tighter definition of the flow units. Core data at the upper and lower most portions of the reservoir were removed when the porosity and permeability values were more typical of shale. The excluded core data points fell outside of either flow unit. As a result model $1-\mathrm{K}$ is built using fewer core data points. The points excluded were largely determined by ANN results during the permeability model building stage.

"Model 2-K" permeability model includes nearly all of core data points. The research identifies two productive flow units and a third potential non-productive flow unit. Model 2-K was primarily developed to incorporate a lower permeability-porosity sand below the recognized flow unit two sand. The prediction accuracy for flow 
unit one improves when additional core data below flow unit two was included in the model. The ANN results of model 2-K suggest the lower sand has properties similar to the above flow unit one and the model is strengthened. For the purposes of model building, model 2-K expands the boundaries of the flow unit. For this research the model 2-K was ultimately used. Model selection is further discussed in chapter six as results are presented. The final permeability model can be utilized to predict permeability for wells in the field when log based data and flow unit designations are known. The flow unit designation is an essential input in the model for permeability prediction. The flow unit designation is required in order to utilize either ANN permeability model.

\subsubsection{Utilizing the Predetermined Test Set}

During ANN modeling the six core wells were regularly used. The total number of core data points used was 95 . The initial standard procedure was to designate one of the six wells as the verification or production well. The verification well is excluded from testing and training of the network. As a result the verification well contains data points not previously seen by the model. The other five wells were used for testing and training. Typically analysis of the model was based on how well the new model predicted permeability as compared to actual results. 
The model developed has a given set of selected inputs. Using the same inputs, an ANN model is built - each time setting aside a different core well as the verification well. This means each ANN model developed does vary - as a result of being built with different sets of data. The testing, training and verification sets are different. When six core wells are used there are six different ANN models generated as each well is set aside for the verification step. The predictive strength of the ANN model is based on the data set used for test and training. If the verification well is unique or has characteristics not previously encountered during modeling, the predicted output when compared to actual results, may not be satisfactory.

The problem becomes more acute as the data set varies and unique inputs of the verification well are not included in the ANN model. The properties of each core well vary in terms of log response and core data. This is likely reflects the heterogeneity of the reservoir. It can become very difficult to determine which set of inputs build the strongest model due to having six $R$ squared values as each verification well is set aside.

A unique approach utilized in this research has been to identify the "best test" set. The test set is held constant for the data set regardless of which well is selected as the verification well. A given set of test data is designated and applied to all of the wells. 
Regardless each which well is used for verification, the same set of test data is used. Identifying the "best" constant test set requires judgment and patience by the modeler.

The objective is to pre-determine the test set which "best" reflects the characteristics of the total data set (Oyerokun, 2002). The same predetermined test set was utilized for the verification well. This approach proved to be productive in terms of analysis and identifying the best model for prediction.

\subsection{Flow Unit Identification - Without Core Data}

\subsubsection{Discussion}

The flow unit identification methodology presented in Figure 5.1 is developed utilizing the core well data. Core permeability and porosity values were available for 95 core points in six wells. The permeability and porosity data allowed the flow unit identification process to advance.

The ANN model for permeability prediction can be applied to approximately 125 wells in the field having digitized log data. A required input of the ANN model is flow unit designation. A very key issue is how to predict flow units from digitized log data when permeability values are not available. The next phase of this methodology is developed in order to address this critical issue. 
Figure 5.2 presents a flow chart of the overall methodology which details the flow unit ANN building phase.

\subsubsection{Flow Unit Prediction Utilizing the Neural Network}

Generating a prediction of the flow unit is a prerequisite in order to utilize model 2-K for permeability prediction. An ANN for flow unit prediction can be developed by utilizing the core data and the flow units which were identified as a part of the initial permeability ANN work. Two flow unit models were developed which drew from the earlier work. In both instances the models used the flow units previously identified and discussed in section 5.3.

The "Model 2-FU" flow unit model used the same data as the previous model 2-K permeability model. Model 2-FU does not include permeability - only the six log based parameters. The output for model 2-FU is the flow unit (one or two) designation. Model 2-FU uses the log data at points where core data was available (points where permeability was measured). The predetermined test set remained the same for both model 2-K and model 2-FU (permeability and flow unit output).

The approach to develop a second ANN model for flow unit prediction was different. The preliminary flow unit screening methods and ANN model 2-K identified the flow units in the six core wells. The digitized log data was available for each core well. The 
digitized log data was available on a $.25 \mathrm{ft}$ interval for each well. "Model 3-FU", a second model for flow unit prediction was built using the digitized log data for each core well. This ANN has significantly more data points for testing and training (306 versus 95).

\subsubsection{Transition Zone near Flow Unit Boundaries}

In a few core wells Kohonen analysis and back propagation modeling identified portions of the core data as having properties of both flow units. This was observed at the core data points near the boundaries of the flow units and is considered a transition section area of the reservoir. The ANN could not predict the flow unit within the transition area. As a result without a properly predicted flow unit the final permeability prediction within a transition zone could be in error. The limited core data in this transition zone does not offer the opportunity to train the network to predict permeability within this area of the reservoir. In order to be able to predict flow unit one or two on the digitized log files a methodology on how to predict flow units in the transition zone was required.

\subsubsection{Predicting Permeability in the Transition Zone}

The transition zone has varying porosity and permeability. Some higher permeability sections exist within the zone. However, 
based on the known core permeability-porosity measurements in the transition zone, permeability is expected to be similar to flow unit one. In addition, the core results indicate low permeability shale streaks as a part of this zone. This limits any impact portions of higher permeability sand would have in this zone.

The transition zone requires the application of an intermediate ANN flow prediction model. Model 3-FU (digitized log data), the flow unit prediction model, was modified in order to recognize the transition zone. "Model 4-FU", an intermediate flow unit model is developed. The intent is to train the model to recognize the transition zone and assign the zone a separate flow unit value. By identifying the zone the modeler can then categorize the transition zone as flow unit one prior to using the predicted flow units in the permeability model. Changes are as follows to model 3-FU:

- Flow unit designation as one remains one.

- Transition zone to be designated as flow unit two.

- Flow unit two to be designated as flow unit three.

- Lower flow unit one remains flow unit one.

Model 4-FU was run on the core well digitized log data having the same six log based inputs as model 3-FU. The output was flow unit. During model testing and training, the same constant test set was used. It is necessary to designate flow units as described above 
for the six digitized core wells. Flow units are an input in this model. The transition zone was identified using Kohonen analysis, the ANN permeability model and model 3-FU, for flow unit prediction, using the six log based inputs. The intermediate model 4-K successfully predicted the flow units in the transition zone.

\subsubsection{Reclassifying the Predicted Flow Units for the ANN} Permeability Model

The flow unit output from model 4-K was manually reclassified in order to utilize the predicted flow units in model $3-\mathrm{K}$, the permeability model. Flow unit reclassifications occurred as follows:

- Flow unit one remains flow unit one.

- Flow unit two (trans area) is classified as flow unit one.

- Flow unit three (initial two) is classified as flow unit two.

- Lower flow unit one remains flow unit one.

With the flow units reclassified, the ANN permeability prediction model could be applied to the digitized well logs in the field (approximately 125 wells). Within the transition zone the ANN permeability prediction model will predict permeability based on the (flow unit one and the transition zone) being categorized as flow unit one. 


\subsubsection{Model Description Summary}

Model 1-K:

Model 2-K:

Model 2-FU:

Model 3-FU:

Model 4-FU:
ANN for permeability prediction. Has tight definition for each flow unit. Core data at upper and lower most portion of the reservoir excluded (low porosityl permeability). Two flow units and six log based inputs used.

ANN for permeability prediction. Includes all applicable core data (95 core data points). Two flow units and six log based inputs used. Model selected as ANN for permeability prediction.

ANN for flow unit prediction. Used the same core data points as model 2-K. Has six log based inputs. ANN developed from 95 core data points. Model 2-K was used for flow unit designation.

ANN for flow unit prediction. Used 306 data points from the core well digitized well log data. Assigned flow units based on flow units designated in model 2-K.

ANN for flow unit prediction. Used 306 data points from the core well digitized well log data. Intermediate ANN for identifying the transition zone. 


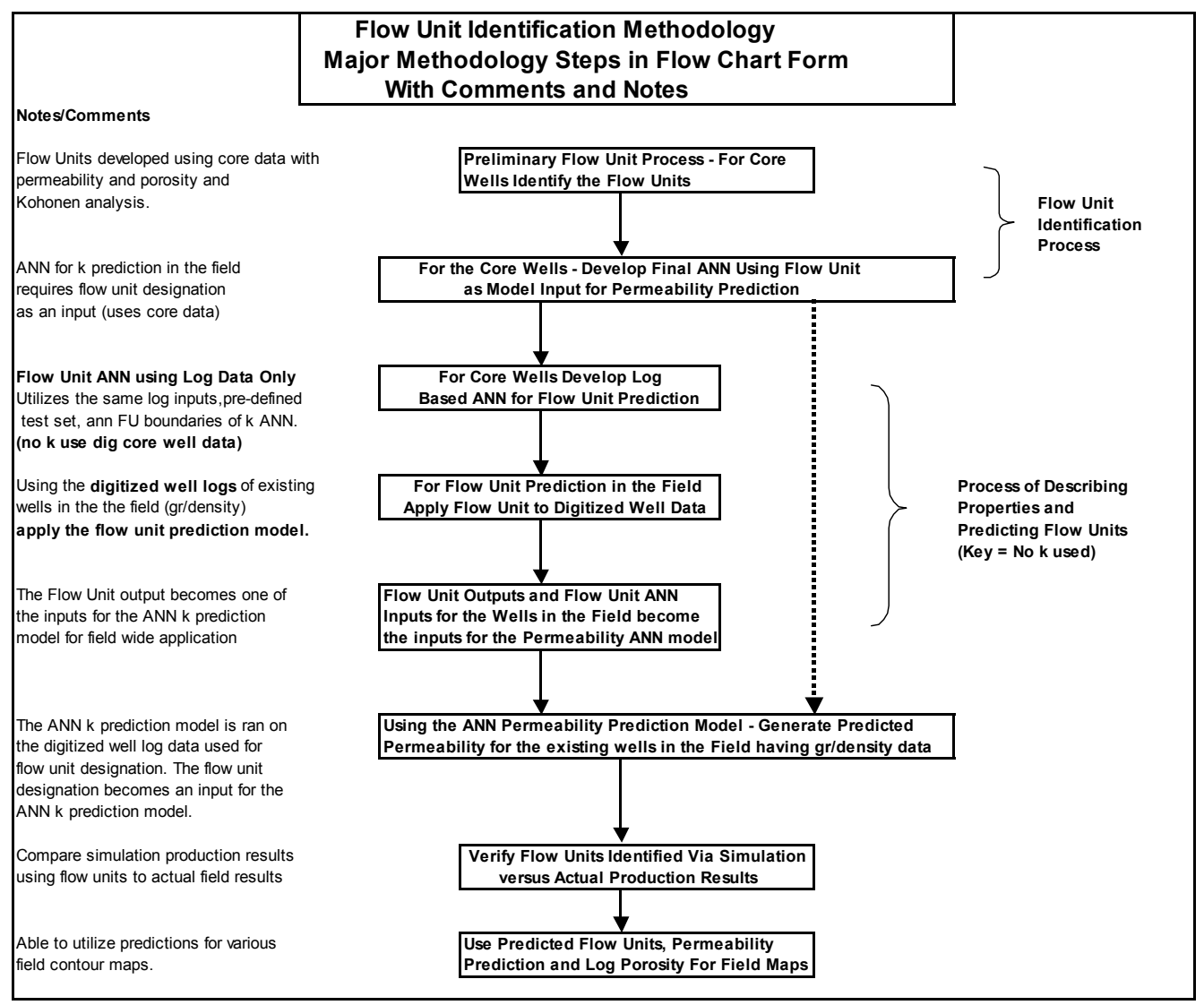

Figure 5.2 Flow Unit Identification Methodology Major Methodology Steps in Flow Chart Form with Comments and Notes

\subsection{Earlier Verification Work}

Gil (2000) previously researched the dual five spot pilot waterflood situated south of the current area of interest in the same field. The author demonstrated that simulated production prediction was enhanced when the producing sand was broken down into two flow units. Gil selected the flow units based strictly on porosity and permeability variation and enhanced simulation results. None of the techniques investigated herein for flow unit identification were utilized. This previous research did not include the flow unit 
designation as an input for ANN modeling. However, the flow units identified and used by Gil in his simulation analysis support these research results. Accordingly, Gil's earlier work in the same field serves as a second verification of the flow units identified.

\subsection{Verification Field}

\subsubsection{Study Area}

Figure 5.3 presents the Jacksonburg-Stringtown field and highlights the core well locations within the field. Two of the original core wells were a part of the two five spot patterns included in the original pilot program. The area of interest for this research is situated north of the pilot flood patterns.

\subsubsection{Core Wells Utilized in the Research}

During field development a total of nine wells were cored. Three core wells were not utilized in the research. Core data could not be located for the D-14. The L-17 did not have any electric log data available. The R-13 was excluded due to the cored section taken being above the sandstone and the well being located outside of the main field area. These three wells were therefore not useful in the research. 


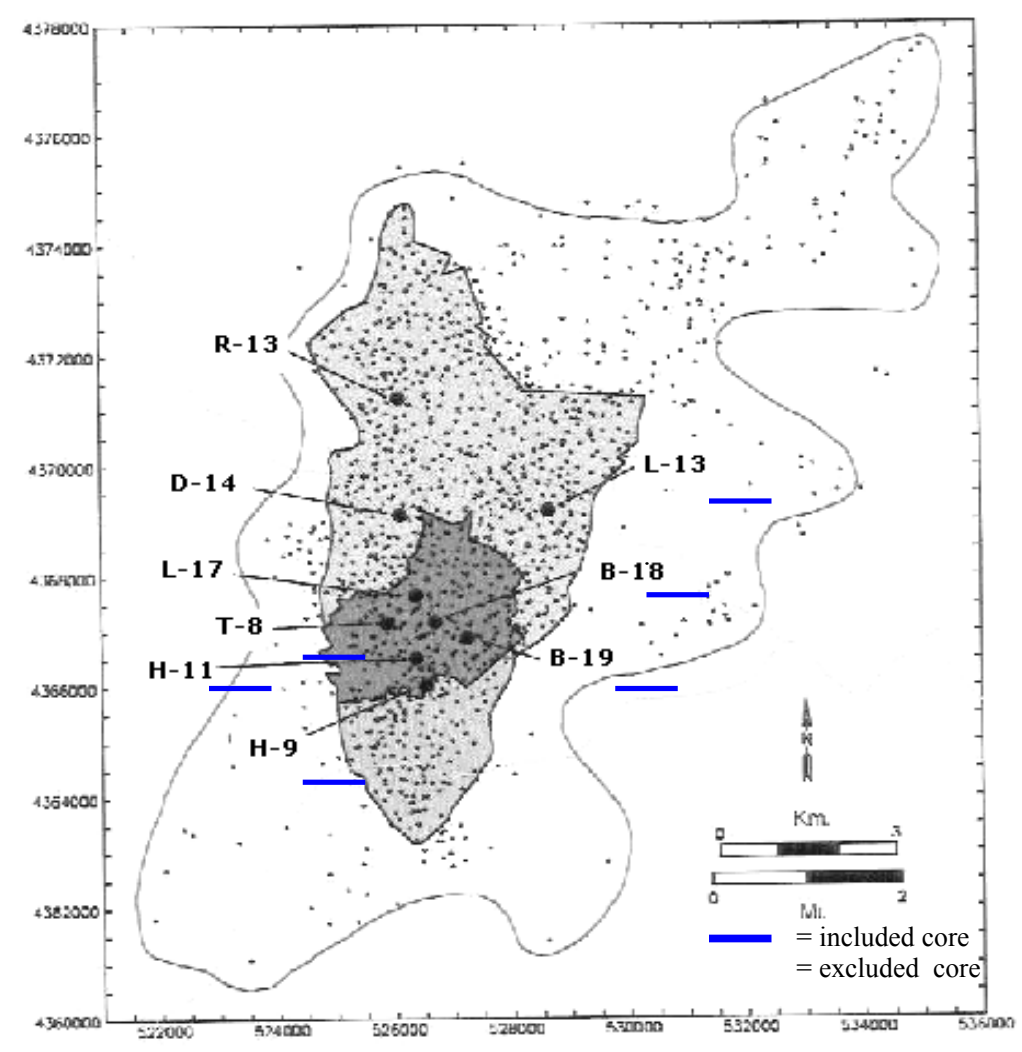

Figure 5.3 Cored Well Locations within the Jacksonburg-Stringtown Field

Six core wells within the verification field were utilized in the research. At the time of drilling, selected portions of the cored sections (core plugs) were directed to Core Laboratories, Inc. for porosity and permeability measurement analysis. In addition, relative permeability analysis was also completed on a few selected core plugs. Five of the cored sections were maintained in storage until recent research commenced. The $\mathrm{H}-11$ cored section was not located for further analysis. However, the Core Laboratory report of porosity and permeability for $\mathrm{H}-11$ (Horner \# 11) was available. 
Table 5.1 summarizes the core wells and the associated core analysis results.

Table 5.1 Summary of Jacksonburg-Stringtown Research Cores

(Gil, 2000)

\begin{tabular}{|c|c|c|c|c|}
\hline Well & \multirow{2}{*}{$\begin{array}{c}\text { Cored } \\
\text { Interval, ft }\end{array}$} & $\begin{array}{l}\text { Avg. porosity, } \\
\%\end{array}$ & \multicolumn{2}{|c|}{ Permeability averages, md } \\
\cline { 3 - 5 } & & Arithmetic & Geometric \\
\hline B-18 & $2988.5-3014$ & 14.7 & 52 & 2.7 \\
\hline B-19 & $3086-3115$ & 14.9 & 41 & 6.2 \\
\hline H-9 & $2980-2908$ & 18.2 & 106 & 57 \\
\hline H-11 & $3083.4-$ & 18.8 & 72 & 19 \\
& 3093.4 & & & 0.75 \\
\hline T-8 & $2781-2797$ & 12.4 & 6.5 & 0.2 \\
\hline L-13 & $3032.4-$ & 8.4 & 2.5 & \\
& 3061.5 & & & \\
& & & & \\
\hline
\end{tabular}

The gamma ray-density electric logs from each core well were digitized on a 1/4 foot basis. In a few isolated instances other types of logs were available for a given well. During the waterflood field development phase, the logging suite was typically limited to the gamma ray-density log. As a result this log is considered universal in the field.

As a part of the Department of Energy Grant (DE-AC2698BC15104) geologists participating in the West Virginia University Research Corporation performed minipermeameter measurements at $1 / 4$ foot intervals on the five cored sections. The TEMCO MP-401 
was the model used in the study. Results as compared to the core plug measurements varied significantly. Typically when the permeability was greater than $10 \mathrm{md}$ the minipermeameter measurements were less than the core plug values. Appendix A. details the Core Laboratory results, minipermeameter and well log measurements for the core wells used in the study.

\subsubsection{Two Five Spots Selected for Verification}

The verification field includes approximately 9,000 acres of reservoir under waterflood operations. Two verfication five spot patterns were selected (Ball \# 18, Ball \# 21). The selection was based on:

- Prolific primary production in the section of the field selected.

- Electric logs were available on all pattern wells.

- Two cored wells exist in the patterns selected.

- The pay section appears to vary laterally across the patterns selected. Figure 5.4 is an east-west cross section of well logs and shows the stratigraphic units in the formation.

- Complete production records were available for each well. 


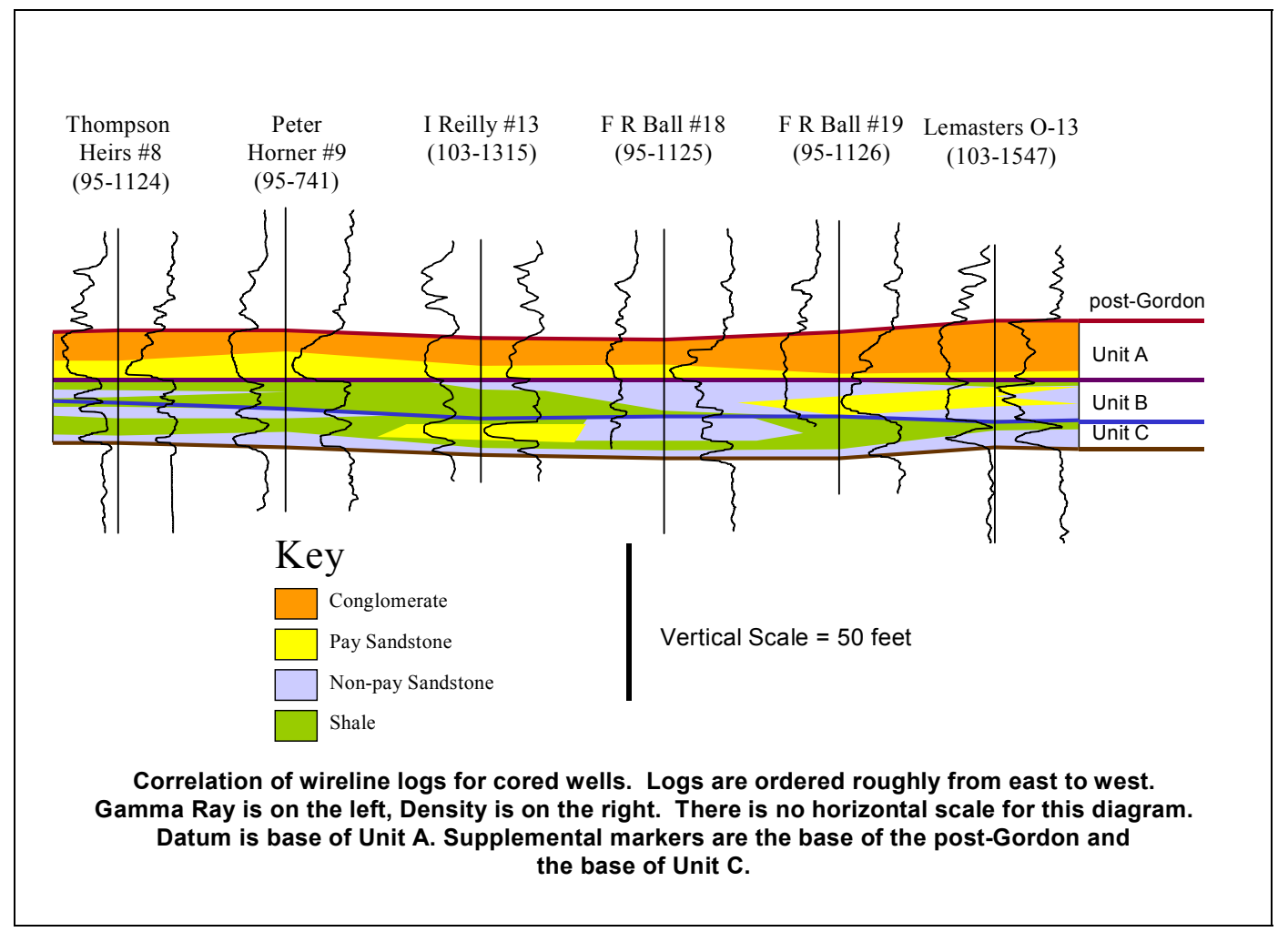

Figure 5.4 East-West Cross Section Shows Logs and Stratigraphic Units

Figures 5.5 and 5.6 present the general area of interest within the field as well as a more detailed map showing the specific patterns selected. 


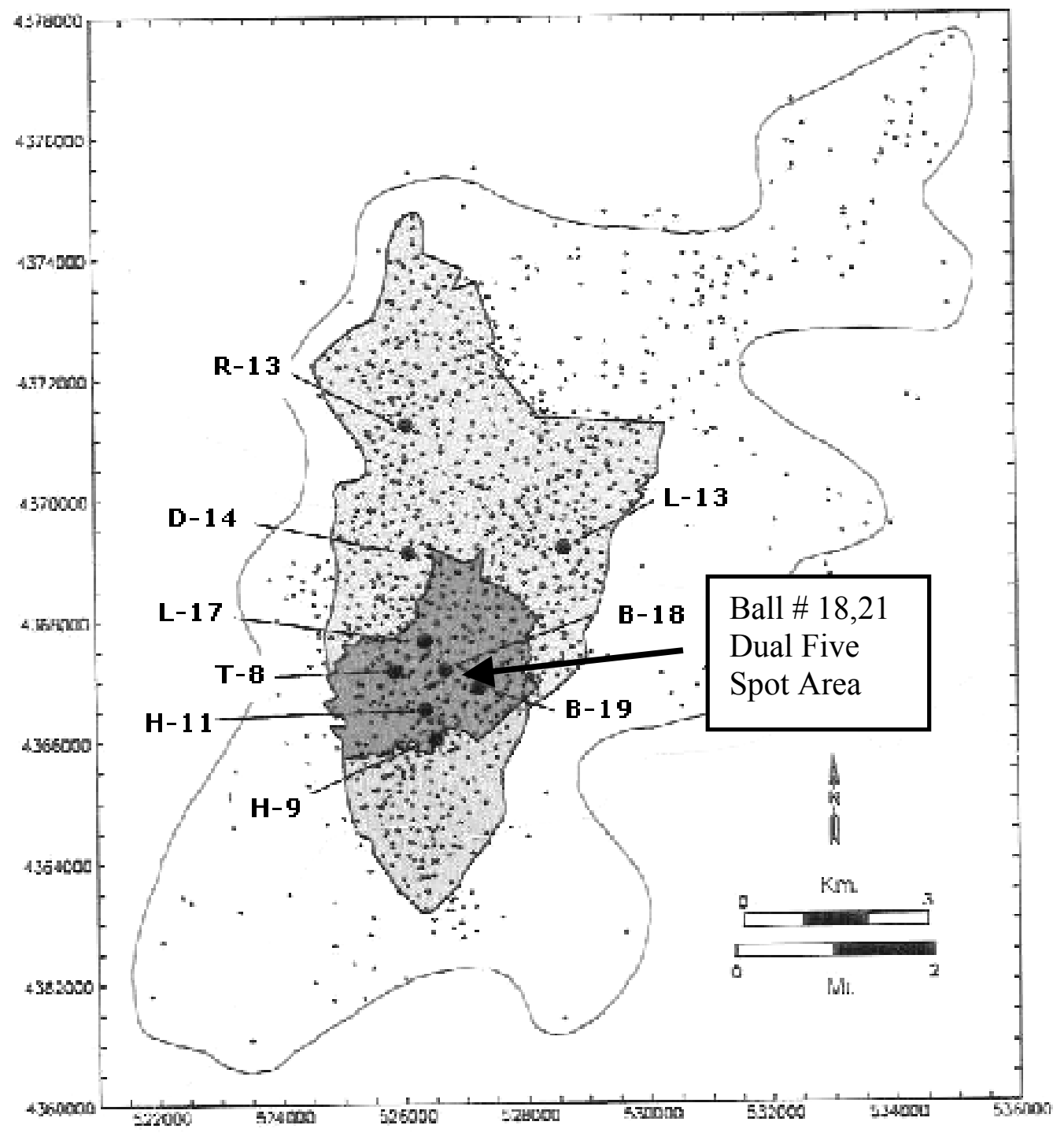

Figure 5.5 Jacksonburg -Stringtown Field Showing Verification Area 


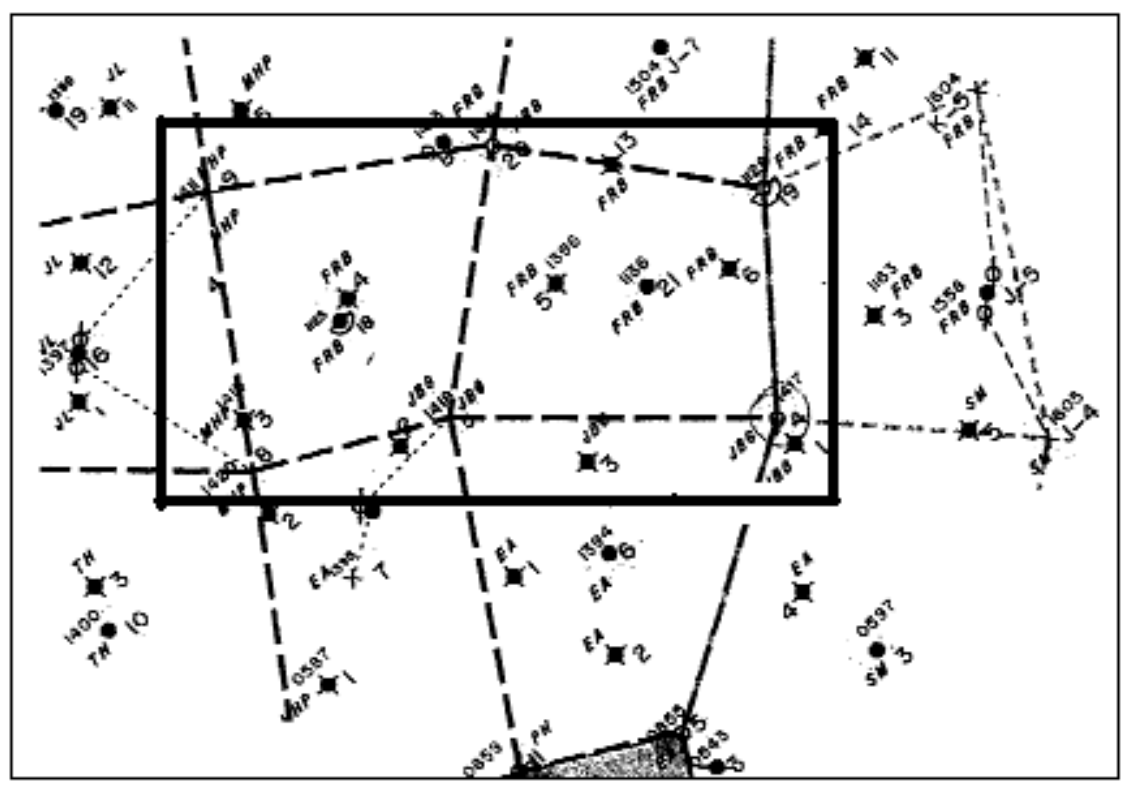

Figure 5.6 Verification Patterns Selected

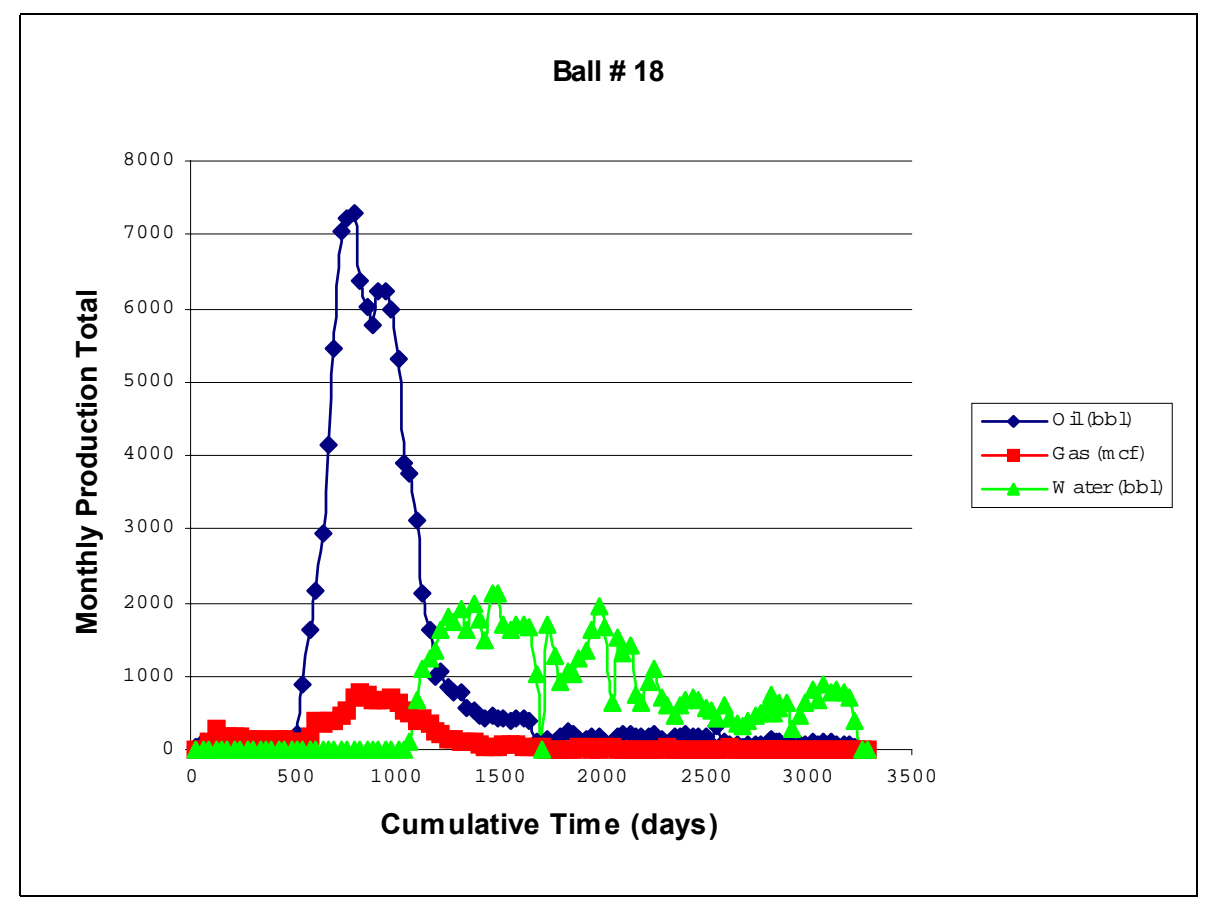

Figure 5.7 Ball \# 18 Secondary Production History 


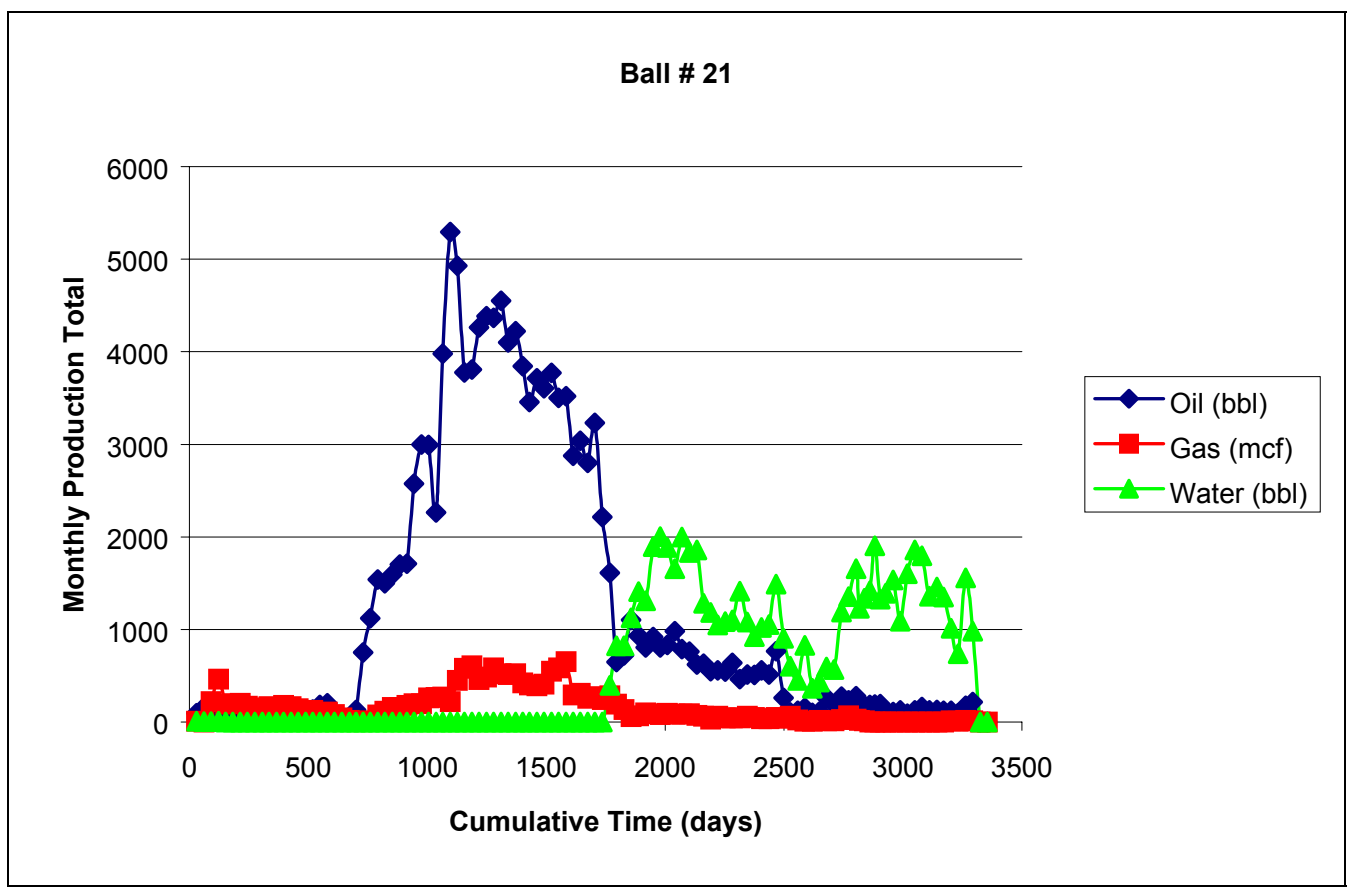

Figure 5.8 Ball \# 21 Secondary Production History

Secondary recovery operations (injection) for this portion of the field and the two verification five spot patterns commenced in January, 1991. The Ball \# 18, 21 production history commencing in April, 1999 is shown graphically in Figures 5.7 and 5.8. The two adjacent five spots had two common injectors in both patterns. The injected volumes and wellhead pressures for each well are presented in Figures 5.9, 5.10 and 5.11. 


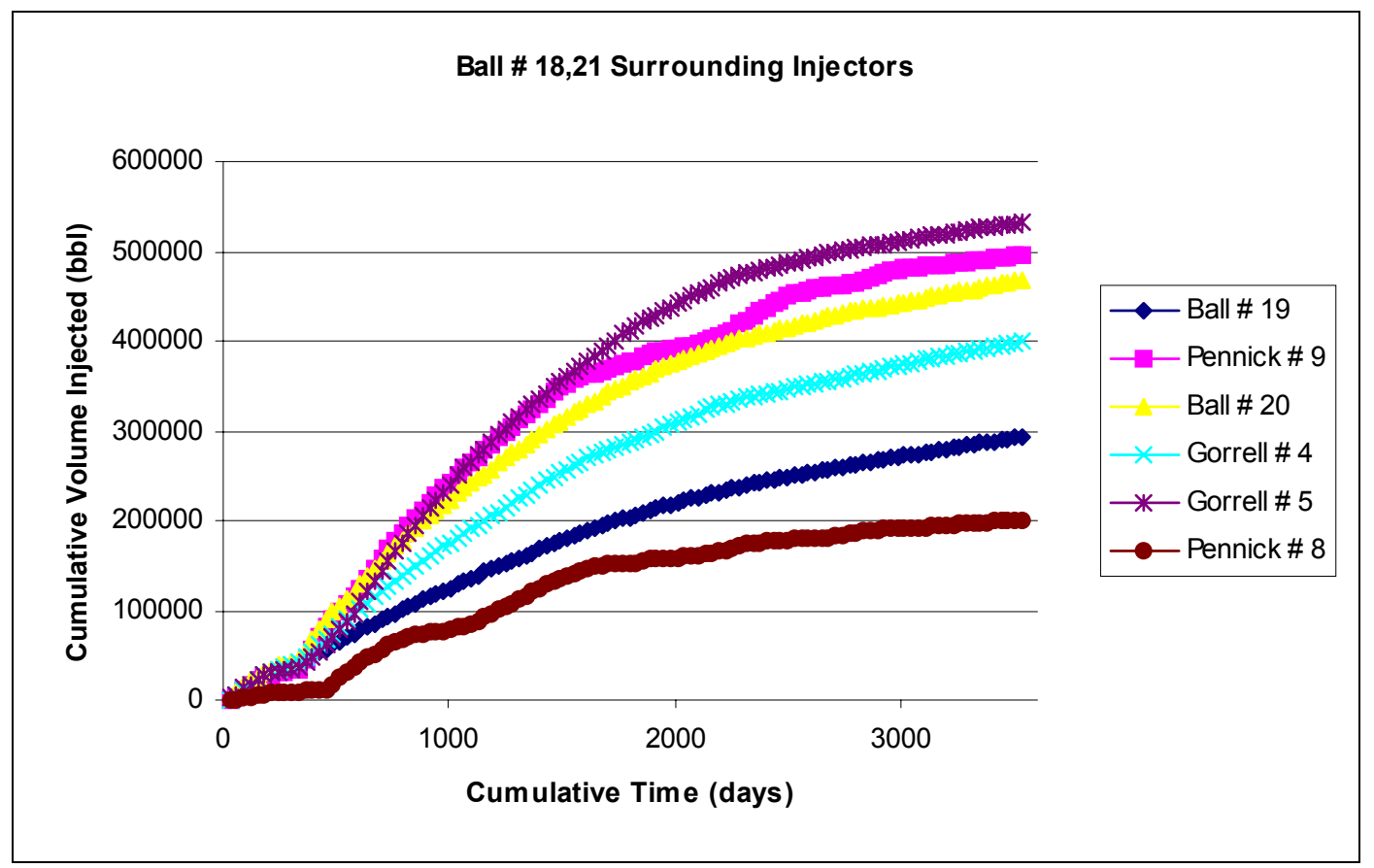

Figure 5.9 Cumulative Injected Volumes Per Well

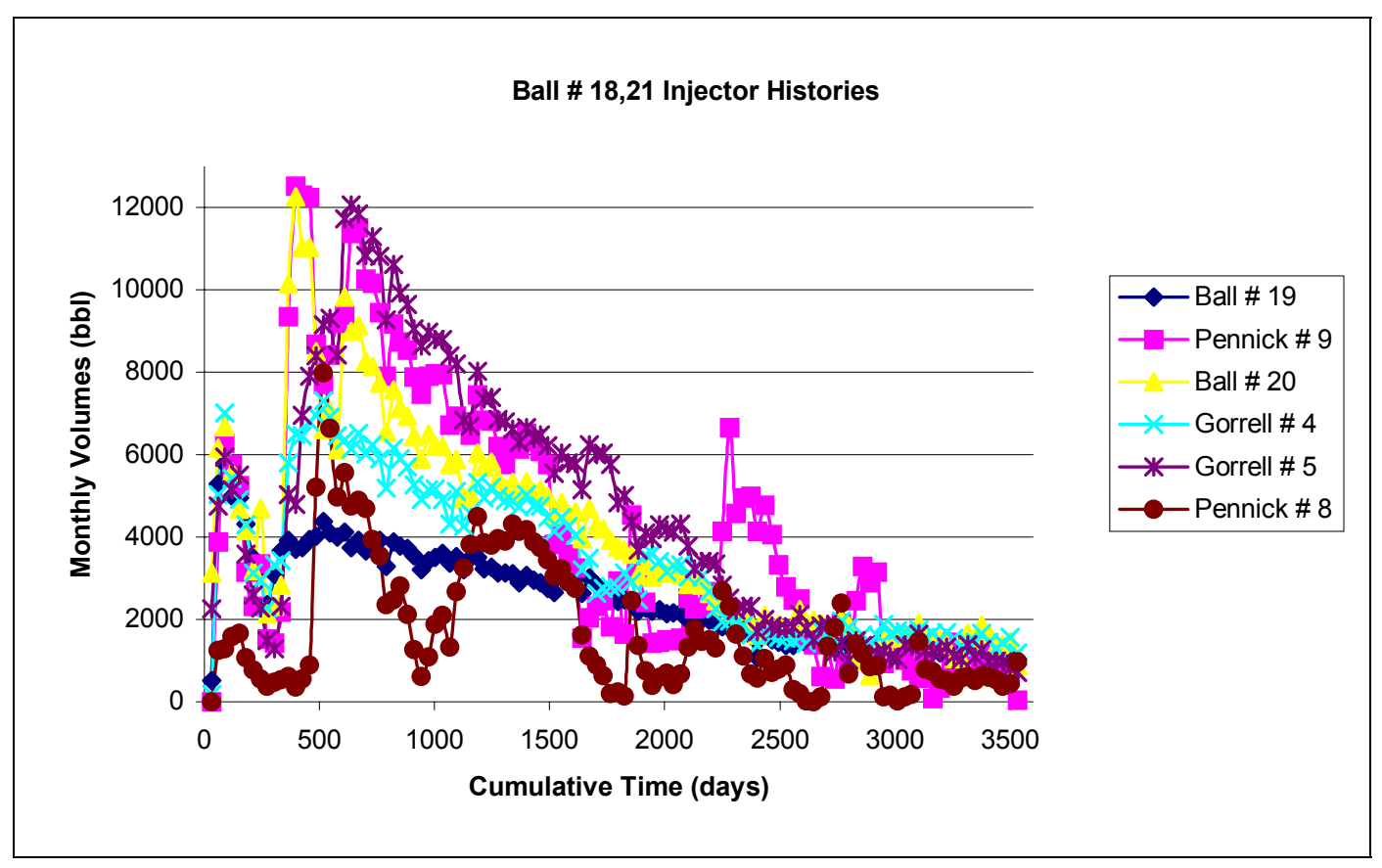

Figure 5.10 Monthly Injected Volumes Per Well 


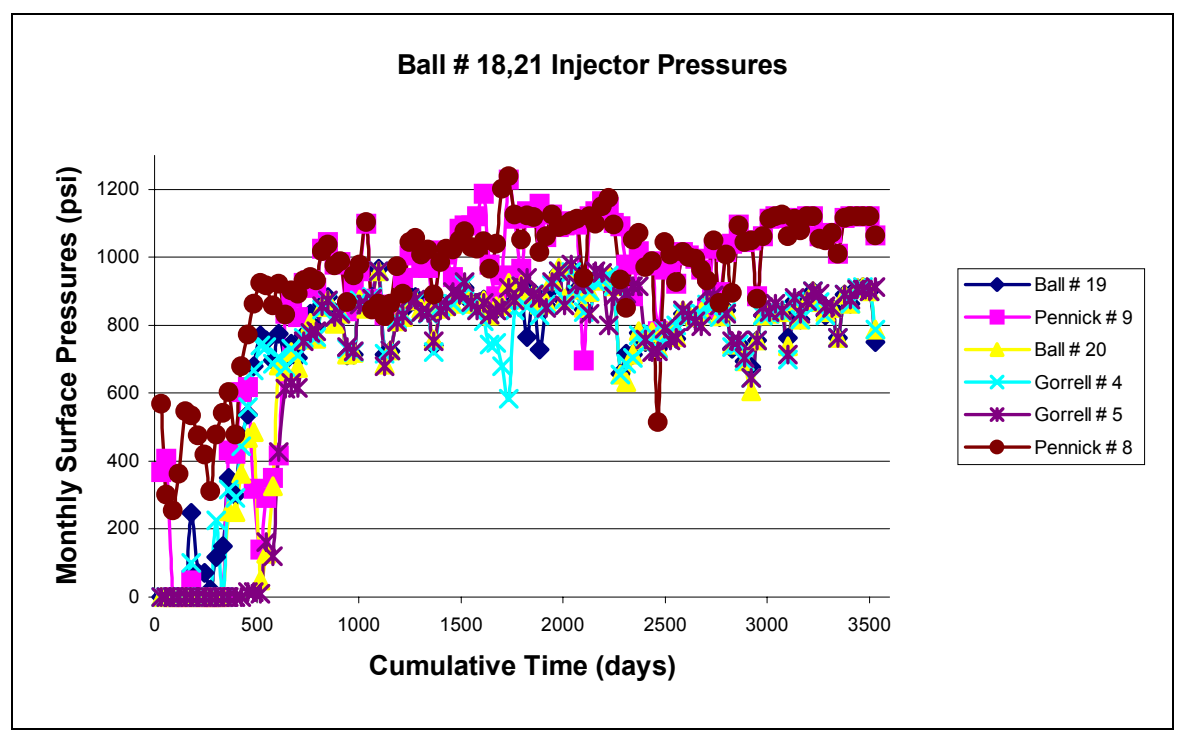

Figure 5.11 Monthly Surface Pressure for Injection Wells

\subsection{Simulation Analysis - Verification Step}

\subsubsection{Simulator Introduction}

The Boast98 simulator was used during the reservoir simulation phase. The simulator required reservoir property and fluid property inputs. In addition, for prediction matching, production and injection history was required for the area of study in the field. The flow unit ANN model 4-FU was used to predict flow units for each well in the dual five spot area - known as Ball \# 18, 21 patterns. The second ANN model 2-K was used to predict permeability in each flow unit. The predicted flow unit was the model 
output from model 4-FU. This flow unit output was then used as an input in the second ANN model for permeability prediction.

\subsubsection{Necessary Input Data for the Simulator}

The grid utilized was a $14 \times 7 \times 2$ grid design. Each grid had an equal length and width of 194 feet. Within the two flow units the average predicted permeability from the ANN and average corresponding porosity from well log data was generated for each well in the two patterns. Permeability and porosity values between the six injectors and two producers within the study area were estimated for each grid using trends within the patterns and interpolation between the known well locations encountered during simulation. Tables $5.2,5.3$ and 5.4 present the PVT properties. Additional information regarding the fluid properties was previously presented in Tables 2.2, 2.3, and 2.4. Other parameters in the simulation model included:

- Initial reservoir pressure @120 psia.

- Fluid saturation of oil, water, gas @ 66.8\%, 17.5\%, $15.7 \%$, respectively.

- Irreducible water saturation @ 16\%.

- Permeability in the $x$ and $y$ directions was equal.

- Vertical permeability was $1 \mathrm{md}$ and $5 \mathrm{md}$ in layers $1,2$. 
Table 5.2 Produced Oil PVT Properties

\begin{tabular}{|c|c|c|c|}
\hline $\begin{array}{c}\text { Pressure, } \\
\text { psia }\end{array}$ & $\begin{array}{c}\text { Viscosity, } \\
\mathrm{cp}\end{array}$ & Bo, RB/STB & $\begin{array}{c}\text { Rs, } \\
\text { SCF, } \\
\text { STB }\end{array}$ \\
\hline 14.7 & 3.600 & 1.0000 & 0.0 \\
\hline 80.0 & 3.229 & 1.0254 & 14.5 \\
\hline 100.0 & 3.132 & 1.0275 & 18.9 \\
\hline 120.0 & 3.038 & 1.0296 & 23.5 \\
\hline 2500.0 & 0.6100 & 1.4234 & 862.5 \\
\hline $\begin{array}{c}\text { Slope } \\
(\mathrm{P}>\mathrm{Pb})\end{array}$ & $\begin{array}{c}0.125 \mathrm{E}-02 \\
\text { cp/psia }\end{array}$ & $\begin{array}{c}-0.800 \mathrm{E}-06 \\
\text { RB/STB/psia }\end{array}$ & 0.0 \\
\hline \multicolumn{3}{|c}{} \\
\hline
\end{tabular}

Table 5.3 Produced Natural Gas PVT Properties

\begin{tabular}{|c|c|c|c|c|}
\hline $\begin{array}{c}\text { Pressure, } \\
\text { Psia }\end{array}$ & $\begin{array}{c}\text { Visco- } \\
\text { sity, } \\
\text { cp }\end{array}$ & $\begin{array}{c}\text { Bg, } \\
\text { RCF/SCF }\end{array}$ & $\begin{array}{c}\text { Pseudo } \\
\text { PRS, } \\
\text { psia }^{2} / \mathrm{cp}\end{array}$ & $\begin{array}{c}\text { Rock } \\
\text { Comp. } \\
1 / \text { psia }\end{array}$ \\
\hline 14.7 & 0.0112 & $0.1048 \mathrm{E}+01$ & $0.00 \mathrm{E}+00$ & $0.380 \mathrm{E}-05$ \\
\hline 120. & 0.0114 & $0.7446 \mathrm{E}-01$ & $\begin{array}{c}0.3592 \mathrm{E}+0 \\
7\end{array}$ & $0.380 \mathrm{E}-05$ \\
& & & 7 & \\
\hline 2500. & 0.0196 & $0.4800 \mathrm{E}-02$ & $\begin{array}{c}0.4800 \mathrm{E}+0 \\
0.380 \mathrm{E}-05\end{array}$ \\
& & & 9 & \\
\hline
\end{tabular}

Table 5.4 Produced Water PVT Properties

\begin{tabular}{|c|c|c|}
\hline Pressure & $\begin{array}{c}\text { Viscosity, } \\
\mathrm{cp}\end{array}$ & Bo, RB/STB \\
\hline 14.7 & 1.4527 & 0.9911 \\
\hline 120.0 & 1.4585 & 0.9909 \\
\hline 2500.0 & 1.465 & 0.9880 \\
\hline
\end{tabular}


Relative permeability data was available from the Horner \# 9 core well. The relative permeability values used in the simulation analysis followed these results closely. In addition, the relative permeability values used in simulation mirrored that used by Gil in his earlier work. This allowed the opportunity to more closely compare Gil's reservoir simulation results to those of this study. Table 5.5 presents the relative permeability test results from the Horner \# 9 well. Figure 5.12 presents a comparison of the relative permeability values associated with the Horner \# 9 and those used in the simulator work.

Table 5.5 Relative Permeability - Horner \#9

\begin{tabular}{|c|c|c|c|}
\hline Sw & Krw & Kro & Kro/Krw \\
\hline 32.7 & 0.0077 & 0.51 & 66.234 \\
\hline 37.7 & 0.012 & 0.436 & 36.333 \\
\hline 41.6 & 0.016 & 0.37 & 23.125 \\
\hline 46.2 & 0.024 & 0.283 & 11.792 \\
\hline 48.5 & 0.029 & 0.235 & 8.103 \\
\hline 50.8 & 0.037 & 0.19 & 5.135 \\
\hline 52.7 & 0.045 & 0.148 & 3.289 \\
\hline 54.1 & 0.052 & 0.114 & 2.192 \\
\hline 55 & 0.06 & 0.098 & 1.633 \\
\hline 55.6 & 0.066 & 0.089 & 1.348 \\
\hline 56.2 & 0.074 & 0.076 & 1.027 \\
\hline 57.3 & 0.08 & 0.05 & 0.625 \\
\hline 58.2 & 0.096 & 0.033 & 0.344 \\
\hline 59.5 & 0.107 & 0.0086 & 0.080 \\
\hline 60.1 & 0.119 & 0.0039 & 0.033 \\
\hline 60.8 & 0.135 & 0 & 0.000 \\
\hline
\end{tabular}




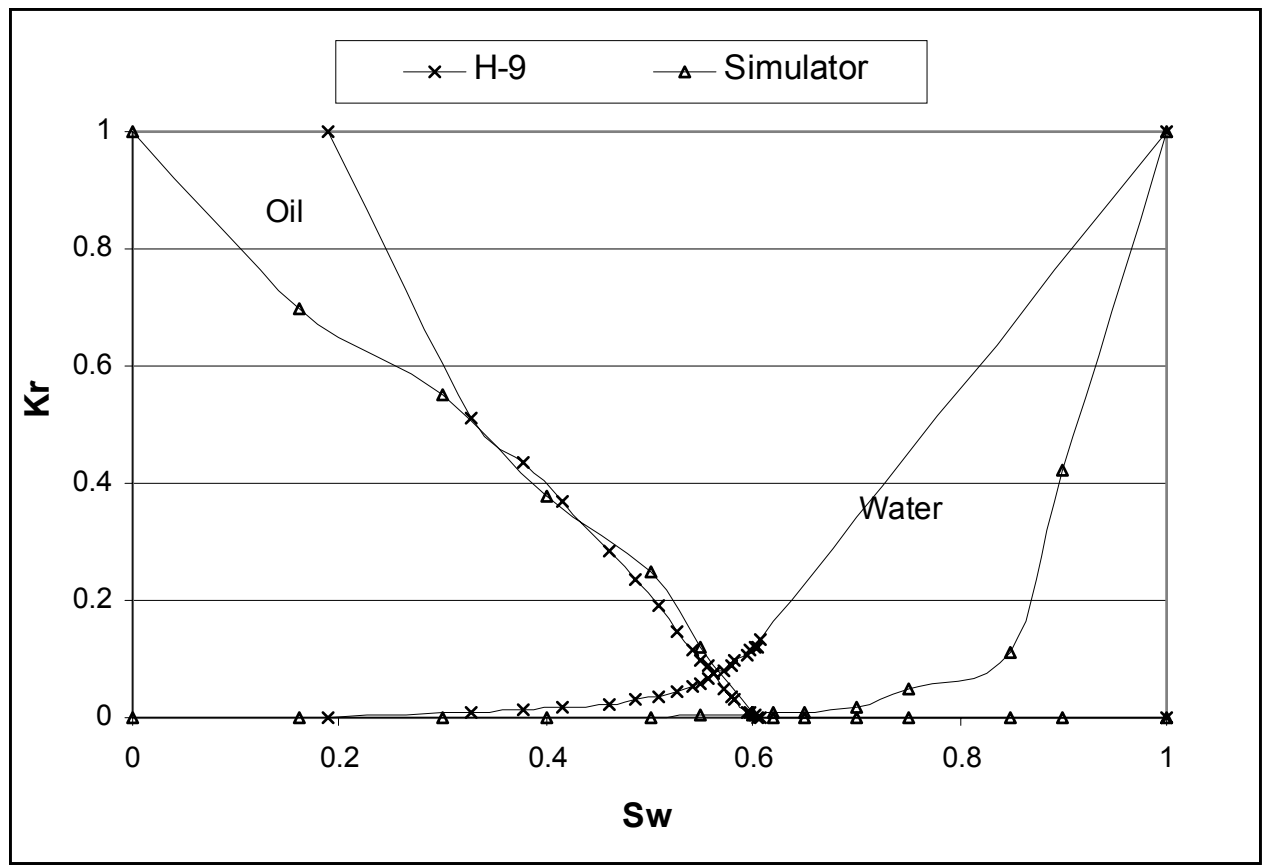

Figure 5.12 Comparisons of Relative Permeability (Gil, 2000)

\subsubsection{Recurrent Data}

During the simulator run the recurrent data section is used to input specifics related to initial and later changes that occur for any producing or injection well in the simulation area. The initial well location, layer completion information, and rates of injection are required inputs. As time proceeds during the simulator run it is necessary to adjust the injection rates to more accurate reflect estimates of water entering the patterns. This occurs in the recurrent data section. In addition, wells can be adjusted for skin damage problems or stimulation treatments. This also occurs in the recurrent section of the simulation program. 


\subsubsection{Comparing Flow Unit Simulation to Single Layer Model}

The simulation results of the two flow unit model are compared to actual production results. A single layer model is also simulated. The single layer is compared to actual production as well.

\subsection{Applying the Reservoir Characterization Results to the Field}

The ANN results were used to construct a series of maps. The field maps include thickness isopachs of each flow unit, average permeability isopachs of each flow unit, combined kh isopachs of each flow unit. The field maps were generated by utilizing the 125 digitized well logs in the field. Figure 5.13 presents the Major Methodology Steps in Flow Chart Form. 


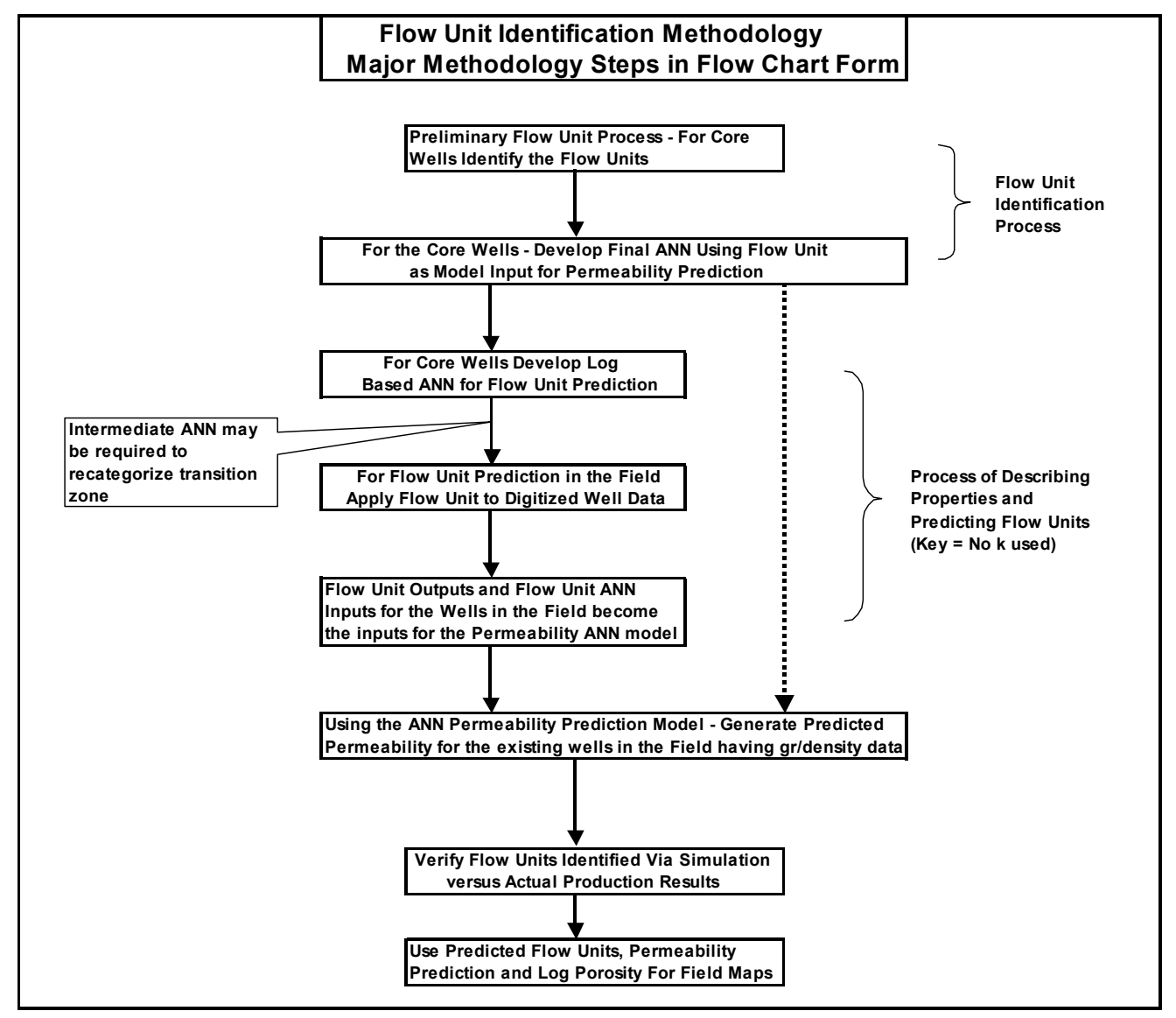

Figure 5.13 Flow Unit Identification Methodology Major Methodology Steps in Flow Chart Form 


\section{CHAPTER 6}

\section{RESULTS AND DISCUSSION}

\subsection{Introduction}

The methodology used to identify flow units and ultimately predict permeability within each flow unit combines a series of screening tools and neural network analysis in a unique manner. The preliminary flow unit identification process proved to be very effective and provided fruitful results when used in combination with neural network analysis. Preliminary flow unit results presented herein are after multiple iterations of the preliminary flow unit tools. Previous results would be reviewed after each screening tool was utilized and further work would continue in terms of preliminary flow unit identification. Although these results appear brief and concise it is important to note that learning and enhanced interpretation occurs as the data is revisited. The preliminary flow units identified then become a part of the artificial neural network phase for flow unit prediction within the field using only log-based data.

\subsection{Preliminary Flow Unit Identification Process Results}

\subsubsection{General Observations}

Early efforts were directed at becoming more familiar with each core well by developing graphs of each well which detailed log 
and core data broken out by depth. The graphs become a source of reference during the research. Table 6.1 presents general observations about cored sections in each well. Key observations are that two wells had comparatively low permeability throughout the pay zone (less than $50 \mathrm{md}$ ). Other wells had a zone of higher permeability in the lower section of the zone (100-250 md). Typically the sand immediately above the high permeability section had good porosity and in some instances good permeability (50-125 md) however, the upper section had noticeably less permeability and porosity than the lower portion of sand. In a few cored wells a lower permeability-porosity sand was present at the base of the high permeability section. After spending significant time with the graphs and as two flow units became more defined, trends and patterns of the gamma ray and density log measurements became more apparent. 


\section{Table 6.1 General Observations Gamma Ray-Density Log and Core Measurement versus Depth}

\begin{tabular}{|c|c|c|c|}
\hline & $\begin{array}{l}\text { Gener } \\
\text { Gamm } \\
\text { Core M } \\
\text { (see Ap }\end{array}$ & $\begin{array}{l}\text { Observations } \\
\text { Ray, Density Log and } \\
\text { surements vs Depth } \\
\text { ndix A. for detail data) }\end{array}$ & \\
\hline WELL NAME & \begin{tabular}{|l} 
Flow Unit \\
Interval (ft)
\end{tabular} & \begin{tabular}{|l} 
Flow Unit \\
Interval (ft)
\end{tabular} & Observations \\
\hline T. Heirs \# 8 & $\begin{array}{l}2790.5-2794.5 \\
\text { Low k }(7-10 \mathrm{md})\end{array}$ & $\begin{array}{l}2794.5-2797.5 \\
\text { higherk }(20-25 \mathrm{md})\end{array}$ & $\begin{array}{l}2782-2790.5 \text { no k } \\
\text { porosity incr steadily to } \\
\text { base of sand from } 7 \% \text { to } 19\end{array}$ \\
\hline Horner \# 9 & $\begin{array}{l}2889-2892 \text { no k } \\
2892-2896 \text { up to } \\
100 m d\end{array}$ & $\begin{array}{l}2896-2903 \mathrm{k} \text { jumps to } 150 \\
2903-2906 \mathrm{k} \text { jumps } \\
\text { to } 200 \mathrm{md}\end{array}$ & $\begin{array}{l}\text { GR initially } 30 \text { increases } \\
\text { to } 60 @ \\
\text { deepest core point. }\end{array}$ \\
\hline Ball \# 19 & $\begin{array}{l}3085-3098 \text { no k } \\
3098-3106 \\
k \text { varies }\end{array}$ & $\begin{array}{l}3106-3112 \mathrm{much} \text { higher } \mathrm{k} \\
(100-200 \mathrm{md})\end{array}$ & $\begin{array}{l}\text { core porosity tracks } \\
\text { with permeability }\end{array}$ \\
\hline Le M a ste rs \# 13 & $\begin{array}{l}3048-3050.5 \\
\text { one pt of } 40 \mathrm{md} \\
20 \% \text { por }\end{array}$ & $\begin{array}{l}3051.5-3053 \\
\text { one pt of } 20 \mathrm{md}, 15 \%\end{array}$ & $\begin{array}{l}\text { cored section has very low } \\
\text { couple of porosity streaks } \\
\text { overall porosity } 10-15 \% \\
\text { up to } 18 \% \text { in streaks }\end{array}$ \\
\hline Ball \# 18 & $\begin{array}{l}2890-2894 \\
40-50 \mathrm{md} \\
G R @ 30 \mathrm{md}\end{array}$ & $\begin{array}{l}2894-3000 \\
125-250 \mathrm{md} \\
G R @ 50 \mathrm{md}\end{array}$ & $\begin{array}{l}\text { GR is increasing as } \\
\text { we go deeper } \\
\text { cored from } 2890-3000\end{array}$ \\
\hline Horner \# 11 & $\begin{array}{l}3088-3091 \\
\text { up to } 70 \mathrm{md} \\
\text { porosity } \\
\text { above } 20 \%\end{array}$ & $\begin{array}{l}3091-3093 \\
\mathrm{k} \text { jumps to } 200-250 \\
\text { core porosity up to } 25 \% \\
\text { log porosity not as much }\end{array}$ & $\begin{array}{l}\text { GR moved from } 60 \text { to } 40 \text { in } \\
\text { higher pay section. }\end{array}$ \\
\hline
\end{tabular}

\subsubsection{Cumulative k-h versus Cumulative $\phi$-h for Core Data}

The cumulative plots of storage capacity $(\phi-h)$ versus flow capacity (k-h) for each core well was a significant tool in the flow unit identification process. Figures 6.1 and 6.2 present the Ball \# 19 and Ball \# 18 cored wells. The two wells plot in a manner consistent with two flow units. In both cases the deflection points tie back well to the 
final flow unit boundaries identified for each well. Two flow units appear to be present in the main section of the sand. Appendix B. can be referenced for all of the cumulative capacity plots for the core wells. Appendix Table B.7 further summarizes the flow unit intervals and deflection points (breaks) for each well. This approach was useful in validating flow units in five of the six wells. The T. Heirs \# 8 well appeared to have two possible flow units. Further analysis supported only one flow unit. The LeMasters \# 13 had no deflection points and appeared to have a single flow unit.

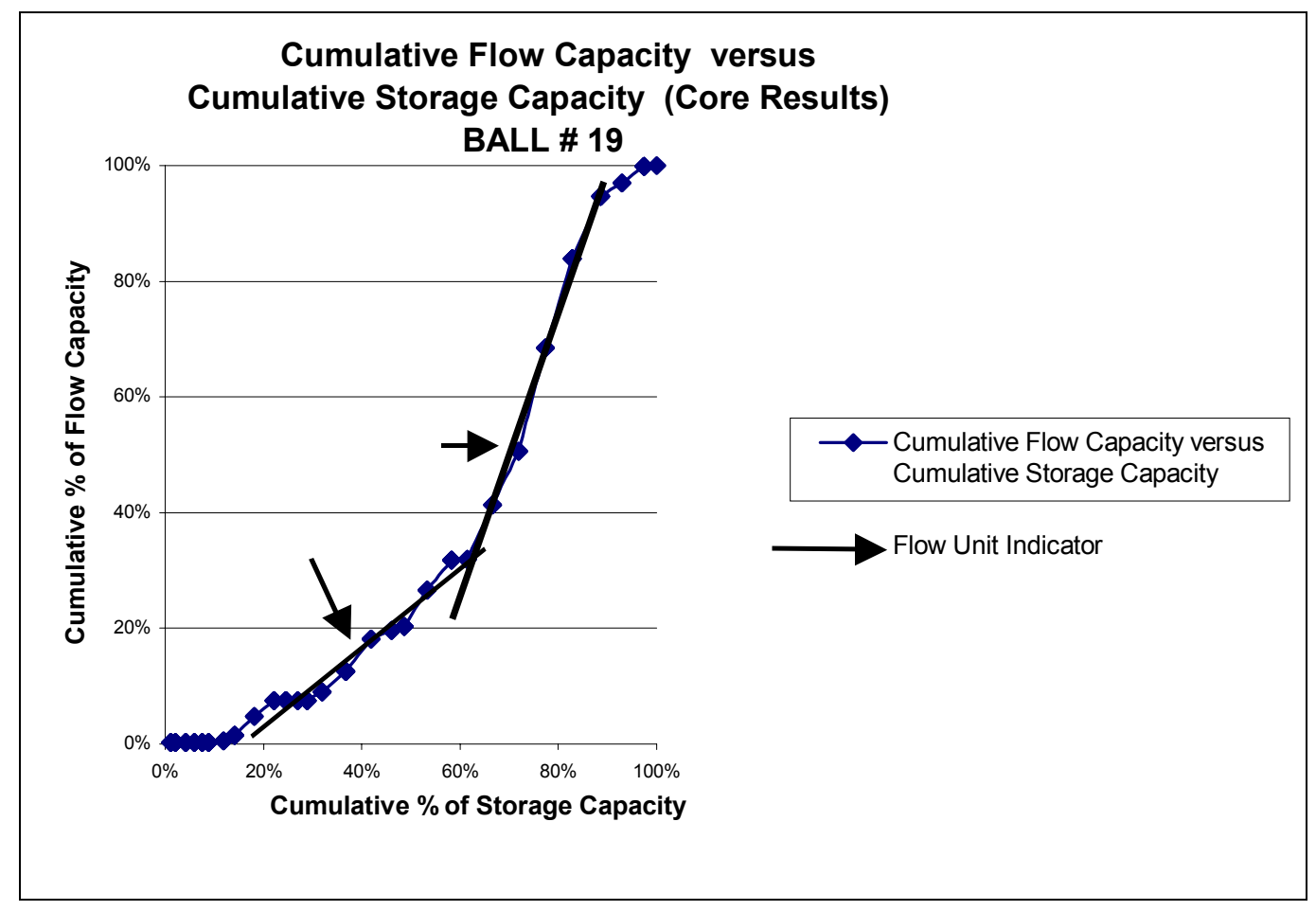

Figure 6.1 Cumulative Flow Capacity versus Cumulative Storage Capacity (Core Results) Ball \# 19 


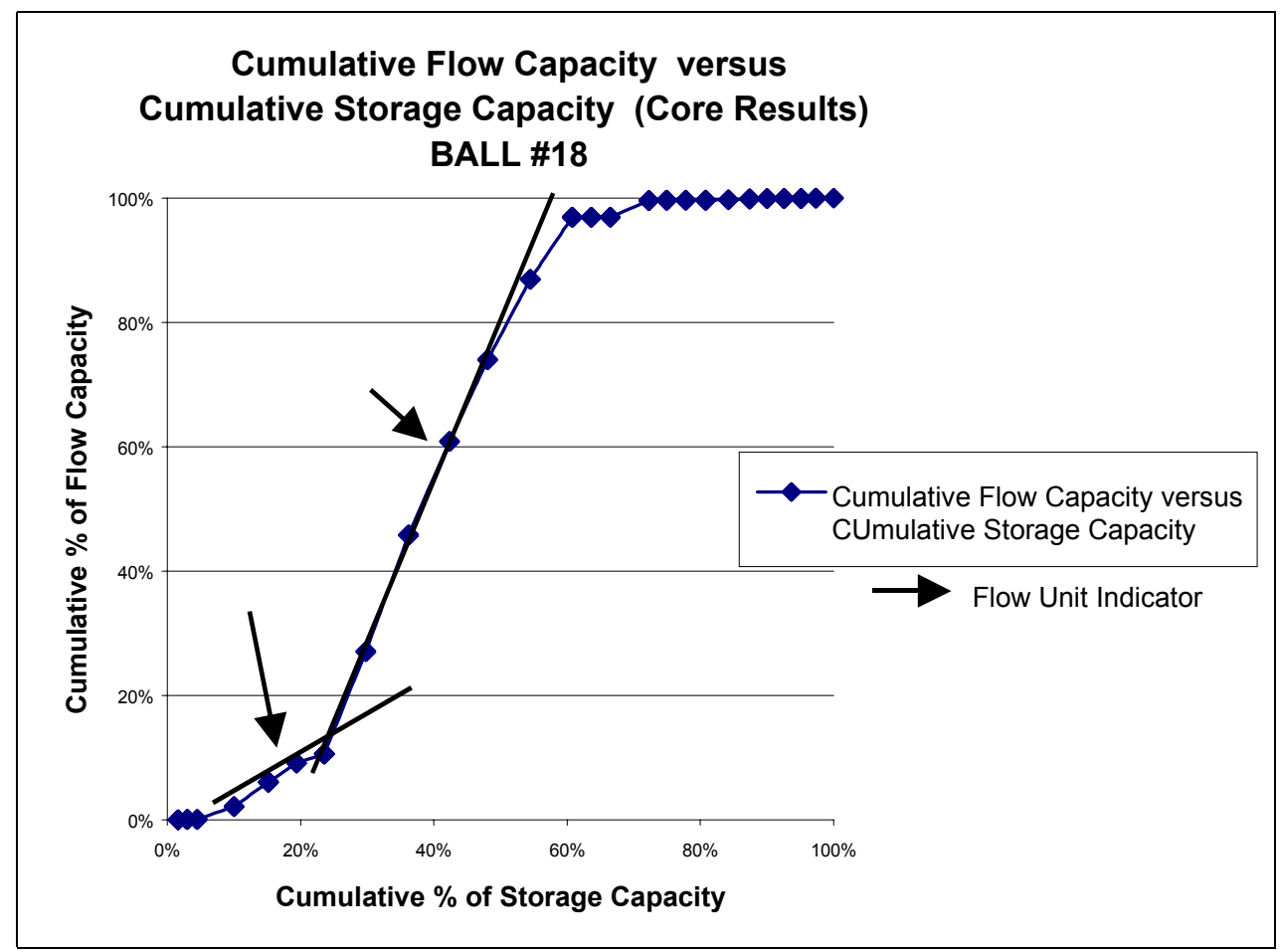

Figure 6.2 Cumulative Flow Capacity versus Cumulative Storage Capacity (Core Results) Ball \# 18

\subsubsection{Cumulative k-h versus Cumulative $\phi-h$ for Miniperm Data}

Five cores were physically available for miniperm measurements. In order to utilize the miniperm measurements the log porosity was used. Results were very positive in terms of identifying the potential flow units and ratifying the earlier cumulative storage capacity plots made from the core data. Figures 6.3 and 6.4 present the Ball \# 19 and Ball \# 18. The overall slopes and deflection points tracked well with the cumulative storage capacity plots made from the core data. Appendix C. includes the minipermeameter plots for five of the core wells. Appendix Table C.6 
summarizes the potential flow unit boundary point analysis for each well based on the minpermeameter measurements and log porosity.

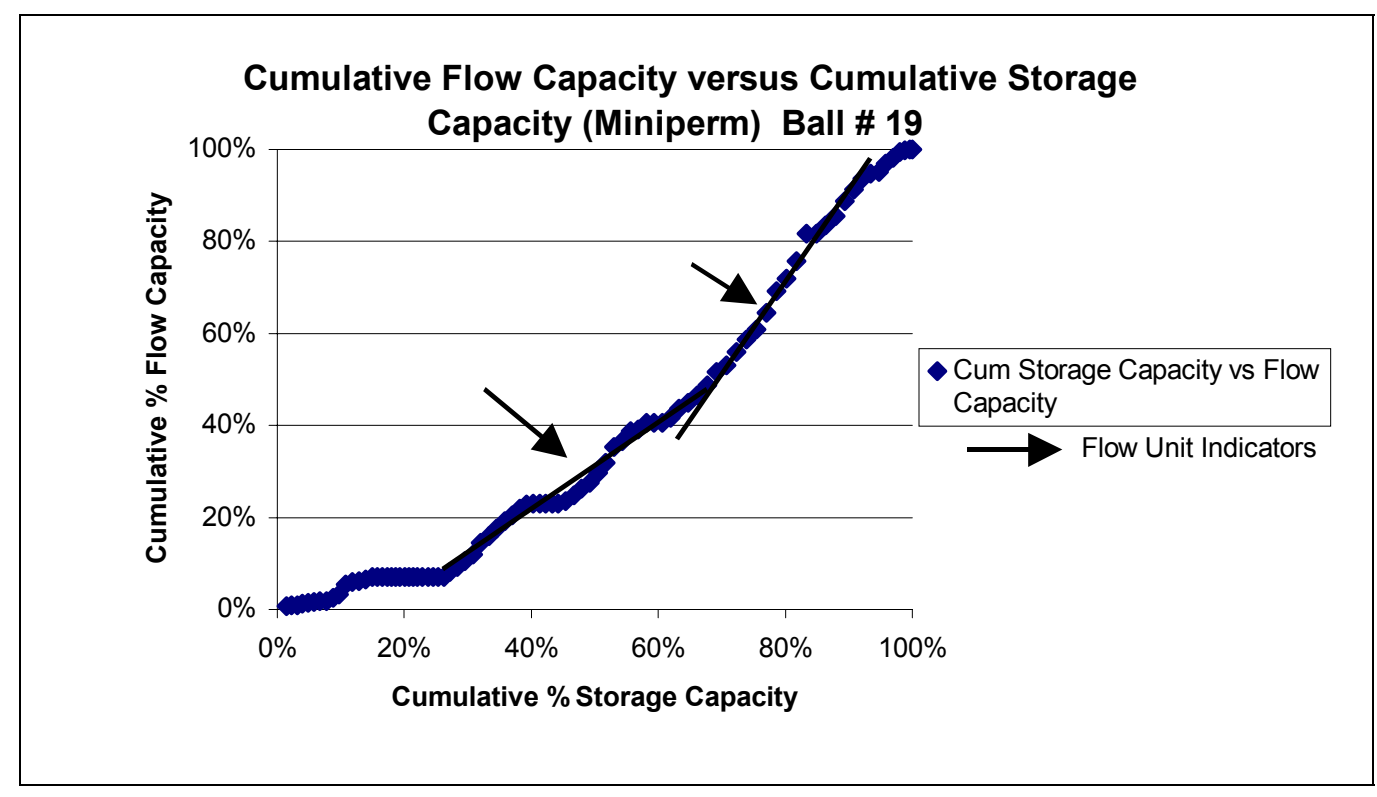

Figure 6.3 Cumulative Flow Capacity versus Cumulative Storage Capacity (Miniperm) Ball \# 19

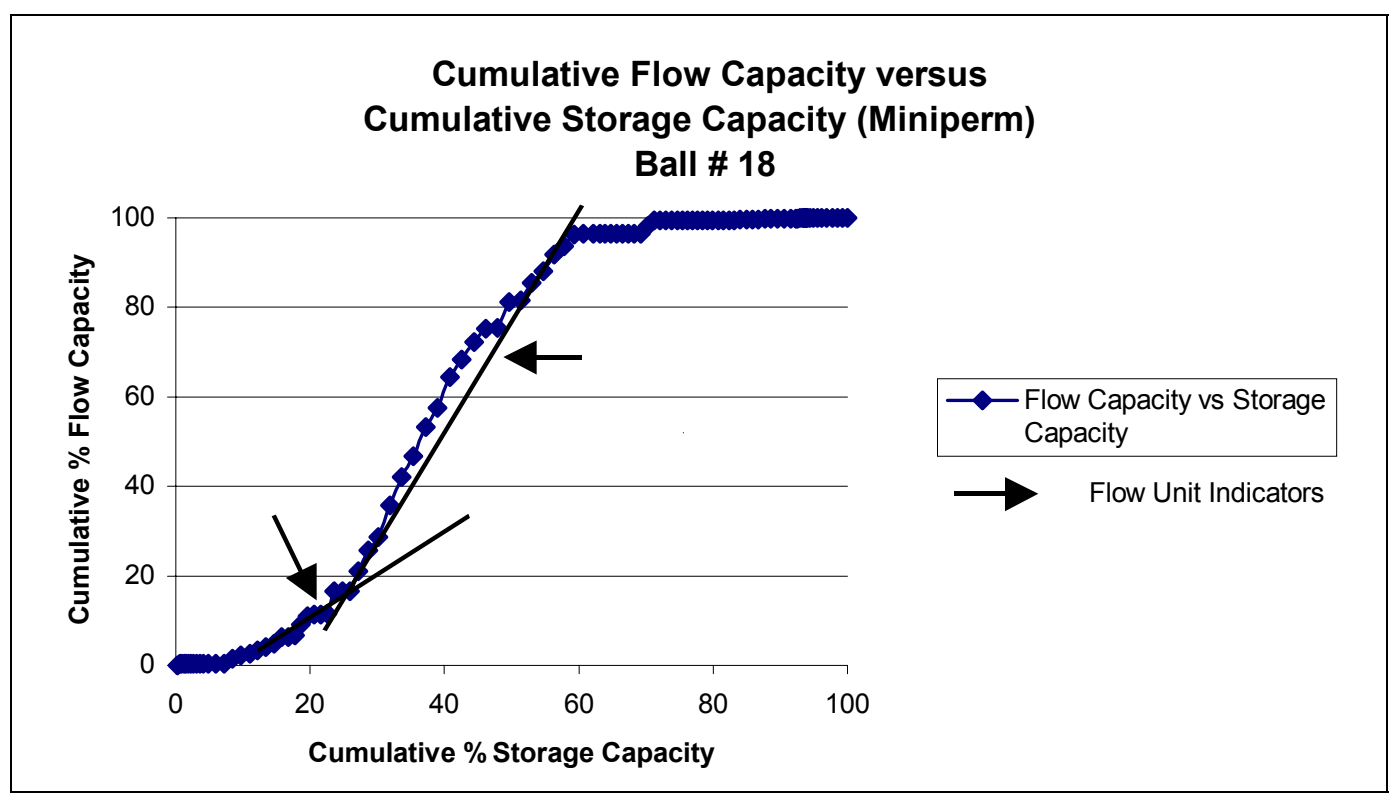

Figure 6.4 Cumulative Flow Capacity versus Cumulative Storage Capacity (Miniperm) Ball \# 18 


\subsubsection{Cumulative $k-h$ versus Cumulative $\phi-h$ - Core Data versus Miniperm Data}

At the time coring and core analysis was being performed, the operator did not test the core on a per foot basis in every well. In some cases, it appears certain sections were tested (better pay) and other sections were passed over. As a result there are data gaps of a few feet between core data in a given well. The minipermeameter and the associated cumulative capacity plots offer valuable information about the gaps or lack of core analysis between core data points. Figure 6.5 (LeMasters \# 13) and 6.6 (Ball \# 18) present a comparison of the two cumulative plots. The miniperm cumulative plots proved to be a valuable screening tool. Appendix G. contains the comparative cumulative plots between the Core Lab report and the miniperm data with log data for the cumulative flow and storage capacity plots for the wells. 


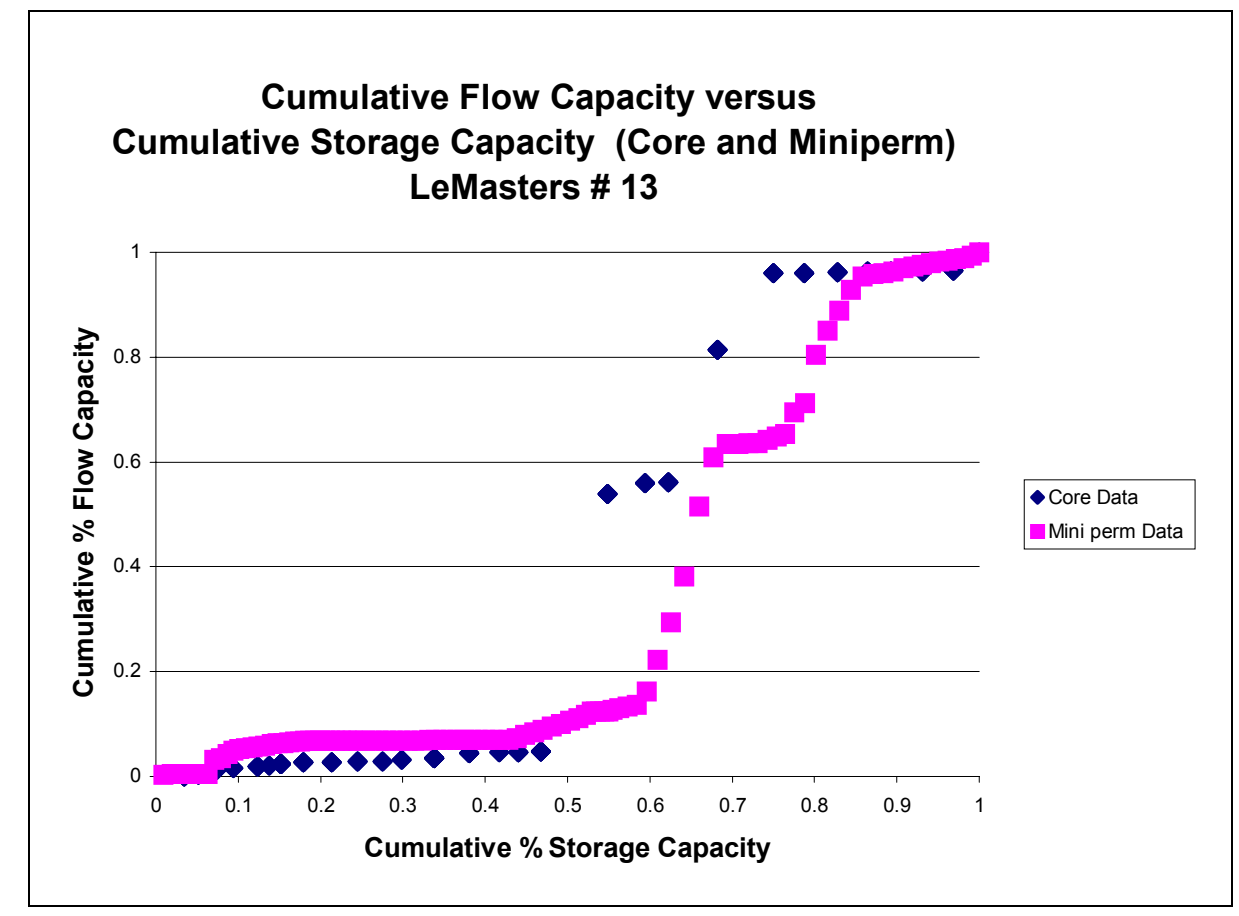

Figure 6.5 Cumulative Flow Capacity versus Cumulative Storage Capacity (Core and Miniperm) LeMasters \# 13

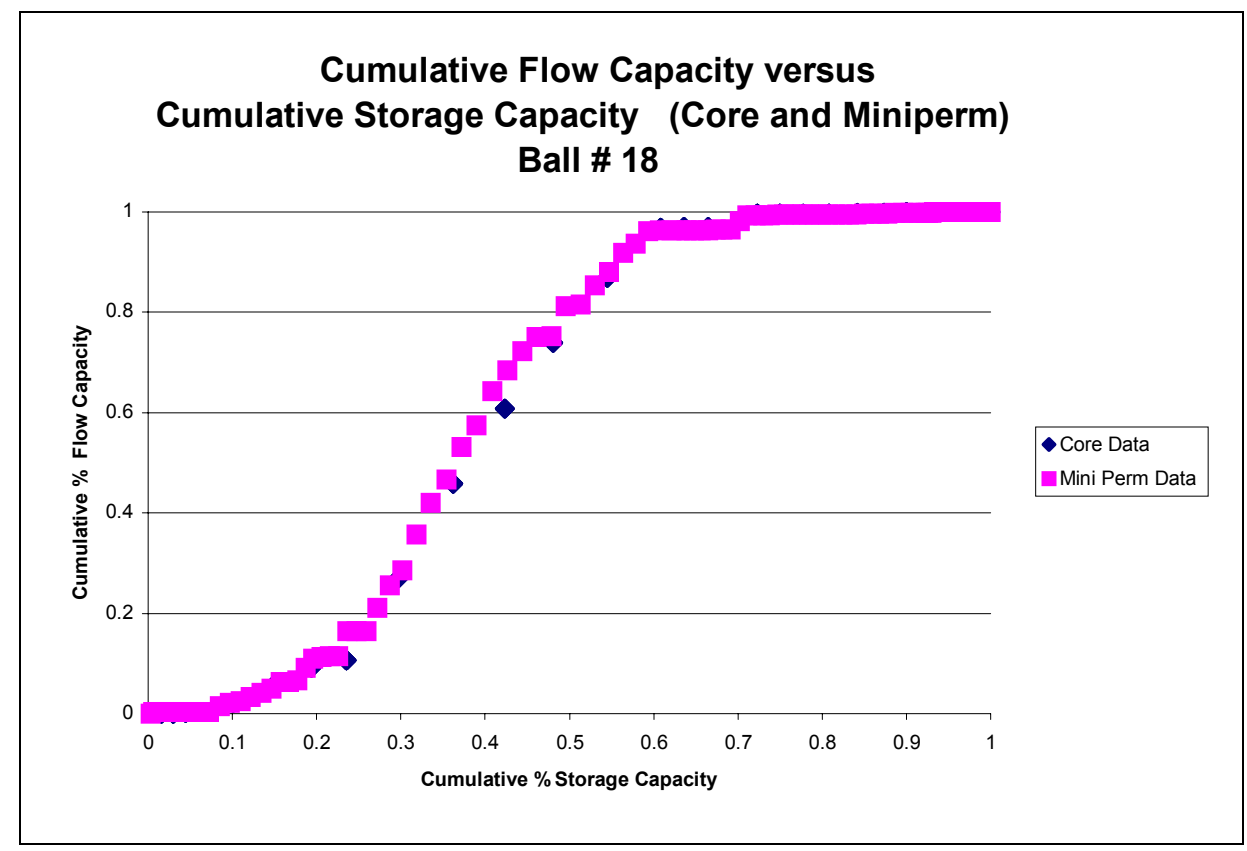

Figure 6.6 Cumulative Flow Capacity versus Cumulative Storage Capacity (Core and Miniperm) Ball \# 18 


\subsubsection{Questionable Flow Unit Below Flow Unit Two}

During the preliminary flow unit identification process the cumulative flow capacity versus storage capacity plots were revisited several times. Two flow units were clearly identified by this analysis. Flow unit one is the upper flow unit encountered. Flow unit two is situated immediately below flow unit one. Flow unit two has much higher permeability and porosity. A third potential flow unit appeared to exist in the Ball \#19 well. The Ball \# 18 and Horner \# 11 also had limited hints of the third unit. The potential flow unit has very low permeability and porosity and was considered to be nonproductive and not a part of the flow units. The low porositypermeability sand at the top and bottom of the core data was not a part of the flow unit analysis due to the lower section being excluded (previously discussed). Figures 6.7 and 6.8 present the Ball \# 19 cumulative plots showing this third potential flow unit for core data and miniperm. 


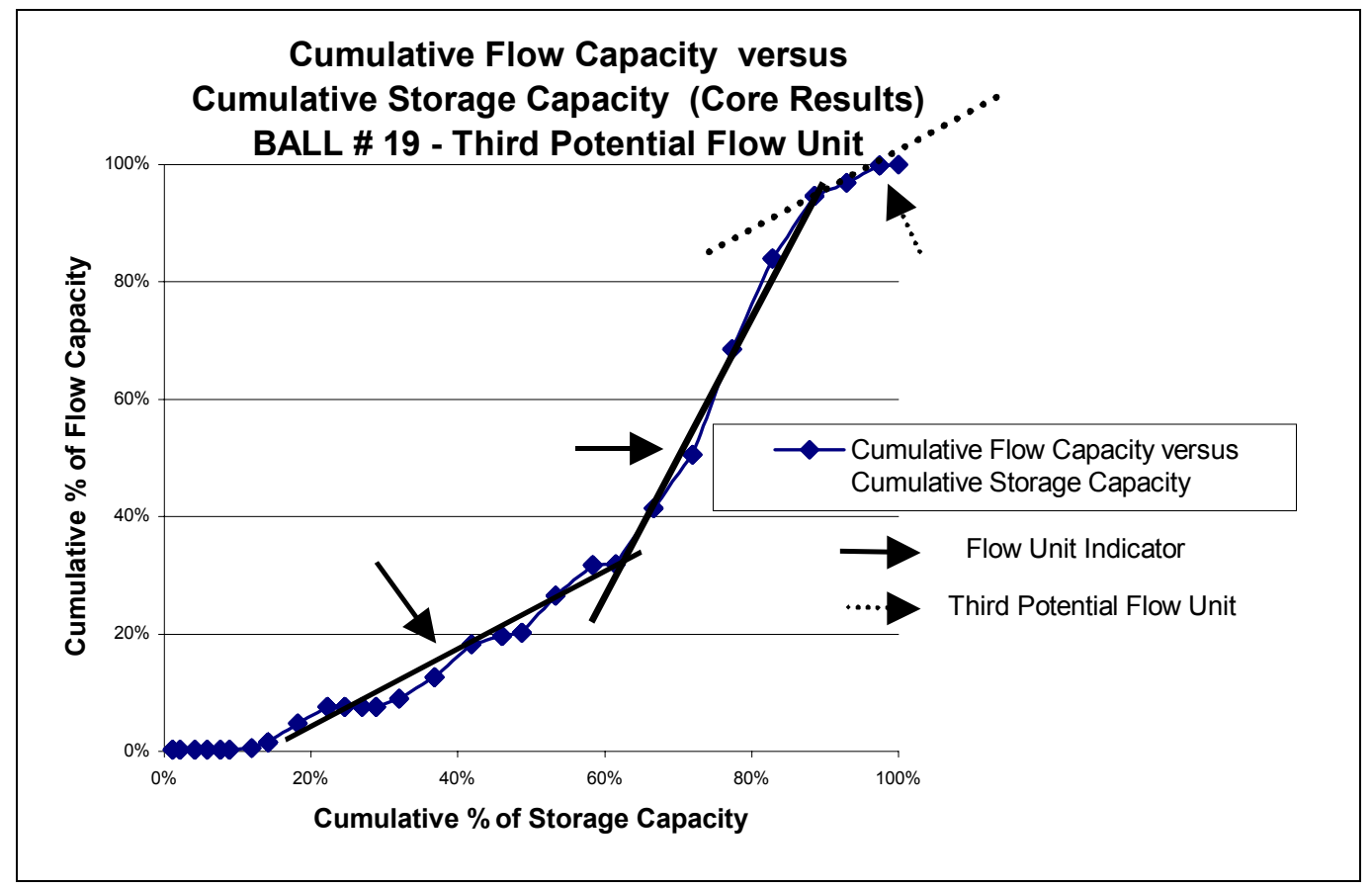

Figure 6.7 Cumulative Flow Capacity versus Cumulative Storage Capacity (Core Results) Ball \#19 - Third Potential Flow Unit

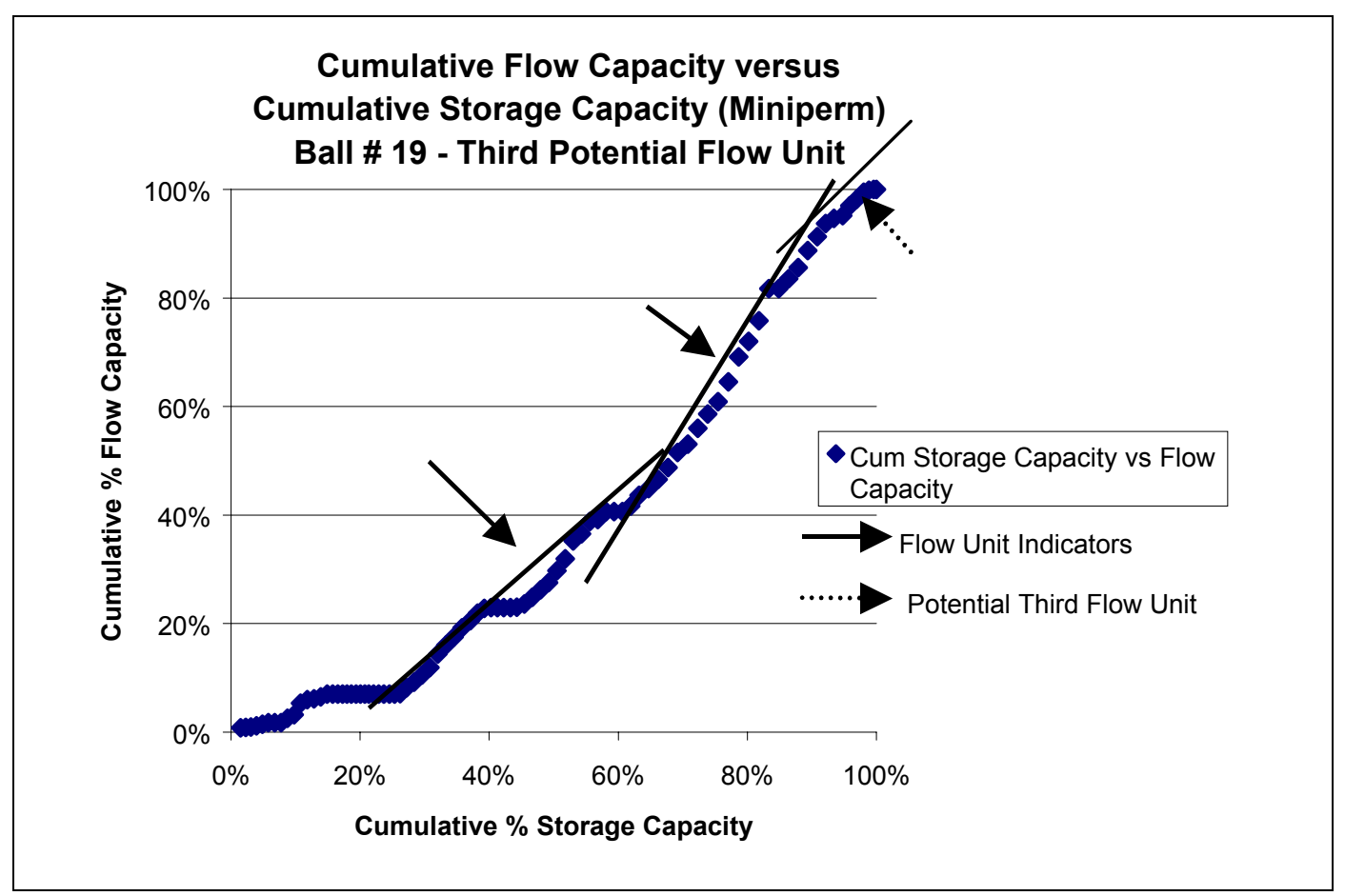

Figure 6.8 Cumulative Flow Capacity versus Cumulative Storage Capacity (Miniperm) Ball \# 19 - Third Potential Flow Unit 


\subsubsection{Permeability-Porosity Scatter Plots}

The relationship between permeability and porosity has a higher correlation within the flow unit. The permeability-porosity scatter plots of each well were developed with the objective of determining the highest correlation within the potential flow units. For wells appearing to have two flow units, boundary or edge points were shifted back and forth between the flow units until the highest correlation was obtained. The upper sand section, which became known as "Flow Unit One" typically reflected greater heterogeneity and therefore had lower correlation. The second sand section, became known as "Flow Unit Two" and is immediately below flow unit one. Flow unit two had much higher permeability and typically reflected a higher correlation.

Figures 6.9 and 6.10 present the permeability-porosity scatter plots for the T. Heirs \# 8, which has a single flow unit, and the Horner \# 9 which two flow units. Each core well and the supporting data for the plots are presented in Appendix D. 


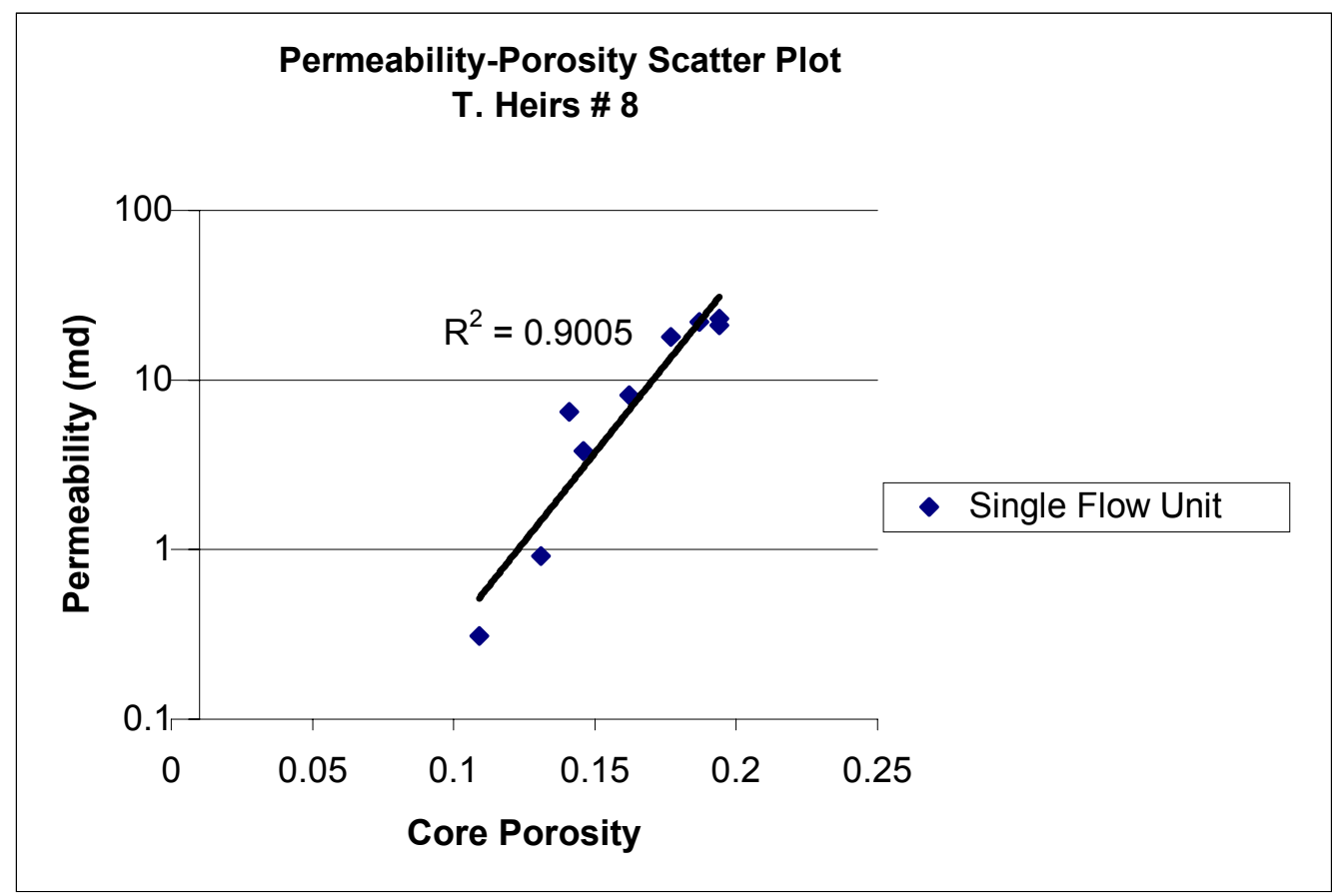

Figure 6.9 Permeability-Porosity Scatter Plot T. Heirs \# 8

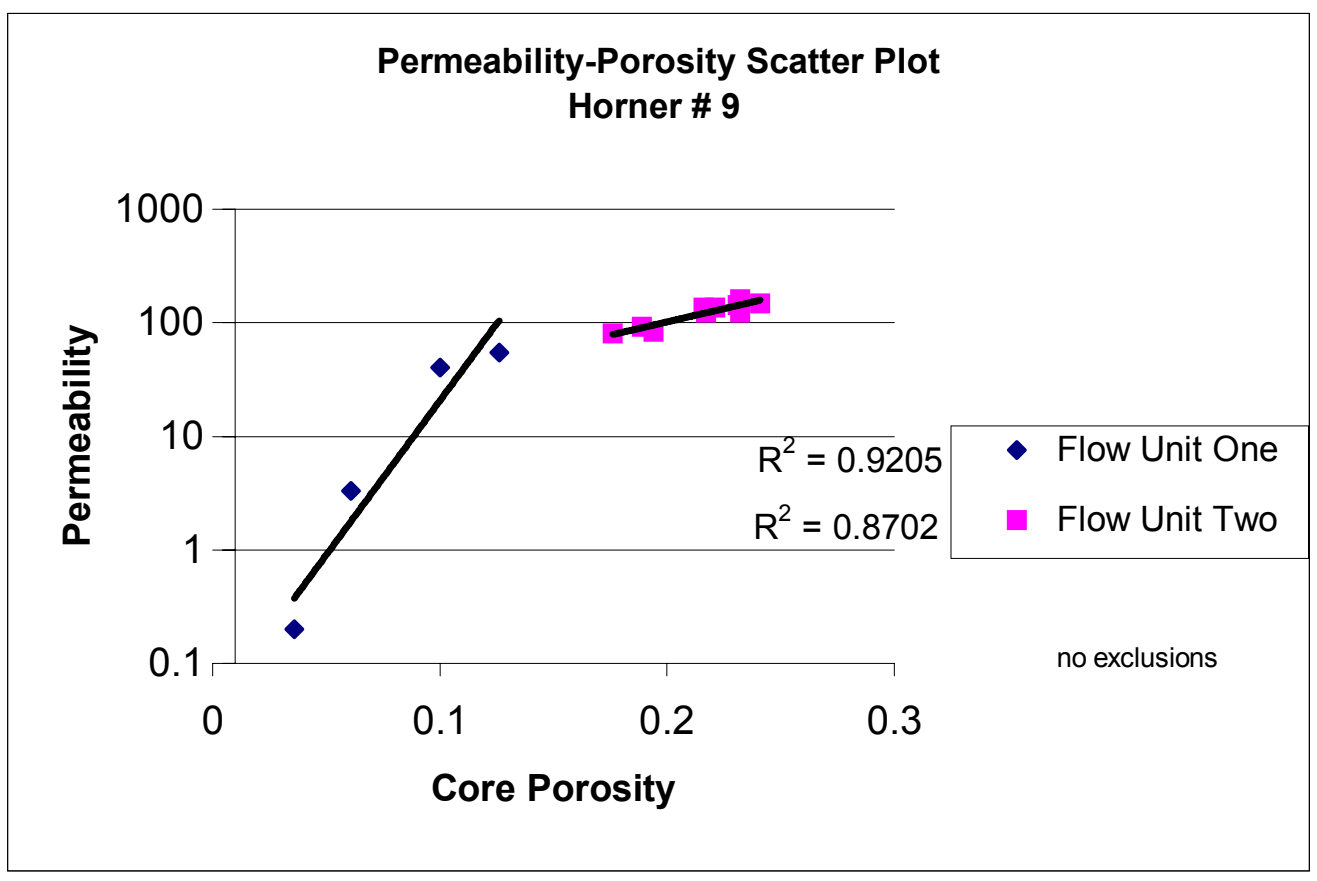

Figure 6.10 Permeability-Porosity Scatter Plot Horner \# 9 
Table 6.2 summarizes the correlation values for each of the core wells. As further comparison Figure 6.11 and Figure 6.12 present composite scatter plots for all six wells combined as a single flow unit (Figure 6.11) as compared to the designated two flow units (Figure 6.12) for the six wells. The R squared value for the six core wells, as a single unit, was .8173 . When the data was broken down into two flow units the $R$ squared values are .7093 and .9281 for flow unit one and two, respectively.

Table 6.2 Summary of R Squared Values for Two Flow Units for Permeability-Porosity Scatter Plots

\begin{tabular}{|lcc|}
\hline Well Name & Flow Unit One & Flow Unit Two \\
\hline T. Heirs \# 8 & .9005 & one unit \\
\hline Horner \# 9 & .9205 & .8702 \\
\hline Ball \# 19 & .8231 & .9523 \\
\hline LeMasters \# 13 & .9277 & one unit \\
\hline Ball \# 18 & .862 & .9612 \\
\hline Horner \# 11 & .9089 & .9999 \\
\hline
\end{tabular}




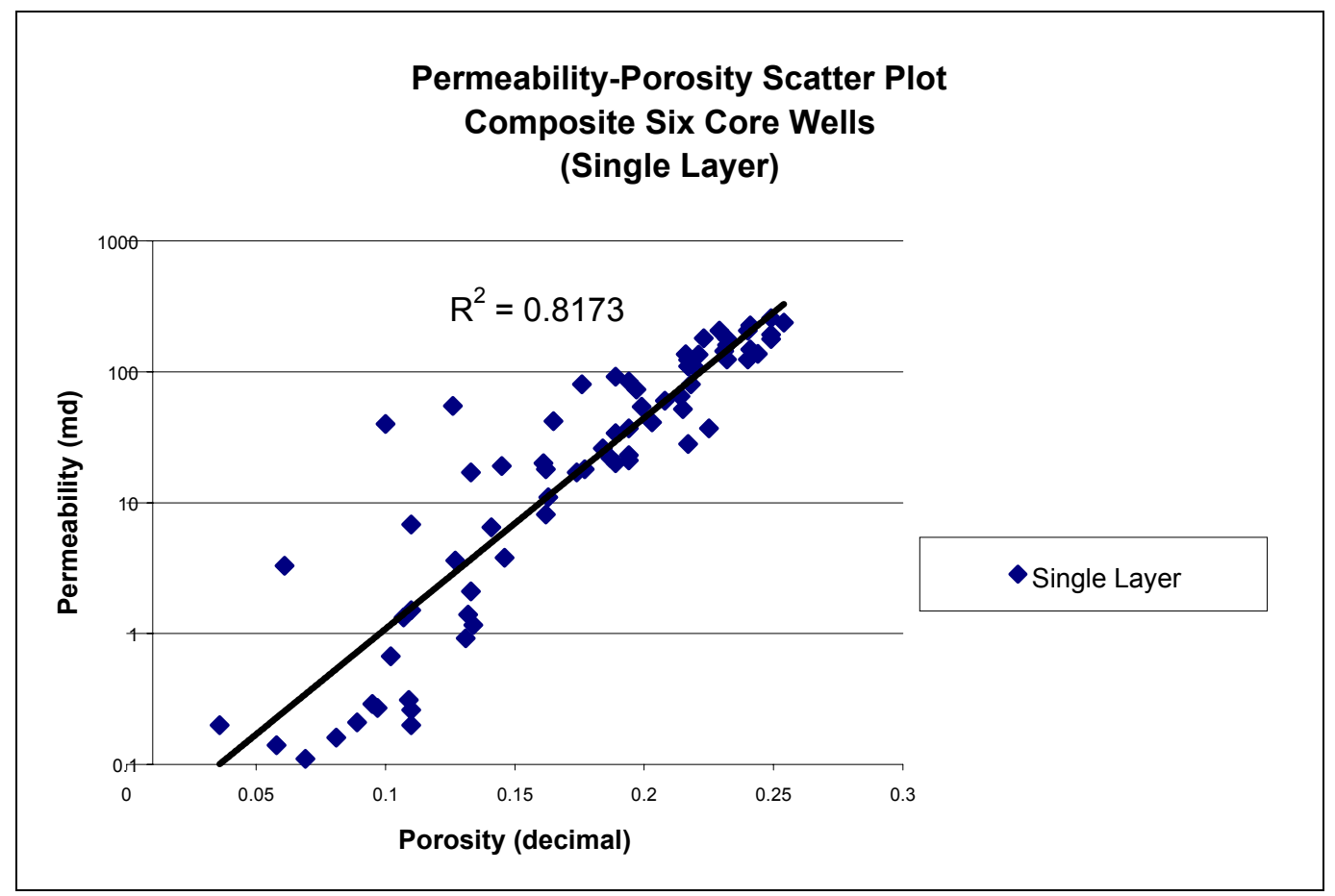

Figure 6.11 Permeability-Porosity Scatter Plot Composite Six Core Wells (Single Layer)

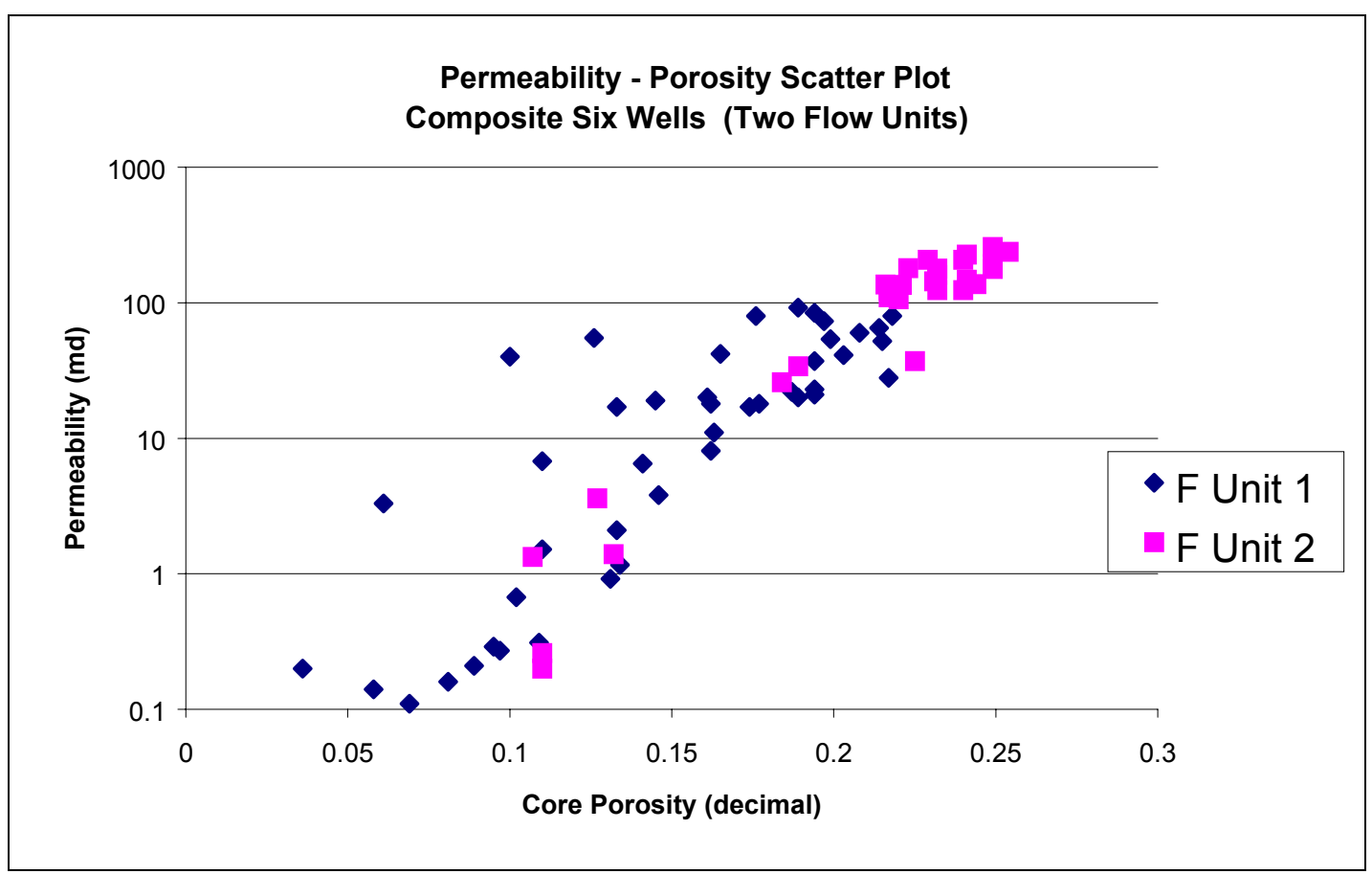

Figure 6.12 Permeability-Porosity Scatter Plot Composite Six Core Wells (Two Flow Units) 


\subsubsection{Flow Zone Indicator (FZI)}

As compared to the permeability-porosity scatter plots, the FZI plots supported the flow unit breaks as well. However, lower $\mathbf{R}$ squared calculations were observed for some of the units. This was likely due to having a very limited number of data points to work with. Table 6.3 summarizes the results. FZI plots are included for the T. Heirs \# 8 and Horner \# 9 - Figures 6.13 and 6.14. Both wells were presented in section 6.2.6 (Permeability-Porosity Scatter Plots) for comparison.

When comparing the $\mathbf{R}$ squared values for the six core wells combined, the values are lower than the $k-\phi$ scatter plots. The $\mathbf{R}$ squared values are .697 for the single flow unit and for the two flow unit model the values are .555 and .9256 for flow units one and two respectively. Figures 6.13 and 6.14 are the six well composite FZI graphs for the single and two flow unit cases. Table 6.3 is a well summary of the preliminary flow units identified using the permeability-porosity scatter plots in conjunction with the FZI method. 
Table 6.3 Summary of R Squared Values for Two Flow Units for Flow Zone Indicator (FZI) Plots

\begin{tabular}{|lll|}
\hline Well Name & Flow Unit One & Flow Unit Two \\
\hline T. Heirs \# 8 & .9036 & one unit \\
\hline Horner \# 9 & .013 & .8468 \\
\hline Ball \# 19 & .7842 & .9652 \\
\hline LeMasters \# 13 & .9243 & one unit \\
\hline Ball \# 18 & .8952 & .9565 \\
\hline Horner \# 11 & .8977 & .9995 \\
\hline
\end{tabular}

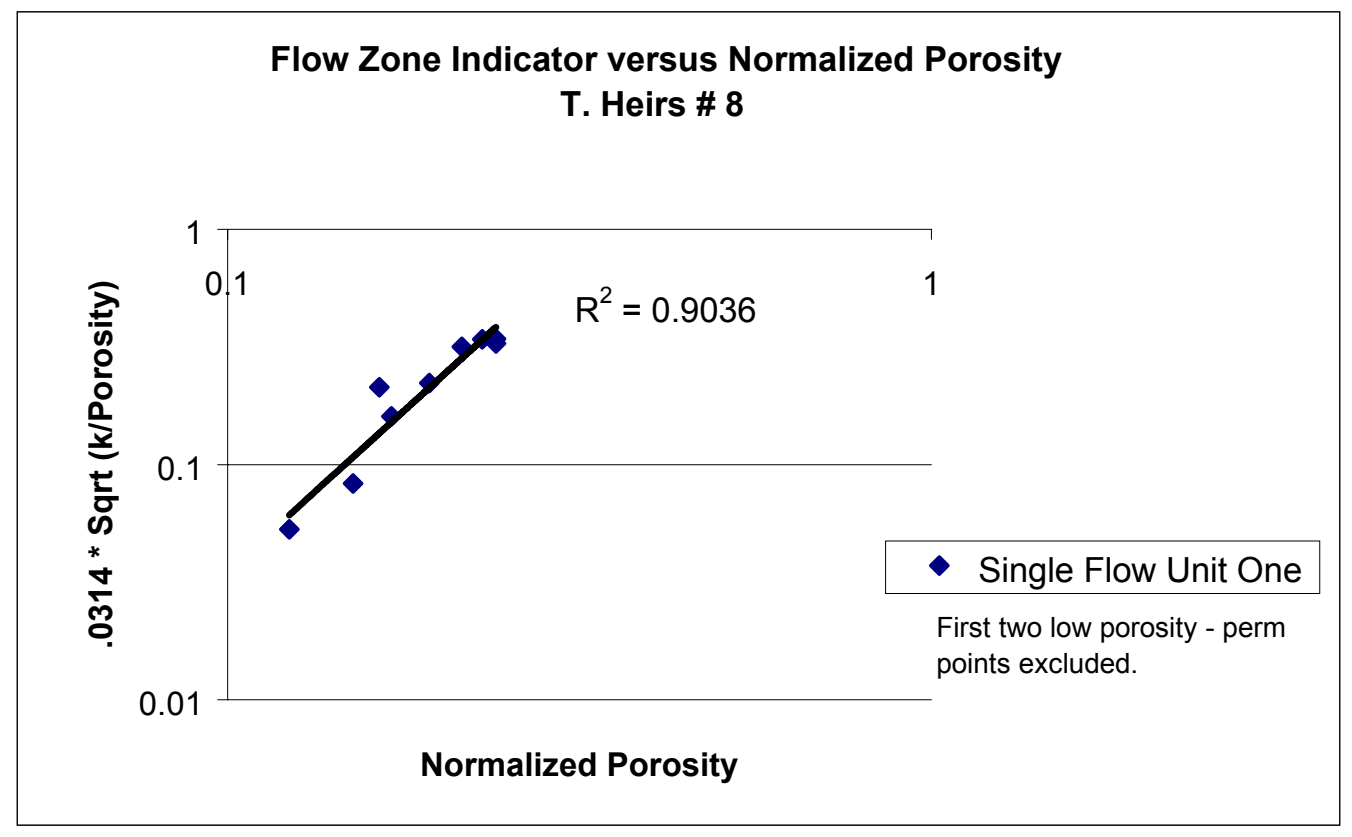

Figure 6.13 Flow Zone Indicator versus Normalized Porosity T. Heirs \# 8 


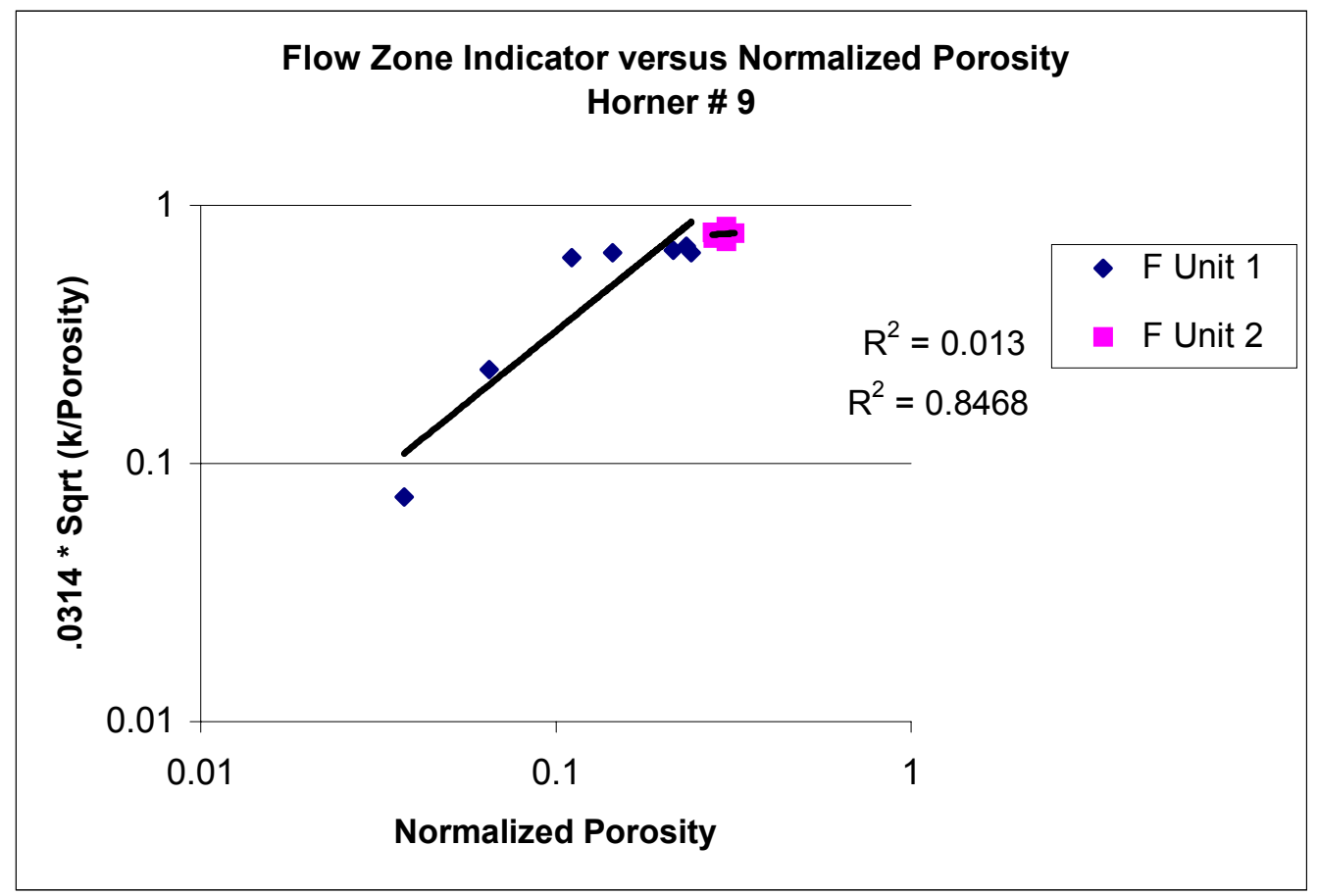

Figure 6.14 Flow Zone Indicator versus Normalized Porosity Horner \# 9

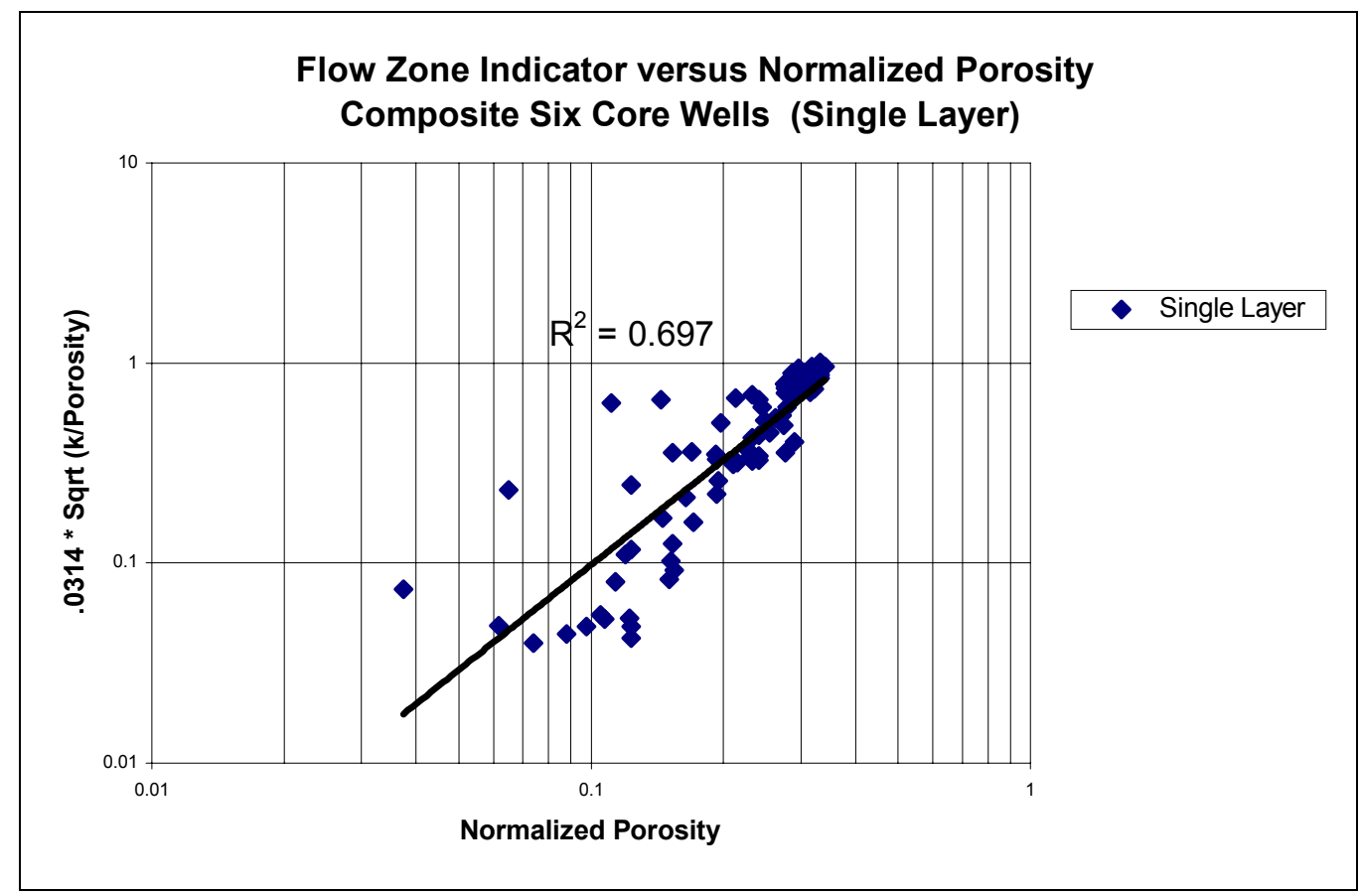

Figure 6.15 Flow Zone Indicator versus Normalized Porosity Composite Six Wells (Single Layer) 


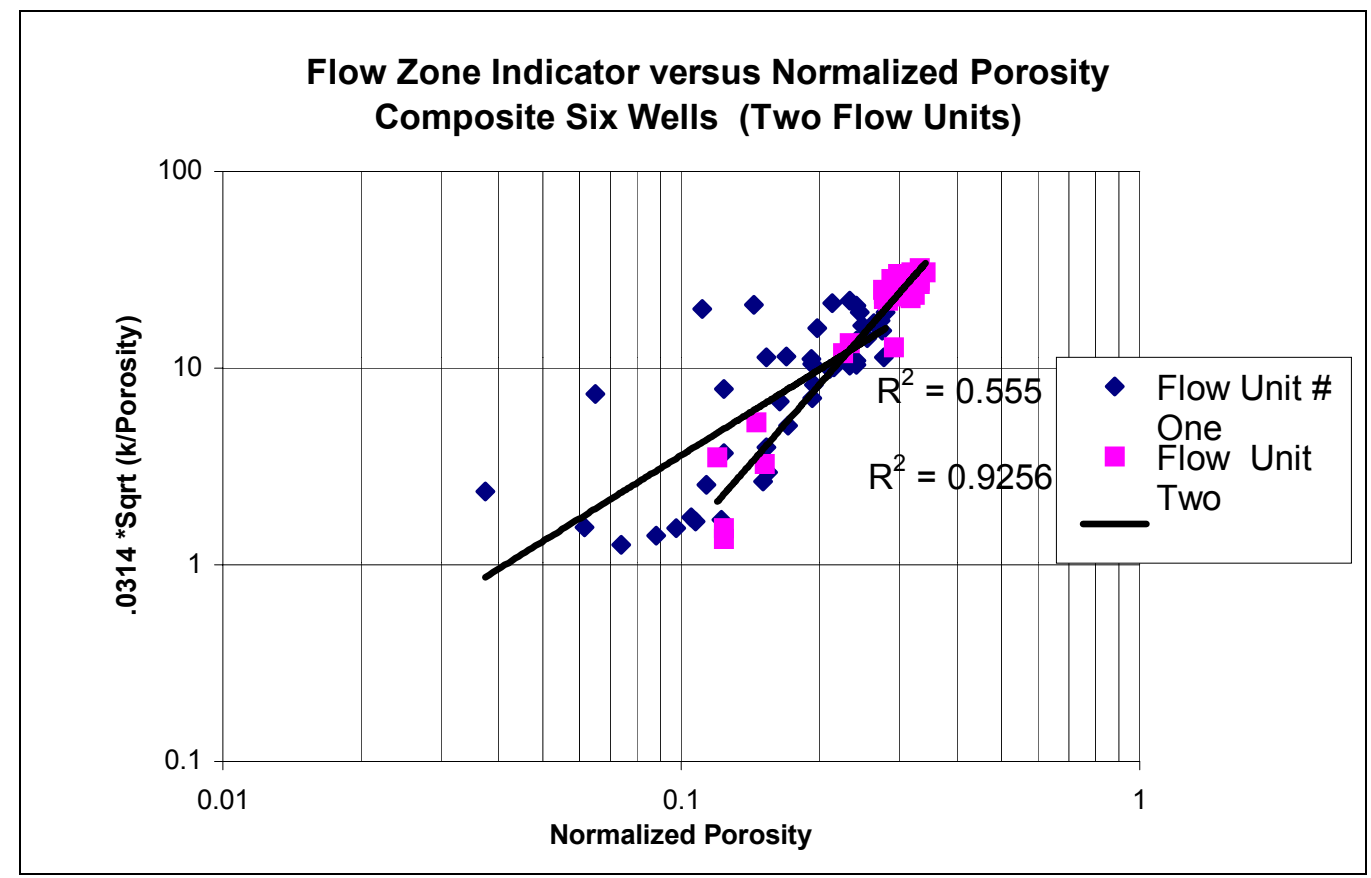

Figure 6.16 Flow Zone Indicator versus Normalized Porosity Composite Six Core Wells (Two Flow Units)

Table 6.4 Summary of the Interval Identified as Flow Units by the $\mathbf{k}-\phi$ Scatter Plot and FZI Plots (Log Depth in Feet)

\begin{tabular}{|llc|}
\hline Well Name & Flow Unit One & Flow Unit Two \\
\hline T. Heirs \# 8 & $2788.75-2797.5$ & single unit \\
\hline Horner \# 9 & $2890-2896.5$ & $2898.25-2903.50$ \\
\hline Ball \# 19 & $3097.25-3106$ & $3107.25-3112.5$ \\
\hline LeMasters \# 13 & $3043.25-3052.75$ & single unit \\
\hline Ball \# 18 & $2989.50-2994$ & $2995.5-3007.25$ \\
\hline Horner \# 11 & $3084.5-3090.5$ & $3092-3093.25$ \\
\hline
\end{tabular}




\subsubsection{Artificial Neural Network Kohonen Analysis}

The final preliminary flow unit identification tool utilized the ANN Kohonen method to separate the data into groups. The other preliminary flow unit identification tools utilized focused strictly on identifying the permeability-porosity relationship within the flow unit. The Kohonen analysis included several log-based inputs. The log inputs included gamma ray, density, gamma ray slope, density slope, gamma ray base line, and density base line. The other input was measured permeability from the core analysis.

Kohonen analysis of all available core data was completed for two, three and four groups. The two and three category models offered very positive results (Tables F.1 and F.2). A four-category model failed as compared to the other two models. The final groups in the four-category model lacked the recognizable patterns of the two and three category models. The groups in the four-category model did not represent flow units.

Certain data points appeared to have characteristics or properties of both flow units. These core points are situated between the two flow units. The three-category Kohonen model had the ability to recognize and categorize these particular points and place them in the center group or category. There were only a few points the ANN handled in this manner. However, these transition 
points became more of an area of focus as the backpropagation ANN model for permeability prediction was finalized.

For certain wells another outcome became more apparent from the two and three category models. Certain core data below flow unit two was being categorized as flow unit one. The producing flow unit one is situated above flow unit two. In a few of the wells a continuation of low quality sand below flow unit two is observed. This lower portion typically exhibits very low porosity and permeability and is considered to be non-productive. Section 6.2.5 previously discussed this additional potential flow unit as a result of the cumulative permeability-porosity analysis. Although nonproductive; the Kohonen analysis suggests a porosity-permeability relationship similar to flow unit one. This discovery was further tested as the final backpropagation model was developed.

The preliminary flow unit identification processes focusing strictly on the permeability-porosity indicated a single flow unit in the Lemasters \# 13. During the preliminary identification process the T. Heirs \# 8 appeared to have a single flow unit and at other times appeared to have two flow units. The balance of the wells reflected two flow units during screening.

Kohonen analysis results categorized the T. Heirs \# 8 data as a single flow unit. This well had appeared to have both flow units present during some of the preliminary tests (cumulative porosity- 
permeability). A distinct advantage of the analysis is for the network to learn from all available core and log data of the six wells. The T. Heirs \# 8 exhibits some permeability-porosity variation. However, based on the characteristics of both flow units in all six wells, the model categorized the T. Heirs well as flow unit one. This was helpful during the backpropagation modeling phase.

Additional Kohonen analysis was performed on model 1-K, the ANN backpropagation model. The difference between the initial work described above and the additional Kohonen analysis related to the core data used. Low permeability-porosity core results at the top or bottom of the sand were excluded for each well. The intent was to include only those core samples actually a part of either flow unit. Low permeability or porosity data indicated non-production sections outside the primary sand and was excluded during this analysis.

In terms of identifying the flow unit breaks between flow unit one and two, the results for this Kohonen analysis were similar to the initial analysis, which included all of the data. Tables F.3, and F.4 can be referenced for each well. Table 6.6 summarizes the per well results for flow units as determined by the Kohonen Self Organizing Map Network. The transition points between the two flow units are better assigned to a given flow unit during the backpropagation ANN modeling. The Kohonen analysis also characterized a section of 
sand below flow unit two as being similar to flow unit one. Tables

F.3, F.4 can be referenced for further detail.

6.2.9 Summary of the Preliminary Flow Unit Identification Process

The preliminary methods identified two flow units within the sandstone:

- Flow unit one is encountered first in the reservoir. A conglomerate is often observed in the upper part of the sand. Flow unit one is situated in the lower part of a conglomerate sand and the upper part of the sandstone section directly below the conglomerate. As compared to flow unit two, the flow unit has lower porosity and much lower permeability.

- Flow unit two is situated below flow unit one. The two flow units exhibit different values for the gamma ray and density logs (Table 6.5). Flow unit two has higher porosity and significantly more permeability.

- Another low permeability flow unit below flow unit two seems to be present in a few of the wells. This flow unit appears to have properties similar to flow unit one.

Table 6.5 Description of the Flow Units

\begin{tabular}{|l|c|c|}
\hline \multicolumn{3}{|c|}{ ONE } \\
WARL LOG \\
PARAMETER & \multicolumn{2}{c|}{ FLOW UNIT FLOW UNIT } \\
\hline Bulk Density (gm/cc) & $2.35-2.45$ & $2.31-2.41$ \\
Porosity (\%) & $13-16$ & $15-20$ \\
Gamma Ray (API) & $31-41$ & $40-60$ \\
\hline
\end{tabular}


Table 6.6 Kohonen Network Summary Core Permeability and Log Measurements

\begin{tabular}{|c|c|c|c|c|c|c|}
\hline Well Name & \begin{tabular}{|l} 
Gro \\
Max
\end{tabular} & $\begin{array}{l}\text { Dups } \\
\text { Used }\end{array}$ & $\begin{array}{c}\text { Flow Unit } \\
\text { One }\end{array}$ & $\begin{array}{c}\text { Flow Unit } \\
\text { Two }\end{array}$ & $\begin{array}{c}\text { Flow Unit } \\
\text { Three }\end{array}$ & Observations \\
\hline T.Heirs \# 8 & $\begin{array}{l}2 \\
3\end{array}$ & $\begin{array}{l}1 \\
1\end{array}$ & $\begin{array}{l}2785.3-2979.5 \\
2785.3-2979.5\end{array}$ & $\begin{array}{l}\text { none } \\
\text { none }\end{array}$ & $\begin{array}{c}\text { na } \\
\text { none }\end{array}$ & $\begin{array}{l}\text { ANN sees single } \\
\text { groups both times. }\end{array}$ \\
\hline Horner \# 9 & $\begin{array}{l}2 \\
3\end{array}$ & $\begin{array}{l}2 \\
2\end{array}$ & $\begin{array}{l}2890-2893.5 \\
2890-2893.5\end{array}$ & $\begin{array}{c}2895-2903.5 \\
\text { none }\end{array}$ & $\begin{array}{r}\text { na } \\
2895- \\
2903.5\end{array}$ & $\begin{array}{l}\text { Break point @ } 2893.5 \\
\text { both same break point } \\
\text { exact same two } \\
\text { groups. }\end{array}$ \\
\hline Ball \# 19 & $\begin{array}{l}2 \\
3\end{array}$ & $\begin{array}{l}2 \\
2\end{array}$ & $\begin{array}{l}3086.25-3100 \\
3086.25-3100\end{array}$ & $\begin{array}{c}3107.25-3110.7 \\
\text { none }\end{array}$ & $\begin{array}{r}\text { na } \\
3107.25- \\
3110.75\end{array}$ & $\begin{array}{l}\text { Between two groups, } \\
6 \text { points back and } \\
\text { forth same break } \\
\text { points for the groups. }\end{array}$ \\
\hline LeMas \# 13 & $\begin{array}{l}2 \\
3\end{array}$ & $\begin{array}{l}1 \\
1\end{array}$ & $\begin{array}{l}3031.8-3052.8 \\
3031.8-3052.8\end{array}$ & $\begin{array}{l}\text { none } \\
\text { none }\end{array}$ & $\begin{array}{c}\text { na } \\
\text { none }\end{array}$ & $\begin{array}{l}\text { ANN sees single unit } \\
\text { both times. }\end{array}$ \\
\hline Ball \# 18 & $\begin{array}{l}2 \\
3\end{array}$ & $\begin{array}{l}2 \\
2\end{array}$ & $\begin{array}{l}2987.5-2990.75 \\
2987.5-2990.75\end{array}$ & $\begin{array}{l}2995.5-2999.75 \\
\text { none }\end{array}$ & $\begin{array}{c}\text { na } \\
2995.5- \\
2999.75\end{array}$ & $\begin{array}{l}\text { Three common points } \\
\text { between the two units } \\
\text { back and forth. }\end{array}$ \\
\hline Horner \# 11 & $\begin{array}{l}2 \\
3\end{array}$ & $\begin{array}{l}2 \\
2\end{array}$ & $\begin{array}{l}3084.5-3089.5 \\
3084.5-3089.5\end{array}$ & $\begin{array}{l}3090.5-3092.5 \\
\text { none }\end{array}$ & $\begin{array}{r}\text { na } \\
3090.5- \\
3092.5\end{array}$ & $\begin{array}{l}\text { Same groups, both } \\
\text { models see two } \\
\text { groups. }\end{array}$ \\
\hline
\end{tabular}

\subsection{The Neural Network for Permeability Prediction}

\subsubsection{Model 1-K for Permeability Prediction}

Two neural networks were ultimately developed for permeability prediction. One ANN designated as model 1-K was defined using a tighter definition of the flow units. This was 
confirmed by the neural network analysis. Other efforts to strengthen the model included revisiting the correlation between log and core depth. Although limited, a few core data points were ultimately shifted $1 / 4$ foot in depth. The slightly changing values of the digitized logs can enhance the final ANN. Any such shift was in keeping with the characteristics of the log data. The 81 core data and log inputs used for developing the ANN model are presented in Appendix H.1. As discussed in chapter 4, the table details the ANN results for the testing, training and production verification well. For each well, the correlation value between predicted permeability and actual permeability was very good (Table 6.7). $R$ squared values between .8924 and .9870 were observed.

Table 6.7 Permeability Prediction Model (Model 1-K) R Squared Values

\begin{tabular}{|l|c|c|c|}
\hline WELL NAME & \multicolumn{1}{l}{ TST } & \multicolumn{1}{l|}{ TRN } & \multicolumn{1}{l|}{ PRO } \\
\hline Horner \# 11 & 0.8017 & 0.8916 & 0.987 \\
T Heirs \# 8 & 0.8185 & 0.885 & 0.9021 \\
Borner \# 9 & 0.8085 & 0.8944 & 0.9064 \\
LeMll \# 19 & 0.8702 & 0.9878 & 0.8924 \\
Ball \# 18 & 0.8494 & 0.9753 & 0.8942 \\
\hline
\end{tabular}




\subsubsection{Model 2-K for Permeability Prediction}

Model 2-K is based on a total of 95 core and log data inputs. This model incorporates the core data for the lower permeabilityporosity section below flow unit two. Appendix $\mathrm{H}$. Table 2.0 details the data used for model developing model 2-K. As can be seen in Table 6.8, model 2-K significantly improves the LeMasters \# 13 permeability prediction ( .8942 increases to .9338 for the production set). Change in permeability prediction of the other core wells was not significant.

Table 6.8 Permeability Prediction Model (Model 2-K) R Squared Values

\begin{tabular}{|l|c|c|c|}
\hline WELL NAME & \multicolumn{1}{c}{ TST } & \multicolumn{1}{l|}{ TRN } & PRO \\
\hline Horner \# 11 & 0.7842 & 0.9334 & 0.9815 \\
T Heirs \# 8 & 0.9019 & 0.9864 & 0.9011 \\
Horner \# 9 & 0.8734 & 0.988 & 0.894 \\
Ball \# 19 & 0.8346 & 0.9866 & 0.888 \\
LeMasters \# 13 & 0.8987 & 0.9843 & 0.9338 \\
Ball \# 18 & 0.7468 & 0.9218 & 0.9768 \\
\hline
\end{tabular}




\subsubsection{Model 2-K Selected as the Final Model for Permeability Prediction}

Model 2-K, the ANN model for permeability prediction, was chosen as the better ANN model for this particular field. Two key factors were considered. The location of the core wells within the field was significant. The LeMasters \# 13 well is situated in the north part of the field. This well exhibits only flow unit one. Model 2-K will better predict the north section of the field, as well as other portions of the field where flow unit one exists either as a single flow unit or when both flow units are present. By including more data similar to flow unit one, the models ability to predict flow unit one (situated above flow unit two) is enhanced. Any impact to the model prediction ability in flow unit two was not significant.

In addition model 2-K more fully utilizes the core data during training. Model $2-\mathrm{K}$ is tested and trained using 95 data points as opposed to 81 core data points included in model 1-K. As a result it is considered a stronger model. Table H. 4.0 presents a flow unit summary breakdown per well. Figures 6.17 and 6.18 graphically present actual versus predicted permeability results for Horner \# 11 and Ball \# 19. Figures H. 1- 6 can be referenced for graphs of all six core wells. 


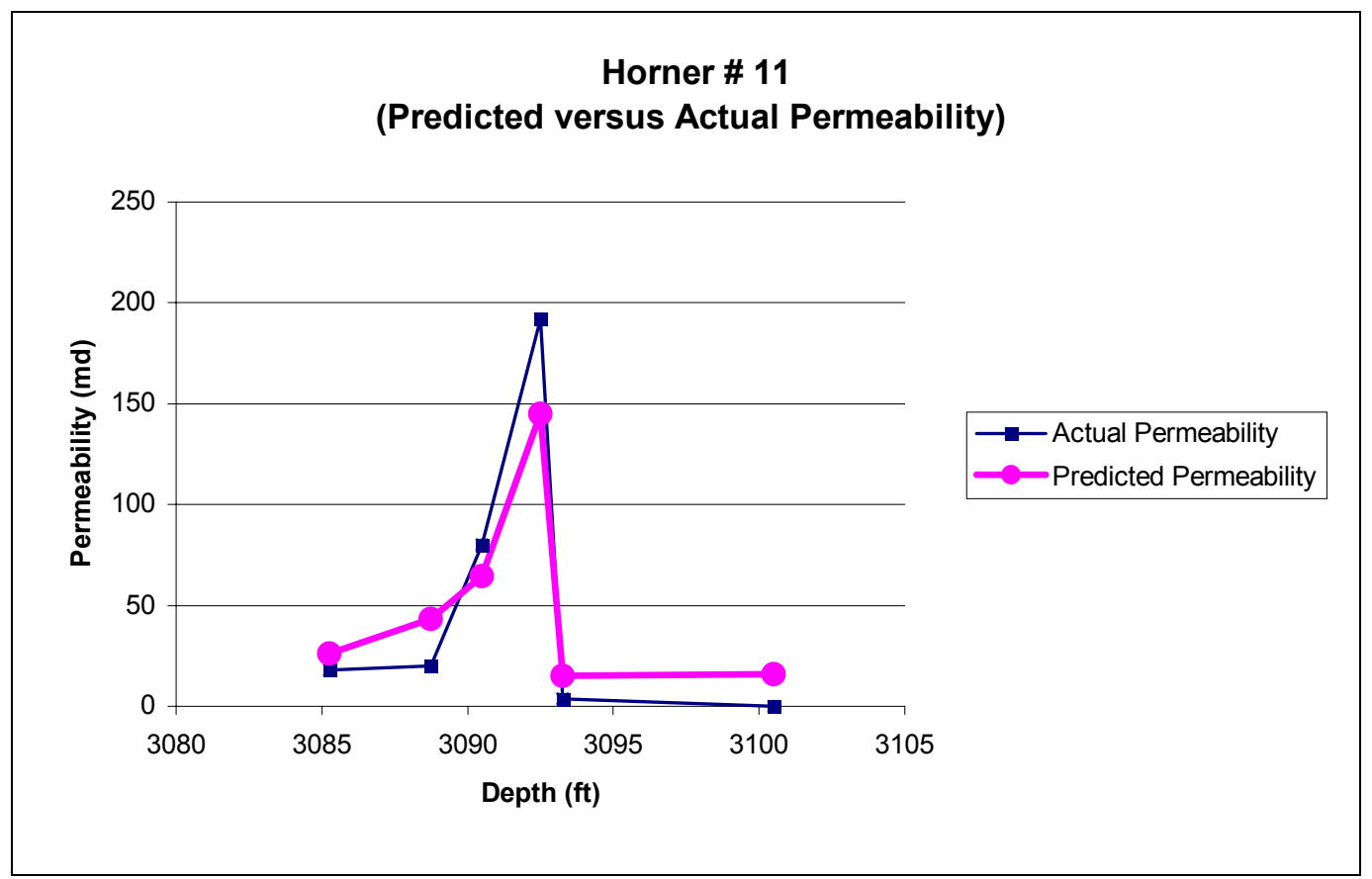

Figure 6.17 Horner \# 11 Predicted versus Actual Permeability

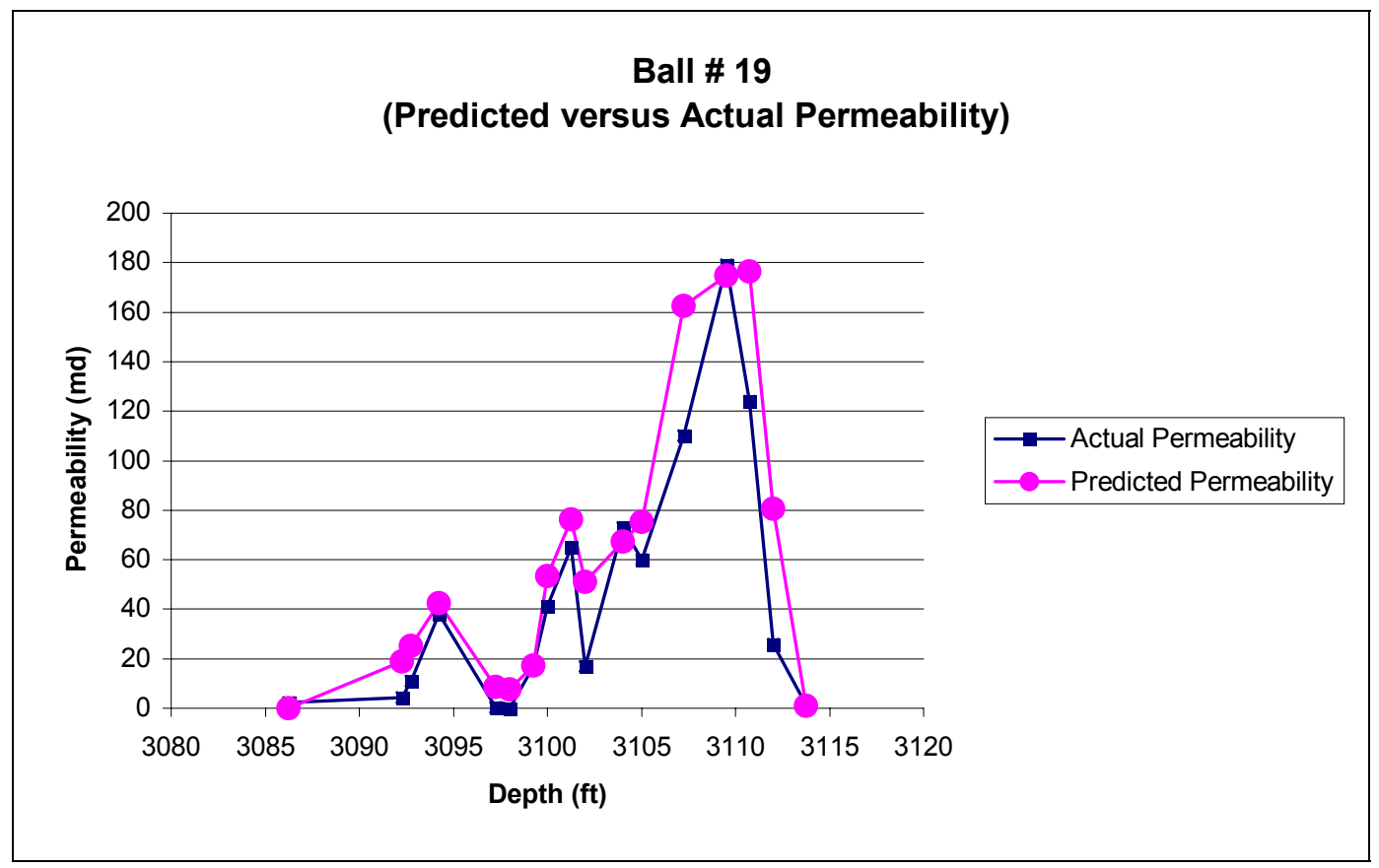

Figure 6.18 Ball \# 19 Predicted versus Actual Permeability 


\subsection{Predicting the Flow Unit}

Two flow unit models were evaluated. Model 2-FU utilized the core data and flow unit designation at each core data point (95 points). Model 3-FU utilized the digitized log data and flow units were assigned utilizing the previous flow unit identification work (306 points). Table 6.9 compares the correlation results for both models. As can be observed certain core wells exhibit excellent correlation while others appear not to correlate well.

\section{Table 6.9 Flow Unit Prediction Model Summary of R Squared Values}

\begin{tabular}{|l|c|c|}
\hline WELL NAME & \multicolumn{1}{c}{$\begin{array}{c}\text { 2-FU } \\
\text { Core }\end{array}$} & $\begin{array}{c}\text { 3-FU } \\
\text { Dig. Log }\end{array}$ \\
\hline Horner \# 11 & .25 & .9021 \\
T Heirs \# 8 & $X$ & $X$ \\
Horner \# 9 & .6857 & .9018 \\
Ball \# 19 & .8595 & .5148 \\
LeMasters \# 13 & 1.0 & 1.0 \\
Ball \# 18 & 1.0 & 1.0 \\
\hline
\end{tabular}

The ANN could not predict the flow unit within the transition area of certain core wells. Outside of the transition zone of the core wells the prediction of flow unit one or two is very accurate. Table 
6.10 illustrates the problem. In the upper portion of sand predictions for flow unit one are excellent. The lower flow unit two is predicted equally well. These results suggest a combination of flow unit properties over a thin transition section. This problem occurs at or near the flow unit boundaries. Table 6.11 is a portion of Table F.2 for the Ball \#19 well. This table presents the results of the Kohonen analysis during the flow unit identification process. The transition zone can readily be seen.

Table 6.10 Portion of the ANN Flow Unit Model 3-FU Ball \# 19

\begin{tabular}{|c|c|c|c|}
\hline \multicolumn{4}{|c|}{$\begin{array}{c}\text { Portion of the ANN Flow } \\
\text { Unit Model 3-FU } \\
\text { Well Name: Ball \# } 19\end{array}$} \\
\hline $\begin{array}{l}\text { Depth } \\
\text { (feet) }\end{array}$ & $\begin{array}{l}\text { Actual } \\
\text { Flow Unit }\end{array}$ & $\begin{array}{l}\text { ANN } \\
\text { Predicted }\end{array}$ & $\begin{array}{l}\text { F Unit Assigned } \\
\text { for R sq Purposes }\end{array}$ \\
\hline 3100 & 1 & 1.0388694 & 1 \\
\hline 3101.25 & 1 & 1.0544004 & 1 \\
\hline 3102 & 1 & 1.1242173 & 1 \\
\hline 3103 & 1 & 1.3730816 & 1 \\
\hline 3104 & 1 & 1.3495631 & 1 \\
\hline 3105 & 1 & 1.1447512 & 1 \\
\hline 3106 & 1 & 1.403694 & 1 \\
\hline 3107.25 & 1 & 1.5270721 & 1.527 transition area \\
\hline 3108 & 1 & 1.476661 & 1.4766 transition area \\
\hline 3108.75 & 2 & 1.9162269 & 2 \\
\hline 3109.5 & 2 & 1.9839251 & 2 \\
\hline 3110.75 & 2 & 1.9939854 & 2 \\
\hline
\end{tabular}




\subsubsection{Predicting Permeability in the Transition Zone}

The transition zone has varying porosity and permeability. Based on the core permeability-porosity measurements in the transition zone, permeability is expected to exhibit permeability similar to flow unit one. In addition, the core results indicate low permeability shale streaks as a part of this zone. This will further limit any impact pockets of higher permeability would have in the transition zone.

Table 6.11 Kohonen Network (Three Categories) (Portion of Table F.2 for the Ball \# 19)

\begin{tabular}{|c|c|c|c|c|c|c|c|c|c|c|c|}
\hline & \multicolumn{11}{|c|}{$\begin{array}{l}\text { ANN Kohonen Analysis of Core Data Set } \\
\text { Winning Neuron is } 1.0 \\
\text { Analysis for Three Categories }\end{array}$} \\
\hline \multicolumn{12}{|c|}{ ANN Inputs =====> input input } \\
\hline & & & & & & & & & Net & twor & \\
\hline Well Name & Depth c & gr & rhob & gr' & rhob' $g$ & gr bl & rhob bl K & $(\mathrm{md})$ & & 23 & 3 \\
\hline Ball \# 19 & 3096 & 41 & 2.469 & -6.648 & 0.128 & 123 & 2.71 & 0.08 & 1 & 0 & 0 \\
\hline Ball \# 19 & 3097 & 35.46 & 2.509 & 2.216 & 0.008 & 123 & 2.71 & 0.27 & 1 & 0 & 0 \\
\hline Ball \# 19 & 3098 & 41 & 2.519 & 7.756 & -0.04 & 123 & 2.71 & 0.16 & 1 & 0 & 0 \\
\hline Ball \# 19 & 3099 & 45.43 & 2.477 & -7.756 & -0.01 & 123 & 2.71 & 17 & 1 & 0 & 0 \\
\hline \multicolumn{12}{|c|}{ Beginning of Transition Zone } \\
\hline Ball \# 19 & 3100 & 37.12 & 2.396 & -8.864 & -0.11 & 123 & 2.71 & 41 & 0 & 1 & 0 \\
\hline Ball \# 19 & 3101 & 36.57 & 2.373 & 3.324 & -0.01 & 123 & 2.71 & 65 & 0 & 1 & 0 \\
\hline Ball \# 19 & 3102 & 41.55 & 2.399 & 7.756 & 0.096 & 123 & 2.71 & 17 & 1 & 0 & 0 \\
\hline Ball \# 19 & 3103 & 43.77 & 2.432 & 0 & 0.008 & 123 & 2.71 & 6.79 & 1 & 0 & 0 \\
\hline Ball \# 19 & 3104 & 44.32 & 2.377 & 2.216 & -0.04 & 123 & 2.71 & 73 & 0 & 0 & \\
\hline Ball \# 19 & 3105 & 43.21 & 2.365 & 4.432 & -0 & 123 & 2.71 & 60 & $\mathbf{0}$ & 1 & 0 \\
\hline Ball \# 19 & 3106 & 43.77 & 2.367 & -4.432 & 0.004 & 123 & 2.71 & 1.16 & 1 & 0 & 0 \\
\hline \multicolumn{12}{|c|}{ Beginning of FU 2 and End of Transition } \\
\hline Ball \# 19 & 3107 & 39.89 & 2.362 & -2.216 & -0.01 & 123 & 2.71 & 110 & 0 & 0 & \\
\hline Ball \# 19 & 3108 & 40.44 & 2.307 & 5.54 & -0.01 & 123 & 2.71 & 106 & 0 & 0 & 1 \\
\hline Ball \# 19 & 3109 & 43.21 & 2.293 & -1.108 & 0 & 123 & 2.71 & 207 & 0 & 0 & 1 \\
\hline
\end{tabular}




\subsubsection{Two Step Process to Model Flow Unit Designation for ANN Permeability Model}

In order to utilize model 2-K to predict permeability using the digitized well logs from 125 wells, the transition area had be properly categorized. A two step process was developed to:

- recognize the transition zone and to

- classify the transition zone as flow unit one prior to running the ANN permeability prediction model on the 125 digitized well logs.

This was accomplished by developing an intermediate ANN flow unit prediction model - model 4-FU. Except for changes to flow unit designations, this model is identical to model 3-FU which utilized the digitized log data. Flow unit designation changes are as follows to the model:

- Flow unit designation as one remains flow unit one.

- Transition zone to be designated as flow unit two.

- Flow unit two to be designated as flow unit three.

- Lower flow unit one to remain as flow unit one.

Model 4-K was ran on the digitized log data having the same six log based inputs as the model $3-\mathrm{K}$. The same constant test set is used. The output was flow unit one, two, or three. The only difference between model 3-FU and model 4-FU is the reclassification of flow units. 
It was necessary to designate the flow units for the six digitized core wells. The transition zone was identified using the Kohonen analysis results in Appendix F. along with model 2-K and model 2-FU. The correlation results of model 4-FU are summarized in Table 6.12. This intermediate model successfully predicted the flow units and the transition zone. Table H.3 can be referenced for data utilized in the 1,3,2,1 ANN model.

Table 6.12 Summary of R Squared Values Flow Unit Prediction for Model 4-FU

\begin{tabular}{|c|c|c|c|}
\hline WELL & TST & TRN & PRO \\
\hline Horner \# 11 & 0.9183 & 0.9719 & 0.7858 \\
\hline & & & \\
\hline T. Heirs \# 8 & 0.9662 & 0.9735 & 1 \\
\hline & & & \\
\hline Horner \# 9 & 0.9472 & 0.9551 & 0.9031 \\
\hline & & & \\
\hline Ball \# 19 & 0.9576 & 0.9858 & 0.9137 \\
\hline & & & \\
\hline LeMasters \# 13 & 0.9596 & 0.9797 & 1 \\
\hline & & & \\
\hline Ball \# 18 & 0.9924 & 0.9761 & 0.8759 \\
\hline
\end{tabular}

6.4.3 Preparing the Predicted Flow Units for the ANN Permeability Model

Model 4-FU was applied to the 125 digitized well logs. The flow unit outputs from model 4-FU were manually changed in order to run model 2-K (permeability prediction) on the 125 digitized well logs. In order to predict permeability via model 2-K the unit 
designations were re-categorized. The reclassified flow unit designations were the output product of model 4-FU. Figure 6.19 presents the flow unit designations of the intermediate model needed to address the transition zone.

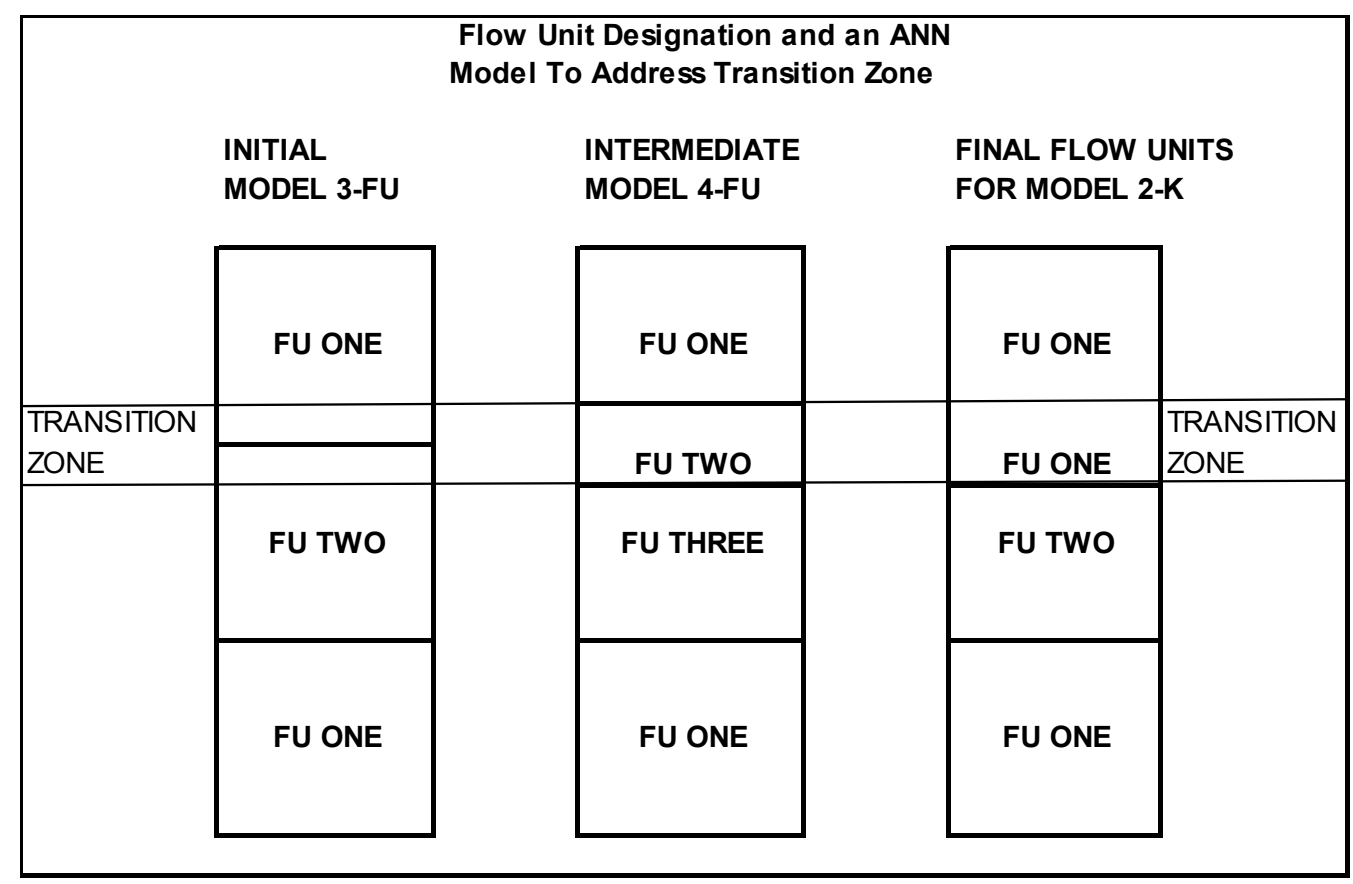

Figure 6.19 Flow Unit Designation and an ANN Model to Address Transition Zone

Flow unit reclassifications occurred as follows:

- Flow unit one remains flow unit one.

- Flow unit two (transition area) is reclassified as flow unit one.

- Flow unit three (initial two) is reclassified as flow unit two.

- Lower flow unit one remains flow unit one. 
Model 2-K, the selected permeability prediction model was trained using the core data of the six core wells and utilized two flow unit designations for permeability prediction. Due to the success of the intermediate step the model treated the transition zone as flow unit one. Model 2-K for permeability prediction was applied to the digitized well logs in the field (approximately 125 wells). Permeability was predicted within each flow unit every $1 / 4$ foot.

\subsection{Two Flow Unit Model Verified via Simulation Results}

The Boast98 simulator was utilized on the two flow unit model. The operator had previously used a $12 \%$ porosity cut-off for determining the productive interval of the sand. This was the initial screening criteria used for building the simulator model. Simulation runs resulted in the net thickness being reduced further as simulation progressed. Table 6.13 offers additional reservoir properties used in the simulation runs. For each well the table includes net thickness, average permeability and average porosity within each flow unit.

Figures 6.20 and 6.21 graphically detail the cumulative actual production versus predicted (oil and water) for the Ball \# 18 well. Figures 6.22 and 6.23 offer a similar presentation for the Ball \# 21 . 
Figures 6.24 and 6.25 are cumulative graphs for both producers combined.

Table 6.13 Average Properties Used in the Simulation

\begin{tabular}{|l|ccc|ccc|}
\hline & \multicolumn{3}{|c|}{ Flow Unit One } & \multicolumn{4}{c|}{ Flow Unit Two } \\
Well Name & Thickness & Porosity & $\mathrm{k}(\mathrm{md})$ & Thickness & Porosity & $\mathrm{k}(\mathrm{md})$ \\
\hline Pennick \# 9 & 2 & 11 & 29 & 6.5 & 25 & 186 \\
Pennick \# 8 & 2 & 12 & 20 & 6 & 25 & 140 \\
Ball \# 18 & 3 & 14 & 31 & 5 & 24 & 190 \\
Ball \# 20 & 1 & 11 & 5 & 7 & 25 & 175 \\
Gorrell \# 5 & 3.5 & 16 & 16 & 5 & 26 & 137 \\
Ball \# 21 & 5 & 15 & 38 & 7 & 23 & 211 \\
Ball \# 19 & 4 & 15 & 18 & 7 & 22 & 140 \\
Gorrell \# 4 & 4 & 16 & 44 & 6 & 24 & 185 \\
\hline
\end{tabular}

Declining rates of injection in the field appeared to be a common problem in certain wells. The operator recognized an early problem with water quality. This problem was addressed by the operator. However, certain wells have continued to require periodic treatment as a means of maintaining acceptable injection rates. Records and pressure build-up information to estimate an after treatment skin value was very limited. A specific records search was made of the well files to refine the PID input. Only a few treatment 
records were found. For the simulation analysis a PID value for each well was calculated which included an assumed skin value of -1 . The skin value of -1 had been used by company engineers in other internal work product.

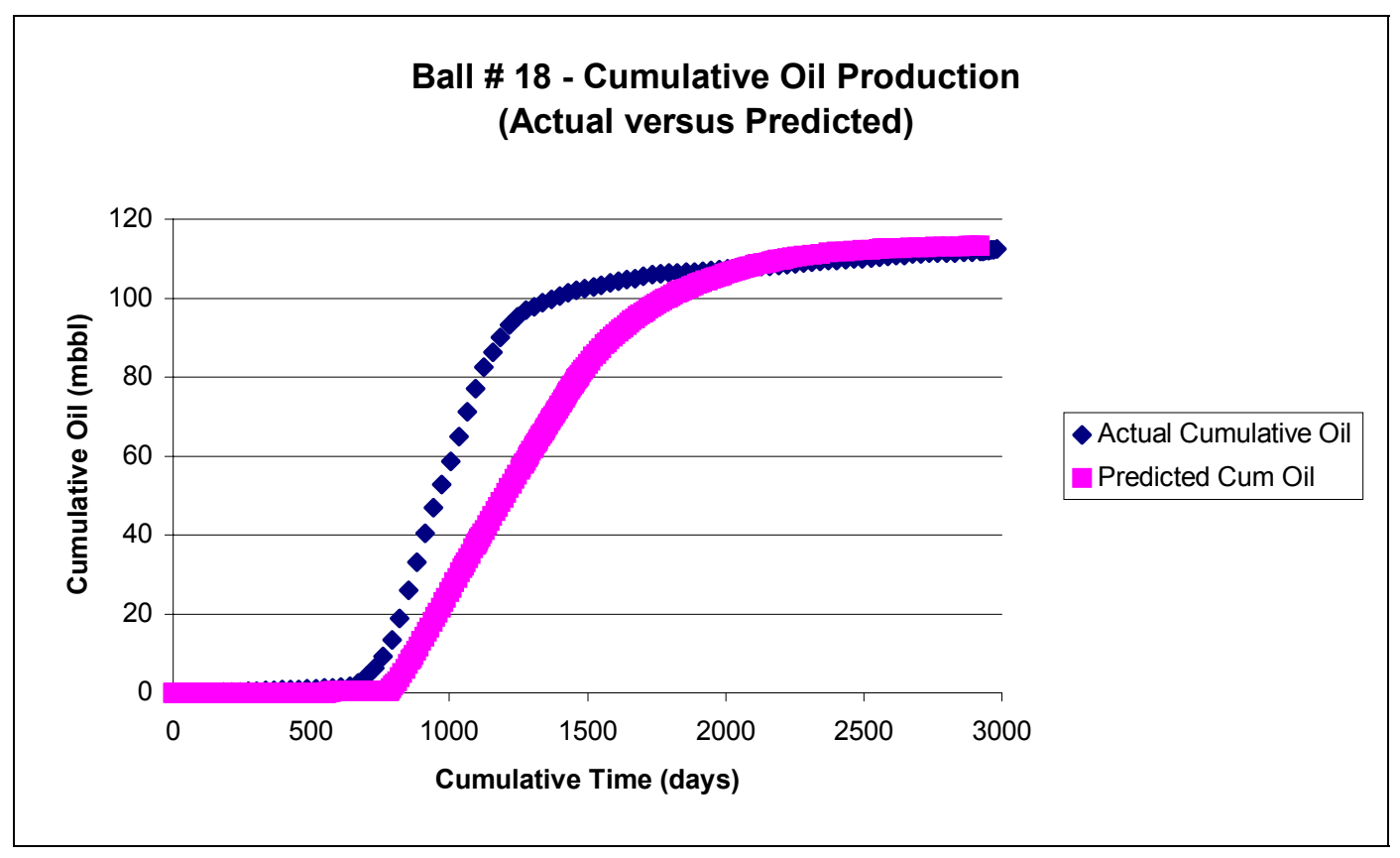

Figure 6.20 Ball \# 18 Cumulative Oil Production (Actual versus Predicted) 


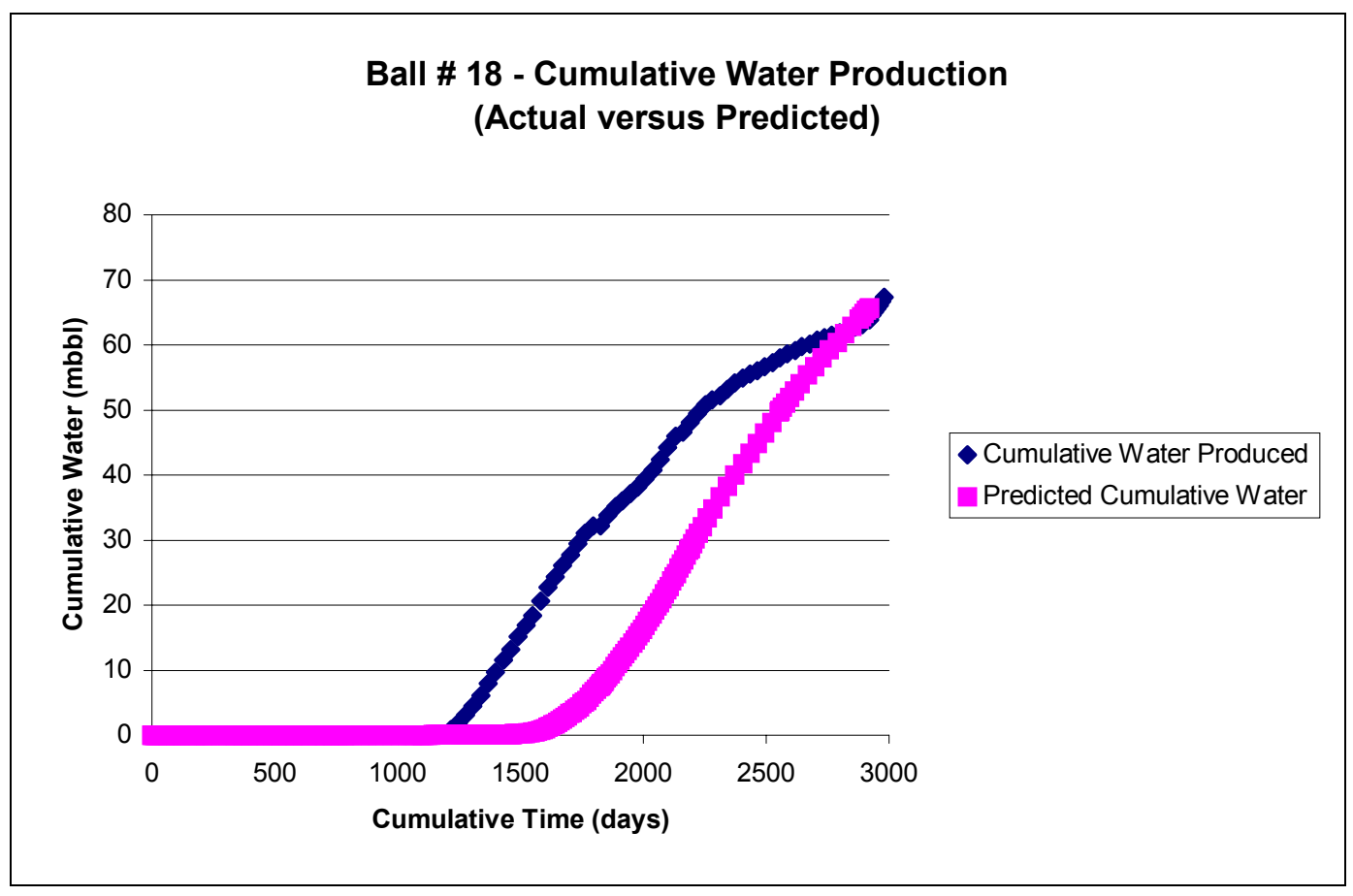

Figure 6.21 Ball \# 18 Cumulative Water Production

(Actual versus Predicted)

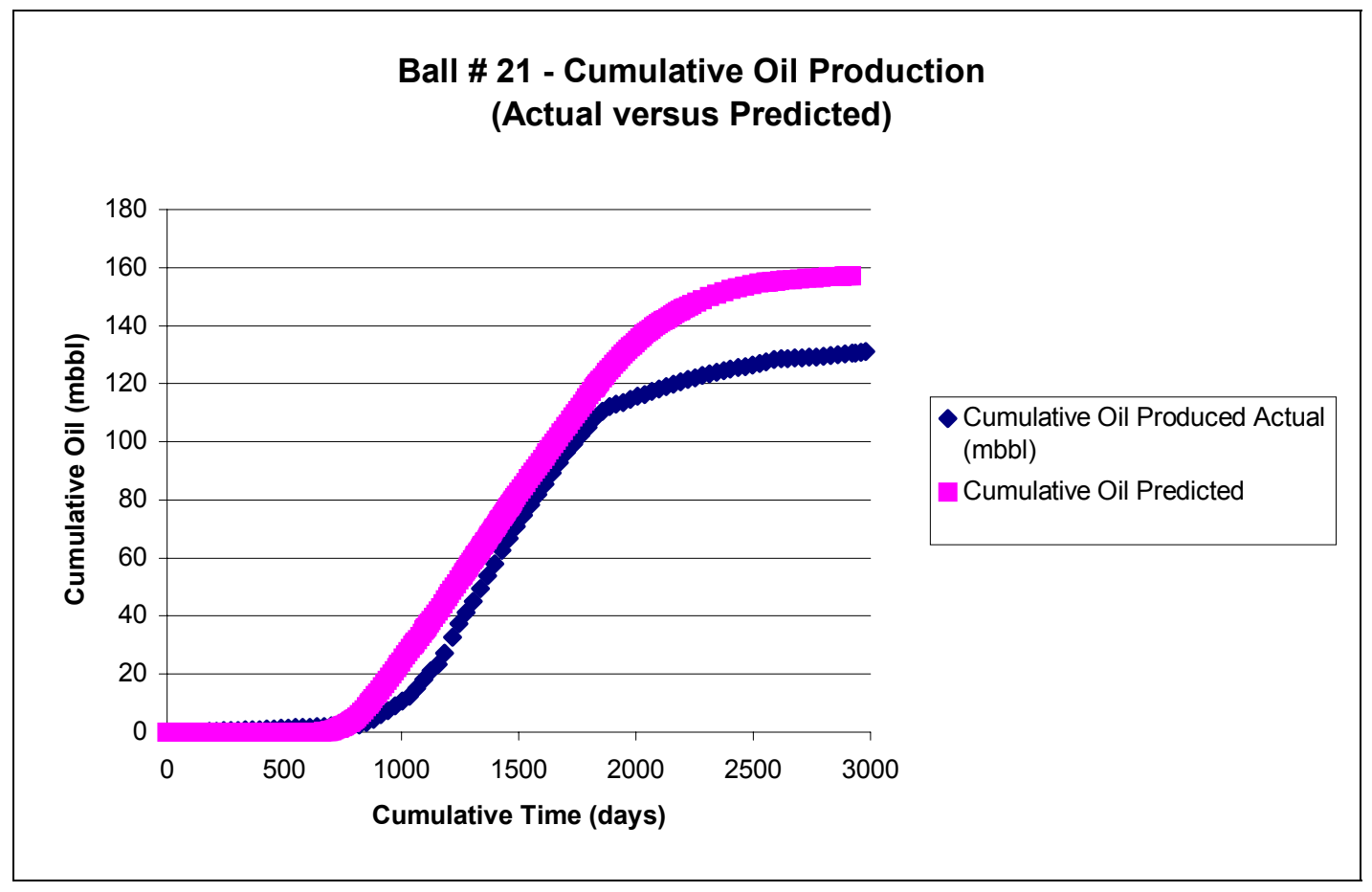

Figure 6.22 Ball \# 21 Cumulative Oil Production (Actual versus Predicted) 


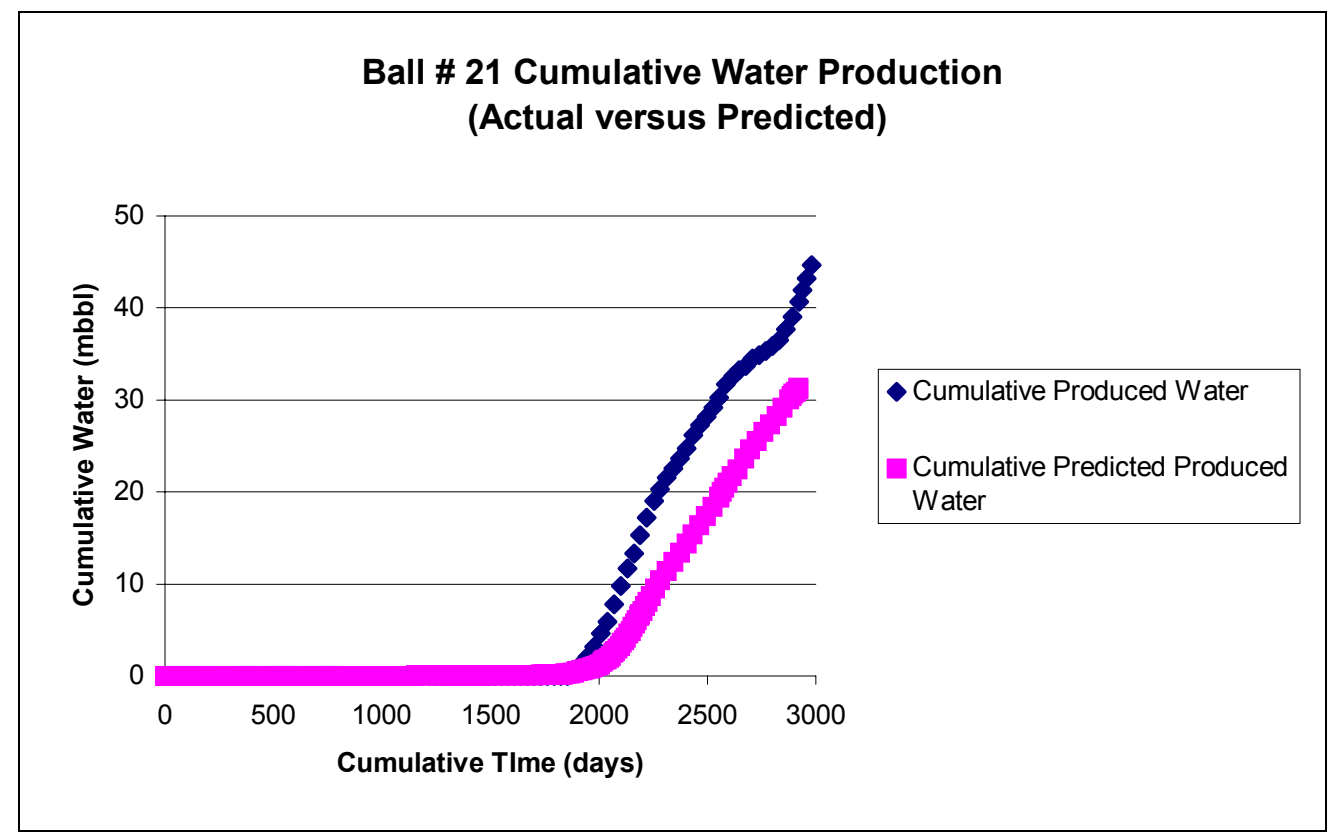

Figure 6.23 Ball \# 21 Cumulative Water Production (Actual versus Predicted)

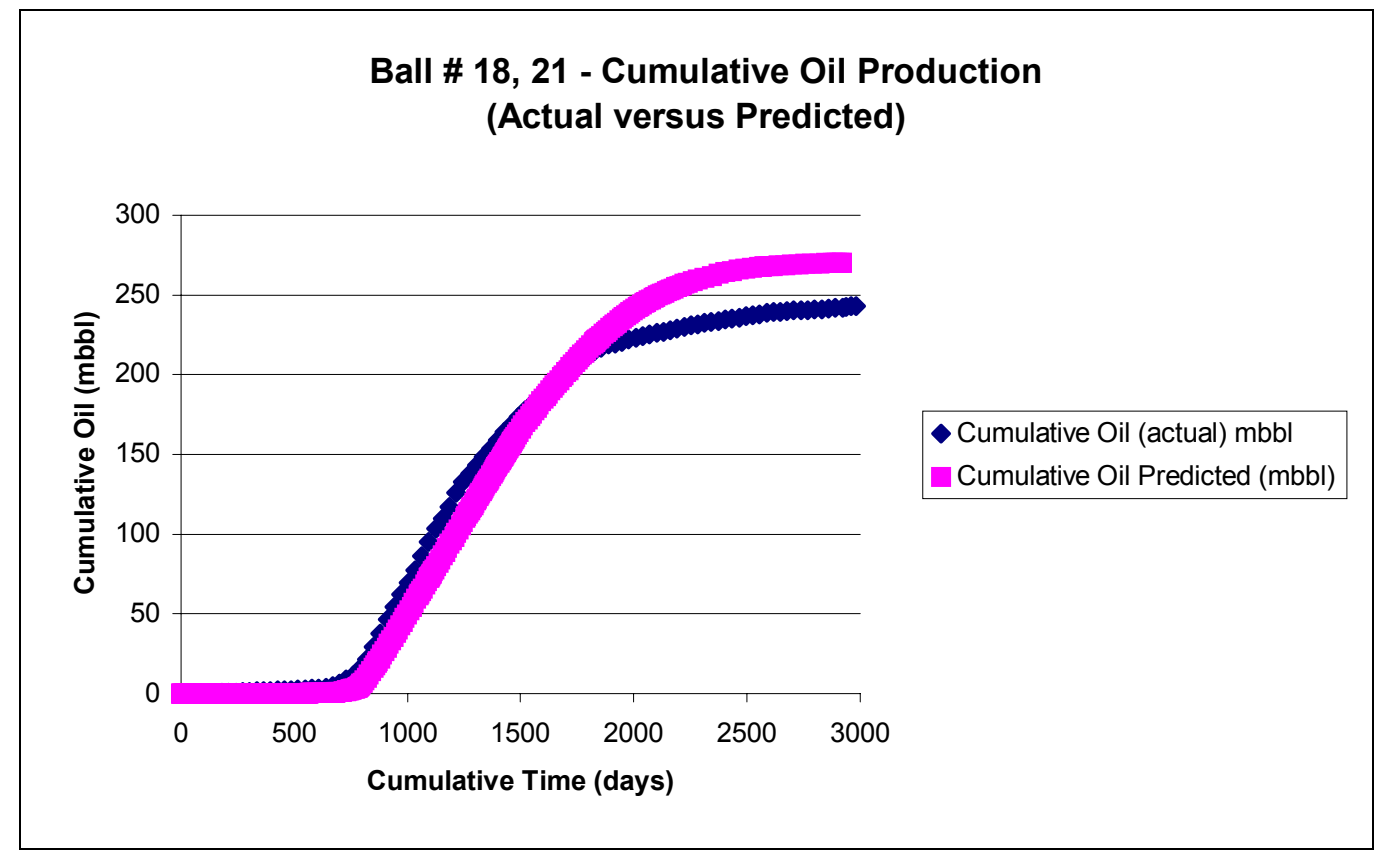

Figure 6.24 Ball \#18, 21 Cumulative Oil Production (Actual versus Predicted) 


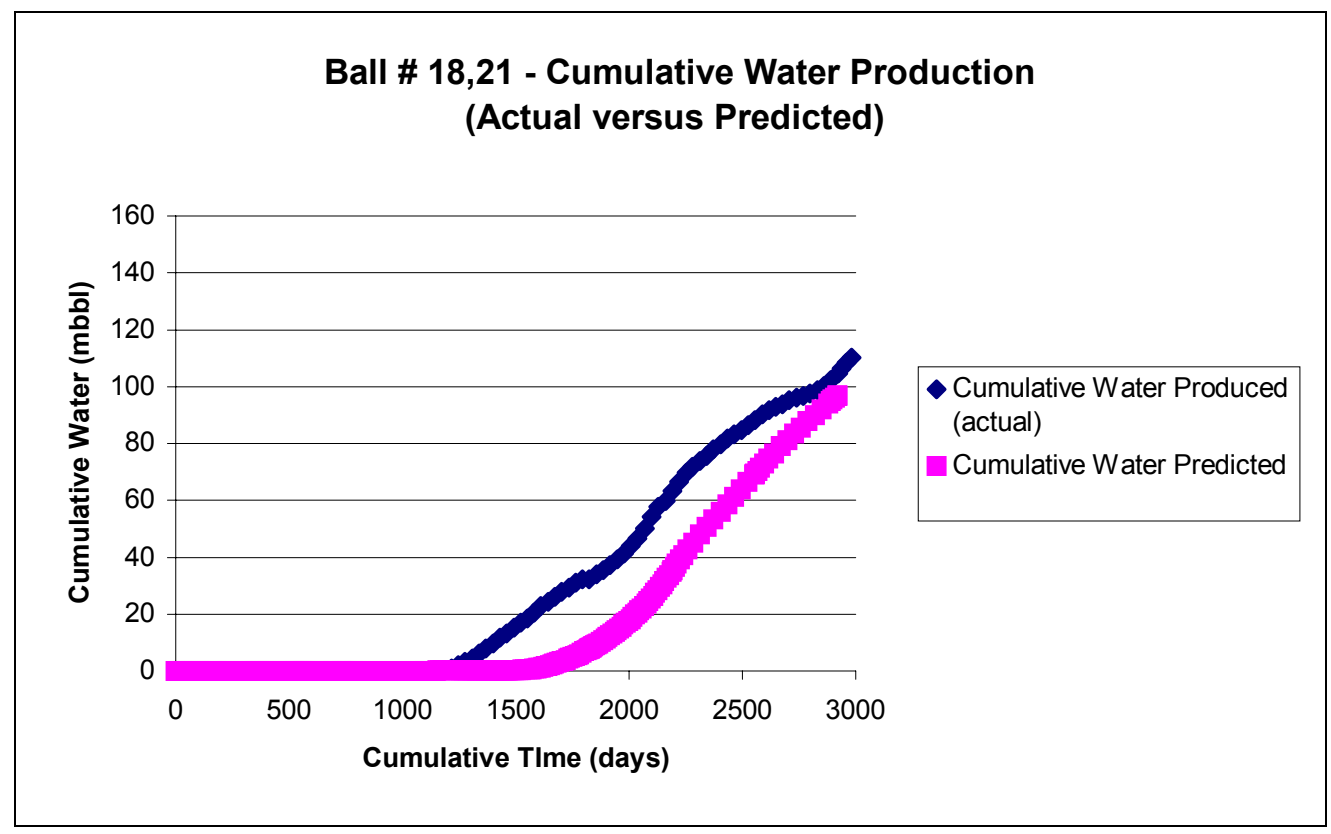

Figure 6.25 Ball \#18, 21 Cumulative Water Production (Actual versus Predicted)

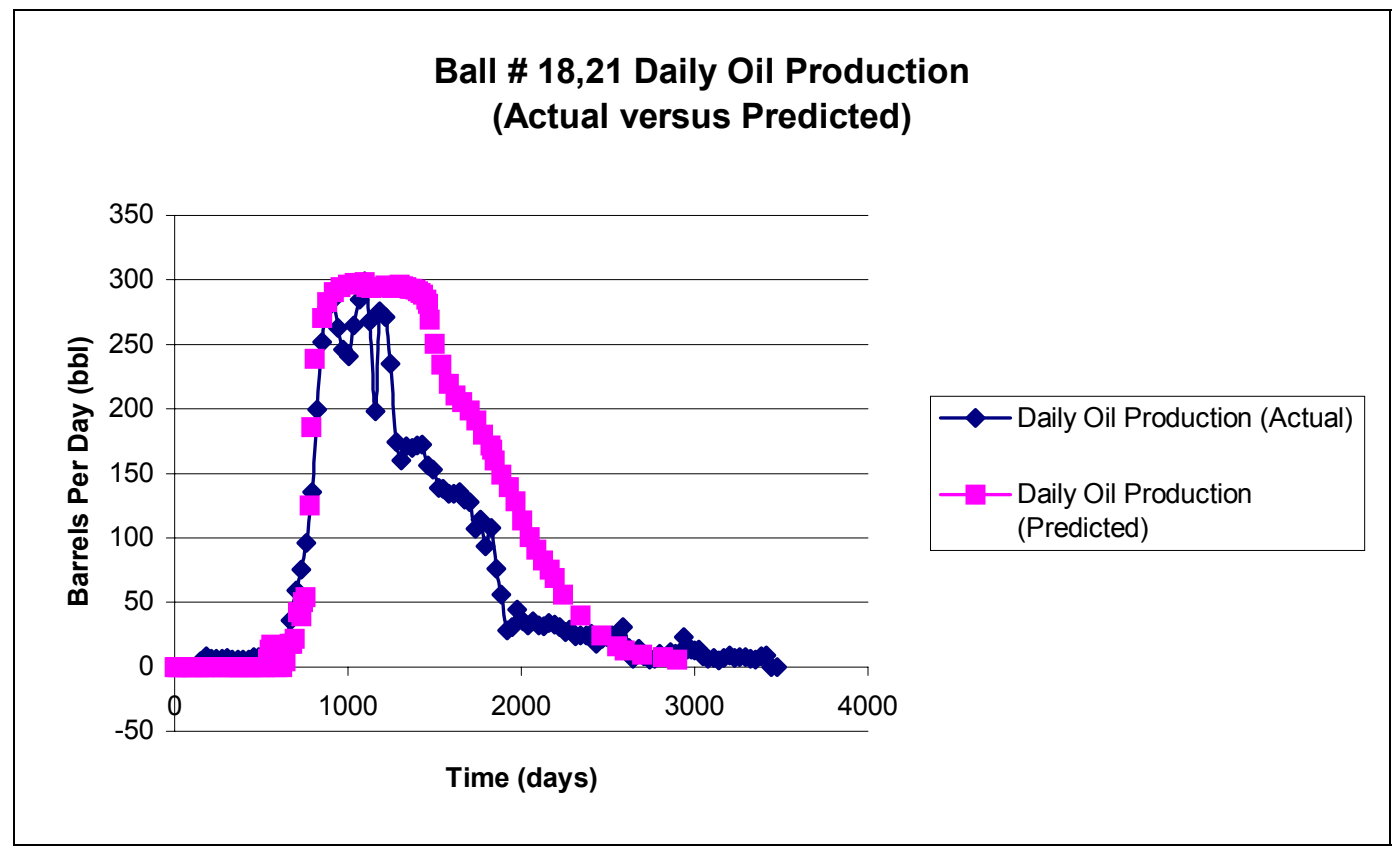

Figure 6.26 Ball \# 18, 21 Daily Oil Production (Actual versus Predicted) 


\subsection{Single Layer Simulation Comparison}

As further study of the Ball \# 18, 21 patterns a single layer simulation was completed. The simulation was done using the core permeability data for the Ball \# 18, 19 wells. Both core wells are situated in the two verification patterns. In order to predict permeability from the digitized logs in the pattern a plot of core permeability versus log porosity was completed for the two core wells (Figure 6.27). An exponential equation was developed as a method of predicting permeability from the best fit trendline. The $\mathbf{R}$ squared is .6864 .

The digitized logs for each well in the pattern were used to predict permeability for the given wells in the pattern. The porosity cut-off was $12 \%$, a historical value used by the operator. Values for average porosity and permeability between the wells in the pattern were extrapolated. 


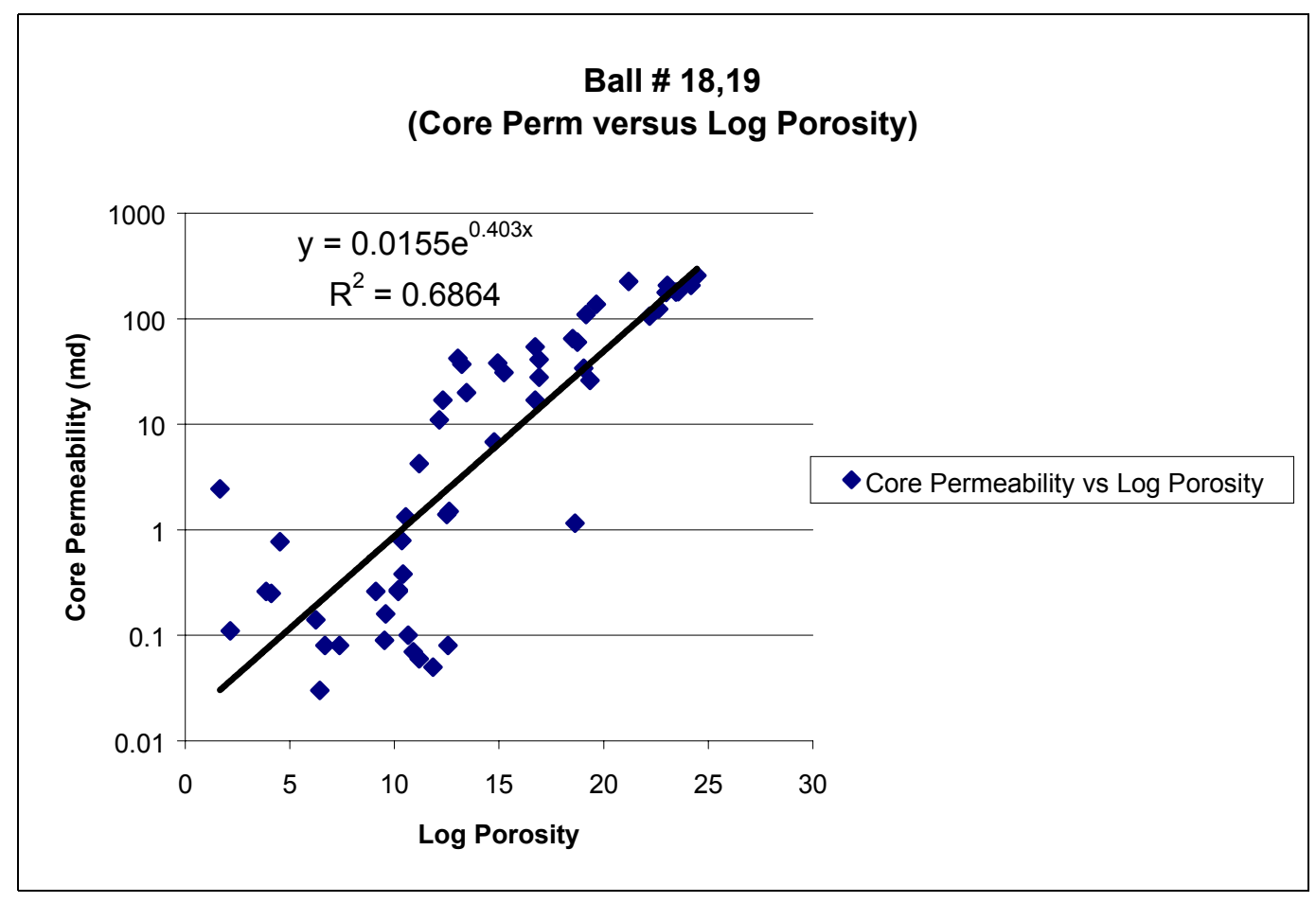

Figure 6.27 Ball \# 18,19 (Core Perm versus Log Porosity)

All other simulation inputs were the same as those used in the two layer simulation model. This included water volumes scheduled into the patterns, relative permeability data and flowing pressures at each producing well. The intent was to develop a valid comparison of the single layer system to the two flow unit model. Figures 6.28 and 6.29 present cumulative oil and water production comparisons of actual versus predicted production for both wells combined. Figures 6.30 and 6.31 present both wells individually. 


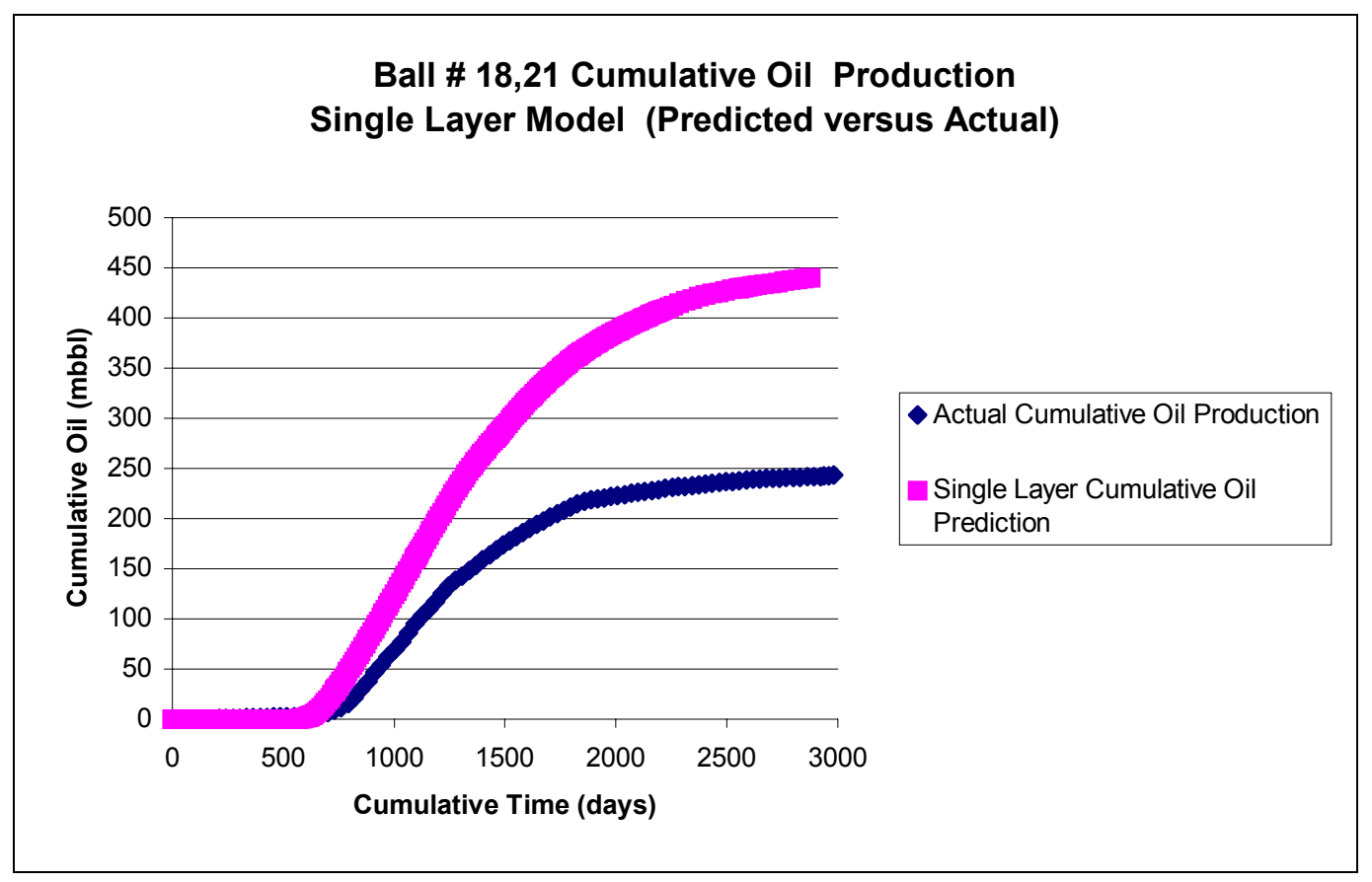

Figure 6.28 Ball \# 18, 21 Cumulative Oil Production Single Layer Model (Predicted versus Actual)

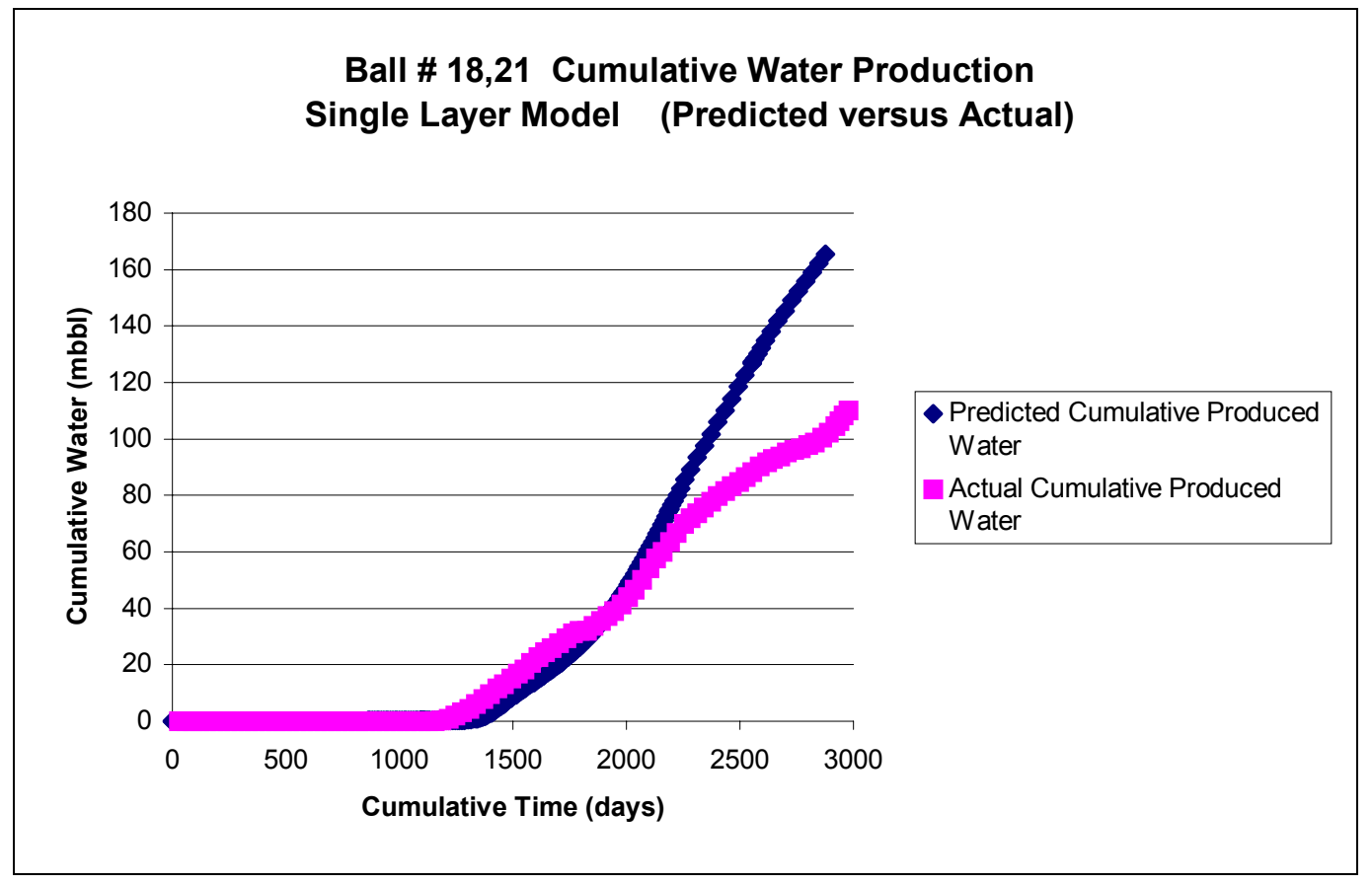

Figure 6.29 Ball \# 18, 21 Cumulative Water Production Single Layer Model (Predicted versus Actual) 


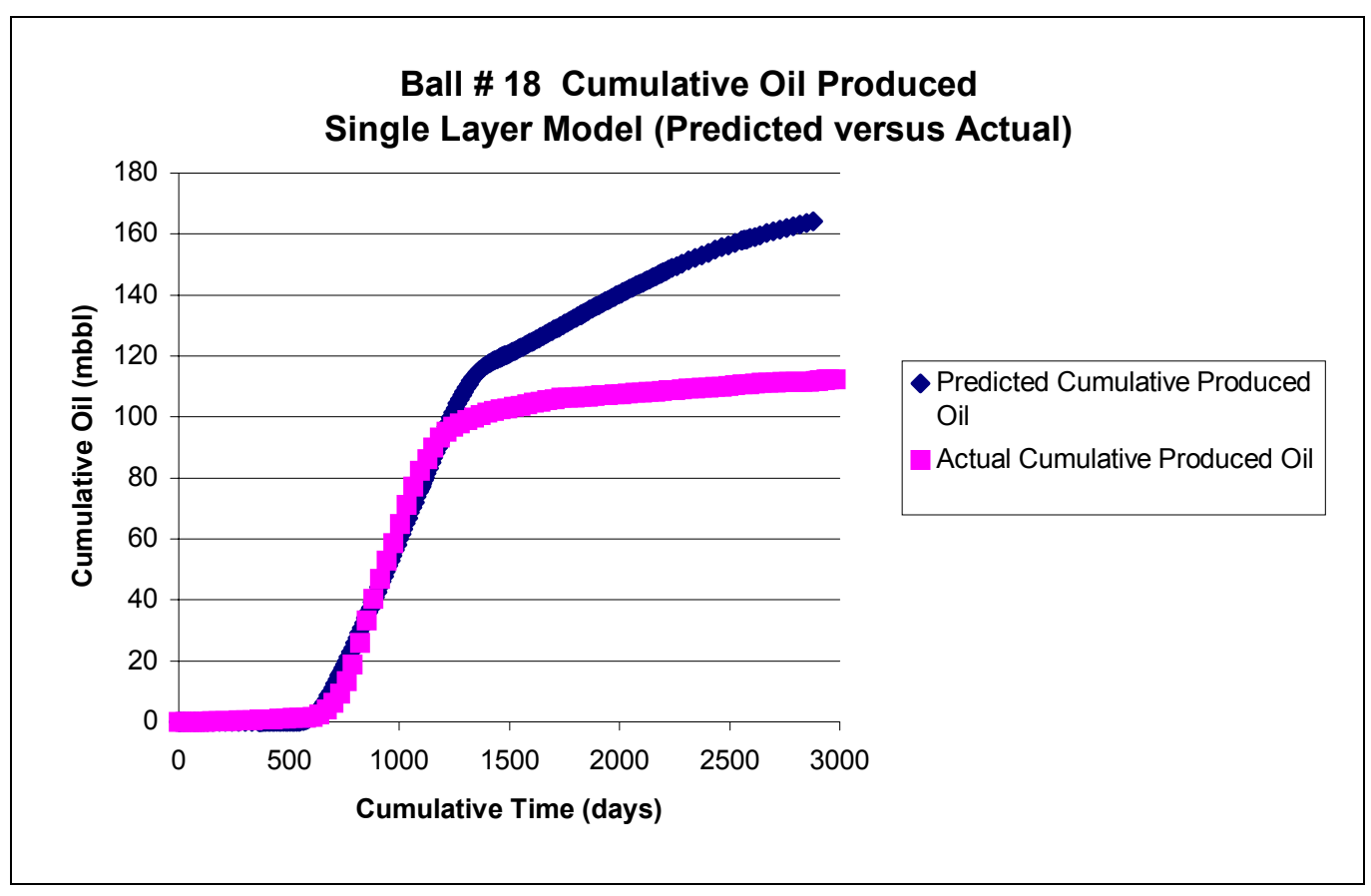

Figure 6.30 Ball \# 18 Cumulative Oil Produced Single Layer Model (Predicted versus Actual)

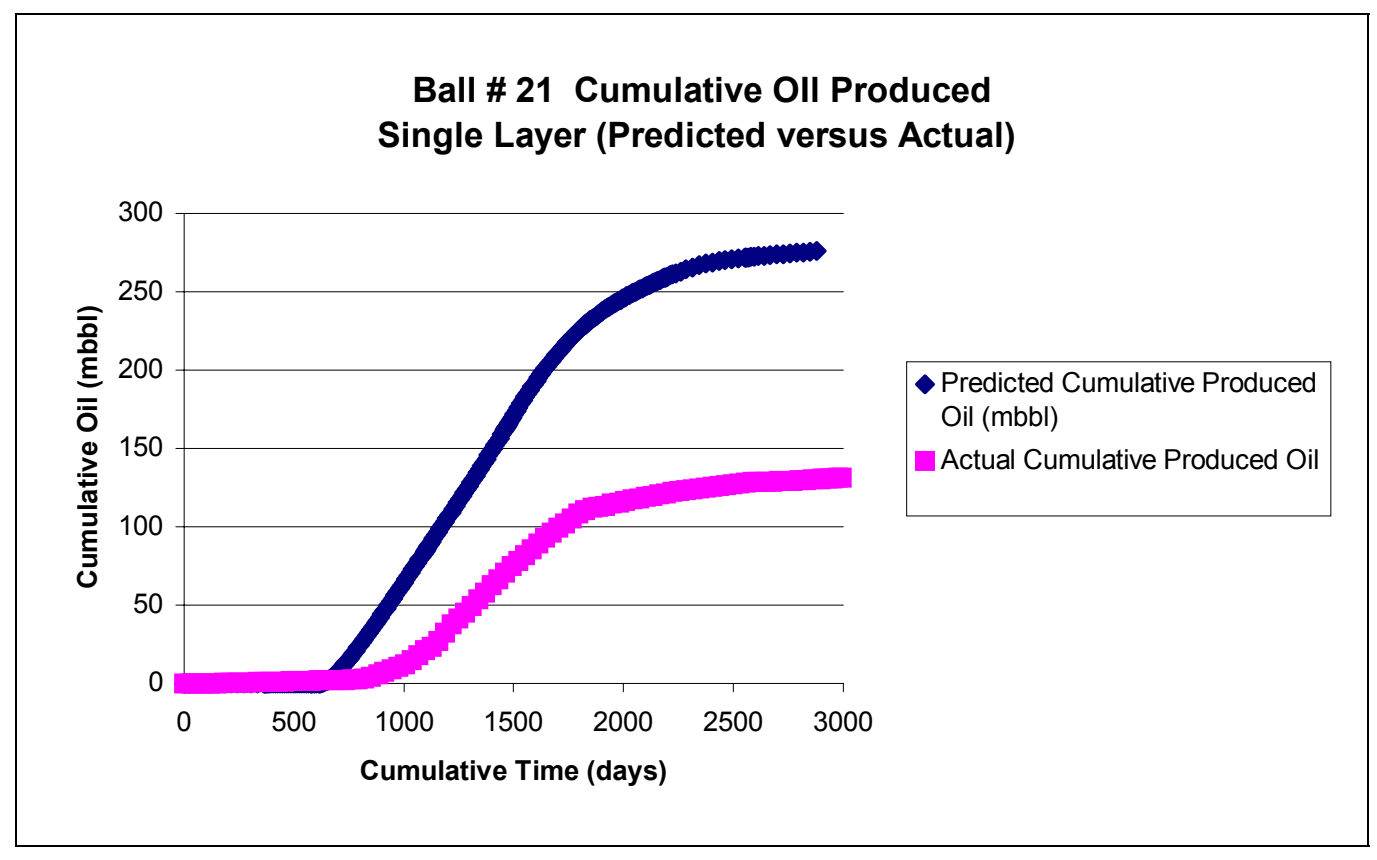

Figure 6.31 Ball \# 21 Cumulative Oil Produced Single Layer Model (Predicted versus Actual) 


\subsection{Field Maps Generated}

The two final neural network models were applied to the digitized well data for 125 wells in the field. Model 4-FU (flow unit prediction) was initially utilized to predict flow units. The flow unit results were then prepared for use as an input in model 3-K (permeability prediction). The results of the neural network permeability prediction were combined with the flow unit thickness data. For each flow unit average permeability and thickness was determined. Appendix Tables I.1 and I.2 detail the 125 well summary data. This well data was utilized to generate a series of field maps showing the distribution of average permeability, thickness, and flow capacity (kh) for each flow unit in the field. Figures $6.32-6.37$ present the field maps for each individual flow unit. It is important to note that only flow units one and two are included on the referenced maps. Other productive intervals of sand do exist in parts of the field at lower intervals.

Figure 6.38 is a field map based on cumulative production records secured from the operator. The production history was maintained on a farm/lease basis. In order to develop a cumulative per well production map, the total farm production was divided by the number of wells on each farm. Figures $6.35-6.37$ present flow unit two. The primary production map for the field correlates well with the predicted flow unit two. Flow two has higher porosity and 
largely accounts for the flow capacity. This further confirms the methodology used to predict flow units and permeability.

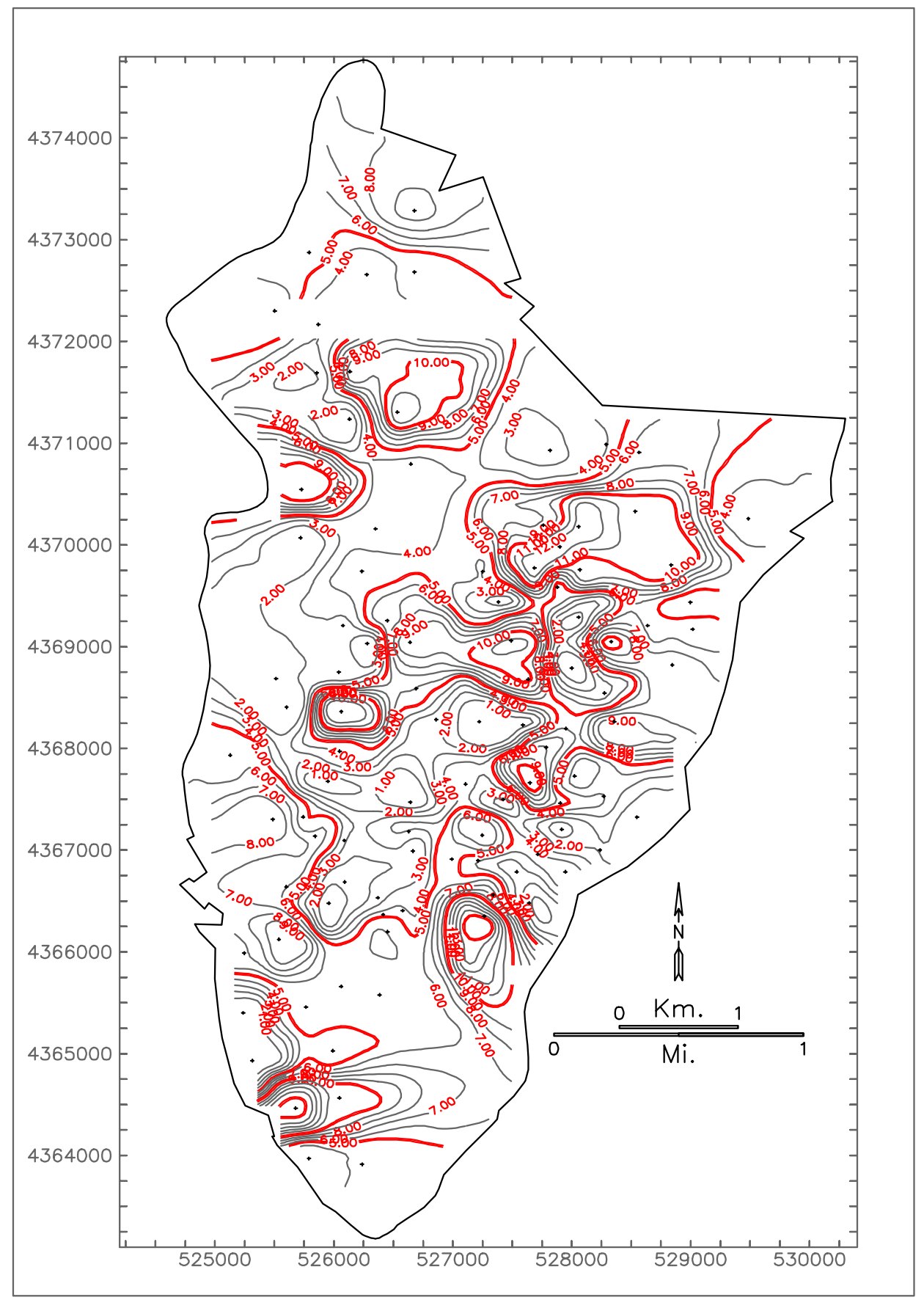

Figure 6.32 Flow Unit One (Thickness) 


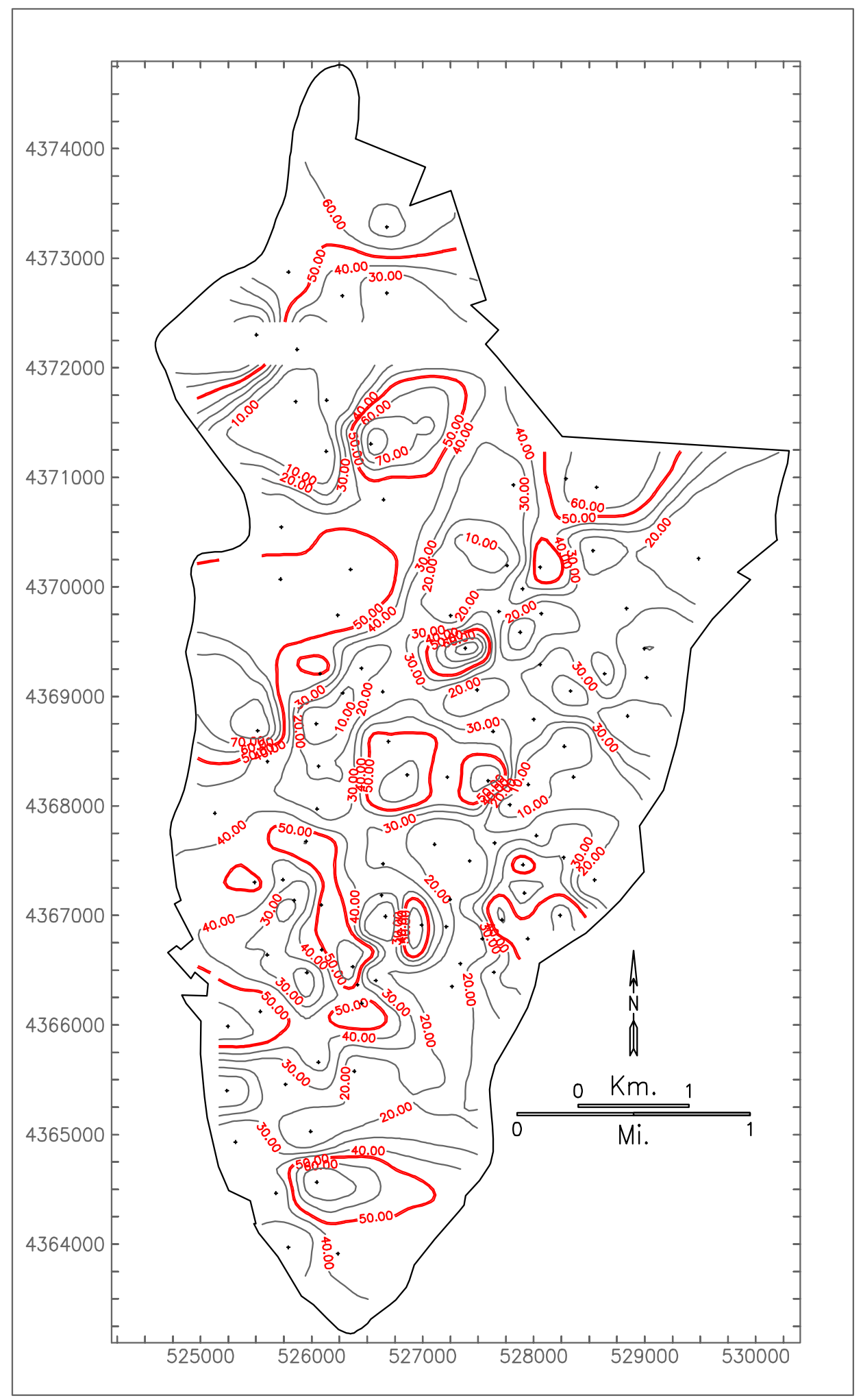

Figure 6.33 Flow Unit One (Average Permeability) 


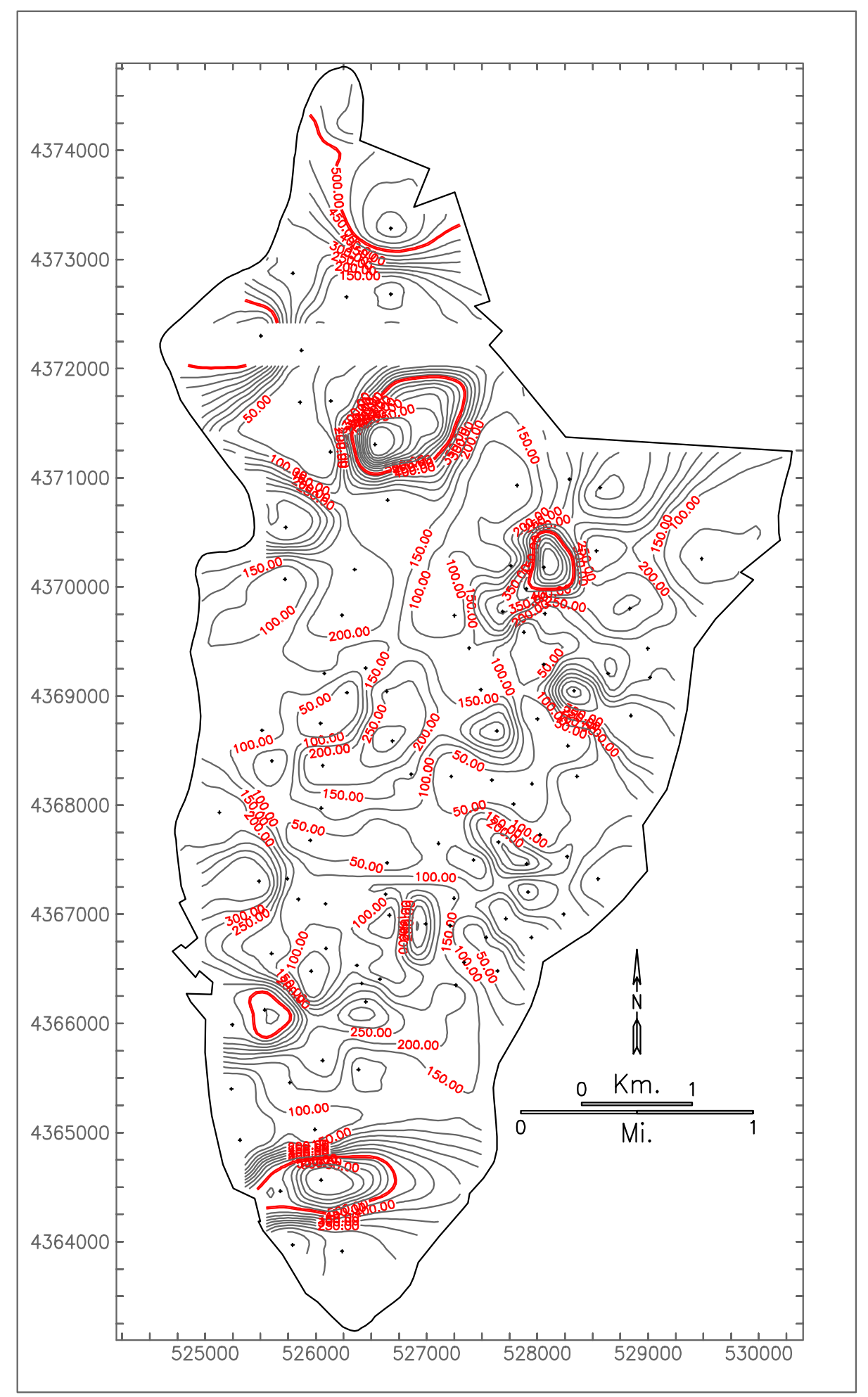

Figure 6.34 Flow Unit One (kh) 


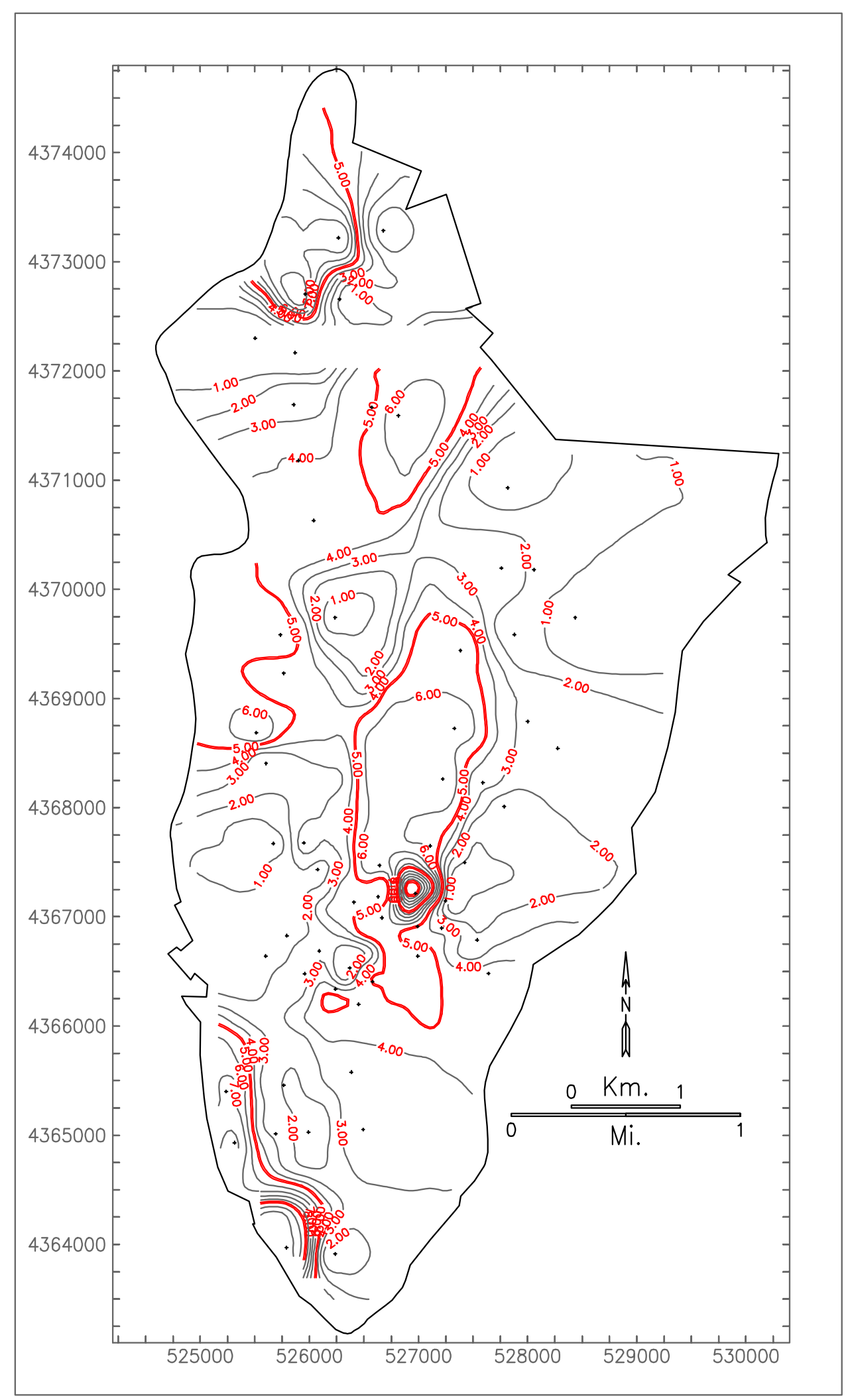

Figure 6.35 Flow Unit Two (Thickness) 


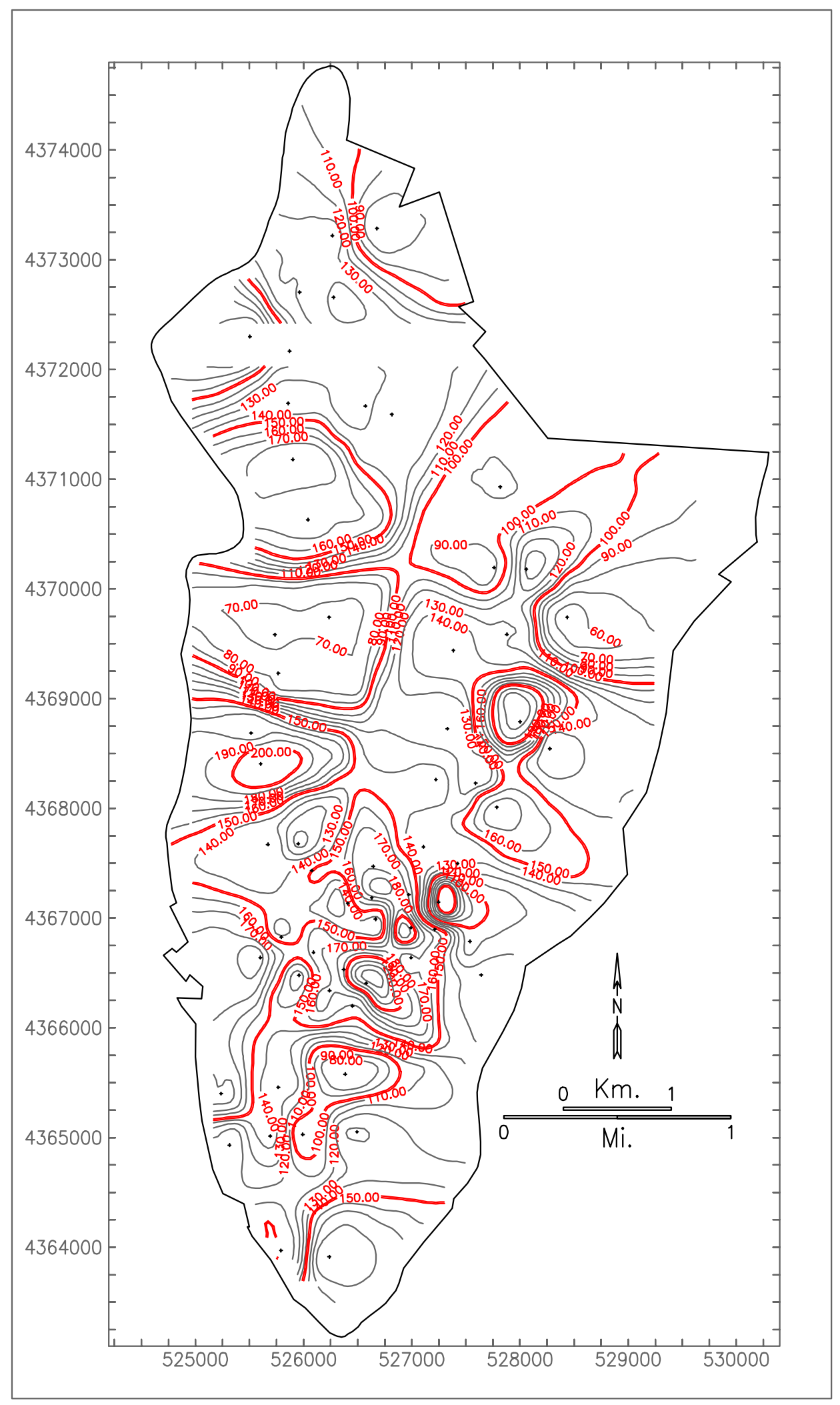

Figure 6.36 Flow Unit Two (Average Permeability) 


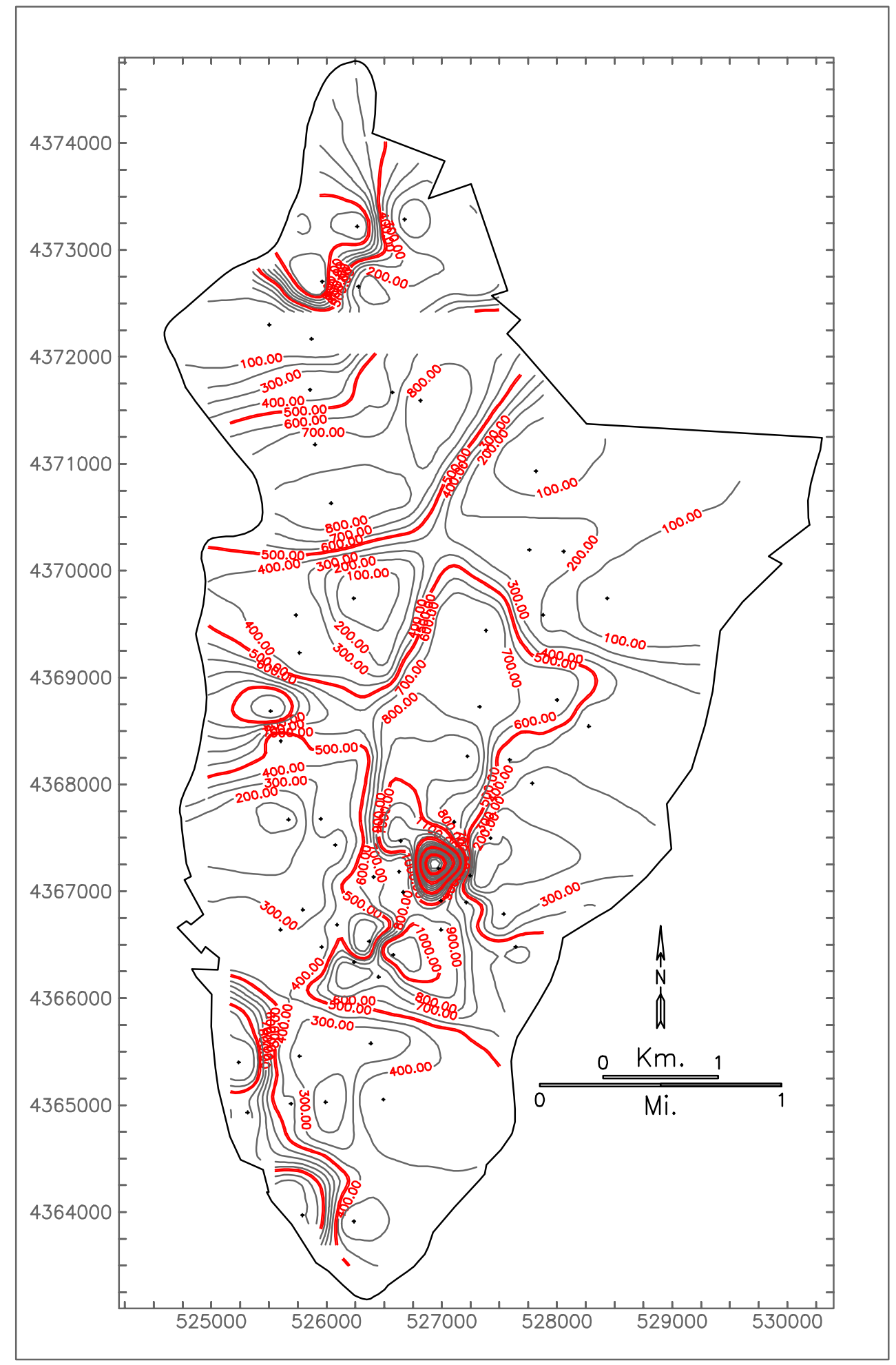

Figure 6.37 Flow Unit Two (kh) 


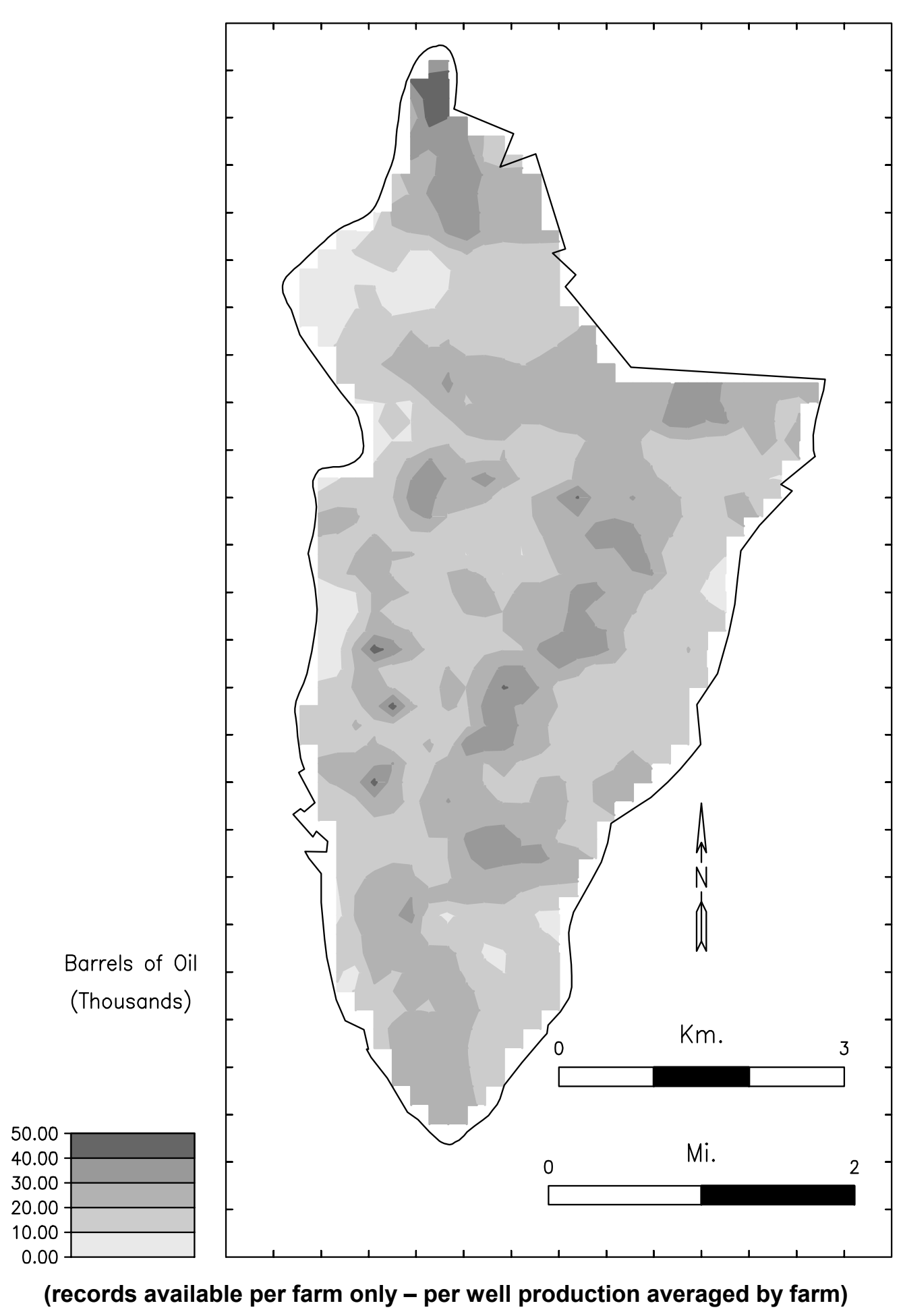

Figure 6.38 Cumulative Primary Production Map - Per Well Basis 


\subsection{Methodology Summary - Overview}

\subsubsection{Flow Unit Value}

Identifying flow units for a given well can be done using complete core data, thin sections and ex-ray diffraction. The ability to predict permeability is improved when flow units are known. However, many fields have limited core data from only a few wells in a given field. Further no special testing of the cores exists as a means of defining flow units. This flow unit prediction methodology for wells having only electric log data is new and can be utilized with limited permeability data.

\subsubsection{Methodology Summary}

This methodology requires a few wells in a given field have some core plug data. From these core plugs, permeability and porosity measurements can be obtained. The core wells should also have electric log data. The methodology calls for utilizing the core data and electric logs to identify the flow units and to build an ANN model to predict flow units. A separate ANN model to predict permeability is also constructed that includes flow unit as an input. The work to this point of the methodology has been strictly using the core wells and their associated logs. The core wells and the ANN models developed are then utilized to predict flow units in the field 
for wells having only log data. Within each predicted flow unit in the field permeability can be predicted using the predicted flow unit as an input in the ANN permeability model.

\subsubsection{Steps Leading to Flow Unit Identification Using Only Well Log Data}

Initial flow unit identification occurs by using the limited core permeability and porosity data from a few wells (in this case six wells - 95 data points). As a part of the methodology, the preliminary flow unit identification is utilized in order to identify flow units in the core wells. Techniques utilized include graphic analysis of the core data to identify the permeability-porosity relationships within each flow unit. In addition neural network analysis of the core wells is performed on the log-based data along with the core permeability.

A backpropagation ANN model was developed to predict permeability. Within each flow unit the log response to permeability is related. The inclusion of the identified flow units as an input significantly enhanced permeability prediction. The use of the ANN model to predict permeability is also a method to confirm that the flow units have been identified correctly. The strongest ANN permeability model occurs when flow units have been correctly identified.

Permeability prediction field wide is a useful product of reservoir characterization. However, the permeability prediction 
model requires flow unit designation. The flow unit was identified in the six core wells due to core data being available. In order to predict permeability the flow unit must be identified in non-cored well. In this study there were 125 digitized electric logs (gamma ray-density) from existing wells in the field.

Having identified the flow units in the core wells a new approach is utilized as a means of flow unit identification. Flow unit identification is accomplished by developing a new backpropagation model for flow unit prediction. The flow units identified in the six core wells and the digitized logs are used for developing an ANN for flow unit prediction. The ANN for flow unit prediction is built using six log-based inputs. The resulting model can predict flow unit using only log-based data. No core permeability data is required. No additional special core testing is required.

By being able to predict the flow unit in the field - we can then predict permeability utilizing the previously developed permeability prediction model. The prediction of flow units can be accomplished for wells having only log data in the field. The permeability field wide can then follow as a result of the key step of flow unit identification using only well logs. 


\section{CHAPTER 7}

\section{CONCLUSIONS}

1. The artificial neural network was successfully developed to predict flow units utilizing only well log data.

2. By including flow unit as an input in the artificial neural network significantly improved permeability prediction.

3. Minipermeameter measurement is a valuable source of information for flow unit identification. The measurements correlated well with actual core permeability-porosity measurements when comparing cumulative storage capacity versus cumulative flow capacity. As a result they provided significant flow unit boundary clues between core data points.

4. The permeability-porosity methods for flow unit identification coupled with neural network analysis successfully identified the flow units in the reservoir. 
5. Neural network analysis (Kohonen) of log based well data with permeability data is a useful tool for flow unit identification. The Kohonen analysis identified a lower flow unit as being the same as flow unit one and identified a transition zone between flow units one and two.

6. Utilizing the predetermined test set resulted in a stronger ANN model being developed for permeability prediction.

7. The flow units identified by the methodology were verified via simulation and the earlier Gil (2000) research.

8. This reservoir characterization methodology has application in any reservoir having multiple flow units. 


\section{CHAPTER 8}

\section{RECOMMENDATIONS}

1. Although not directly a part of this research thin section analysis evaluated the grain size of samples taken from selected core sections. It would have been helpful if the thin section work had been from samples adjacent to the core plugs used as a part of this research. The opportunity to include grain size as another flow unit identification method could have been further strengthened the flow unit boundaries identified herein.

2. During simulation the percentage of total water entering the patterns from each injector was low. Corner and center injectors were $19 \%$ and $32 \%$, respectively. Ideal percentages would have been $25 \%$ and $50 \%$. The low percentage of water scheduled into the pattern may be inherent of the simulator or may have actually occurred. In the event another part of the field is simulated another simulator may be useful to interpret the injection results. 
3. The minipermeameter measurements were done on old, partially preserved cores. Measurements on fresh cores offer obvious advantages. If coring is planned a plan to measure miniperm measurements for the entire cored section is recommended.

4. Further investigation of the transition zone in another part of the reservoir should be considered. 


\section{REFERENCES}

Amaefule, J., Altunbay, M., Taib, D., Kersey, D., "Enhanced Reservoir Description: Using Core and Log Data to Identify Hydraulic (flow units) and Predict Permeability in Uncored Intervals/Wells," Society of Petroleum Engineers paper 26436. Presented at the sixty eighth Annual SPE Conference. October 1993.

Aminian, K., Ameri, S., Avary, K.L., Bilgesu, H.I., Hohn, M.E., McDowell, R.R., and Matchen, D.L., "Reservoir Characterization of the Upper Devonian Gordon Sandstone, Jacksonburg, Stringtown Oil Field, Northwestern West Virginia," Semi-Annual Report, October 1, 1999 - March 31, 2000. October 1999.

Aminian, K., Ameri, S., Avary, K.L., Bilgesu, H.I., Hohn, M.E., McDowell, R.R., and Matchen, D.L., "Reservoir Characterization of the Upper Devonian Gordon Sandstone, Jacksonburg, Stringtown Oil Field, Northwestern West Virginia," Semi-Annual Report, April 1, 1999 - September 30, 1999. October 1999.

Boone, D.A., King, P.E., Jr., Ferrebee, Mack, "Stringtown Field Report and 1986 Proposed Waterflood Development, Tyler and Wetzel Counties, West Virginia" internal Pennzoil memo. April 14, 1986, p. 25.

Craig, F., Wilcox, P., Ballard, J., Nation, W., "Optimized Recovery Through Continuous Interdisciplinary Cooperation," Society of Petroleum Engineers paper 6108. Journal of Petroleum Technology. July 1977. 755-60.

Davies, D., Vessell, R., Auman, J., "Improved Prediction of Reservoir Behavior Through Integration of Quantitative Geological and Petrophysical Data," Society of Petroleum Engineers Reservoir Evaluation \& Engineering, April 1999. 149-160.

Ebanks, W. J., "Flow Unit Concept - Integrated Approach for Engineering Projects," Abstract presented June 8, 1987 during the roundtable sessions at the 1987 American Association of Petroleum Geologists Annual Convention.

Gil, E., "Improving The Simulation of a Waterflood Recovery Process Using Artificial Neural Networks," West Virginia University. Thesis Publication 2000. 
Gunter, G., Finneran, J., Hartmann, D., Miller, J., "Early Determination of Reservoir Flow Units Using An Integrated Petrophysical Method," Society of Petroleum Engineers paper 38679. Presented at the 1997 SPE Annual Technical Conference. October 1997.

Harris, D.G., "The Role of Geology in Reservoir Simulation Studies," Society of Petroleum Engineers paper 5022.

Hearn, C. L., "Geological Factors Influencing Reservoir Performance of the Hartzog Draw Field," Journal of Petroleum Technology.

August 1984. 1335-1346.

Holtz, M.H., Hamilton, D.S., "Reservoir Characterization Methodology to Identify Reserve Growth Potential," Society of Petroleum Engineers paper 35434. Presented at the 1996 SPE/DOE Tenth Symposium on Improved Oil Recovery.

Lewis, J.J.M., "Outcrop-Derived Quantitative Models of Permeability Heterogeneity for Genetically Different Sand Bodies," Society of Petroleum Engineers paper 18153. Presented at the sixty third Annual Technical Conference and Exhibit of the Society of Petroleum Engineers. 1988.

Monroe, J. S., Wicander R., "Physical Geology - Exploring The Earth,” West Publishing Company, St. Paul, MN. 1992.

NeuroShell tutorial program, (c) Ward Systems Group, Inc.

Mohaghegh, S., Arefi, R., Ameri, S., Rose, D., "Design and Development of an Artificial Neural Network for Estimation of Formation Permeability," Society of Petroleum Engineers paper 28237. Presented at the SPE Petroleum Computer Conference. 1994.

Mohaghegh, S., Arefi, R., Ameri, S., Hefner, M., "A Methodology Approach For Reservoir Heterogeneity Characterization Using Artificial Neural Networks," Society of Petroleum Engineers paper 28394. Presented at the SPE Annual Technical Conference and Exhibit. September 1988.

Mohaghegh, S., "Virtual-Intelligence Applications in Petroleum Engineering: Part 1-Artificial Neural Networks," Journal of Petroleum Technology. September 2000. 
Neog, P.K., Borah, N.M., "Reservoir Characterization Through Well Test Analysis Assists in Reservoir Simulation - A Case Study," Society of Petroleum Engineers paper 64447.

Oyerokun, A.A., "A New Approach For Training and Testing Artificial Neural Networks For Permeability Prediction," West Virginia University. Thesis Publication 2002.

Petroleum Technology Transfer Council (PTTC)., "New Methods of Acquiring Permeability Data from Appalachian Basin Reservoir Rocks," NRCCE/WVU, Morgantown, WV. October 11, 2000.

Slatt, R.M., Hopkins, G.L., "Scales of Geological Reservoir Description for Engineering Applications: North Sea Oilfield Example," Society of Petroleum Engineers paper 18136. Presented at the sixty third Annual Technical Conference and Exhibition of the SPE. October 1988.

Soto, R.B., Torres, F., Arango, S., Cobaleda, G., "Improved Permeability Models from Flow Units and Soft Computing Techniques: A Case Study, Suria and Reforma-Libertad Fields, Columbia," Society of Petroleum Engineers paper 69625. Presented at the SPE Lation American and Caribbean Petroleum Engineering Conference. March 2001.

Soto, R.B., Garcia, J.C., Torres, F., Perez, G.S., "Permeability Using Hydraulic Flow Units and Hybrid Soft Computing Systems," Society of Petroleum Engineers paper 71455. Presented at the 2001 annual SPE Conference. October 2001.

Tiab, D., Donaldson, E., "Petrophysics - Theory and Practice of Measuring Reservoir Rock and Fluid Transport Properties," Gulf Publishing Company, Houston, Texas. 1996.

Triola, M.F., "Elementary Statistics," Seventh Edition, Addison Wesley Longman, Inc., Reading, Massachusetts. 1998.

Willhite, G. P., Waterflooding, Monogram Series, Society of Petroleum Engineers, Richardson, Texas (1986). Chapter 7 referred to extensively. 


\section{APPENDIX A.}

Appendix A. presents graphs of core porosity, log density, core permeability, minipermeability and gamma ray versus depth for each core well. The associated tables used to develop graphs are also included. 


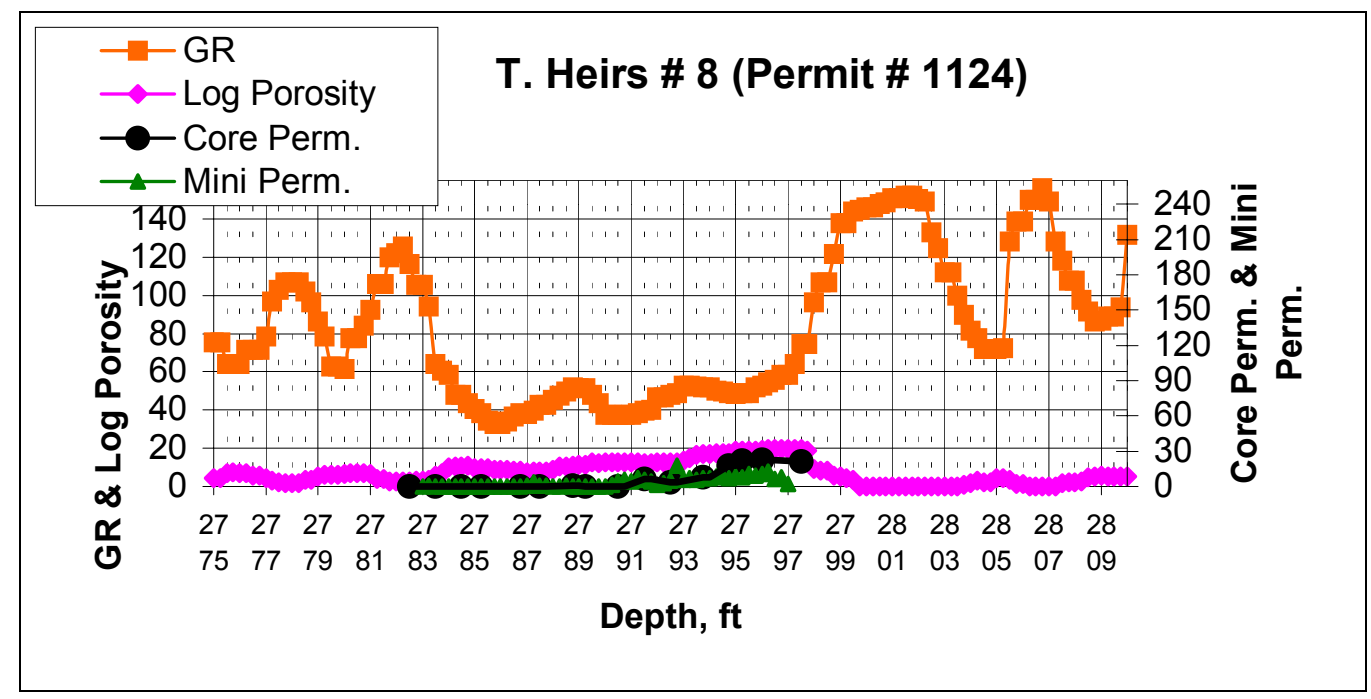

Figure A.1 T. Heirs \# 8 Gamma Ray-Log Porosity and Core Measurements

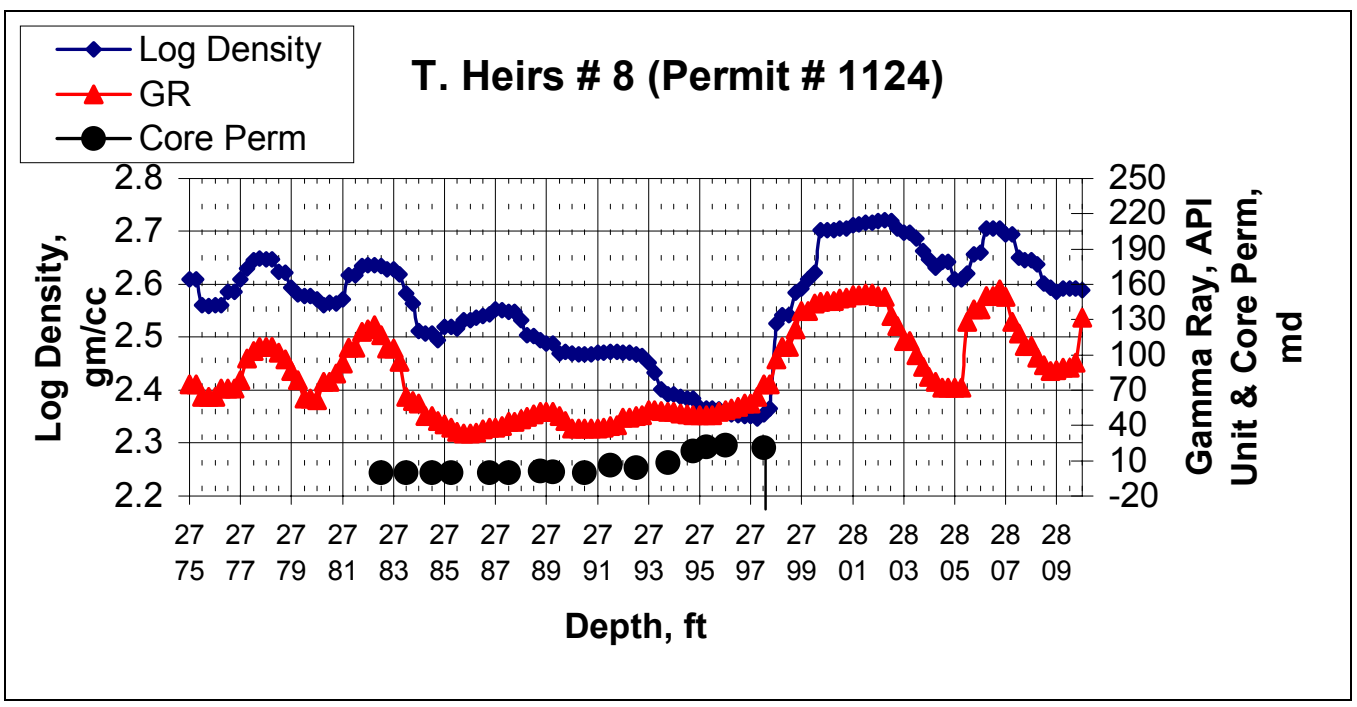

Figure A.2 T. Heirs \# 8 Gamma Ray-Log Density and Core Permeability 


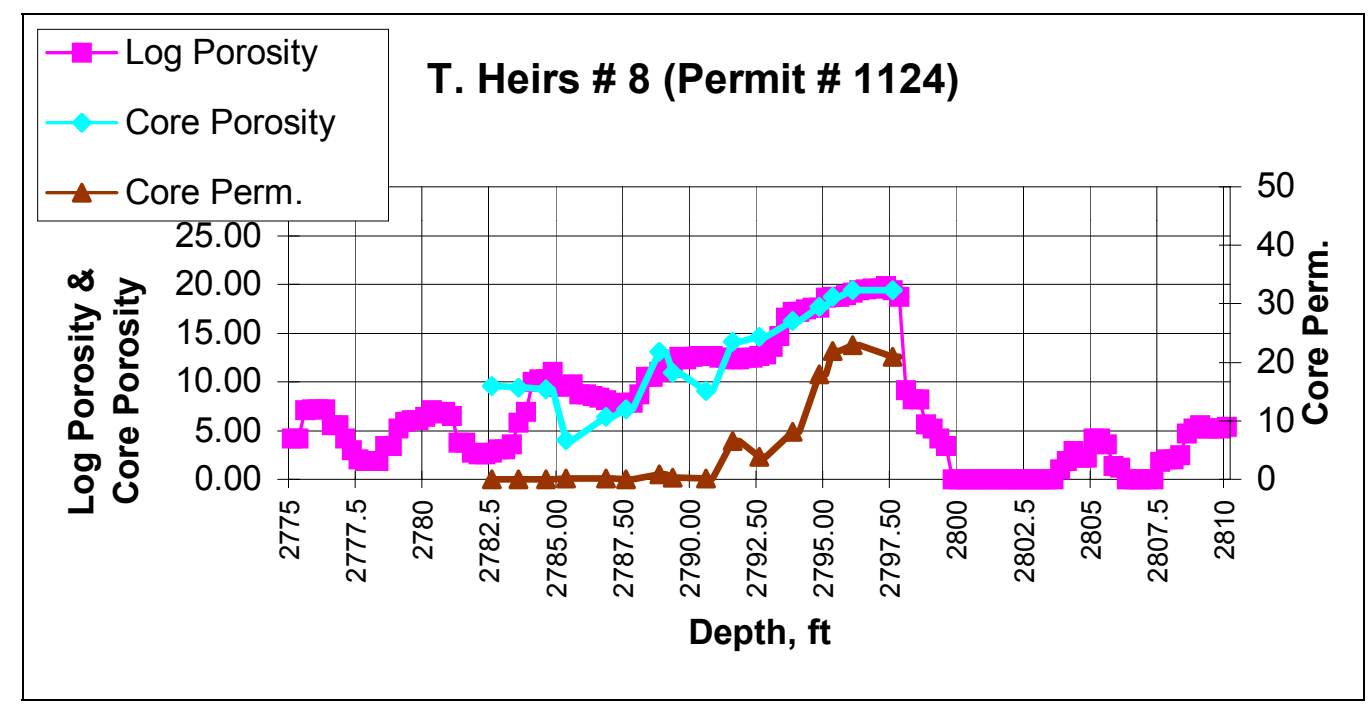

Figure A.3 T. Heirs \# 8 Log Porosity versus Core Porosity with Core Permeability

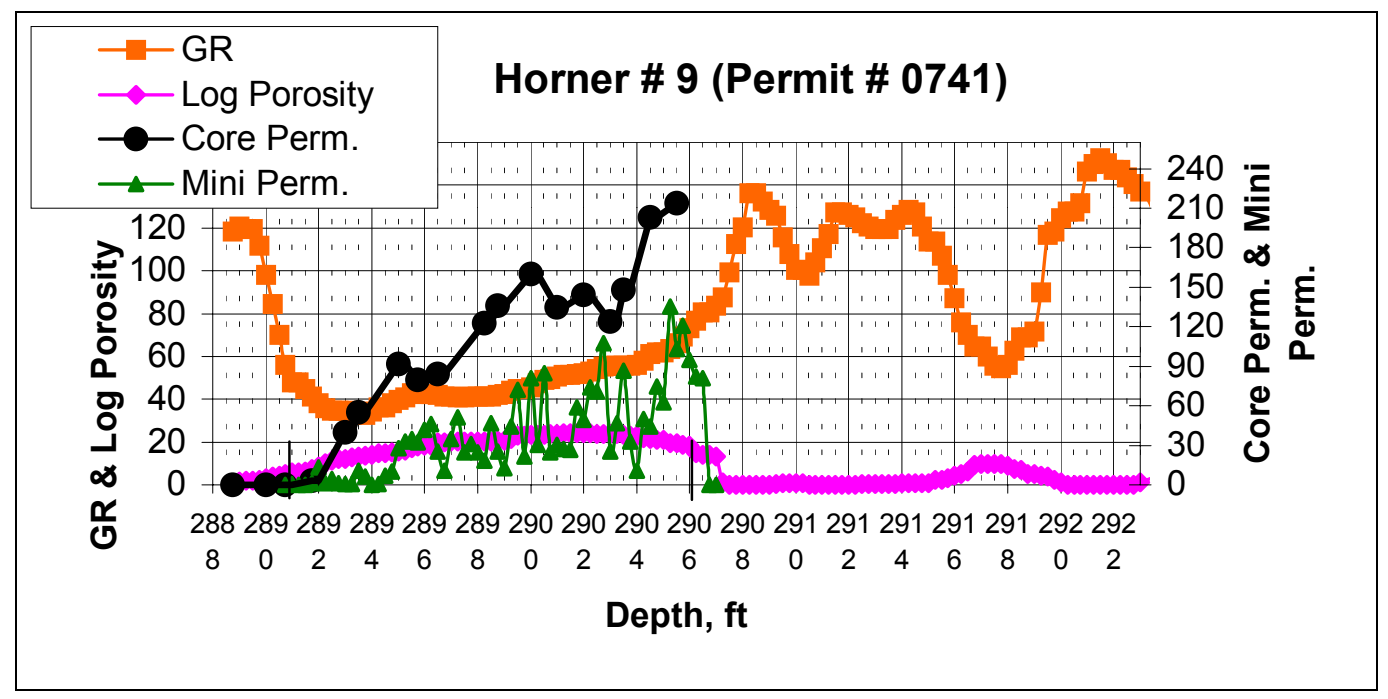

Figure A.4 Horner \# 9 Gamma Ray-Log Porosity and Core Measurements 


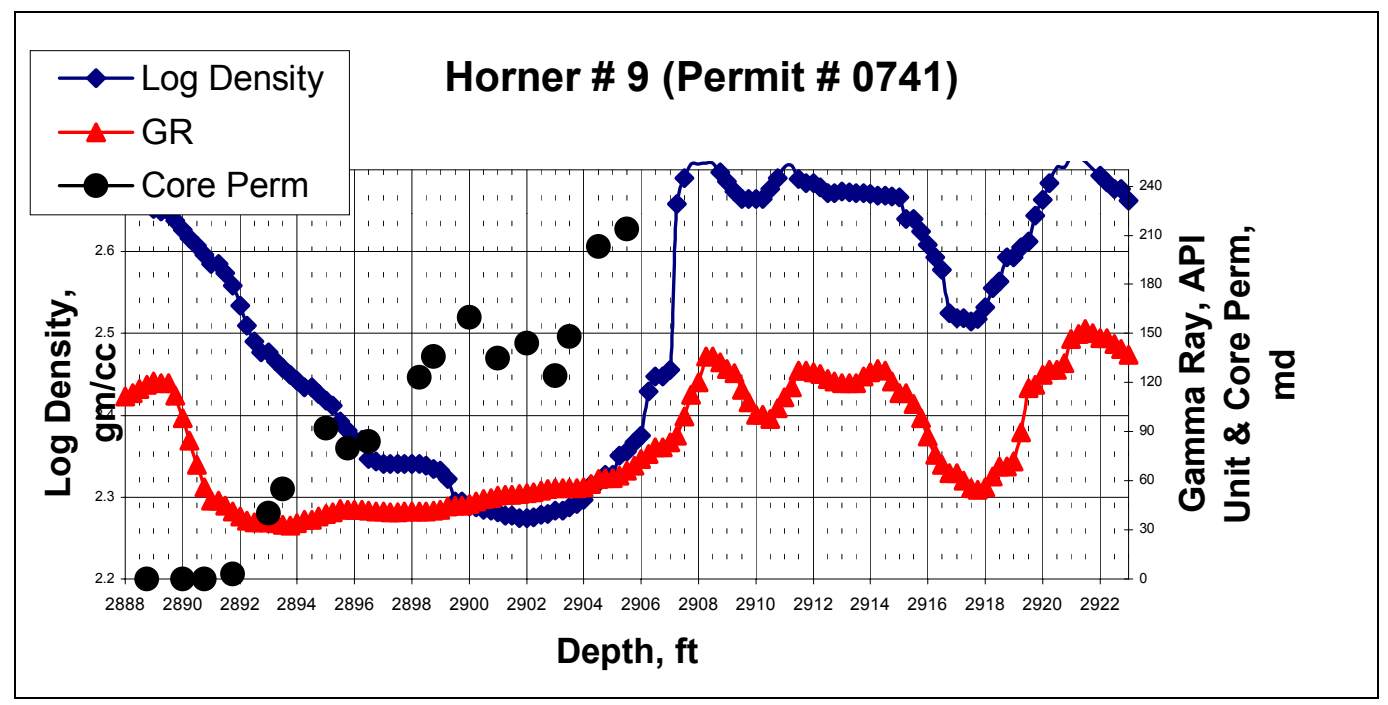

Figure A.5 Horner \# 9 Gamma Ray-Log Density and Core Permeability

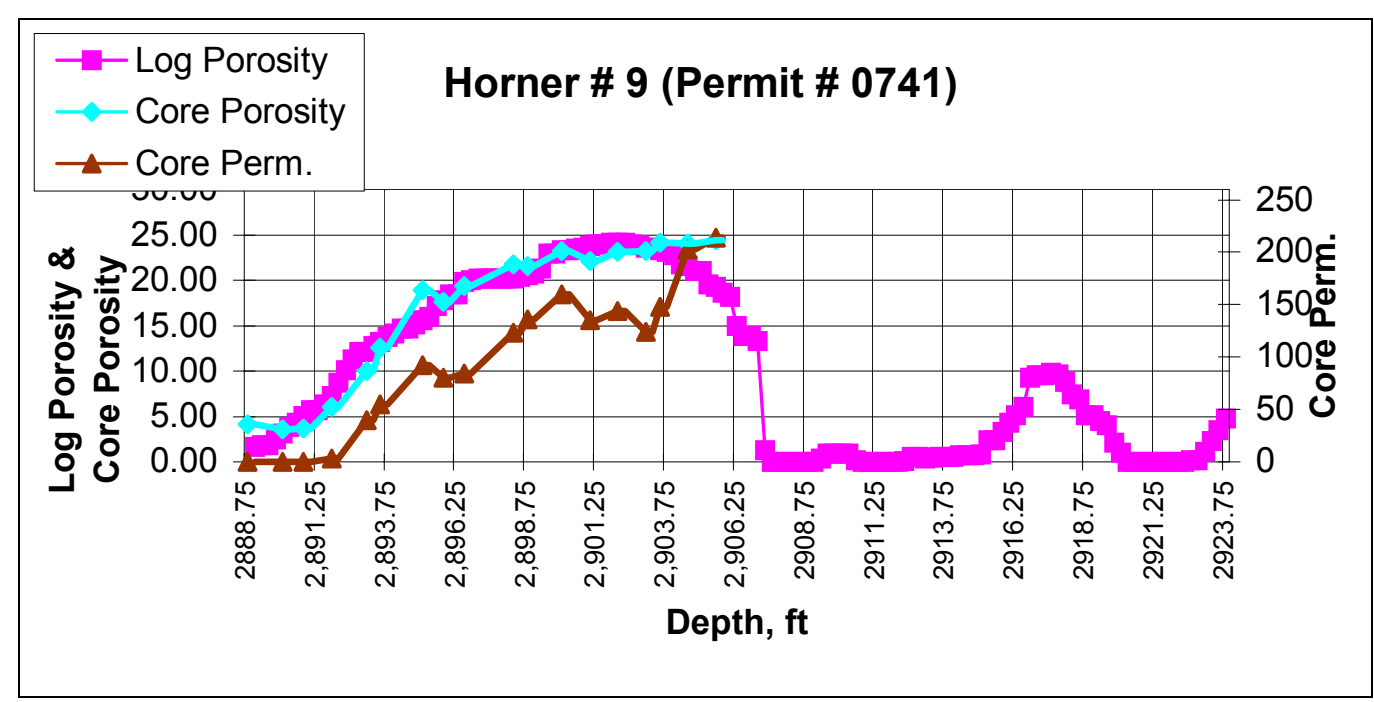

Figure A.6 Horner \# 9 Log Porosity versus Core Porosity with Core Permeability 


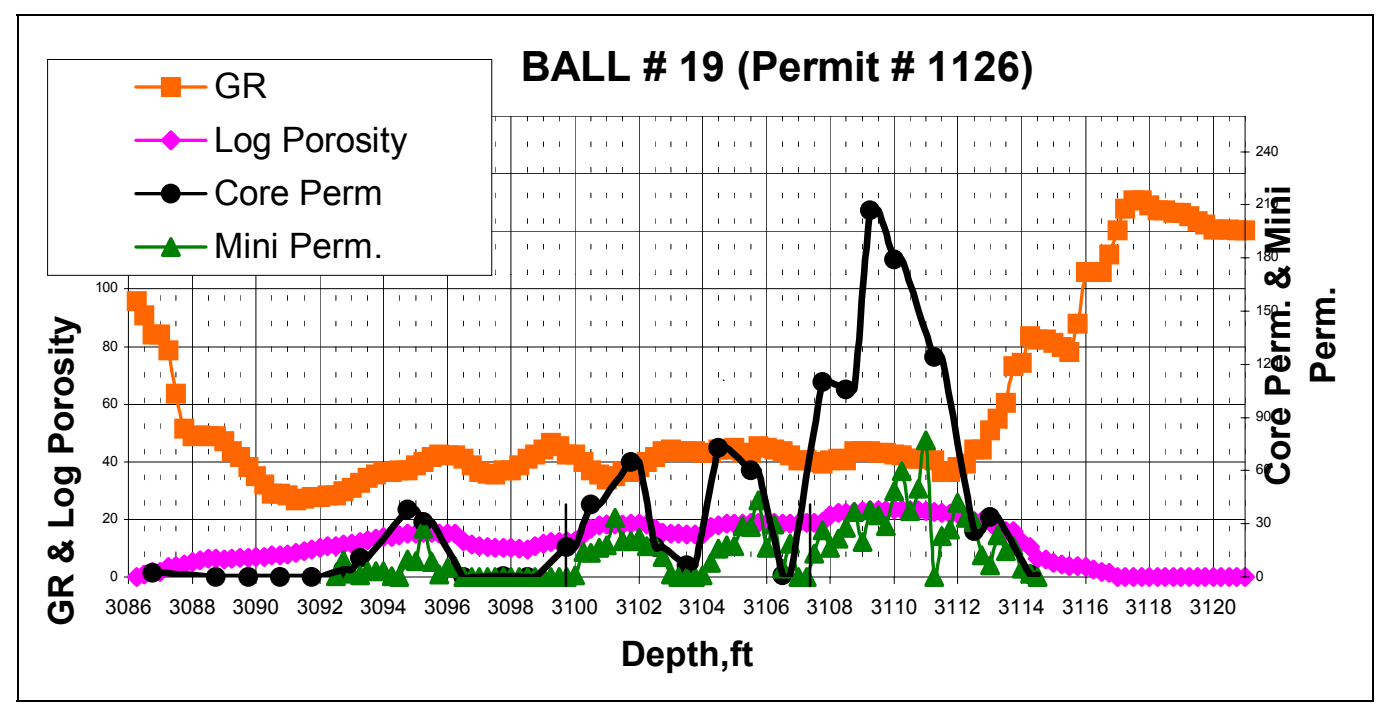

Figure A.7 Ball \# 19 Gamma Ray-Log Porosity and Core Measurements

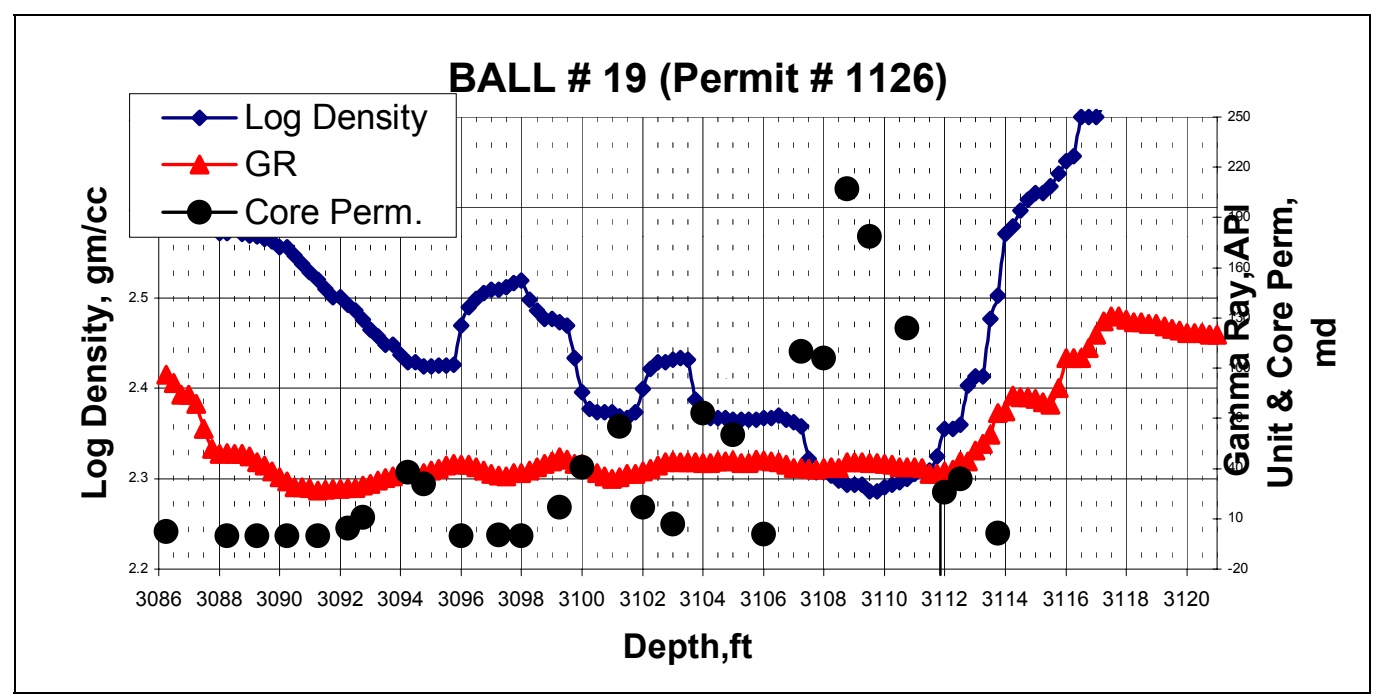

Figure A.8 Ball \# 19 Gamma Ray-Log Density and Core Permeability 


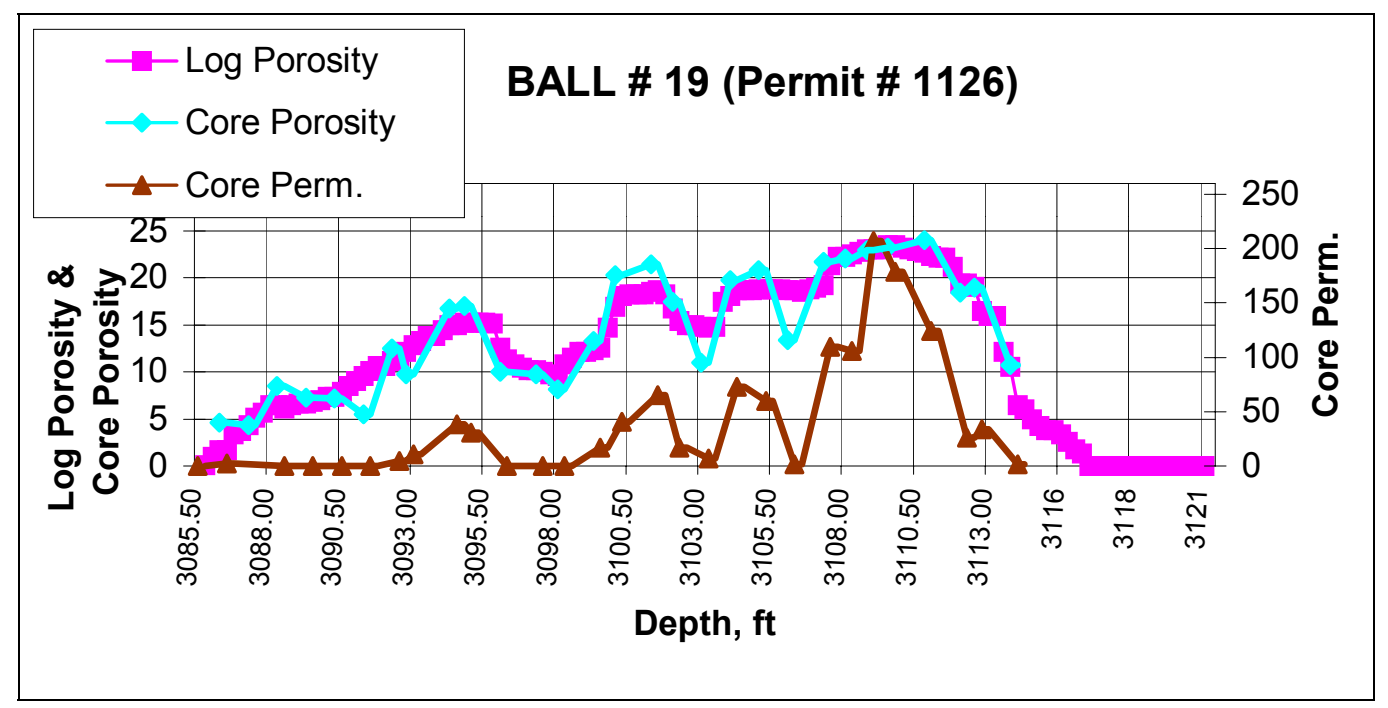

Figure A.9 Ball \# 19 Log Porosity versus Core Porosity with Core Permeability

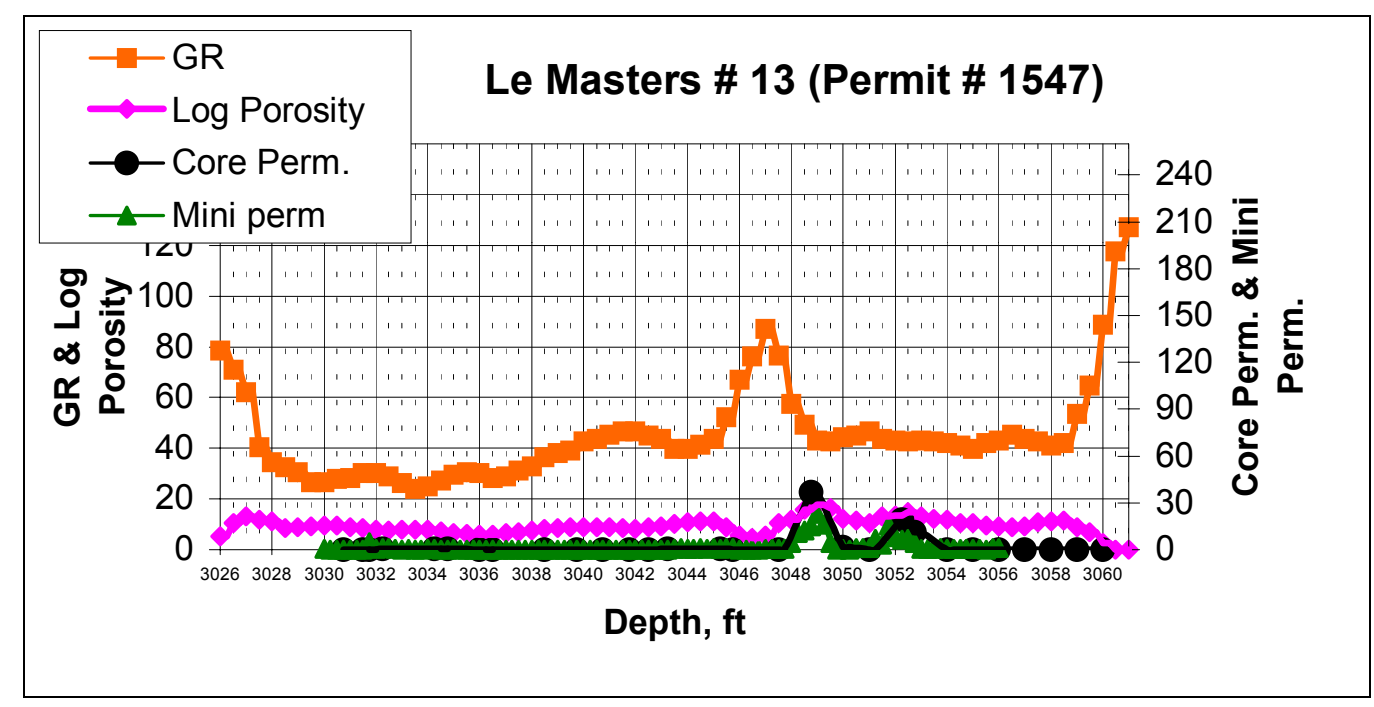

Figure A.10 LeMasters \# 13 Gamma Ray-Log Porosity and Core Measurements 


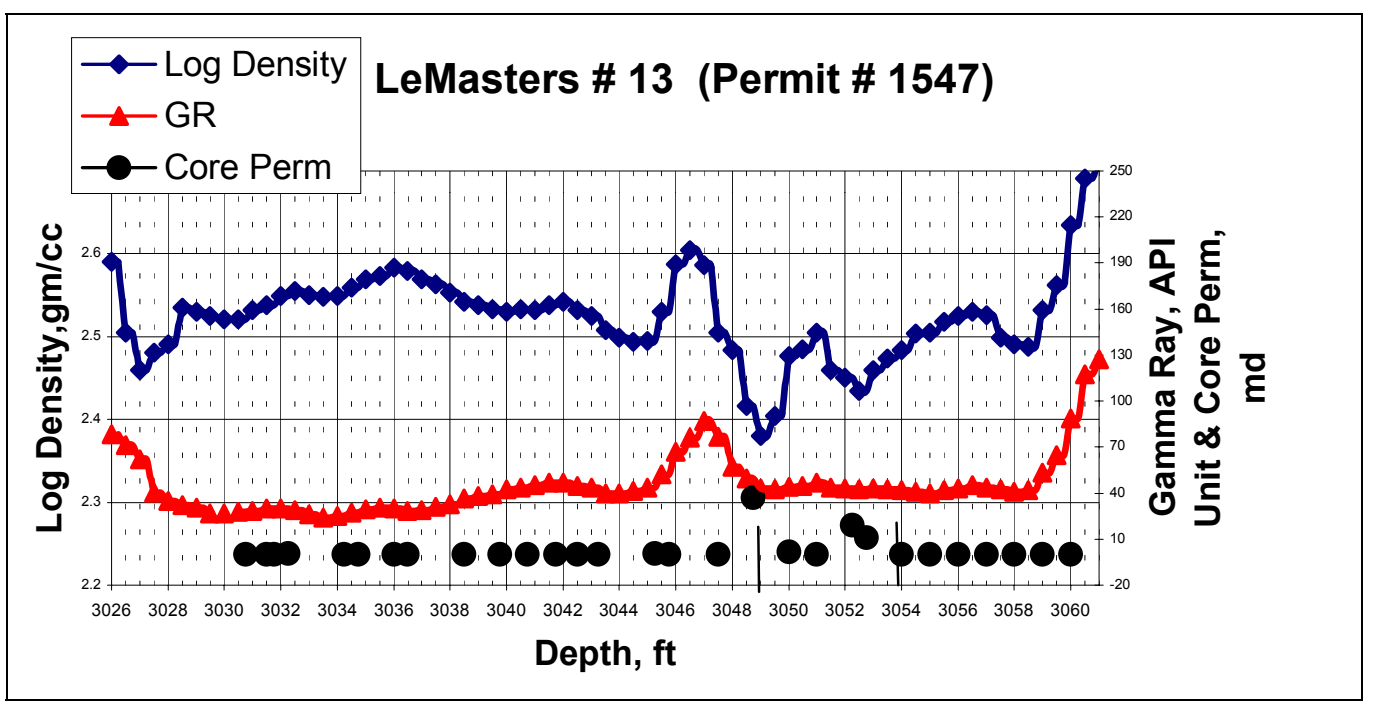

Figure A.11 LeMasters \# 13 Gamma Ray-Log Density and Core Permeability

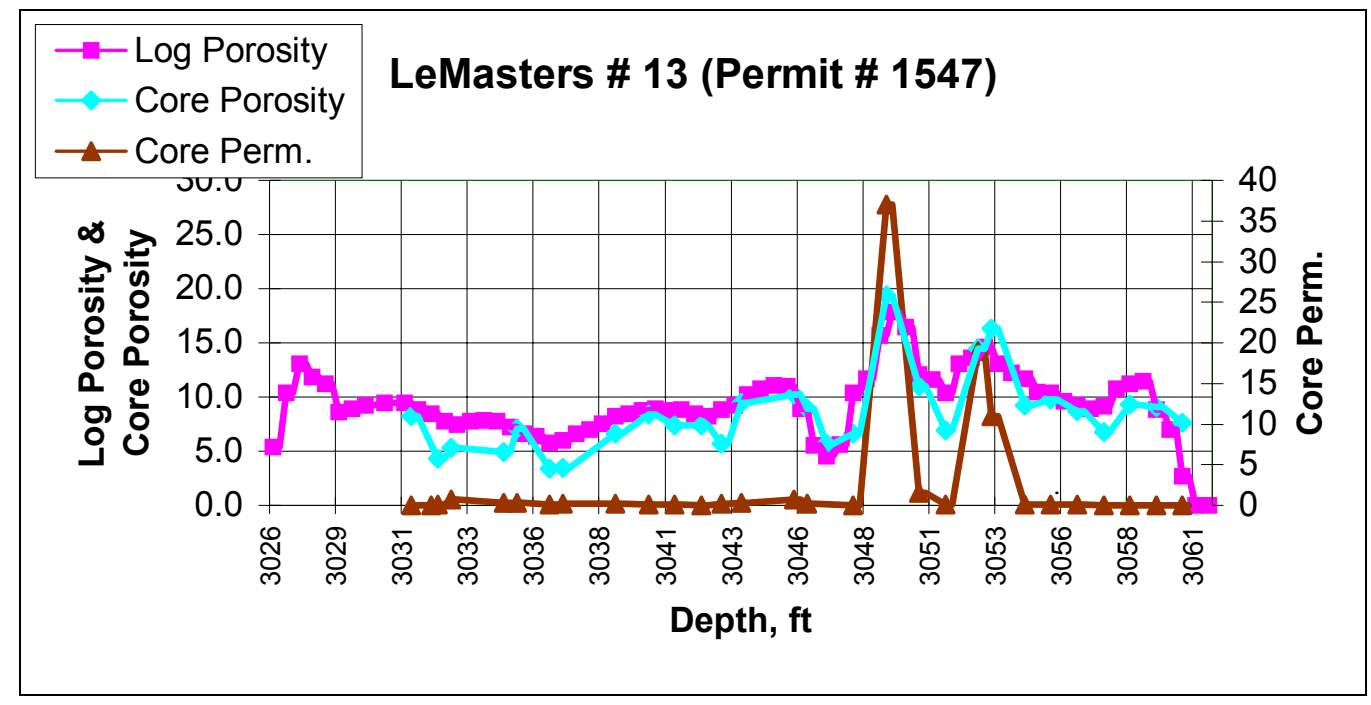

Figure A.12 LeMasters \# 13 Log Porosity versus Core Porosity with Core Permeability 


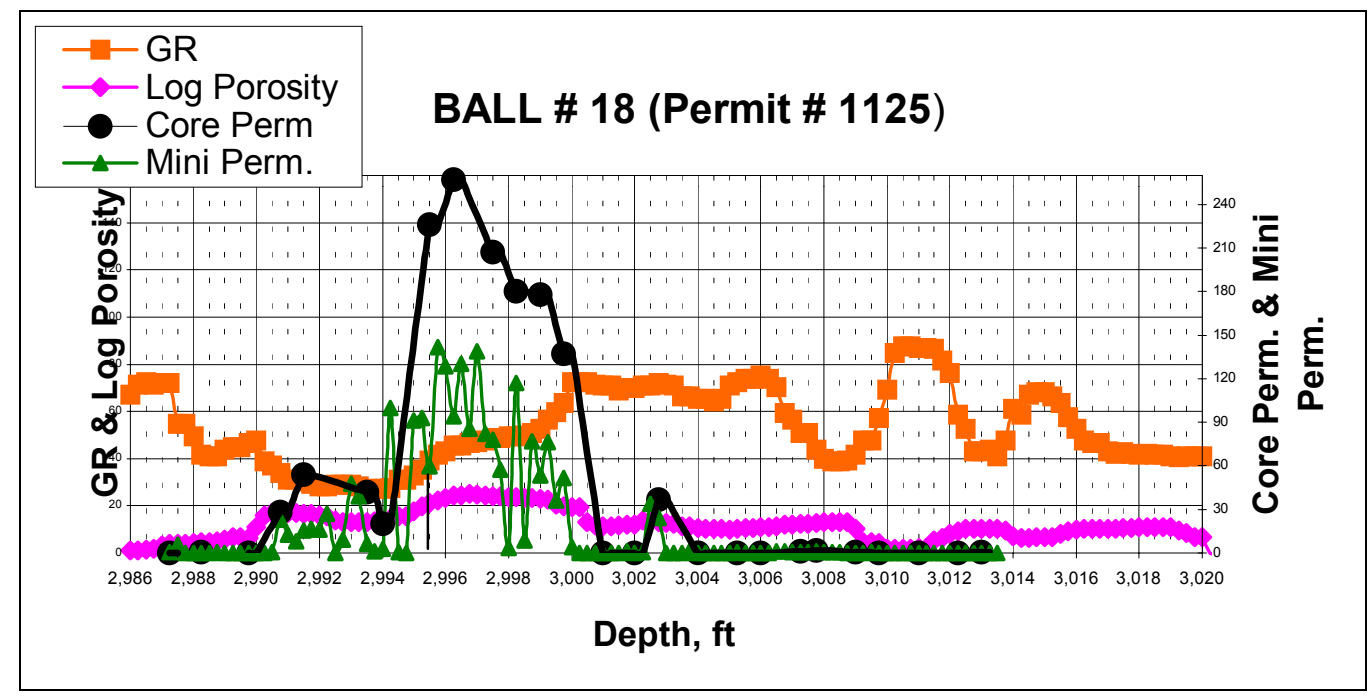

Figure A.13 Ball \# 18 Gamma Ray-Log Porosity and Core Measurements

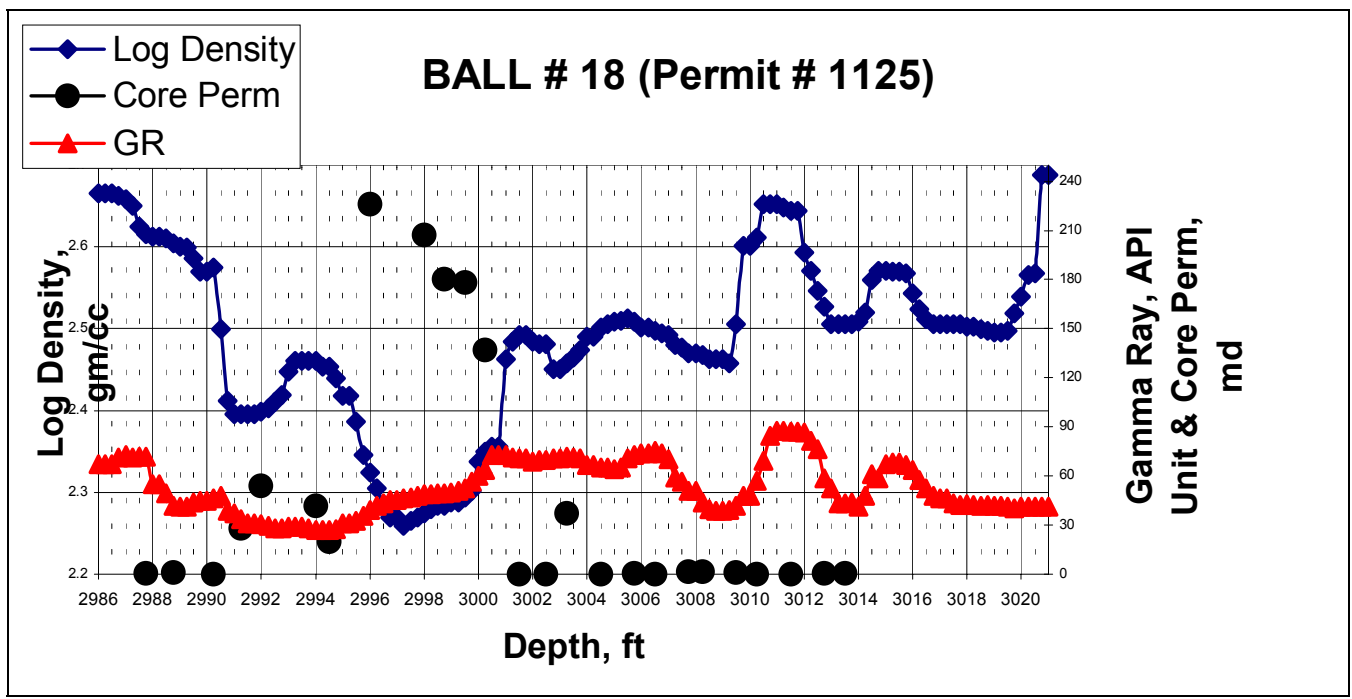

Figure A.14 Ball \# 18 Gamma Ray-Log Density and Core Permeability 


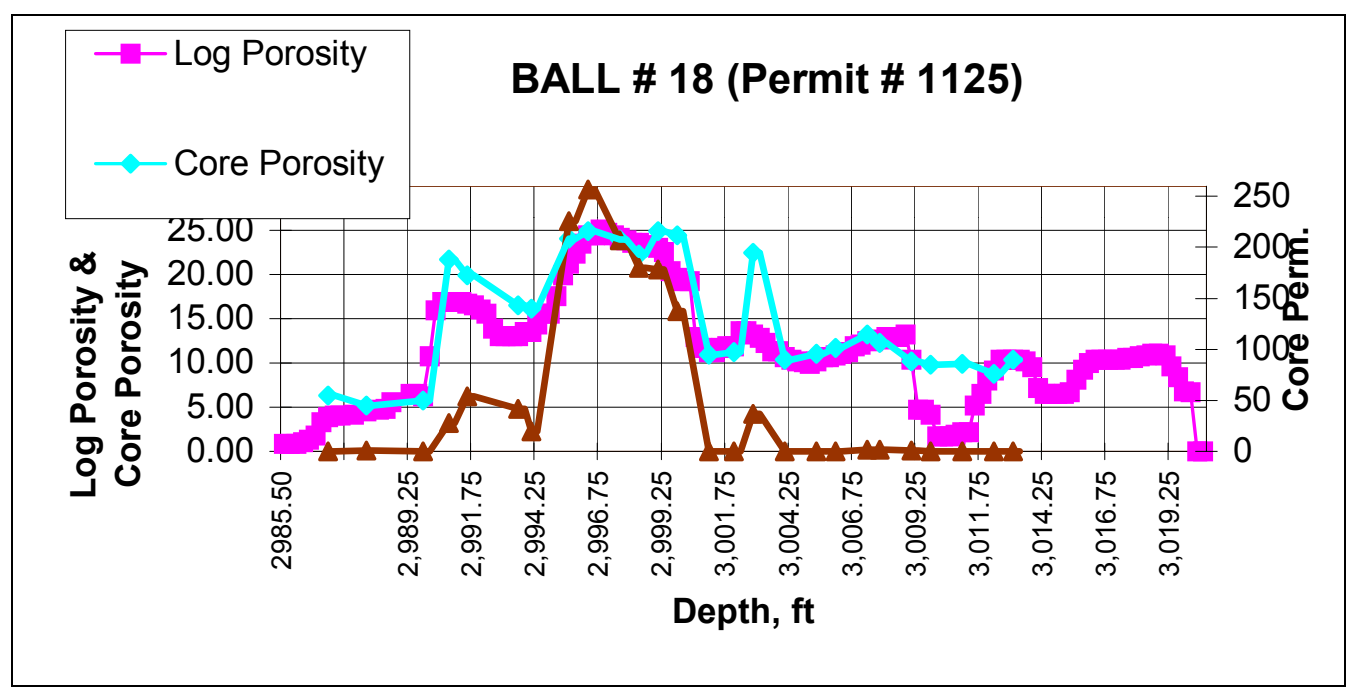

Figure A.15 Ball \# 18 Log Porosity versus Core Porosity with Core Permeability

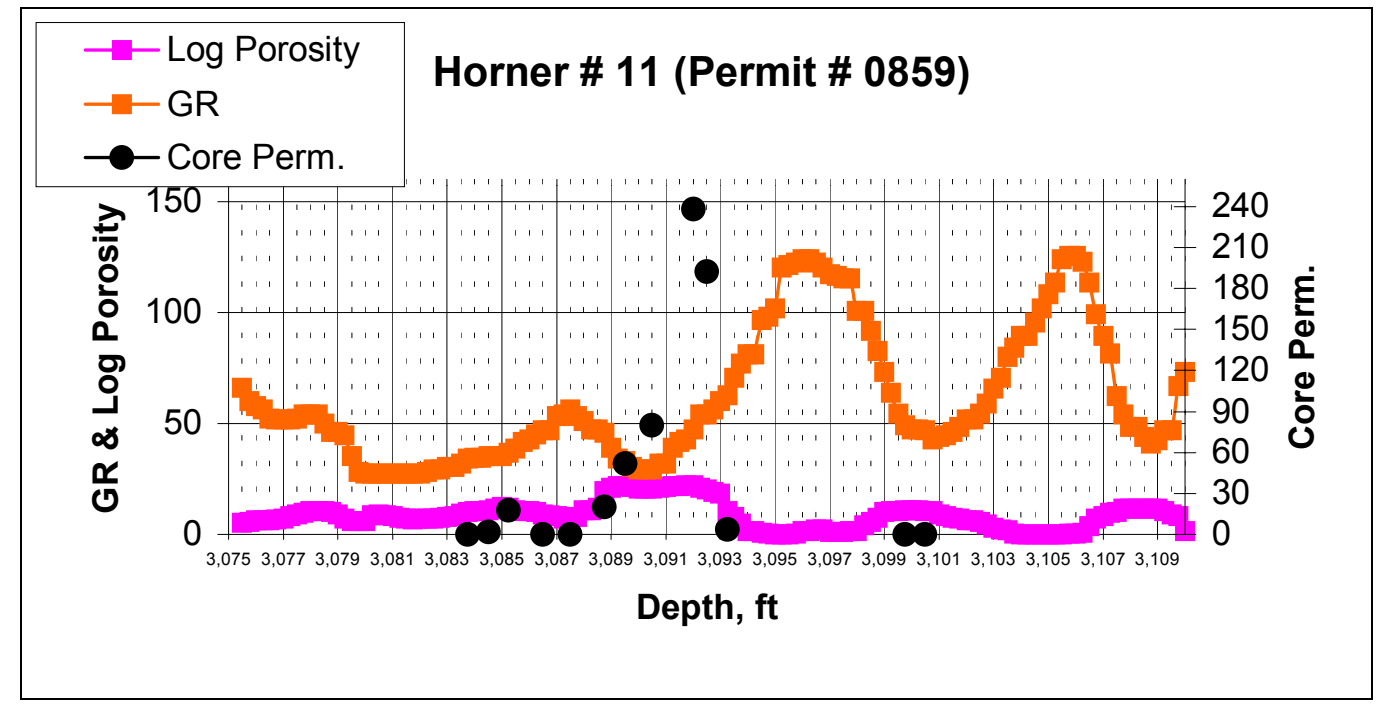

Figure A.16 Horner \# 11 Gamma Ray-Log Porosity and Core Measurements 


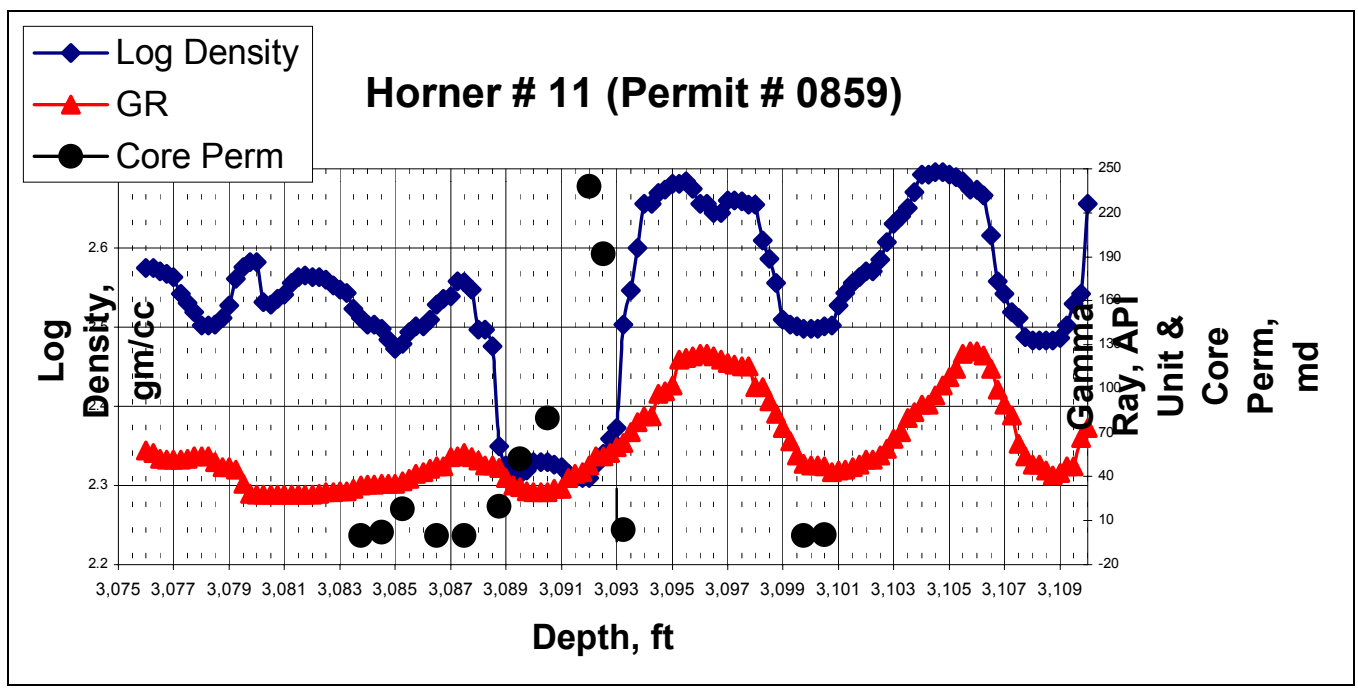

Figure A.17 Horner \# 11 Gamma Ray-Log Density and Core Permeability

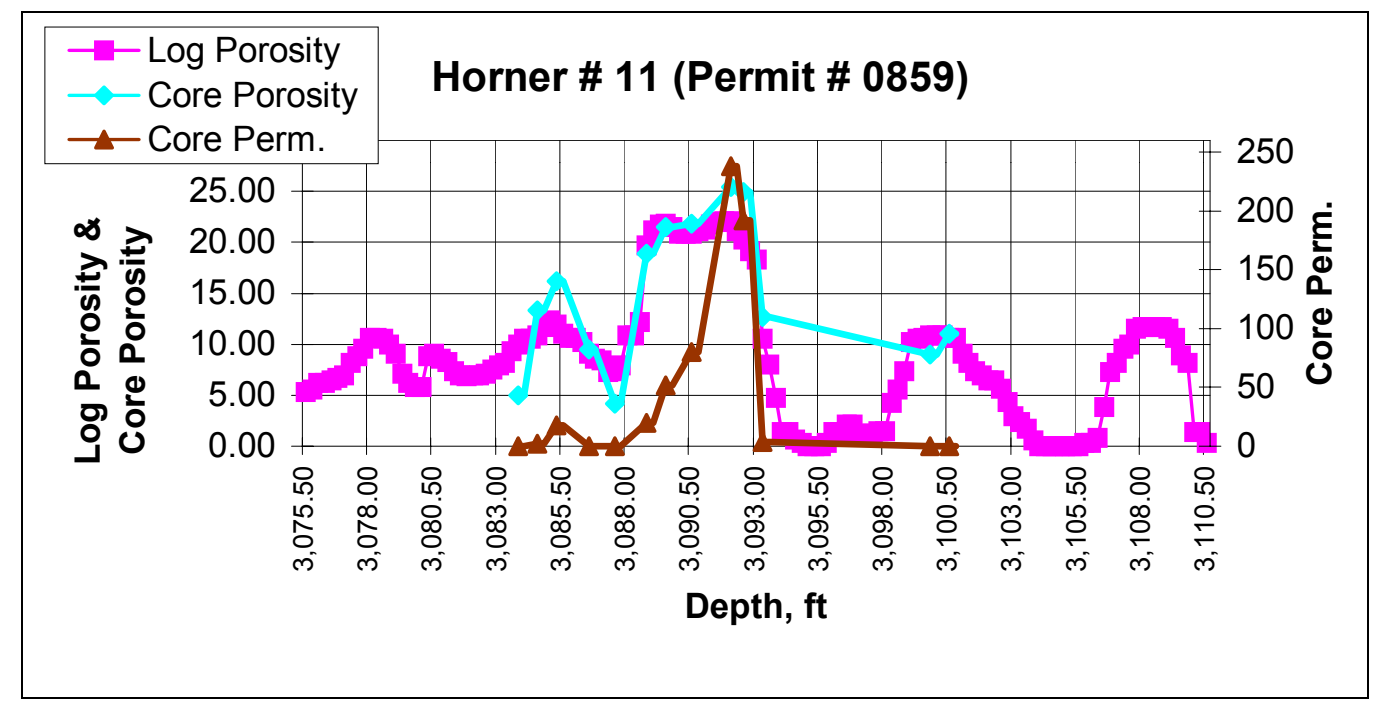

Figure A.18 Horner \# 11 Log Porosity versus Core Porosity with Core Permeability 


\begin{tabular}{|c|c|c|c|c|c|c|}
\hline & & $\begin{array}{l}\text { Table A.1 } \\
\text { T. Heirs \# }\end{array}$ & & & & \\
\hline Depth & GR & $\begin{array}{l}\text { Log } \\
\text { Density }\end{array}$ & $\begin{array}{l}\text { Log } \\
\text { Porosity }\end{array}$ & $\begin{array}{l}\text { Core } \\
\text { Porosity }\end{array}$ & $\begin{array}{l}\text { Core } \\
\text { Perm }\end{array}$ & Miniperm \\
\hline 2783.000 & 105.292 & 2.628 & $3.10 \%$ & & & 0.01 \\
\hline 2783.250 & 94.150 & 2.619 & $3.60 \%$ & & & 0.84 \\
\hline 2783.500 & 64.067 & 2.582 & $5.80 \%$ & & & 0.01 \\
\hline 2783.750 & 60.724 & 2.563 & $7.00 \%$ & & & 0.01 \\
\hline 2784.000 & 58.496 & 2.512 & $10.00 \%$ & & & 0.01 \\
\hline 2784.250 & 47.911 & 2.507 & $10.30 \%$ & & & 0.01 \\
\hline 2784.500 & 47.911 & 2.507 & $10.30 \%$ & & & 0.01 \\
\hline 2784.750 & 43.454 & 2.495 & $11.00 \%$ & & & 0.01 \\
\hline 2785.000 & 40.669 & 2.52 & $9.50 \%$ & & & 0.01 \\
\hline 2785.250 & 38.440 & 2.519 & $9.60 \%$ & $4.00 \%$ & 0.11 & 0.28 \\
\hline 2785.500 & 34.540 & 2.516 & $9.80 \%$ & & & 0.01 \\
\hline 2785.750 & 32.869 & 2.533 & $8.80 \%$ & & & 0.01 \\
\hline 2786.000 & 32.869 & 2.533 & $8.80 \%$ & & & 0.01 \\
\hline 2786.250 & 33.983 & 2.537 & $8.50 \%$ & $6.40 \%$ & 0.12 & 0.01 \\
\hline 2786.500 & 36.769 & 2.54 & $8.30 \%$ & & & 0.23 \\
\hline 2786.750 & 38.440 & 2.544 & $8.10 \%$ & & & 0.05 \\
\hline 2787.000 & 37.883 & 2.552 & $7.60 \%$ & & & 0.67 \\
\hline 2787.250 & 39.554 & 2.551 & $7.70 \%$ & & & 3.2 \\
\hline 2787.500 & 42.897 & 2.548 & $7.90 \%$ & & & 0.53 \\
\hline 2787.750 & 42.897 & 2.548 & $7.90 \%$ & & & 0.46 \\
\hline 2788.000 & 45.125 & 2.533 & $8.80 \%$ & & & 0.01 \\
\hline 2788.250 & 47.354 & 2.504 & $10.50 \%$ & & & 0.01 \\
\hline 2788.500 & 49.582 & 2.503 & $10.50 \%$ & & & 0.38 \\
\hline 2788.750 & 51.811 & 2.495 & $11.00 \%$ & $13.10 \%$ & 0.92 & 0.01 \\
\hline 2789.000 & 51.253 & 2.488 & $11.40 \%$ & & & 0.01 \\
\hline 2789.250 & 51.253 & 2.488 & $11.40 \%$ & $10.90 \%$ & 0.31 & 0.01 \\
\hline 2789.500 & 47.911 & 2.469 & $12.60 \%$ & & & 0.01 \\
\hline 2789.750 & 43.454 & 2.473 & $12.30 \%$ & & & 0.01 \\
\hline 2790.000 & 37.326 & 2.469 & $12.60 \%$ & & & 0.2 \\
\hline 2790.250 & 37.326 & 2.467 & $12.70 \%$ & & & 1.07 \\
\hline 2790.500 & 37.326 & 2.467 & $12.70 \%$ & & & 3.99 \\
\hline 2790.750 & 37.326 & 2.467 & $12.70 \%$ & & & 5.57 \\
\hline 2791.000 & 37.326 & 2.471 & $12.40 \%$ & & & 4.27 \\
\hline 2791.250 & 38.440 & 2.471 & $12.40 \%$ & & & 7.08 \\
\hline 2791.500 & 39.554 & 2.473 & $12.30 \%$ & $14.10 \%$ & 6.5 & 5.59 \\
\hline 2791.750 & 40.111 & 2.473 & $12.30 \%$ & & & 3.93 \\
\hline 2792.000 & 46.797 & 2.471 & $12.40 \%$ & & & 1.38 \\
\hline 2792.250 & 46.797 & 2.471 & $12.40 \%$ & & & 3.13 \\
\hline 2792.500 & 47.911 & 2.467 & $12.70 \%$ & $14.60 \%$ & 3.8 & 4.72 \\
\hline 2792.750 & 49.025 & 2.464 & $12.90 \%$ & & & 17.95 \\
\hline
\end{tabular}




\begin{tabular}{|c|c|c|c|c|c|c|}
\hline \multirow[b]{2}{*}{ Depth } & \multirow[b]{2}{*}{ GR } & \multicolumn{4}{|c|}{$\begin{array}{l}\text { Table A.1 } \\
\text { T. Heirs \# } 8\end{array}$} & \multirow[b]{2}{*}{ Miniperm } \\
\hline & & $\begin{array}{c}\text { Log } \\
\text { Density }\end{array}$ & $\begin{array}{l}\text { Log } \\
\text { Porosity }\end{array}$ & $\begin{array}{c}\text { Core } \\
\text { Porosity }\end{array}$ & $\begin{array}{l}\text { Core } \\
\text { Perm }\end{array}$ & \\
\hline 2793.00 & 52.925 & 2.452 & $13.60 \%$ & & & 5.83 \\
\hline 2793.25 & 52.925 & 2.433 & $14.70 \%$ & & & 6.87 \\
\hline 2793.50 & 52.368 & 2.402 & $16.50 \%$ & & & 5.7 \\
\hline 2793.75 & 51.811 & 2.392 & $17.10 \%$ & $16.20 \%$ & 8.1 & 6.97 \\
\hline 2794.00 & 51.811 & 2.392 & $17.10 \%$ & & & 7.39 \\
\hline 2794.25 & 50.139 & 2.387 & $17.40 \%$ & & & 8.26 \\
\hline 2794.50 & 49.582 & 2.384 & $17.60 \%$ & & & 7.88 \\
\hline 2794.75 & 49.025 & 2.384 & $17.60 \%$ & $17.70 \%$ & 18 & 7.26 \\
\hline 2795.00 & 48.468 & 2.367 & $18.60 \%$ & & & 8.69 \\
\hline 2795.25 & 49.025 & 2.365 & $18.80 \%$ & $18.70 \%$ & 22 & 7.64 \\
\hline 2795.50 & 49.025 & 2.365 & $18.80 \%$ & & & 10.47 \\
\hline 2795.75 & 51.811 & 2.363 & $18.90 \%$ & & & 9.08 \\
\hline 2796.000 & 52.925 & 2.359 & $19.10 \%$ & $19.40 \%$ & 23 & 10.35 \\
\hline 2796.250 & 54.596 & 2.354 & $19.40 \%$ & & & 12.52 \\
\hline 2796.500 & 55.710 & 2.352 & $19.50 \%$ & $19.40 \%$ & 21 & 6.59 \\
\hline 2796.750 & 58.496 & 2.351 & $19.60 \%$ & & & 7.62 \\
\hline
\end{tabular}




\begin{tabular}{|c|c|c|c|c|c|c|}
\hline & & $\begin{array}{l}\text { Table A.2 } \\
\text { Horner \# } 9\end{array}$ & & & & \\
\hline Depth & GR & $\begin{array}{c}\text { Log } \\
\text { Density }\end{array}$ & $\begin{array}{l}\text { Log } \\
\text { Porosity }\end{array}$ & $\begin{array}{c}\text { Core } \\
\text { Porosity }\end{array}$ & $\begin{array}{l}\text { Core } \\
\text { Perm }\end{array}$ & Miniperm \\
\hline 2891.50 & 44.63 & 2.57 & $6.30 \%$ & & & 0.01 \\
\hline 2891.75 & 41.32 & 2.56 & $7.30 \%$ & $6.10 \%$ & 3.3 & 1.14 \\
\hline 2892.00 & 38.02 & 2.53 & $8.70 \%$ & & & 13.4 \\
\hline 2892.25 & 35.81 & 2.51 & $10.10 \%$ & & & 1.54 \\
\hline 2892.50 & 34.71 & 2.49 & $11.30 \%$ & & & 4.29 \\
\hline 2892.75 & 34.71 & 2.48 & $12.10 \%$ & & & 1.14 \\
\hline 2893.00 & 34.71 & 2.48 & $12.10 \%$ & $10.00 \%$ & 40 & 0.41 \\
\hline 2893.25 & 34.16 & 2.47 & $12.70 \%$ & & & 0.66 \\
\hline 2893.50 & 33.06 & 2.46 & $13.20 \%$ & $12.60 \%$ & 55 & 10.81 \\
\hline 2893.75 & 32.51 & 2.45 & $13.80 \%$ & & & 6.63 \\
\hline 2894.00 & 34.16 & 2.44 & $14.20 \%$ & & & 0.01 \\
\hline 2894.25 & 36.36 & 2.43 & $14.60 \%$ & & & 0.43 \\
\hline 2894.50 & 36.36 & 2.43 & $14.60 \%$ & & & 6.83 \\
\hline 2894.75 & 38.02 & 2.43 & $15.10 \%$ & & & 9.88 \\
\hline 2895.00 & 39.67 & 2.42 & $15.60 \%$ & $18.90 \%$ & 92 & 27.55 \\
\hline 2895.25 & 40.77 & 2.41 & $16.00 \%$ & & & 33.02 \\
\hline 2895.50 & 42.98 & 2.39 & $17.10 \%$ & & & 34.49 \\
\hline 2895.75 & 42.42 & 2.38 & $17.80 \%$ & $17.60 \%$ & 80 & 32.09 \\
\hline 2896.00 & 42.42 & 2.37 & $18.50 \%$ & & & 41.57 \\
\hline 2896.25 & 42.42 & 2.37 & $18.50 \%$ & & & 46.26 \\
\hline 2896.50 & 41.87 & 2.35 & $19.80 \%$ & $19.40 \%$ & 84 & 25.27 \\
\hline 2896.75 & 41.32 & 2.34 & $20.00 \%$ & & & 10.64 \\
\hline 2897.00 & 41.32 & 2.34 & $20.20 \%$ & & & 34.83 \\
\hline 2897.25 & 40.77 & 2.34 & $20.20 \%$ & & & 51.34 \\
\hline 2897.50 & 40.77 & 2.34 & $20.20 \%$ & & & 24.91 \\
\hline 2897.75 & 41.32 & 2.34 & $20.20 \%$ & & & 31.3 \\
\hline 2898.00 & 41.32 & 2.34 & $20.20 \%$ & & & 24.5 \\
\hline 2898.25 & 41.32 & 2.34 & $20.20 \%$ & $21.70 \%$ & 123 & 18.61 \\
\hline 2898.50 & 41.32 & 2.34 & $20.40 \%$ & & & 47.08 \\
\hline 2898.75 & 41.87 & 2.33 & $20.60 \%$ & $21.60 \%$ & 136 & 25.16 \\
\hline 2899.00 & 42.42 & 2.33 & $20.70 \%$ & & & 12.87 \\
\hline 2899.25 & 44.08 & 2.32 & $21.30 \%$ & & & 44.54 \\
\hline 2899.50 & 44.63 & 2.3 & $22.90 \%$ & & & 71.82 \\
\hline 2899.75 & 44.63 & 2.3 & $22.90 \%$ & & & 21.59 \\
\hline 2900.00 & 45.73 & 2.29 & $23.30 \%$ & $23.20 \%$ & 160 & 80.8 \\
\hline 2900.25 & 47.38 & 2.29 & $23.30 \%$ & & & 30.55 \\
\hline 2900.50 & 49.04 & 2.29 & $23.50 \%$ & & & 85.07 \\
\hline 2900.75 & 49.59 & 2.28 & $23.60 \%$ & & & 24.44 \\
\hline 2901.00 & 50.69 & 2.28 & $23.80 \%$ & $22.10 \%$ & 135 & 30.41 \\
\hline 2901.25 & 51.24 & 2.28 & $24.00 \%$ & & & 27.07 \\
\hline 2901.50 & 51.24 & 2.28 & $24.00 \%$ & & & 26.39 \\
\hline 2901.75 & 51.79 & 2.27 & $24.20 \%$ & & & 58.8 \\
\hline
\end{tabular}




\begin{tabular}{|c|c|c|c|c|c|c|}
\hline \multirow[b]{2}{*}{$\begin{array}{l}\text { Depth } \\
2902.00\end{array}$} & \multirow[b]{2}{*}{$\begin{array}{c}\text { GR } \\
52.34\end{array}$} & \multicolumn{4}{|c|}{$\begin{array}{l}\text { Table A.2 } \\
\text { Horner \# } 9\end{array}$} & \multirow[b]{2}{*}{$\begin{array}{c}\text { Miniperm } \\
49.53\end{array}$} \\
\hline & & $\begin{array}{c}\text { Log } \\
\text { Density } \\
2.27\end{array}$ & $\begin{array}{l}\text { Log } \\
\text { Porosity } \\
24.20 \%\end{array}$ & $\begin{array}{c}\text { Core } \\
\text { Porosity } \\
23.10 \%\end{array}$ & $\begin{array}{c}\text { Core } \\
\text { Perm } \\
144\end{array}$ & \\
\hline 2902.25 & 52.89 & 2.28 & $24.10 \%$ & & & 73.82 \\
\hline 2902.50 & 53.99 & 2.28 & $23.90 \%$ & & & 70.55 \\
\hline 2902.75 & 55.1 & 2.28 & $23.90 \%$ & & & 107.35 \\
\hline 2903.00 & 55.65 & 2.28 & $23.60 \%$ & $23.20 \%$ & 124 & 25.05 \\
\hline 2903.25 & 55.65 & 2.28 & $23.60 \%$ & & & 46.88 \\
\hline 2903.50 & 55.65 & 2.29 & $23.30 \%$ & $24.10 \%$ & 148 & 86.69 \\
\hline 2903.75 & 55.65 & 2.29 & $23.10 \%$ & & & 32.88 \\
\hline 2904.00 & 56.2 & 2.3 & $22.80 \%$ & & & 10.48 \\
\hline 2904.25 & 57.85 & 2.32 & $21.70 \%$ & & & 50.21 \\
\hline 2904.50 & 61.16 & 2.32 & $21.50 \%$ & $24.00 \%$ & 203 & 44.08 \\
\hline 2904.75 & 61.71 & 2.33 & $21.00 \%$ & & & 74.49 \\
\hline 2905.00 & 61.71 & 2.33 & $21.00 \%$ & & & 62.9 \\
\hline 2905.25 & 63.36 & 2.35 & $19.60 \%$ & & & 135.24 \\
\hline 2905.50 & 66.12 & 2.36 & $19.30 \%$ & $24.40 \%$ & 214 & 103.16 \\
\hline 2905.75 & 69.42 & 2.37 & $18.60 \%$ & & & 120.78 \\
\hline 2906.00 & 73.28 & 2.38 & $18.20 \%$ & & & 95.16 \\
\hline 2906.25 & 76.58 & 2.43 & $14.90 \%$ & & & 82.17 \\
\hline 2906.50 & 80.44 & 2.45 & $13.90 \%$ & & & 80.69 \\
\hline 2906.75 & 80.44 & 2.45 & $13.90 \%$ & & & 0.01 \\
\hline 2907.00 & 83.75 & 2.46 & $13.30 \%$ & & & 0.01 \\
\hline
\end{tabular}

Table A.3

Ball \# 19

\begin{tabular}{|c|c|c|c|c|c|c|}
\hline Depth & GR & $\begin{array}{c}\text { Log } \\
\text { Density }\end{array}$ & $\begin{array}{l}\text { Log } \\
\text { Porosity }\end{array}$ & $\begin{array}{l}\text { Core } \\
\text { Porosity }\end{array}$ & $\begin{array}{l}\text { Core } \\
\text { Perm }\end{array}$ & Miniperm \\
\hline 3092.00 & 28.255 & 2.501 & 10.65 & & & 0.47 \\
\hline 3092.25 & 29.917 & 2.492 & 11.19 & 12.5 & 4.24 & 9.63 \\
\hline 3092.50 & 31.025 & 2.486 & 11.55 & & & 1.65 \\
\hline 3092.75 & 32.687 & 2.476 & 12.14 & 9.7 & 11 & 0.74 \\
\hline 3093.00 & 34.349 & 2.465 & 12.8 & & & 3.12 \\
\hline 3093.25 & 35.457 & 2.457 & 13.27 & & & 3.5 \\
\hline 3093.50 & 36.565 & 2.448 & 13.81 & & & 3.25 \\
\hline 3093.75 & 36.565 & 2.448 & 13.81 & & & 0.58 \\
\hline 3094.00 & 37.119 & 2.437 & 14.46 & & & 0.01 \\
\hline 3094.25 & 37.119 & 2.429 & 14.94 & 16.7 & 38 & 10.1 \\
\hline 3094.50 & 38.781 & 2.429 & 14.94 & & & 9.07 \\
\hline
\end{tabular}




\begin{tabular}{|c|c|c|c|c|c|c|}
\hline & & $\begin{array}{l}\text { Table A.3 } \\
\text { Ball \# } 19\end{array}$ & & & & \\
\hline $\begin{array}{l}\text { Depth } \\
3094.75\end{array}$ & $\begin{array}{c}\text { GR } \\
39.889\end{array}$ & $\begin{array}{c}\text { Log } \\
\text { Density } \\
2.424\end{array}$ & $\begin{array}{c}\log \\
\text { Porosity } \\
15.24\end{array}$ & $\begin{array}{c}\text { Core } \\
\text { Porosity } \\
17\end{array}$ & $\begin{array}{c}\text { Core } \\
\text { Perm } \\
31\end{array}$ & $\begin{array}{c}\text { Miniperm } \\
27.49\end{array}$ \\
\hline 3095.00 & 41.551 & 2.424 & 15.24 & & & 8.65 \\
\hline 3095.25 & 42.659 & 2.425 & 15.18 & & & 1.61 \\
\hline 3095.50 & 42.105 & 2.425 & 15.18 & & & 4.97 \\
\hline 3095.75 & 42.105 & 2.426 & 15.12 & & & 6.21 \\
\hline 3096.00 & 40.997 & 2.469 & 12.56 & & & 0.01 \\
\hline 3096.25 & 38.781 & 2.49 & 11.31 & & & 0.01 \\
\hline 3096.50 & 36.565 & 2.499 & 10.77 & & & 0.01 \\
\hline 3096.75 & 36.011 & 2.505 & 10.42 & & & 0.01 \\
\hline 3097.00 & 35.457 & 2.509 & 10.18 & & & 0.01 \\
\hline 3097.25 & 37.119 & 2.509 & 10.18 & 9.7 & 0.27 & 0.23 \\
\hline 3097.50 & 37.119 & 2.512 & 10 & & & 0.01 \\
\hline 3097.75 & 38.781 & 2.516 & 9.76 & & & 0.01 \\
\hline 3098.00 & 40.997 & 2.519 & 9.58 & 8.1 & 0.16 & 0.01 \\
\hline 3098.25 & 42.659 & 2.498 & 10.83 & & & 0.01 \\
\hline 3098.50 & 44.321 & 2.486 & 11.55 & & & 0.01 \\
\hline 3098.75 & 46.537 & 2.477 & 12.08 & & & 0.01 \\
\hline 3099.00 & 45.429 & 2.477 & 12.08 & & & 0.01 \\
\hline 3099.25 & 42.659 & 2.473 & 12.32 & 13.3 & 17 & 0.01 \\
\hline 3099.50 & 42.659 & 2.469 & 12.56 & & & 0.99 \\
\hline 3099.75 & 39.889 & 2.433 & 14.7 & & & 14.3 \\
\hline 3100.00 & 37.119 & 2.396 & 16.9 & 20.3 & 41 & 13.5 \\
\hline 3100.25 & 35.457 & 2.377 & 18.04 & & & 16.28 \\
\hline 3100.50 & 33.795 & 2.373 & 18.27 & & & 18.08 \\
\hline 3100.75 & 34.903 & 2.373 & 18.27 & & & 33.15 \\
\hline 3101.00 & 36.565 & 2.373 & 18.27 & & & 20.29 \\
\hline 3101.25 & 36.565 & 2.369 & 18.51 & 21.4 & 65 & 20.39 \\
\hline 3101.50 & 38.227 & 2.367 & 18.63 & & & 21.9 \\
\hline 3101.75 & 39.889 & 2.373 & 18.27 & & & 17.17 \\
\hline 3102.00 & 41.551 & 2.399 & 16.73 & 17.4 & 17 & 17.98 \\
\hline 3102.25 & 43.767 & 2.421 & 15.42 & & & 11.28 \\
\hline 3102.50 & 44.321 & 2.429 & 14.94 & & & 1.59 \\
\hline 3102.75 & 43.767 & 2.429 & 14.94 & & & 0.01 \\
\hline 3103.00 & 43.767 & 2.432 & 14.76 & 11 & 6.79 & 0.01 \\
\hline 3103.25 & 43.767 & 2.433 & 14.7 & & & 0.01 \\
\hline 3103.50 & 43.213 & 2.432 & 14.76 & & & 1.05 \\
\hline
\end{tabular}




\begin{tabular}{|c|c|c|c|c|c|c|}
\hline & & $\begin{array}{l}\text { Table A.3 } \\
\text { Ball \# } 19\end{array}$ & & & & \\
\hline $\begin{array}{c}\text { Depth } \\
3103.75\end{array}$ & $\begin{array}{c}\text { GR } \\
43.213\end{array}$ & $\begin{array}{c}\text { Log } \\
\text { Density } \\
2.387\end{array}$ & $\begin{array}{l}\text { Log } \\
\text { Porosity } \\
17.44\end{array}$ & $\begin{array}{c}\text { Core } \\
\text { Porosity }\end{array}$ & $\begin{array}{l}\text { Core } \\
\text { Perm }\end{array}$ & $\begin{array}{c}\text { Miniperm } \\
8.02\end{array}$ \\
\hline 3104.00 & 44.321 & 2.377 & 18.04 & 19.7 & 73 & 15.93 \\
\hline 3104.25 & 44.321 & 2.367 & 18.63 & & & 17.68 \\
\hline 3104.50 & 44.875 & 2.367 & 18.63 & & & 17.44 \\
\hline 3104.75 & 43.213 & 2.367 & 18.63 & & & 28.9 \\
\hline 3105.00 & 43.213 & 2.365 & 18.75 & 20.8 & 60 & 28.01 \\
\hline 3105.25 & 45.429 & 2.365 & 18.75 & & & 43.44 \\
\hline 3105.50 & 44.875 & 2.365 & 18.75 & & & 16.64 \\
\hline 3105.75 & 44.321 & 2.365 & 18.75 & & & 29.54 \\
\hline 3106.00 & 43.767 & 2.367 & 18.63 & 13.4 & 1.16 & 4.69 \\
\hline 3106.25 & 42.105 & 2.367 & 18.63 & & & 18.8 \\
\hline 3106.50 & 40.443 & 2.37 & 18.45 & & & 0.18 \\
\hline 3106.75 & 40.443 & 2.365 & 18.75 & & & 0.01 \\
\hline 3107.00 & 39.889 & 2.362 & 18.93 & & & 12.94 \\
\hline 3107.25 & 39.335 & 2.358 & 19.17 & 21.7 & 110 & 26.24 \\
\hline 3107.50 & 40.443 & 2.322 & 21.31 & & & 16.46 \\
\hline 3107.75 & 40.997 & 2.307 & 22.2 & & & 21.59 \\
\hline 3108.00 & 40.443 & 2.307 & 22.2 & 22 & 106 & 27.96 \\
\hline 3108.25 & 43.767 & 2.303 & 22.44 & & & 36.78 \\
\hline 3108.50 & 43.767 & 2.298 & 22.74 & & & 19.89 \\
\hline 3108.75 & 43.767 & 2.293 & 23.04 & 22.9 & 207 & 37.84 \\
\hline 3109.00 & 43.213 & 2.293 & 23.04 & & & 34.58 \\
\hline 3109.25 & 43.213 & 2.293 & 23.04 & & & 28.89 \\
\hline 3109.50 & 42.659 & 2.286 & 23.45 & 23.2 & 179 & 48.23 \\
\hline 3109.75 & 42.105 & 2.286 & 23.45 & & & 59.52 \\
\hline 3110.00 & 40.997 & 2.29 & 23.21 & & & 37.05 \\
\hline 3110.25 & 40.997 & 2.293 & 23.04 & & & 49.62 \\
\hline 3110.50 & 40.997 & 2.296 & 22.86 & & & 77.1 \\
\hline 3110.75 & 40.443 & 2.3 & 22.62 & 24 & 124 & 0.01 \\
\hline 3111.00 & 36.565 & 2.305 & 22.32 & & & 23.13 \\
\hline 3111.25 & 36.565 & 2.309 & 22.08 & & & 26.66 \\
\hline 3111.50 & 38.227 & 2.309 & 22.08 & & & 41.7 \\
\hline 3111.75 & 39.335 & 2.325 & 21.13 & & & 33.32 \\
\hline 3112.00 & 44.321 & 2.355 & 19.35 & 18.4 & 26 & 31.11 \\
\hline 3112.25 & 44.321 & 2.355 & 19.35 & & & 12.41 \\
\hline 3112.50 & 50.97 & 2.36 & 19.05 & 18.9 & 34 & 6.6 \\
\hline 3112.75 & 54.848 & 2.403 & 16.49 & & & 23.62 \\
\hline 3113.00 & 60.388 & 2.413 & 15.89 & & & 14.79 \\
\hline 3113.25 & 73.13 & 2.413 & 15.89 & & & 17.36 \\
\hline 3113.50 & 74.238 & 2.477 & 12.08 & & & 4.86 \\
\hline 3113.75 & 83.657 & 2.503 & 10.54 & 10.7 & 1.33 & 1.82 \\
\hline 3114.00 & 82.548 & 2.571 & 6.49 & & & 0.14 \\
\hline
\end{tabular}




\begin{tabular}{|c|c|c|c|c|c|c|}
\hline \multirow[b]{2}{*}{ Depth } & \multicolumn{3}{|c|}{ Table A.4 } & \multirow[b]{2}{*}{$\begin{array}{c}\text { Core } \\
\text { Porosity }\end{array}$} & \multirow[b]{2}{*}{$\begin{array}{l}\text { Core } \\
\text { Perm }\end{array}$} & \multirow[b]{2}{*}{ Miniperm } \\
\hline & GR & $\begin{array}{c}\text { Log } \\
\text { Density }\end{array}$ & $\begin{array}{c}\log \\
\text { Porosity }\end{array}$ & & & \\
\hline 3032.00 & 30.11 & 2.549 & $7.80 \%$ & $4.30 \%$ & 0.15 & 0.56 \\
\hline 3032.25 & & & & & & 1.25 \\
\hline 3032.50 & 28.98 & 2.555 & $7.40 \%$ & $5.30 \%$ & 0.72 & 0.97 \\
\hline 3032.75 & & & & & & 0.72 \\
\hline 3033.00 & 26.14 & 2.55 & $7.70 \%$ & & & 0.25 \\
\hline 3033.25 & & & & & & 0.32 \\
\hline 3033.50 & 23.86 & 2.548 & $7.90 \%$ & & & 0.2 \\
\hline 3033.75 & & & & & & 0.22 \\
\hline 3034.00 & 25 & 2.549 & $7.80 \%$ & $4.90 \%$ & 0.28 & 0.49 \\
\hline 3034.25 & & & & & & 0.34 \\
\hline 3034.50 & 27.27 & 2.559 & $7.20 \%$ & $7.10 \%$ & 0.27 & 0.05 \\
\hline 3034.75 & & & & & & 0.18 \\
\hline 3035.00 & 29.55 & 2.569 & $6.60 \%$ & & & 0.32 \\
\hline 3034.25 & & & & & & 0.14 \\
\hline 3035.50 & 30.68 & 2.573 & $6.40 \%$ & & & 0.1 \\
\hline 3035.75 & & & & & & 0.01 \\
\hline 3036.00 & 30.11 & 2.583 & $5.80 \%$ & $3.40 \%$ & 0.12 & 0.01 \\
\hline 3036.25 & & & & & & 0.01 \\
\hline 3036.50 & 28.41 & 2.579 & $6.00 \%$ & $3.50 \%$ & 0.22 & 0.01 \\
\hline 3036.75 & & & & & & 0.01 \\
\hline 3037.00 & 28.98 & 2.569 & $6.60 \%$ & & & 0.01 \\
\hline 3037.25 & & & & & & 0.01 \\
\hline 3037.50 & 31.25 & 2.563 & $7.00 \%$ & & & 0.01 \\
\hline 3037.75 & & & & & & 0.01 \\
\hline 3038.00 & 32.96 & 2.553 & $7.60 \%$ & & & 0.01 \\
\hline 3038.25 & & & & & & 0.01 \\
\hline 3038.50 & 36.36 & 2.542 & $8.20 \%$ & $6.60 \%$ & 0.18 & 0.01 \\
\hline 3038.75 & & & & & & 0.01 \\
\hline 3039.00 & 38.07 & 2.538 & $8.50 \%$ & & & 0.01 \\
\hline 3039.25 & & & & & & 0.01 \\
\hline 3039.50 & 39.21 & 2.533 & $8.80 \%$ & & & 0.01 \\
\hline 3039.75 & & & & & & 0.01 \\
\hline 3040.00 & 42.61 & 2.53 & $8.90 \%$ & & & 0.01 \\
\hline 3040.25 & & & & & & 0.01 \\
\hline 3040.50 & 43.75 & 2.533 & $8.80 \%$ & & & 0.01 \\
\hline 3040.75 & & & & & & 0.01 \\
\hline 3041.00 & 45.46 & 2.532 & $8.80 \%$ & & & 0.01 \\
\hline 3041.25 & & & & & & 0.01 \\
\hline 3041.50 & 46.59 & 2.538 & $8.50 \%$ & & & 0.01 \\
\hline 3041.75 & & & & & & 0.01 \\
\hline 3042.00 & 46.59 & 2.542 & $8.20 \%$ & & & 0.01 \\
\hline 3042.25 & & & & & & 0.01 \\
\hline 3042.50 & 44.89 & 2.532 & $8.80 \%$ & $5.70 \%$ & 0.19 & 0.01 \\
\hline 3042.75 & & & & & & 0.01 \\
\hline 3043.00 & 43.75 & 2.525 & $9.20 \%$ & $9.50 \%$ & 0.29 & 0.01 \\
\hline
\end{tabular}




\begin{tabular}{|c|c|c|c|c|c|c|}
\hline \multirow[b]{2}{*}{ Depth } & \multicolumn{3}{|c|}{ Table A.4 } & \multirow[b]{2}{*}{$\begin{array}{c}\text { Core } \\
\text { Porosity }\end{array}$} & \multirow[b]{2}{*}{$\begin{array}{l}\text { Core } \\
\text { Perm }\end{array}$} & \multirow[b]{2}{*}{ Miniperm } \\
\hline & GR & $\begin{array}{l}\text { Log } \\
\text { Density }\end{array}$ & $\begin{array}{l}\text { Log } \\
\text { Porosity }\end{array}$ & & & \\
\hline 3043.50 & 39.77 & 2.508 & $10.20 \%$ & & & 0.57 \\
\hline 3043.75 & & & & & & 1.14 \\
\hline 3044.00 & 39.77 & 2.499 & $10.80 \%$ & & & 0.78 \\
\hline 3044.25 & & & & & & 0.69 \\
\hline 3044.50 & 41.48 & 2.494 & $11.10 \%$ & & & 1.24 \\
\hline 3044.75 & & & & & & 0.74 \\
\hline 3045.00 & 43.75 & 2.495 & $11.00 \%$ & $10.20 \%$ & 0.67 & 1.21 \\
\hline 3045.25 & & & & & & 0.76 \\
\hline 3045.50 & 52.27 & 2.53 & $8.90 \%$ & & & 1.01 \\
\hline 3045.25 & & & & & & 1.22 \\
\hline 3046.00 & 67.05 & 2.587 & $5.50 \%$ & $8.90 \%$ & 0.21 & 0.01 \\
\hline 3046.25 & & & & & & 0.01 \\
\hline 3046.50 & 76.14 & 2.604 & $4.50 \%$ & & & 0.01 \\
\hline 3046.75 & & & & & & 0.01 \\
\hline 3047.00 & 86.93 & 2.586 & $5.60 \%$ & & & 0.39 \\
\hline 3047.25 & & & & & & 0.61 \\
\hline 3047.50 & 76.71 & 2.505 & $10.40 \%$ & & & 0.51 \\
\hline 3047.75 & & & & & & 0.42 \\
\hline 3048.00 & 57.39 & 2.484 & $11.70 \%$ & & & 4.37 \\
\hline 3048.25 & & & & & & 10.59 \\
\hline 3048.50 & 49.43 & 2.416 & $15.70 \%$ & & & 12.25 \\
\hline 3048.75 & & & & & & 14.94 \\
\hline 3049.00 & 43.18 & 2.38 & $17.90 \%$ & $19.40 \%$ & 37 & 22.88 \\
\hline 3049.25 & & & & & & 15.88 \\
\hline 3049.50 & 42.61 & 2.404 & $16.40 \%$ & & & 4.38 \\
\hline 3049.75 & & & & & & 0.01 \\
\hline 3050.00 & 44.32 & 2.477 & $12.10 \%$ & $11.00 \%$ & 1.51 & 0.39 \\
\hline 3050.25 & & & & & & 0.01 \\
\hline 3050.50 & 44.89 & 2.485 & $11.60 \%$ & & & 0.98 \\
\hline 3050.75 & & & & & & 1.13 \\
\hline 3051.00 & 46.59 & 2.505 & $10.40 \%$ & $6.90 \%$ & 0.11 & 0.81 \\
\hline 3051.25 & & & & & & 7.01 \\
\hline 3051.50 & 43.75 & 2.46 & $13.10 \%$ & & & 3.19 \\
\hline 3051.75 & & & & & & 15.63 \\
\hline 3052.00 & 43.18 & 2.451 & $13.60 \%$ & $14.50 \%$ & 19 & 8.03 \\
\hline 3052.25 & & & & & & 6.54 \\
\hline 3052.50 & 42.61 & 2.434 & $14.60 \%$ & & & 6.7 \\
\hline 3052.75 & & & & & & 4.44 \\
\hline 3053.00 & 43.18 & 2.46 & $13.10 \%$ & $16.30 \%$ & 11 & 0.71 \\
\hline 3053.25 & & & & & & 0.31 \\
\hline 3053.50 & 42.61 & 2.474 & $12.30 \%$ & & & 0.56 \\
\hline 3053.75 & & & & & & 1.07 \\
\hline
\end{tabular}




\begin{tabular}{|ccccccc|}
\hline \multicolumn{7}{c|}{ Table A.4 } \\
LeMasters \# 13 \\
Depth & GR & $\begin{array}{c}\text { Log } \\
\text { Density }\end{array}$ & $\begin{array}{c}\text { Log } \\
\text { Porosity } \\
\text { Den }\end{array}$ & $\begin{array}{c}\text { Core } \\
\text { Porosity }\end{array}$ & $\begin{array}{c}\text { Core } \\
\text { Perm }\end{array}$ & Miniperm \\
3054.00 & 42.05 & 2.484 & $11.70 \%$ & & & 0.6 \\
3054.25 & & & & & 0.5 \\
3054.50 & 40.91 & 2.504 & $10.50 \%$ & & 0.56 \\
3055.75 & & & & & 0.41 \\
3055.00 & 39.77 & 2.505 & $10.40 \%$ & & 0.45 \\
3055.25 & & & & & 0.57 \\
3055.50 & 42.05 & 2.518 & $9.60 \%$ & & 0.12 \\
3055.75 & & & & & 0.84 \\
3056.00 & 43.18 & 2.525 & $9.20 \%$ & & 1.13 \\
\hline
\end{tabular}

\begin{tabular}{|c|c|c|c|c|c|c|}
\hline & & $\begin{array}{l}\text { Table A.5 } \\
\text { Ball \# } 18\end{array}$ & & & & \\
\hline Depth & GR & $\begin{array}{c}\text { Log } \\
\text { Density }\end{array}$ & $\begin{array}{c}\text { Log } \\
\text { Porosity }\end{array}$ & $\begin{array}{c}\text { Core } \\
\text { Porosity }\end{array}$ & $\begin{array}{l}\text { Core } \\
\text { Perm }\end{array}$ & Miniperm \\
\hline 2987.25 & 72.022 & 2.615 & 3.87 & 6.3 & 0.26 & 0.74 \\
\hline 2987.50 & 54.848 & 2.612 & 4.05 & & & 5.53 \\
\hline 2987.75 & 54.848 & 2.612 & 4.05 & & & 0.01 \\
\hline 2988.00 & 49.307 & 2.61 & 4.17 & & & 0.01 \\
\hline 2988.25 & 41.551 & 2.604 & 4.52 & 5.2 & 0.77 & 0.01 \\
\hline 2988.50 & 40.997 & 2.6 & 4.76 & & & 0.01 \\
\hline 2988.75 & 40.997 & 2.599 & 4.82 & & & 0.69 \\
\hline 2989.00 & 43.767 & 2.586 & 5.6 & & & 0.01 \\
\hline 2989.25 & 44.875 & 2.57 & 6.55 & & & 0.01 \\
\hline 2989.50 & 44.875 & 2.57 & 6.55 & & & 0.01 \\
\hline 2989.75 & 46.537 & 2.575 & 6.25 & 5.8 & 0.14 & 0.01 \\
\hline 2990.00 & 47.645 & 2.499 & 10.77 & & & 0.01 \\
\hline 2990.25 & 38.781 & 2.412 & 15.95 & & & 0.01 \\
\hline 2990.50 & 37.119 & 2.396 & 16.9 & & & 0.48 \\
\hline 2990.75 & 33.795 & 2.396 & 16.9 & 21.7 & 28 & 23.19 \\
\hline 2991.00 & 31.025 & 2.396 & 16.9 & & & 12.86 \\
\hline 2991.25 & 31.025 & 2.396 & 16.9 & & & 7.82 \\
\hline 2991.50 & 30.471 & 2.399 & 16.73 & 19.9 & 54 & 15.22 \\
\hline 2991.75 & 29.363 & 2.403 & 16.49 & & & 16.54 \\
\hline 2992.00 & 28.255 & 2.411 & 16.01 & & & 16.05 \\
\hline 2992.25 & 28.255 & 2.419 & 15.54 & & & 26.73 \\
\hline 2992.50 & 28.809 & 2.447 & 13.87 & & & 0.01 \\
\hline 2992.75 & 28.809 & 2.461 & 13.04 & & & 9.22 \\
\hline 2993.00 & 28.809 & 2.461 & 13.04 & & & 47.61 \\
\hline
\end{tabular}




\begin{tabular}{|c|c|c|c|c|c|c|}
\hline & & $\begin{array}{l}\text { Table A.5 } \\
\text { Ball \# } 18\end{array}$ & & & & \\
\hline Depth & GR & $\begin{array}{c}\text { Log } \\
\text { Density }\end{array}$ & $\begin{array}{l}\log \\
\text { Porosity }\end{array}$ & $\begin{array}{c}\text { Core } \\
\text { Porosity }\end{array}$ & $\begin{array}{l}\text { Core } \\
\text { Perm }\end{array}$ & Miniperm \\
\hline 2993.25 & 28.255 & 2.461 & 13.04 & & & 38.84 \\
\hline 2993.50 & 27.147 & 2.461 & 13.04 & 16.5 & 42 & 6.18 \\
\hline 2993.75 & 27.147 & 2.454 & 13.45 & & & 1.29 \\
\hline 2994.00 & 27.147 & 2.454 & 13.45 & 16.1 & 20 & 2.76 \\
\hline 2994.25 & 27.701 & 2.439 & 14.35 & & & 99.82 \\
\hline 2994.50 & 31.025 & 2.418 & 15.6 & & & 0.39 \\
\hline 2994.75 & 31.025 & 2.418 & 15.6 & & & 0.06 \\
\hline 2995.00 & 32.687 & 2.386 & 17.5 & & & 91.38 \\
\hline 2995.25 & 35.457 & 2.346 & 19.88 & & & 92.78 \\
\hline 2995.50 & 39.335 & 2.324 & 21.19 & 24.1 & 226 & 59.59 \\
\hline 2995.75 & 41.551 & 2.305 & 22.32 & & & 141.62 \\
\hline 2996.00 & 43.213 & 2.286 & 23.45 & & & 128.31 \\
\hline 2996.25 & 45.429 & 2.269 & 24.46 & 24.9 & 257 & 94.26 \\
\hline 2996.50 & 45.429 & 2.269 & 24.46 & & & 130.29 \\
\hline 2996.75 & 46.537 & 2.259 & 25.06 & & & 85.42 \\
\hline 2997.00 & 47.091 & 2.265 & 24.7 & & & 138.7 \\
\hline 2997.25 & 47.645 & 2.269 & 24.46 & & & 82.26 \\
\hline 2997.50 & 48.753 & 2.274 & 24.17 & 24 & 207 & 78.01 \\
\hline 2997.75 & 48.753 & 2.279 & 23.87 & & & 57.26 \\
\hline 2998.00 & 49.307 & 2.284 & 23.57 & & & 3.5 \\
\hline 2998.25 & 49.307 & 2.284 & 23.57 & 22.3 & 180 & 117.37 \\
\hline 2998.50 & 49.861 & 2.288 & 23.33 & & & 8.5 \\
\hline 2998.75 & 50.97 & 2.288 & 23.33 & & & 76.85 \\
\hline 2999.00 & 52.632 & 2.294 & 22.98 & 24.9 & 178 & 53.64 \\
\hline 2999.25 & 56.51 & 2.302 & 22.5 & & & 76.14 \\
\hline 2999.50 & 59.834 & 2.337 & 20.42 & & & 35.98 \\
\hline 2999.75 & 63.712 & 2.35 & 19.64 & 24.4 & 137 & 51.54 \\
\hline 3000.00 & 72.576 & 2.356 & 19.29 & & & 3.76 \\
\hline 3000.25 & 72.576 & 2.356 & 19.29 & & & 0.01 \\
\hline 3000.50 & 72.576 & 2.463 & 12.92 & & & 0.01 \\
\hline 3000.75 & 71.468 & 2.484 & 11.67 & & & 0.04 \\
\hline 3001.00 & 70.914 & 2.492 & 11.19 & & & 0.01 \\
\hline 3001.25 & 70.914 & 2.492 & 11.19 & & & 0.01 \\
\hline 3001.50 & 68.698 & 2.484 & 11.67 & & & 0.01 \\
\hline 3001.75 & 69.806 & 2.481 & 11.85 & & & 1.03 \\
\hline 3002.00 & 69.806 & 2.481 & 11.85 & & & 0.01 \\
\hline 3002.25 & 70.914 & 2.451 & 13.63 & & & 0.84 \\
\hline 3002.50 & 70.914 & 2.451 & 13.63 & & & 34.04 \\
\hline 3002.75 & 72.022 & 2.458 & 13.21 & 22.5 & 37 & 23.86 \\
\hline 3003.00 & 71.468 & 2.465 & 12.8 & & & 0.01 \\
\hline 3003.25 & 70.914 & 2.474 & 12.26 & & & 0.01 \\
\hline
\end{tabular}




\begin{tabular}{|c|c|c|c|c|c|c|}
\hline & & $\begin{array}{l}\text { Table A.5 } \\
\text { Ball \# } 18\end{array}$ & & & & \\
\hline Depth & GR & $\begin{array}{c}\text { Log } \\
\text { Density }\end{array}$ & $\begin{array}{l}\text { Log } \\
\text { Porosity }\end{array}$ & $\begin{array}{c}\text { Core } \\
\text { Porosity }\end{array}$ & $\begin{array}{l}\text { Core } \\
\text { Perm }\end{array}$ & Miniperm \\
\hline 3003.50 & 66.482 & 2.49 & 11.31 & & & 0.01 \\
\hline 3003.75 & 66.482 & 2.49 & 11.31 & & & 1.33 \\
\hline 3004.00 & 65.374 & 2.501 & 10.65 & & & 0.01 \\
\hline 3004.25 & 65.374 & 2.506 & 10.36 & & & 0.01 \\
\hline 3004.50 & 64.266 & 2.509 & 10.18 & & & 0.01 \\
\hline 3004.75 & 65.374 & 2.51 & 10.12 & & & 0.26 \\
\hline 3005.00 & 70.914 & 2.513 & 9.94 & & & 0.1 \\
\hline 3005.25 & 72.576 & 2.509 & 10.18 & 11 & 0.26 & 0.4 \\
\hline 3005.50 & 73.684 & 2.501 & 10.65 & & & 0.01 \\
\hline 3005.75 & 73.684 & 2.501 & 10.65 & & & 0.01 \\
\hline 3006.00 & 75.346 & 2.497 & 10.89 & & & 0.01 \\
\hline 3006.25 & 73.684 & 2.494 & 11.07 & & & 0.01 \\
\hline 3006.50 & 70.36 & 2.492 & 11.19 & & & 1.08 \\
\hline 3006.75 & 59.28 & 2.48 & 11.9 & & & 0.89 \\
\hline 3007.00 & 56.51 & 2.477 & 12.08 & & & 0.78 \\
\hline 3007.25 & 50.97 & 2.47 & 12.5 & 13.2 & 1.4 & 0.79 \\
\hline 3007.50 & 50.97 & 2.47 & 12.5 & & & 0.69 \\
\hline 3007.75 & 43.767 & 2.468 & 12.62 & 12.3 & 1.5 & 0.97 \\
\hline 3008.00 & 39.889 & 2.463 & 12.92 & & & 0.7 \\
\hline 3008.25 & 38.781 & 2.463 & 12.92 & & & 0.74 \\
\hline 3008.50 & 38.781 & 2.463 & 12.92 & & & 0.81 \\
\hline 3008.75 & 39.335 & 2.458 & 13.21 & & & 0.21 \\
\hline 3009.00 & 41.551 & 2.506 & 10.36 & 10.2 & 0.79 & 0.22 \\
\hline 3009.25 & 47.645 & 2.601 & 4.7 & & & 0.09 \\
\hline 3009.50 & 47.645 & 2.601 & 4.7 & & & 0.78 \\
\hline 3009.75 & 57.064 & 2.611 & 4.11 & 9.8 & 0.25 & 0.16 \\
\hline 3010.00 & 69.252 & 2.652 & 1.67 & & & 0.01 \\
\hline 3010.25 & 84.765 & 2.652 & 1.67 & & & 0.01 \\
\hline 3010.50 & 87.535 & 2.652 & 1.67 & & & 0.01 \\
\hline 3010.75 & 87.535 & 2.648 & 1.9 & & & 0.01 \\
\hline 3011.00 & 86.981 & 2.644 & 2.14 & 9.9 & 0.11 & 0.01 \\
\hline 3011.25 & 86.981 & 2.644 & 2.14 & & & 0.01 \\
\hline 3011.50 & 86.427 & 2.593 & 5.18 & & & 0.23 \\
\hline 3011.75 & 81.44 & 2.571 & 6.49 & & & 0.11 \\
\hline 3012.00 & 76.454 & 2.546 & 7.98 & & & 0.13 \\
\hline 3012.25 & 58.726 & 2.527 & 9.11 & 8.8 & 0.26 & 0.05 \\
\hline 3012.50 & 52.632 & 2.506 & 10.36 & & & 0.12 \\
\hline 3012.75 & 43.213 & 2.505 & 10.42 & & & 0.23 \\
\hline 3013.00 & 43.213 & 2.505 & 10.42 & 10.4 & 0.38 & 0.22 \\
\hline 3013.25 & 43.767 & 2.505 & 10.42 & & & 0.23 \\
\hline
\end{tabular}




\begin{tabular}{|c|c|c|c|c|c|}
\hline \multirow[b]{2}{*}{ Depth } & \multicolumn{3}{|c|}{$\begin{array}{l}\text { Table A.6 } \\
\text { Horner \# } 11\end{array}$} & \multirow[b]{2}{*}{$\begin{array}{c}\text { Core } \\
\text { Porosity }\end{array}$} & \multirow[b]{2}{*}{$\begin{array}{l}\text { Core } \\
\text { Perm }\end{array}$} \\
\hline & GR & $\begin{array}{l}\text { Log } \\
\text { Density }\end{array}$ & $\begin{array}{l}\text { Log } \\
\text { Porosity }\end{array}$ & & \\
\hline 3084.25 & 34.711 & 2.503 & $10.50 \%$ & & \\
\hline 3084.50 & 35.262 & 2.498 & $10.80 \%$ & $13.30 \%$ & 2.1 \\
\hline 3084.75 & 35.262 & 2.484 & $11.70 \%$ & & \\
\hline 3085.00 & 35.262 & 2.473 & $12.30 \%$ & & \\
\hline 3085.25 & 36.915 & 2.479 & $12.00 \%$ & $16.20 \%$ & 18 \\
\hline 3085.50 & 38.567 & 2.494 & $11.10 \%$ & & \\
\hline 3085.75 & 41.873 & 2.501 & $10.70 \%$ & & \\
\hline 3086.00 & 42.975 & 2.501 & $10.70 \%$ & & \\
\hline 3086.25 & 45.179 & 2.509 & $10.20 \%$ & & \\
\hline 3086.50 & 46.832 & 2.528 & $9.00 \%$ & & \\
\hline 3086.75 & 46.832 & 2.536 & $8.60 \%$ & & \\
\hline 3087.00 & 53.444 & 2.539 & $8.40 \%$ & & \\
\hline 3087.25 & 53.994 & 2.558 & $7.30 \%$ & & \\
\hline 3087.50 & 56.198 & 2.557 & $7.30 \%$ & & \\
\hline 3087.75 & 53.444 & 2.547 & $7.90 \%$ & & \\
\hline 3088.00 & 51.24 & 2.497 & $10.90 \%$ & & \\
\hline 3088.25 & 47.383 & 2.497 & $10.90 \%$ & & \\
\hline 3088.50 & 47.383 & 2.476 & $12.10 \%$ & & \\
\hline 3088.75 & 45.73 & 2.349 & $19.70 \%$ & $18.90 \%$ & 20 \\
\hline 3089.00 & 39.118 & 2.325 & $21.10 \%$ & & \\
\hline 3089.25 & 34.16 & 2.315 & $21.70 \%$ & & \\
\hline 3089.50 & 33.058 & 2.314 & $21.80 \%$ & $21.50 \%$ & 52 \\
\hline 3089.75 & 30.303 & 2.319 & $21.50 \%$ & & \\
\hline 3090.00 & 29.201 & 2.33 & $20.80 \%$ & & \\
\hline 3090.25 & 29.201 & 2.33 & $20.80 \%$ & & \\
\hline 3090.50 & 29.201 & 2.33 & $20.80 \%$ & $21.80 \%$ & 80 \\
\hline 3090.75 & 31.956 & 2.326 & $21.10 \%$ & & \\
\hline 3091.00 & 31.956 & 2.323 & $21.30 \%$ & & \\
\hline 3091.25 & 39.118 & 2.315 & $21.70 \%$ & & \\
\hline 3091.50 & 41.873 & 2.311 & $22.00 \%$ & & \\
\hline 3091.75 & 42.975 & 2.309 & $22.10 \%$ & & \\
\hline 3092.00 & 47.383 & 2.309 & $22.10 \%$ & $25.40 \%$ & 238 \\
\hline 3092.25 & 53.994 & 2.326 & $21.10 \%$ & & \\
\hline 3092.50 & 53.994 & 2.34 & $20.20 \%$ & $24.90 \%$ & 192 \\
\hline 3092.75 & 56.198 & 2.359 & $19.10 \%$ & & \\
\hline 3093.00 & 60.055 & 2.373 & $18.30 \%$ & & \\
\hline 3093.25 & 62.81 & 2.503 & $10.50 \%$ & $12.70 \%$ & 3.6 \\
\hline 3093.50 & 70.523 & 2.546 & $8.00 \%$ & & \\
\hline
\end{tabular}




\section{APPENDIX B.}

Appendix B. presents cumulative flow capacity versus cumulative storage capacity graphs for each core well. The graphs and supporting tables use core measurements for porosity and permeability. Flow unit indicators are shown on each graph. 

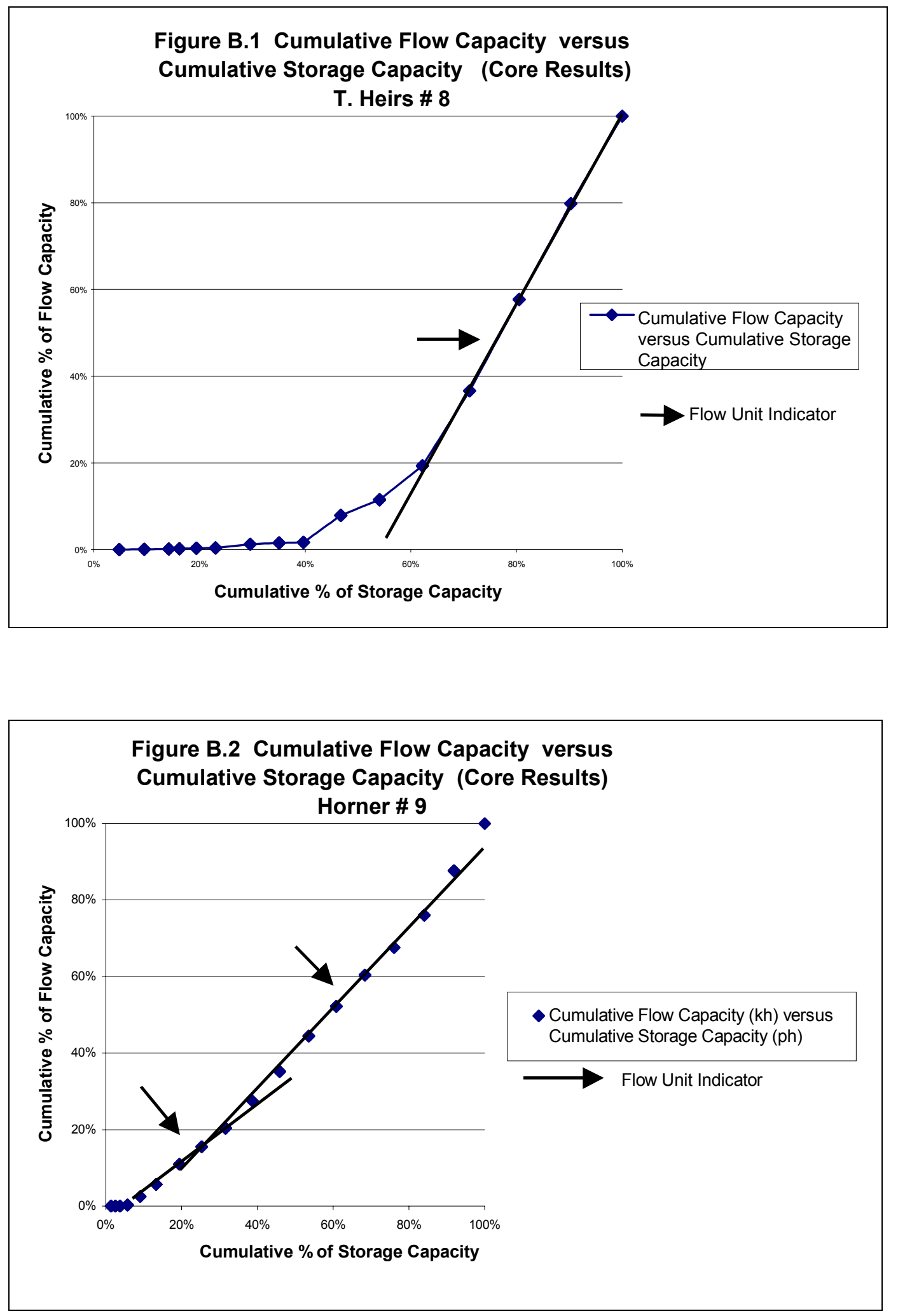

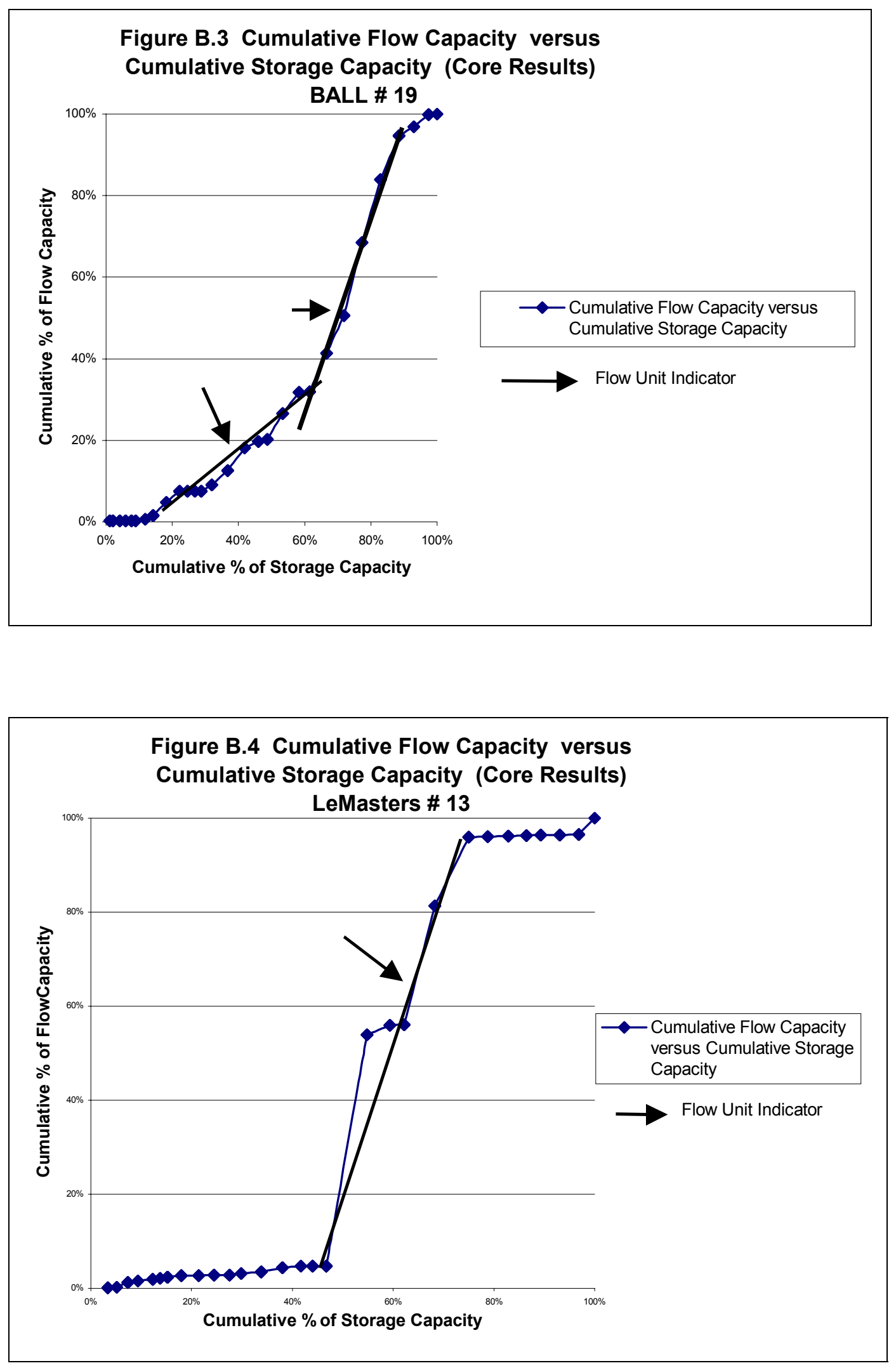

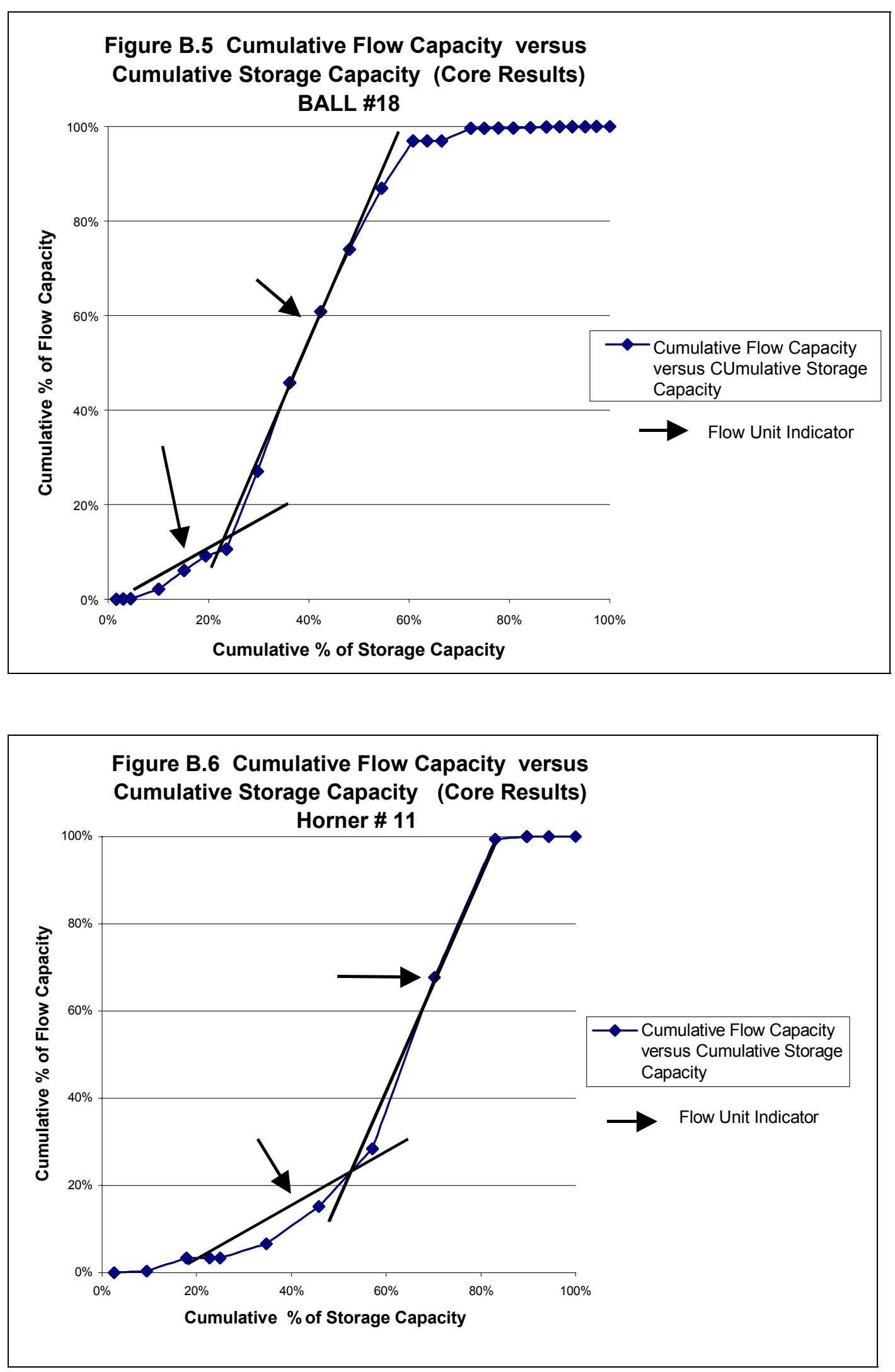


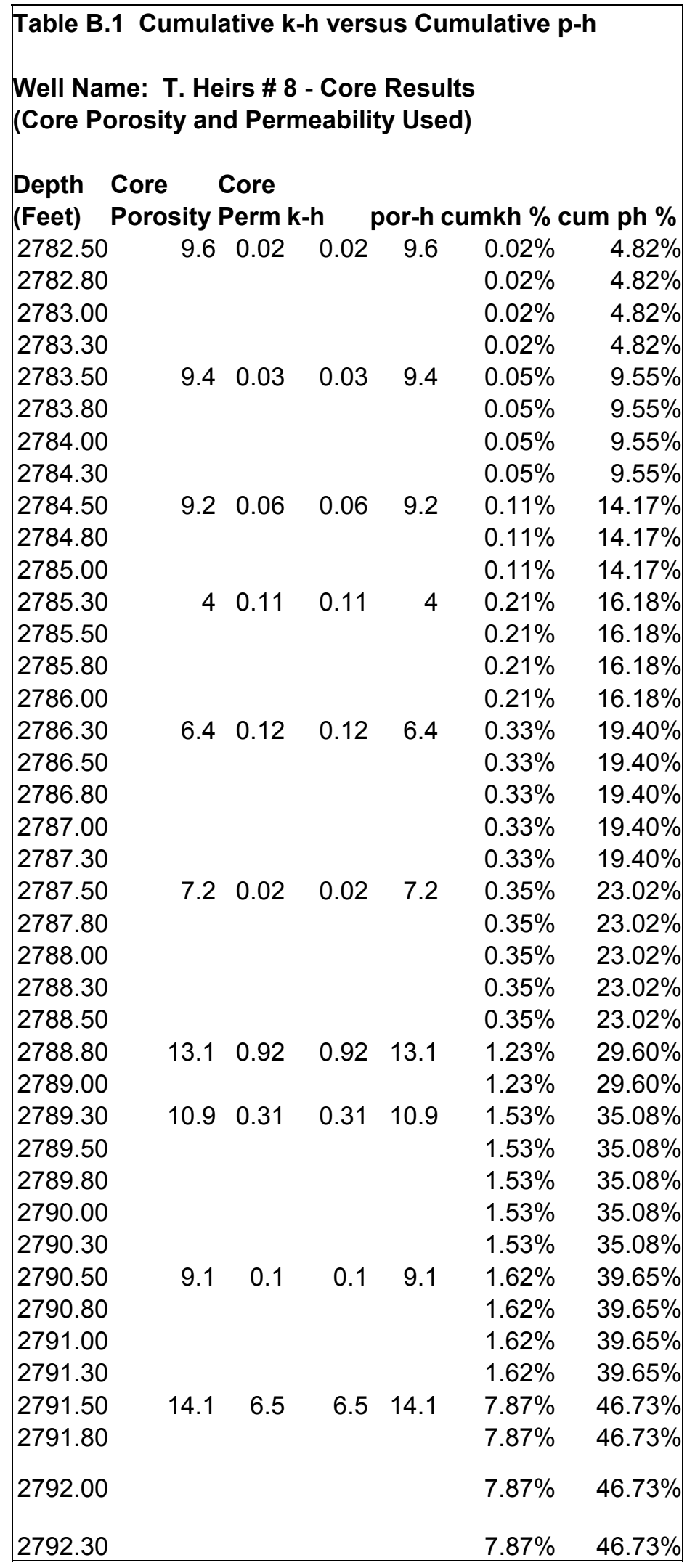




\begin{tabular}{|c|c|c|c|c|c|c|}
\hline \multicolumn{7}{|c|}{$\begin{array}{l}\text { Table B.1 Cumulative k-h versus Cumulative } \\
\text { Well Name: T. Heirs \# } 8 \text { - Core Results } \\
\text { (Core Porosity and Permeability Used) }\end{array}$} \\
\hline \multirow{2}{*}{$\begin{array}{l}\text { Depth } \\
\text { (Feet) } \\
2792.50\end{array}$} & $\begin{array}{l}\text { Core } \\
\text { Porosity }\end{array}$ & $\begin{array}{l}\text { Core } \\
\text { Perm k-h }\end{array}$ & \multicolumn{4}{|c|}{ por-h cumkh \% cum ph \% } \\
\hline & $\quad 14.6$ & 3.8 & 3.8 & 14.6 & $11.52 \%$ & $54.07 \%$ \\
\hline 2792.80 & & & & & $11.52 \%$ & $54.07 \%$ \\
\hline 2793.00 & & & & & $11.52 \%$ & $54.07 \%$ \\
\hline 2793.30 & & & & & $11.52 \%$ & $54.07 \%$ \\
\hline 2793.50 & & & & & $11.52 \%$ & $54.07 \%$ \\
\hline 2793.80 & 16.2 & 8.1 & 8.1 & 16.2 & $19.30 \%$ & $62.21 \%$ \\
\hline 2794.00 & & & & & $19.30 \%$ & $62.21 \%$ \\
\hline 2794.30 & & & & & $19.30 \%$ & $62.21 \%$ \\
\hline 2794.50 & & & & & $19.30 \%$ & $62.21 \%$ \\
\hline 2794.80 & 17.7 & 18 & 18 & 17.7 & $36.59 \%$ & $71.11 \%$ \\
\hline 2795.00 & & & & & $36.59 \%$ & $71.11 \%$ \\
\hline 2795.30 & 18.7 & 22 & 22 & 18.7 & $57.73 \%$ & $80.50 \%$ \\
\hline 2795.50 & & & & & $57.73 \%$ & $80.50 \%$ \\
\hline 2795.80 & & & & & $57.73 \%$ & $80.50 \%$ \\
\hline 2796.00 & 19.4 & 23 & 23 & 19.4 & $79.83 \%$ & $90.25 \%$ \\
\hline 2796.30 & & & & & $79.83 \%$ & $90.25 \%$ \\
\hline 2796.50 & 19.4 & 21 & 21 & 19.4 & $100.00 \%$ & $100.00 \%$ \\
\hline & & & 4.09 & 199 & & \\
\hline
\end{tabular}




\begin{tabular}{|c|c|c|c|c|c|c|}
\hline \multicolumn{7}{|c|}{$\begin{array}{l}\text { Table B.2 Cumulative k-h versus Cumu } \\
\text { Well Name: Horner \# } 9 \text { - Core Results } \\
\text { (Core Porosity and Permeability Used) }\end{array}$} \\
\hline $\begin{array}{l}\text { Depth } \\
\text { (Feet) }\end{array}$ & $\begin{array}{l}\text { Core } \\
\text { Porosity }\end{array}$ & $\begin{array}{l}\text { Core } \\
\text { Perm k-h }\end{array}$ & \multicolumn{4}{|c|}{ por-h cumkh \% cum ph \% } \\
\hline 2888.75 & 4.1 & 0.1 & 0.1 & 4.1 & $1.35 \%$ & $0.01 \%$ \\
\hline 2889.00 & & & & & $1.35 \%$ & $0.01 \%$ \\
\hline 2889.25 & & & & & $1.35 \%$ & $0.01 \%$ \\
\hline 2889.50 & & & & & $1.35 \%$ & $0.01 \%$ \\
\hline 2889.75 & 3.6 & 0.2 & 0.2 & 3.6 & $2.54 \%$ & $0.02 \%$ \\
\hline 2890.00 & & & & & $2.54 \%$ & $0.02 \%$ \\
\hline 2890.25 & & & & & $2.54 \%$ & $0.02 \%$ \\
\hline 2890.50 & & & & & $2.54 \%$ & $0.02 \%$ \\
\hline 2890.75 & 3.7 & 0.1 & 0.1 & 3.7 & $3.76 \%$ & $0.02 \%$ \\
\hline 2891.00 & & & & & $3.76 \%$ & $0.02 \%$ \\
\hline 2891.25 & & & & & $3.76 \%$ & $0.02 \%$ \\
\hline 2891.50 & & & & & $3.76 \%$ & $0.02 \%$ \\
\hline 2891.75 & 6.1 & 3.3 & 3.3 & 6.1 & $5.77 \%$ & $0.21 \%$ \\
\hline 2892.00 & & & & & $5.77 \%$ & $0.21 \%$ \\
\hline 2892.25 & & & & & $5.77 \%$ & $0.21 \%$ \\
\hline 2892.50 & & & & & $5.77 \%$ & $0.21 \%$ \\
\hline 2892.75 & & & & & $5.77 \%$ & $0.21 \%$ \\
\hline 2893.00 & 10 & 40 & 40 & 10 & $9.06 \%$ & $2.51 \%$ \\
\hline 2893.25 & & & & & $9.06 \%$ & $2.51 \%$ \\
\hline 2893.50 & 12.6 & 55 & 55 & 12.6 & $13.22 \%$ & $5.67 \%$ \\
\hline 2893.75 & & & & & $13.22 \%$ & $5.67 \%$ \\
\hline 2894.00 & & & & & $13.22 \%$ & $5.67 \%$ \\
\hline 2894.25 & & & & & $13.22 \%$ & $5.67 \%$ \\
\hline 2894.50 & & & & & $13.22 \%$ & $5.67 \%$ \\
\hline 2894.75 & & & & & $13.22 \%$ & $5.67 \%$ \\
\hline 2895.00 & 18.9 & 92 & 92 & 18.9 & $19.45 \%$ & $10.95 \%$ \\
\hline 2895.25 & & & & & $19.45 \%$ & $10.95 \%$ \\
\hline 2895.50 & & & & & $19.45 \%$ & $10.95 \%$ \\
\hline 2895.75 & 17.6 & 80 & 80 & 17.6 & $25.25 \%$ & $15.54 \%$ \\
\hline 2896.00 & & & & & $25.25 \%$ & $15.54 \%$ \\
\hline 2896.25 & & & & & $25.25 \%$ & $15.54 \%$ \\
\hline 2896.50 & 19.4 & 84 & 84 & 19.4 & $31.64 \%$ & $20.37 \%$ \\
\hline 2896.75 & & & & & $31.64 \%$ & $20.37 \%$ \\
\hline 2897.00 & & & & & $31.64 \%$ & $20.37 \%$ \\
\hline 2897.25 & & & & & $31.64 \%$ & $20.37 \%$ \\
\hline 2897.50 & & & & & $31.64 \%$ & $20.37 \%$ \\
\hline 2897.75 & & & & & $31.64 \%$ & $20.37 \%$ \\
\hline 2898.00 & & & & & $31.64 \%$ & $20.37 \%$ \\
\hline 2898.25 & 21.7 & 123 & 123 & 21.7 & $38.79 \%$ & $27.43 \%$ \\
\hline 2898.50 & & & & & $38.79 \%$ & $27.43 \%$ \\
\hline 2898.75 & 21.6 & 136 & 136 & 21.6 & $45.91 \%$ & $35.24 \%$ \\
\hline 2899.00 & & & & & $45.91 \%$ & $35.24 \%$ \\
\hline
\end{tabular}




\begin{tabular}{|c|c|c|c|c|c|c|}
\hline $\begin{array}{l}\text { Well Nar } \\
\text { (Core Pc }\end{array}$ & $\begin{array}{l}\text { me: Horn } \\
\text { orosity an }\end{array}$ & $\begin{array}{l}\text { ler \# } 9 \\
\text { Id Perm }\end{array}$ & $\begin{array}{l}\text { ore R } \\
\text { abilit }\end{array}$ & $\begin{array}{l}\text { Result } \\
\text { y Usec }\end{array}$ & & \\
\hline $\begin{array}{l}\text { Depth } \\
\text { (Feet) }\end{array}$ & $\begin{array}{l}\text { Core } \\
\text { Porosity }\end{array}$ & $\begin{array}{l}\text { Core } \\
\text { Perm k }\end{array}$ & & por-h & :umkh \% & um ph \% \\
\hline 2899.25 & & & & & $45.91 \%$ & $35.24 \%$ \\
\hline 2899.50 & & & & & $45.91 \%$ & $35.24 \%$ \\
\hline 2899.75 & & & & & $45.91 \%$ & $35.24 \%$ \\
\hline 2900.00 & 23.2 & 160 & 160 & 23.2 & $53.56 \%$ & $44.42 \%$ \\
\hline 2900.25 & & & & & $53.56 \%$ & $44.42 \%$ \\
\hline 2900.50 & & & & & $53.56 \%$ & $44.42 \%$ \\
\hline 2900.75 & & & & & $53.56 \%$ & $44.42 \%$ \\
\hline 2901.00 & 22.1 & 135 & 135 & 22.1 & $60.84 \%$ & $52.17 \%$ \\
\hline 2901.25 & & & & & $60.84 \%$ & $52.17 \%$ \\
\hline 2901.50 & & & & & $60.84 \%$ & $52.17 \%$ \\
\hline 2901.75 & & & & & $60.84 \%$ & $52.17 \%$ \\
\hline 2902.00 & 23.1 & 144 & 144 & 23.1 & $68.46 \%$ & $60.44 \%$ \\
\hline 2902.25 & & & & & $68.46 \%$ & $60.44 \%$ \\
\hline 2902.50 & & & & & $68.46 \%$ & $60.44 \%$ \\
\hline 2902.75 & & & & & $68.46 \%$ & $60.44 \%$ \\
\hline 2903.00 & 23.2 & 124 & 124 & 23.2 & $76.10 \%$ & $67.56 \%$ \\
\hline 2903.25 & & & & & $76.10 \%$ & $67.56 \%$ \\
\hline 2903.50 & 24.1 & 148 & 148 & 24.1 & $84.05 \%$ & $76.06 \%$ \\
\hline 2903.75 & & & & & $84.05 \%$ & $76.06 \%$ \\
\hline 2904.00 & & & & & $84.05 \%$ & $76.06 \%$ \\
\hline 2904.25 & & & & & $84.05 \%$ & $76.06 \%$ \\
\hline 2904.50 & 24 & 203 & 203 & 24 & $91.96 \%$ & $87.71 \%$ \\
\hline 2904.75 & & & & & $91.96 \%$ & $87.71 \%$ \\
\hline 2905.00 & & & & & $91.96 \%$ & $87.71 \%$ \\
\hline 2905.25 & & & & & $91.96 \%$ & $87.71 \%$ \\
\hline 2905.50 & 24.4 & 214 & 214 & 24.4 & $100.00 \%$ & $100.00 \%$ \\
\hline & & & 41.7 & 303 & & \\
\hline
\end{tabular}




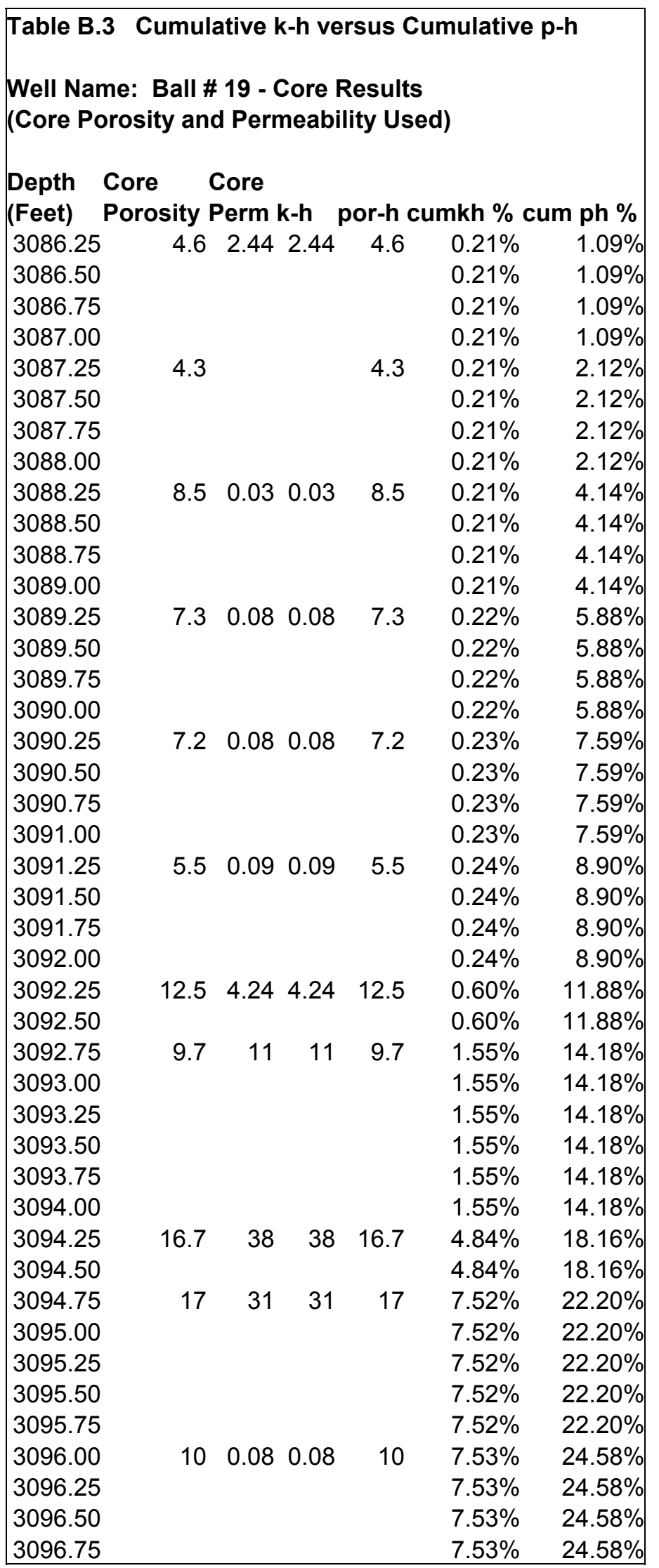




\begin{tabular}{|c|c|c|c|c|c|c|}
\hline \multicolumn{7}{|c|}{$\begin{array}{l}\text { Table B.3 Cumulative k-h versus Cumu } \\
\text { Well Name: Ball \# } 19 \text { - Core Results } \\
\text { (Core Porosity and Permeability Used) }\end{array}$} \\
\hline \multirow{2}{*}{$\begin{array}{l}\text { Depth } \\
\text { (Feet) } \\
3097.00\end{array}$} & $\begin{array}{l}\text { Core } \\
\text { Porosity }\end{array}$ & \multicolumn{2}{|c|}{$\begin{array}{l}\text { Core } \\
\text { Perm k-h }\end{array}$} & \multicolumn{3}{|c|}{ por-h cumkh \% cum ph $\%$} \\
\hline & & & & & $7.53 \%$ & $24.58 \%$ \\
\hline 3097.25 & 9.7 & 0.27 & 0.27 & 9.7 & $7.55 \%$ & $26.89 \%$ \\
\hline 3097.50 & & & & & $7.55 \%$ & $26.89 \%$ \\
\hline 3097.75 & & & & & $7.55 \%$ & $26.89 \%$ \\
\hline 3098.00 & 8.1 & 0.16 & 0.16 & 8.1 & $7.57 \%$ & $28.82 \%$ \\
\hline 3098.25 & & & & & $7.57 \%$ & $28.82 \%$ \\
\hline 3098.50 & & & & & $7.57 \%$ & $28.82 \%$ \\
\hline 3098.75 & & & & & $7.57 \%$ & $28.82 \%$ \\
\hline 3099.00 & & & & & 7.5 & $28.82 \%$ \\
\hline 3099.25 & 13.3 & 17 & 17 & 13.3 & 9.0 & $31.98 \%$ \\
\hline 3099.50 & & & & & & $31.98 \%$ \\
\hline 3099.75 & & & & & 9.04 & $31.98 \%$ \\
\hline 3100.00 & 20.3 & 41 & 41 & 20.3 & $12.59 \%$ & $36.82 \%$ \\
\hline 3100.25 & & & & & 12.5 & $36.82 \%$ \\
\hline 3100.50 & & & & & $12.59 \%$ & $36.82 \%$ \\
\hline 3100.75 & & & & & & $36.82 \%$ \\
\hline 3101.00 & & & & & 12.5 & $36.82 \%$ \\
\hline 3101.25 & 21.4 & 65 & 65 & 21.4 & 18.21 & $41.91 \%$ \\
\hline 3101.50 & & & & & 18.2 & $41.91 \%$ \\
\hline 3101.75 & & & & & 18.2 & $41.91 \%$ \\
\hline 3102.00 & 17.4 & 17 & 17 & 17.4 & & $05 \%$ \\
\hline 3102.25 & & & & & $19.68 \%$ & $46.05 \%$ \\
\hline 3102.50 & & & & & 19.6 & $46.05 \%$ \\
\hline 3102.75 & & & & & 19.6 & $46.05 \%$ \\
\hline 3103.00 & 11 & 6.79 & 6.79 & 11 & $20.27 \%$ & $48.67 \%$ \\
\hline 3103.25 & & & & & $20.27 \%$ & $48.67 \%$ \\
\hline 3103.50 & & & & & 20.2 & $48.67 \%$ \\
\hline 3103.75 & & & & & $20.27 \%$ & $48.67 \%$ \\
\hline 3104.00 & 19.7 & 73 & 73 & 19.7 & 26.59 & $53.36 \%$ \\
\hline 3104.25 & & & & & $26.59 \%$ & $53.36 \%$ \\
\hline 3104.50 & & & & & 26.59 & $53.36 \%$ \\
\hline 3104.75 & & & & & 26. & $53.36 \%$ \\
\hline 3105.00 & 20.8 & 60 & 60 & 20.8 & $31.78 \%$ & $58.31 \%$ \\
\hline 3105.25 & & & & & $31.78 \%$ & $58.31 \%$ \\
\hline 3105.50 & & & & & $31.78 \%$ & $58.31 \%$ \\
\hline 3105.75 & & & & & $31.78 \%$ & $58.31 \%$ \\
\hline 3106.00 & 13.4 & 1.16 & 1.16 & 13.4 & $31.88 \%$ & $61.49 \%$ \\
\hline 3106.25 & & & & & $31.88 \%$ & $61.49 \%$ \\
\hline 3106.50 & & & & & $31.88 \%$ & $61.49 \%$ \\
\hline 3106.75 & & & & & $31.88 \%$ & $61.49 \%$ \\
\hline 3107.00 & & & & & $31.88 \%$ & $61.49 \%$ \\
\hline 3107.25 & 21.7 & 110 & 110 & 21.7 & $41.39 \%$ & $66.66 \%$ \\
\hline 3107.50 & & & & & $41.39 \%$ & $66.66 \%$ \\
\hline
\end{tabular}




\begin{tabular}{|c|c|c|c|c|c|c|}
\hline \multicolumn{7}{|c|}{$\begin{array}{l}\text { Table B.3 Cumulative k-h versus Cumul } \\
\text { Well Name: Ball \# } 19 \text { - Core Results } \\
\text { (Core Porosity and Permeability Used) }\end{array}$} \\
\hline \multirow{2}{*}{$\begin{array}{l}\text { Depth } \\
\text { (Feet) } \\
3107.75\end{array}$} & $\begin{array}{l}\text { Core } \\
\text { Porosity } \mathrm{P}\end{array}$ & \multicolumn{2}{|c|}{$\begin{array}{l}\text { Core } \\
\text { Perm k-h }\end{array}$} & \multicolumn{3}{|c|}{ por-h cumkh \% cum ph $\%$} \\
\hline & & & & & $41.39 \%$ & $66.66 \%$ \\
\hline 3108.00 & 22 & 106 & 106 & 22 & $50.57 \%$ & $71.89 \%$ \\
\hline 3108.25 & & & & & $50.57 \%$ & $71.89 \%$ \\
\hline 3108.50 & & & & & $50.57 \%$ & $71.89 \%$ \\
\hline 3108.75 & 22.9 & 207 & 207 & 22.9 & $68.48 \%$ & $77.34 \%$ \\
\hline 3109.00 & & & & & $68.48 \%$ & $77.34 \%$ \\
\hline 3109.25 & & & & & $68.48 \%$ & $77.34 \%$ \\
\hline 3109.50 & 23.2 & 179 & 179 & 23.2 & $83.96 \%$ & $82.87 \%$ \\
\hline 3109.75 & & & & & $83.96 \%$ & $82.87 \%$ \\
\hline 3110.00 & & & & & $83.96 \%$ & $82.87 \%$ \\
\hline 3110.25 & & & & & $83.96 \%$ & $82.87 \%$ \\
\hline 3110.50 & & & & & $83.96 \%$ & $82.87 \%$ \\
\hline 3110.75 & 24 & 124 & 124 & 24 & $94.69 \%$ & $88.58 \%$ \\
\hline 3111.00 & & & & & $94.69 \%$ & $88.58 \%$ \\
\hline 3111.25 & & & & & $94.69 \%$ & $88.58 \%$ \\
\hline 3111.50 & & & & & 94.6 & $88.58 \%$ \\
\hline 3111.75 & & & & & 94.6 & $88.58 \%$ \\
\hline 3112.00 & 18.4 & 26 & 26 & 18.4 & $96.94 \%$ & $92.96 \%$ \\
\hline 3112.25 & & & & & $96.94 \%$ & $92.96 \%$ \\
\hline 3112.50 & 18.9 & 34 & 34 & 18.9 & $99.88 \%$ & $97.45 \%$ \\
\hline 3112.75 & & & & & $99.88 \%$ & $97.45 \%$ \\
\hline 3113.00 & & & & & 99.8 & $97.45 \%$ \\
\hline 3113.25 & & & & & $99.88 \%$ & $97.45 \%$ \\
\hline 3113.50 & & & & & $99.88 \%$ & $97.45 \%$ \\
\hline 3113.75 & 10.7 & 1.33 & 1.33 & 10.7 & $100.00 \%$ & $100.00 \%$ \\
\hline 3114.00 & & & & & $100.00 \%$ & $100.00 \%$ \\
\hline 3114.25 & & & & & $100.00 \%$ & $100.00 \%$ \\
\hline 3114.50 & & & & & 100.0 & $100.00 \%$ \\
\hline 3114.75 & & & & & $100.00 \%$ & $100.00 \%$ \\
\hline 3115.00 & & & & & $100.00 \%$ & $100.00 \%$ \\
\hline 3115.25 & & & & & $100.00 \%$ & $100.00 \%$ \\
\hline 3115.50 & & & & & $100.00 \%$ & $100.00 \%$ \\
\hline 3115.75 & & & & & 100.0 & $100.00 \%$ \\
\hline 3116.00 & & & & & $100.00 \%$ & $100.00 \%$ \\
\hline 3116.25 & & & & & $100.00 \%$ & $100.00 \%$ \\
\hline 3116.50 & & & & & $100.00 \%$ & $100.00 \%$ \\
\hline 3116.75 & & & & & $100.00 \%$ & $100.00 \%$ \\
\hline 3117.00 & & & & & $100.00 \%$ & $100.00 \%$ \\
\hline 3117.25 & & & & & $100.00 \%$ & $100.00 \%$ \\
\hline 3117.50 & & & & & $100.00 \%$ & $100.00 \%$ \\
\hline 3117.75 & & & & & $100.00 \%$ & $100.00 \%$ \\
\hline 3118.00 & & & & & $100.00 \%$ & $100.00 \%$ \\
\hline 3118.25 & & & & & $100.00 \%$ & $100.00 \%$ \\
\hline
\end{tabular}




\begin{tabular}{|l|ll|}
\hline Table B.3 & Cumulative k-h versus Cumulative p-h \\
Well Name: Ball \# 19 - Core Results \\
(Core Porosity and Permeability Used) \\
Depth Core Core \\
(Feet) Porosity Perm k-h por-h cumkh \% cum ph \% \\
3118.50 & $100.00 \%$ & $100.00 \%$ \\
3118.75 & $100.00 \%$ & $100.00 \%$ \\
3119.00 & $100.00 \%$ & $100.00 \%$ \\
3119.25 & $100.00 \%$ & $100.00 \%$ \\
3119.50 & $100.00 \%$ & $100.00 \%$ \\
3119.75 & $100.00 \%$ & $100.00 \%$ \\
3120.00 & $100.00 \%$ & $100.00 \%$ \\
3120.25 & $100.00 \%$ & $100.00 \%$ \\
3120.50 & $100.00 \%$ & $100.00 \%$ \\
3120.75 & $100.00 \%$ & $100.00 \%$ \\
3121.00 & $100.00 \%$ & \\
\hline \multicolumn{4}{l}{} \\
\hline
\end{tabular}




\begin{tabular}{|c|c|c|c|c|c|}
\hline \multicolumn{6}{|c|}{$\begin{array}{l}\text { Well Name: LeMasters \# } 13 \text { - Core Results } \\
\text { (Core Porosity and Permeability Used) }\end{array}$} \\
\hline $\begin{array}{l}\text { Depth } \\
\text { (Feet) }\end{array}$ & $\begin{array}{l}\text { Core } \\
\text { Porosity }\end{array}$ & $\begin{array}{l}\text { Core } \\
\text { Perm k-h }\end{array}$ & or-h c & Imkh \% & um ph \% \\
\hline 3030.80 & 8.2 & 0.050 .1 & 8.2 & $0.07 \%$ & $3.39 \%$ \\
\hline 3031.00 & & & & $0.07 \%$ & $3.39 \%$ \\
\hline 3031.30 & & & & $0.07 \%$ & $3.39 \%$ \\
\hline 3031.50 & & & & $0.07 \%$ & $3.39 \%$ \\
\hline 3031.80 & & & & $0.07 \%$ & $3.39 \%$ \\
\hline 3032.00 & 4.3 & 0.150 .2 & 4.3 & $0.27 \%$ & $5.17 \%$ \\
\hline 3032.30 & & & & $0.27 \%$ & $5.17 \%$ \\
\hline 3032.50 & 5.3 & 0.720 .7 & 5.3 & $1.22 \%$ & $7.36 \%$ \\
\hline 3032.80 & & & & $1.22 \%$ & $7.36 \%$ \\
\hline 3033.00 & & & & $1.22 \%$ & $7.36 \%$ \\
\hline 3033.30 & & & & 1.2 & $7.36 \%$ \\
\hline 3033.50 & & & & $1.22 \%$ & $7.36 \%$ \\
\hline 3033.80 & & & & $1.22 \%$ & $7.36 \%$ \\
\hline 3034.00 & 4.9 & 0.280 .3 & 4.9 & $1.60 \%$ & $9.39 \%$ \\
\hline 3034.30 & & & & $1.60 \%$ & $9.39 \%$ \\
\hline 3034.50 & 7.1 & 0.270 .3 & 7.1 & $1.96 \%$ & $12.33 \%$ \\
\hline 3034.80 & & & & 1.9 & $12.33 \%$ \\
\hline 3035.00 & & & & $1.96 \%$ & $12.33 \%$ \\
\hline 3035.30 & & & & $1.96 \%$ & $12.33 \%$ \\
\hline 3035.50 & & & & $1.96 \%$ & $12.33 \%$ \\
\hline 3035.80 & & & & $1.96 \%$ & $12.33 \%$ \\
\hline 3036.00 & 3.4 & 0.120 .1 & 3.4 & $2.11 \%$ & $13.74 \%$ \\
\hline 3036.30 & & & & $2.11 \%$ & $13.74 \%$ \\
\hline 3036.50 & 3.5 & 0.220 .2 & 3.5 & $2.41 \%$ & $15.18 \%$ \\
\hline 3036.80 & & & & $2.41 \%$ & $15.18 \%$ \\
\hline 3037.00 & & & & $2.41 \%$ & $15.18 \%$ \\
\hline 3037.30 & & & & 2.41 & $15.18 \%$ \\
\hline 3037.50 & & & & $2.41 \%$ & $15.18 \%$ \\
\hline 3037.80 & & & & $2.41 \%$ & $15.18 \%$ \\
\hline 3038.00 & & & & $2.41 \%$ & $15.18 \%$ \\
\hline 3038.30 & & & & $2.41 \%$ & $15.18 \%$ \\
\hline 3038.50 & 6.6 & 0.180 .2 & 6.6 & $2.65 \%$ & $17.91 \%$ \\
\hline 3038.80 & & & & $2.65 \%$ & $17.91 \%$ \\
\hline 3039.00 & & & & $2.65 \%$ & $17.91 \%$ \\
\hline 3039.30 & & & & $2.65 \%$ & $17.91 \%$ \\
\hline 3039.50 & & & & $2.65 \%$ & $17.91 \%$ \\
\hline 3039.80 & 8.4 & 0.060 .1 & 8.4 & $2.73 \%$ & $21.39 \%$ \\
\hline 3040.00 & & & & $2.73 \%$ & $21.39 \%$ \\
\hline 3040.30 & & & & $2.73 \%$ & $21.39 \%$ \\
\hline 3040.50 & & & & $2.73 \%$ & $21.39 \%$ \\
\hline 3040.80 & 7.4 & 0.060 .1 & 7.4 & $2.81 \%$ & $24.45 \%$ \\
\hline 3041.00 & & & & $2.81 \%$ & $24.45 \%$ \\
\hline 3041.30 & & & & $2.81 \%$ & $24.45 \%$ \\
\hline
\end{tabular}




\begin{tabular}{|c|c|c|c|c|c|}
\hline \multicolumn{6}{|c|}{$\begin{array}{l}\text { Well Name: LeMasters \# } 13 \text { - Core Results } \\
\text { (Core Porosity and Permeability Used) }\end{array}$} \\
\hline $\begin{array}{l}\text { Depth } \\
\text { (Feet) }\end{array}$ & $\begin{array}{l}\text { Core } \\
\text { Porosity }\end{array}$ & $\begin{array}{l}\text { Core } \\
\text { Perm k-h }\end{array}$ & & umkh $\%$ & Im ph \% \\
\hline 3041.50 & & & & $2.81 \%$ & $24.45 \%$ \\
\hline 3041.80 & 7.4 & 0.04 & 7.4 & $2.86 \%$ & $27.51 \%$ \\
\hline 3042.00 & & & & $2.86 \%$ & $27.51 \%$ \\
\hline 3042.30 & & & & $2.86 \%$ & $27.51 \%$ \\
\hline 3042.50 & 5.7 & 0.190 .2 & 5.7 & 3.1 & $29.87 \%$ \\
\hline 3042.80 & & & & & $29.87 \%$ \\
\hline 3043.00 & 9.5 & 0.290 .3 & 9.5 & 3.5 & $3.80 \%$ \\
\hline 3043.30 & & & & 3.50 & $33.80 \%$ \\
\hline 3043.50 & & & & 3.5 & $33.80 \%$ \\
\hline 3043.80 & & & & & $.80 \%$ \\
\hline 3044.00 & & & & & $.80 \%$ \\
\hline 3044.30 & & & & & $30 \%$ \\
\hline 3044.50 & & & & & $80 \%$ \\
\hline 3044.80 & & & & 3.5 & $33.80 \%$ \\
\hline 3045.00 & 10.2 & 0.670 .7 & 10 & 4.35 & $38.02 \%$ \\
\hline 3045.30 & & & & 4.3 & $38.02 \%$ \\
\hline 3045.5 & & & & & $2 \%$ \\
\hline 3045.80 & & & & & $8.02 \%$ \\
\hline 3046.00 & 8.9 & 0.210 .2 & 8.9 & 4.6 & $41.70 \%$ \\
\hline 3046.30 & & & & 4.67 & $41.70 \%$ \\
\hline 3046.50 & 5.7 & & 5.7 & 4.67 & $44.06 \%$ \\
\hline 3046.80 & & & & & $6 \%$ \\
\hline 3047.00 & & & & 4.6 & $44.06 \%$ \\
\hline 3047.30 & & & & $4.67 \%$ & $44.06 \%$ \\
\hline 3047.50 & 6.6 & 0.04 & 6.6 & $4.72 \%$ & $46.79 \%$ \\
\hline 3047.80 & & & & 4.72 & $46.79 \%$ \\
\hline 3048.00 & & & & 4.72 & $46.79 \%$ \\
\hline 3048 & & & & 4.7 & $46.79 \%$ \\
\hline 3048.50 & & & & $4.72 \%$ & $46.79 \%$ \\
\hline 3048.80 & & & & $4.72 \%$ & $46.79 \%$ \\
\hline 3049.00 & 19.4 & 3737 & 19 & $53.93 \%$ & $54.82 \%$ \\
\hline 3049.30 & & & & 53.9 & $54.82 \%$ \\
\hline 3049.50 & & & & & $4.82 \%$ \\
\hline 3049.80 & & & & $53.93 \%$ & $54.82 \%$ \\
\hline 3050.00 & 11 & 1.511 .5 & 11 & $55.94 \%$ & $59.37 \%$ \\
\hline 3050.30 & & & & 55.94 & $59.37 \%$ \\
\hline 3050.50 & & & & 55.94 & $59.37 \%$ \\
\hline 3050.80 & & & & & $59.37 \%$ \\
\hline 3051.00 & 6.9 & 0.110 .1 & 6.9 & $56.08 \%$ & $62.23 \%$ \\
\hline 3051.30 & & & & $56.08 \%$ & $62.23 \%$ \\
\hline 3051.50 & & & & $56.08 \%$ & $62.23 \%$ \\
\hline 3051.80 & & & & $56.08 \%$ & $62.23 \%$ \\
\hline 3052.00 & 14.5 & 1919 & 15 & $81.35 \%$ & $68.23 \%$ \\
\hline
\end{tabular}




\begin{tabular}{|c|c|c|c|c|c|c|}
\hline \multicolumn{7}{|c|}{$\begin{array}{l}\text { Table B.4 Cumulative k-h versus Cumulati } \\
\text { Well Name: LeMasters \# } 13 \text { - Core Results } \\
\text { (Core Porosity and Permeability Used) }\end{array}$} \\
\hline \multicolumn{7}{|c|}{$\begin{array}{ll}\text { Depth } & \text { Core Core } \\
\text { (Feet) } & \text { Porosity Perm k-h por-h cumkh \% cum ph \% }\end{array}$} \\
\hline 3052.30 & & & & & $81.35 \%$ & $68.23 \%$ \\
\hline 3052.50 & & & & & $81.35 \%$ & $68.23 \%$ \\
\hline 3052.80 & & & & & 81.3 & $68.23 \%$ \\
\hline 3053.00 & 16.3 & 111 & & 16 & $95 . c$ & $74.97 \%$ \\
\hline 3053.30 & & & & & 95. & $74.97 \%$ \\
\hline 3053.50 & & & & & & $.97 \%$ \\
\hline 3053.80 & & & & & & $.97 \%$ \\
\hline 3054.00 & 9.2 & 0.070 & & 9.2 & 96.0 & $78.78 \%$ \\
\hline 3054.30 & & & & & 96. & $78.78 \%$ \\
\hline 3054.50 & & & & & 96. & $8.78 \%$ \\
\hline 3054.80 & & & & & & $8.78 \%$ \\
\hline 3055.00 & 9.8 & 0.10 . & & 9.8 & 96.2 & $82.83 \%$ \\
\hline 3055.30 & & & & & 96.2 & $82.83 \%$ \\
\hline 3055.50 & & & & & 96. & $82.83 \%$ \\
\hline 3055.80 & & & & & 96. & $82.83 \%$ \\
\hline 3056.00 & 8.7 & 0.090 & & 8.7 & & $43 \%$ \\
\hline 3056.30 & & & & & & $86.43 \%$ \\
\hline 3056.50 & & & & & 96.3 & $86.43 \%$ \\
\hline 3056.80 & & & & & & $86.43 \%$ \\
\hline 3057.00 & 6.8 & 0.02 & 0 & 6.8 & 96.36 & $89.24 \%$ \\
\hline 3057.30 & & & & & & $89.24 \%$ \\
\hline 3057. & & & & & & $89.24 \%$ \\
\hline 3057.80 & & & & & $96.36 \%$ & $89.24 \%$ \\
\hline 3058.00 & 9.3 & 0.04 & 0 & 9.3 & $96.41 \%$ & $93.09 \%$ \\
\hline 3058.30 & & & & & $96.41 \%$ & $93.09 \%$ \\
\hline 3058.50 & & & & & $96.41 \%$ & $93.09 \%$ \\
\hline 3058.80 & & & & & 96. & $93.09 \%$ \\
\hline 3059.00 & 9.1 & 0.04 & 0 & 9.1 & $96.46 \%$ & $96.86 \%$ \\
\hline 3059.30 & & & & & $96.46 \%$ & $96.86 \%$ \\
\hline 3059.50 & & & & & $96.46 \%$ & $96.86 \%$ \\
\hline 3059.80 & & & & & $96.46 \%$ & $96.86 \%$ \\
\hline 3060.00 & 7.6 & $\begin{array}{l}2.662 \\
242\end{array}$ & & $\begin{array}{r}7.6 \\
75\end{array}$ & $100.00 \%$ & $100.00 \%$ \\
\hline
\end{tabular}




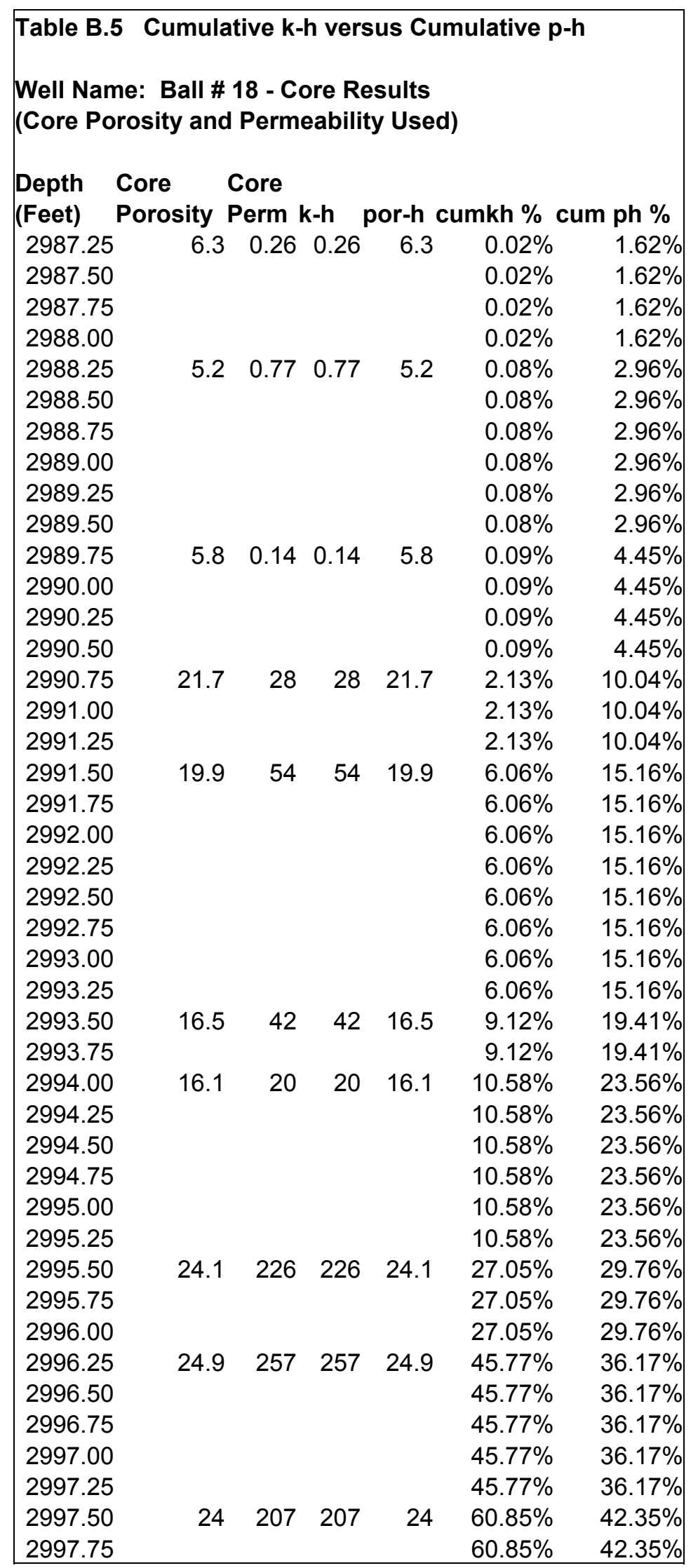




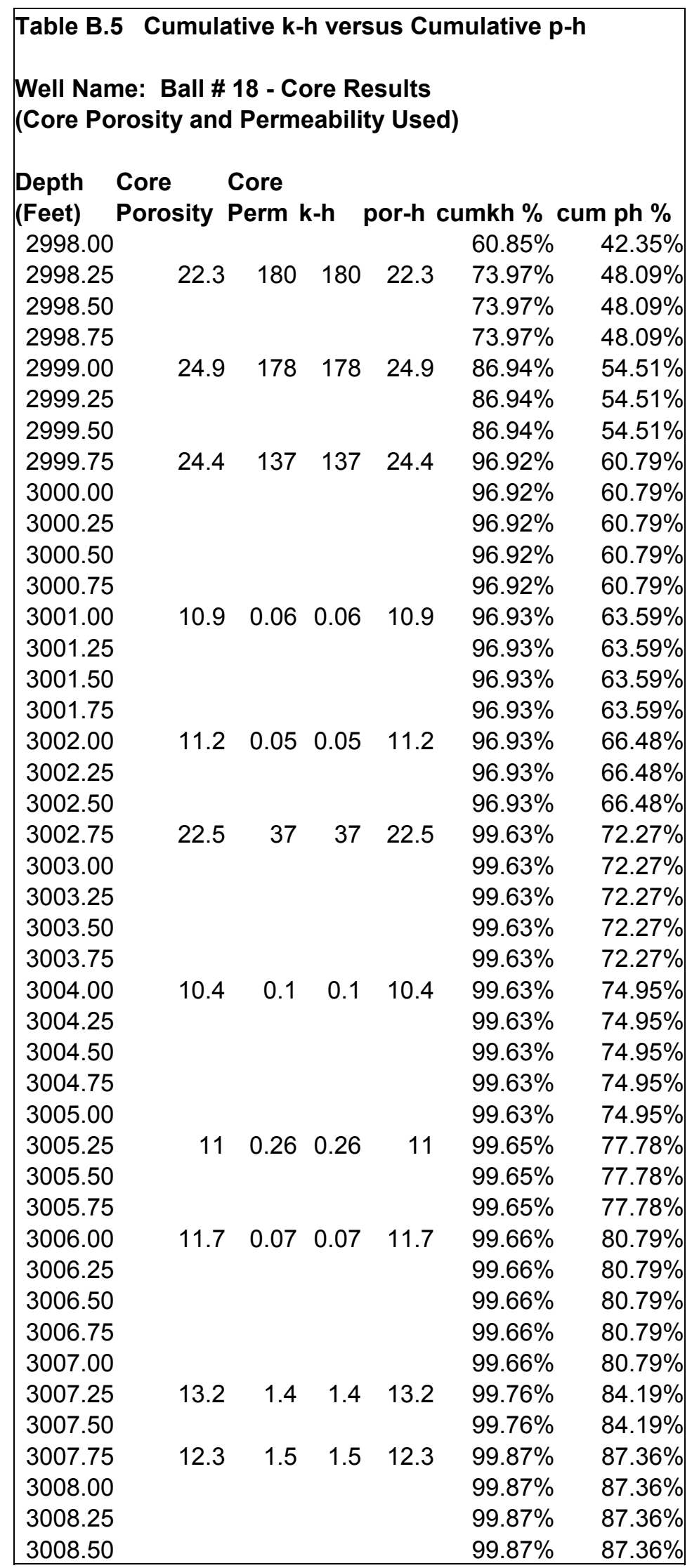




\begin{tabular}{|c|c|c|c|c|c|c|}
\hline \multicolumn{7}{|c|}{$\begin{array}{l}\text { Table B.5 Cumulative k-h versus Cumulative p-h } \\
\text { Well Name: Ball \# } 18 \text { - Core Results } \\
\text { (Core Porosity and Permeability Used) }\end{array}$} \\
\hline $\begin{array}{l}\text { Depth } \\
\text { (Feet) }\end{array}$ & $\begin{array}{l}\text { Core } \\
\text { Porosity }\end{array}$ & $\begin{array}{l}\text { Core } \\
\text { Perm }\end{array}$ & & por-h c & umkh \% & cum ph \% \\
\hline 3008.75 & & & & & $99.87 \%$ & $6 \quad 87.36 \%$ \\
\hline 3009.00 & 10.2 & 0.79 & 0.79 & 10.2 & $99.93 \%$ & $89.98 \%$ \\
\hline 3009.25 & & & & & 99. & $89.98 \%$ \\
\hline 3009 & & & & & 99. & $89.98 \%$ \\
\hline 3009.7 & 9.8 & 0.25 & 0.25 & 9.8 & & \\
\hline 3010.00 & & & & & & $51 \%$ \\
\hline 3010.2 & & & & & 99. & $92.51 \%$ \\
\hline 3010.5 & & & & & & $92.51 \%$ \\
\hline 3010.7 & & & & & & $92.51 \%$ \\
\hline 3011. & 9.9 & 0.11 & 0.11 & 9.9 & & $95.06 \%$ \\
\hline 3011.2 & & & & & & $95.06 \%$ \\
\hline 3011.50 & & & & & 99.9 & $95.06 \%$ \\
\hline 3011.75 & & & & & & $95.06 \%$ \\
\hline 3012.00 & & & & & 99.9 & $95.06 \%$ \\
\hline 3012.25 & 8.8 & 0.26 & 0.26 & 8.8 & $99.97 \%$ & $97.32 \%$ \\
\hline 3012.50 & & & & & $99.97 \%$ & $97.32 \%$ \\
\hline 3012.75 & & & & & $99.97 \%$ & $97.32 \%$ \\
\hline 3013.00 & 10.4 & 0.38 & $\begin{array}{r}0.38 \\
1372\end{array}$ & $\begin{array}{r}10.4 \\
388\end{array}$ & $100.00 \%$ & $100.00 \%$ \\
\hline
\end{tabular}




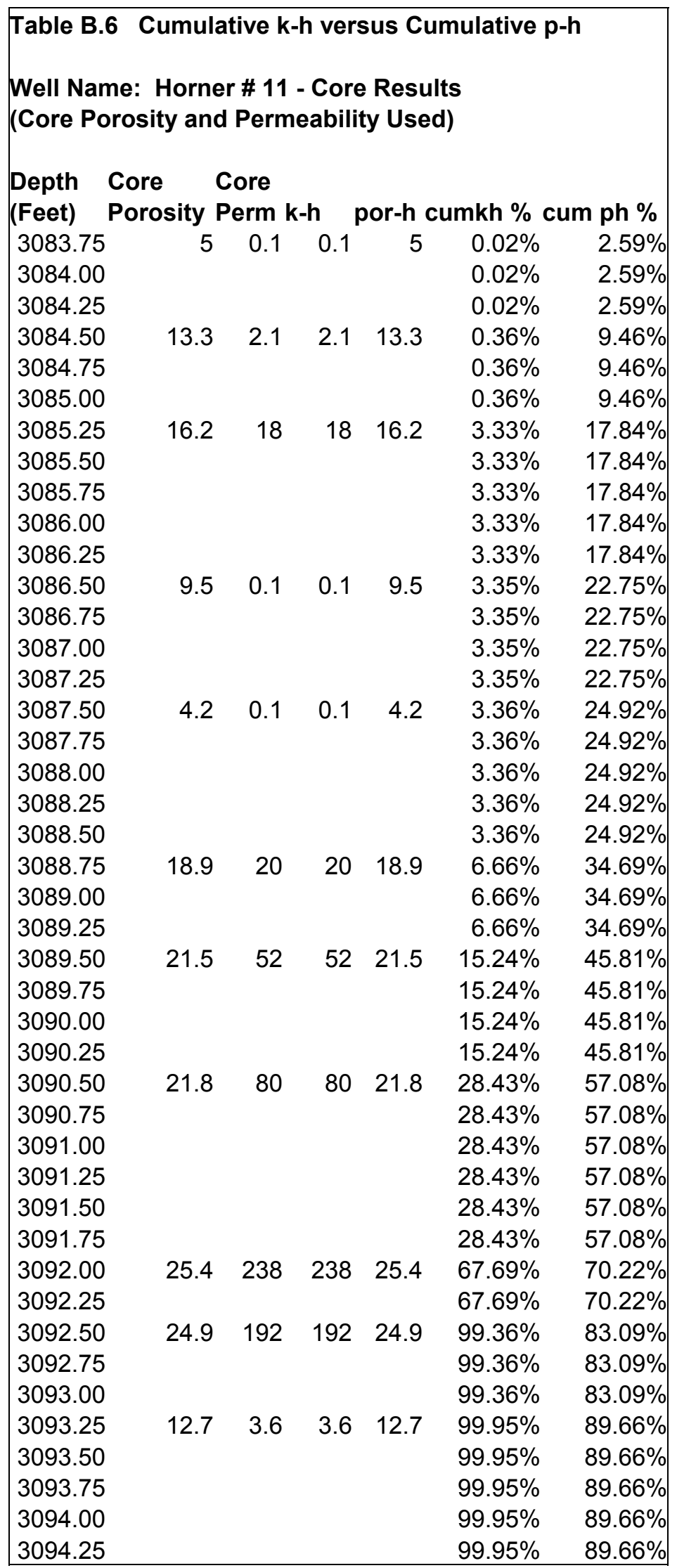




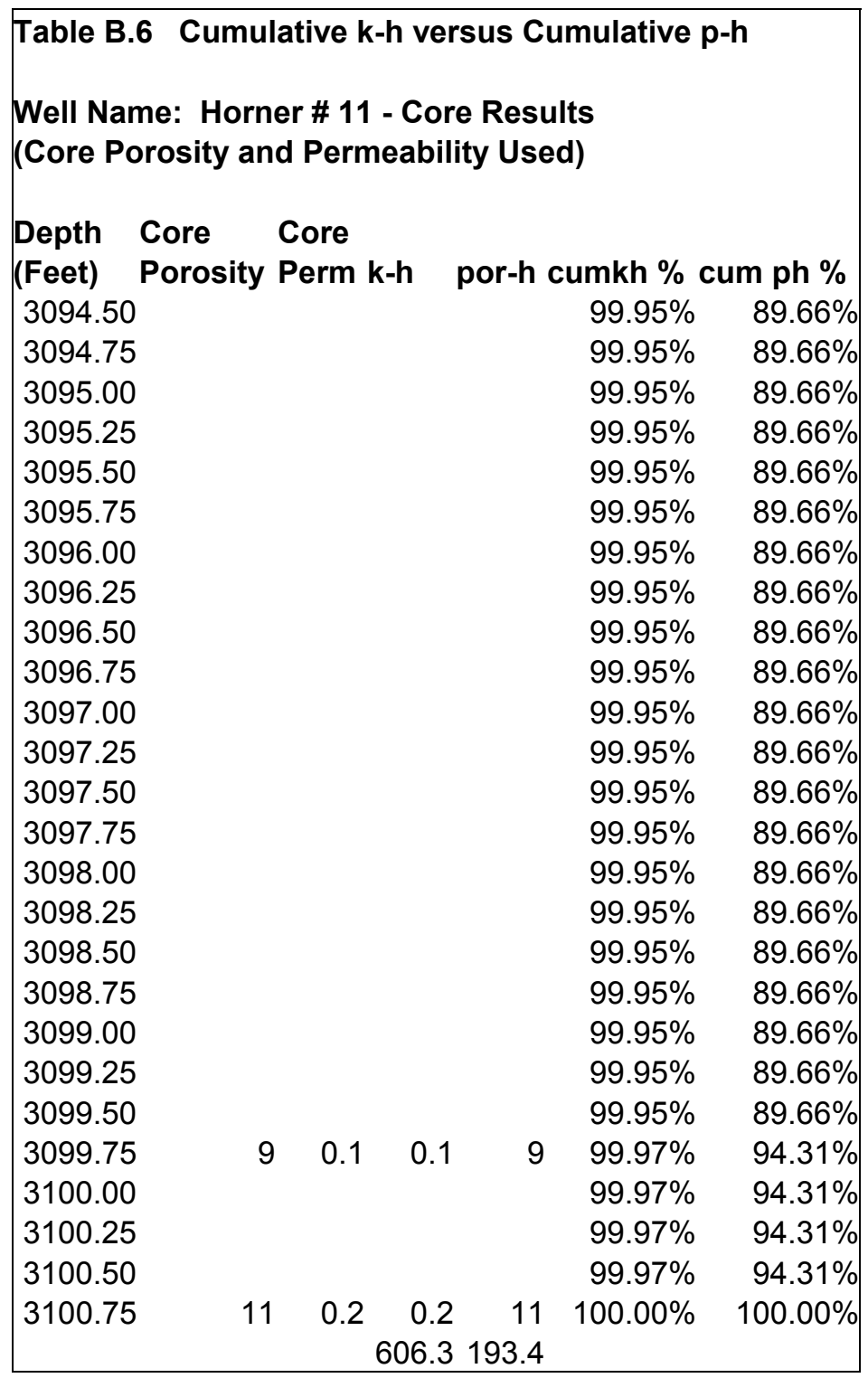




\begin{tabular}{|c|c|c|c|}
\hline \multicolumn{4}{|c|}{$\begin{array}{l}\text { Table B.7 Potential Flow Unit Boundary Point Analysis } \\
\text { Core Permeability and Core Measurement }\end{array}$} \\
\hline Well Name & $\begin{array}{c}\text { Flow Unit } \\
\text { Interval (Feet) }\end{array}$ & $\begin{array}{c}\text { Flow Unit } \\
\text { Interval (Feet) }\end{array}$ & Observation \\
\hline T. Heirs \# 8 & $2791.50-2794.00$ & $2794.00-2796.00$ & $\begin{array}{l}k \text { in all sections low. } \\
\text { Distance between core } \\
\text { points vary. }\end{array}$ \\
\hline Horner \# 9 & $2892.75-2898.00$ & $2898.00-2905.50$ & $\begin{array}{l}\text { k much better overall. } \\
\text { Much higher in } \\
\text { second zone. }\end{array}$ \\
\hline Ball \# 19 & $3086.25-3106.00$ & $3107.25-3110.75$ & $\begin{array}{l}\text { Much higher } \mathrm{k} \text { in } \\
\text { second zone. }\end{array}$ \\
\hline LeMasters \# 13 & $3047.00-3053.00$ & & $\begin{array}{l}\text { Appears to be single zone. } \\
\text { Very low k. }\end{array}$ \\
\hline Ball \# 18 & $2987.50-2994.00$ & $2994.00-2999.75$ & $\begin{array}{l}\text { High k second zone. } \\
\text { Below sand no k, but sand } \\
@ 3002.75-3013.00\end{array}$ \\
\hline Horner \# 11 & $3084.50-3090.50$ & $3092.00-3093.00$ & $\begin{array}{l}\text { Some good k lower zone. } \\
\text { High k zone. } \\
\text { Possible few points of } \\
\text { sand below. }\end{array}$ \\
\hline
\end{tabular}


APPENDIX C.

Appendix C. presents cumulative flow capacity versus cumulative storage capacity graphs for each core well. The graphs use log measurements for porosity and minipermeameter measurements for permeability. 

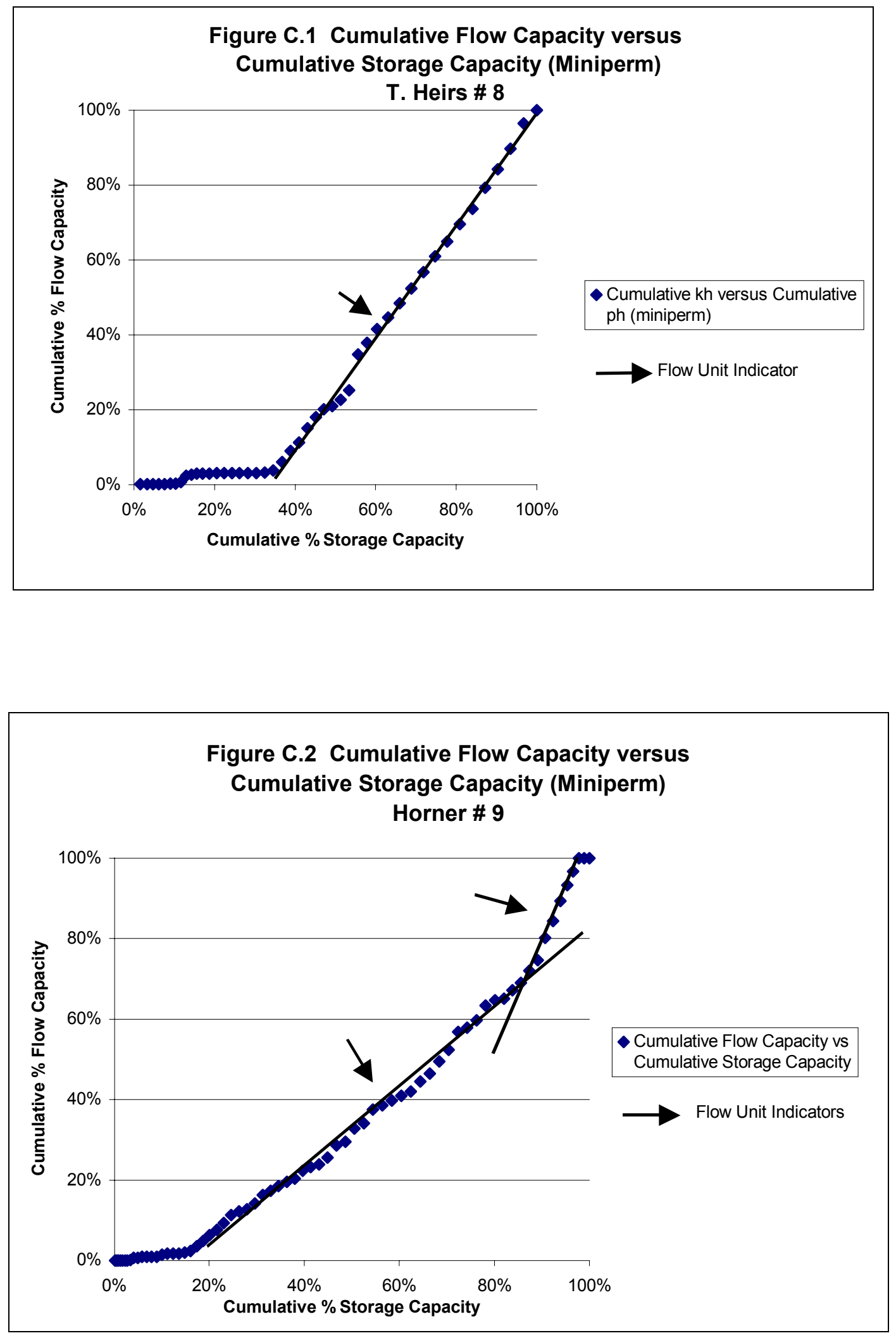

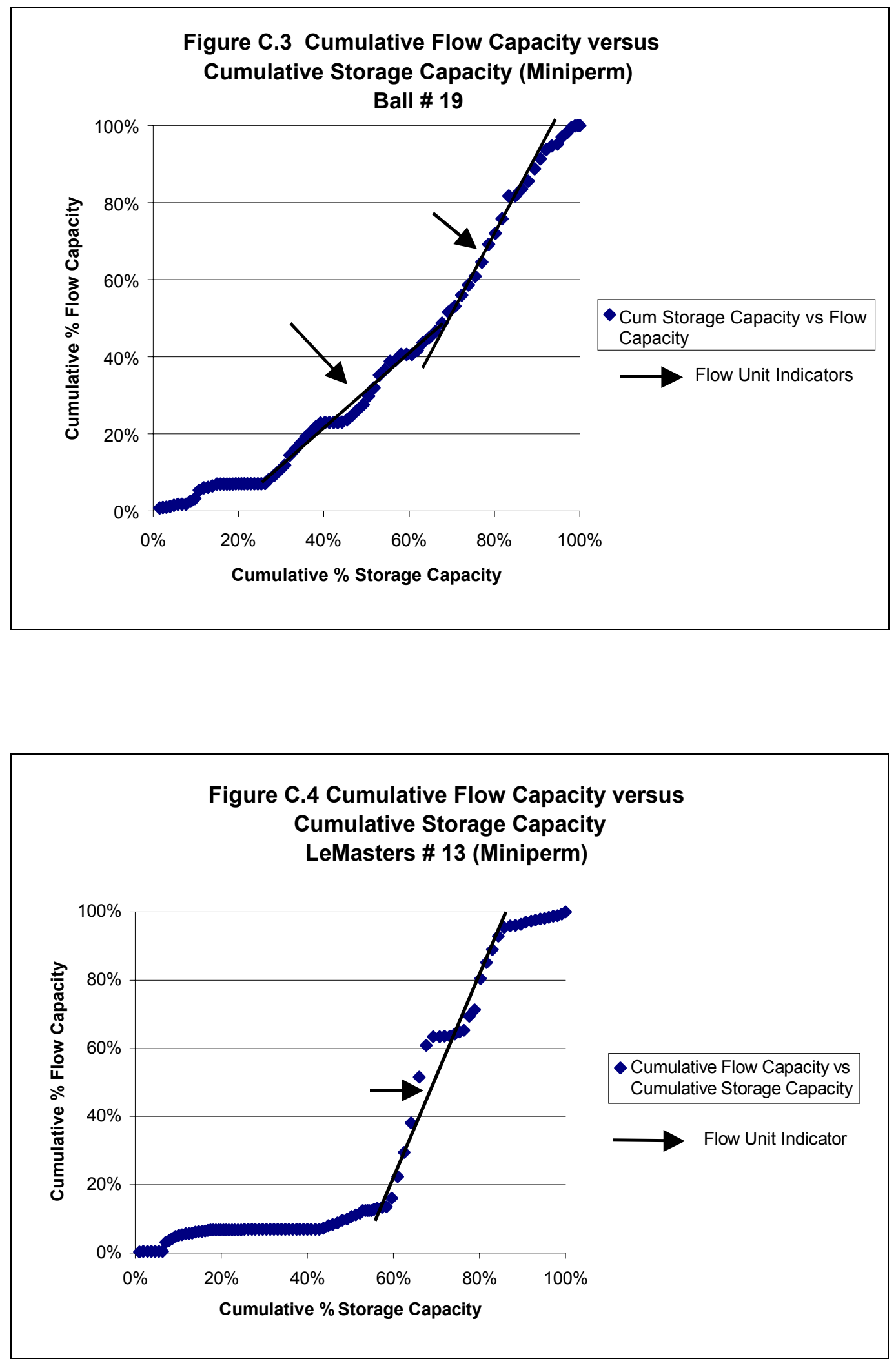


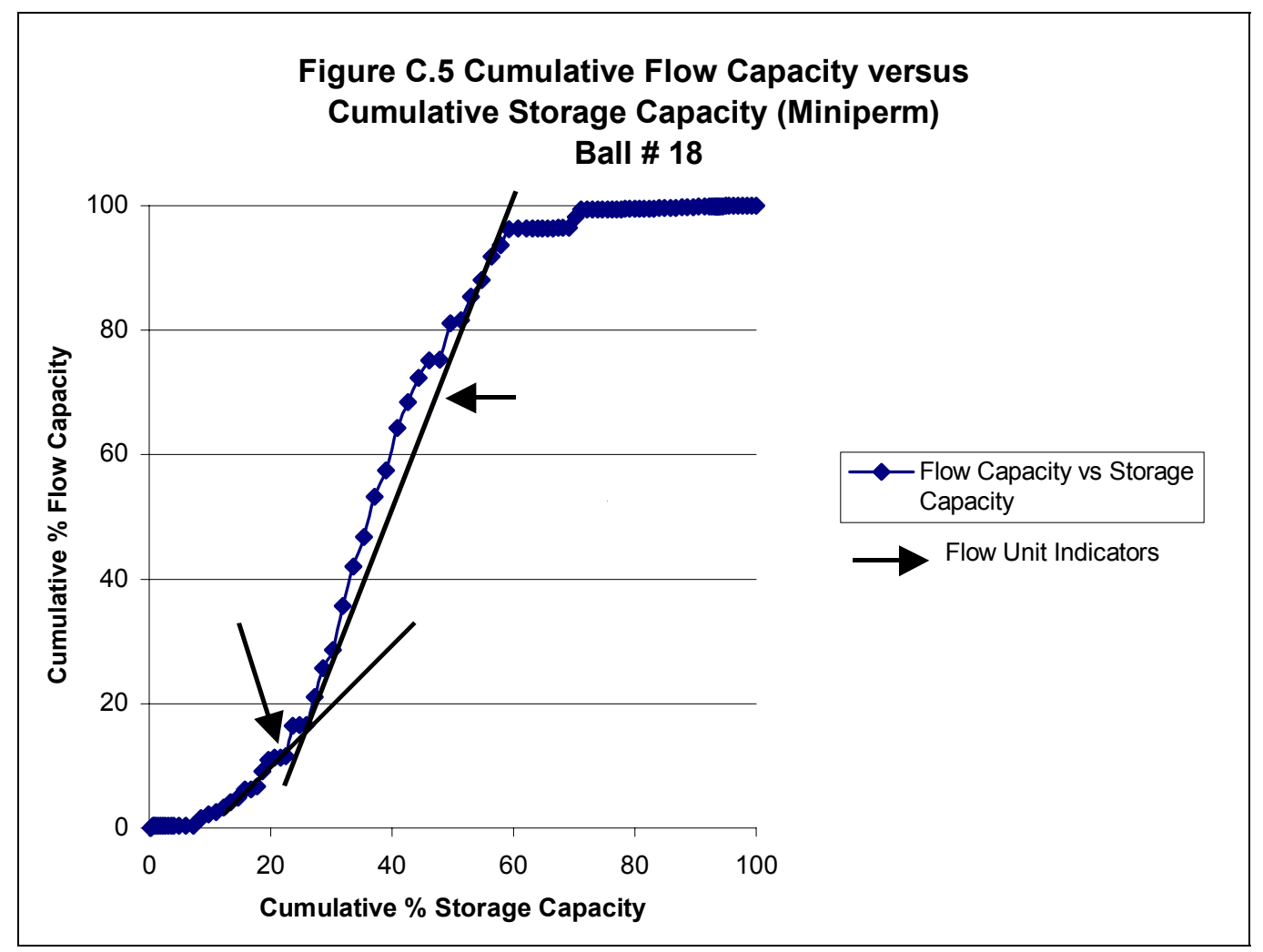




\begin{tabular}{|c|c|c|c|c|c|c|c|}
\hline \multicolumn{8}{|c|}{ Well Name: T. Heirs \# 8} \\
\hline Depth & $\begin{array}{c}\text { Log } \\
\text { Porosity }\end{array}$ & $\begin{array}{c}\text { Log } \\
\text { Density }\end{array}$ & $\begin{array}{c}\text { Miniperm } \\
\text { Perm. }\end{array}$ & kh & Cum kh \% & Por-h & Cum Por-h \% \\
\hline 2785.25 & 0.095833 & 2.519 & 0.280998 & 0.07025 & 0.001508 & 0.023958 & 0.016061 \\
\hline 2785.50 & 0.097619 & 2.5160 & 0.0100 & 0.00 & 0.0016 & 0.024405 & 0.0324 \\
\hline 2785.75 & 0.0875 & 2.5330 & 0.0100 & 0.00 & 0.0016 & 0.021875 & 0.0471 \\
\hline 2786.00 & 0.0875 & 2.5330 & 0.0100 & 0.00 & 0.0017 & 0.021875 & 0.0618 \\
\hline 2786.25 & 0.085119 & 2.5370 & 0.0100 & 0.00 & 0.0017 & 0.02128 & 0.0760 \\
\hline 2786.50 & 0.083333 & 2.5400 & 0.2279 & 0.06 & 0.0029 & 0.020833 & 0.0900 \\
\hline 2786.75 & 0.080952 & 2.5440 & 0.0491 & 0.01 & 0.0032 & 0.020238 & 0.1036 \\
\hline 2787.00 & 0.07619 & 2.5520 & 0.6748 & 0.17 & 0.0068 & 0.019048 & 0.1163 \\
\hline 2787.25 & 0.076786 & 2.5510 & 3.1960 & 0.80 & 0.0240 & 0.019196 & 0.1292 \\
\hline 2787.50 & 0.078571 & 2.5480 & 0.5264 & 0.13 & 0.0268 & 0.019643 & 0.1424 \\
\hline 2787.75 & 0.078571 & 2.5480 & 0.4585 & 0.11 & 0.0293 & 0.019643 & 0.1555 \\
\hline 2788.00 & 0.0875 & 2.5330 & 0.0100 & 0.00 & 0.0293 & 0.021875 & 0.1702 \\
\hline 2788.25 & 0.104762 & 2.5040 & 0.0100 & 0.00 & 0.0294 & 0.02619 & 0.1877 \\
\hline 2788.50 & 0.105357 & 2.5030 & 0.3779 & 0.09 & 0.0314 & 0.026339 & 0.2054 \\
\hline 2788.75 & 0.110119 & 2.4950 & 0.0100 & 0.00 & 0.0315 & 0.02753 & 0.2239 \\
\hline 2789.00 & 0.114286 & 2.4880 & 0.0100 & 0.00 & 0.0315 & 0.028571 & 0.2430 \\
\hline 2789.25 & 0.114286 & 2.4880 & 0.0100 & 0.00 & 0.0316 & 0.028571 & 0.2622 \\
\hline 2789.50 & 0.125595 & 2.4690 & 0.0100 & 0.00 & 0.0316 & 0.031399 & 0.2832 \\
\hline 2789.75 & 0.123214 & 2.4730 & 0.0100 & 0.00 & 0.0317 & 0.030804 & 0.3039 \\
\hline 2790.00 & 0.125595 & 2.4690 & 0.2035 & 0.05 & 0.0328 & 0.031399 & 0.3249 \\
\hline 2790.25 & 0.126786 & 2.4670 & 1.0651 & 0.27 & 0.0385 & 0.031696 & 0.3462 \\
\hline 2790.50 & 0.126786 & 2.4670 & 3.9927 & 1.00 & 0.0599 & 0.031696 & 0.3674 \\
\hline 2790.75 & 0.126786 & 2.4670 & 5.5744 & 1.39 & 0.0898 & 0.031696 & 0.3887 \\
\hline 2791.00 & 0.124405 & 2.4710 & 4.2682 & 1.07 & 0.1128 & 0.031101 & 0.4095 \\
\hline 2791.25 & 0.124405 & 2.4710 & 7.0817 & 1.77 & 0.1508 & 0.031101 & 0.4304 \\
\hline 2791.50 & 0.123214 & 2.4730 & 5.5858 & 1.40 & 0.1808 & 0.030804 & 0.4510 \\
\hline 2791.75 & 0.123214 & 2.4730 & 3.9277 & 0.98 & 0.2018 & 0.030804 & 0.4717 \\
\hline 2792.00 & 0.124405 & 2.4710 & 1.3847 & 0.35 & 0.2093 & 0.031101 & 0.4925 \\
\hline 2792.25 & 0.124405 & 2.4710 & 3.1343 & 0.78 & 0.2261 & 0.031101 & 0.5134 \\
\hline 2792.50 & 0.126786 & 2.4670 & 4.7175 & 1.18 & 0.2514 & 0.031696 & 0.5346 \\
\hline 2792.75 & 0.128571 & 2.4640 & 17.9513 & 4.49 & 0.3478 & 0.032143 & 0.5562 \\
\hline 2793.00 & 0.135714 & 2.4520 & 5.8257 & 1.46 & 0.3791 & 0.033929 & 0.5789 \\
\hline 2793.25 & 0.147024 & 2.4330 & 6.8743 & 1.72 & 0.4160 & 0.036756 & \\
\hline 2793.50 & 0.165476 & 2.4020 & 5.6983 & 1.42 & 0.4466 & 0.041369 & 0.6313 \\
\hline 2793.75 & 0.171429 & 2.3920 & 6.9719 & 1.74 & 0.4840 & 0.042857 & 0.6600 \\
\hline 2794.00 & 0.171429 & 2.3920 & 7.3910 & 1.85 & 0.5237 & 0.042857 & 0.6887 \\
\hline 2794.25 & 0.174405 & 2.3870 & 8.2618 & 2.07 & 0.5680 & 0.043601 & 0.7180 \\
\hline 2794.50 & 0.17619 & 2.3840 & 7.8833 & 1.97 & 0.6103 & 0.044048 & 0.7475 \\
\hline 2794.75 & 0.17619 & 2.3840 & 7.2555 & 1.81 & 0.6493 & 0.044048 & 0.7770 \\
\hline 2795.00 & 0.18631 & 2.3670 & 8.6903 & 2.17 & 0.6959 & 0.046577 & 0.8083 \\
\hline 2795.25 & 0.1875 & 2.3650 & 7.6390 & 1.91 & 0.7369 & 0.046875 & 0.8397 \\
\hline 2795.50 & 0.1875 & 2.3650 & 10.4653 & 2.62 & 0.7931 & 0.046875 & 0.8711 \\
\hline 2795.75 & 0.18869 & 2.3630 & 9.0789 & 2.27 & 0.8419 & 0.047173 & 0.9027 \\
\hline 2796.00 & 0.191071 & 2.3590 & 10.3483 & 2.59 & 0.8974 & 0.047768 & 0.9348 \\
\hline
\end{tabular}


Table C.1 Cumulative kh versus Cumulative Por-h (Minipermeameter Readings)

Well Name: T. Heirs \# 8

\begin{tabular}{|cccccccc|}
\multicolumn{7}{c}{ Log } & \multicolumn{2}{c}{ Log } & \multicolumn{2}{c|}{ Miniperm } & & & \\
Depth & Porosity & Density & Perm. & kh & Cum kh \% & Por-h & Cum Por-h \% \\
\hline 2796.25 & 0.194048 & 2.3540 & 12.5202 & 3.13 & 0.9646 & 0.048512 & 0.9673 \\
2796.50 & 0.195238 & 2.3520 & 6.5908 & 1.65 & 1.0000 & 0.04881 & 1.0000 \\
& & & & 46.57 & & 1.491667 & \\
\hline
\end{tabular}




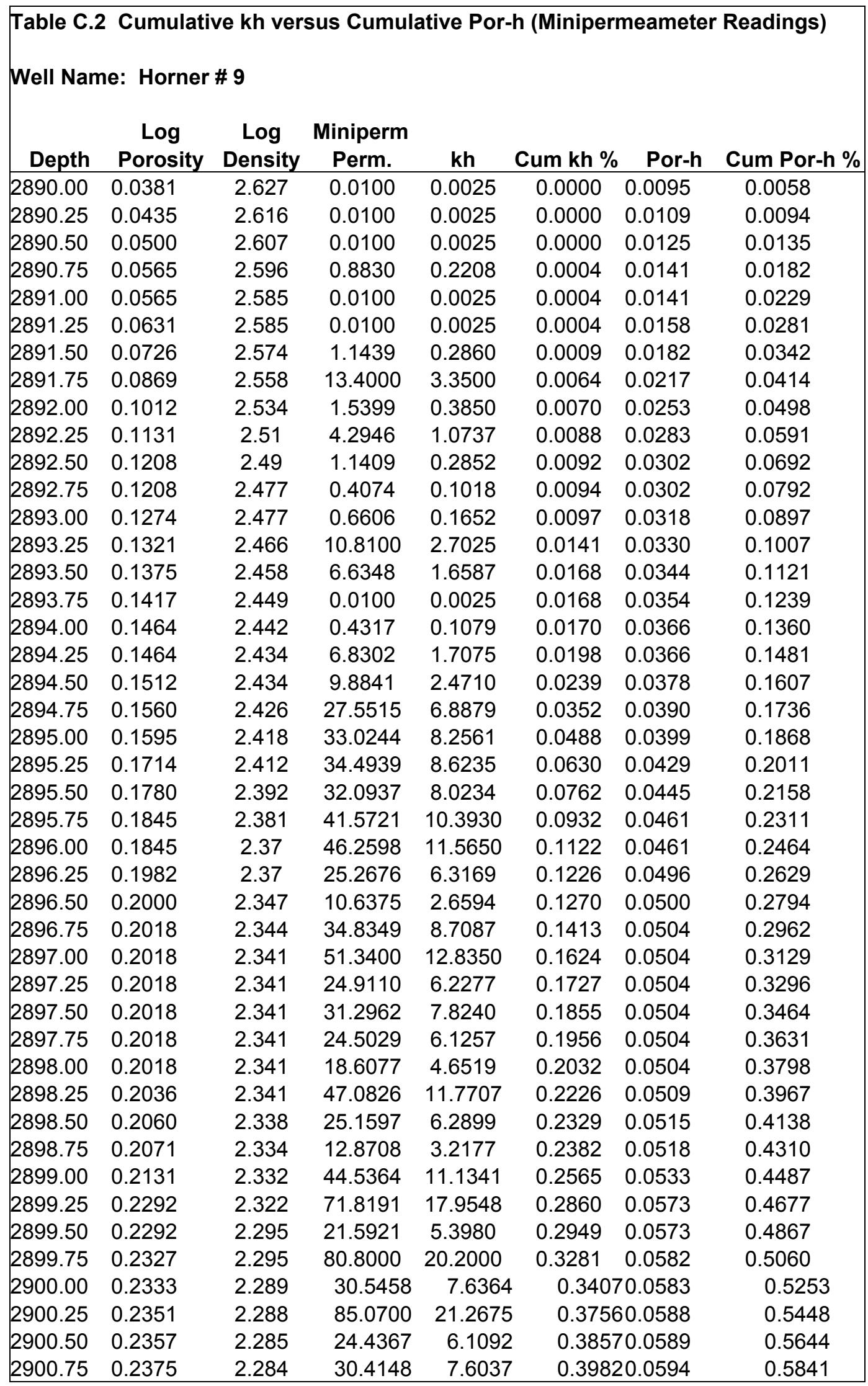




\begin{tabular}{|c|c|c|c|c|c|c|c|}
\hline \multicolumn{8}{|c|}{ Well Name: Horner \# 9} \\
\hline Depth & $\begin{array}{l}\text { Log } \\
\text { Porosity }\end{array}$ & $\begin{array}{c}\text { Log } \\
\text { Density }\end{array}$ & $\begin{array}{l}\text { Miniperm } \\
\text { Perm. }\end{array}$ & kh & Cum kh \% & Por-h & Cum Por-h \% \\
\hline 2901.00 & 0.2399 & 2.281 & 27.0736 & 6.7684 & 0.40930 & .0600 & 0.6040 \\
\hline 2901.25 & 0.2399 & 2.277 & 26.3850 & 6.5963 & 0.42010 & .0600 & 0.6239 \\
\hline 2901.50 & 0.2417 & 2.277 & 58.8000 & 14.7000 & 0.44430 & .0604 & 0.6439 \\
\hline 2901.75 & 0.2417 & 2.274 & 49.5306 & 12.3826 & $0.4647 C$ & .0604 & 0.6639 \\
\hline 2902.00 & 0.2411 & 2.274 & 73.8187 & 18.4547 & 0.49500 & .0603 & 0.6839 \\
\hline 2902.25 & 0.2393 & 2.275 & 70.5482 & 17.6371 & 0.52400 & .0598 & 0.7038 \\
\hline 2902.50 & 0.2387 & 2.278 & 107.3500 & 26.8375 & 0.56810 & .0597 & 0.7236 \\
\hline 2902.75 & 0.2357 & 2.279 & 25.0521 & 6.2630 & $0.5784 C$ & .0589 & 0.7431 \\
\hline 2903.00 & 0.2357 & 2.284 & 46.8822 & 11.7206 & 0.59770 & .0589 & 0.7627 \\
\hline 2903.25 & 0.2333 & 2.284 & 86.6900 & 21.6725 & 0.63330 & .0583 & 0.7820 \\
\hline 2903.50 & 0.2310 & 2.288 & 32.8846 & 8.2211 & 0.64680 & .0577 & 0.8012 \\
\hline 2903.75 & 0.2280 & 2.292 & 10.4806 & 2.6201 & 0.65110 & .0570 & 0.8201 \\
\hline 2904.00 & 0.2173 & 2.297 & 50.2100 & 12.5525 & 0.67180 & .0543 & 0.8381 \\
\hline 2904.25 & 0.2155 & 2.315 & 44.0806 & 11.0202 & 0.68990 & .0539 & 0.8560 \\
\hline 2904.50 & 0.2101 & 2.318 & 74.4946 & 18.6237 & $0.7205 c$ & .0525 & 0.8734 \\
\hline 2904.75 & 0.2101 & 2.327 & 62.8958 & 15.7239 & 0.74630 & .0525 & 0.8908 \\
\hline 2905.00 & 0.1958 & 2.327 & 135.2400 & 33.8100 & $0.8019 c$ & .0490 & 0.9070 \\
\hline 2905.25 & 0.1929 & 2.351 & 103.1568 & 25.7892 & 0.84430 & .0482 & 0.9230 \\
\hline 2905.50 & 0.1863 & 2.356 & 120.7821 & 30.1955 & 0.89400 & .0466 & 0.9385 \\
\hline 2905.75 & 0.1815 & 2.367 & 95.1579 & 23.7895 & 0.93310 & .0454 & 0.9535 \\
\hline 2906.00 & 0.1494 & 2.375 & 82.1700 & 20.5425 & 0.96680 & .0374 & 0.9659 \\
\hline 2906.25 & 0.1387 & 2.429 & 80.6947 & 20.1737 & 1.00000 & .0347 & 0.9774 \\
\hline 2906.50 & 0.1387 & 2.447 & 0.0100 & 0.0025 & 1.00000 & .0347 & 0.9889 \\
\hline 2906.75 & 0.1333 & 2.447 & 0.0100 & 0.0025 & 1.00000 & .0333 & 1.0000 \\
\hline 2907.00 & & 2.456 & & 608.3126 & & .0146 & \\
\hline
\end{tabular}




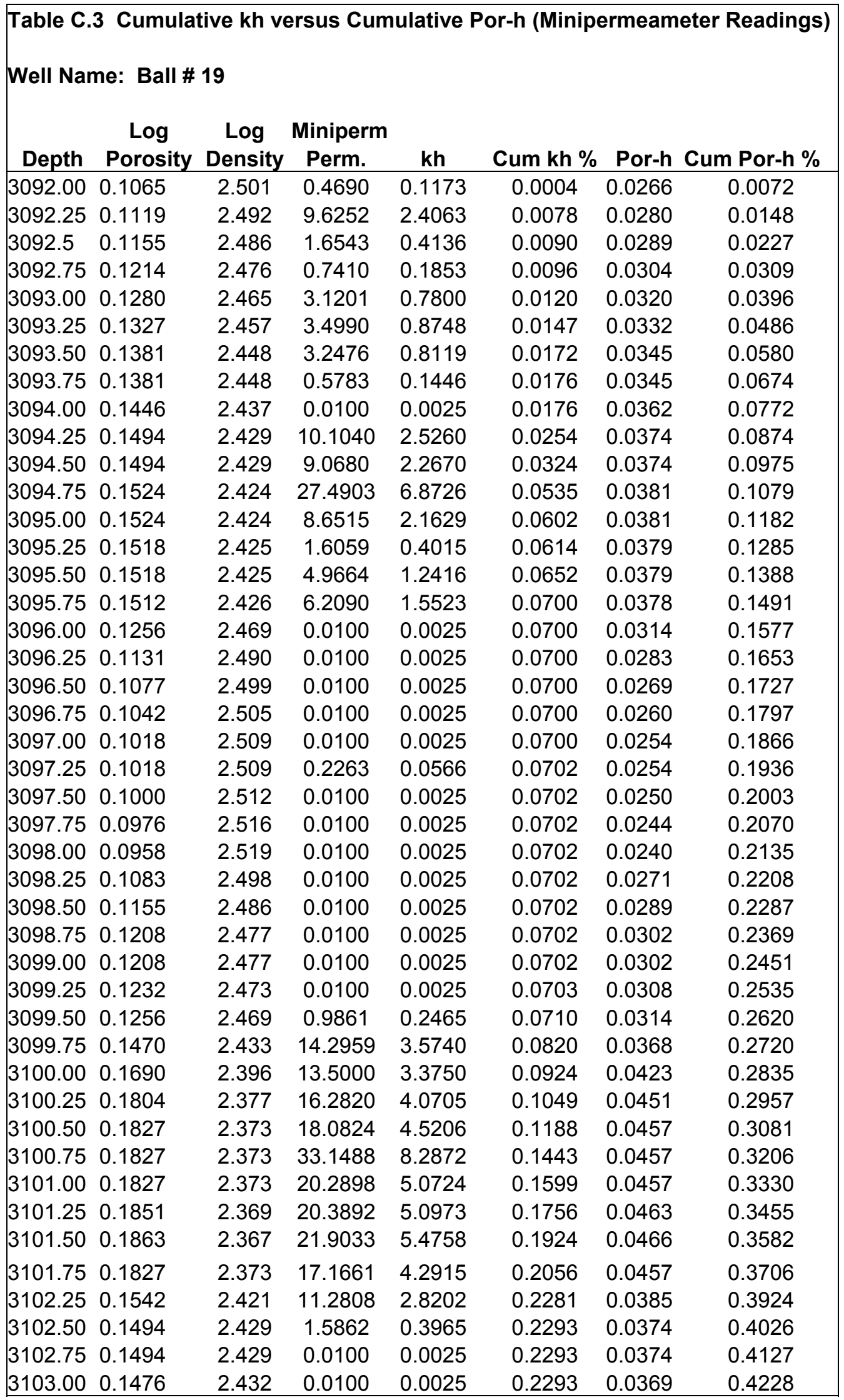




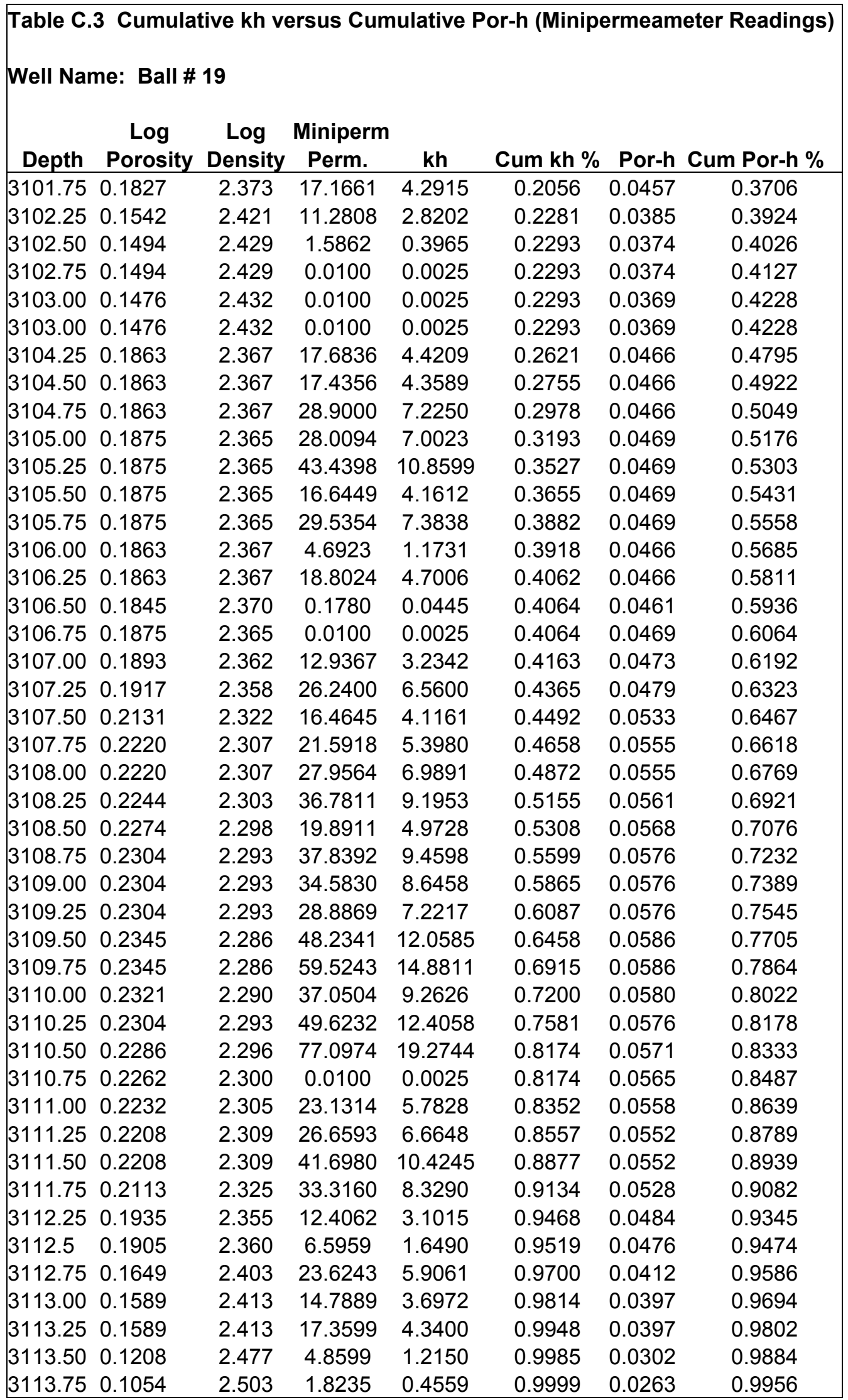




Table C.3
Wumulative kh versus Cumulative Por-h (Minipermeameter Readings)
Well Name: Ball \# 19
\begin{tabular}{|cccccccc|} 
\\
Log & Log & Miniperm & & & & \\
Depth & Porosity & Density & Perm. & kh & Cum kh \% & Por-h & Cum Por-h \% \\
\hline 3114.00 & 0.0649 & 2.571 & 0.1378 & 0.0345 & 1.0000 & 0.0162 & 1.0000 \\
& & & 325.2191 & & 3.6804 & \\
\hline
\end{tabular}




\begin{tabular}{|c|c|c|c|c|c|c|c|}
\hline \multicolumn{8}{|c|}{ Well Name: LeMasters \# 13} \\
\hline Depth & $\begin{array}{c}\text { Log } \\
\text { Porosity }\end{array}$ & $\begin{array}{c}\text { Log } \\
\text { Density }\end{array}$ & $\begin{array}{c}\text { Miniperm } \\
\text { Perm. }\end{array}$ & kh & Cum kh \% & Por-h & Cum Por-h \% \\
\hline 3030.00 & 0.0946 & 2.521 & 0.6421 & 0.1605 & 0.0037 & 0.0237 & 0.0094 \\
\hline 3030.25 & 0.0946 & 2.521 & 0.0412 & 0.0103 & 0.0040 & 0.0237 & 0.0189 \\
\hline 3030.50 & 0.0946 & 2.521 & 0.0100 & 0.0025 & 0.0040 & 0.0237 & 0.0283 \\
\hline 3030.75 & 0.0914 & 2.5265 & 0.0100 & 0.0025 & 0.0041 & 0.0228 & 0.0374 \\
\hline 3031.00 & 0.0881 & 2.532 & 0.0100 & 0.0025 & 0.0042 & 0.0220 & 0.0462 \\
\hline 3031.25 & 0.0863 & 2.535 & 0.1014 & 0.0253 & 0.0048 & 0.0216 & 0.0548 \\
\hline 3031.50 & 0.0845 & 2.538 & 0.1230 & 0.0308 & 0.0055 & 0.0211 & 0.0632 \\
\hline 3031.75 & 0.0813 & 2.5435 & 4.5938 & 1.1485 & 0.0323 & 0.0203 & 0.0713 \\
\hline 3032.00 & 0.0780 & 2.549 & 0.5637 & 0.1409 & 0.0356 & 0.0195 & 0.0790 \\
\hline 3032.25 & 0.0762 & 2.552 & 1.2516 & 0.3129 & 0.0429 & 0.0190 & 0.0866 \\
\hline 3032.50 & 0.0744 & 2.555 & 0.9737 & 0.2434 & 0.0486 & 0.0186 & 0.0941 \\
\hline 3032.75 & 0.0759 & 2.5525 & 0.7179 & 0.1795 & 0.0528 & 0.0190 & 0.1016 \\
\hline 3033.00 & 0.0774 & 2.55 & 0.2536 & 0.0634 & 0.0542 & 0.0193 & 0.1093 \\
\hline 3033.25 & 0.0780 & 2.549 & 0.3176 & 0.0794 & 0.0561 & 0.0195 & 0.1171 \\
\hline 3033.50 & 0.0786 & 2.548 & 0.2019 & 0.0505 & 0.0573 & 0.0196 & 0.1249 \\
\hline 3033.75 & 0.0783 & 2.5485 & 0.2180 & 0.0545 & 0.0585 & 0.0196 & 0.1327 \\
\hline 3034.00 & 0.0780 & 2.549 & 0.4881 & 0.1220 & 0.0614 & 0.0195 & 0.1405 \\
\hline 3034.25 & 0.0750 & 2.554 & 0.3417 & 0.0854 & 0.0634 & 0.0188 & 0.1480 \\
\hline 3034.50 & 0.0720 & 2.559 & 0.0528 & 0.0132 & 0.0637 & 0.0180 & 0.1551 \\
\hline 3034.75 & 0.0690 & 2.564 & 0.1782 & 0.0446 & 0.0647 & 0.0173 & 0.1620 \\
\hline 3035.00 & 0.0661 & 2.569 & 0.3239 & 0.0810 & 0.0666 & 0.0165 & 0.1686 \\
\hline 3035.25 & 0.0649 & 2.571 & 0.1413 & 0.0353 & 0.0674 & 0.0162 & 0.1751 \\
\hline 3035.50 & 0.0637 & 2.573 & 0.0951 & 0.0238 & 0.0680 & 0.0159 & 0.1814 \\
\hline 3035.75 & 0.0607 & 2.578 & 0.0100 & 0.0025 & 0.0681 & 0.0152 & 0.1875 \\
\hline 3036.00 & 0.0577 & 2.583 & 0.0100 & 0.0025 & 0.0681 & 0.0144 & 0.1932 \\
\hline 3036.25 & 0.0589 & 2.581 & 0.0100 & 0.0025 & 0.0682 & 0.0147 & 0.1991 \\
\hline 3036.50 & 0.0601 & 2.579 & 0.0100 & 0.0025 & 0.0682 & 0.0150 & 0.2051 \\
\hline 3036.75 & 0.0631 & 2.574 & 0.0100 & 0.0025 & 0.0683 & 0.0158 & 0.2114 \\
\hline 3037.00 & 0.0661 & 2.569 & 0.0100 & 0.0025 & 0.0684 & 0.0165 & 0.2179 \\
\hline 3037.25 & 0.0679 & 2.566 & 0.0100 & 0.0025 & 0.0684 & 0.0170 & 0.2247 \\
\hline 3037.50 & 0.0696 & 2.563 & 0.0100 & 0.0025 & 0.0685 & 0.0174 & 0.2316 \\
\hline 3037.75 & 0.0726 & 2.558 & 0.0100 & 0.0025 & 0.0685 & 0.0182 & 0.2389 \\
\hline 3038.00 & 0.0756 & 2.553 & 0.0100 & 0.0025 & 0.0686 & 0.0189 & 0.2464 \\
\hline 3038.25 & 0.0789 & 2.5475 & 0.0100 & 0.0025 & 0.0686 & 0.0197 & 0.2543 \\
\hline 3038.50 & 0.0821 & 2.542 & 0.0100 & 0.0025 & 0.0687 & 0.0205 & 0.2624 \\
\hline 3038.75 & 0.0833 & 2.54 & 0.0100 & 0.0025 & 0.0688 & 0.0208 & 0.2707 \\
\hline 3039.00 & 0.0845 & 2.538 & 0.0100 & 0.0025 & 0.0688 & 0.0211 & 0.2792 \\
\hline 3039.25 & 0.0860 & 2.5355 & 0.0100 & 0.0025 & 0.0689 & 0.0215 & 0.2877 \\
\hline 3039.50 & 0.0875 & 2.533 & 0.0100 & 0.0025 & 0.0689 & 0.0219 & 0.2964 \\
\hline 3039.75 & 0.0884 & 2.5315 & 0.0100 & 0.0025 & 0.0690 & 0.0221 & 0.3053 \\
\hline 3040.25 & 0.0884 & 2.5315 & 0.0100 & 0.0025 & 0.0691 & 0.0221 & 0.3230 \\
\hline 3040.50 & 0.0875 & 2.533 & 0.0100 & 0.0025 & 0.0692 & 0.0219 & 0.3317 \\
\hline 3040.75 & 0.0878 & 2.5325 & 0.0100 & 0.0025 & 0.0692 & 0.0219 & 0.3404 \\
\hline 3041.00 & 0.0881 & 2.532 & 0.0100 & 0.0025 & 0.0693 & 0.0220 & 0.3492 \\
\hline
\end{tabular}




\begin{tabular}{|c|c|c|c|c|c|c|c|}
\hline \multicolumn{8}{|c|}{ Well Name: LeMasters \# 13} \\
\hline Depth & $\begin{array}{c}\text { Log } \\
\text { Porosity }\end{array}$ & $\begin{array}{c}\text { Log } \\
\text { Density }\end{array}$ & $\begin{array}{c}\text { Miniperm } \\
\text { Perm. }\end{array}$ & kh & Cum kh \% & Por-h & Cum Por-h \% \\
\hline 3041.25 & 0.0863 & 2.535 & 0.0100 & 0.0025 & 0.0693 & 0.0216 & 0.3578 \\
\hline 3041.50 & 0.0845 & 2.538 & 0.0100 & 0.0025 & 0.0694 & 0.0211 & 0.3662 \\
\hline 3041.75 & 0.0833 & 2.54 & 0.0100 & 0.0025 & 0.0695 & 0.0208 & 0.3745 \\
\hline 3042.00 & 0.0821 & 2.542 & 0.0100 & 0.0025 & 0.0695 & 0.0205 & 0.3827 \\
\hline 3042.25 & 0.0851 & 2.537 & 0.0100 & 0.0025 & 0.0696 & 0.0213 & 0.3912 \\
\hline 3042.50 & 0.0881 & 2.532 & 0.0100 & 0.0025 & 0.0696 & 0.0220 & 0.4000 \\
\hline 3042.75 & 0.0902 & 2.5285 & 0.0100 & 0.0025 & 0.0697 & 0.0225 & 0.4089 \\
\hline 3043.00 & 0.0923 & 2.525 & 0.0100 & 0.0025 & 0.0698 & 0.0231 & 0.4181 \\
\hline 3043.25 & 0.0973 & 2.5165 & 0.0100 & 0.0025 & 0.0698 & 0.0243 & 0.4278 \\
\hline 3043.50 & 0.1024 & 2.508 & 0.5673 & 0.1418 & 0.0731 & 0.0256 & 0.4380 \\
\hline 3043.75 & 0.1051 & 2.5035 & 1.1433 & 0.2858 & 0.0798 & 0.0263 & 0.4485 \\
\hline 3044.00 & 0.1077 & 2.499 & 0.7807 & 0.1952 & 0.0844 & 0.0269 & 0.4592 \\
\hline 3044.25 & 0.1092 & 2.4965 & 0.6904 & 0.1726 & 0.0884 & 0.0273 & 0.4701 \\
\hline 3044.50 & 0.1107 & 2.494 & 1.2410 & 0.3102 & 0.0956 & 0.0277 & 0.4811 \\
\hline 3044.75 & 0.1104 & 2.4945 & 0.7391 & 0.1848 & 0.0999 & 0.0276 & 0.4921 \\
\hline 3045.00 & 0.1101 & 2.495 & 1.2144 & 0.3036 & 0.1070 & 0.0275 & 0.5031 \\
\hline 3045.25 & 0.0997 & 2.5125 & 0.7577 & 0.1894 & 0.1115 & 0.0249 & 0.5130 \\
\hline 3045.50 & 0.0893 & 2.53 & 1.0071 & 0.2518 & 0.1173 & 0.0223 & 0.5219 \\
\hline 3045.75 & 0.0723 & 2.5585 & 1.2182 & 0.3046 & 0.1244 & 0.0181 & 0.5291 \\
\hline 3046.00 & 0.0554 & 2.587 & 0.0100 & 0.0025 & 0.1245 & 0.0138 & 0.5347 \\
\hline 3046.25 & 0.0503 & 2.5955 & 0.0100 & 0.0025 & 0.1246 & 0.0126 & 0.5397 \\
\hline 3046.50 & 0.0452 & 2.604 & 0.0100 & 0.0025 & 0.1246 & 0.0113 & 0.5442 \\
\hline 3046.75 & 0.0506 & 2.595 & 0.0100 & 0.0025 & 0.1247 & 0.0126 & 0.5492 \\
\hline 3047.00 & 0.0560 & 2.586 & 0.3936 & 0.0984 & 0.1270 & 0.0140 & 0.5548 \\
\hline 3047.25 & 0.0801 & 2.5455 & 0.6110 & 0.1528 & 0.1305 & 0.0200 & 0.5628 \\
\hline 3047.50 & 0.1042 & 2.505 & 0.5092 & 0.1273 & 0.1335 & 0.0260 & 0.5731 \\
\hline 3047.75 & 0.1104 & 2.4945 & 0.4229 & 0.1057 & 0.1360 & 0.0276 & 0.5841 \\
\hline 3048.00 & 0.1167 & 2.484 & 4.3701 & 1.0925 & 0.1615 & 0.0292 & 0.5958 \\
\hline 3048.25 & 0.1369 & 2.45 & 10.5897 & 2.6474 & 0.2233 & 0.0342 & 0.6094 \\
\hline 3048.50 & 0.1571 & 2.416 & 12.2493 & 3.0623 & 0.2948 & 0.0393 & 0.6251 \\
\hline 3048.75 & 0.1679 & 2.398 & 14.9449 & 3.7362 & 0.3820 & 0.0420 & 0.6418 \\
\hline 3049.00 & 0.1786 & 2.38 & 22.8823 & 5.7206 & 0.5156 & 0.0446 & 0.6596 \\
\hline 3049.25 & 0.1714 & 2.392 & 15.8823 & 3.9706 & 0.6083 & 0.0429 & 0.6767 \\
\hline 3049.50 & 0.1643 & 2.404 & 4.3813 & 1.0953 & 0.6339 & 0.0411 & 0.6930 \\
\hline 3049.75 & 0.1426 & 2.4405 & 0.0100 & 0.0025 & 0.6339 & 0.0356 & 0.7072 \\
\hline 3050.00 & 0.1208 & 2.477 & 0.3942 & 0.0986 & 0.6362 & 0.0302 & 0.7193 \\
\hline 3050.50 & 0.1161 & 2.485 & 0.9759 & 0.2440 & 0.6420 & 0.0290 & 0.7426 \\
\hline 3050.75 & 0.1101 & 2.495 & 1.1329 & 0.2832 & 0.6486 & 0.0275 & 0.7536 \\
\hline 3051.00 & 0.1042 & 2.505 & 0.8146 & 0.2036 & 0.6533 & 0.0260 & 0.7640 \\
\hline 3051.25 & 0.1176 & 2.4825 & 7.0110 & 1.7528 & 0.6943 & 0.0294 & 0.7757 \\
\hline 3051.50 & 0.1310 & 2.46 & 3.1885 & 0.7971 & 0.7129 & 0.0327 & 0.7887 \\
\hline 3051.75 & 0.1336 & 2.4555 & 15.6280 & 3.9070 & 0.8041 & 0.0334 & 0.8021 \\
\hline 3052.00 & 0.1363 & 2.451 & 8.0326 & 2.0081 & 0.8510 & 0.0341 & 0.8156 \\
\hline 3052.25 & 0.1414 & 2.4425 & 6.5426 & 1.6356 & 0.8892 & 0.0353 & 0.8297 \\
\hline
\end{tabular}




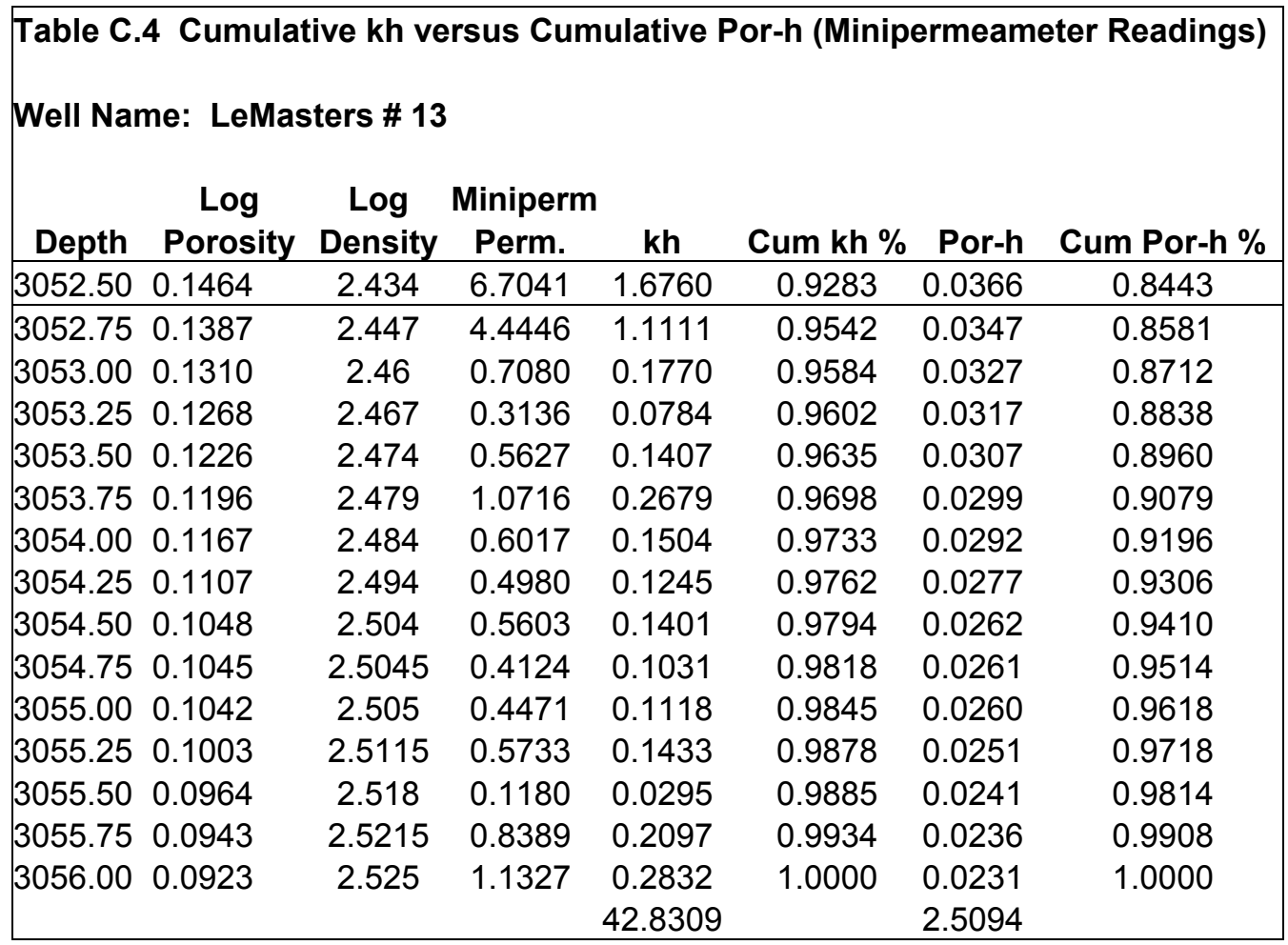




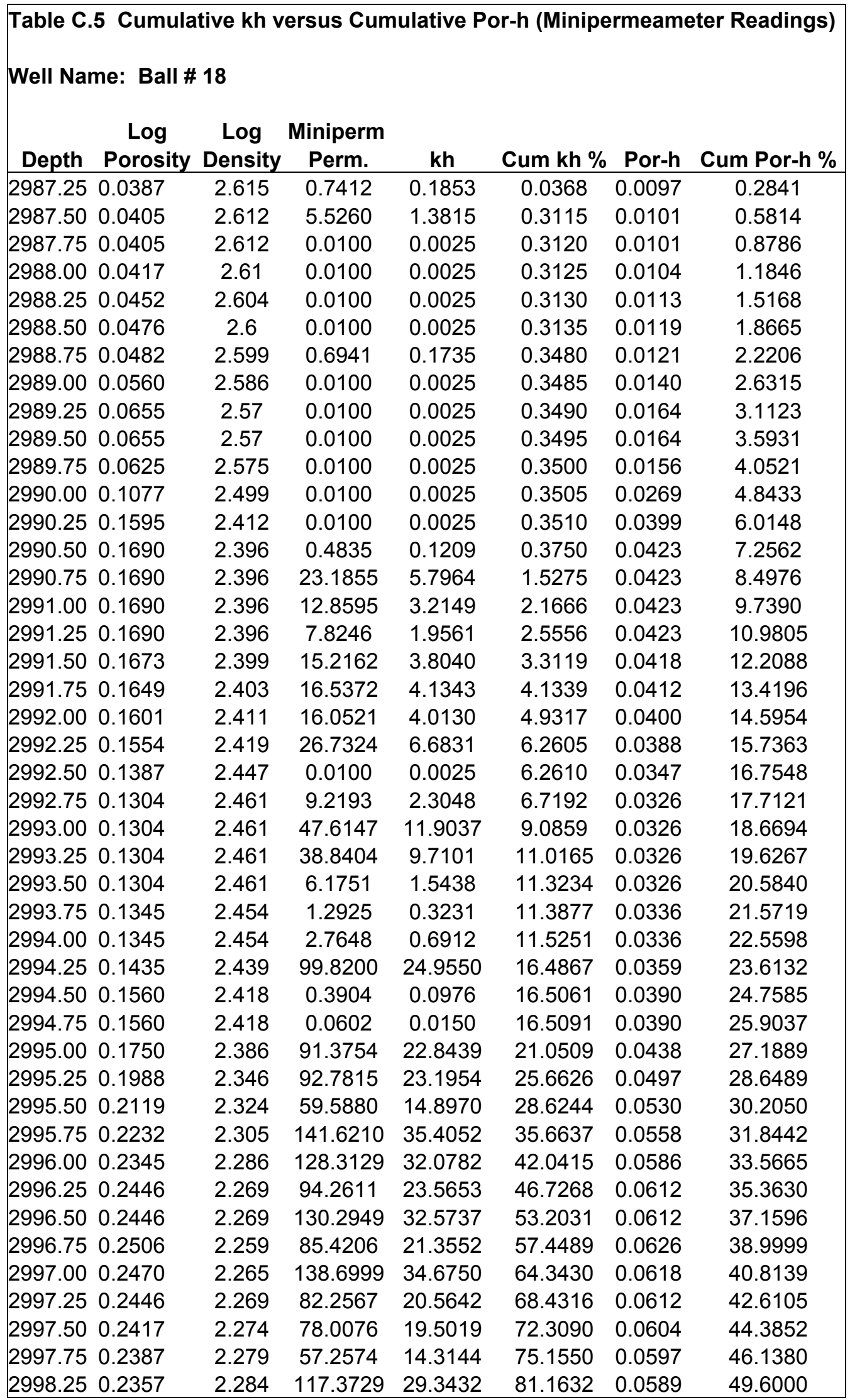




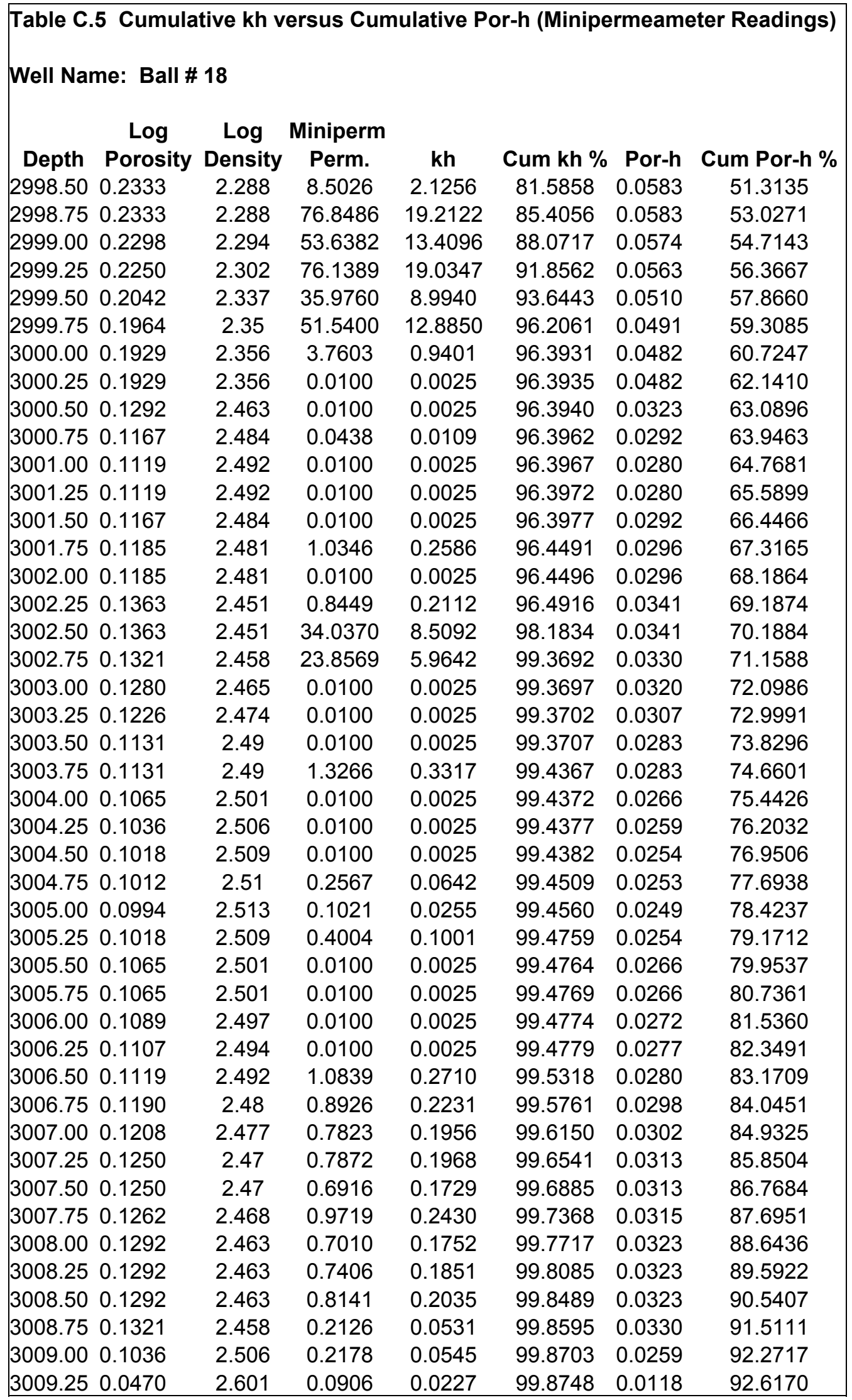




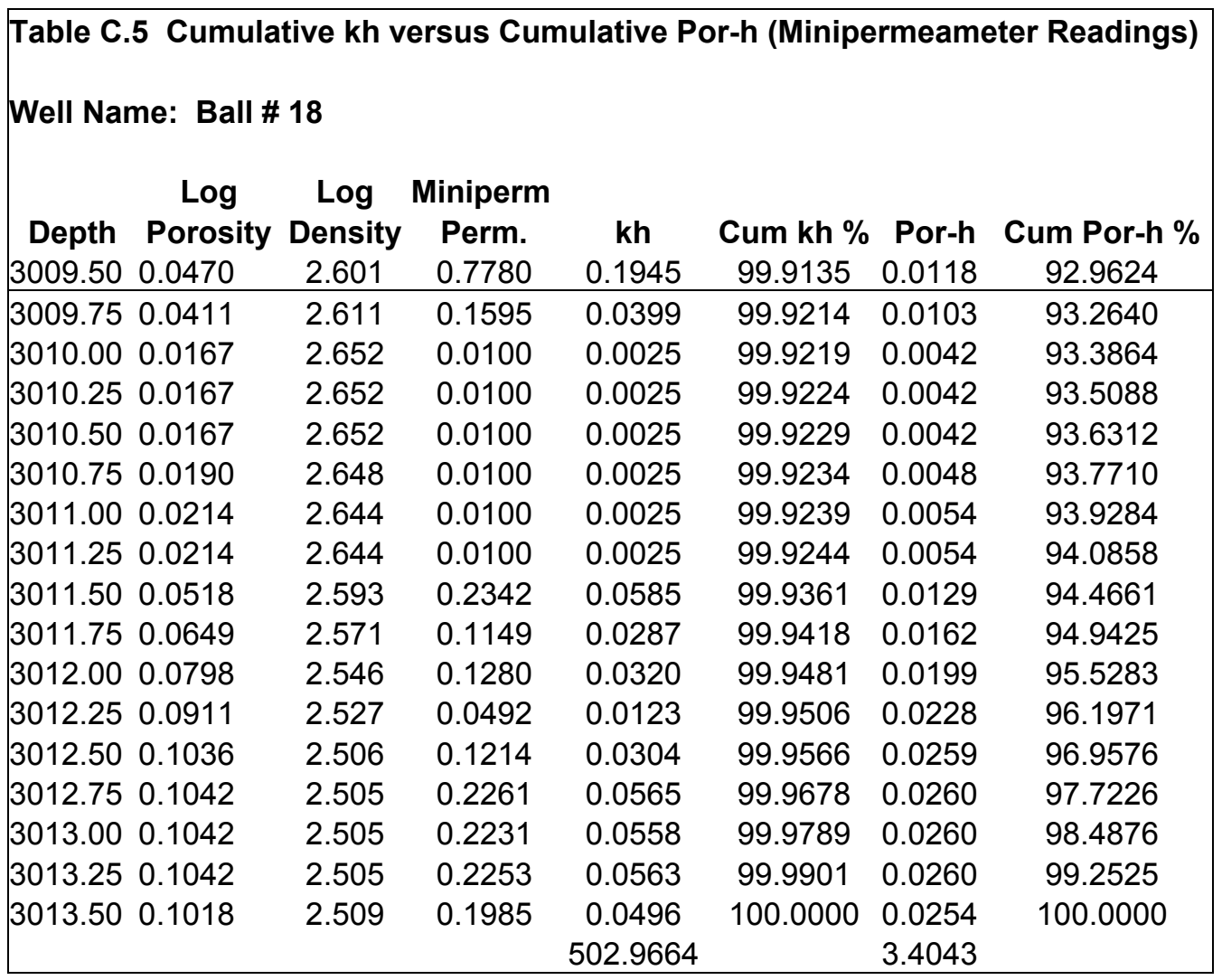




\begin{tabular}{|c|c|c|c|}
\hline \multicolumn{4}{|c|}{$\begin{array}{l}\text { Table C.6 Potential Flow Unit Boundary Point Analysis } \\
\text { Miniperm Values and Core Porosity } \\
\text { (see Appendix C. for detail data) }\end{array}$} \\
\hline Well Name & $\begin{array}{c}\text { Flow Unit } \\
\text { Interval (Feet) } \\
\end{array}$ & $\begin{array}{c}\text { Flow Unit } \\
\text { Interval (Feet) } \\
\end{array}$ & Observation \\
\hline T. Heirs \# 8 & $\begin{array}{c}2785.00-2791.00 \\
(\text { No k) }\end{array}$ & $\begin{array}{c}2791.00-2795.00 \\
\text { (Looks like } \\
\text { single FU) }\end{array}$ & $\begin{array}{l}\text { Similar shape to core plot. } \\
\text { Lower section very low } \mathrm{k} \text {, } \\
\text { don't include. }\end{array}$ \\
\hline Horner \# 9 & $2895.00-2905.00$ & $2905.00-2906.00$ & $\begin{array}{l}\text { FU1 has } \mathrm{k}=20-70 \mathrm{md} \\
\text { FU2 has } \mathrm{k}=90-135 \mathrm{md}\end{array}$ \\
\hline Ball \# 19 & $3100.00-3107.00$ & $3107.00-3114.00$ & $\begin{array}{l}\text { Steady k in upper zone. } \\
\text { Second FU has higher k. }\end{array}$ \\
\hline LeMasters \# 13 & 3048.50 - 3049.00 & $3051.50-3052.75$ & $\begin{array}{l}\text { Appears to be one unit. } \\
\text { Low k streak in center @ } \\
3049.00-3051.50 \text { feet. }\end{array}$ \\
\hline Ball \# 18 & $2987.50-2994.50$ & $2994.50-3000.00$ & $\begin{array}{l}\text { Upper section up to } 50 \mathrm{md} \\
\text { Lower section high } \mathrm{k} \text {. }\end{array}$ \\
\hline Horner \# 11 & $3084.00-3088.00$ & $3088.00-3093.00$ & High $\mathrm{k}$ in lower section. \\
\hline
\end{tabular}


APPENDIX D.

Appendix D. presents permeability versus porosity scatter plots (semi-log) and associated tables for each core well. The core porosity and permeability were used for values in Appendixes D. and E. The log porosity is included as a part of these tables but was not used for computations. 

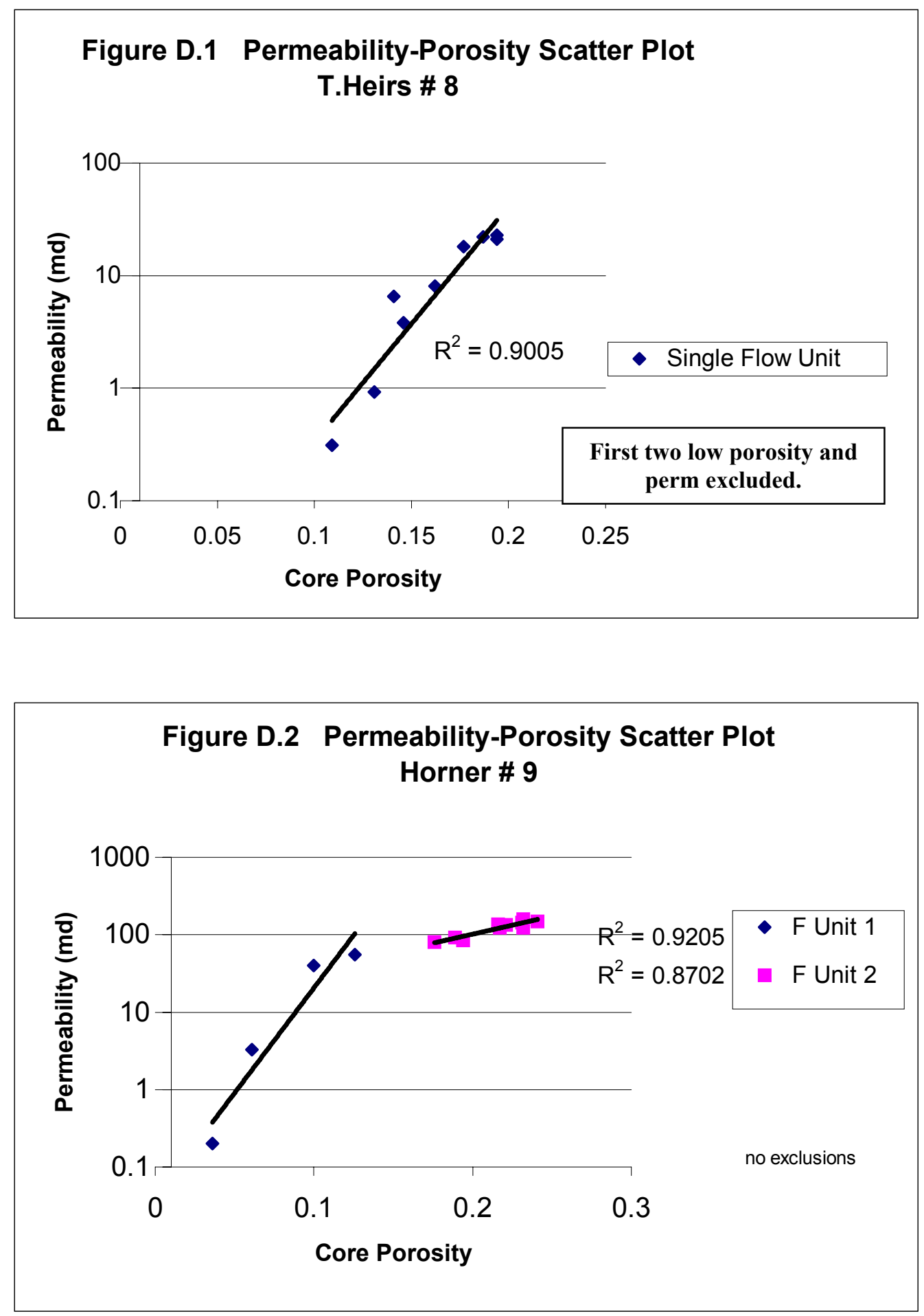

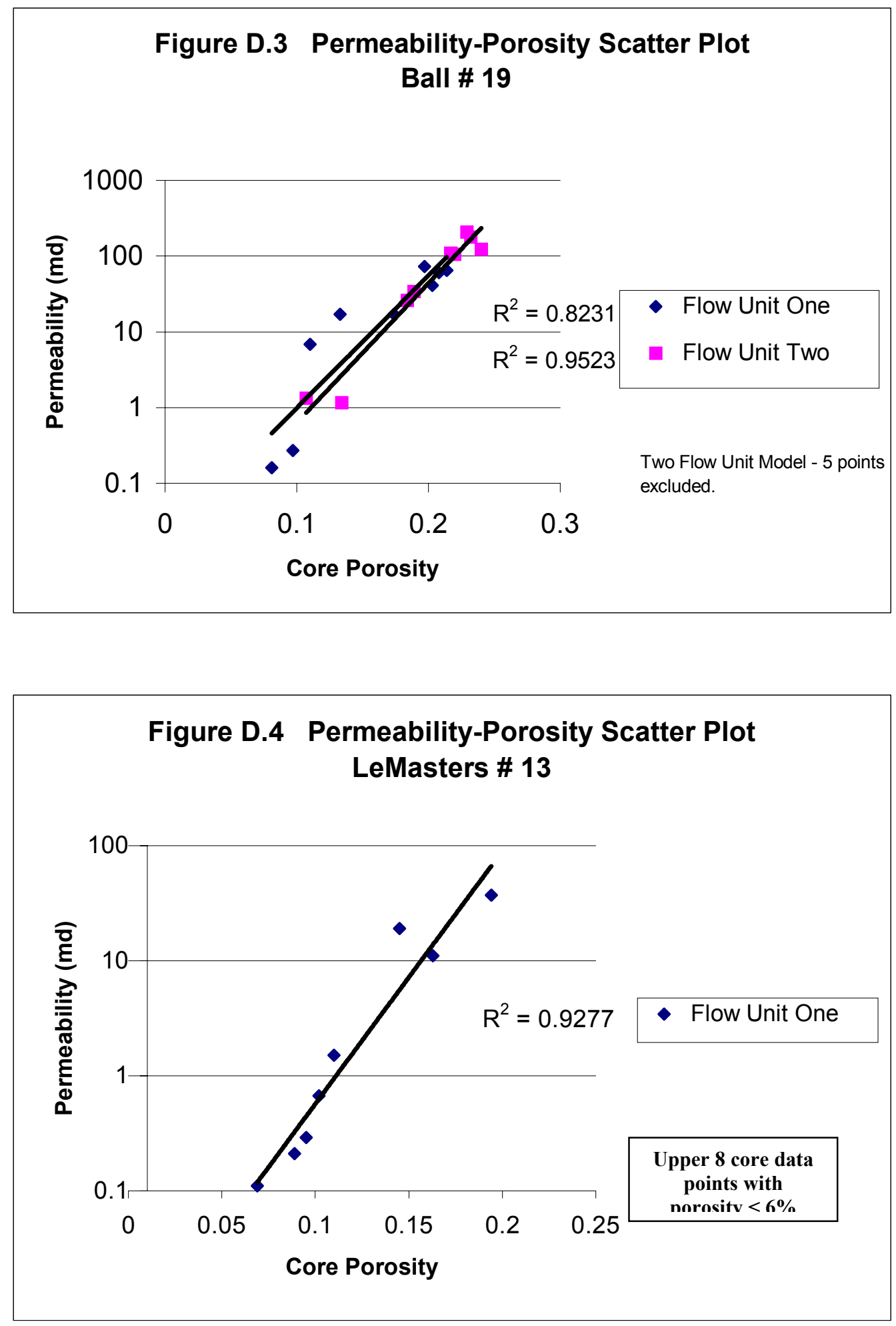

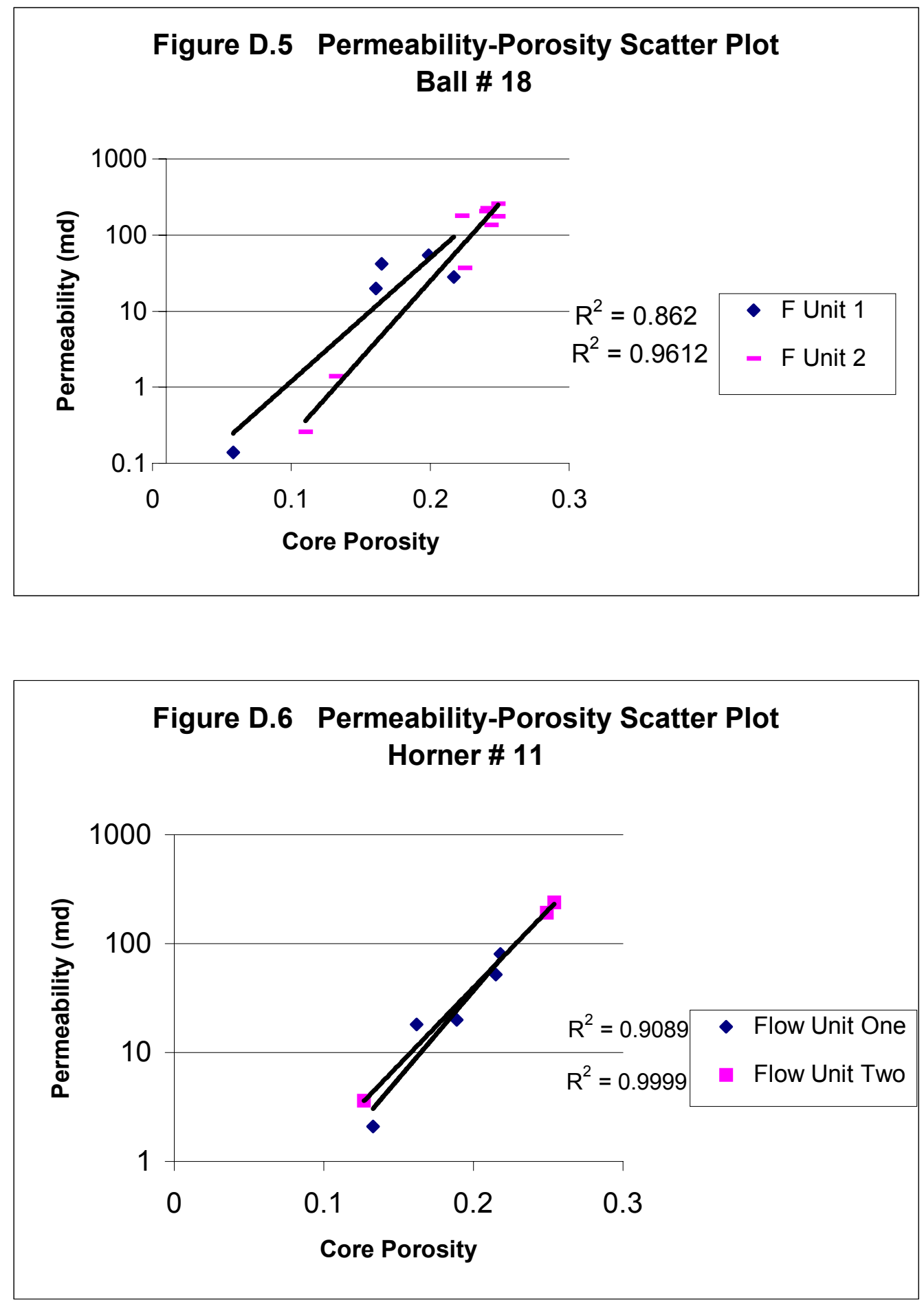


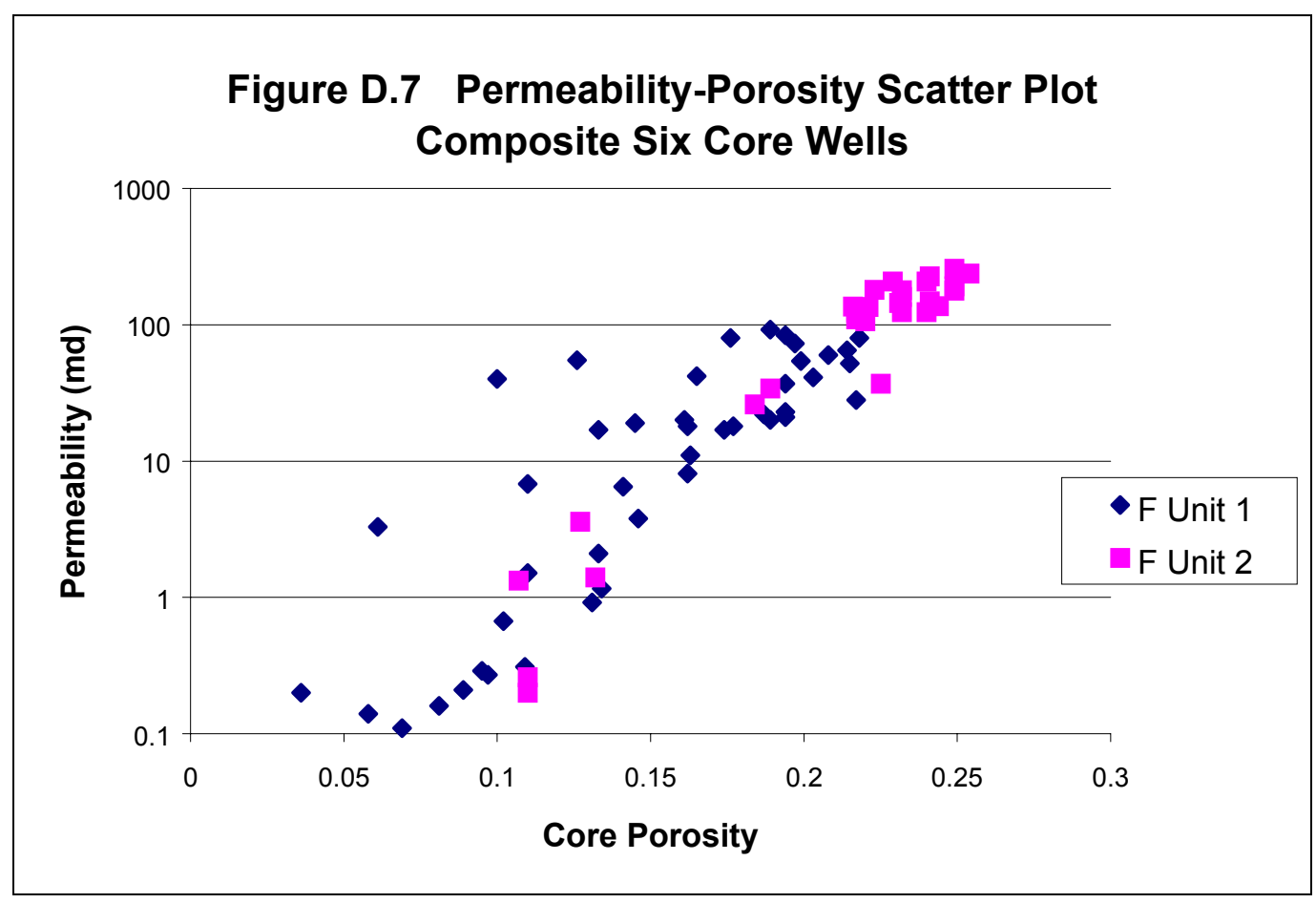

Figure D.8 Permeability-Porosity Scatter Plot Composite Six Core Wells

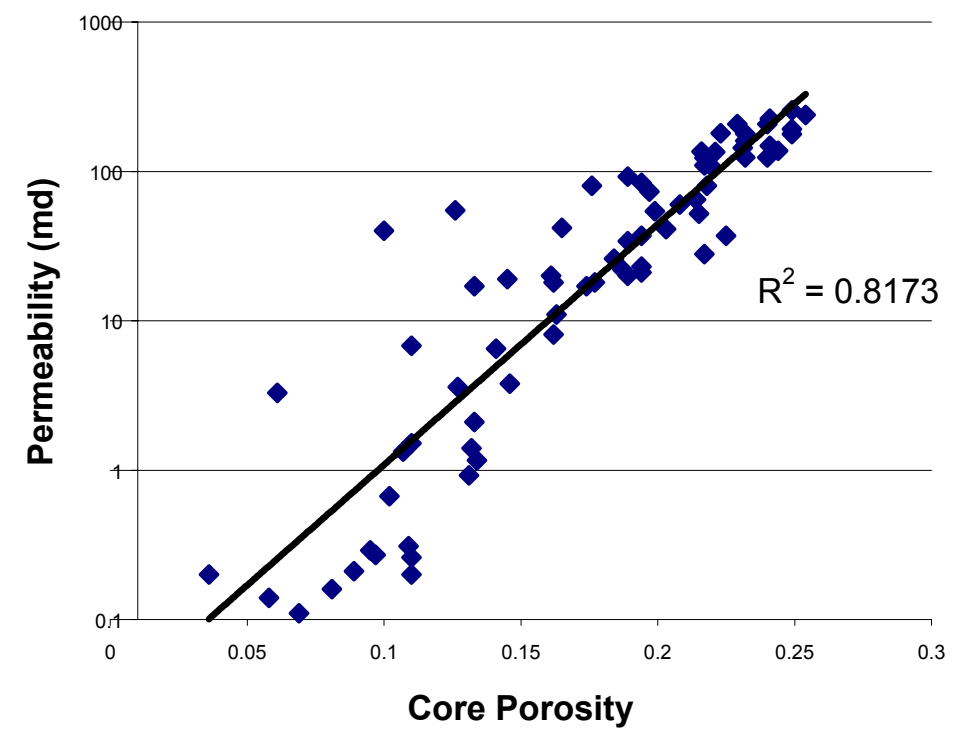




\begin{tabular}{|c|c|c|c|c|c|c|c|c|c|c|}
\hline \multirow{3}{*}{$\begin{array}{c}\text { DEPTH } \\
2785.25\end{array}$} & \multirow[b]{2}{*}{ F Unit } & & \multicolumn{5}{|c|}{$\begin{array}{l}\text { Table D.1 Data for Figures D.1 and E.1 } \\
\text { Well Name: T. Heirs \# } 8 \\
\text { Single Flow Unit Model } \\
\text { Highest Correlation with Two Points Excluded } \\
\text { Best Fit Results }\end{array}$} & \multirow{2}{*}{$.0314^{*}$} & \multirow[b]{2}{*}{$k(m d)$} & \multirow[b]{2}{*}{ exc } \\
\hline & & gr & cpor/1-c por & density & log por & core por & k/c por & & & \\
\hline & & 38.44 & 0.041667 & 2.519 & 0.09583 & 0.04 & 2.75 & 0.052071 & 0.11 & out \\
\hline 2786.75 & & 38.44 & 0.068376 & 2.544 & 0.08095 & 0.064 & 1.875 & 0.042996 & 0.12 & out \\
\hline 2788.75 & 1 & 51.811 & 0.150748 & 2.495 & 0.11012 & 0.131 & 7.0229 & 0.083212 & 0.92 & \\
\hline 2789.25 & 1 & 51.253 & 0.122335 & 2.488 & 0.11429 & 0.109 & 2.84404 & 0.052954 & 0.31 & \\
\hline 2791.5 & 1 & 39.554 & 0.164144 & 2.473 & 0.12321 & 0.141 & 46.0993 & 0.213195 & 6.5 & \\
\hline 2792.5 & 1 & 47.911 & 0.17096 & 2.467 & 0.12679 & 0.146 & 26.0274 & 0.160194 & 3.8 & \\
\hline 2793.75 & 1 & 51.811 & 0.193317 & 2.392 & 0.17143 & 0.162 & 50 & 0.222032 & 8.1 & \\
\hline 2794.75 & 1 & 49.025 & 0.215067 & 2.384 & 0.17619 & 0.177 & 101.695 & 0.31665 & 18 & \\
\hline 2795.25 & 1 & 49.025 & 0.230012 & 2.365 & 0.1875 & 0.187 & 117.647 & 0.340581 & 22 & \\
\hline 2796 & 1 & 52.925 & 0.240695 & 2.359 & 0.19107 & 0.194 & 118.557 & 0.341895 & 23 & \\
\hline 2797.5 & 1 & 74.652 & 0.240695 & 2.354 & 0.19405 & 0.194 & 108.247 & 0.326692 & 21 & \\
\hline
\end{tabular}

Table D.2 Data for Figures D.2 and E.2

Well Name: Horner \# 9

Two Flow Unit Model

Correlation with Zero Points Excluded

Best Fit Results

\begin{tabular}{ccccccccccc} 
Depth & F Unit & gr & c por/1-c por & Dens & $\begin{array}{c}\text { Log } \\
\text { Por }\end{array}$ & $\begin{array}{c}\text { Core } \\
\text { Por }\end{array}$ & k/ c por & Sqrt k/c por & k (md) & exc \\
2890 & 1 & 98.072 & 0.037344 & 2.627 & 0.03155 & 0.036 & 5.55556 & 0.074011 & 0.2 & \\
2891.75 & 1 & 41.322 & 0.064963 & 2.558 & 0.07262 & 0.061 & 54.0984 & 0.230952 & 3.3 & \\
2893 & 1 & 34.711 & 0.111111 & 2.477 & 0.12083 & 0.1 & 400 & 0.628 & 40 & \\
2893.5 & 1 & 33.058 & 0.144165 & 2.458 & 0.13214 & 0.126 & 436.508 & 0.656033 & 55 & \\
2895 & 1 & 39.669 & 0.233046 & 2.418 & 0.15595 & 0.189 & 486.772 & 0.692776 & 92 & \\
2895.75 & 1 & 42.424 & 0.213592 & 2.381 & 0.17798 & 0.176 & 454.545 & 0.66945 & 80 & \\
2896.5 & 1 & 41.873 & 0.240695 & 2.347 & 0.19821 & 0.194 & 432.99 & 0.653384 & 84 & \\
2898.25 & 2 & 41.322 & 0.277139 & 2.341 & 0.20179 & 0.217 & 566.82 & 0.747571 & 123 & \\
2898.75 & 2 & 41.873 & 0.27551 & 2.334 & 0.20595 & 0.216 & 629.63 & 0.787902 & 136 & \\
2900 & 2 & 45.73 & 0.302083 & 2.289 & 0.23274 & 0.232 & 689.655 & 0.824604 & 160 & \\
2901 & 2 & 50.689 & 0.283697 & 2.281 & 0.2375 & 0.221 & 610.86 & 0.776069 & 135 & \\
2902 & 2 & 52.342 & 0.30039 & 2.274 & 0.24167 & 0.231 & 623.377 & 0.78398 & 144 & \\
2903 & 2 & 55.647 & 0.302083 & 2.284 & 0.23571 & 0.232 & 534.483 & 0.725933 & 124 & \\
2903.5 & 2 & 55.647 & 0.317523 & 2.288 & 0.23333 & 0.241 & 614.108 & 0.77813 & 148 & \\
\hline
\end{tabular}




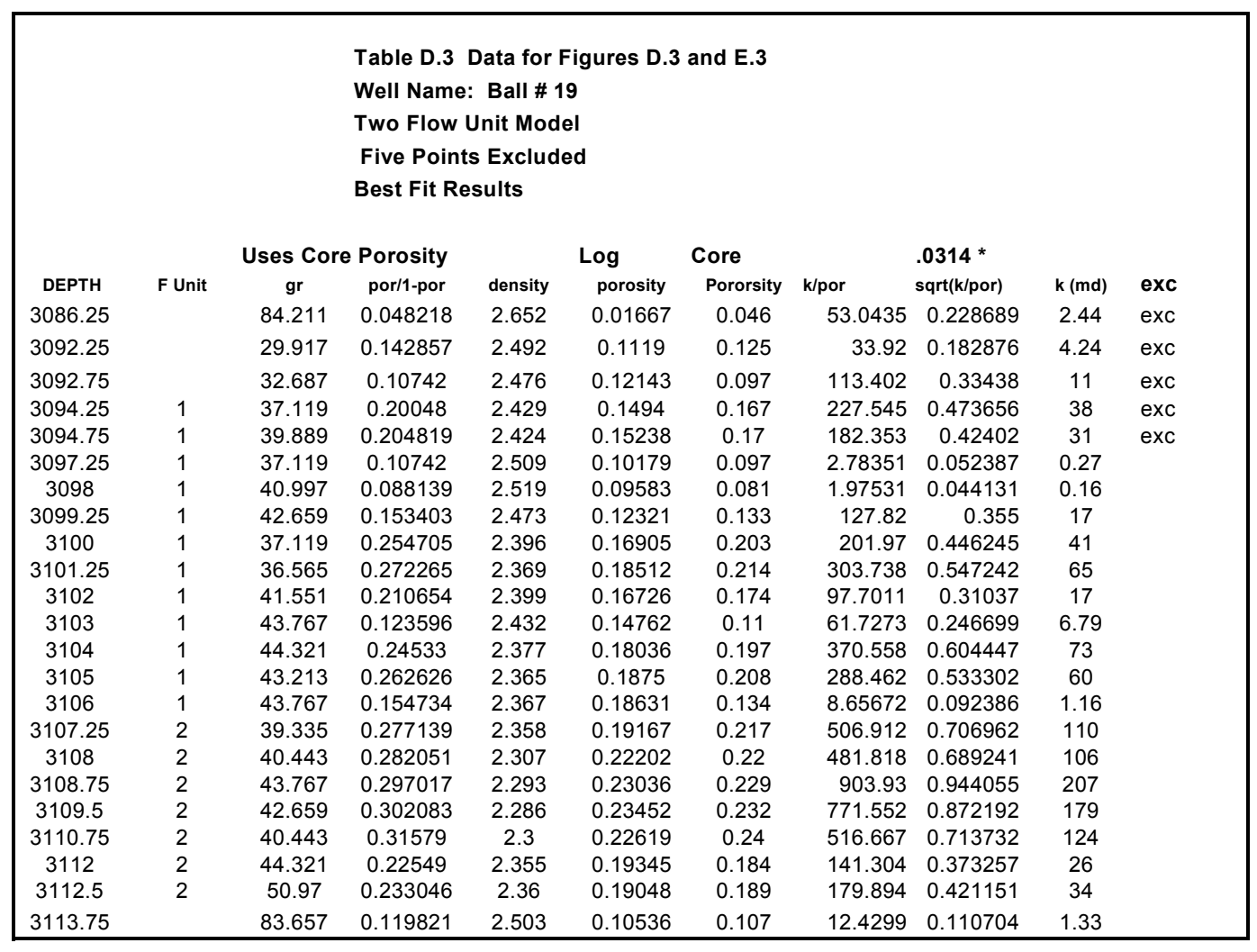

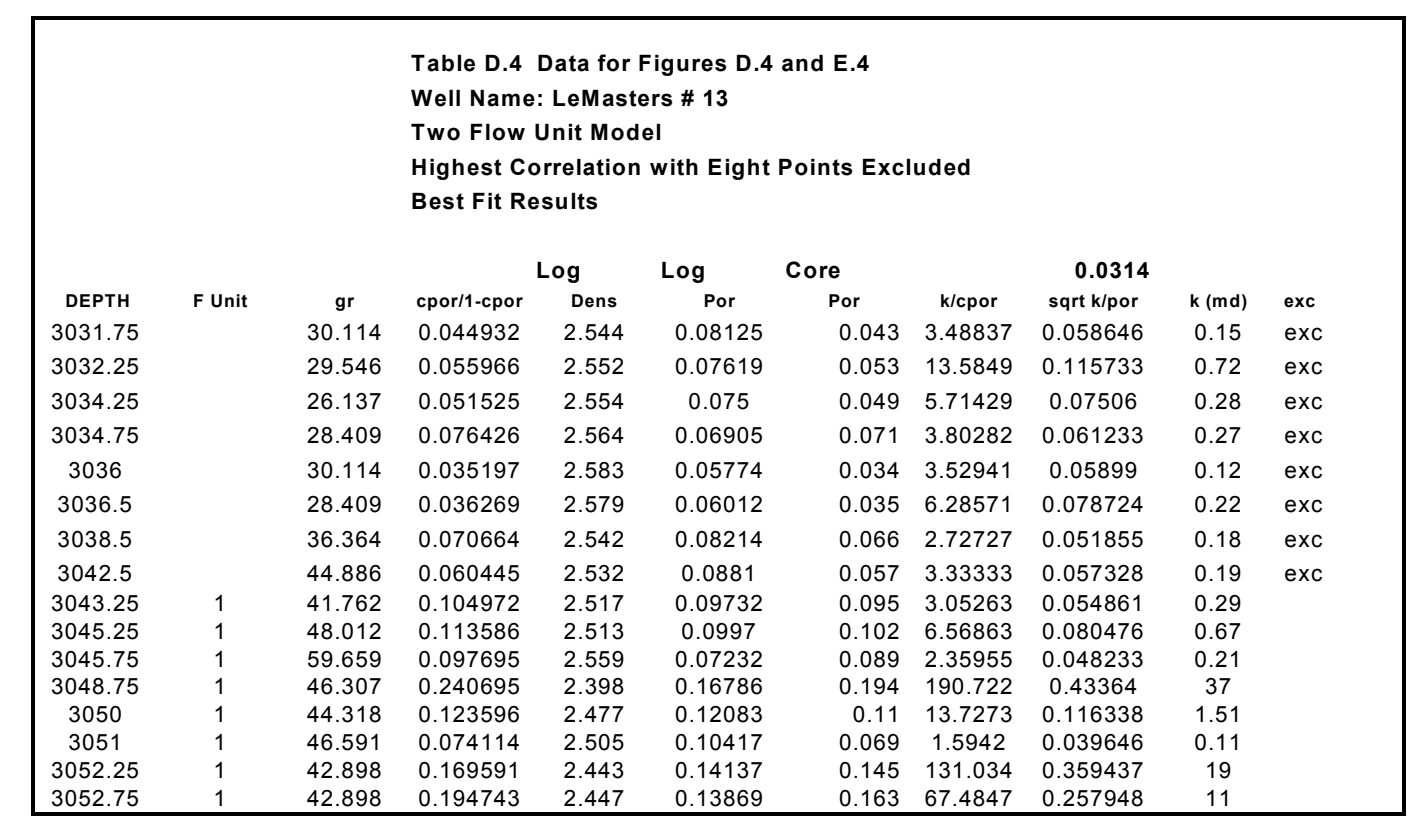




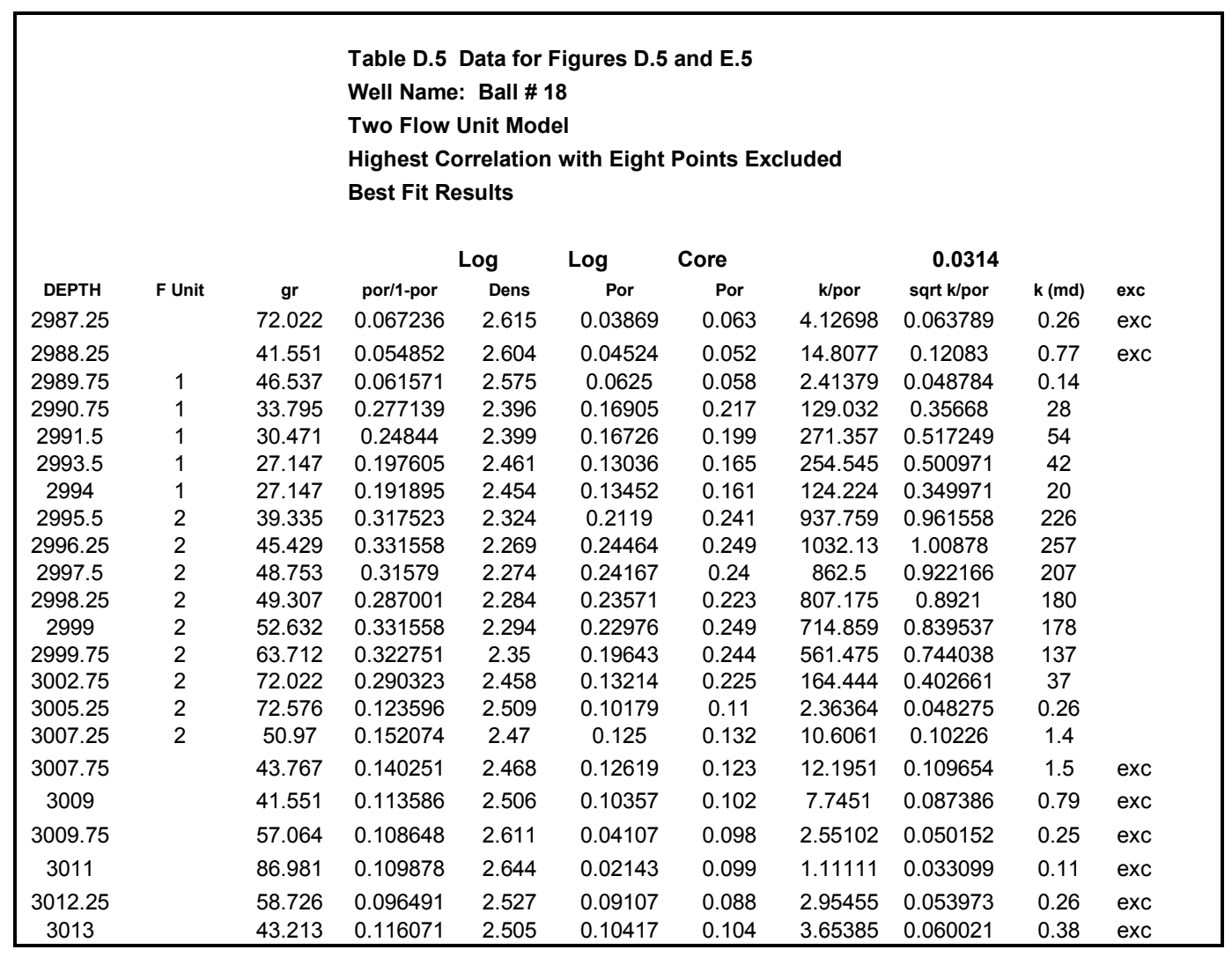

\begin{tabular}{|c|c|c|c|c|c|c|c|c|c|c|}
\hline \multirow[b]{2}{*}{ DEPTH } & \multirow[b]{2}{*}{ F Unit } & & $\begin{array}{l}\text { Table D.6 } \\
\text { Well Name } \\
\text { Two Flow } \\
\text { Highest Co } \\
\text { Best Fit Re } \\
\text { Data for Fi }\end{array}$ & $\begin{array}{l}\text { Perm-Pc } \\
\text { : Horner } \\
\text { Unit Moc } \\
\text { rrelation } \\
\text { sults } \\
\text { gures D. }\end{array}$ & $\begin{array}{l}\text { osity Sca } \\
\neq 11 \\
\text { Nith One } \\
\text { and E. } 6\end{array}$ & Points Excl & uded & 0.0314 & & \\
\hline & & $\mathrm{gr}$ & : por/1-c pol & density & log por & core por & $k / c$ por & Sqrt k/c por & $k(m d)$ & exc \\
\hline 3084.5 & 1 & 35.262 & 0.153403 & 2.498 & 0.10833 & 0.133 & 15.7895 & 0.124771 & 2.1 & \\
\hline 3085.25 & 1 & 36.915 & 0.193317 & 2.479 & 0.11964 & 0.162 & 111.111 & 0.330985 & 18 & \\
\hline 3088.75 & 1 & 45.73 & 0.233046 & 2.349 & 0.19702 & 0.189 & 105.82 & 0.323008 & 20 & \\
\hline 3089.5 & 1 & 33.058 & 0.273885 & 2.314 & 0.21786 & 0.215 & 241.86 & 0.488329 & 52 & \\
\hline 3090.5 & 1 & 29.201 & 0.278772 & 2.33 & 0.20833 & 0.218 & 366.972 & 0.601515 & 80 & \\
\hline 3092 & 2 & 47.383 & 0.340483 & 2.309 & 0.22083 & 0.254 & 937.008 & 0.961172 & 238 & \\
\hline 3092.5 & 2 & 53.994 & 0.331558 & 2.34 & 0.20238 & 0.249 & 771.084 & 0.871928 & 192 & \\
\hline 3093.25 & 2 & 62.81 & 0.145475 & 2.503 & 0.10536 & 0.127 & 28.3465 & 0.167178 & 3.6 & \\
\hline 3100.5 & 2 & 46.832 & 0.123596 & 2.501 & 0.10655 & 0.11 & 1.81818 & 0.04234 & 0.2 & exc \\
\hline
\end{tabular}




\section{APPENDIX E.}

Appendix E. presents flow zone indicator scatter plots and associated tables for each core well. Supporting data for Appendix E. is included as a part of Appendix D. 

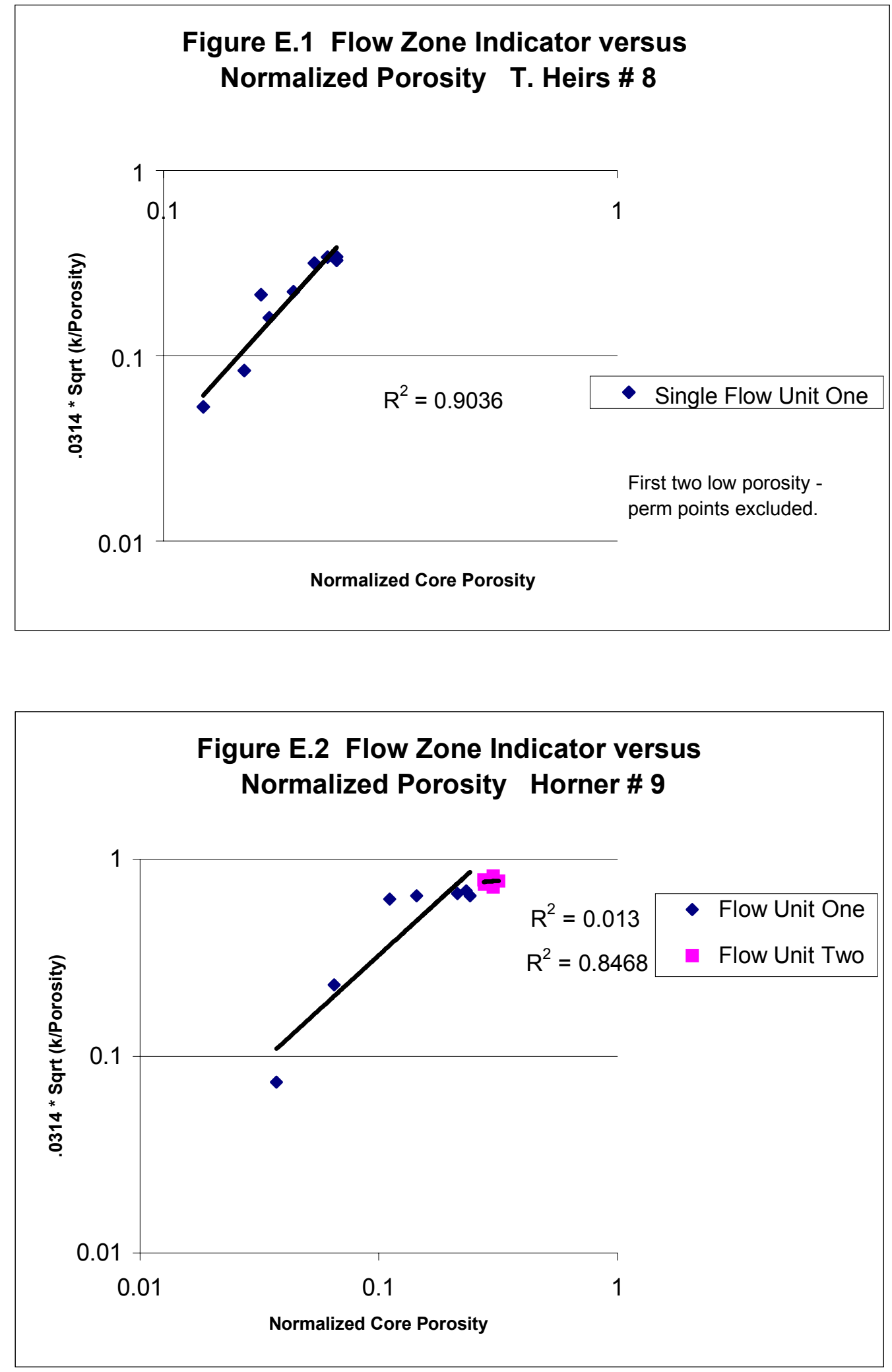

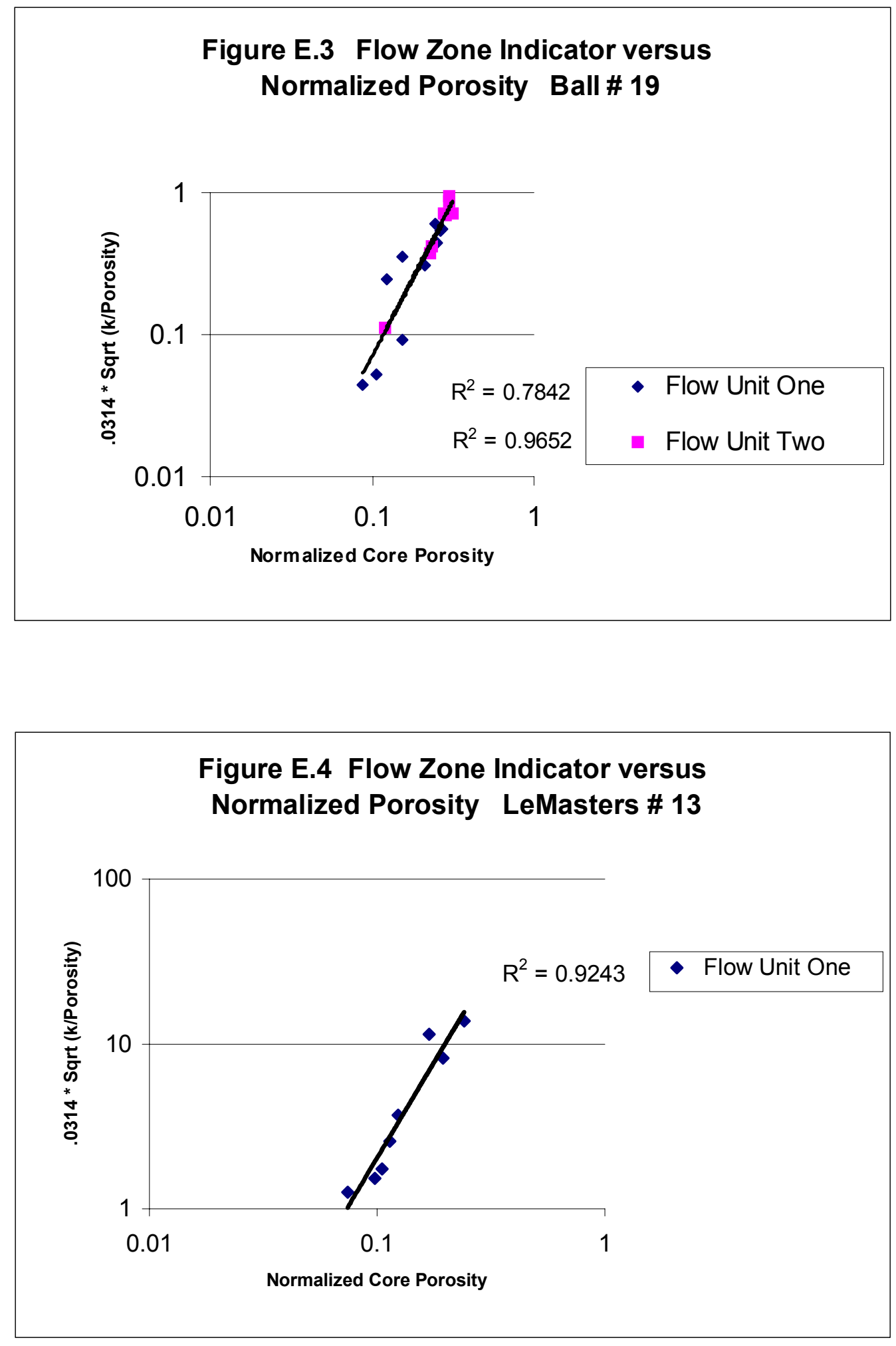

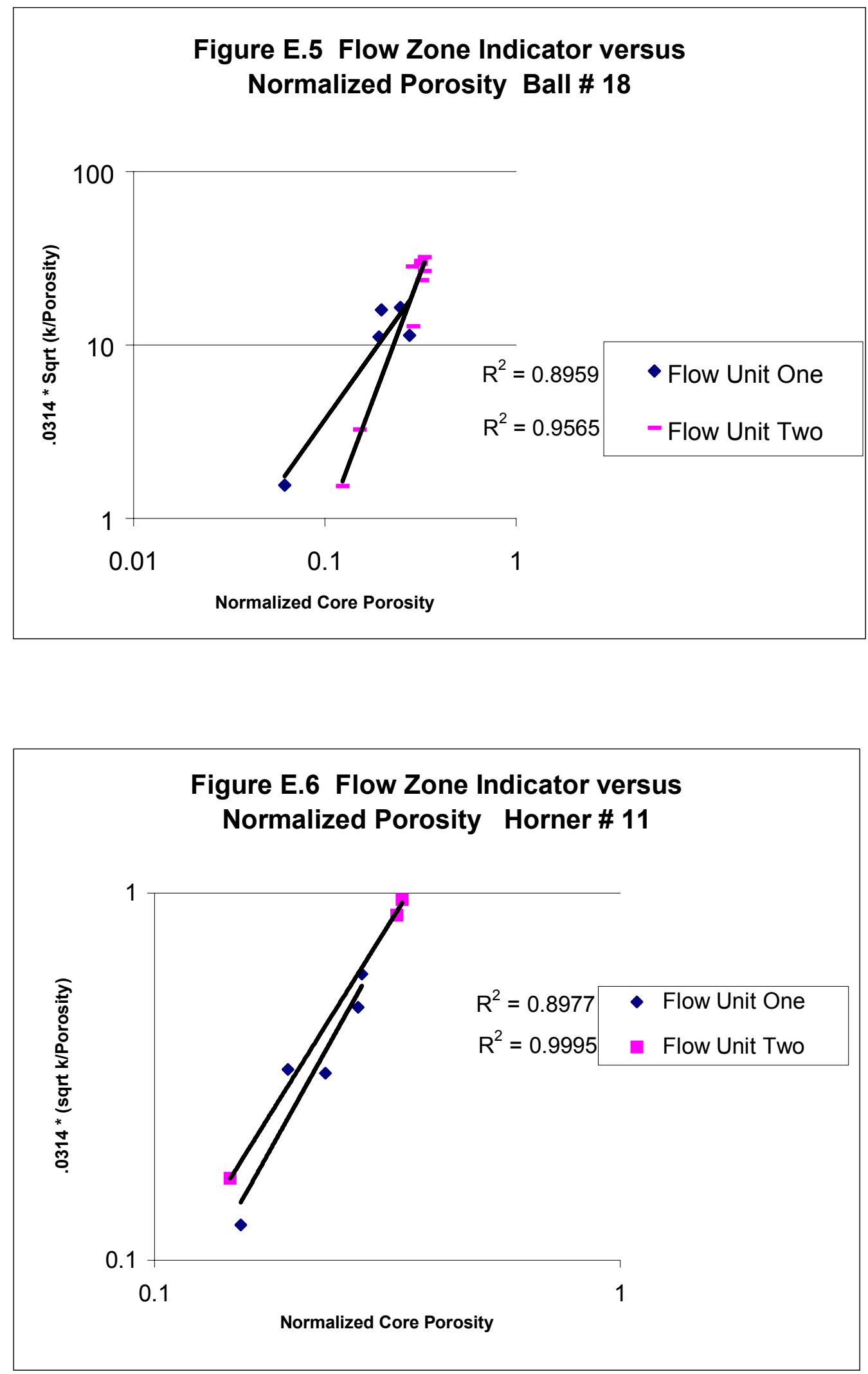

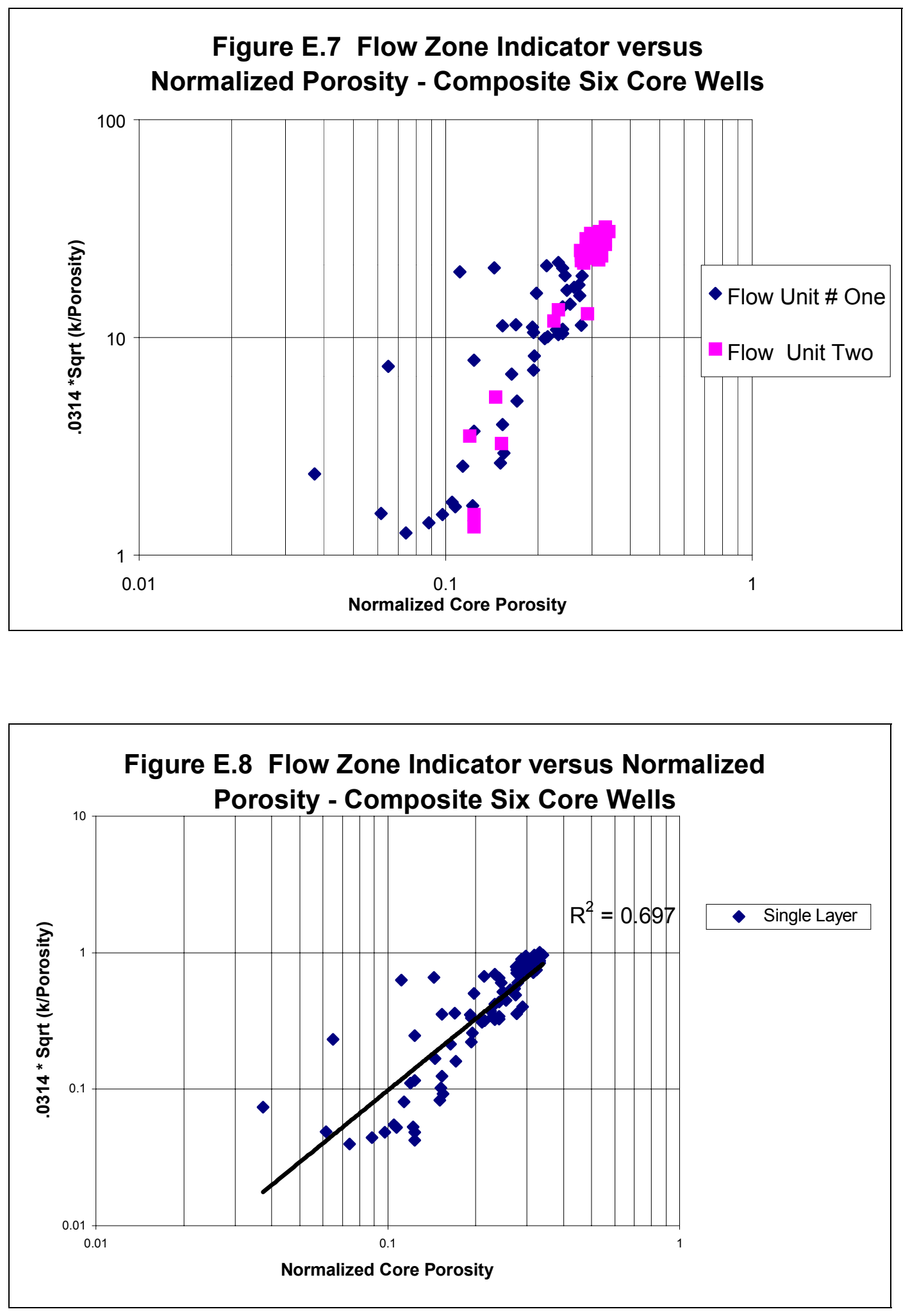


\section{APPENDIX F.}

Appendix F. presents the results of Kohonen Artificial Neural Network analysis for two and three output categories. 


\begin{tabular}{|c|c|c|c|c|c|c|c|c|c|c|}
\hline & \multicolumn{10}{|c|}{$\begin{array}{l}\text { Table F.1 Kohonen Network (Two Output C } \\
\text { ANN Analysis of Core Data Set } \\
\text { Winning Neuron is Set at } 1.0 \\
\text { Analysis for Two Sets }\end{array}$} \\
\hline $\begin{array}{l}\text { ANN Inputs } \\
\text { Well Name }\end{array}$ & Depth & $\begin{array}{c}\text { input } \\
\text { gr }\end{array}$ & $\begin{array}{l}\text { input } \\
\text { rhob }\end{array}$ & $\begin{array}{c}\text { input } \\
\text { gr' }\end{array}$ & $\begin{array}{l}\text { input } \\
\text { rhob' }\end{array}$ & $\begin{array}{l}\text { input } \\
\text { gr bl }\end{array}$ & $\begin{array}{c}\text { input } \\
\text { rhob bl }\end{array}$ & $\begin{array}{l}\text { input } \\
k \text { (md) }\end{array}$ & Nwk 1 & Nwk 2 \\
\hline Ball \# 18 & 2987.25 & 572.02 & 22.615 & -34.35 & -0.026 & 107 & 2.72 & 0.26 & 1 & 0 \\
\hline Ball \# 18 & 2988 & 49.31 & 12.61 & -26.59 & -0.016 & 107 & 2.72 & 0.77 & 1 & 0 \\
\hline Ball \# 18 & 2989 & 43.77 & 72.586 & 7.756 & -0.058 & 107 & 2.72 & 0.06 & 1 & 0 \\
\hline Ball \# 18 & 2990 & 47.65 & 52.499 & -15.51 & -0.326 & 107 & 2.72 & 0.14 & 1 & 0 \\
\hline \multirow[t]{2}{*}{ Ball \# 18} & 2991 & 31.03 & 32.396 & -5.54 & 0 & 107 & 2.72 & 28 & 1 & 0 \\
\hline & & Beginr & ining of & transitior & n zone & & & & & \\
\hline Ball \# 18 & 2992 & 28.26 & 62.411 & -2.216 & 0.032 & 107 & 2.72 & 54 & 0 & 1 \\
\hline Ball \# 18 & 2993 & 28.81 & 12.461 & -1.108 & 30 & 107 & 2.72 & 42 & 1 & 0 \\
\hline \multirow[t]{2}{*}{ Ball \# 18} & 2994 & 27.15 & 52.454 & 1.108 & $3-0.03$ & 107 & 2.72 & 20 & 1 & 0 \\
\hline & & End of & f FU 1 a & and begir & inning of & f FU 2 & & & & \\
\hline Ball \# 18 & 2995 & 32.69 & 92.386 & 8.864 & -0.144 & 107 & 2.72 & 226 & 0 & 1 \\
\hline Ball \# 18 & 2996 & 43.21 & 12.286 & 7.756 & -0.072 & 107 & 2.72 & 257 & 0 & 1 \\
\hline Ball \# 18 & 2997 & 47.09 & 92.265 & 2.216 & 0.02 & 107 & 2.72 & 207 & 0 & 1 \\
\hline Ball \# 18 & 2998 & 49.31 & 12.284 & 1.108 & 0.01 & 107 & 2.72 & 180 & 0 & 1 \\
\hline Ball \# 18 & 2999 & 52.63 & 32.294 & 11.08 & 0.028 & 107 & 2.72 & 178 & 0 & 1 \\
\hline \multirow[t]{2}{*}{ Ball \# 18} & 3000 & 72.58 & B 2.356 & 17.728 & 0.012 & 107 & 2.72 & 137 & 0 & 1 \\
\hline & & End of & f FU 2 a & and low $\mathrm{k}$ & $\mathrm{k}$ below & & & & & \\
\hline Ball \# 18 & 3001 & 70.91 & 12.492 & -1.108 & 0.016 & 107 & 2.72 & 0.06 & 1 & 0 \\
\hline Ball \# 18 & 3002 & 69.81 & 12.481 & 2.216 & -0.06 & 107 & 2.72 & 0.05 & 1 & 0 \\
\hline Ball \# 18 & 3003 & 71.47 & 72.465 & -2.216 & 0.032 & 107 & 2.72 & 37 & 1 & 0 \\
\hline Ball \# 18 & 3004 & 65.37 & 72.501 & -2.216 & 0.032 & 107 & 2.72 & 0.1 & 1 & 0 \\
\hline Ball \# 18 & 3005 & 70.91 & 12.513 & 14.404 & -0.002 & 107 & 2.72 & 0.26 & 1 & 0 \\
\hline Ball \# 18 & 3006 & 75.35 & 52.497 & 0 & -0.014 & 107 & 2.72 & 0.07 & 1 & 0 \\
\hline Ball \# 18 & 3007 & 56.51 & 12.477 & -16.62 & -0.02 & 107 & 2.72 & 1.4 & 1 & 0 \\
\hline Ball \# 18 & 3008 & 39.89 & 92.463 & -9.972 & -0.01 & 107 & 2.72 & 1.5 & 1 & 0 \\
\hline Ball \# 18 & 3009 & 41.55 & 52.506 & 16.62 & 0.286 & 107 & 2.72 & 0.79 & 1 & 0 \\
\hline Ball \# 18 & 3010 & 69.25 & 52.652 & 55.402 & 0.082 & 107 & 2.72 & 0.25 & 1 & 0 \\
\hline Ball \# 18 & 3011 & 86.98 & $\begin{array}{l}82.644 \\
\end{array}$ & -1.108 & $3-0.008$ & 107 & 2.72 & 0.11 & 1 & 0 \\
\hline Ball \# 18 & 3012 & 76.45 & 52.546 & -45.43 & -0.088 & 107 & 2.72 & 0.26 & 1 & 0 \\
\hline Ball \# 18 & 3013 & 43.21 & 12.505 & 1.108 & $3 \quad 0$ & 107 & 2.72 & 0.38 & 1 & 0 \\
\hline
\end{tabular}




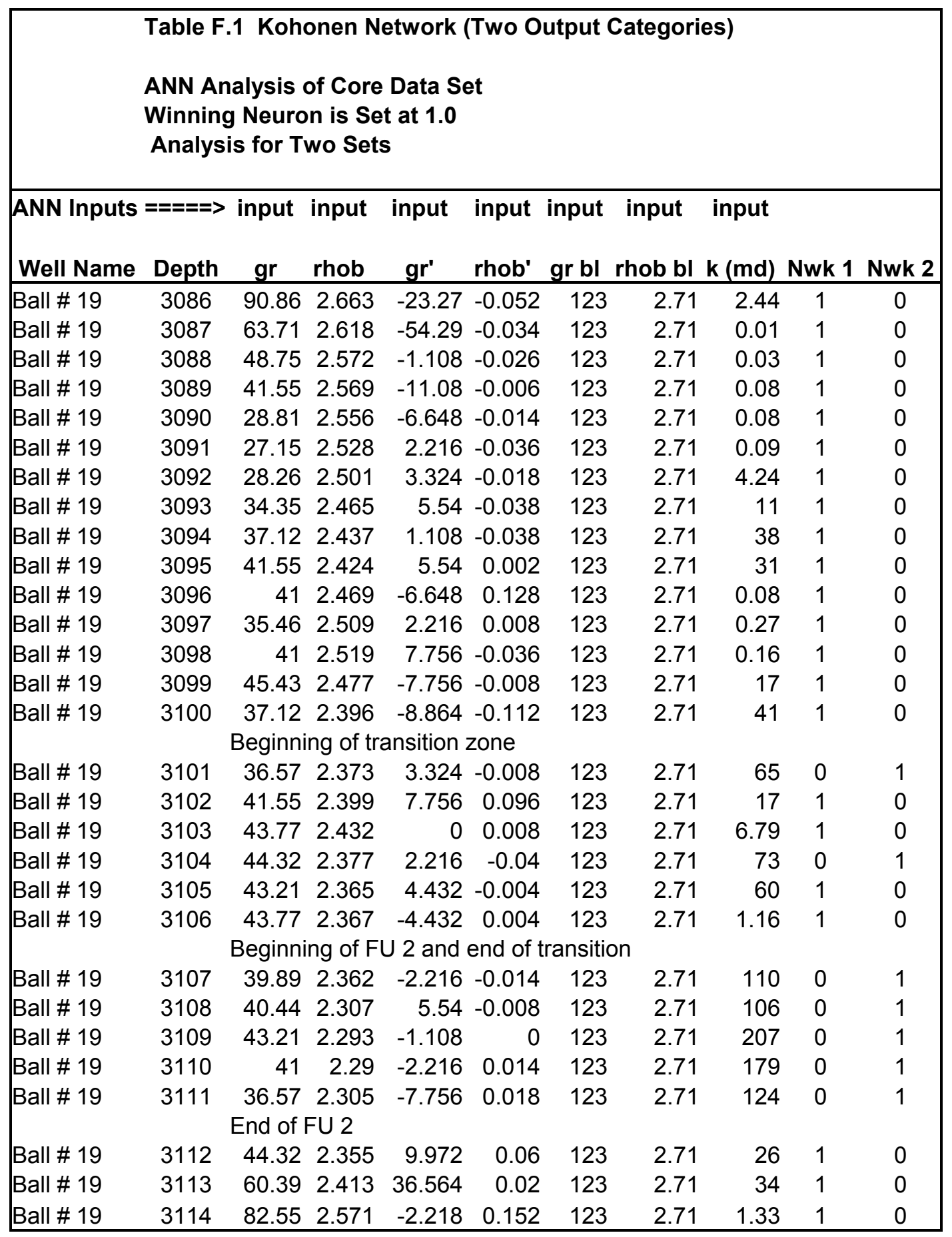




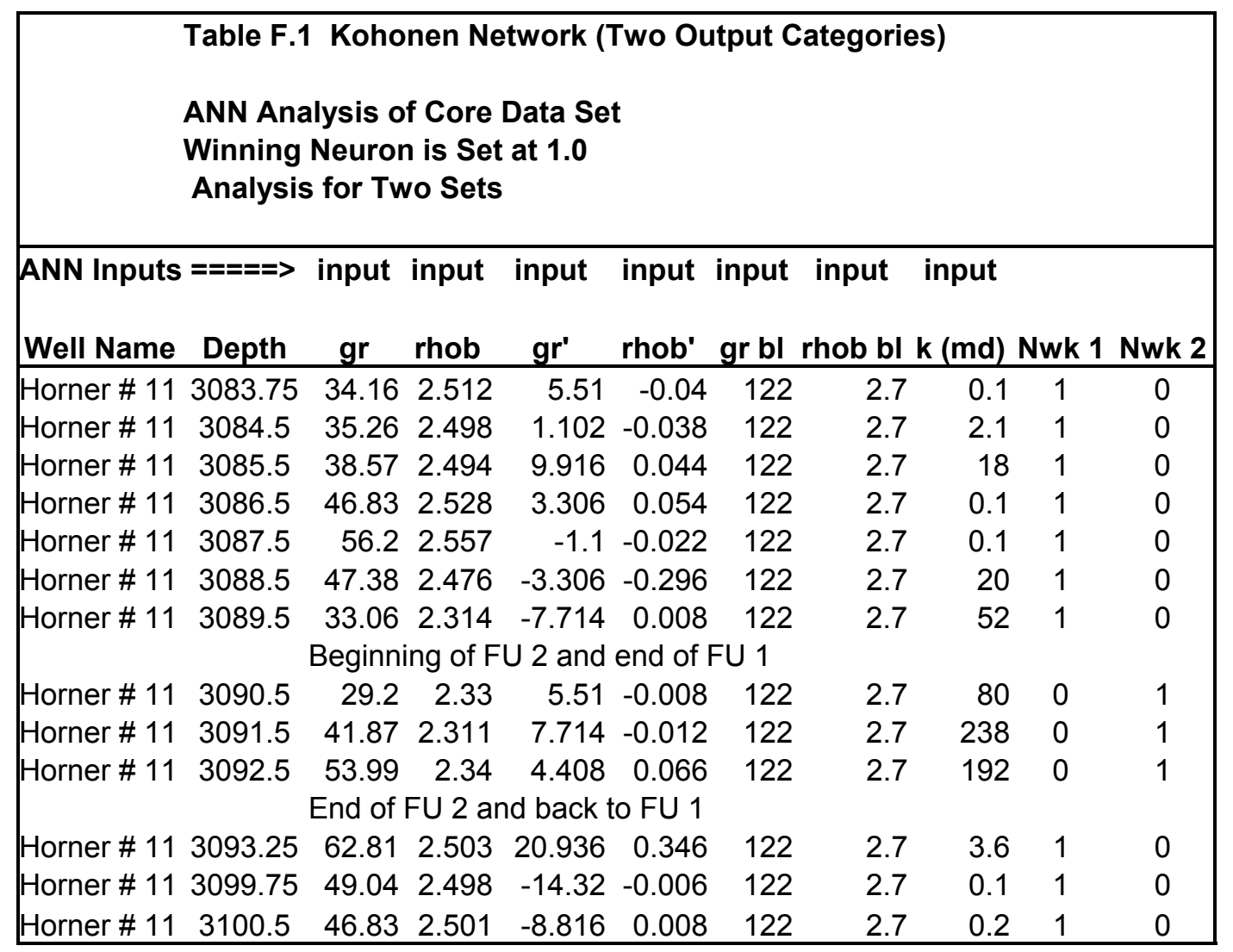

\begin{tabular}{|c|c|c|c|c|c|c|c|c|c|c|}
\hline Horner \# 9 & 2889 & 120.7 & 2.652 & 2.204 & -0.014 & 130 & 2.71 & 0.1 & 1 & 0 \\
\hline Horner \# 9 & 2890 & 98.07 & 2.627 & -55.1 & -0.044 & 130 & 2.71 & 0.2 & 1 & 0 \\
\hline Horner \# 9 & 2891 & 47.93 & 2.585 & -16.53 & -0.022 & 130 & 2.71 & 0.1 & 1 & 0 \\
\hline Horner \# 9 & 2892 & 38.02 & 2.534 & -11.02 & -0.096 & 130 & 2.71 & 3.3 & 1 & 0 \\
\hline Horner \# 9 & 2893 & 34.71 & 2.477 & -1.102 & -0.022 & 130 & 2.71 & 40 & 1 & 0 \\
\hline Horner \# 9 & 2894 & 34.16 & 2.442 & 7.714 & -0.03 & 130 & 2.71 & 55 & 1 & 0 \\
\hline \multicolumn{11}{|c|}{ End of FU 1 and beginning of FU 2} \\
\hline Horner \# 9 & 2895 & 39.67 & 2.418 & 5.508 & -0.028 & 130 & 2.71 & 92 & 0 & 1 \\
\hline Horner \# 9 & 2896 & 42.42 & 2.37 & 0 & -0.022 & 130 & 2.71 & 80 & 0 & 1 \\
\hline Horner \# 9 & 2897 & 41.32 & 2.341 & -1.102 & -0.006 & 130 & 2.71 & 84 & 0 & 1 \\
\hline Horner \# 9 & 2898 & 41.32 & 2.341 & 0 & 0 & 130 & 2.71 & 123 & 0 & 1 \\
\hline Horner \# 9 & 2899 & 42.42 & 2.332 & 4.408 & -0.024 & 130 & 2.71 & 136 & 0 & 1 \\
\hline Horner \# 9 & 2900 & 45.73 & 2.289 & 5.51 & -0.014 & 130 & 2.71 & 160 & 0 & 1 \\
\hline Horner \# 9 & 2901 & 50.69 & 2.281 & 3.306 & -0.014 & 130 & 2.71 & 135 & 0 & 1 \\
\hline Horner \# 9 & 2902 & 52.34 & 2.274 & 2.204 & 0.002 & 130 & 2.71 & 144 & 0 & 1 \\
\hline Horner \# 9 & 2903 & 55.65 & 2.284 & 1.102 & 0.01 & 130 & 2.71 & 124 & 0 & 1 \\
\hline Horner \# 9 & 2904 & 56.2 & 2.297 & 4.408 & 0.046 & 130 & 2.71 & 148 & 0 & 1 \\
\hline Horner \# 9 & 2905 & 61.71 & 2.327 & 3.306 & 0.048 & 130 & 2.71 & 203 & 0 & 1 \\
\hline Horner \# 9 & 2906 & 73.28 & 2.375 & 14.326 & 0.124 & 130 & 2.71 & 214 & 0 & 1 \\
\hline
\end{tabular}




\begin{tabular}{|c|c|c|c|c|c|c|c|c|c|c|}
\hline & $\begin{array}{l}\text { Table F. } \\
\text { ANN Ana } \\
\text { Winning } \\
\text { Analysis }\end{array}$ & $\begin{array}{l}\text { Koh } \\
\text { alysis } \\
\text { Neuro } \\
5 \text { for T }\end{array}$ & $\begin{array}{l}\text { onen N } \\
\text { of Core } \\
\text { on is Se } \\
\text { wo Set }\end{array}$ & $\begin{array}{l}\text { etwork } \\
\text { Data S } \\
\text { at } 1.0 \\
\text { s }\end{array}$ & $\begin{array}{l}\text { (Two O } \\
\text { set }\end{array}$ & Jutput & t Categor & ries) & & \\
\hline $\begin{array}{l}\text { ANN Inputs } \\
\text { Well Name }\end{array}$ & $s====\Rightarrow$ & $\begin{array}{c}\text { input } \\
\text { gr }\end{array}$ & $\begin{array}{l}\text { input } \\
\text { rhob }\end{array}$ & $\begin{array}{c}\text { input } \\
\text { gr' } \\
\end{array}$ & $\begin{array}{l}\text { input } \\
\text { rhob' }\end{array}$ & $\begin{array}{l}\text { input } \\
\text { gr bl }\end{array}$ & $\begin{array}{l}\text { input } \\
\text { rhob bl }\end{array}$ & $\begin{array}{l}\text { input } \\
\text { k (md) }\end{array}$ & Nwk 1 & Nwk 2 \\
\hline LeMas \# 13 & 33030.75 & 28.13 & 32.527 & 1.136 & 0.022 & 115 & $5 \quad 2.72$ & 0.05 & 1 & 0 \\
\hline LeMas \# 13 & 3031.75 & 30.11 & 2.544 & 0 & 0.022 & 115 & 2.72 & 0.15 & 1 & 0 \\
\hline LeMas \# 13 & 3032.75 & 27.56 & 2.553 & -5.682 & -0.01 & 115 & 2.72 & 0.72 & 1 & 0 \\
\hline LeMas \# 13 & 3033.75 & 24.43 & 2.549 & 2.272 & 0.002 & 115 & 2.72 & 0.28 & 1 & 0 \\
\hline LeMas \# 13 & 3034.75 & 28.41 & 2.564 & 4.544 & 0.02 & 115 & 2.72 & 0.27 & 1 & 0 \\
\hline LeMas \# 13 & 3035.75 & 30.4 & 2.578 & -1.136 & 0.02 & 115 & 2.72 & 0.12 & 1 & 0 \\
\hline LeMas \# 13 & 3036.75 & 28.69 & 2.574 & 1.136 & -0.02 & 115 & 2.72 & 0.22 & 1 & 0 \\
\hline LeMas \# 13 & 3037.75 & 32.1 & 2.558 & 3.41 & -0.02 & 115 & 2.72 & 0.1 & 1 & 0 \\
\hline LeMas \# 13 & 3038.75 & 37.22 & 2.54 & 3.408 & -0.008 & 115 & 2.72 & 0.18 & 1 & 0 \\
\hline LeMas \# 13 & 3039.75 & 40.91 & 2.532 & 6.818 & -0.006 & 115 & 2.72 & 0.06 & 1 & 0 \\
\hline LeMas \# 13 & 3040.75 & 44.6 & 2.533 & 3.41 & -0.002 & 115 & 2.72 & 0.06 & 1 & 0 \\
\hline LeMas \# 13 & 3041.75 & 46.59 & 2.54 & 0 & 0.008 & 115 & 2.72 & 0.04 & 1 & 0 \\
\hline LeMas \# 13 & 3042.75 & 44.32 & 2.529 & -2.272 & -0.014 & 115 & 2.72 & 0.19 & 1 & 0 \\
\hline LeMas \# 13 & 3043.75 & 39.77 & 2.504 & 0 & -0.018 & 115 & 2.72 & 0.29 & 1 & 0 \\
\hline LeMas \# 13 & 3044.75 & 42.61 & 2.495 & 4.546 & 0.002 & 115 & 2.72 & 0.67 & 1 & 0 \\
\hline LeMas \# 13 & 3045.75 & 59.66 & 2.559 & 29.544 & 0.114 & 115 & 2.72 & 0.21 & 1 & 0 \\
\hline LeMas \# 13 & 3046.25 & 71.59 & 2.596 & 18.182 & 0.034 & 115 & 2.72 & 0.01 & 1 & 0 \\
\hline LeMas \# 13 & 3048 & 57.39 & 2.484 & -27.27 & -0.089 & 115 & 2.72 & 0.04 & 1 & 0 \\
\hline LeMas \# 13 & 3048.75 & 46.31 & 2.398 & -12.5 & -0.072 & 115 & 2.72 & 37 & 1 & 0 \\
\hline LeMas \# 13 & 3049.75 & 43.47 & 2.441 & 3.408 & 0.146 & 115 & 2.72 & 1.51 & 1 & 0 \\
\hline LeMas \# 13 & 3050.75 & 45.74 & 2.495 & 3.41 & 0.04 & 115 & 2.72 & 0.11 & 1 & 0 \\
\hline LeMas \# 13 & 3052 & 43.18 & 2.451 & -1.136 & -0.026 & 115 & 2.72 & 19 & 1 & 0 \\
\hline LeMas \# 13 & 3052.75 & 42.9 & 2.447 & 1.136 & 0.052 & 115 & 2.72 & 11 & 1 & 0 \\
\hline LeMas \# 13 & 3053.75 & 42.33 & 2.479 & -1.138 & 0.02 & 115 & 2.72 & 0.07 & 1 & 0 \\
\hline LeMas \# 13 & 3054.75 & 40.34 & 2.505 & -2.272 & 0.002 & 115 & 2.72 & 0.1 & 1 & 0 \\
\hline LeMas \# 13 & 3055.75 & 42.61 & 2.522 & 2.274 & 0.014 & 115 & 2.72 & 0.09 & 1 & 0 \\
\hline LeMas \# 13 & 3056.75 & 44.6 & 2.528 & -3.41 & -0.008 & 115 & 2.72 & 0.02 & 1 & 0 \\
\hline LeMas \# 13 & 3057.75 & 41.76 & 2.495 & -3.41 & -0.016 & 115 & 2.72 & 0.04 & 1 & 0 \\
\hline LeMas \# 13 & 3058.75 & 47.73 & $3 \quad 2.51$ & 22.728 & 0.088 & 115 & 2.72 & 0.04 & 1 & 0 \\
\hline LeMas \# 13 & 3059.75 & 76.7 & 2.599 & 47.726 & 0.146 & 115 & 2.72 & 0.05 & 1 & 0 \\
\hline
\end{tabular}




\begin{tabular}{|c|c|c|c|c|c|c|c|c|c|c|}
\hline & \multicolumn{10}{|c|}{$\begin{array}{l}\text { Table F.1 Kohonen Network (Tw } \\
\text { ANN Analysis of Core Data Set } \\
\text { Winning Neuron is Set at } 1.0 \\
\text { Analysis for Two Sets }\end{array}$} \\
\hline $\begin{array}{l}\text { ANN Inputs } \\
\text { Well Name }\end{array}$ & $====>$ & input & rhob & $\begin{array}{c}\text { input } \\
\text { gr' } \\
\end{array}$ & $\begin{array}{l}\text { input } \\
\text { rhob' }\end{array}$ & $\begin{array}{l}\text { input } \\
\text { gr bl }\end{array}$ & $\begin{array}{l}\text { input } \\
\text { rhob bl }\end{array}$ & $\begin{array}{l}\text { input } \\
\mathrm{k}(\mathrm{md})\end{array}$ & Nwk 1 & Nwk 2 \\
\hline T Heirs \# 8 & 2781.5 & 105.9 & 2.617 & 27.854 & 0.034 & 145 & 2.71 & 0.02 & 1 & 0 \\
\hline T Heirs \# 8 & 2782.5 & 116.4 & 2.634 & -40.11 & -0.018 & 145 & 2.71 & 0.03 & 1 & 0 \\
\hline T Heirs \# 8 & 2783.5 & 64.07 & 2.582 & -66.85 & -0.112 & 145 & 2.71 & 0.06 & 1 & 0 \\
\hline T Heirs \# 8 & 2784.5 & 47.91 & 2.507 & -8.914 & -0.024 & 145 & 2.71 & 0.11 & 1 & 0 \\
\hline T Heirs \# 8 & 2785.5 & 34.54 & 2.516 & -11.14 & 0.028 & 145 & 2.71 & 0.12 & 1 & 0 \\
\hline T Heirs \# 8 & 2786.5 & 36.77 & 2.54 & 8.914 & 0.014 & 145 & 2.71 & 0.02 & 1 & 0 \\
\hline T Heirs \# 8 & 2787.5 & 42.9 & 2.548 & 6.686 & -0.006 & 145 & 2.71 & 0.92 & 1 & 0 \\
\hline T Heirs \# 8 & 2788.5 & 49.58 & 2.503 & 8.914 & -0.018 & 145 & 2.71 & 0.31 & 1 & 0 \\
\hline T Heirs \# 8 & 2789.5 & 47.91 & 2.469 & -15.6 & -0.03 & 145 & 2.71 & 0.1 & 1 & 0 \\
\hline T Heirs \# 8 & 2790.5 & 37.33 & 2.467 & 0 & 0 & 145 & 2.71 & 6.5 & 1 & 0 \\
\hline T Heirs \# 8 & 2791.5 & 39.55 & 2.473 & 3.342 & 0.004 & 145 & 2.71 & 3.8 & 1 & 0 \\
\hline T Heirs \# 8 & 2792.5 & 47.91 & 2.467 & 4.456 & -0.014 & 145 & 2.71 & 8.1 & 1 & 0 \\
\hline T Heirs \# 8 & 2793.5 & 52.37 & 2.402 & -2.228 & -0.082 & 145 & 2.71 & 18 & 1 & 0 \\
\hline T Heirs \# 8 & 2794.5 & 49.58 & 2.384 & -2.228 & -0.006 & 145 & 2.71 & 22 & 1 & 0 \\
\hline T Heirs \# 8 & 2795.5 & 49.03 & 2.365 & 5.572 & -0.004 & 145 & 2.71 & 23 & 1 & 0 \\
\hline T Heirs \# 8 & 2796.5 & 55.71 & 2.352 & 7.8 & -0.006 & 145 & 2.71 & 21 & 1 & 0 \\
\hline
\end{tabular}




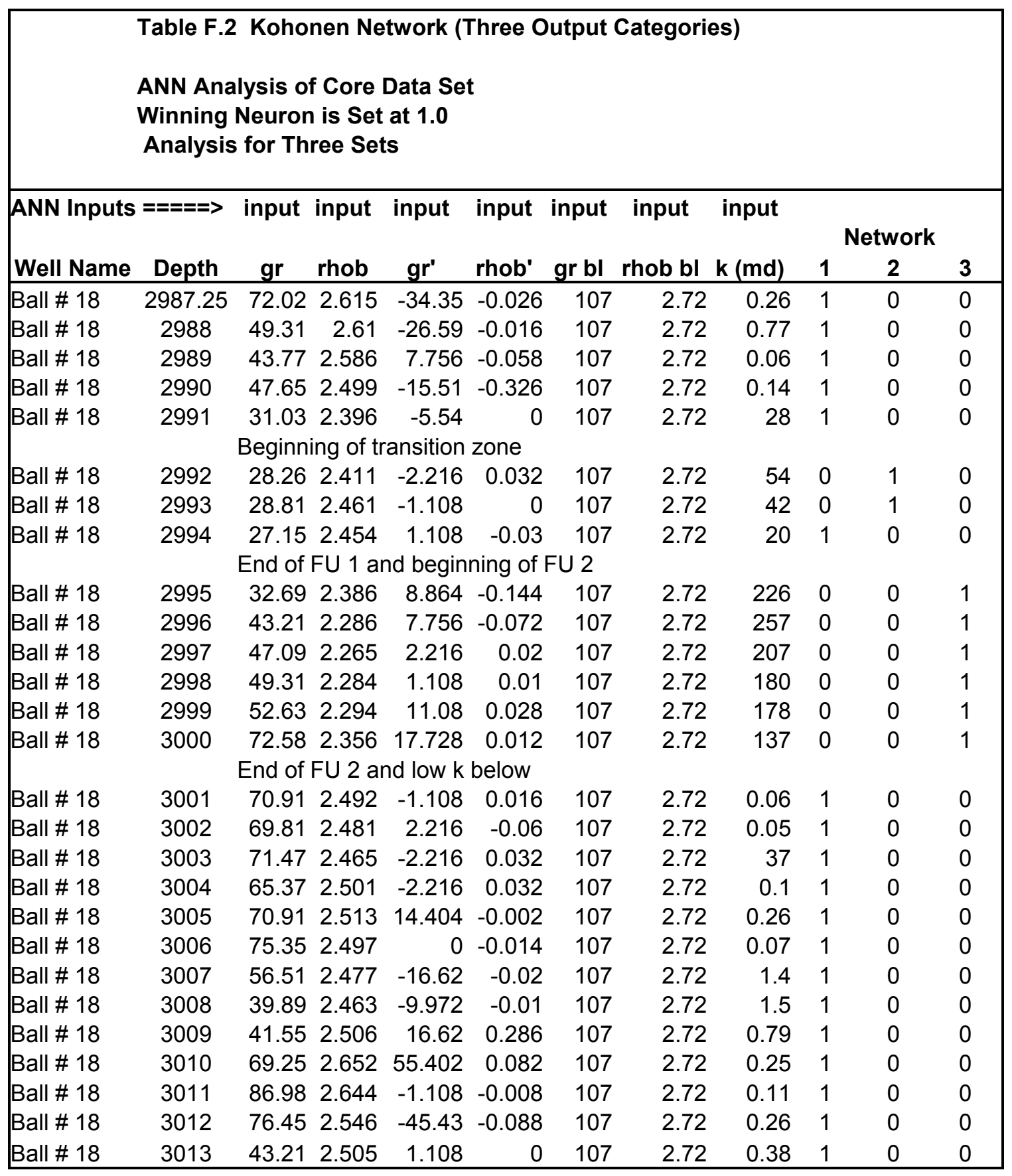




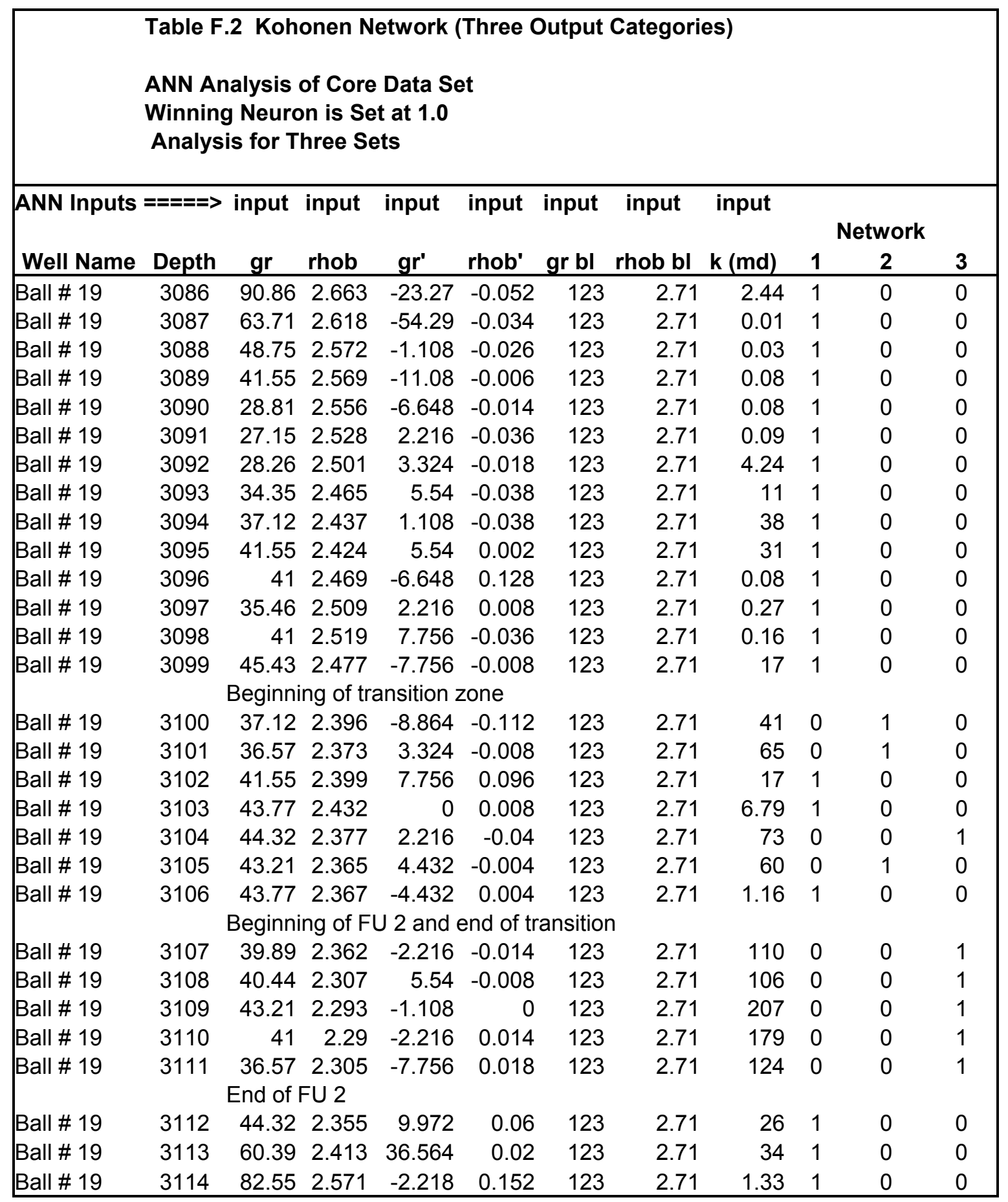




\begin{tabular}{|c|c|c|c|c|c|c|c|c|c|c|c|}
\hline & $\begin{array}{l}\text { Table F.2 } \\
\text { ANN Ana } \\
\text { Winning } \\
\text { Analysis }\end{array}$ & $\begin{array}{l}\text { Koho } \\
\text { lysis o } \\
\text { Neuror } \\
\text { for Th }\end{array}$ & $\begin{array}{l}\text { nen Ne } \\
\text { f Core I } \\
n \text { is Set } \\
\text { ree Set }\end{array}$ & $\begin{array}{l}\text { twork (T } \\
\text { Data Set } \\
\text { at } 1.0 \\
\text { s }\end{array}$ & hree O & utput & Categor & & & & \\
\hline ANN Inputs & $====>$ & input & input & input & input & input & input & input & & twc & \\
\hline Well Name & Depth & gr & rhob & $g^{\prime}$ & rhob' & gr bl & rhob bl & $k(m d)$ & 1 & 2 & 3 \\
\hline Horner \# 11 & 3083.75 & 34.16 & 2.512 & 5.51 & -0.04 & 122 & 2.7 & 0.1 & 1 & 0 & 0 \\
\hline Horner \# 11 & 3084.5 & 35.26 & 2.498 & 1.102 & -0.038 & 122 & 2.7 & 2.1 & 1 & 0 & 0 \\
\hline Horner \# 11 & 3085.5 & 38.57 & 2.494 & 9.916 & 0.044 & 122 & 2.7 & 18 & 1 & 0 & 0 \\
\hline Horner \# 11 & 3086.5 & 46.83 & 2.528 & 3.306 & 0.054 & 122 & 2.7 & 0.1 & 1 & 0 & 0 \\
\hline Horner \# 11 & 3087.5 & 56.2 & 2.557 & -1.1 & -0.022 & 122 & 2.7 & 0.1 & 1 & 0 & 0 \\
\hline Horner \# 11 & 3088.5 & $\begin{array}{r}47.38 \\
\text { Beginn }\end{array}$ & $\begin{array}{l}2.476 \\
\text { ing of } \mathrm{tr}\end{array}$ & $\begin{array}{r}-3.306 \\
\text { ansition }\end{array}$ & -0.296 & 122 & 2.7 & 20 & 1 & 0 & 0 \\
\hline Horner \# 11 & 3089.5 & 33.06 & 2.314 & -7.714 & 0.008 & 122 & 2.7 & 52 & 0 & 1 & 0 \\
\hline & & Beginn & ing of $F$ & U 2 and & end of $F$ & FU 1 & & & & & \\
\hline Horner \# 11 & 3090.5 & 29.2 & 2.33 & 5.51 & -0.008 & 122 & 2.7 & 80 & 0 & 0 & 1 \\
\hline Horner \# 11 & 3091.5 & 41.87 & 2.311 & 7.714 & -0.012 & 122 & 2.7 & 238 & 0 & 0 & 1 \\
\hline Horner \# 11 & 3092.5 & 53.99 & 2.34 & 4.408 & 0.066 & 122 & 2.7 & 192 & 0 & 0 & 1 \\
\hline & & End of & FU 2 ar & d back & to FU 1 & & & & & & \\
\hline Horner \# 11 & 3093.25 & 62.81 & 2.503 & 20.936 & 0.346 & 122 & 2.7 & 3.6 & 1 & 0 & 0 \\
\hline Horner \# 11 & 3099.75 & 49.04 & 2.498 & -14.32 & -0.006 & 122 & 2.7 & 0.1 & 1 & 0 & 0 \\
\hline Horner \# 11 & 3100.5 & 46.83 & 2.501 & -8.816 & 0.008 & 122 & 2.7 & 0.2 & 1 & 0 & 0 \\
\hline Horner \# 9 & 2889 & 120.7 & 2.652 & 2.204 & -0.014 & 130 & 2.71 & 0.1 & 1 & 0 & 0 \\
\hline Horner \# 9 & 2890 & 98.07 & 2.627 & -55.1 & -0.044 & 130 & 2.71 & 0.2 & 1 & 0 & 0 \\
\hline Horner \# 9 & 2891 & 47.93 & 2.585 & -16.53 & -0.022 & 130 & 2.71 & 0.1 & 1 & 0 & 0 \\
\hline Horner \# 9 & 2892 & 38.02 & 2.534 & -11.02 & -0.096 & 130 & 2.71 & 3.3 & 1 & 0 & 0 \\
\hline & & Beginn & ing of $t r$ & ansition & & & & & & & \\
\hline Horner \# 9 & 2893 & 34.71 & 2.477 & -1.102 & -0.022 & 130 & 2.71 & 40 & 0 & 1 & 0 \\
\hline Horner \# 9 & 2894 & 34.16 & 2.442 & 7.714 & -0.03 & 130 & 2.71 & 55 & 0 & 1 & 0 \\
\hline & & End of & FU 1 ar & d begin & ning of $F$ & FU 2 & & & & & \\
\hline Horner \# 9 & 2895 & 39.67 & 2.418 & 5.508 & -0.028 & 130 & 2.71 & 92 & 0 & 0 & 1 \\
\hline Horner \# 9 & 2896 & 42.42 & 2.37 & 0 & -0.022 & 130 & 2.71 & 80 & 0 & 0 & 1 \\
\hline Horner \# 9 & 2897 & 41.32 & 2.341 & -1.102 & -0.006 & 130 & 2.71 & 84 & 0 & 0 & 1 \\
\hline Horner \# 9 & 2898 & 41.32 & 2.341 & 0 & 0 & 130 & 2.71 & 123 & 0 & 0 & 1 \\
\hline Horner \# 9 & 2899 & 42.42 & 2.332 & 4.408 & -0.024 & 130 & 2.71 & 136 & 0 & 0 & 1 \\
\hline Horner \# 9 & 2900 & 45.73 & 2.289 & 5.51 & -0.014 & 130 & 2.71 & 160 & 0 & 0 & 1 \\
\hline Horner \# 9 & 2901 & 50.69 & 2.281 & 3.306 & -0.014 & 130 & 2.71 & 135 & 0 & 0 & 1 \\
\hline Horner \# 9 & 2902 & 52.34 & 2.274 & 2.204 & 0.002 & 130 & 2.71 & 144 & 0 & 0 & 1 \\
\hline Horner \# 9 & 2903 & 55.65 & 2.284 & 1.102 & 0.01 & 130 & 2.71 & 124 & 0 & 0 & 1 \\
\hline Horner \# 9 & 2904 & 56.2 & 2.297 & 4.408 & 0.046 & 130 & 2.71 & 148 & 0 & 0 & 1 \\
\hline Horner \# 9 & 2905 & 61.71 & 2.327 & 3.306 & 0.048 & 130 & 2.71 & 203 & 0 & 0 & 1 \\
\hline Horner \# 9 & 2906 & 73.28 & 2.375 & 14.326 & 0.124 & 130 & 2.71 & 214 & 0 & 0 & 1 \\
\hline
\end{tabular}




\begin{tabular}{|c|c|c|c|c|c|c|c|c|c|c|c|}
\hline & $\begin{array}{c}\text { Table F.2 } \\
\text { ANN Ana } \\
\text { Winning } \\
\text { Analysis }\end{array}$ & $\begin{array}{l}\text { Koho } \\
\text { Iysis o } \\
\text { Neuror } \\
\text { for Th }\end{array}$ & $\begin{array}{l}\text { onen Ne } \\
\text { of Core } \\
n \text { is Set } \\
\text { hree Set }\end{array}$ & $\begin{array}{l}\text { twork ( } \\
\text { Data Se } \\
\text { at } 1.0 \\
\text { ts }\end{array}$ & Three C & Jutput & Catego & es) & & & \\
\hline ANN Inputs & =====> & input & input & input & input & input & input & input & & tw & \\
\hline Well Name & Depth & gr & rhob & gr' & rhob' & gr bl & rhob bl & $k(\mathrm{md})$ & 1 & 2 & 3 \\
\hline LeMas \# 13 & 3030.75 & 28.13 & 2.527 & 1.136 & 0.022 & 115 & 2.72 & 0.05 & 1 & 0 & 0 \\
\hline LeMas \# 13 & 3031.75 & 30.11 & 2.544 & 0 & 0.022 & 115 & 2.72 & 0.15 & 1 & 0 & \\
\hline LeMas \# 13 & 3032.75 & 27.56 & 2.553 & -5.682 & -0.01 & 115 & 2.72 & 0.72 & 1 & 0 & 0 \\
\hline LeMas \# 13 & 3033.75 & 24.43 & 2.549 & 2.272 & 0.002 & 115 & 2.72 & 0.28 & 1 & 0 & 0 \\
\hline LeMas \# 13 & 3034.75 & 28.41 & 2.564 & 4.544 & 0.02 & 115 & 2.72 & 0.27 & 1 & 0 & 0 \\
\hline LeMas \# 13 & 3035.75 & 30.4 & 2.578 & -1.136 & 0.02 & 115 & 2.72 & 0.12 & 1 & 0 & 0 \\
\hline LeMas \# 13 & 3036.75 & 28.69 & 2.574 & 1.136 & -0.02 & 115 & 2.72 & 0.22 & 1 & 0 & 0 \\
\hline LeMas \# 13 & 3037.75 & 32.1 & 2.558 & 3.41 & -0.02 & 115 & 2.72 & 0.1 & 1 & 0 & \\
\hline LeMas \# 13 & 3038.75 & 37.22 & 2.54 & 3.408 & -0.008 & 115 & 2.72 & 0.18 & 1 & 0 & 0 \\
\hline LeMas \# 13 & 3039.75 & 40.91 & 2.532 & 6.818 & -0.006 & 115 & 2.72 & 0.06 & 1 & 0 & 0 \\
\hline LeMas \# 13 & 3040.75 & 44.6 & 2.533 & 3.41 & -0.002 & 115 & 2.72 & 0.06 & 1 & 0 & 0 \\
\hline LeMas \# 13 & 3041.75 & 46.59 & 2.54 & 0 & 0.008 & 115 & 2.72 & 0.04 & 1 & 0 & 0 \\
\hline LeMas \# 13 & 3042.75 & 44.32 & 2.529 & -2.272 & -0.014 & 115 & 2.72 & 0.19 & 1 & 0 & 0 \\
\hline LeMas \# 13 & 3043.75 & 39.77 & 2.504 & 0 & -0.018 & 115 & 2.72 & 0.29 & 1 & 0 & c \\
\hline LeMas \# 13 & 3044.75 & 42.61 & 2.495 & 4.546 & 0.002 & 115 & 2.72 & 0.67 & 1 & 0 & 0 \\
\hline LeMas \# 13 & 3045.75 & 59.66 & 2.559 & 29.544 & 0.114 & 115 & 2.72 & 0.21 & 1 & 0 & 0 \\
\hline LeMas \# 13 & 3046.25 & 71.59 & 2.596 & 18.182 & 0.034 & 115 & 2.72 & 0.01 & 1 & 0 & 0 \\
\hline LeMas \# 13 & 3048 & 57.39 & 2.484 & -27.27 & -0.089 & 115 & 2.72 & 0.04 & 1 & 0 & 0 \\
\hline LeMas \# 13 & 3048.75 & 46.31 & 2.398 & -12.5 & -0.072 & 115 & 2.72 & 37 & 1 & 0 & \\
\hline LeMas \# 13 & 3049.75 & 43.47 & 2.441 & 3.408 & 0.146 & 115 & 2.72 & 1.51 & 1 & 0 & 0 \\
\hline LeMas \# 13 & 3050.75 & 45.74 & 2.495 & 3.41 & 0.04 & 115 & 2.72 & 0.11 & 1 & 0 & 0 \\
\hline LeMas \# 13 & 3052 & 43.18 & 2.451 & -1.136 & -0.026 & 115 & 2.72 & 19 & 1 & 0 & 0 \\
\hline LeMas \# 13 & 3052.75 & 42.9 & 2.447 & 1.136 & 0.052 & 115 & 2.72 & 11 & 1 & 0 & 0 \\
\hline LeMas \# 13 & 3053.75 & 42.33 & 2.479 & -1.138 & 0.02 & 115 & 2.72 & 0.07 & 1 & 0 & 0 \\
\hline LeMas \# 13 & 3054.75 & 40.34 & 2.505 & -2.272 & 0.002 & 115 & 2.72 & 0.1 & 1 & 0 & 0 \\
\hline LeMas \# 13 & 3055.75 & 42.61 & 2.522 & 2.274 & 0.014 & 115 & 2.72 & 0.09 & 1 & 0 & 0 \\
\hline LeMas \# 13 & 3056.75 & 44.6 & 2.528 & -3.41 & -0.008 & 115 & 2.72 & 0.02 & 1 & 0 & 0 \\
\hline LeMas \# 13 & 3057.75 & 41.76 & 2.495 & -3.41 & -0.016 & 115 & 2.72 & 0.04 & 1 & 0 & 0 \\
\hline LeMas \# 13 & 3058.75 & 47.73 & 2.51 & 22.728 & 0.088 & 115 & 2.72 & 0.04 & 1 & 0 & 0 \\
\hline LeMas \# 13 & 3059.75 & 76.7 & 2.599 & 47.726 & 0.146 & 115 & 2.72 & 0.05 & 1 & 0 & 0 \\
\hline
\end{tabular}




\begin{tabular}{|c|c|c|c|c|c|c|c|c|c|c|c|}
\hline \multicolumn{12}{|c|}{$\begin{array}{l}\text { Table F.2 Kohonen Network (Three Output Categories) } \\
\text { ANN Analysis of Core Data Set } \\
\text { Winning Neuron is Set at } 1.0 \\
\text { Analysis for Three Sets }\end{array}$} \\
\hline \multirow{2}{*}{$\begin{array}{l}\text { ANN Inputs } \\
\text { Well Name }\end{array}$} & \multirow{2}{*}{$\begin{array}{l}\text { ====> } \\
\text { Depth }\end{array}$} & \multirow{2}{*}{$\begin{array}{c}\text { input } \\
\text { gr } \\
\end{array}$} & \multirow{2}{*}{$\begin{array}{l}\text { input } \\
\text { rhob } \\
\end{array}$} & \multirow{2}{*}{$\begin{array}{c}\text { input } \\
\text { gr' } \\
\end{array}$} & \multirow{2}{*}{$\begin{array}{l}\text { input } \\
\text { rhob' }\end{array}$} & \multirow{2}{*}{$\begin{array}{l}\text { input } \\
\text { gr bl }\end{array}$} & \multirow{2}{*}{$\begin{array}{l}\text { input } \\
\text { rhob bl }\end{array}$} & \multirow{2}{*}{$\begin{array}{l}\text { input } \\
\text { k (md) }\end{array}$} & \multicolumn{3}{|c|}{ Network } \\
\hline & & & & & & & & & 1 & 2 & 3 \\
\hline T Heirs \# 8 & 2781.5 & 105.9 & 2.617 & 27.854 & 0.034 & 145 & 2.71 & 0.02 & 1 & 0 & \\
\hline T Heirs \# 8 & 2782.5 & 116.4 & 2.634 & -40.11 & -0.018 & 145 & 2.71 & 0.03 & 1 & & \\
\hline TT Heirs \# 8 & 2783.5 & 64.07 & 2.582 & -66.85 & -0.112 & 145 & 2.71 & 0.06 & 1 & 0 & 0 \\
\hline T Heirs \# 8 & 2784.5 & 47.91 & 2.507 & -8.914 & -0.024 & 145 & 2.71 & 0.11 & 1 & 0 & \\
\hline T Heirs \# 8 & 2785.5 & 34.54 & 2.516 & -11.14 & 0.028 & 145 & 2.71 & 0.12 & 1 & 0 & \\
\hline T Heirs \# 8 & 2786.5 & 36.77 & 2.54 & 8.914 & 0.014 & 145 & 2.71 & 0.02 & 1 & 0 & \\
\hline T Heirs \# 8 & 2787.5 & 42.9 & 2.548 & 6.686 & -0.006 & 145 & 2.71 & 0.92 & 1 & & \\
\hline T Heirs \# 8 & 2788.5 & 49.58 & 2.503 & 8.914 & -0.018 & 145 & 2.71 & 0.31 & 1 & 0 & 0 \\
\hline T Heirs \# 8 & 2789.5 & 47.91 & 2.469 & -15.6 & -0.03 & 145 & 2.71 & 0.1 & 1 & 0 & 0 \\
\hline T Heirs \# 8 & 2790.5 & 37.33 & 2.467 & 0 & 0 & 145 & 2.71 & 6.5 & 1 & 0 & \\
\hline T Heirs \# 8 & 2791.5 & 39.55 & 2.473 & 3.342 & 0.004 & 145 & 2.71 & 3.8 & 1 & 0 & \\
\hline T Heirs \# 8 & 2792.5 & 47.91 & 2.467 & 4.456 & -0.014 & 145 & 2.71 & 8.1 & 1 & 0 & \\
\hline T Heirs \# 8 & 2793.5 & 52.37 & 2.402 & -2.228 & -0.082 & 145 & 2.71 & 18 & 1 & 0 & \\
\hline T Heirs \# 8 & 2794.5 & 49.58 & 2.384 & -2.228 & -0.006 & 145 & 2.71 & 22 & 1 & 0 & 0 \\
\hline T Heirs \# 8 & 2795.5 & 49.03 & 2.365 & 5.572 & -0.004 & 145 & 2.71 & 23 & 1 & 0 & 0 \\
\hline T Heirs \# 8 & 2796.5 & 55.71 & 2.352 & 7.8 & -0.006 & 145 & 2.71 & 21 & 1 & 0 & 0 \\
\hline
\end{tabular}




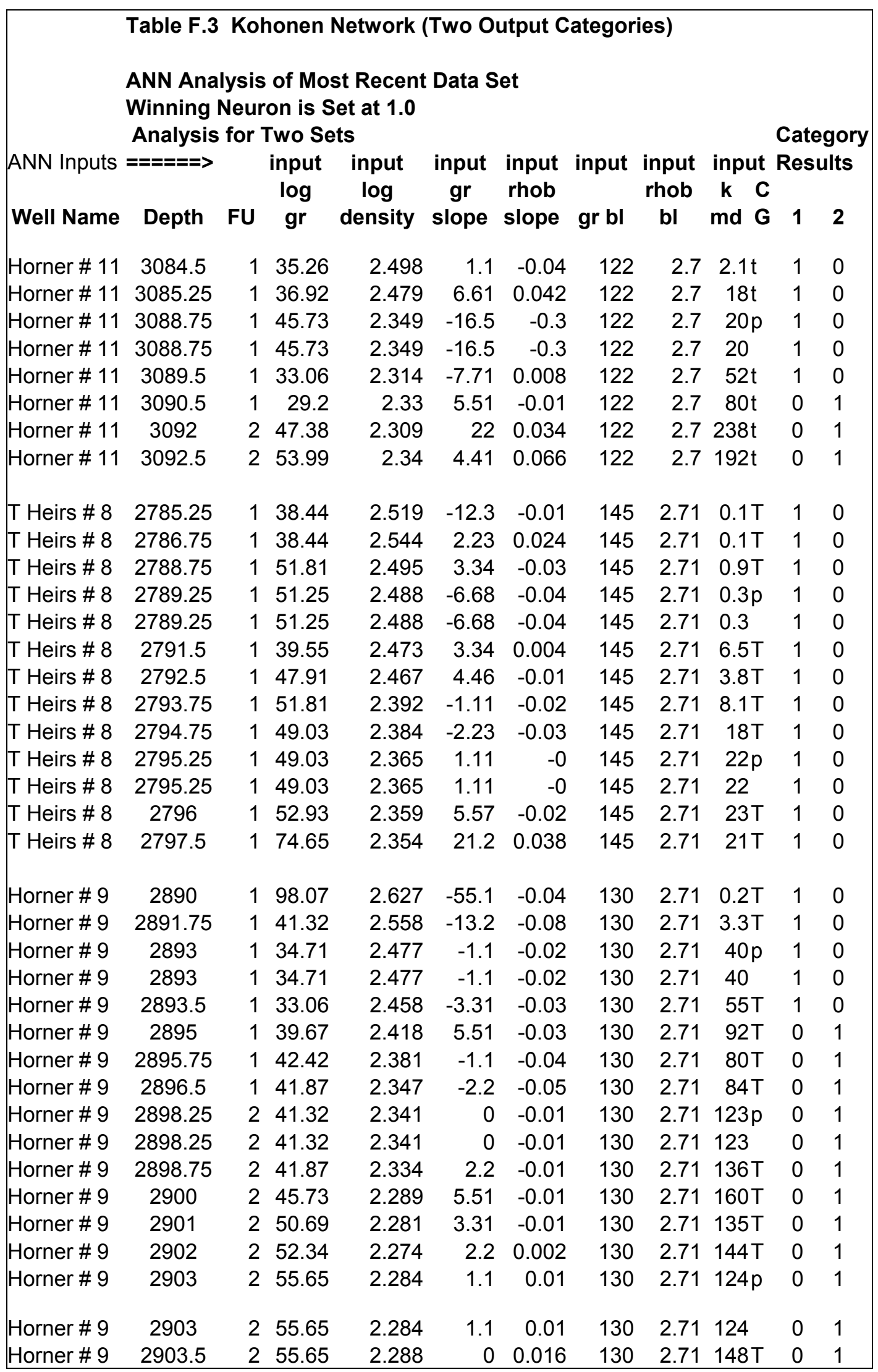




\begin{tabular}{|c|c|c|c|c|c|c|c|c|c|c|c|}
\hline & $\begin{array}{l}\text { ANN Anal } \\
\text { Winning } \\
\text { Analysis }\end{array}$ & $\begin{array}{l}\text { lysis } \\
\text { Veur } \\
\text { for }\end{array}$ & $\begin{array}{l}\text { of Mos } \\
\text { on is S } \\
\text { Two Se }\end{array}$ & $\begin{array}{l}\text { st Recent } \\
\text { eet at } 1.0 \\
\text { ts }\end{array}$ & Data & & & & & Cate & \\
\hline ANN Inputs = & $=====>$ & & $\begin{array}{l}\text { input } \\
\text { log }\end{array}$ & $\begin{array}{c}\text { input } \\
\text { log }\end{array}$ & $\begin{array}{l}\text { input } \\
\text { gr }\end{array}$ & $\begin{array}{l}\text { input } \\
\text { rhob }\end{array}$ & input & $\begin{array}{l}\text { input } \\
\text { rhob }\end{array}$ & $\begin{array}{c}\text { input } \\
k \quad C\end{array}$ & & ults \\
\hline Well Name & Depth & FU & gr & density & slope & slope & gr bl & bl & md $G$ & 1 & 2 \\
\hline Ball \# 19 & 3086.25 & 1 & 84.21 & 2.652 & -13.3 & -0.02 & 123 & 2.71 & $2.4 \mathrm{P}$ & 1 & 0 \\
\hline Ball \# 19 & 3086.25 & 1 & 84.21 & 2.652 & -13.3 & -0.02 & 123 & 2.71 & 2.4 & 1 & 0 \\
\hline Ball \# 19 & 3092.25 & 1 & 29.92 & 2.492 & 5.54 & -0.03 & 123 & 2.71 & $4.2 \mathrm{~T}$ & 1 & 0 \\
\hline Ball \# 19 & 3092.75 & 1 & 32.69 & 2.476 & 6.65 & -0.04 & 123 & 2.71 & $11 \mathrm{~T}$ & 1 & 0 \\
\hline Ball \# 19 & 3094.25 & 1 & 37.12 & 2.429 & 3.32 & -0.02 & 123 & 2.71 & $38 \mathrm{~T}$ & 1 & 0 \\
\hline Ball \# 19 & 3094.75 & 1 & 39.89 & 2.424 & 5.54 & -0.01 & 123 & 2.71 & $31 \mathrm{~T}$ & 1 & 0 \\
\hline Ball \# 19 & 3097.25 & 1 & 37.12 & 2.509 & 3.32 & 0.006 & 123 & 2.71 & $0.3 P$ & 1 & 0 \\
\hline Ball \# 19 & 3097.25 & 1 & 37.12 & 2.509 & 3.32 & 0.006 & 123 & 2.71 & 0.3 & 1 & 0 \\
\hline Ball \# 19 & 3098 & 1 & 41 & 2.519 & 7.76 & -0.04 & 123 & 2.71 & $0.2 \mathrm{~T}$ & 1 & 0 \\
\hline Ball \# 19 & 3099.25 & 1 & 42.66 & 2.473 & -5.54 & -0.02 & 123 & 2.71 & $17 \mathrm{~T}$ & 1 & 0 \\
\hline Ball \# 19 & 3100 & 1 & 37.12 & 2.396 & -8.86 & -0.11 & 123 & 2.71 & $41 \mathrm{~T}$ & 1 & 0 \\
\hline Ball \# 19 & 3101.25 & 1 & 36.57 & 2.369 & 3.32 & -0.01 & 123 & 2.71 & $65 \mathrm{~T}$ & 0 & 1 \\
\hline Ball \# 19 & 3102 & 1 & 41.55 & 2.399 & 7.76 & 0.096 & 123 & 2.71 & $17 \mathrm{~T}$ & 1 & 0 \\
\hline Ball \# 19 & 3103 & 1 & 43.77 & 2.432 & 0 & 0.008 & 123 & 2.71 & $6.8 \mathrm{~T}$ & 1 & 0 \\
\hline Ball \# 19 & 3104 & 1 & 44.32 & 2.377 & 2.22 & -0.04 & 123 & 2.71 & $73 \mathrm{~T}$ & 0 & 1 \\
\hline Ball \# 19 & 3105 & 1 & 43.21 & 2.365 & 4.43 & -0 & 123 & 2.71 & $60 \mathrm{~T}$ & 0 & 1 \\
\hline Ball \# 19 & 3106 & 1 & 43.77 & 2.367 & -4.43 & 0.004 & 123 & 2.71 & $1.2 \mathrm{~T}$ & 1 & 0 \\
\hline Ball \# 19 & 3107.25 & 2 & 39.34 & 2.358 & 1.11 & -0.08 & 123 & 2.71 & $110 \mathrm{P}$ & 0 & 1 \\
\hline Ball \# 19 & 3107.25 & 2 & 39.34 & 2.358 & 1.11 & -0.08 & 123 & 2.71 & 110 & 0 & 1 \\
\hline Ball \# 19 & 3108 & 2 & 40.44 & 2.307 & 5.54 & -0.01 & 123 & 2.71 & $106 \mathrm{~T}$ & 0 & 1 \\
\hline Ball \# 19 & 3108.75 & 2 & 43.77 & 2.293 & -1.11 & -0.01 & 123 & 2.71 & $207 \mathrm{~T}$ & 0 & 1 \\
\hline Ball \# 19 & 3109.5 & 2 & 42.66 & 2.286 & -2.22 & -0.01 & 123 & 2.71 & $179 \mathrm{~T}$ & 0 & 1 \\
\hline Ball \# 19 & 3110.75 & 2 & 40.44 & 2.3 & -8.86 & 0.018 & 123 & 2.71 & $124 \mathrm{~T}$ & 0 & 1 \\
\hline LeMas \#13 & 3031.75 & 1 & 30.11 & 2.544 & 0 & 0.022 & 115 & 2.72 & $0.2 p$ & 1 & 0 \\
\hline LeMas \#13 & 3031.75 & 1 & 30.11 & 2.544 & 0 & 0.022 & 115 & 2.72 & 0.2 & 1 & 0 \\
\hline LeMas \#13 & 3032.25 & 1 & 29.55 & 2.552 & -2.27 & 0.012 & 115 & 2.72 & $0.7 \mathrm{~T}$ & 1 & 0 \\
\hline LeMas \#13 & 3034.25 & 1 & 26.14 & 2.554 & 4.55 & 0.02 & 115 & 2.72 & $0.3 \mathrm{~T}$ & 1 & 0 \\
\hline LeMas \#13 & 3034.75 & 1 & 28.41 & 2.564 & 4.54 & 0.02 & 115 & 2.72 & $0.3 \mathrm{~T}$ & 1 & 0 \\
\hline LeMas \#13 & 3036 & 1 & 30.11 & 2.583 & -2.27 & 0.006 & 115 & 2.72 & $0.1 \mathrm{~T}$ & 1 & 0 \\
\hline LeMas \#13 & 3036.5 & 1 & 28.41 & 2.579 & -1.14 & -0.01 & 115 & 2.72 & $0.2 p$ & 1 & 0 \\
\hline LeMas \#13 & 3036.5 & 1 & 28.41 & 2.579 & -1.14 & -0.01 & 115 & 2.72 & 0.2 & 1 & 0 \\
\hline LeMas \#13 & 3038.5 & 1 & 36.36 & 2.542 & 5.11 & -0.02 & 115 & 2.72 & $0.2 \mathrm{~T}$ & 1 & 0 \\
\hline LeMas \#13 & 3042.5 & 1 & 44.89 & 2.532 & -2.84 & -0.02 & 115 & 2.72 & $0.2 \mathrm{~T}$ & 1 & 0 \\
\hline LeMas \#13 & 3043.25 & 1 & 41.76 & 2.517 & -7.95 & -0.03 & 115 & 2.72 & $0.3 P$ & 1 & 0 \\
\hline LeMas \#13 & 3043.25 & 1 & 41.76 & 2.517 & -7.95 & -0.03 & 115 & 2.72 & 0.3 & 1 & 0 \\
\hline LeMas \#13 & 3045.25 & 1 & 48.01 & 2.513 & 17 & 0.07 & 115 & 2.72 & $0.7 \mathrm{~T}$ & 1 & 0 \\
\hline LeMas \#13 & 3045.75 & 1 & 59.66 & 2.559 & 29.5 & 0.114 & 115 & 2.72 & $0.2 \mathrm{~T}$ & 1 & 0 \\
\hline LeMas \#13 & 3048.75 & 1 & 46.31 & 2.398 & -12.5 & -0.07 & 115 & 2.72 & $37 \mathrm{P}$ & 1 & 0 \\
\hline LeMas \#13 & 3048.75 & 1 & 46.31 & 2.398 & -12.5 & -0.07 & 115 & 2.72 & 37 & 1 & 0 \\
\hline LeMas \#13 & 3050 & 1 & 44.32 & 2.477 & 2.27 & 0.081 & 115 & 2.72 & $1.5 \mathrm{~T}$ & 1 & 0 \\
\hline
\end{tabular}




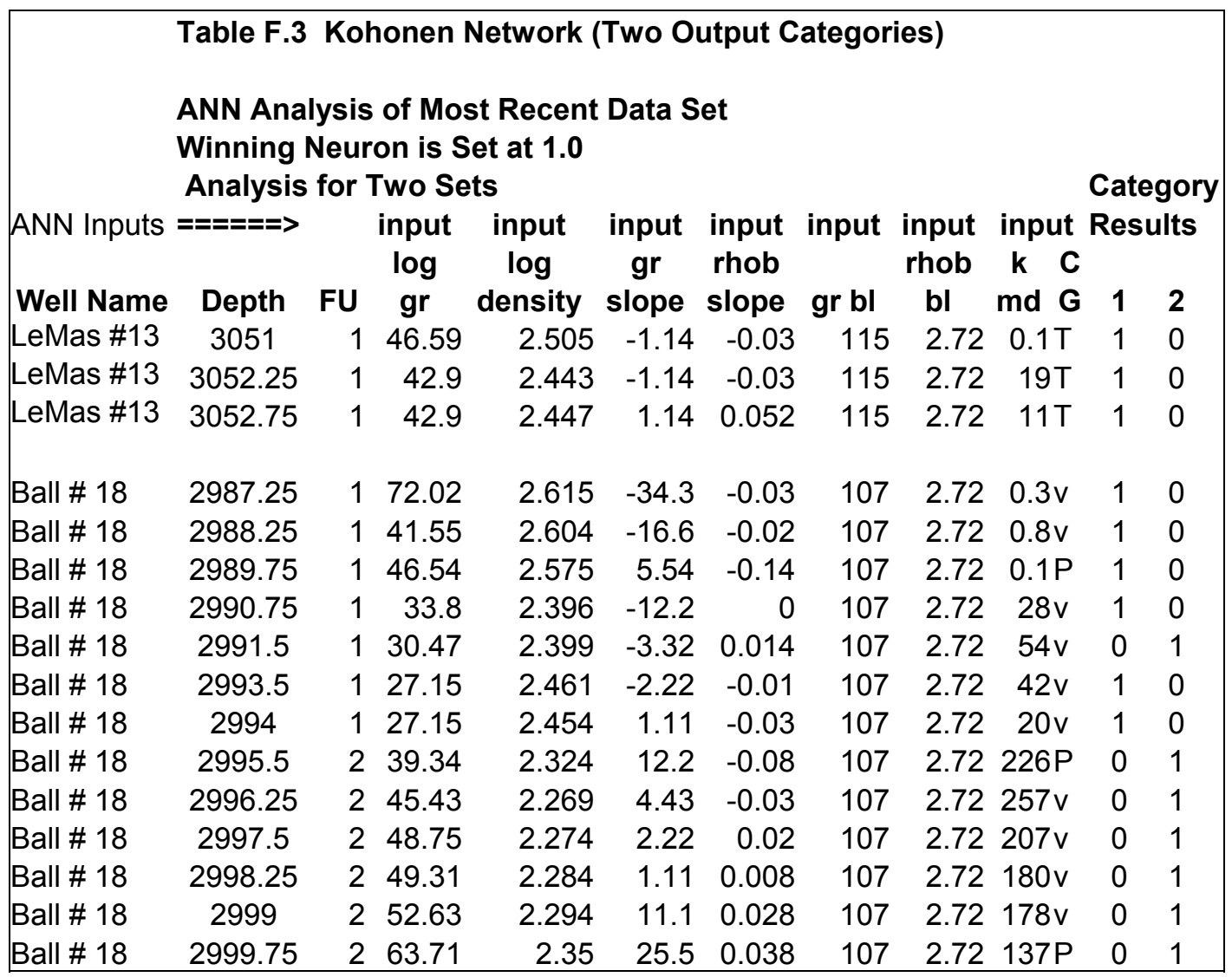




\begin{tabular}{|c|c|c|c|c|c|c|c|c|c|c|c|c|}
\hline \multicolumn{13}{|c|}{ Table F.4 Kohonen Network (Three Output Categories) } \\
\hline \multirow{3}{*}{$\begin{array}{l}\text { ANN Inputs } \\
\text { Well Name }\end{array}$} & \multicolumn{9}{|c|}{$\begin{array}{l}\text { ANN Analysis of Most Recent Data Set } \\
\text { Winning Neuron is Set at } 1.0 \\
\text { Analysis for Two Sets }\end{array}$} & \multicolumn{3}{|c|}{ Category } \\
\hline & $=====>$ & & $\begin{array}{l}\text { input } \\
\text { log }\end{array}$ & $\begin{array}{c}\text { input } \\
\text { log }\end{array}$ & $\begin{array}{l}\text { input } \\
\text { gr }\end{array}$ & $\begin{array}{l}\text { input } \\
\text { rhob }\end{array}$ & & $\begin{array}{l}\text { input } \\
\text { rhob }\end{array}$ & $\begin{array}{c}\text { input } \\
k \mathrm{C}\end{array}$ & Resı & & \\
\hline & Depth & FU & $g r$ & & slope & lope & gr bl & & & 1 & 2 & 3 \\
\hline Horner \# 11 & 3084.5 & 1 & 35.26 & 2.498 & 1.1 & -0.04 & 122 & 2.7 & $2.1 \mathrm{t}$ & 1 & 0 & 0 \\
\hline Horner \# 11 & 3085.3 & 1 & 36.92 & 2.47 & & & & 2.7 & & 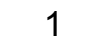 & 0 & 0 \\
\hline Horner \# 11 & 3088.8 & 1 & 45.73 & & -16 & & 122 & 2.7 & & & 0 & 0 \\
\hline Horne & 3088.8 & 1 & & & & & & 2.7 & & 1 & 0 & 0 \\
\hline Horne & 3089.5 & 1 & 33.06 & & -7.7 & 0. & 122 & 2.7 & 52 & 1 & 0 & 0 \\
\hline Horne & 3090.5 & 1 & 29.2 & 2.33 & 5.51 & $-0 .($ & 122 & 2.7 & & 0 & 0 & 1 \\
\hline Horn & 3092 & 2 & 47.3 & 2.3 & 22 & & & 7 & & 0 & 0 & 1 \\
\hline Horner \# 11 & 3092.5 & 2 & 53.99 & & 4.41 & & & 2.7 & $192 t$ & 0 & 0 & 1 \\
\hline T Heirs \# 8 & & 1 & & & & & & 2.71 & & 1 & 0 & 0 \\
\hline $\mathrm{T} \mathrm{He}$ & 2786.8 & 1 & 38.44 & & & & & 2.71 & & 1 & 0 & 0 \\
\hline T Heir & 2788.8 & 1 & 51.8 & 495 & & -0. & & 2.7 & & 1 & 0 & 0 \\
\hline T Heir & 278 & 1 & 51. & 8 & -6.6 & & & & 0.3 & & 0 & 0 \\
\hline T Hei & & 1 & & & & & & & & & & 0 \\
\hline T Heir & $27 \subseteq$ & 1 & & & & 0 & & 2. & & 1 & 0 & 0 \\
\hline T Hei & 2792.5 & 1 & 47 & & 4. & & & & & 1 & 0 & 0 \\
\hline T Hei & & 1 & 51.8 & 392 & -1.1 & & & & & & 0 & 0 \\
\hline T Heirs \# 8 & 2794 & 1 & & & -2.2 & & & & & & 0 & 0 \\
\hline T Hei & & 1 & & & & & & & & & 0 & 0 \\
\hline T Heirs \# 8 & 279 & 1 & & & & & & & & & 0 & 0 \\
\hline T Heirs \# 8 & 96 & 1 & 52.9 & & 5.57 & -0.02 & & 2.71 & & 1 & 0 & 0 \\
\hline T Heirs \# 8 & 2797.5 & 1 & 74.65 & 354 & 21.2 & & 145 & 2.71 & & 1 & 0 & 0 \\
\hline Horn & & 1 & & & & & & & & & 0 & 0 \\
\hline Horn & $28 s$ & 1 & & & & & & & 3 & & 0 & 0 \\
\hline Horn & & 1 & 34.71 & 2.477 & -1.1 & $-0 .($ & & 2.71 & $40 p$ & 1 & 0 & 0 \\
\hline Horn & & 1 & 34.71 & & & & & 2.71 & 40 & 1 & 0 & 0 \\
\hline Horn & 2893 & 1 & 33.06 & & -3.31 & & & & & 1 & 0 & 0 \\
\hline Horn & & 1 & & & & & & & & & 0 & \\
\hline Horn & & 1 & & & & & & & & 0 & 0 & 1 \\
\hline Horne & & 1 & & & -2.2 & & & 2.71 & $84 \mathrm{~T}$ & 0 & 0 & \\
\hline Horner \# 9 & 2898.3 & 2 & 41.32 & 2.341 & 0 & -0.01 & 130 & 2.71 & $123 p$ & 0 & 0 & \\
\hline Horne & 2898.3 & 2 & 41.32 & & 0 & -0.0 & 130 & 2.71 & 123 & 0 & 0 & 1 \\
\hline Horr & $289 \varepsilon$ & 2 & 41. & & 2.2 & & & 2.71 & 13 & 0 & 0 & \\
\hline Horne & & 2 & & & 5.51 & & 13 & 2.71 & $160 \mathrm{~T}$ & 0 & 0 & \\
\hline Horner \# 9 & 2901 & 2 & 50.69 & & 3.31 & -0.01 & 130 & 2.71 & $135 \mathrm{~T}$ & 0 & 0 & \\
\hline Horner \# 9 & 2902 & 2 & 52.34 & 2.274 & 2.2 & 0 & 130 & 2.71 & $144 \mathrm{~T}$ & 0 & 0 & \\
\hline Horner \# 9 & 2903 & 2 & 55.65 & 2.284 & 1.1 & 0.01 & 130 & 2.71 & $124 p$ & 0 & 0 & 1 \\
\hline & & 2 & & & & & & 2.71 & 124 & 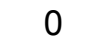 & & \\
\hline Horner \# 9 & 2903.5 & 2 & 55.65 & 2.288 & 0 & 0.02 & 130 & 2.71 & $148 \mathrm{~T}$ & 0 & 0 & \\
\hline
\end{tabular}




\begin{tabular}{|c|c|c|c|c|c|c|c|c|c|c|c|c|}
\hline \multicolumn{13}{|c|}{ Table F.4 Kohonen Network (Three Output Categories) } \\
\hline \multirow{3}{*}{$\begin{array}{l}\text { ANN Inputs } \\
\text { Well Name }\end{array}$} & \multicolumn{9}{|c|}{$\begin{array}{l}\text { ANN Analysis of Most Recent Data Set } \\
\text { Winning Neuron is Set at } 1.0 \\
\text { Analysis for Two Sets }\end{array}$} & \multicolumn{3}{|c|}{ Category } \\
\hline & $=====>$ & & $\begin{array}{l}\text { input } \\
\text { log }\end{array}$ & $\begin{array}{c}\text { input } \\
\text { log }\end{array}$ & $\begin{array}{l}\text { input } \\
\text { gr }\end{array}$ & $\begin{array}{l}\text { input } \\
\text { rhob }\end{array}$ & & $\begin{array}{l}\text { input } \\
\text { rhob }\end{array}$ & $\begin{array}{c}\text { input } \\
\text { k C }\end{array}$ & Resı & & \\
\hline & Depth & FU & $g r$ & & & & gr bl & & md $\mathbf{G}$ & 1 & 2 & 3 \\
\hline Ball \# 19 & 3086.3 & 1 & 84.21 & 2.652 & -13.3 & -0.02 & 123 & 2.71 & $2.4 \mathrm{P}$ & 1 & 0 & 0 \\
\hline Ball \# 19 & 3086.3 & 1 & 84.2 & 2.65 & -13.3 & -0.02 & 123 & & 2.4 & 1 & 0 & 0 \\
\hline Ball \# 19 & 3092.3 & 1 & 29. & 2.4 & 5.54 & -0.03 & 123 & 2.71 & $4.2 \mathrm{~T}$ & & 0 & 0 \\
\hline Ball \# 19 & 3092. & 1 & 32. & 2.4 & 6.65 & & 12 & 2.71 & & 1 & 0 & 0 \\
\hline Ball \# 19 & 3094.3 & 1 & 37.12 & 2.42 & 3.32 & -0.02 & 123 & 2.71 & $38 \mathrm{~T}$ & 1 & 0 & 0 \\
\hline Ball \# 19 & 3094.8 & 1 & 39.89 & 2.42 & 5.54 & -0.01 & 123 & 2.71 & 31 & 1 & 0 & 0 \\
\hline Ball \# 19 & 3097.3 & 1 & 37.12 & 2.5 & 3.3 & & 12 & 2. & $0.3 P$ & 1 & 0 & 0 \\
\hline Ball \# 19 & 3097 & 1 & 37. & & 3. & & & & & & U & 0 \\
\hline Ball \# 19 & & 1 & & & & & & & & & 0 & 0 \\
\hline Ball \# 19 & 3099.3 & 1 & 42.66 & 2.473 & -5.54 & -0. & 12 & 2.71 & & 1 & 0 & 0 \\
\hline Ball \# 19 & 3100 & 1 & 37.1 & 2.396 & -8.86 & -0.11 & 123 & 2.71 & & 1 & 0 & 0 \\
\hline Ball \# 19 & 3101.3 & 1 & 36. & 2.3 & 3.3 & -0.0 & 12 & 2.7 & & 0 & 0 & 1 \\
\hline Ball \# 19 & 31 & 1 & 41. & & 7.76 & & & & & & 0 & 0 \\
\hline Ball \# 19 & & 1 & 43. & & 0 & 0. & & & 6. & & 0 & 0 \\
\hline Ball \# 19 & 3104 & 1 & 44.32 & 2.3 & 2.22 & -0.04 & 12 & 2.71 & & 0 & 0 & 1 \\
\hline Ball \# 19 & 3105 & 1 & 43.21 & 2.3 & 4.43 & -0 & & & & 1 & 0 & 0 \\
\hline Ball \# 19 & 3106 & 1 & 43.77 & 2.3 & -4.4 & & 12 & 2.7 & 1.2 & 1 & 0 & 0 \\
\hline Ball \# 19 & 3107.3 & 2 & 39. & 2.3 & 1.1 & -0.08 & 12 & 2.7 & 110 & & 0 & 1 \\
\hline Ball f & & 2 & & & & & & & & & 0 & 1 \\
\hline Ball \# 19 & 3108 & 2 & 40.44 & 2.3 & 5.54 & -0. & 123 & 2.71 & $106 \mathrm{~T}$ & 0 & 0 & 1 \\
\hline Ball \# 19 & 3108.8 & 2 & 43.77 & 2.2 & -1.11 & -0. & 12 & & & 0 & 0 & 1 \\
\hline Ball \# 19 & 3109.5 & 2 & 42.66 & 2.286 & -2.22 & -0.0 & 123 & 2.71 & $17 \mathrm{~s}$ & 0 & 0 & 1 \\
\hline Ball \# 19 & 3110.8 & 2 & 40.44 & 2.3 & -8.86 & 0.0 & 123 & 2.71 & $124 \mathrm{~T}$ & 0 & 0 & 1 \\
\hline LeMas $\neq$ & & 1 & & & 0 & & & & & 1 & 0 & 0 \\
\hline LeMas \#13 & 3031.8 & 1 & 30.11 & 2.5435 & 0 & & 115 & 2.72 & 0.2 & 1 & 0 & 0 \\
\hline LeMas \#13 & 3032.3 & 1 & 29.55 & & -2.27 & & 115 & 2.72 & 0.7 & 1 & 0 & 0 \\
\hline LeMas \#13 & 3034.3 & 1 & 26.14 & 2.554 & 4.55 & 0.02 & 115 & 2.72 & 0.3 & 1 & 0 & 0 \\
\hline LeMas \#13 & 3034.8 & 1 & 28.41 & 2.5 & 4.5 & & & 2.72 & & 1 & 0 & 0 \\
\hline LeMas \#13 & & 1 & & & -2.2 & & & & & 1 & 0 & 0 \\
\hline LeMas \#13 & 3036.5 & 1 & 28.41 & 2.579 & -1.14 & -0.01 & 115 & 2.72 & $0.2 p$ & 1 & 0 & 0 \\
\hline LeMas \#13 & 3036.5 & 1 & 28.41 & 2.579 & -1.14 & -0.01 & 115 & 2.72 & 0.2 & 1 & 0 & 0 \\
\hline LeMas \#13 & 3038.5 & 1 & 36.36 & 2.542 & 5.11 & -0.02 & 115 & 2.72 & $0.2 \mathrm{~T}$ & 1 & 0 & 0 \\
\hline LeMas \#13 & 3042.5 & 1 & 44.89 & 2.532 & -2.84 & -0.0 & 115 & 2.72 & 0.2 & 1 & 0 & 0 \\
\hline LeMas \#13 & 3043.3 & 1 & 41.76 & 2.5165 & -7.95 & & 115 & 2.72 & $0.3 P$ & 1 & 0 & 0 \\
\hline LeMas \#13 & 3043.3 & 1 & 41.76 & 2.5165 & -7.95 & -0.03 & 115 & 2.72 & 0.3 & 1 & 0 & 0 \\
\hline LeMas \#13 & 3045.3 & 1 & 48.01 & 2.5125 & 17 & 0.07 & 115 & 2.72 & $0.7 \mathrm{~T}$ & 1 & 0 & 0 \\
\hline LeMas \#13 & 3045.8 & 1 & 59.66 & 2.5585 & 29.5 & 0.11 & 115 & 2.72 & $0.2 \mathrm{~T}$ & 1 & 0 & 0 \\
\hline LeMas \#13 & 3048.8 & 1 & 46.31 & 2.398 & -12.5 & -0.07 & 115 & 2.72 & $37 P$ & 1 & 0 & 0 \\
\hline LeMas \#13 & 3048.8 & 1 & 46.31 & 2.398 & -12.5 & -0.07 & 115 & 2.72 & 37 & 1 & 0 & 0 \\
\hline LeMas \#13 & 3050 & 1 & 44.32 & 2.477 & 2.27 & 0.08 & 115 & 2.72 & $1.5 \mathrm{~T}$ & 1 & 0 & 0 \\
\hline
\end{tabular}




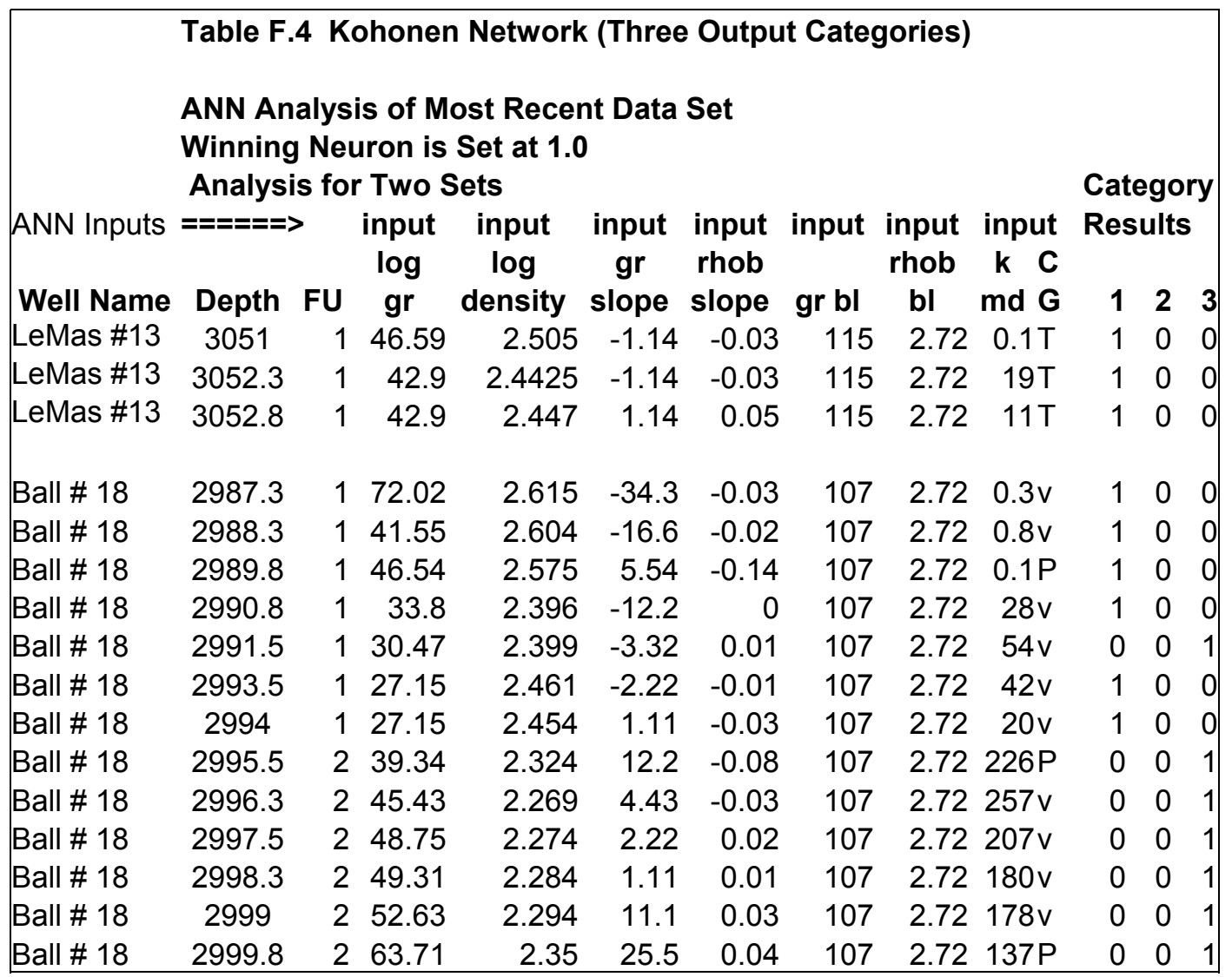




\section{APPENDIX G.}

Appendix G. details graphs comparing core data to minpermeameter data for cumulative flow capacity versus cumulative storage capacity for each core well having miniperm data. Appendixes B. and C. can be referenced for each type of graph and the supporting tables of data. 
Figure G.1 T. Heirs \# 8 Cumulative Flow Capacity versus Cumulative Storage Capacity (Core and Miniperm)

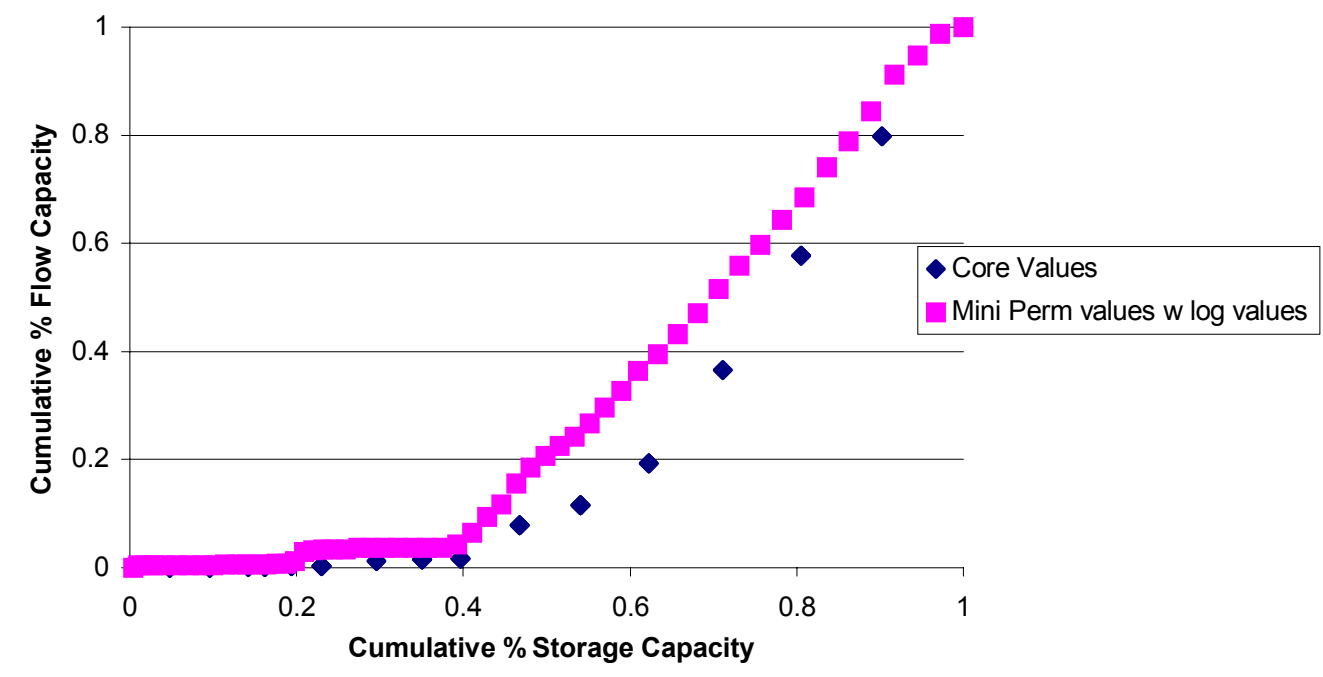

Figure G.2 Horner \# 9 Cumulative Flow Capacity versus Cumulative Storage Capacity (Core and Miniperm)

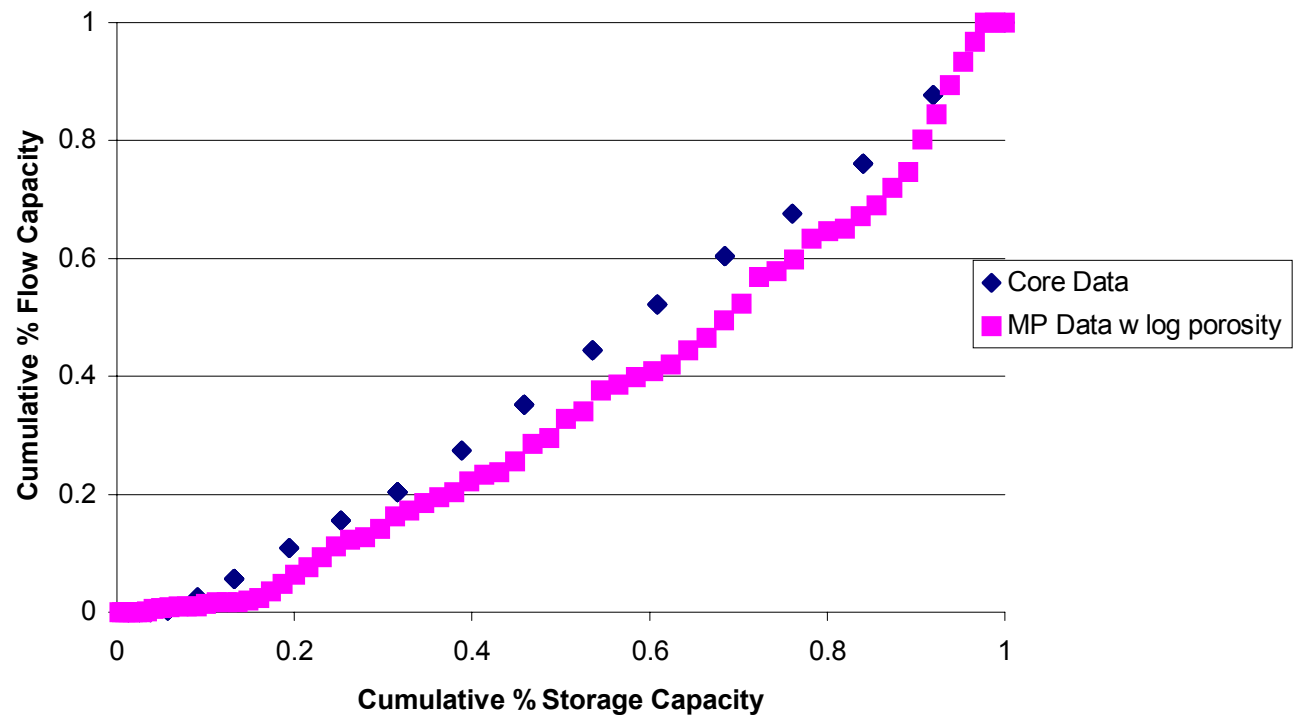




\section{Figure G.3 Ball \# 19 Cumulative Flow Capacity versus Cumulative Storage Capacity \\ (Core and Miniperm)}

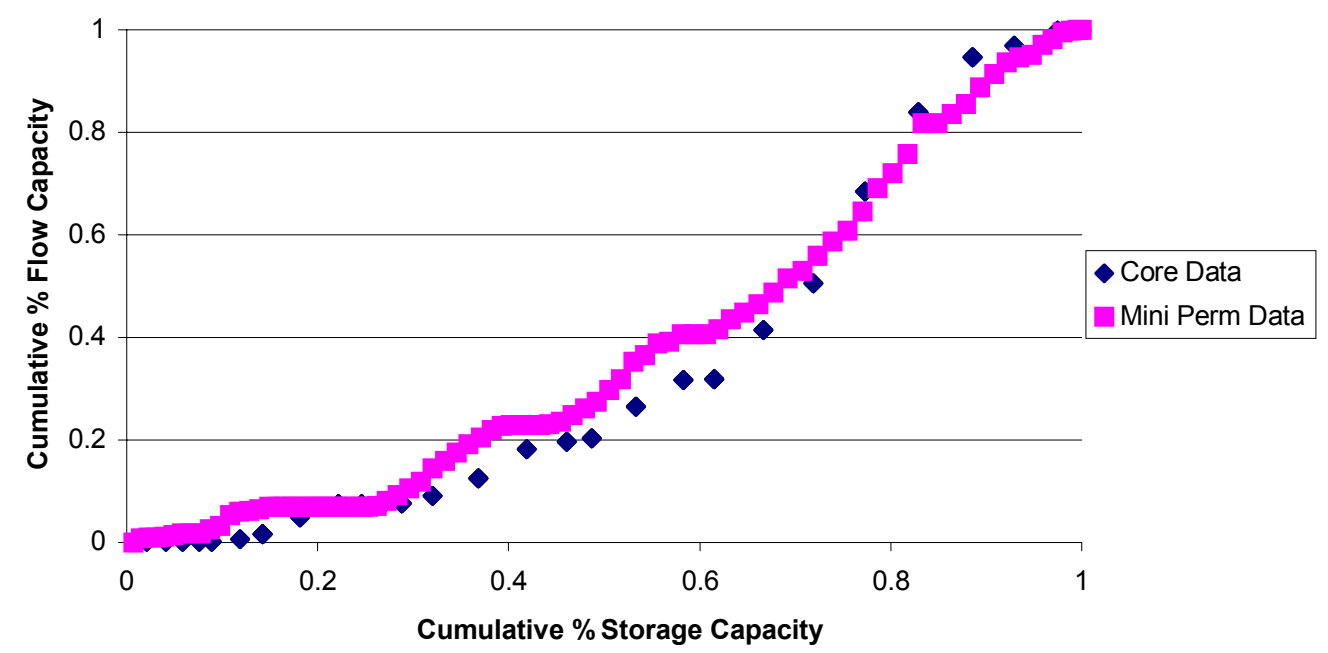

Figure G.4 LeMasters \# 13 Cumulative Flow Capacity versus Cumulative Storage Capacity

(Core and Miniperm)

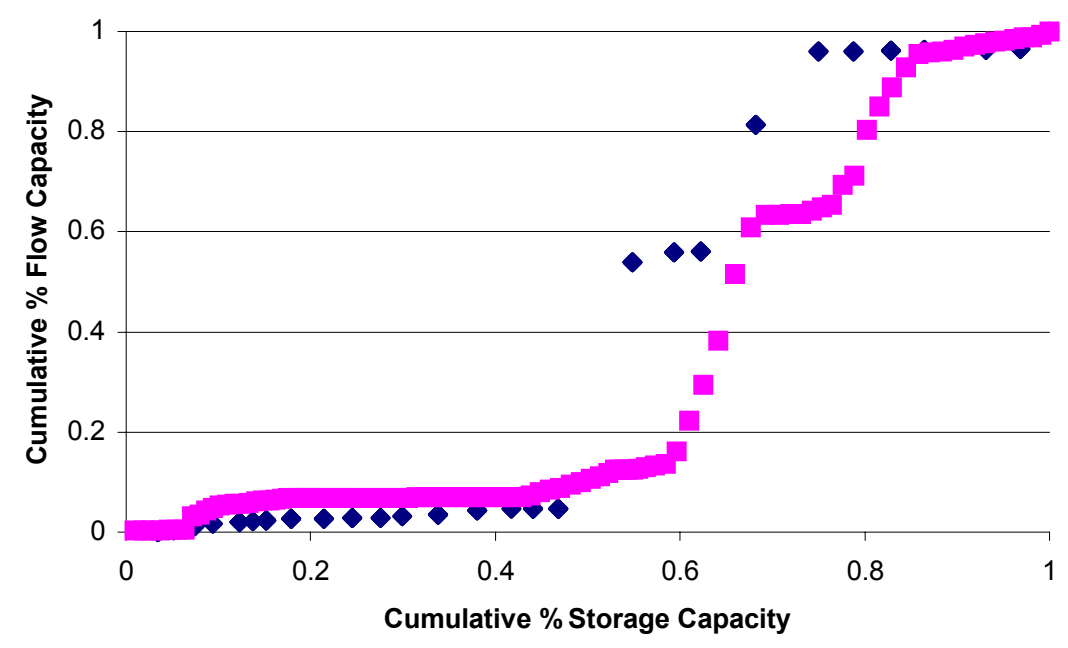


Figure G.5 Ball \# 18 Cumulative Flow Capacity versus Cumulative Storage Capacity

(Core and Miniperm)

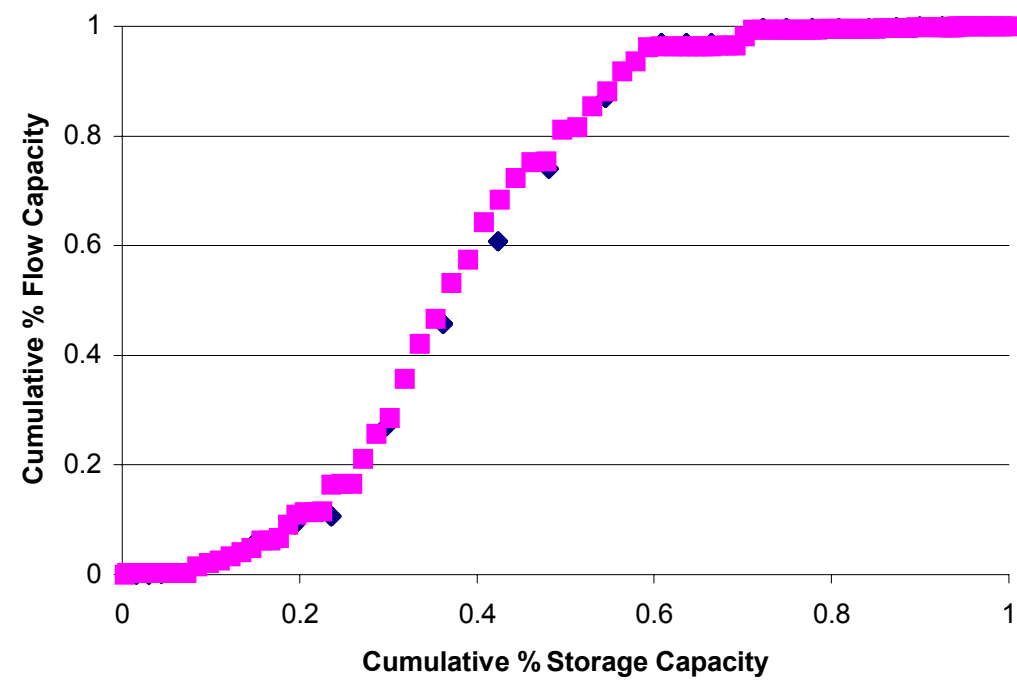

- Core Data

Mini Perm Data 


\section{APPENDIX H.}

Table H.1 and H.2 are the final backpropagation models for permeability prediction. Table $\mathrm{H.3}$ is the final backpropagation model (4-FU) for flow unit prediction. Figures H.1 - H.6 are graphs of actual versus predicted permeability for each core well. 


\begin{tabular}{|c|c|c|c|c|c|c|c|c|c|c|}
\hline & $\begin{array}{l}\text { Table H.1 } \\
\text { Model 1-K } \\
\text { (Seven Inf }\end{array}$ & Neur & thetwor & $\begin{array}{l}\text { k Model } \\
\text { nt Test } \subseteq\end{array}$ & $\begin{array}{l}\text { for Per } \\
\text { et) }\end{array}$ & eabili & & & & \\
\hline & & INPU & T .. & & & ------. & 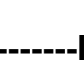 & NPUT & $\begin{array}{l}\text { OUT } \\
\text { PUT }\end{array}$ & \\
\hline & & flow & & & gr & rhob & gr & rhob & k & Cgy \\
\hline Well Name & Depth & unit & gr & density & slope & slope & bl & bl & (md) & A \\
\hline Horner \# 11 & 3084.50 & 1 & 35.262 & 2.498 & 1.102 & -0.038 & 122 & 2.7 & 2.1 & $\mathrm{p}$ \\
\hline Horner \# 11 & 3085.25 & 1 & 36.915 & 2.479 & 6.61 & 0.042 & 122 & 2.7 & 18 & $\mathrm{~T}$ \\
\hline Horner \# 11 & 3088.75 & 1 & 45.73 & 2.349 & -16.5 & -0.302 & 122 & 2.7 & 20 & $\mathrm{~T}$ \\
\hline Horner \# 11 & 3089.50 & 1 & 33.058 & 2.314 & -7.71 & 0.008 & 122 & 2.7 & 52 & $p$ \\
\hline Horner \# 11 & 3090.50 & 1 & 29.201 & 2.33 & 5.51 & -0.008 & 122 & 2.7 & 80 & p \\
\hline Horner \# 11 & 3092.00 & 2 & 47.383 & 2.309 & 22.04 & 0.034 & 122 & 2.7 & 238 & p \\
\hline Horner \# 11 & 3092.50 & 2 & 53.994 & 2.34 & 4.408 & 0.066 & 122 & 2.7 & 192 & $T$ \\
\hline T. Heirs \# 8 & 2785.25 & 1 & 38.44 & 2.519 & -12.3 & -0.008 & 145 & 2.71 & 0.11 & $\mathrm{~T}$ \\
\hline T. Heirs \# 8 & 2786.75 & 1 & 38.44 & 2.544 & 2.228 & 0.024 & 145 & 2.71 & 0.12 & $\mathrm{~T}$ \\
\hline T. Heirs \# 8 & 2788.75 & 1 & 51.811 & 2.495 & 3.342 & -0.03 & 145 & 2.71 & 0.92 & $\mathrm{~T}$ \\
\hline T. Heirs \# 8 & 2789.25 & 1 & 51.253 & 2.488 & -6.68 & -0.038 & 145 & 2.71 & 0.31 & $\mathrm{~T}$ \\
\hline T. Heirs \# 8 & 2791.50 & 1 & 39.554 & 2.473 & 3.342 & 0.004 & 145 & 2.71 & 6.5 & $\mathrm{~T}$ \\
\hline T. Heirs \# 8 & 2792.50 & 1 & 47.911 & 2.467 & 4.456 & -0.014 & 145 & 2.71 & 3.8 & p \\
\hline T. Heirs \# 8 & 2793.75 & 1 & 51.811 & 2.392 & -1.11 & -0.02 & 145 & 2.71 & 8.1 & $\mathrm{~T}$ \\
\hline T. Heirs \# 8 & 2794.75 & 1 & 49.025 & 2.384 & -2.23 & -0.034 & 145 & 2.71 & 18 & $T$ \\
\hline T. Heirs \# 8 & 2795.25 & 1 & 49.025 & 2.365 & 1.114 & -0.004 & 145 & 2.71 & 22 & $\mathrm{~T}$ \\
\hline T. Heirs \# 8 & 2796.00 & 1 & 52.925 & 2.359 & 5.57 & -0.018 & 145 & 2.71 & 23 & $\mathrm{~T}$ \\
\hline T. Heirs \# 8 & 2797.50 & 1 & 74.652 & 2.354 & 21.17 & 0.038 & 145 & 2.71 & 21 & $T$ \\
\hline Horner \# 9 & 2890.00 & 1 & 98.072 & 2.627 & -55.1 & -0.044 & 130 & 2.71 & 0.2 & $\mathrm{~T}$ \\
\hline Horner \# 9 & 2891.75 & 1 & 41.322 & 2.558 & -13.2 & -0.08 & 130 & 2.71 & 3.3 & $T$ \\
\hline Horner \# 9 & 2893.00 & 1 & 34.711 & 2.477 & -1.1 & -0.022 & 130 & 2.71 & 40 & $\mathrm{~T}$ \\
\hline Horner \# 9 & 2893.50 & 1 & 33.058 & 2.458 & -3.31 & -0.034 & 130 & 2.71 & 55 & $p$ \\
\hline Horner \# 9 & 2895.00 & 1 & 39.669 & 2.418 & 5.508 & -0.028 & 130 & 2.71 & 92 & p \\
\hline Horner \# 9 & 2895.75 & 1 & 42.424 & 2.381 & -1.1 & -0.044 & 130 & 2.71 & 80 & $T$ \\
\hline Horner \# 9 & 2896.50 & 1 & 41.873 & 2.347 & -2.2 & -0.052 & 130 & 2.71 & 84 & $p$ \\
\hline Horner \# 9 & 2898.25 & 2 & 41.322 & 2.341 & 0 & -0.006 & 130 & 2.71 & 123 & $\mathrm{~T}$ \\
\hline Horner \# 9 & 2898.75 & 2 & 41.873 & 2.334 & 2.204 & -0.012 & 130 & 2.71 & 136 & $\mathrm{~T}$ \\
\hline Horner \# 9 & 2900.00 & 2 & 45.73 & 2.289 & 5.51 & -0.014 & 130 & 2.71 & 160 & $\mathrm{~T}$ \\
\hline Horner \# 9 & 2901.00 & 2 & 50.689 & 2.281 & 3.306 & -0.014 & 130 & 2.71 & 135 & $\mathrm{~T}$ \\
\hline Horner \# 9 & 2902.00 & 2 & 52.342 & 2.274 & 2.204 & 0.002 & 130 & 2.71 & 144 & $p$ \\
\hline Horner \# 9 & 2903.00 & 2 & 55.647 & 2.284 & 1.102 & 0.01 & 130 & 2.71 & 124 & p \\
\hline Horner \# 9 & 2903.50 & 2 & 55.647 & 2.288 & 0 & 0.016 & 130 & 2.71 & 148 & $\mathrm{~T}$ \\
\hline
\end{tabular}




\begin{tabular}{|c|c|c|c|c|c|c|c|c|c|c|}
\hline & $\begin{array}{l}\text { Table H.1 } \\
\text { Model 1-K } \\
\text { (Seven In }\end{array}$ & $\begin{array}{l}\text { Neur } \\
\text { outs n }\end{array}$ & $\begin{array}{l}\text { al Netwo } \\
\text { ith Const }\end{array}$ & $\begin{array}{l}\text { rk Mode } \\
\text { ant Test }\end{array}$ & $\begin{array}{l}\text { for PeI } \\
\text { Set) }\end{array}$ & neabilit & & & & \\
\hline & & INPL & |T--. & & & ------. & 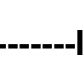 & NPUT & $\begin{array}{l}\text { PUT } \\
\text { PUT }\end{array}$ & \\
\hline & & flow & & & gr & rhob & gr & rhob & k & Cgy \\
\hline Well Name & Depth & unit & $\mathbf{g r}$ & density & slope & slope & bl & bl & $(\mathrm{md})$ & A \\
\hline Ball \# 19 & 3086.25 & 1 & 84.211 & 2.652 & -13.3 & -0.022 & 123 & 2.71 & 2.44 & $\mathrm{~T}$ \\
\hline Ball \# 19 & 3092.25 & 1 & 29.917 & 2.492 & 5.54 & -0.03 & 123 & 2.71 & 4.24 & $\mathrm{~T}$ \\
\hline Ball \# 19 & 3092.75 & 1 & 32.687 & 2.476 & 6.648 & -0.042 & 123 & 2.71 & 11 & $\mathrm{~T}$ \\
\hline Ball \# 19 & 3094.25 & 1 & 37.119 & 2.429 & 3.324 & -0.016 & 123 & 2.71 & 38 & $\mathrm{~T}$ \\
\hline Ball \# 19 & 3094.75 & 1 & 39.889 & 2.424 & 5.54 & -0.01 & 123 & 2.71 & 31 & $\mathrm{p}$ \\
\hline Ball \# 19 & 3097.25 & 1 & 37.119 & 2.509 & 3.324 & 0.006 & 123 & 2.71 & 0.27 & $\mathrm{~T}$ \\
\hline Ball \# 19 & 3098.00 & 1 & 40.997 & 2.519 & 7.756 & -0.036 & 123 & 2.71 & 0.16 & $\mathrm{~T}$ \\
\hline Ball \# 19 & 3099.25 & 1 & 42.659 & 2.473 & -5.54 & -0.016 & 123 & 2.71 & 17 & $\mathrm{~T}$ \\
\hline Ball \# 19 & 3100.00 & 1 & 37.119 & 2.396 & -8.86 & -0.112 & 123 & 2.71 & 41 & $\mathrm{~T}$ \\
\hline Ball \# 19 & 3101.25 & 1 & 36.565 & 2.369 & 3.324 & -0.012 & 123 & 2.71 & 65 & $\mathrm{~T}$ \\
\hline Ball \# 19 & 3102.00 & 1 & 41.551 & 2.399 & 7.756 & 0.096 & 123 & 2.71 & 17 & $\mathrm{p}$ \\
\hline Ball \# 19 & 3103.00 & 1 & 43.767 & 2.432 & 0 & 0.008 & 123 & 2.71 & 6.79 & $\mathrm{p}$ \\
\hline Ball \# 19 & 3104.00 & 1 & 44.321 & 2.377 & 2.216 & -0.04 & 123 & 2.71 & 73 & $\mathrm{~T}$ \\
\hline Ball \# 19 & 3105.00 & 1 & 43.213 & 2.365 & 4.432 & -0.004 & 123 & 2.71 & 60 & $\mathrm{~T}$ \\
\hline Ball \# 19 & 3106.00 & 1 & 43.767 & 2.367 & -4.43 & 0.004 & 123 & 2.71 & 1.16 & $\mathrm{p}$ \\
\hline Ball \# 19 & 3107.25 & 2 & 39.335 & 2.358 & 1.108 & -0.08 & 123 & 2.71 & 110 & $\mathrm{~T}$ \\
\hline Ball \# 19 & 3108.00 & 2 & 40.443 & 2.307 & 5.54 & -0.008 & 123 & 2.71 & 106 & $\mathrm{~T}$ \\
\hline Ball \# 19 & 3108.75 & 2 & 43.767 & 2.293 & -1.11 & -0.01 & 123 & 2.71 & 207 & $\mathrm{p}$ \\
\hline Ball \# 19 & 3109.50 & 2 & 42.659 & 2.286 & -2.22 & -0.014 & 123 & 2.71 & 179 & $\mathrm{~T}$ \\
\hline Ball \# 19 & 3110.75 & 2 & 40.443 & 2.3 & -8.86 & 0.018 & 123 & 2.71 & 124 & $\mathrm{~T}$ \\
\hline LeMasters \# 13 & 3031.75 & 1 & 30.114 & 2.544 & 0 & 0.022 & 115 & 2.72 & 0.15 & $\mathrm{~T}$ \\
\hline LeMasters \# 13 & 3032.25 & 1 & 29.546 & 2.552 & -2.27 & 0.012 & 115 & 2.72 & 0.72 & $\mathrm{~T}$ \\
\hline LeMasters \# 13 & 3034.25 & 1 & 26.137 & 2.554 & 4.546 & 0.02 & 115 & 2.72 & 0.28 & $\mathrm{~T}$ \\
\hline LeMasters \# 13 & 3034.75 & 1 & 28.409 & 2.564 & 4.544 & 0.02 & 115 & 2.72 & 0.27 & $\mathrm{~T}$ \\
\hline LeMasters \# 13 & 3036.00 & 1 & 30.114 & 2.583 & -2.27 & 0.006 & 115 & 2.72 & 0.12 & $\mathrm{~T}$ \\
\hline LeMasters \# 13 & 3036.50 & 1 & 28.409 & 2.579 & -1.14 & -0.014 & 115 & 2.72 & 0.22 & $\mathrm{~T}$ \\
\hline LeMasters \# 13 & 3038.50 & 1 & 36.364 & 2.542 & 5.113 & -0.015 & 115 & 2.72 & 0.18 & $\mathrm{~T}$ \\
\hline LeMasters \# 13 & 3042.50 & 1 & 44.886 & 2.532 & -2.84 & -0.017 & 115 & 2.72 & 0.19 & $\mathrm{~T}$ \\
\hline LeMasters \# 13 & 3043.25 & 1 & 41.762 & 2.517 & -7.95 & -0.034 & 115 & 2.72 & 0.29 & $\mathrm{~T}$ \\
\hline LeMasters \# 13 & 3045.25 & 1 & 48.012 & 2.513 & 17.05 & 0.07 & 115 & 2.72 & 0.67 & $\mathrm{~T}$ \\
\hline LeMasters \# 13 & 3045.75 & 1 & 59.659 & 2.559 & 29.54 & 0.114 & 115 & 2.72 & 0.21 & $\mathrm{~T}$ \\
\hline LeMasters \# 13 & 3048.75 & 1 & 46.307 & 2.398 & -12.5 & -0.072 & 115 & 2.72 & 37 & $\mathrm{~T}$ \\
\hline LeMasters \# 13 & 3050.00 & 1 & 44.318 & 2.477 & 2.272 & 0.081 & 115 & 2.72 & 1.51 & $\mathrm{p}$ \\
\hline LeMasters \# 13 & 3051.00 & 1 & 46.591 & 2.505 & -1.14 & -0.025 & 115 & 2.72 & 0.11 & $\mathrm{~T}$ \\
\hline LeMasters \# 13 & 3052.25 & 1 & 42.898 & 2.443 & -1.14 & -0.034 & 115 & 2.72 & 19 & $\mathrm{~T}$ \\
\hline LeMasters \# 13 & 3052.75 & 1 & 42.898 & 2.447 & 1.136 & 0.052 & 115 & 2.72 & 11 & $p$ \\
\hline
\end{tabular}




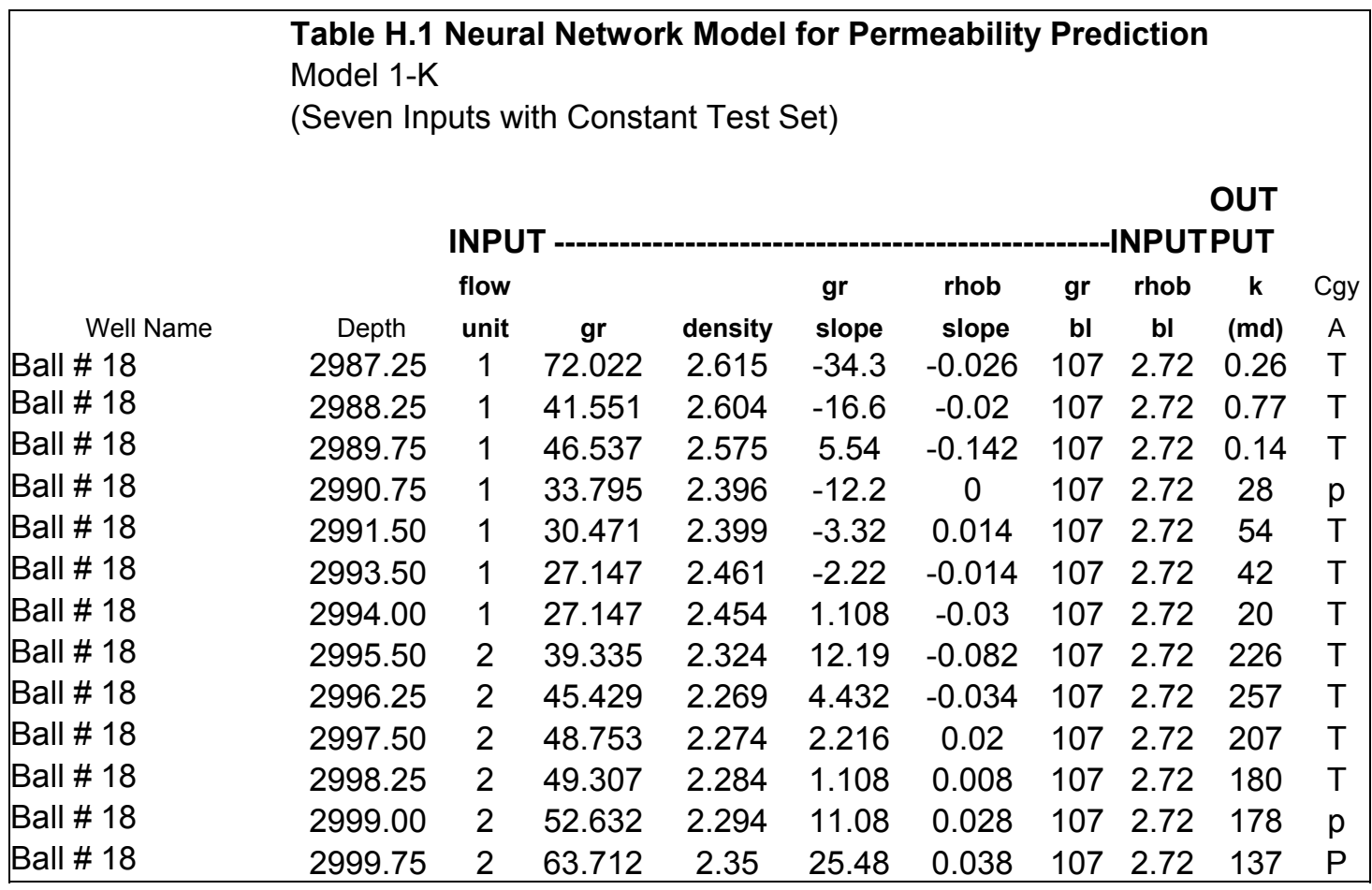




\begin{tabular}{|c|c|c|c|c|c|c|c|c|c|c|}
\hline & $\begin{array}{l}\text { Table H.2 } \\
\text { Model 2-K } \\
\text { (Seven In }\end{array}$ & $\mathrm{Neu}$ & $\begin{array}{l}\text { ral Netwo } \\
\text { ith Const }\end{array}$ & $\begin{array}{l}\text { rk Mode } \\
\text { ant Test }\end{array}$ & Set) & neabil & Pr & icti & & \\
\hline & & & & & & & & & OUT & \\
\hline & & INPL & & & & & & 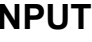 & PUT & \\
\hline & & flow & & & gr & rhob & gr & rhob & k & Cgy \\
\hline Well Name & Depth & unit & gr & density & slope & slope & bl & bl & (md) & A \\
\hline Horner \# 11 & 3084.50 & 1 & 35.262 & 2.498 & 1.102 & -0.038 & 122 & 2.7 & 2.1 & $p$ \\
\hline Horner \# 11 & 3085.30 & 1 & 36.915 & 2.479 & 6.61 & 0.042 & 122 & 2.7 & 18 & $\mathrm{t}$ \\
\hline Horner \# 11 & 3088.80 & 1 & 45.73 & 2.349 & -16.53 & -0.302 & 122 & 2.7 & 20 & $\mathrm{t}$ \\
\hline Horner \# 11 & 3089.50 & 1 & 33.058 & 2.314 & -7.714 & 0.008 & 122 & 2.7 & 52 & $\mathrm{p}$ \\
\hline Horner \# 11 & 3090.50 & 1 & 29.201 & 2.33 & 5.51 & -0.008 & 122 & 2.7 & 80 & $\mathrm{t}$ \\
\hline Horner \# 11 & 3092.00 & 2 & 47.383 & 2.309 & 22.04 & 0.034 & 122 & 2.7 & 238 & $\mathrm{p}$ \\
\hline Horner \# 11 & 3092.50 & 2 & 53.994 & 2.34 & 4.408 & 0.066 & 122 & 2.7 & 192 & $\mathrm{t}$ \\
\hline Horner \# 11 & 3093.30 & 1 & 62.81 & 2.503 & 20.94 & 0.346 & 122 & 2.7 & 3.6 & $\mathrm{t}$ \\
\hline Horner \# 11 & 3100.50 & 1 & 46.832 & 2.501 & -8.816 & 0.008 & 122 & 2.7 & 0.2 & $\mathrm{t}$ \\
\hline T. Heirs \# 8 & 2785.30 & 1 & 38.44 & 2.519 & -12.26 & -0.008 & 145 & 2.71 & 0.11 & $\mathrm{~T}$ \\
\hline T. Heirs \# 8 & 2786.80 & 1 & 38.44 & 2.544 & 2.228 & 0.024 & 145 & 2.71 & 0.12 & $\mathrm{~T}$ \\
\hline T. Heirs \# 8 & 2788.80 & 1 & 51.811 & 2.495 & 3.342 & -0.03 & 145 & 2.71 & 0.92 & $\mathrm{~T}$ \\
\hline T. Heirs \# 8 & 2789.30 & 1 & 51.253 & 2.488 & -6.684 & -0.038 & 145 & 2.71 & 0.31 & $\mathrm{~T}$ \\
\hline T. Heirs \# 8 & 2791.50 & 1 & 39.554 & 2.473 & 3.342 & 0.004 & 145 & 2.71 & 6.5 & $T$ \\
\hline T. Heirs \# 8 & 2792.50 & 1 & 47.911 & 2.467 & 4.456 & -0.014 & 145 & 2.71 & 3.8 & $\mathrm{~T}$ \\
\hline T. Heirs \# 8 & 2793.80 & 1 & 51.811 & 2.392 & -1.114 & -0.02 & 145 & 2.71 & 8.1 & $\mathrm{~T}$ \\
\hline T. Heirs \# 8 & 2794.80 & 1 & 49.025 & 2.384 & -2.228 & -0.034 & 145 & 2.71 & 18 & $\mathrm{~T}$ \\
\hline T. Heirs \# 8 & 2795.30 & 1 & 49.025 & 2.365 & 1.114 & -0.004 & 145 & 2.71 & 22 & $\mathrm{~T}$ \\
\hline T. Heirs \# 8 & 2796.00 & 1 & 52.925 & 2.359 & 5.57 & -0.018 & 145 & 2.71 & 23 & $\mathrm{~T}$ \\
\hline T. Heirs \# 8 & 2797.50 & 1 & 74.652 & 2.354 & 21.17 & 0.038 & 145 & 2.71 & 21 & $T$ \\
\hline Horner \# 9 & 2890.00 & 1 & 98.072 & 2.627 & -55.1 & -0.044 & 130 & 2.71 & 0.2 & $\mathrm{~T}$ \\
\hline Horner \# 9 & 2891.80 & 1 & 41.322 & 2.558 & -13.22 & -0.08 & 130 & 2.71 & 3.3 & $\mathrm{~T}$ \\
\hline Horner \# 9 & 2893.00 & 1 & 34.711 & 2.477 & -1.102 & -0.022 & 130 & 2.71 & 40 & $t$ \\
\hline Horner \# 9 & 2893.50 & 1 & 33.058 & 2.458 & -3.306 & -0.034 & 130 & 2.71 & 55 & $p$ \\
\hline Horner \# 9 & 2895.00 & 1 & 39.669 & 2.418 & 5.508 & -0.028 & 130 & 2.71 & 92 & $p$ \\
\hline Horner \# 9 & 2895.80 & 1 & 42.424 & 2.381 & -1.102 & -0.044 & 130 & 2.71 & 80 & $T$ \\
\hline Horner \# 9 & 2896.50 & 1 & 41.873 & 2.347 & -2.204 & -0.052 & 130 & 2.71 & 84 & $p$ \\
\hline Horner \# 9 & 2898.30 & 2 & 41.322 & 2.341 & 0 & -0.006 & 130 & 2.71 & 123 & $\mathrm{t}$ \\
\hline Horner \# 9 & 2898.80 & 2 & 41.873 & 2.334 & 2.204 & -0.012 & 130 & 2.71 & 136 & $\mathrm{~T}$ \\
\hline Horner \# 9 & 2900.00 & 2 & 45.73 & 2.289 & 5.51 & -0.014 & 130 & 2.71 & 160 & $\mathrm{p}$ \\
\hline Horner \# 9 & 2901.00 & 2 & 50.689 & 2.281 & 3.306 & -0.014 & 130 & 2.71 & 135 & $\mathrm{~T}$ \\
\hline Horner \# 9 & 2902.00 & 2 & 52.342 & 2.274 & 2.204 & 0.002 & 130 & 2.71 & 144 & $\mathrm{~T}$ \\
\hline Horner \# 9 & 2903.00 & 2 & 55.647 & 2.284 & 1.102 & 0.01 & 130 & 2.71 & 124 & $p$ \\
\hline Horner \# 9 & 2903.50 & 2 & 55.647 & 2.288 & 0 & 0.016 & 130 & 2.71 & 148 & $\mathrm{~T}$ \\
\hline
\end{tabular}




\begin{tabular}{|c|c|c|c|c|c|c|c|c|c|c|}
\hline \multirow{5}{*}{ Well Name } & \multicolumn{10}{|c|}{$\begin{array}{l}\text { Table H.2 Neural Network Model for Permeability Prediction } \\
\text { Model 2-K } \\
\text { (Seven Inputs with Constant Test Set) }\end{array}$} \\
\hline & \multicolumn{5}{|c|}{ INPUT } & \multicolumn{5}{|c|}{$\begin{array}{r}\text { OUT } \\
\text { ITPUT }\end{array}$} \\
\hline & & flow & & & & & gr & & & \\
\hline & Depth & unit & gr & density & & & bl & bl & (md) & A \\
\hline & 3086.30 & 1 & 84.211 & & & -0.022 & 123 & 2.71 & 2.44 & $\mathrm{t}$ \\
\hline Ball \# 19 & 092.30 & 1 & 29.917 & & & & 123 & 2.71 & 4.24 & $\mathrm{~T}$ \\
\hline Ball \# 19 & 92.80 & 1 & 32. & & & & 123 & 2.71 & 11 & $\mathrm{~T}$ \\
\hline Ball \# 19 & & 1 & 37. & & & & 123 & & 38 & $\mathrm{~T}$ \\
\hline Ball \# 19 & 30 & 1 & 39. & & & & 123 & 2.71 & 31 & $\mathrm{p}$ \\
\hline Ball \# 19 & 30 & 1 & 37. & & & & 123 & 2.71 & 0.27 & $\mathrm{t}$ \\
\hline Ball \# 19 & 098.00 & 1 & $40 . c$ & & 7.7 & & 123 & 2.71 & 0.16 & $\mathrm{~T}$ \\
\hline Ball \# 19 & 099.30 & 1 & & & & & 123 & 2.71 & 17 & $\mathrm{~T}$ \\
\hline Ball \# 19 & 100.00 & 1 & & & & & 123 & 2.71 & 41 & $\mathrm{~T}$ \\
\hline Ball \# 19 & 101.30 & 1 & & & & & 123 & 2.71 & 65 & $\mathrm{~T}$ \\
\hline Ball \# & & 1 & & & & & 123 & 71 & 17 & $\mathrm{~T}$ \\
\hline Ball \# & & 1 & & & & & 123 & 2.71 & 6.79 & $\mathrm{p}$ \\
\hline Ball \# & & 1 & & & & & 123 & 2.71 & & $\mathrm{~T}$ \\
\hline Ball \# & & 1 & & & & & 123 & 2.71 & 60 & $\mathrm{~T}$ \\
\hline Ball \# 19 & & 1 & & & & & 123 & 2.71 & 1.16 & $\mathrm{p}$ \\
\hline Ball \# 19 & 30 & 2 & & & & & 123 & 2.71 & 110 & $\mathrm{t}$ \\
\hline Ball \# 19 & 8.00 & 2 & & & & & 123 & 2.71 & 106 & $\mathrm{p}$ \\
\hline Ball \# 1 & & 2 & & & & & 123 & & & $p$ \\
\hline Ball \# & & 2 & & & & & 123 & .71 & 1 & $\mathrm{~T}$ \\
\hline Ball \# & & 2 & & & & & 123 & 2.71 & 124 & $\mathrm{~T}$ \\
\hline Ball \# 19 & & 1 & & & & & 123 & 2.71 & 26 & $\mathrm{~T}$ \\
\hline Ball \# 19 & & 1 & & & 21. & & 123 & 2.71 & 34 & $\mathrm{p}$ \\
\hline Ball \# 19 & & 1 & 83.657 & & 16.62 & & 123 & 2.71 & 1.33 & $\mathrm{t}$ \\
\hline LeMast & & 1 & & & & & 115 & & & $\mathrm{~T}$ \\
\hline LeMas & & 1 & & & & & 115 & 2.72 & & \\
\hline LeMas & & 1 & & & & & & 2.72 & & $\mathrm{~T}$ \\
\hline LeMas & & 1 & & & & & 11 & 2.72 & 0.2 & $\mathrm{~T}$ \\
\hline LeMas & & 1 & & & -2.2 & & 115 & 2.72 & 0.12 & $\mathrm{~T}$ \\
\hline LeMaste & & 1 & & & & & 115 & 2.72 & 0.22 & $\mathrm{~T}$ \\
\hline LeMasters \# 13 & & 1 & 36.3 & & 5.113 & & 115 & 2.72 & 0.18 & $\mathrm{~T}$ \\
\hline LeMasters \# 13 & 3042.50 & 1 & 44.88 & & -2.841 & & 115 & 2.72 & 0.19 & $\mathrm{~T}$ \\
\hline LeMasters \# 13 & & 1 & 41.7615 & & -7.954 & & 115 & 2.72 & 0.29 & \\
\hline LeMasters \# 13 & & 1 & & & & & 115 & 2.72 & 0.67 & $\mathrm{~T}$ \\
\hline LeMast & & 1 & & & & & 115 & 2.72 & 0.21 & $\mathrm{~T}$ \\
\hline LeMast & & 1 & & & & & 115 & 2.72 & 37 & $\mathrm{~T}$ \\
\hline LeMast & & 1 & & & 2.272 & & 115 & 2.72 & 1.51 & \\
\hline LeMasters \# 13 & & 1 & & & & & 115 & 2.72 & 0.11 & $\mathrm{~T}$ \\
\hline LeMasters \# 13 & & 1 & 42.8 & 2.4 & -1.136 & -0.0 & 115 & 2.72 & 19 & $\mathrm{~T}$ \\
\hline LeMasters \# 13 & 3052.80 & 1 & 42.898 & 2.447 & 1.136 & 0.052 & 115 & 2.72 & 11 & $\mathrm{p}$ \\
\hline
\end{tabular}




\begin{tabular}{|c|c|c|c|c|c|c|c|c|c|c|}
\hline & $\begin{array}{l}\text { Table H.2 } \\
\text { Model 2-K } \\
\text { (Seven In }\end{array}$ & Neu & $\begin{array}{l}\text { ral Netwo } \\
\text { ith Const }\end{array}$ & $\begin{array}{l}\text { rk Mode } \\
\text { ant Test }\end{array}$ & I for $\mathrm{Pe}$ & meabili & Preo & & & \\
\hline & & INPU & IT ---. & & & 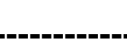 & . & NPUT & PUT & \\
\hline & & flow & & & gr & rhob & gr & rhob & k & Cgy \\
\hline Well Name & Depth & unit & gr & density & slope & slope & bl & bl & (md) & $A$ \\
\hline Ball \# 18 & 2987.30 & 1 & 72.022 & 2.615 & -34.35 & -0.026 & 107 & 2.72 & 0.26 & $\mathrm{t}$ \\
\hline Ball \# 18 & 2988.30 & 1 & 41.551 & 2.604 & -16.62 & -0.02 & 107 & 2.72 & 0.77 & $\mathrm{t}$ \\
\hline Ball \# 18 & 2989.80 & 1 & 46.537 & 2.575 & 5.54 & -0.142 & 107 & 2.72 & 0.14 & $\mathrm{t}$ \\
\hline Ball \# 18 & 2990.80 & 1 & 33.795 & 2.396 & -12.19 & 0 & 107 & 2.72 & 28 & $p$ \\
\hline Ball \# 18 & 2991.50 & 1 & 30.471 & 2.399 & -3.324 & 0.014 & 107 & 2.72 & 54 & $\mathrm{t}$ \\
\hline Ball \# 18 & 2993.50 & 1 & 27.147 & 2.461 & -2.216 & -0.014 & 107 & 2.72 & 42 & $\mathrm{t}$ \\
\hline Ball \# 18 & 2994.00 & 1 & 27.147 & 2.454 & 1.108 & -0.03 & 107 & 2.72 & 20 & $\mathrm{t}$ \\
\hline Ball \# 18 & 2995.50 & 2 & 39.335 & 2.324 & 12.19 & -0.082 & 107 & 2.72 & 226 & $\mathrm{t}$ \\
\hline Ball \# 18 & 2996.30 & 2 & 45.429 & 2.269 & 4.432 & -0.034 & 107 & 2.72 & 257 & $\mathrm{p}$ \\
\hline Ball \# 18 & 2997.50 & 2 & 48.753 & 2.274 & 2.216 & 0.02 & 107 & 2.72 & 207 & $\mathrm{t}$ \\
\hline Ball \# 18 & 2998.30 & 2 & 49.307 & 2.284 & 1.108 & 0.008 & 107 & 2.72 & 180 & $\mathrm{t}$ \\
\hline Ball \# 18 & 2999.00 & 2 & 52.632 & 2.294 & 11.08 & 0.028 & 107 & 2.72 & 178 & $t$ \\
\hline Ball \# 18 & 2999.80 & 2 & 63.712 & 2.35 & 25.48 & 0.038 & 107 & 2.72 & 137 & $P$ \\
\hline Ball \# 18 & 3002.80 & 1 & 72.022 & 2.458 & 1.108 & 0.028 & 107 & 2.72 & 37 & $\mathrm{t}$ \\
\hline Ball \# 18 & 3005.30 & 1 & 72.576 & 2.509 & 5.54 & -0.024 & 107 & 2.72 & 0.26 & $\mathrm{t}$ \\
\hline Ball \# 18 & 3007.30 & 1 & 50.97 & 2.47 & -11.08 & -0.014 & 107 & 2.72 & 1.4 & $p$ \\
\hline Ball \# 18 & 3007.80 & 1 & 43.767 & 2.468 & -22.16 & -0.014 & 107 & 2.72 & 1.5 & $\mathrm{t}$ \\
\hline Ball \# 18 & 3009.00 & 1 & 41.551 & 2.506 & 16.62 & 0.286 & 107 & 2.72 & 0.79 & $\mathrm{t}$ \\
\hline Ball \# 18 & 3009.80 & 1 & 57.064 & 2.611 & 43.21 & 0.102 & 107 & 2.72 & 0.25 & $\mathrm{t}$ \\
\hline Ball \# 18 & 3011.00 & 1 & 86.981 & 2.644 & -1.108 & -0.008 & 107 & 2.72 & 0.11 & $\mathrm{t}$ \\
\hline Ball \# 18 & 3012.30 & 1 & 58.726 & 2.527 & -47.64 & -0.08 & 107 & 2.72 & 0.26 & $\mathrm{t}$ \\
\hline Ball \# 18 & 3013.00 & 1 & 43.213 & 2.505 & 1.108 & 0 & 107 & 2.72 & 0.38 & $\mathrm{t}$ \\
\hline
\end{tabular}




\begin{tabular}{|c|c|c|c|c|c|c|c|c|}
\hline \multirow[b]{4}{*}{ Well Name } & \multicolumn{8}{|c|}{$\begin{array}{l}\text { Table H.3 Table of ANN Model for Flow Unit Prediction } \\
\text { Model 4-FU } \\
\text { (Constant Test Set) }\end{array}$} \\
\hline & & OUTPUT & INPUT & & 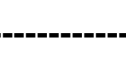 & --------. & --- INPUT & \\
\hline & & flow & & & gr & rhob & gr rhob & Cat \\
\hline & Depth & unit & gr & density & slope & slope & bl bl & A \\
\hline T Heirs \# 8 & 2789.50 & 1 & 47.91 & 2.469 & -15.60 & -0.030 & 1452.71 & $\mathrm{~T}$ \\
\hline T Heirs \# 8 & 2789.75 & 1 & 43.45 & 2.473 & -21.17 & 0.000 & 1452.71 & $T$ \\
\hline T Heirs \# 8 & 2790.00 & 1 & 37.33 & 2.469 & -12.26 & -0.012 & 1452.71 & $T$ \\
\hline T Heirs \# 8 & 2790.25 & 1 & 37.33 & 2.467 & 0.00 & -0.004 & 1452.71 & $\mathrm{~T}$ \\
\hline T Heirs \# 8 & 2790.50 & 1 & 37.33 & 2.467 & 0.00 & 0.000 & 1452.71 & $\mathrm{~T}$ \\
\hline T Heirs \# 8 & 2790.75 & 1 & 37.33 & 2.467 & 0.00 & 0.008 & 1452.71 & $T$ \\
\hline T Heirs \# 8 & 2791.00 & 1 & 37.33 & 2.471 & 2.23 & 0.008 & 1452.71 & $\mathrm{~T}$ \\
\hline T Heirs \# 8 & 2791.25 & 1 & 38.44 & 2.471 & 4.46 & 0.004 & 1452.71 & $\mathrm{~T}$ \\
\hline T Heirs \# 8 & 2791.50 & 1 & 39.55 & 2.473 & 3.34 & 0.004 & 1452.71 & $T$ \\
\hline T Heirs \# 8 & 2791.75 & 1 & 40.11 & 2.473 & 14.49 & -0.004 & 1452.71 & $T$ \\
\hline T Heirs \# 8 & 2792.00 & 1 & 46.8 & 2.471 & 13.37 & -0.004 & 1452.71 & $T$ \\
\hline T Heirs \# 8 & 2792.25 & 1 & 46.8 & 2.471 & 2.23 & -0.008 & 1452.71 & $T$ \\
\hline T Heirs \# 8 & 2792.50 & 1 & 47.91 & 2.467 & 4.46 & -0.014 & 1452.71 & $\mathrm{~T}$ \\
\hline T Heirs \# 8 & 2792.75 & 1 & 49.03 & 2.464 & 10.03 & -0.030 & 1452.71 & $\mathrm{~T}$ \\
\hline T Heirs \# 8 & 2793.00 & 1 & 52.93 & 2.452 & 7.80 & -0.062 & 1452.71 & $T$ \\
\hline T Heirs \# 8 & 2793.25 & 1 & 52.93 & 2.433 & -1.11 & -0.100 & 1452.71 & $T$ \\
\hline T Heirs \# 8 & 2793.50 & 1 & 52.37 & 2.402 & -2.23 & -0.082 & 1452.71 & $T$ \\
\hline T Heirs \# 8 & 2793.75 & 1 & 51.81 & 2.392 & -1.11 & -0.020 & 1452.71 & $\mathrm{~T}$ \\
\hline T Heirs \# 8 & 2794.00 & 1 & 51.81 & 2.392 & -3.34 & -0.010 & 1452.71 & $\mathrm{~T}$ \\
\hline T Heirs \# 8 & 2794.25 & 1 & 50.14 & 2.387 & -4.46 & -0.016 & 1452.71 & $T$ \\
\hline T Heirs \# 8 & 2794.50 & 1 & 49.58 & 2.384 & -2.23 & & 1452.71 & $T$ \\
\hline T Heirs \# 8 & 2794.75 & 1 & 49.03 & 2.384 & -2.23 & -0.034 & 1452.71 & $T$ \\
\hline T Heirs \# 8 & 2795.00 & 1 & 48.47 & 2.367 & 0.00 & -0.038 & 1452.71 & $T$ \\
\hline T Heirs \# 8 & 2795.25 & 1 & 49.03 & 2.365 & 1.11 & -0.004 & 1452.71 & $\mathrm{~T}$ \\
\hline T Heirs \# 8 & 2795.50 & 1 & 49.03 & 2.365 & 5.57 & -0.004 & 1452.71 & $\mathrm{~T}$ \\
\hline T Heirs \# 8 & 2795.75 & 1 & 51.81 & 2.363 & 7.80 & -0.012 & 1452.71 & $T$ \\
\hline T Heirs \# 8 & 2796.00 & 1 & 52.93 & 2.359 & 5.57 & -0.018 & 1452.71 & $T$ \\
\hline T Heirs \# 8 & 2796.25 & 1 & 54.6 & 2.354 & 5.57 & -0.014 & 1452.71 & $T$ \\
\hline T Heirs \# 8 & 2796.50 & 1 & 55.71 & 2.352 & 7.80 & -0.006 & 1452.71 & $\mathrm{~T}$ \\
\hline T Heirs \# 8 & 2796.75 & 1 & 58.5 & 2.351 & 5.57 & -0.002 & 1452.71 & $\mathrm{~T}$ \\
\hline T Heirs \# 8 & 2797.00 & 1 & 58.5 & 2.351 & 11.14 & -0.008 & 1452.71 & $T$ \\
\hline
\end{tabular}




\begin{tabular}{|c|c|c|c|c|c|c|c|c|c|}
\hline & Table H. & $\begin{array}{l}3 \text { Table } \\
\text { Model } 4 \\
\text { (Constal }\end{array}$ & $\begin{array}{l}\text { ANN } \\
\text { Test S }\end{array}$ & ner & Flo & nit & & & \\
\hline & & OUTPUT & INPU & & & ----------' & --- IN & NPUT & \\
\hline & & flow & & & gr & rhob & gr & rhob & Cat \\
\hline Well Name & Depth & unit & gr & density & slope & slope & & bl & A \\
\hline LeMasters \# 13 & 33048.00 & 1 & 57.39 & 2.484 & -27.27 & -0.089 & 115 & 2.72 & $\mathrm{~T}$ \\
\hline LeMasters \# 13 & 33048.25 & 1 & 53.41 & 2.450 & -15.91 & -0.136 & 115 & 2.72 & $\mathrm{~T}$ \\
\hline LeMasters \# 13 & 33048.50 & 1 & 9.43 & 2.416 & -14.20 & & 115 & 2.72 & $\mathrm{~T}$ \\
\hline LeMaster & 33048. & 1 & 46.31 & 2.398 & -12.50 & -0.0 & 115 & 2.72 & $\mathrm{~T}$ \\
\hline LeMasters \# 13 & & 1 & & & -6.82 & & & 2.72 & $\mathrm{~T}$ \\
\hline LeMas & & 1 & & & -1.14 & & & 2.72 & $\mathrm{~T}$ \\
\hline LeMc & 33049.50 & 1 & 42.61 & 2.4 & 1.14 & 0.097 & 115 & 2.72 & $\mathrm{~T}$ \\
\hline LeMa & 33049.75 & 1 & 43.47 & 2.4 & 3.41 & 0.146 & 115 & 2.72 & $\mathrm{~T}$ \\
\hline LeMas & & 1 & & & 2.27 & & 115 & 2.72 & \\
\hline LeMas & & 1 & & & 1.14 & & 15 & 2.72 & $\mathrm{~T}$ \\
\hline LeMa & 330 & 1 & 44.89 & 2.4 & 2.27 & 0.028 & 1 & 2.72 & $\mathrm{~T}$ \\
\hline LeM & 33050.75 & 1 & 4 & & 3.41 & & 115 & 2.72 & $\mathrm{~T}$ \\
\hline LeMa & 33051.00 & 1 & 46.59 & 2.5 & -1.14 & -0.0 & 115 & 2.72 & $\mathrm{~T}$ \\
\hline LeMa & 33051.25 & 1 & 45.17 & 2.4 & -5.68 & -0.0 & 115 & 2.72 & $\mathrm{~T}$ \\
\hline LeMas & & 1 & & & -3.41 & & 15 & 2.72 & $\mathrm{~T}$ \\
\hline LeMa & & 1 & 43.47 & 2.456 & -1.14 & -0.0 & 15 & 52.72 & $\mathrm{~T}$ \\
\hline LeMa & 33052.00 & 1 & 43.18 & 2.451 & -1.14 & -0.026 & 115 & 52.72 & $\mathrm{~T}$ \\
\hline LeMasters \# 13 & 33052.25 & 1 & 42.90 & 2.443 & -1.14 & -0.034 & 115 & 2.72 & $\mathrm{~T}$ \\
\hline LeMasters \# 13 & 33052.50 & 1 & 42.61 & 2.434 & 0.00 & 0.009 & 115 & 52.72 & $\mathrm{~T}$ \\
\hline LeMas & 33052.75 & 1 & 42. & & 1.14 & & 115 & 2.72 & p \\
\hline LeMas & & 1 & & & 0.00 & & 115 & 2.72 & $T$ \\
\hline LeMasters \# 13 & 33053.25 & 1 & 42.90 & 2.467 & -1.14 & 0.028 & 115 & 2.72 & $\mathrm{~T}$ \\
\hline LeMasters \# 13 & 33053.50 & 1 & 42.61 & 2.474 & -1.14 & 0.024 & 115 & 2.72 & $\mathrm{~T}$ \\
\hline LeMasters \# 13 & 33053.75 & 1 & 42.33 & 2.479 & -1.14 & 0.020 & 115 & 2.72 & $\mathrm{~T}$ \\
\hline LeMasters \# 13 & 33054.00 & 1 & 42.05 & 2.484 & -1.70 & 0.030 & 115 & 2.72 & $\mathrm{~T}$ \\
\hline
\end{tabular}




\begin{tabular}{|c|c|c|c|c|c|c|c|c|c|}
\hline & Table H.3 & $\begin{array}{l}3 \text { Table } \\
\text { Model } 4 \\
\text { (Constar }\end{array}$ & $\begin{array}{l}\text { ANN Mc } \\
\text { U } \\
\text { Test Set }\end{array}$ & odel & & & & & \\
\hline & & OUTPUT & INPUT. & & & & & INPUT & \\
\hline & & flow & & & gr & rhob & $\mathbf{g r}$ & rhob & Cat \\
\hline Well Name & Depth & unit & gr & density & slope & slope & bl & bl & A \\
\hline Horner \# 9 & 2892.75 & 1 & 34.71 & 2.48 & 0.00 & -0.026 & 130 & 2.71 & $\mathrm{~T}$ \\
\hline Horner \# 9 & 2893.00 & 1 & 34.71 & 2.48 & -1.10 & -0.022 & 130 & 2.71 & $\mathrm{~T}$ \\
\hline Horner \# 9 & 2893.25 & 1 & 34.16 & 2.47 & -3.31 & -0.038 & 130 & 2.71 & $\mathrm{~T}$ \\
\hline Horner \# 9 & 2893.5 & 1 & .06 & 2.46 & & -0. & 130 & 2.71 & $p$ \\
\hline Horner \# 9 & 2893. & 1 & .51 & 2.45 & 2.20 & -0 . & 130 & 2.71 & $\mathrm{~T}$ \\
\hline Horner \# 9 & & 1 & & & & & 30 & 2.71 & $\mathrm{~T}$ \\
\hline Horner \# 9 & 2894.25 & 1 & & 2.43 & 4.41 & & 130 & 2.71 & $\mathrm{~T}$ \\
\hline Horner \# 9 & 2894.50 & 1 & 36.36 & 2.43 & 3.31 & -0. & 130 & 2.71 & $\mathrm{~T}$ \\
\hline Horne & 2894.7 & 1 & 38.02 & 2. & & & 130 & & $\mathrm{~T}$ \\
\hline Horne & & 1 & & & & & 30 & & $p$ \\
\hline Horner \# 9 & & 1 & & & & & & & $\mathrm{~T}$ \\
\hline Horner \# 9 & 289 & 1 & & 2.3 & 3.2 & & 130 & 2.71 & $\mathrm{~T}$ \\
\hline Horner \# 9 & 2895.7 & 1 & & & -1.10 & & 130 & 2.71 & $\mathrm{~T}$ \\
\hline Horn & 2896.0 & 1 & 42.4 & 2.37 & 0.00 & & 130 & 2.71 & $\mathrm{~T}$ \\
\hline Horne & 289 & 1 & 42. & & -1 & & 130 & 2.71 & $\mathrm{~T}$ \\
\hline Horne & & 2 & & & & & & & $p$ \\
\hline Horn & $28 \varsigma$ & 2 & & 2. & & & 130 & 2.71 & $T$ \\
\hline Horn & & 2 & & & & & 130 & 2.71 & $\mathrm{~T}$ \\
\hline Horn & 2897.2 & 2 & 40.77 & 2.34 & & & 130 & 2.71 & $\mathrm{~T}$ \\
\hline Horn & & 2 & & & & & & 2.71 & $\mathrm{~T}$ \\
\hline Horr & & 2 & & & & & 30 & & $\mathrm{~T}$ \\
\hline Horn & & 2 & & & & & 130 & 2.71 & $\mathrm{~T}$ \\
\hline Horn & 2898.25 & 2 & 41.32 & 2.34 & 0.00 & -0.006 & 130 & 2.71 & $\mathrm{~T}$ \\
\hline Horn & & 2 & & & 1.10 & & 130 & 2.71 & $\mathrm{~T}$ \\
\hline \# 9 & & 2 & & & & & 130 & 2.71 & $\mathrm{~T}$ \\
\hline Horn & & 2 & & & & & 30 & 2.71 & $\mathrm{~T}$ \\
\hline Horn & 289 & 2 & 44. & 2.3 & 4.41 & & 130 & 2.71 & $\mathrm{~T}$ \\
\hline Horner \# 9 & 2899.50 & 3 & 44.63 & 2.30 & 1.10 & -0.054 & 130 & 2.71 & $\mathrm{~T}$ \\
\hline Horner \# 9 & 2899.7 & 3 & 44.63 & & 2.20 & -0. & 130 & 2.71 & $\mathrm{~T}$ \\
\hline Horn & 2900.0 & 3 & & 2.29 & 5.51 & -0. & 130 & 2.71 & $p$ \\
\hline Horr & 2900. & 3 & & & & & 130 & 2.71 & $\mathrm{~T}$ \\
\hline Horner \# 9 & & 3 & & 2.29 & & & 130 & 2.71 & $\mathrm{~T}$ \\
\hline Horner \# 9 & 2900.75 & 3 & 49.59 & 2.28 & 3.31 & -0.008 & 130 & 2.71 & $\mathrm{~T}$ \\
\hline Horner \# 9 & 2901.00 & 3 & 50.69 & 2.28 & 3.31 & -0.014 & 130 & 2.71 & $\mathrm{~T}$ \\
\hline Horner \# 9 & 2901.25 & 3 & 51.24 & 2.28 & 1.10 & -0.008 & 130 & 2.71 & $\mathrm{~T}$ \\
\hline Horner \# 9 & 2901.50 & 3 & 51.24 & 2.28 & 1.10 & -0.006 & 130 & 2.71 & $\mathrm{~T}$ \\
\hline Horner \# 9 & 2901.75 & 3 & 51.79 & 2.27 & 2.20 & -0.006 & 130 & 2.71 & $\mathrm{~T}$ \\
\hline Horner \# 9 & 2902.00 & 3 & 52.34 & 2.27 & 2.20 & 0.002 & 130 & 2.71 & $\mathrm{~T}$ \\
\hline
\end{tabular}




\begin{tabular}{|c|c|c|c|c|c|c|c|c|}
\hline & Table H & $\begin{array}{l}\text { Table of } \\
\text { Model 4-F } \\
\text { (Constant }\end{array}$ & $\begin{array}{l}\text { ANN M } \\
\text { U } \\
\text { Test Se }\end{array}$ & $\begin{array}{l}\text { hodel } \\
\text { et) }\end{array}$ & FIc & Unit P & rediction & \\
\hline & & OUTPUT & INPUT & & & --------. & T----- INPUT & \\
\hline & & flow & & & gr & rhob & gr rhob & Cat \\
\hline Well Name & Depth & unit & gr & density & slope & slope & bl bl & $A$ \\
\hline Horner \# 9 & 2902.75 & 3 & 55.10 & 2.28 & 3.31 & 0.012 & 1302.71 & $\mathrm{~T}$ \\
\hline Horner \# 9 & 2903.00 & 3 & 55.65 & 2.28 & 1.10 & 0.010 & 1302.71 & $p$ \\
\hline Horner \# 9 & 2903.25 & 3 & 55.65 & 2.28 & 0.00 & 0.008 & 1302.71 & $\mathrm{~T}$ \\
\hline Horner \# 9 & 2903.50 & 3 & 55.65 & 2.29 & 0.00 & 0.016 & 1302.71 & $\mathrm{~T}$ \\
\hline Horner \# 9 & 2903.75 & 3 & 55.65 & 2.29 & 1.10 & 0.018 & 1302.71 & $\mathrm{~T}$ \\
\hline Horner \# 9 & 2904.00 & 3 & 56.20 & 2.30 & 4.41 & 0.046 & 1302.71 & $\mathrm{~T}$ \\
\hline Horner \# 9 & 2904.25 & 3 & 57.85 & 2.32 & 9.92 & 0.042 & 1302.71 & $\mathrm{~T}$ \\
\hline Horner \# 9 & 2904.50 & 3 & 61.16 & 2.32 & 7.71 & 0.024 & 1302.71 & $\mathrm{~T}$ \\
\hline Horner \# 9 & 2904.75 & 2 & 61.71 & 2.33 & 1.10 & 0.018 & 1302.71 & $\mathrm{~T}$ \\
\hline Horner \# 9 & 2905.00 & 2 & 61.71 & 2.33 & 3.31 & 0.048 & 1302.71 & $\mathrm{~T}$ \\
\hline Horner \# 9 & 2905.25 & 1 & 63.36 & 2.35 & 8.82 & 0.058 & 1302.71 & $\mathrm{~T}$ \\
\hline Horner \# 9 & 2905.50 & 1 & 66.12 & 2.36 & 12.12 & 0.032 & 1302.71 & $\mathrm{~T}$ \\
\hline Horner \# 9 & 2905.75 & 1 & 69.42 & 2.37 & 14.32 & 0.038 & 1302.71 & $\mathrm{~T}$ \\
\hline Horner \# 9 & 2906.00 & 1 & 73.28 & 2.38 & 14.33 & 0.124 & 1302.71 & $\mathrm{~T}$ \\
\hline Horner \# 9 & 2906.25 & 1 & 76.58 & 2.43 & 14.33 & 0.144 & 1302.71 & $\mathrm{~T}$ \\
\hline Horner \# 9 & 2906.50 & 1 & 80.44 & 2.45 & 7.71 & 0.036 & 1302.71 & $\mathrm{~T}$ \\
\hline
\end{tabular}




\begin{tabular}{|c|c|c|c|c|c|c|c|c|}
\hline \multirow[b]{4}{*}{ Well Name } & \multicolumn{8}{|c|}{$\begin{array}{c}\text { Table H.3 Table of ANN Model for Flow Unit Prediction } \\
\text { Model 4-FU } \\
\text { (Constant Test Set) }\end{array}$} \\
\hline & \multirow[b]{3}{*}{ Depth } & \multirow{2}{*}{$\begin{array}{l}\text { OUTPUT } \\
\text { flow }\end{array}$} & \multicolumn{6}{|c|}{ 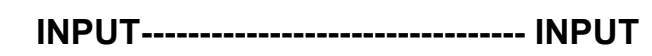 } \\
\hline & & & & & gr & rhob & gr rhob $C$ & \\
\hline & & unit & $\mathrm{gr}$ & density & slope & slope & bl & A \\
\hline Ball \# 19 & 3092.50 & 1 & 31.03 & 2.486 & 5.54 & -0.032 & 1232.71 & $\mathrm{~T}$ \\
\hline Ball \# 19 & 3092.75 & 1 & 32.69 & 2.476 & 6.65 & -0.042 & 1232.71 & $\mathrm{~T}$ \\
\hline Ball \# 19 & 3093.00 & 1 & 34.35 & 2.465 & 5.54 & -0.038 & 1232.71 & $\mathrm{~T}$ \\
\hline Ball \# 19 & 3093.25 & 1 & 35.46 & 2.457 & 4.43 & -0.0 & 1232.71 & $\mathrm{~T}$ \\
\hline Ball \# 19 & 3093.50 & 1 & 36.57 & 2.448 & 2.22 & -0. & 1232.71 & $\mathrm{~T}$ \\
\hline Ball \# 19 & 3093.75 & 1 & 36.57 & 2.448 & 1.11 & -0.022 & 1232.71 & $\mathrm{~T}$ \\
\hline Ball \# 19 & 3094.00 & 1 & 37.12 & 2.437 & 1.11 & -0.038 & 1232.71 & $\mathrm{~T}$ \\
\hline Ball \# 19 & 3094.25 & 1 & 37.12 & 2.429 & 3.32 & -0.016 & 1232.71 & $\mathrm{~T}$ \\
\hline Ball \# 19 & 3094.50 & 1 & 38.78 & 2.429 & 5.54 & $-0 . C$ & 1232.71 & $\mathrm{~T}$ \\
\hline Ball \# 19 & 3094.75 & 1 & 39. & 2.424 & 5.54 & & 1232.71 & $p$ \\
\hline Ball \# 19 & 3095.00 & 1 & 41.55 & 2.424 & 5.54 & 0.002 & 1232.71 & $\mathrm{~T}$ \\
\hline Ball \# 19 & 3095.25 & 1 & 42.66 & 2.425 & 1.11 & 0.002 & 1232.71 & $\mathrm{~T}$ \\
\hline Ball \# 19 & 3095.50 & 1 & 42.11 & 2.425 & -1.11 & 0.002 & 1232.71 & $\mathrm{~T}$ \\
\hline Ball \# 19 & 3095.75 & 1 & 42.11 & 2.426 & -2.22 & 0.088 & 1232.71 & $\mathrm{~T}$ \\
\hline Ball \# 19 & 309 & 1 & 41 & 2.469 & -6.6 & 0.1 & 1232.71 & $\mathrm{~T}$ \\
\hline Ball \# 19 & 3096.25 & 1 & 38.78 & 2.49 & -8.86 & 0.060 & 1232.71 & $\mathrm{~T}$ \\
\hline Ball \# 19 & 3096.50 & 1 & 36.57 & 2.499 & -5.54 & 30 & 1232.71 & $\mathrm{~T}$ \\
\hline Ball \# 19 & 3096.75 & 1 & 36.01 & 2.505 & -2.22 & 0.020 & 1232.71 & $\mathrm{~T}$ \\
\hline Ball \# 19 & 3097.00 & 1 & 35.46 & 2.509 & 2.22 & 0.008 & 1232.71 & $\mathrm{~T}$ \\
\hline Ball \# 19 & 3097.25 & 1 & 37.1 & 2.509 & & & 1232.71 & $\mathrm{~T}$ \\
\hline Ball \# 19 & 3097.50 & 1 & 37.1 & 2.512 & 3.32 & 0.014 & 1232.71 & $\mathrm{~T}$ \\
\hline Ball \# 19 & 3097.75 & 1 & 38.78 & 2.516 & 7.76 & 0.014 & 1232.71 & $\mathrm{~T}$ \\
\hline Ball \# 19 & 3098.00 & 1 & 41 & 2.519 & 7.76 & -0.036 & 1232.71 & $\mathrm{~T}$ \\
\hline Ball \# 19 & 3098.25 & 1 & 42.66 & 2.498 & 6.65 & -0.066 & 1232.71 & $\mathrm{~T}$ \\
\hline Ball \# 19 & 3098.50 & 1 & 44.32 & 2.486 & 7.76 & -0.042 & 1232.71 & $\mathrm{~T}$ \\
\hline Ball \# 19 & 3098.75 & 1 & 46. & 2.477 & 2.22 & $-0 .($ & 1232.71 & $\mathrm{~T}$ \\
\hline Ball \# 19 & 3099.00 & 1 & 45.43 & 2.477 & -7.76 & -0.008 & 1232.71 & $\mathrm{~T}$ \\
\hline Ball \# 19 & 3099.25 & 1 & 42.66 & 2.473 & -5.54 & -0.016 & 1232.71 & $\mathrm{~T}$ \\
\hline Ball \# 19 & 3099.50 & 1 & 42.66 & 2.469 & -5.54 & -0.080 & 1232.71 & $\mathrm{~T}$ \\
\hline Ball \# 19 & 3099.75 & 1 & 39.89 & 2.433 & -11.08 & -0.146 & 1232.71 & $\mathrm{~T}$ \\
\hline Ball \# 19 & 3100.00 & 1 & 37.12 & 2.396 & -8.86 & -0.112 & 1232.71 & $\mathrm{~T}$ \\
\hline Ball \# 19 & 3100.25 & 1 & 35.46 & 2.377 & -6.65 & -0.046 & 1232.71 & $\mathrm{~T}$ \\
\hline Ball \# 19 & 3100.50 & 1 & 33.8 & 2.373 & -1.11 & -0.008 & 1232.71 & $\mathrm{~T}$ \\
\hline Ball \# 19 & 3100.75 & 1 & 34.9 & 2.373 & 5.54 & 0.000 & 1232.71 & $\mathrm{~T}$ \\
\hline Ball \# 19 & 3101.00 & 1 & 36.57 & 2.373 & 3.32 & -0.008 & 1232.71 & $\mathrm{~T}$ \\
\hline Ball \# 19 & 3101.25 & 1 & 36.57 & 2.369 & 3.32 & -0.012 & 1232.71 & $\mathrm{~T}$ \\
\hline Ball \# 19 & 3101.50 & 1 & 38.23 & 2.367 & 6.65 & 0.008 & 1232.71 & $\mathrm{~T}$ \\
\hline Ball \# 19 & 3101.75 & 1 & 39.89 & 2.373 & 6.65 & 0.064 & 1232.71 & $\mathrm{~T}$ \\
\hline Ball \# 19 & 3102.00 & 1 & 41.55 & 2.399 & 7.76 & 0.096 & 1232.71 & $\mathrm{~T}$ \\
\hline
\end{tabular}




\begin{tabular}{|c|c|c|c|c|c|c|c|c|c|}
\hline \multirow[b]{4}{*}{ Well Name } & \multicolumn{9}{|c|}{$\begin{array}{l}\text { Table H.3 Table of ANN Model for Flow Unit Prediction } \\
\text { Model 4-FU } \\
\text { (Constant Test Set) }\end{array}$} \\
\hline & & OUPUT & INPUT. & ---------- & ---------- & |---------. & ---- IT & NPUT & \\
\hline & & flow & & & gr & rhob & gr & rhob & Cat \\
\hline & Depth & unit & gr & density & slope & slope & bl & bl & A \\
\hline Ball \# 19 & 3102.25 & 1 & 43.77 & 2.421 & 5.54 & 0.060 & 123 & 2.71 & $\mathrm{~T}$ \\
\hline Ball \# 19 & 3102.50 & 1 & 44.32 & 2.429 & 0.00 & 0.016 & 123 & 2.71 & $\mathrm{~T}$ \\
\hline Ball \# 19 & 3102.75 & 1 & 43.77 & 2.429 & -1.11 & 0.006 & 123 & 2.71 & $\mathrm{~T}$ \\
\hline Ball \# 19 & 3103.00 & 1 & 43.77 & 2.432 & 0.00 & 0.008 & 123 & 2.71 & $\mathrm{p}$ \\
\hline Ball \# 19 & 3103.25 & 1 & 43.77 & 2.433 & -1.11 & 0.000 & 123 & 2.71 & $\mathrm{~T}$ \\
\hline Ball \# 19 & 3103.50 & 1 & 43.21 & 2.432 & -1.11 & -0.092 & 123 & 2.71 & $\mathrm{~T}$ \\
\hline Ball \# 19 & 3103.75 & 1 & 43.21 & 2.387 & 2.22 & -0.110 & 123 & 2.71 & $\mathrm{~T}$ \\
\hline Ball \# 19 & 3104.00 & 1 & 44.32 & 2.377 & 2.22 & -0.040 & 123 & 2.71 & $\mathrm{~T}$ \\
\hline Ball \# 19 & 3104.25 & 1 & 44.32 & 2.367 & 1.11 & -0.020 & 123 & 2.71 & $\mathrm{~T}$ \\
\hline Ball \# 19 & 3104.50 & 1 & 44.88 & 2.367 & -2.22 & 0.000 & 123 & 2.71 & $\mathrm{~T}$ \\
\hline Ball \# 19 & 3104.75 & 1 & 43.21 & 2.367 & -3.32 & -0.004 & 123 & 2.71 & $\mathrm{~T}$ \\
\hline Ball \# 19 & 3105.00 & 1 & 43.21 & 2.365 & 4.43 & -0.004 & 123 & 2.71 & $\mathrm{~T}$ \\
\hline Ball \# 19 & 3105.25 & 1 & 45.43 & 2.365 & 3.32 & 0.000 & 123 & 2.71 & $\mathrm{~T}$ \\
\hline Ball \# 19 & 3105.50 & 1 & 44.88 & 2.365 & -2.22 & 0.000 & 123 & 2.71 & $\mathrm{~T}$ \\
\hline Ball \# 19 & 3105.75 & 1 & 44.32 & 2.365 & -2.22 & 0.004 & 123 & 2.71 & $\mathrm{~T}$ \\
\hline Ball \# 19 & 3106.00 & 1 & 43.77 & 2.367 & -4.43 & 0.004 & 123 & 2.71 & $p$ \\
\hline Ball \# 19 & 3106.25 & 1 & 42.11 & 2.367 & -6.65 & 0.006 & 123 & 2.71 & $\mathrm{~T}$ \\
\hline Ball \# 19 & 3106.50 & 1 & 40.44 & 2.37 & -3.32 & -0.004 & 123 & 2.71 & $\mathrm{~T}$ \\
\hline Ball \# 19 & 3106.75 & 1 & 40.44 & 2.365 & -1.11 & -0.016 & 123 & 2.71 & $\mathrm{~T}$ \\
\hline Ball \# 19 & 3107.00 & 2 & 39.89 & 2.362 & -2.22 & -0.014 & 123 & 2.71 & $\mathrm{~T}$ \\
\hline Ball \# 19 & 3107.25 & 2 & 39.34 & 2.358 & 1.11 & -0.080 & 123 & 2.71 & $\mathrm{~T}$ \\
\hline Ball \# 19 & 3107.50 & 3 & 40.44 & 2.322 & 3.32 & -0.102 & 123 & 2.71 & $\mathrm{~T}$ \\
\hline Ball \# 19 & 3107.75 & 3 & 41 & 2.307 & 0.00 & -0.030 & 123 & 2.71 & $\mathrm{~T}$ \\
\hline Ball \# 19 & 3108.00 & 3 & 40.44 & 2.307 & 5.54 & -0.008 & 123 & 2.71 & $p$ \\
\hline Ball \# 19 & 3108.25 & 3 & 43.77 & 2.303 & 6.65 & -0.018 & 123 & 2.71 & $\mathrm{~T}$ \\
\hline Ball \# 19 & 3108.50 & 3 & 43.77 & 2.298 & 0.00 & -0.020 & 123 & 2.71 & $\mathrm{~T}$ \\
\hline Ball \# 19 & 3108.75 & 3 & 43.77 & 2.293 & -1.11 & -0.010 & 123 & 2.71 & $p$ \\
\hline Ball \# 19 & 3109.00 & 3 & 43.21 & 2.293 & -1.11 & 0.000 & 123 & 2.71 & $\mathrm{~T}$ \\
\hline Ball \# 19 & 3109.25 & 3 & 43.21 & 2.293 & -1.11 & -0.014 & 123 & 2.71 & $\mathrm{~T}$ \\
\hline Ball \# 19 & 3109.50 & 3 & 42.66 & 2.286 & -2.22 & -0.014 & 123 & 2.71 & $\mathrm{~T}$ \\
\hline Ball \# 19 & 3109.75 & 3 & 42.11 & 2.286 & -3.32 & 0.008 & 123 & 2.71 & $\mathrm{~T}$ \\
\hline Ball \# 19 & 3110.00 & 3 & 41 & 2.29 & -2.22 & 0.014 & 123 & 2.71 & $\mathrm{~T}$ \\
\hline Ball \# 19 & 3110.25 & 3 & 41 & 2.293 & 0.00 & 0.012 & 123 & 2.71 & $\mathrm{~T}$ \\
\hline Ball \# 19 & 3110.50 & 3 & 41 & 2.296 & -1.11 & 0.014 & 123 & 2.71 & $\mathrm{~T}$ \\
\hline Ball \# 19 & 3110.75 & 3 & 40.44 & 2.3 & -8.86 & 0.018 & 123 & 2.71 & $\mathrm{~T}$ \\
\hline
\end{tabular}




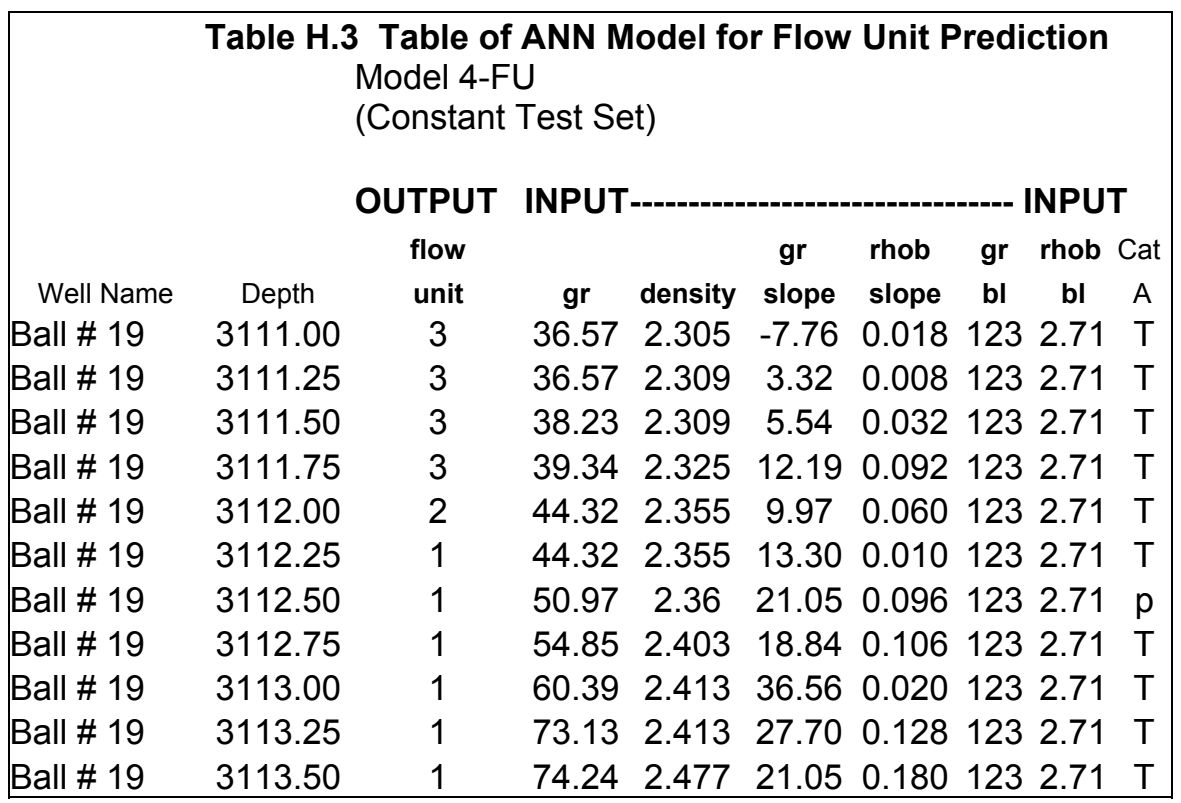

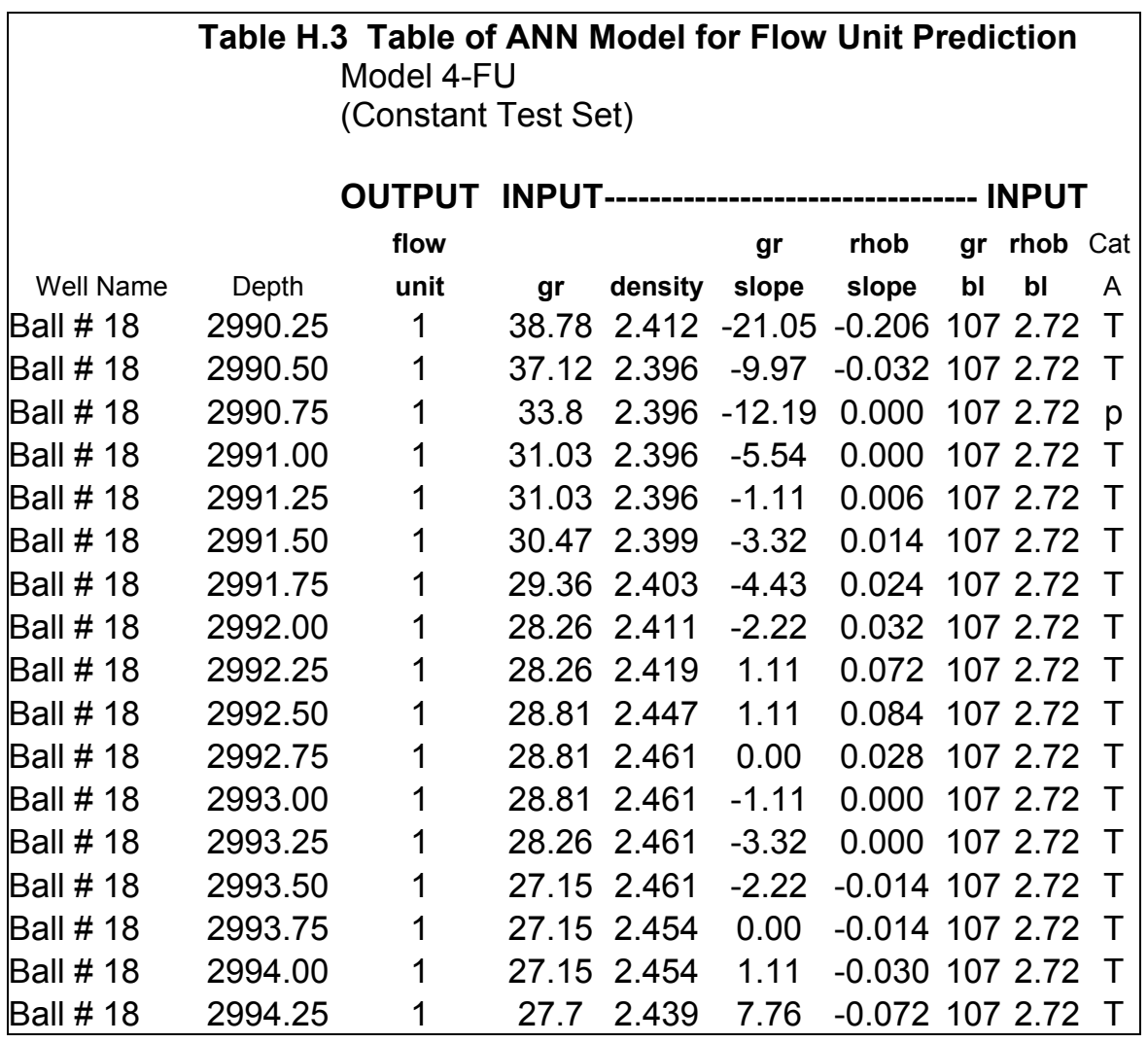




\begin{tabular}{|c|c|c|c|c|c|c|c|c|c|}
\hline \multirow[b]{4}{*}{ Well Name } & \multicolumn{9}{|c|}{$\begin{array}{l}\text { Table H.3 Table of ANN Model for Flow Unit Prediction } \\
\text { Model 4-FU } \\
\text { (Constant Test Set) }\end{array}$} \\
\hline & & OUTPUT & INPUT & - & & 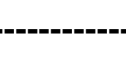 & ----- I & INPUT & \\
\hline & & flow & & & gr & rhob & gr & rhob & Cat \\
\hline & Depth & unit & gr & density & slope & slope & bl & bl & A \\
\hline Ball \# 18 & 2994.50 & 1 & 31.03 & 2.418 & 6.65 & -0.042 & 107 & 2.72 & $\mathrm{~T}$ \\
\hline Ball \# 18 & 2994.75 & 1 & 31.03 & 2.418 & 3.32 & -0.064 & 107 & 2.72 & $\mathrm{~T}$ \\
\hline Ball \# 18 & 2995.00 & 1 & 32.69 & 2.386 & 8.86 & -0.144 & 107 & 2.72 & $\mathrm{~T}$ \\
\hline Ball \# 18 & 2995.25 & 1 & 35.46 & 2.346 & 13.30 & -0.124 & 107 & 2.72 & \\
\hline Ball \# 18 & 2995.50 & 2 & & 2.324 & 12.19 & -0.0 & 107 & 2.72 & $\mathrm{~T}$ \\
\hline Ball \# 18 & 2995.75 & 2 & 41.55 & 2.305 & 7.76 & -0.076 & 107 & 2.72 & $\mathrm{~T}$ \\
\hline Ball \# 18 & 2996.00 & 3 & 43.21 & 2.2 & 7.76 & -0.072 & 107 & 2.72 & $\mathrm{~T}$ \\
\hline Ball \# 18 & 2996.25 & 3 & 45.43 & 2.269 & 4.43 & -0.034 & 107 & 2.72 & $p$ \\
\hline Ball \# 18 & & 3 & & 2.26 & 2.22 & & 107 & 2.72 & \\
\hline Ball \# 18 & & 3 & & 2.2 & 3.32 & & 107 & 2.72 & $\mathrm{~T}$ \\
\hline Ball \# 18 & 2997.00 & 3 & & 2.265 & 2.22 & & 107 & 2.72 & $\mathrm{~T}$ \\
\hline Ball \# 18 & 2997.25 & 3 & 47.65 & 2.269 & 3.32 & 0.018 & 107 & 2.72 & $\mathrm{~T}$ \\
\hline Ball \# 18 & 2997.50 & 3 & 48.7 & 2.27 & 2.22 & 0.020 & 107 & 2.72 & $\mathrm{~T}$ \\
\hline Ball \# 18 & 2997.75 & 3 & 48.75 & 2.279 & 1.11 & 0.020 & 107 & 2.72 & $\mathrm{~T}$ \\
\hline Ball \# 18 & & 3 & & 2.2 & 1.11 & & 107 & 2.72 & \\
\hline Ball \# 18 & $29 s$ & 3 & & $2.2 \varepsilon$ & 1.11 & 08 & 107 & 2.72 & $\mathrm{~T}$ \\
\hline Ball \# 18 & 2998.5 & 3 & & 2.2 & 3.33 & & 107 & 2.72 & $\mathrm{~T}$ \\
\hline Ball \# 18 & 2998 & 3 & 50.97 & 2.288 & 5.54 & 0.012 & 107 & 2.72 & $\mathrm{~T}$ \\
\hline Ball \# 18 & 2999.0 & 3 & 52.63 & $2.2 \mathrm{~S}$ & 11.08 & & 107 & 2.72 & $\mathrm{~T}$ \\
\hline Ball \# 18 & & 3 & & & & & 107 & 2.72 & \\
\hline Ball \# 18 & & 3 & & 2.33 & 14. & 96 & 107 & 2.72 & $\mathrm{~T}$ \\
\hline Ball \# 18 & 2999.7 & 3 & 63.71 & 2.35 & 25.48 & 0.038 & 107 & 2.72 & $p$ \\
\hline Ball \# 18 & 3000.00 & 2 & 72.58 & 2.356 & 17.73 & 0.012 & 107 & 2.72 & $\mathrm{~T}$ \\
\hline Ball \# 18 & 3000.25 & 2 & 72.58 & 2.356 & 0.00 & 0.214 & 107 & 2.72 & $\mathrm{~T}$ \\
\hline Ball \# 18 & & 1 & 72.5 & 2.46 & -2.22 & 0.256 & 107 & 2.72 & $\mathrm{~T}$ \\
\hline Ball \# 18 & 30 & 1 & 71. & 2.484 & -3.32 & 0.058 & 107 & 2.72 & $\mathrm{~T}$ \\
\hline Ball \# 18 & 3001.00 & 1 & 70.91 & 2.492 & -1.11 & 0.016 & 107 & 2.72 & $\mathrm{~T}$ \\
\hline Ball \# 18 & 3001.25 & 1 & 70.91 & 2.492 & -4.43 & -0.016 & 107 & 2.72 & $\mathrm{~T}$ \\
\hline Ball \# 18 & 3001.50 & 1 & 68.7 & 2.484 & -2.22 & -0.022 & 107 & 2.72 & $\mathrm{~T}$ \\
\hline Ball \# 18 & 3001.75 & 1 & 69.81 & 2.481 & 2.22 & -0.006 & 107 & 2.72 & $\mathrm{~T}$ \\
\hline Ball \# 18 & & 1 & 69.81 & 2.481 & 2.22 & -0.060 & 107 & 2.72 & $\mathrm{~T}$ \\
\hline Ball \# 18 & 3002.25 & 1 & 70.91 & 2.451 & 2.22 & -0.060 & 107 & 2.72 & \\
\hline Ball \# 18 & 3002.50 & 1 & 70.91 & 2.451 & 2.22 & 0.014 & 107 & 2.72 & $\mathrm{~T}$ \\
\hline Ball \# 18 & 3002.75 & 1 & 72.02 & 2.458 & 1.11 & 0.028 & 107 & 2.72 & $\mathrm{~T}$ \\
\hline Ball \# 18 & 3003.00 & 1 & 71.47 & 2.465 & -2.22 & 0.032 & 107 & 2.72 & $\mathrm{~T}$ \\
\hline Ball \# 18 & 3003.25 & 1 & 70.91 & 2.474 & -9.97 & 0.050 & 107 & 2.72 & $\mathrm{~T}$ \\
\hline
\end{tabular}




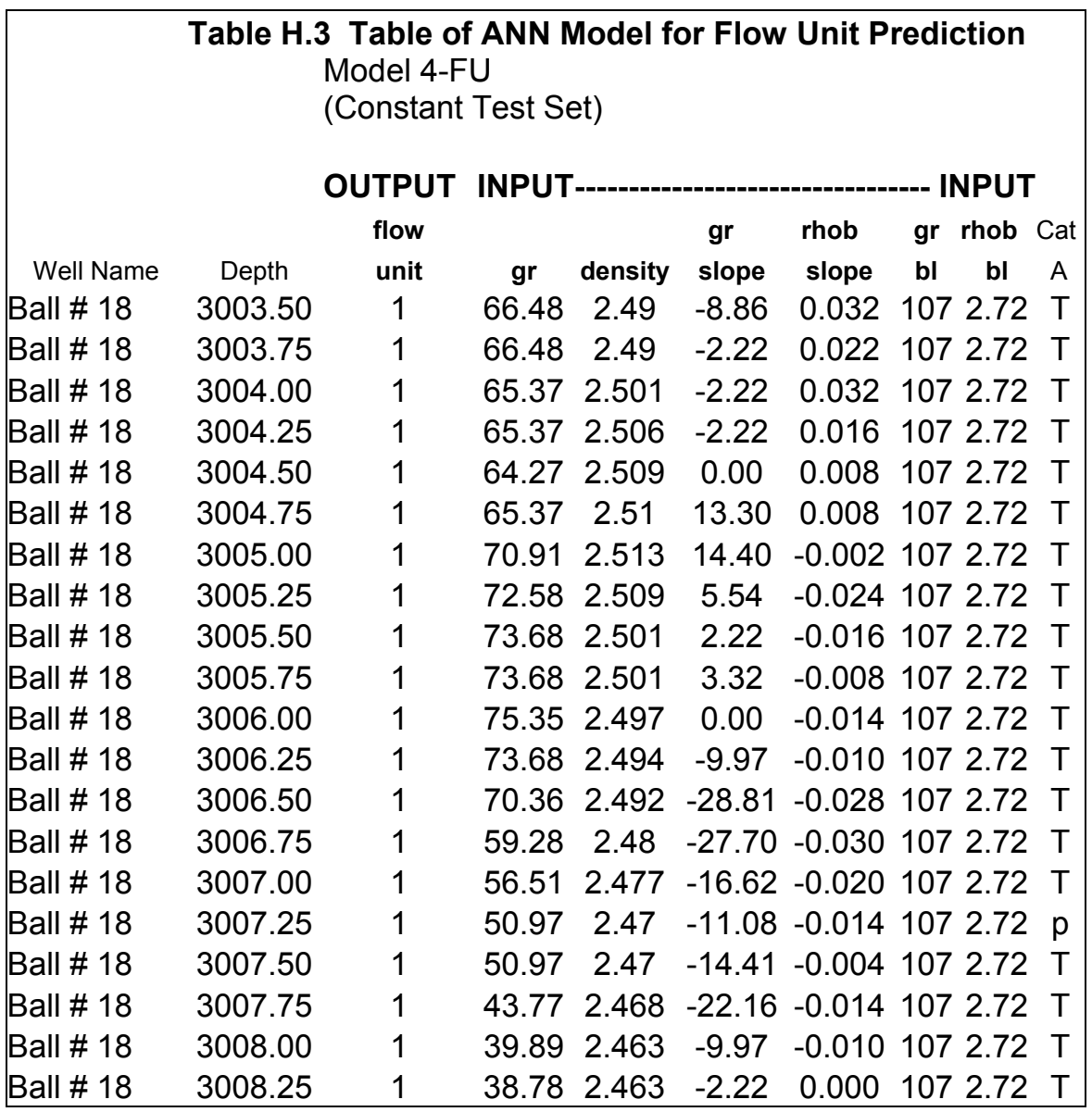

\begin{tabular}{|c|c|c|c|c|c|c|c|c|}
\hline & Table H.3 & $\begin{array}{l}\text { Table of } \\
\text { Model 4-F } \\
\text { (Constant }\end{array}$ & $\begin{array}{l}\text { ANN M } \\
\text { U } \\
\text { Test Se }\end{array}$ & $\begin{array}{l}\text { odel fo } \\
\text { t) }\end{array}$ & r Flow & Unit $P_{1}$ & diction & \\
\hline & & OUTPUT & INPUT & '--------.' & ---------- & ---------. & -----INPUT & \\
\hline & & flow & & & gr & rhob & gr rhob & Cat \\
\hline Well Name & Depth & unit & gr & density & slope & slope & bl bl & A \\
\hline Horner \# 11 & $3,084.50$ & 1 & 35.26 & 2.498 & 1.10 & -0.038 & 1222.71 & $p$ \\
\hline Horner \# 11 & 3084.75 & 1 & 35.26 & 2.484 & 0 & -0.05 & 1222.71 & $\mathrm{~T}$ \\
\hline Horner \# 11 & 3085.00 & 1 & 35.26 & 2.473 & 3.306 & -0.01 & 1222.71 & $\mathrm{~T}$ \\
\hline Horner \# 11 & 3085.25 & 1 & 36.92 & 2.479 & 6.61 & 0.042 & 1222.71 & $\mathrm{~T}$ \\
\hline Horner \# 11 & 3085.50 & 1 & 38.57 & 2.494 & 9.916 & 0.044 & 1222.71 & $\mathrm{~T}$ \\
\hline Horner \# 11 & 3085.75 & 1 & 41.87 & 2.501 & 8.816 & 0.014 & 1222.71 & $\mathrm{~T}$ \\
\hline
\end{tabular}




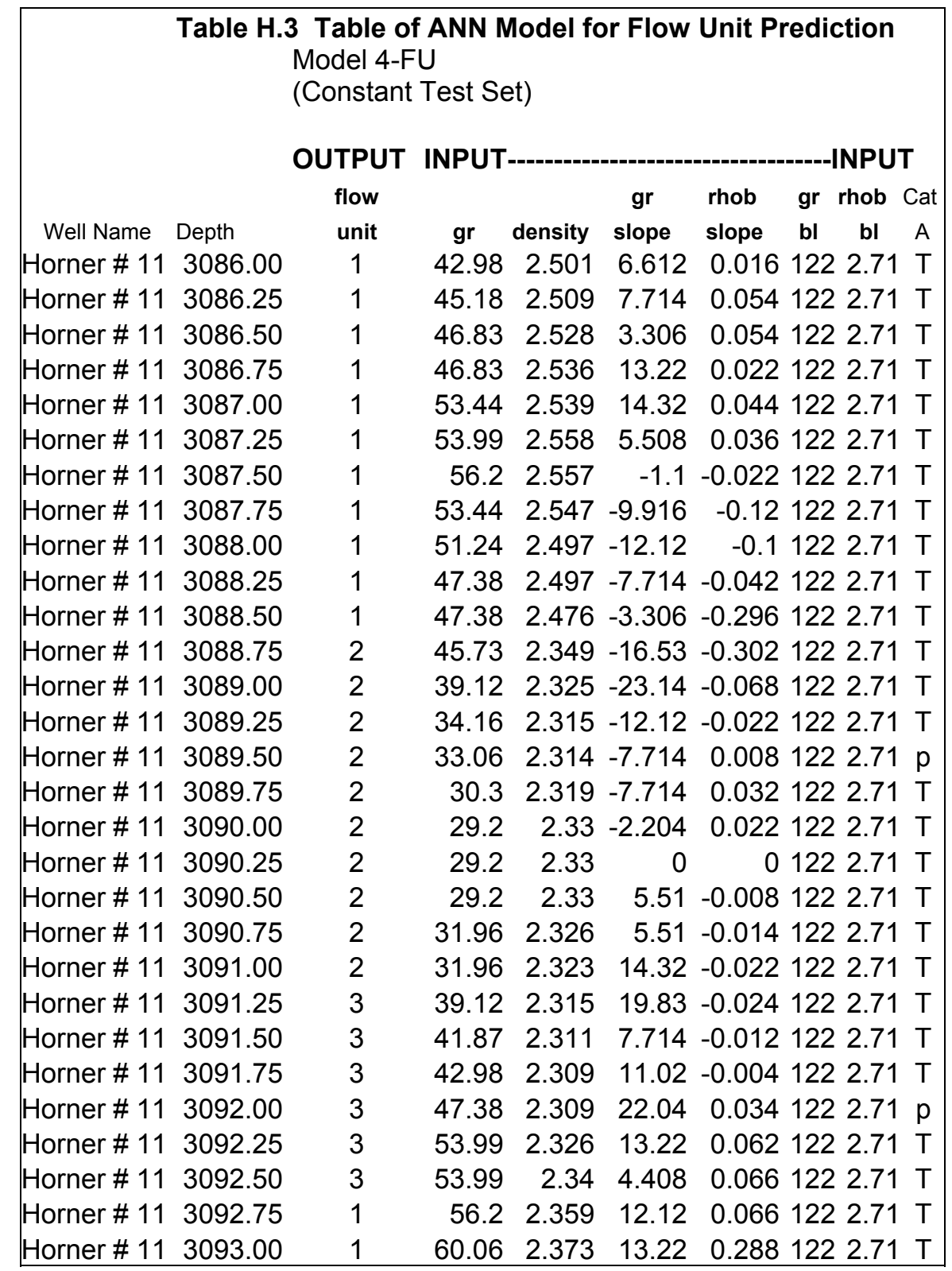




\begin{tabular}{|lcc|}
\hline & \multicolumn{2}{l}{$\begin{array}{l}\text { Table H.4 } \\
\text { Summary of Final Flow Units }\end{array}$} \\
Well Name & Flow Unit One (Feet) & Flow Unit Two (Feet) \\
\hline T Heirs \# 8 & $2789.50-2797.00$ & None \\
LeMasters \# 13 & $3048.00-3054.00$ & None \\
Horner \# 9 & $2892.75-2899.25$ & $2899.25-2904.50$ \\
Ball \# 19 & $3092.50-3107.25$ & $3107.25-3111.75$ \\
Ball \# 18 & $2990.25-2995.75$ & $2995.75-2999.75$ \\
Horner \# 11 & $3084.50-3091.00$ & $3091.00-3092.50$ \\
\hline
\end{tabular}




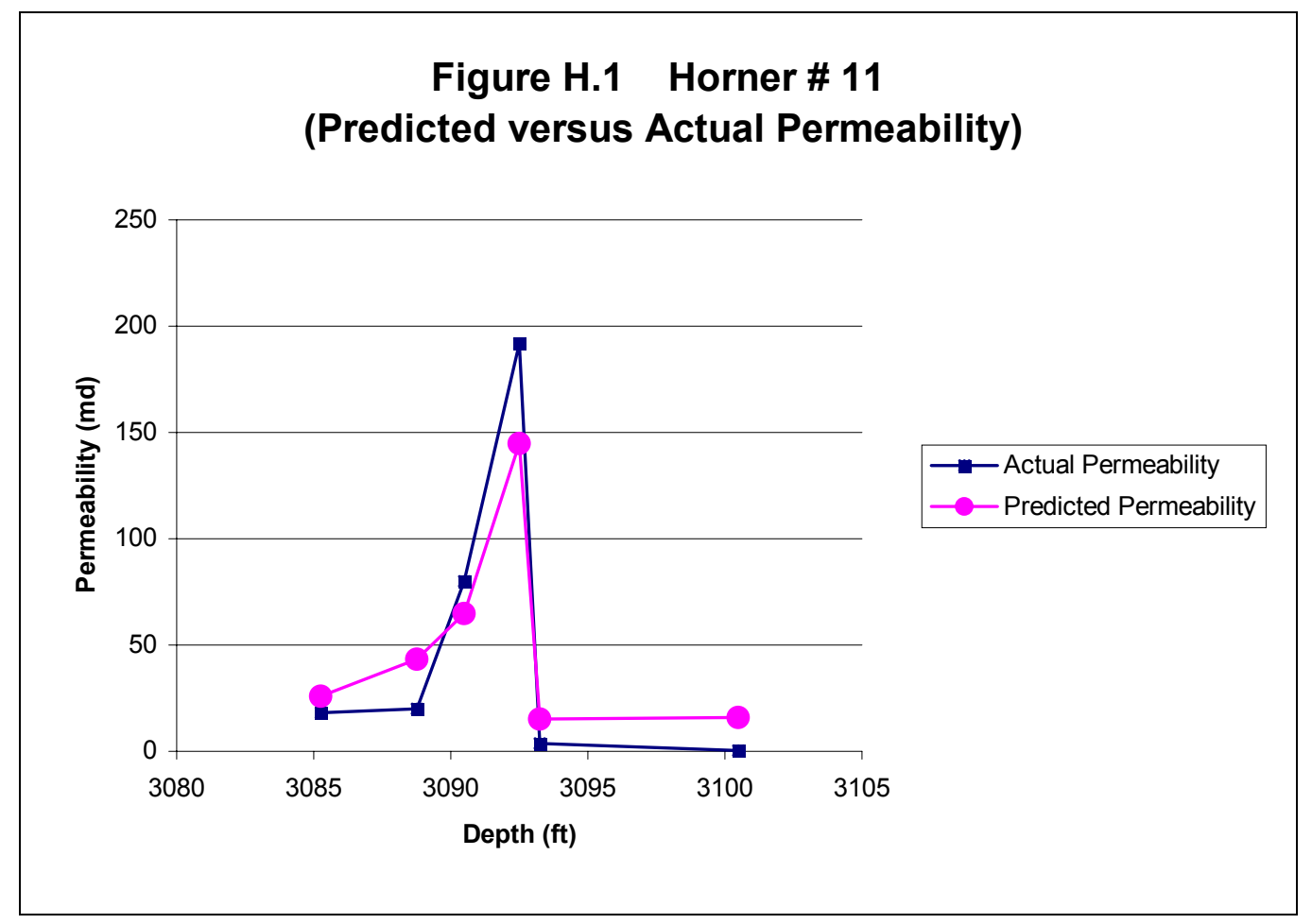

Figure H.2 T. Heirs \# 8

(Predicted versus Actual Permeability)

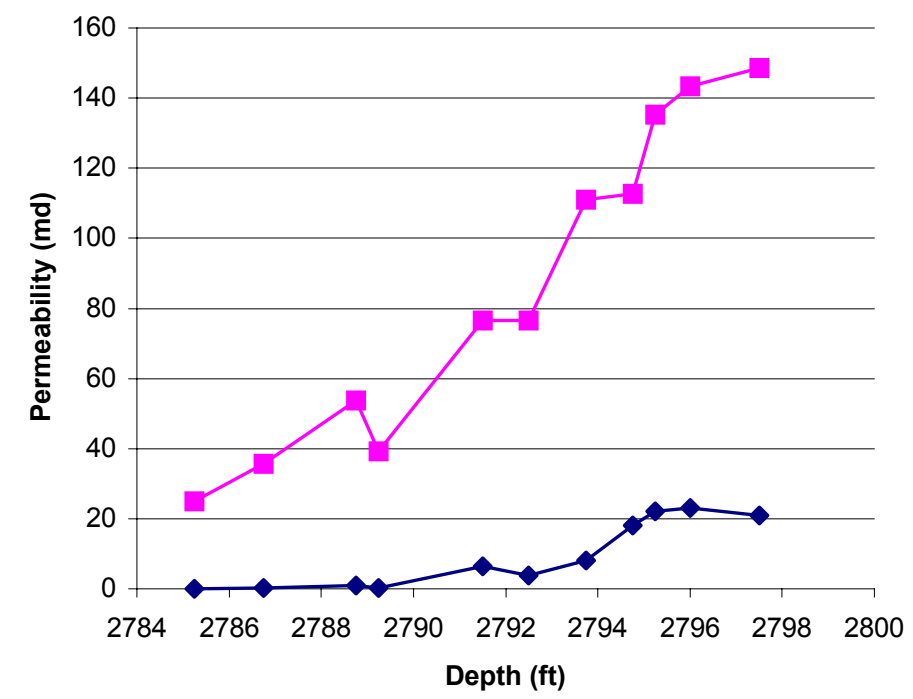

$\multimap$ Actual Permeability

_ Predicted Permeability 
Figure H.3 Horner \# 9

(Predicted versus Actual Permeability)
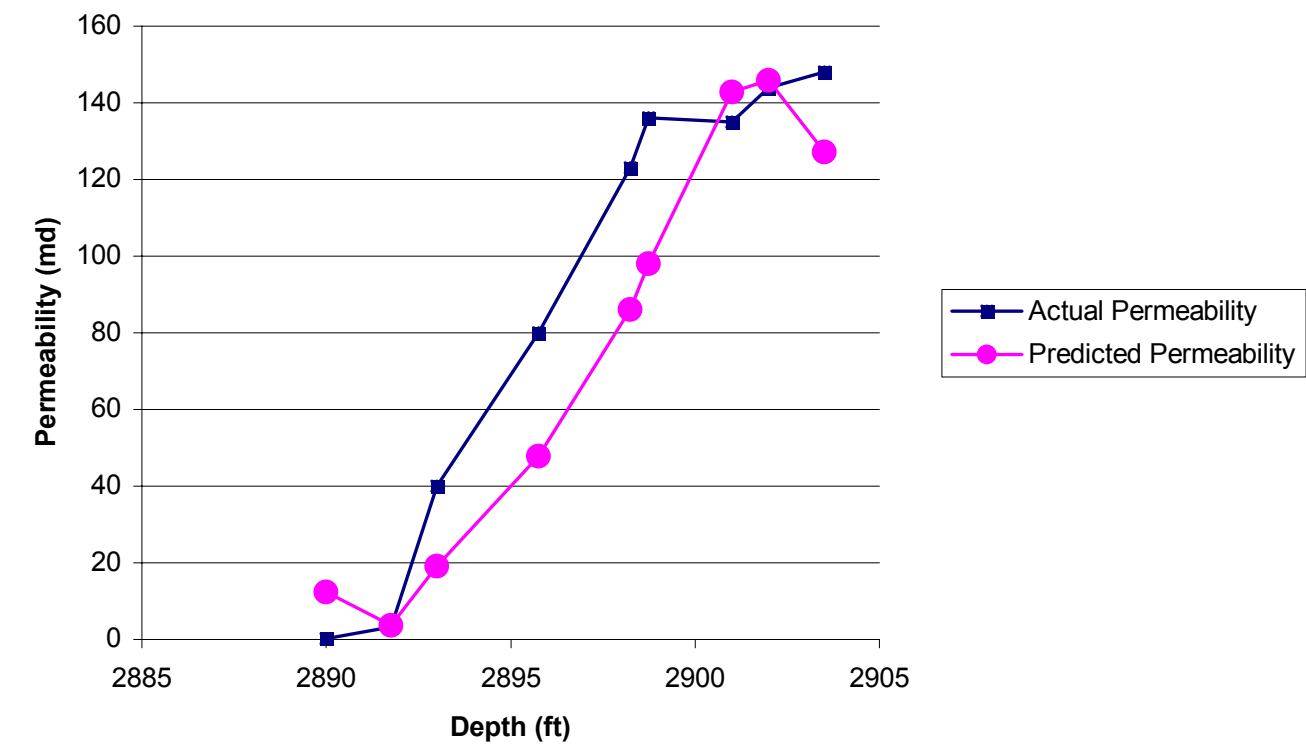

Figure H.4 Ball \# 19

(Predicted versus Actual Permeability)

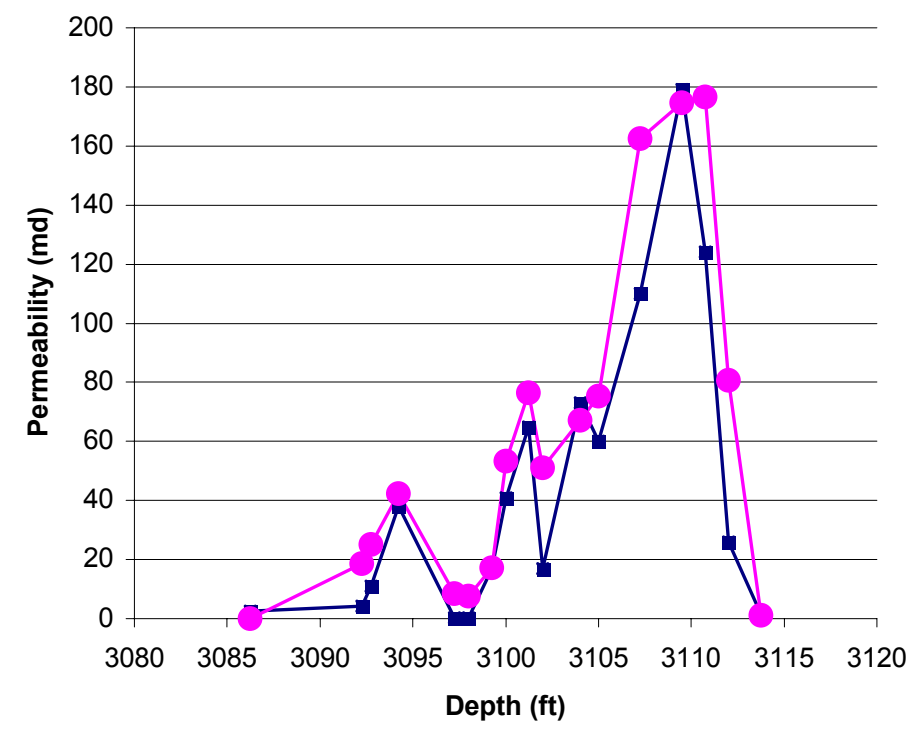




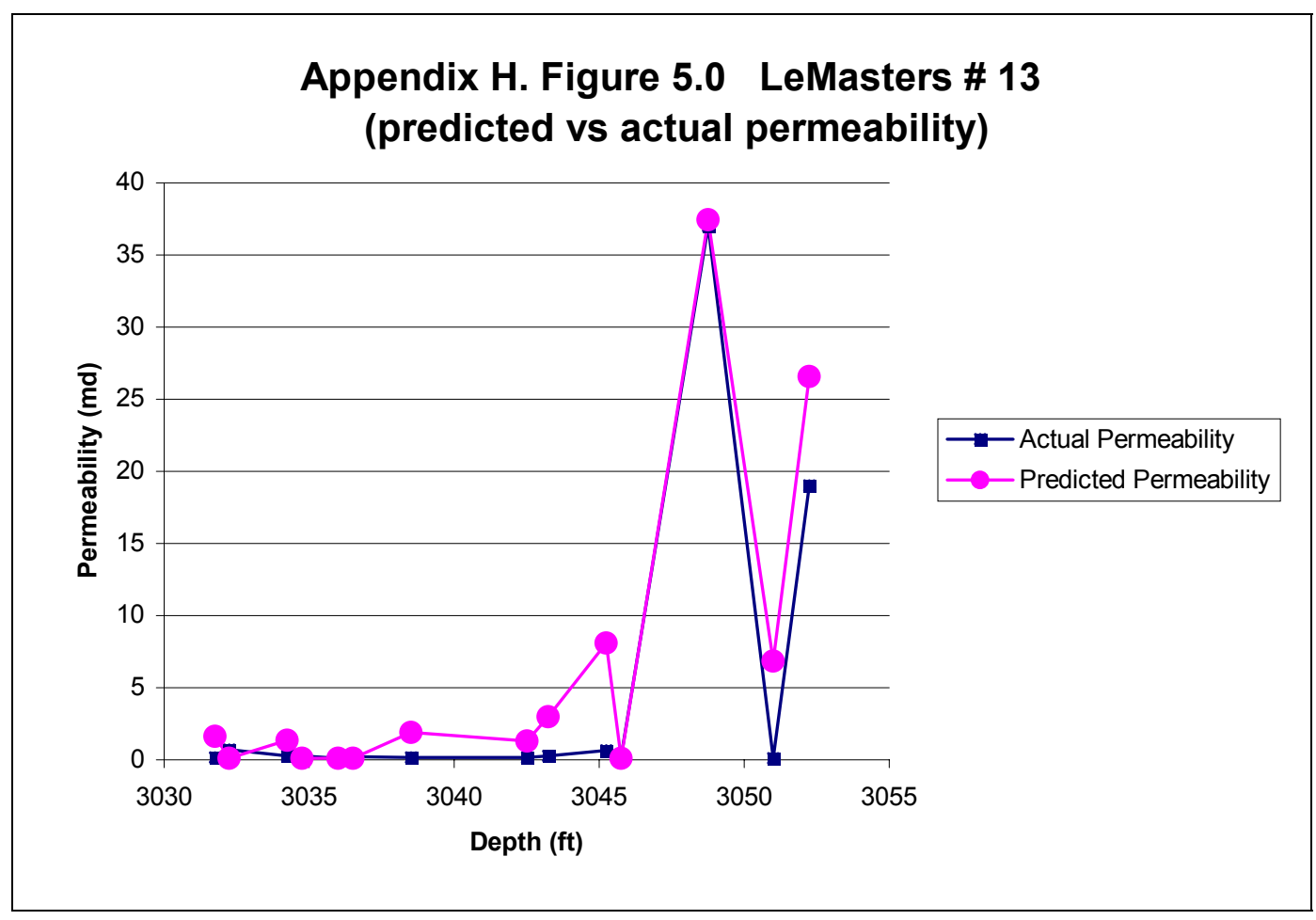

Figure H.6 Ball \# 18

(Predicted versus Actual Permeability)
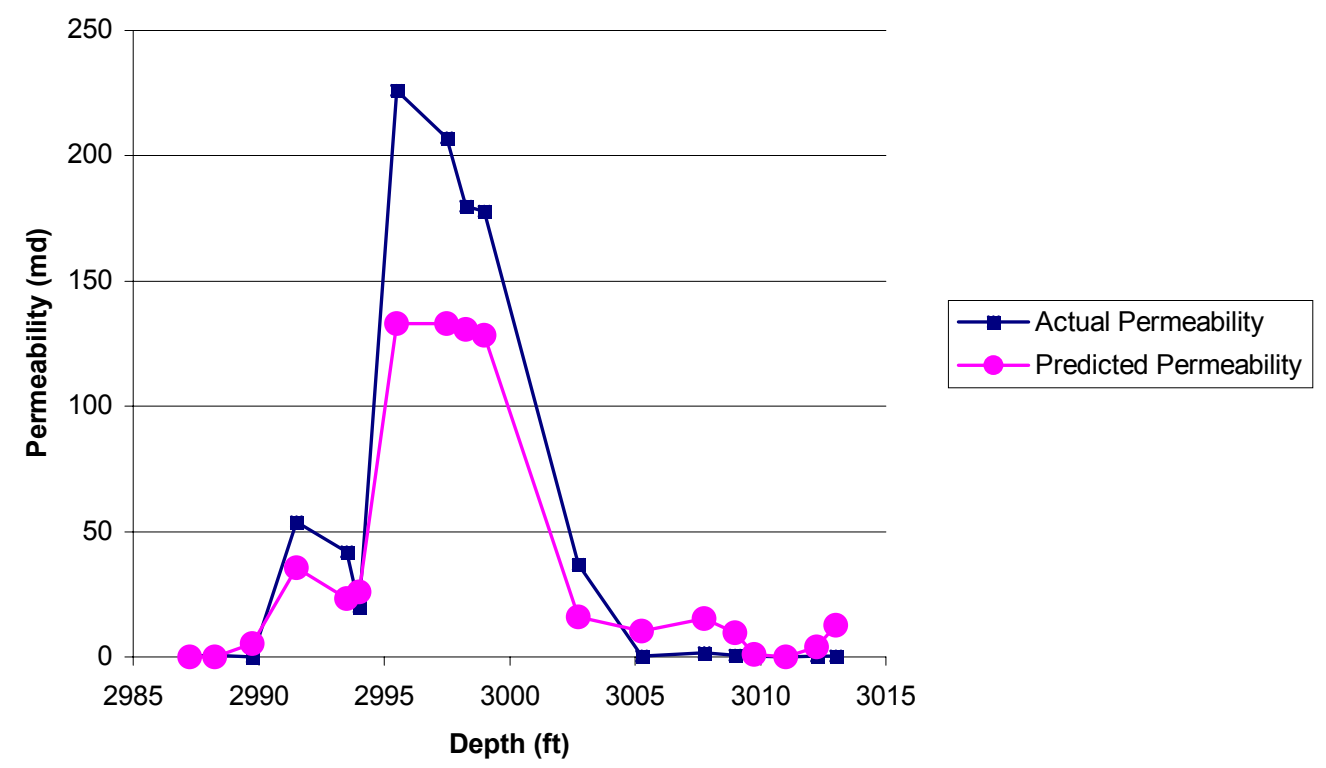


\section{APPENDIX I.}

Tables I.1 and I.2 are the individual well summaries of predicted permeability within each flow unit. The tables include flow capacity and storage capacity data for each well. The summaries are for the 125 wells in the field. 


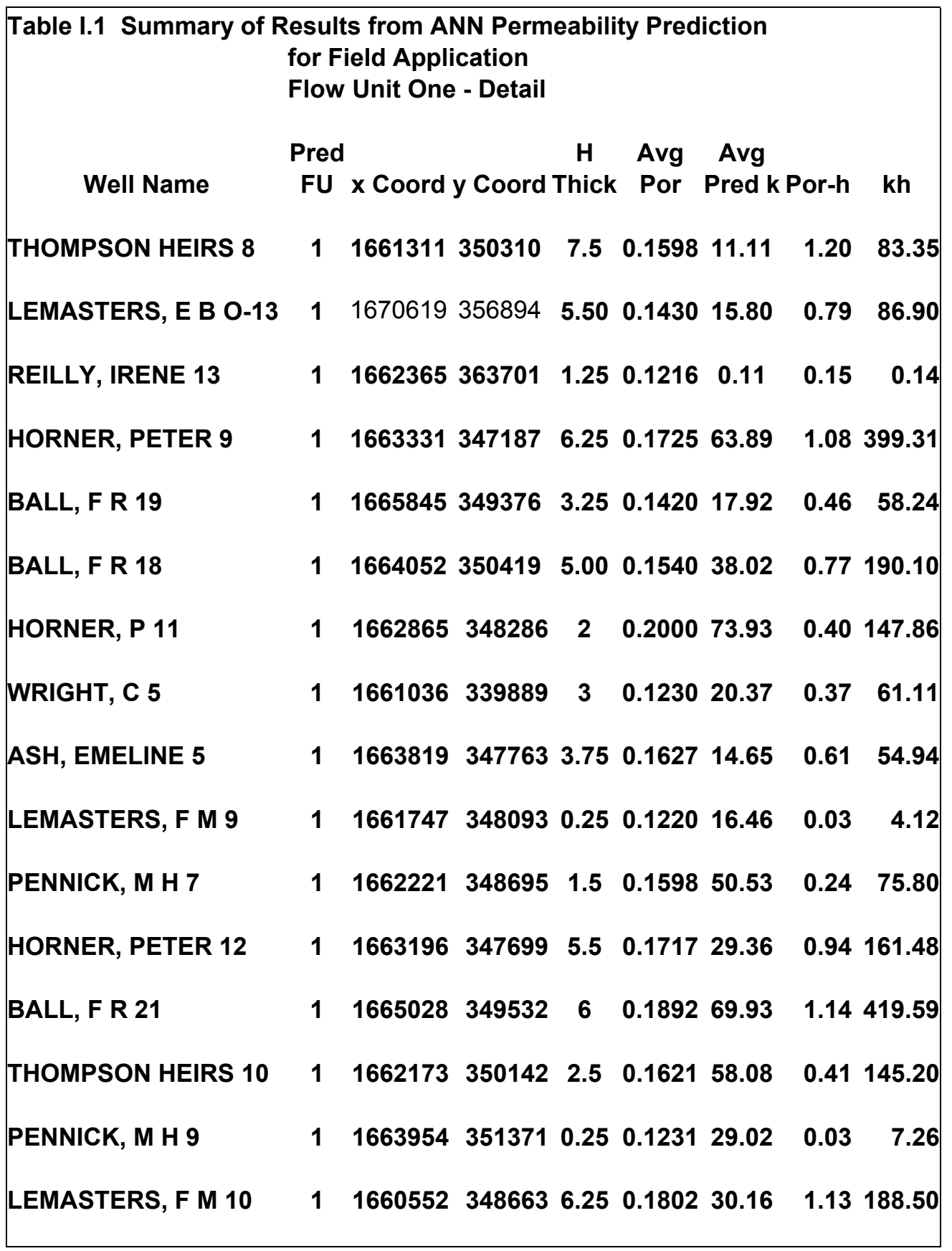




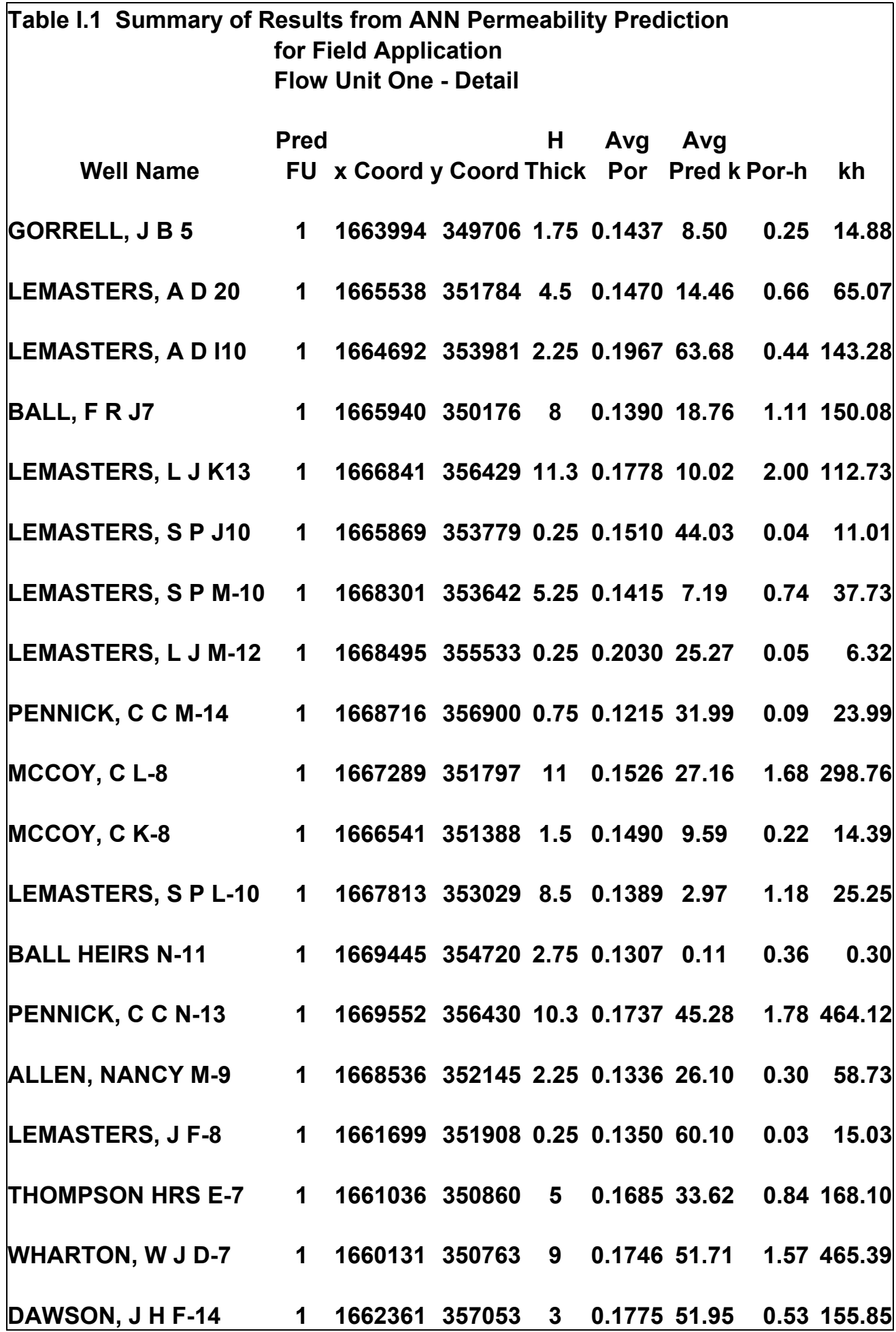




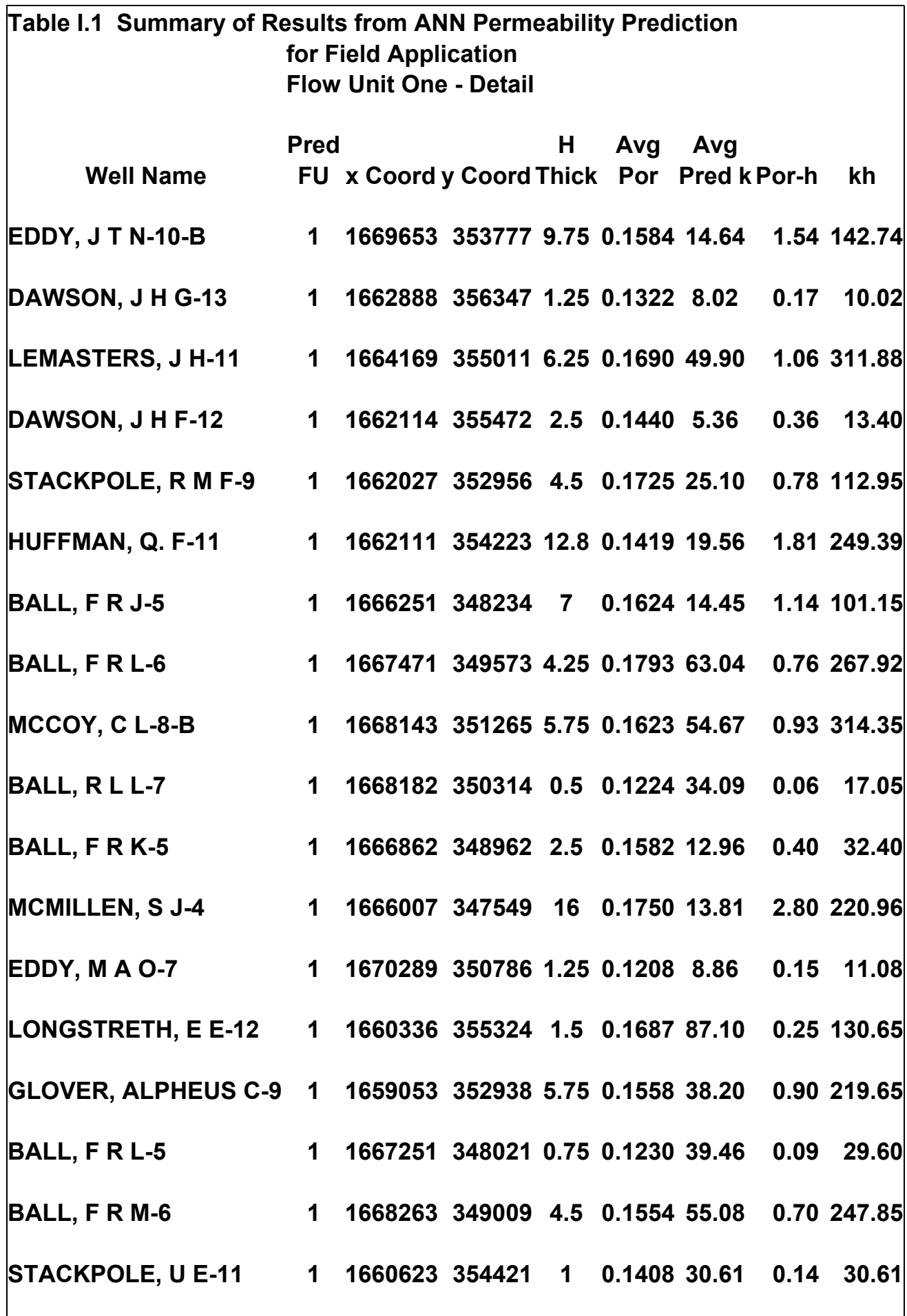




\begin{tabular}{|c|c|c|c|c|c|c|c|c|}
\hline \multicolumn{9}{|c|}{$\begin{array}{r}\text { Table I.1 Summary of Results from ANN Perme } \\
\text { for Field Application } \\
\text { Flow Unit One - Detail }\end{array}$} \\
\hline Well Name & $\begin{array}{c}\text { Pred } \\
\text { FU }\end{array}$ & x Coord y & y Coord & $\begin{array}{c}\text { H } \\
\text { Thick }\end{array}$ & $\begin{array}{l}\text { Avg } \\
\text { Por }\end{array}$ & $\begin{array}{c}\text { Avg } \\
\text { Pred k }\end{array}$ & Por-h & kh \\
\hline WRIGHT, P G D-3 & 1 & 1659323 & 346574 & 6.5 & 0.1806 & 63.18 & 1.17 & 410.64 \\
\hline ELDER, MARTHA 12 & 1 & 1661964 & 341880 & 10.5 & 0.1942 & 76.12 & 2.04 & 799.22 \\
\hline MCINTYRE, E 11 & 1 & 1662537 & 339719 & 4 & 0.1639 & 42.00 & 0.66 & 168.00 \\
\hline BAKER, I 5 & 1 & 1660658 & 341599 & 15.5 & 0.1433 & 35.45 & 2.22 & 549.55 \\
\hline HAUGHT, JOSHUA 6 & 1 & 1659528 & 343063 & 0.25 & 0.1226 & 38.29 & 0.03 & 9.57 \\
\hline PITTS, OLIVER 8 & 1 & 1661002 & 344748 & 5.75 & 0.1377 & 25.42 & 0.79 & 146.15 \\
\hline PITTS, OLIVER 9 & 1 & 1661994 & 345384 & 5.5 & 0.1530 & 43.26 & 0.84 & 237.93 \\
\hline SWIGER, B A 7 & 1 & 1659297 & 344622 & 0.25 & 0.1300 & 4.43 & 0.03 & 1.11 \\
\hline MCINTYRE, J L 12 & 1 & 1663109 & 345121 & 5.75 & 0.1723 & 16.06 & 0.99 & 92.35 \\
\hline ELDER, MARTHA 13 & 1 & 1662085 & 343583 & 4.5 & 0.1426 & 13.85 & 0.64 & 62.32 \\
\hline ALLEN, NANCY N-8 & 1 & 1669370 & 351399 & 4 & 0.1479 & 39.79 & 0.59 & 159.15 \\
\hline BALL, R L N-6 & 1 & 1669223 & 349648 & 2 & 0.1335 & 62.77 & 0.27 & 125.53 \\
\hline WYATT, SILAS E-3 & 1 & 1660280 & 346911 & 10 & 0.2092 & 55.18 & 2.09 & 551.82 \\
\hline LEMASTERS, L J 3-A & 1 & 1667342 & 355232 & 9.5 & 0.1644 & 33.17 & 1.56 & 315.10 \\
\hline LEMASTERS, A D 13-A & 1 & 1667342 & 355232 & 0.25 & 0.1370 & 68.74 & 0.03 & 17.19 \\
\hline HALL, C T K14 & 1 & 1666859 & 357777 & 1.75 & 0.1552 & 82.21 & 0.27 & 143.87 \\
\hline PENNICK, C C J15 & 1 & 1666121 & 357777 & 4.25 & 50.1283 & 15.98 & 0.55 & 67.89 \\
\hline PENNICK, C C L15 & 1 & 1667485 & 357777 & 13 & 0.1545 & 27.67 & 2.01 & 359.74 \\
\hline NOLAN, HENRY L-16 & 1 & 1668293 & 357777 & 12.5 & 0.1888 & 36.31 & 2.36 & 453.90 \\
\hline
\end{tabular}




\begin{tabular}{|c|c|c|c|c|c|c|c|c|}
\hline \multicolumn{9}{|c|}{$\begin{array}{c}\text { Table I.1 Summary of Results from ANN Permeability Prediction } \\
\text { for Field Application } \\
\text { Flow Unit One - Detail }\end{array}$} \\
\hline Well Name & $\begin{array}{c}\text { Pred } \\
\text { FU }\end{array}$ & x Coord & y Coord & $\begin{array}{c}\text { H } \\
\text { Thick }\end{array}$ & $\begin{array}{l}\text { Avg } \\
k \text { Por }\end{array}$ & $\begin{array}{c}\text { Avg } \\
\text { Pred k }\end{array}$ & Por-h & kh \\
\hline LEMASTERS, A D H-13 & 1 & 1663875 & 357777 & 10 & 0.1618 & 26.11 & 1.62 & 261.09 \\
\hline HOGE, F L H-14 & 1 & 1663435 & 357777 & 6.75 & 0.1347 & 17.57 & 0.91 & 118.60 \\
\hline NOLAN, HENRY L-17 & 1 & 1667777 & 357777 & 7.5 & 0.1344 & 4.74 & 1.01 & 35.52 \\
\hline PENNICK, C C M-15 & 1 & 1668790 & 357777 & 9.5 & 0.1428 & 15.88 & 1.36 & 150.84 \\
\hline NOLAN, HENRY M-17 & 1 & 1668809 & 357777 & 12.5 & 0.1642 & 60.44 & 2.05 & 5755.55 \\
\hline PENNICK, C C L-15B & 1 & 1668133 & 357777 & 5 & 0.1585 & 1.84 & 0.79 & 9.20 \\
\hline LEMASTERS, E B P-12 & 1 & 1671304 & 357777 & 7.75 & 0.1619 & 44.94 & 1.25 & 348.32 \\
\hline LEMASTERS, MARY P-14 & 1 & 1671831 & 357777 & 4 & 0.1922 & 40.26 & 0.77 & 161.04 \\
\hline REILLY, T W N-17 & 1 & 1670315 & 357777 & 10.5 & 0.1713 & 17.36 & 1.80 & 182.28 \\
\hline REILLY, G V L-19 & 1 & 1668041 & 357777 & 2.75 & 0.1821 & 25.73 & 0.50 & 70.76 \\
\hline REILLY, G V N-19 & 1 & 1669545 & 357777 & 3.75 & 0.2000 & 59.21 & 0.75 & 5222.05 \\
\hline REILLY, MARY J 0-19 & 1 & 1670467 & 357777 & 6.75 & 0.1789 & 70.44 & 1.21 & 475.48 \\
\hline PENNICK, C C 0-15 & 1 & 1671346 & 357777 & 11 & 0.1445 & 27.52 & 1.59 & 302.69 \\
\hline JAMISON, H M Q-17 & 1 & 1673425 & 357777 & 3.75 & 0.1380 & 11.90 & 0.52 & 44.62 \\
\hline WILEY, ISAAC G-22 & 1 & 1661620 & 357777 & 1.5 & 0.1490 & 2.40 & 0.22 & 3.61 \\
\hline WILEY, S H G-23 & 1 & 1661635 & 357777 & 2.75 & 0.1688 & 9.58 & 0.46 & 26.34 \\
\hline REILLY, IRENE I-20 & 1 & 1663804 & 357777 & 11.5 & 0.1896 & 82.05 & 2.18 & 943.52 \\
\hline PENNICK, C C G-15 & 1 & 1662785 & 357777 & 4.5 & 0.1812 & 54.42 & 0.82 & 244.89 \\
\hline WILEY, J E G-25 & 1 & 1663056 & 357777 & 3.25 & 0.2022 & 36.12 & 0.66 & 117.40 \\
\hline
\end{tabular}




\begin{tabular}{|c|c|c|c|c|c|c|c|c|}
\hline Table I.1 Summary of & $\begin{array}{l}\text { Result } \\
\text { for } \mathrm{Fi} \\
\text { Flow }\end{array}$ & $\begin{array}{l}\text { ts from Al } \\
\text { ield Appli } \\
\text { Unit One }\end{array}$ & $\begin{array}{l}\text { NN Perm } \\
\text { cation } \\
\text { - Detail }\end{array}$ & eabilit & ity Pred & diction & & \\
\hline Well Name & $\begin{array}{c}\text { Pred } \\
\text { FU }\end{array}$ & x Coord & y Coord & $\begin{array}{c}\text { H } \\
\text { Thick }\end{array}$ & $\begin{array}{l}\text { Avg } \\
\text { Por }\end{array}$ & $\begin{array}{c}\text { Avg } \\
\text { Pred k }\end{array}$ & Por-h & $\mathbf{k h}$ \\
\hline FLUHARTY, WM. E-16 & 1 & 1661046 & 357777 & 1 & 0.1292 & 53.87 & 0.13 & 53.87 \\
\hline FLUHARTY, J K E-18 & 1 & 1661118 & 357777 & 10.8 & 0.1746 & 44.31 & 1.88 & 476.31 \\
\hline FLUHARTY, H G-17 & 1 & 1663204 & 357777 & 3.5 & 0.1641 & 58.44 & 0.57 & 204.53 \\
\hline WILEY, I G-22-B & 1 & 1662521 & 357777 & 9.5 & 0.1451 & 13.12 & 1.38 & 124.61 \\
\hline REILLY, IRENE H-19 & 1 & 1664183 & 357777 & 3.75 & 0.1618 & 40.46 & 0.61 & 151.71 \\
\hline WILEY, JACOB H-25 & 1 & 1664361 & 357777 & 4.25 & 0.1786 & 22.28 & 0.76 & 94.69 \\
\hline MCCOY HRS. H-27 & 1 & 1664336 & 357777 & 9.25 & 0.1582 & 71.71 & 1.46 & 663.35 \\
\hline WILEY, A E-26 & 1 & 1661466 & 357777 & 5.25 & 0.1576 & 55.50 & 0.83 & 291.36 \\
\hline WILEY, S H E-24 & 1 & 1660426 & 357777 & 6.75 & 0.1788 & 95.08 & 1.21 & 641.79 \\
\hline LEMASTERS, E B P-13 & 1 & 1671869 & 357777 & 5.5 & 0.1392 & 36.84 & 0.77 & 202.62 \\
\hline
\end{tabular}




\begin{tabular}{|c|c|c|c|c|c|c|c|c|}
\hline \multicolumn{9}{|c|}{$\begin{array}{c}\text { Table I.2 Summary of Results from ANN Permeability Prediction } \\
\text { for Field Application } \\
\text { Flow Unit Two - Detail }\end{array}$} \\
\hline Well Name & $\begin{array}{c}\text { Pred } \\
\text { FU }\end{array}$ & x Coord & y Coord & $\begin{array}{c}\text { H } \\
\text { Thick }\end{array}$ & $\begin{array}{l}\text { Avg } \\
\text { Por }\end{array}$ & $\begin{array}{c}\text { Avg } \\
\text { Pred k }\end{array}$ & Por-h & $\mathbf{k h}$ \\
\hline HORNER, PETER 8 & 2 & 1663331 & 347187 & 4.50 & 0.2350 & 143.40 & 1.06 & 645.30 \\
\hline BALL, F R 19 & 2 & 1665845 & 349376 & 3.75 & 0.2270 & 152.78 & 0.85 & 572.93 \\
\hline BALL, F R 18 & 2 & 1664052 & 350419 & 3.75 & 0.2360 & 201.76 & 0.89 & 756.60 \\
\hline HORNER, P 11 & 2 & 1662865.4 & 348286 & 0.75 & 0.2150 & 180.14 & 0.16 & 135.11 \\
\hline WRIGHT, C 5 & 2 & 1661036.1 & 339889 & 12.8 & 0.3010 & 98.40 & 3.84 & 1254.60 \\
\hline ASH, EMELINE 5 & 2 & 1663818.6 & 347763 & 5.25 & 0.2420 & 241.30 & 1.27 & 1266.83 \\
\hline LEMASTERS, F M 9 & 2 & 1661747.3 & 348093 & 2.5 & 0.2126 & 124.79 & 0.53 & 311.98 \\
\hline PENNICK, M H 7 & 2 & 1662221.3 & 348695 & 2.75 & 0.2272 & 167.83 & 0.62 & 461.53 \\
\hline HORNER, PETER 10 & 2 & 1662517.8 & 347635 & 5.25 & 0.2636 & 175.30 & 1.38 & 920.33 \\
\hline BALL, F R 21 & 2 & 1665028.2 & ? 349532 & 4.25 & 0.2394 & 223.17 & 1.02 & 948.47 \\
\hline THOMPSON HEIRS 9 & 2 & 1661161.2 & 349256 & 1.5 & 0.2044 & 137.38 & 0.31 & 206.07 \\
\hline PENNICK, M H 9 & 2 & 1663954 & 351371 & 6.75 & 0.2472 & 177.00 & 1.67 & 1194.75 \\
\hline LEMASTERS, F M 10 & 2 & 1660551.8 & 348663 & 1.75 & 0.2147 & 199.36 & 0.38 & 348.88 \\
\hline BALL, F R 20 & 2 & 1665067 & 350333 & 16 & 0.2504 & 175.62 & 4.01 & 2809.92 \\
\hline GORRELL, J B 4 & 2 & 1665100.4 & 348584 & 5.5 & 0.2452 & 167.76 & 1.35 & 922.68 \\
\hline GORRELL, J B 5 & 2 & 1663994.1 & 349706 & 6 & 0.2650 & 133.53 & 1.59 & 801.18 \\
\hline LEMASTERS, A D 20 & 2 & 1665537.9 & 351784 & 5.75 & 0.2680 & 136.67 & 1.54 & 785.85 \\
\hline PENNICK, M H 8 & 2 & 1663167.6 & 350205 & 5 & 0.2478 & 123.85 & 1.24 & 619.25 \\
\hline BALL, F R J7 & 2 & 1665940.3 & 350176 & 0.25 & 0.1340 & 30.73 & 0.03 & 7.68 \\
\hline
\end{tabular}




\begin{tabular}{|c|c|c|c|c|c|c|c|c|}
\hline Table I.2 Summary of Res & $\begin{array}{l}\text { sults } \\
\text { for } F \\
\text { Flow }\end{array}$ & $\begin{array}{l}\text { from ANN } \\
\text { ield Applic } \\
\text { v Unit Two }\end{array}$ & $\begin{array}{l}\text { Permeab } \\
\text { cation } \\
\text { - Detail }\end{array}$ & bility $F$ & Predicti & tion & & \\
\hline Well Name & $\begin{array}{c}\text { Pred } \\
\text { FU }\end{array}$ & x Coord & y Coord & $\begin{array}{c}\text { H } \\
\text { I Thick }\end{array}$ & $\begin{array}{ll}\text { Avg } \\
k \text { Por }\end{array}$ & $\begin{array}{l}\text { Avg } \\
\text { Pred k }\end{array}$ & Por-h & kh \\
\hline LEMASTERS, L J K12 & 2 & 1666263 & 355381 & 6.25 & 0.2530 & 0121.93 & 1.58 & 762.06 \\
\hline LEMASTERS, S P J10 & 2 & 1665869.2 & 353779 & 6.75 & 0.2202 & 2143.34 & 1.49 & 967.55 \\
\hline LEMASTERS, L J M-12 & 2 & 1668495.4 & 355533 & 3 & 0.2181 & 1224.23 & 0.65 & 672.69 \\
\hline MCCOY, C K-8 & 2 & 1666540.8 & 351388 & 0.75 & 0.1790 & 0130.23 & 0.13 & 97.67 \\
\hline LEMASTERS, S P L-10 & 2 & 1667813.2 & 353029 & 1.5 & 0.1765 & 5175.29 & 0.26 & 262.94 \\
\hline BALL HEIRS N-11 & 2 & 1669444.7 & 354720 & 2.5 & 0.2033 & 3118.54 & 0.51 & 296.35 \\
\hline LEMASTERS, J F-8 & 2 & 1661699.3 & 351908 & 3.5 & 0.1995 & 5107.96 & 0.70 & 377.86 \\
\hline LEMASTERS, JASPER 15 & 2 & 1661987.4 & 351070 & 1.75 & 0.1943 & 3151.29 & 0.34 & 264.76 \\
\hline GLOVER, J N E-8 & 2 & 1660843 & 352065 & 0.5 & 0.1289 & 9138.77 & 0.06 & 69.39 \\
\hline BALL, F R K-5 & 2 & 1666861.9 & 348962 & 2 & 0.1829 & 9105.64 & 0.37 & 211.28 \\
\hline LONGSTRETH, E E-12 & 2 & 1660336 & 355324 & 6.75 & 0.2400 & 0176.05 & 1.62 & 1188.34 \\
\hline BALL, F R L-5 & 2 & 1667250.6 & 348021 & 4.75 & 0.2093 & 3128.38 & 0.99 & 609.81 \\
\hline ELDER, MARTHA 11 & 2 & 1663385.3 & 343413 & 3.5 & 0.2352 & 2140.38 & 0.82 & 491.32 \\
\hline STACKPOLE, U E-11 & 2 & 1660623.2 & 354421 & 2 & 0.2038 & 8211.21 & 0.41 & 422.42 \\
\hline MCINTYRE, E 11 & 2 & 1662536.8 & 339719 & 1.25 & 0.1938 & 8188.97 & 0.24 & 236.21 \\
\hline HAUGHT, JOSHUA 6 & 2 & 1659527.7 & 343063 & 8 & 0.2187 & 7112.34 & 1.75 & 898.72 \\
\hline BAKER HRS., D 11 & 2 & 1660731.4 & 343299 & 2.75 & 0.1981 & 1144.54 & 0.54 & 397.49 \\
\hline PITTS, OLIVER 8 & 2 & 1661002.2 & 344748 & 2 & 0.2094 & 4135.08 & 0.42 & 270.16 \\
\hline SWIGER, B A 7 & 2 & 1659297.3 & 344622 & 7 & 0.2827 & 7182.72 & 1.98 & 1279.02 \\
\hline No Name & 2 & 1660951.8 & 345958 & 6.25 & 0.2191 & 1178.32 & 1.37 & 1114.50 \\
\hline
\end{tabular}




\begin{tabular}{|c|c|c|c|c|c|c|c|c|}
\hline \multicolumn{9}{|c|}{$\begin{array}{r}\text { Table I.2 Summary of Results from ANN Permeak } \\
\text { for Field Application } \\
\text { Flow Unit Two - Detail }\end{array}$} \\
\hline Well Name & $\begin{array}{l}\text { Pred } \\
\text { FU }\end{array}$ & x Coord & y Coord & $\begin{array}{c}\text { H } \\
\text { Thick }\end{array}$ & $\begin{array}{l}\text { Avg } \\
\text { Por }\end{array}$ & $\begin{array}{c}\text { Avg } \\
\text { Pred k }\end{array}$ & Por-h & kh \\
\hline MCINTYRE, J L 12 & 2 & 1663108.6 & 345121 & 3.5 & 0.1942 & 272.57 & 0.68 & 254.01 \\
\hline ELDER, MARTHA 13 & 2 & 1662085.4 & 343583 & 1.5 & 0.1307 & 791.94 & 0.20 & 137.91 \\
\hline LEMASTERS, A D 13-A & 2 & 1667342.4 & 355232 & 3.5 & 0.2048 & 8122.16 & 0.72 & 427.55 \\
\hline HALL, C T K14 & 2 & 1666859.1 & 357777 & 5.5 & 0.2216 & 6144.83 & 1.22 & 796.57 \\
\hline NOLAN, HENRY L-17 & 2 & 1667776.7 & 357777 & 3 & 0.2137 & 783.01 & 0.64 & 249.03 \\
\hline NOLAN, HENRY M-17 & 2 & 1668809.5 & 357777 & 1.5 & 0.1545 & 5144.43 & 0.23 & 216.65 \\
\hline NOLAN, HENRY N-15 & 2 & 1669992.9 & 357777 & 0.25 & 0.2368 & 36.85 & 0.06 & 14.21 \\
\hline PENNICK, C C L-15B & 2 & 1668132.6 & 357777 & 1.5 & 0.2075 & 5131.01 & 0.31 & 196.52 \\
\hline REILLY, G V L-19 & 2 & 1668040.7 & 357777 & 0.75 & 0.1500 & 89.62 & 0.11 & 67.21 \\
\hline WILEY, ISAAC G-22 & 2 & 1661620.1 & 357777 & 2.75 & 0.2002 & 2135.39 & 0.55 & 372.32 \\
\hline WILEY, S H G-23 & 2 & 1661635.2 & 357777 & 0.25 & 0.1470 & 120.67 & 0.04 & 30.17 \\
\hline REILLY, IRENE G-20 & 2 & 1661747 & 357777 & 4 & 0.2280 & 190.14 & 0.91 & 760.56 \\
\hline FLUHARTY, WM. E-14 & 2 & 1661209.8 & 357777 & 4.25 & 0.2541 & 78.41 & 1.08 & 333.26 \\
\hline PENNICK, C C G-15 & 2 & 1662784.9 & 357777 & 0.75 & 0.1558 & 68.92 & 0.12 & 51.69 \\
\hline WILEY, ANDERSON F-25 & 2 & 1662059.2 & 357777 & 9.5 & 0.2735 & 5129.66 & 2.60 & 1231.77 \\
\hline WILEY, J E G-25 & 2 & 1663056 & 357777 & 0.25 & 0.1550 & 141.75 & 0.04 & 35.44 \\
\hline FLUHARTY, WM. E-15 & 2 & 1661075.6 & 357777 & 6 & 0.2976 & 66.74 & 1.79 & 400.45 \\
\hline WILEY, ISAAC H-22 & 2 & 1663970 & 357777 & 4.5 & 0.2512 & 2126.08 & 1.13 & 567.35 \\
\hline CUNNINGHAM, D F-18-B & 2 & 1662124.3 & 357777 & 5 & 0.2623 & 3171.40 & 1.31 & 857.00 \\
\hline
\end{tabular}




\begin{tabular}{|c|c|c|c|c|c|c|c|c|}
\hline \multicolumn{9}{|c|}{$\begin{array}{c}\text { Table I.2 Summary of Results from ANN Permeability Prediction } \\
\text { for Field Application } \\
\text { Flow Unit Two - Detail }\end{array}$} \\
\hline Well Name & $\begin{array}{l}\text { Pred } \\
\text { FU }\end{array}$ & x Coord & y Coord & $\begin{array}{c}\text { H } \\
\text { Thick }\end{array}$ & $\begin{array}{l}\text { Avg } \\
\text { Por }\end{array}$ & $\begin{array}{l}\text { Avg } \\
\text { Pred k }\end{array}$ & Por-h & kh \\
\hline MCCOY HRS. H-27 & 2 & 1664335.9 & 357777 & 0.25 & 0.1200 & 69.13 & 0.03 & 17.28 \\
\hline MCCOY HRS. G-27 & 2 & 1663080.6 & 357777 & 8.75 & 0.2247 & 134.28 & 1.97 & 1174.99 \\
\hline WILEY, S H E-24 & 2 & 1660426.1 & 357777 & 0.25 & 0.1279 & 53.78 & 0.03 & 13.45 \\
\hline LEASURE, E I-21 & 2 & 1663995.4 & 357777 & 6.75 & 0.2500 & 136.26 & 1.69 & 919.77 \\
\hline
\end{tabular}




\section{VITAE}

Benjamin Hale Thomas was born July 5, 1954, in Parkersburg, West Virginia. He is the son of Kenneth Berl Thomas and the late Glenna Marie Rymer Thomas.

He received his B.B.A. degree from Kent State University in 1975, his B.S. degree in Petroleum Engineering from Marietta College in 1981, his M.B.A. from Ashland University in 1987, his M.S. in Petroleum and Natural Gas Engineering in 1997 and his Doctor of Philosophy in Petroleum and Natural Gas Engineering in 2002, both from West Virginia University.

He is a member of the Honor Society of Petroleum Engineers (Pi Epsilon Tau), a member of the Society of Petroleum Engineers (SPE) since 1979, has been active in the Ohio Oil \& Gas Association (OOGA), and was Governor appointed to serve on the Technical Advisory Council (TAC) for the Ohio Division of Oil and Gas from $1987-2002$.

He is married to Connie Ruth Buck Thomas and has one son, Jeremy John Thomas. They currently reside in Dover, Ohio.

He was President of MB Operating Co., Inc., and Chief Executive Officer of Marbel Energy Corporation, both located in Canton, Ohio. In 2000, he retired to complete his Doctorate studies. He plans to teach and research topics related to Petroleum and Natural Gas Engineering. 